UNIVERSIDAD POLITÉCNICA DE MADRID

\author{
ESCUELA TÉCNICA SUPERIOR DE \\ INGENIEROS DE MINAS Y ENERGÍA
}

\title{
ESTRATIGRAFÍA Y SEDIMENTOLOGÍA DE LAS FORMACIONES CON ICNITAS DE DINOSAURIOS DEL GRUPO ENCISO (CAMEROS, LA RIOJA, APTIENSE) MEMORIA
}

\section{TESIS DOCTORAL}

\author{
FRANCISCOJ AVIER HERNÁN MARTÍNEZ \\ Ingeniero de Minas
}




\title{
DEPARTAMENTO DE INGENIERÍA GEOLÓGICA Y MINERA
}

ESCUELA TÉCNICA SUPERIOR DE INGENIEROS DE MINAS Y ENERGÍA

\section{ESTRATIGRAFÍA Y SEDIMENTOLOGÍA DE LAS FORMACIONES CON ICNITAS DE DINOSAURIOS DEL GRUPO ENCISO (CAMEROS, LA RIOJA, APTIENSE) MEMORIA}

FRANCISCO J AVIER HERNÁN MARTÍNEZ Ingeniero de Minas

\author{
DIRECTOR \\ TRINIDAD DE TORRES PÉREZ-HIDALGO \\ Dr. Ingeniero de Minas
}

2018 
Bortey Richand

Ia vida. Una biografla no autorizrada

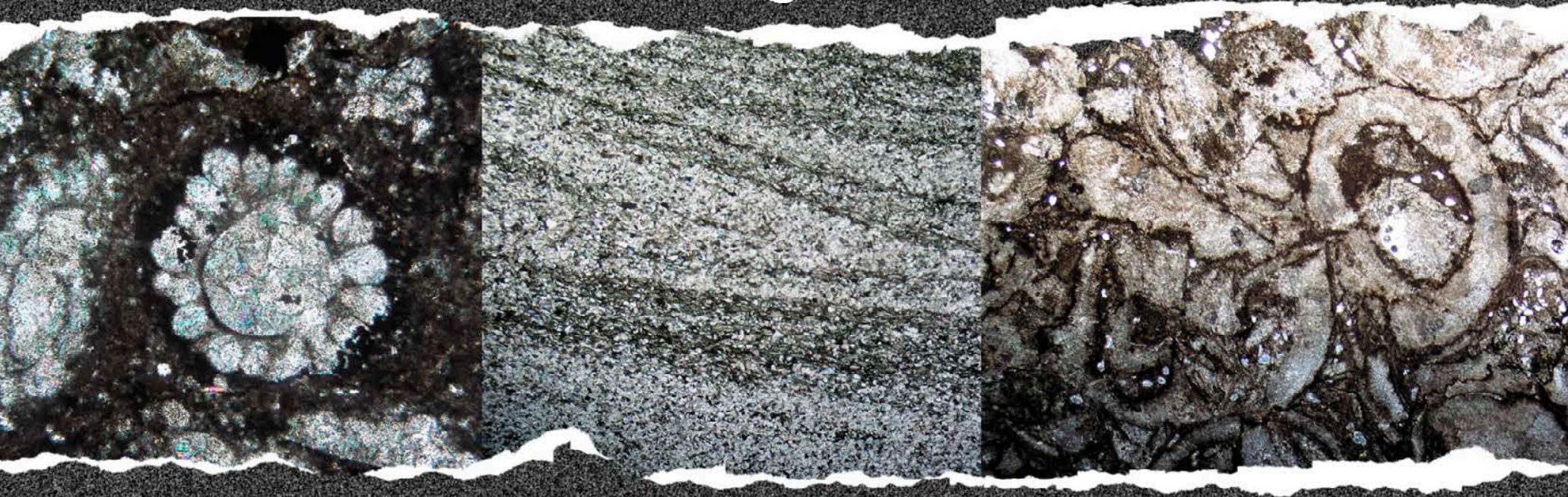

y cuando esta historia ha sido ensamblada a partir de jiezas pequenas tomadas de secciones de roca donde la casualidad ha tomado parte en el rebote de cada golpe de martilito, encontraremos evidente que esta pobrecilita historila es un rela to aproximativo divuligado por un optimista

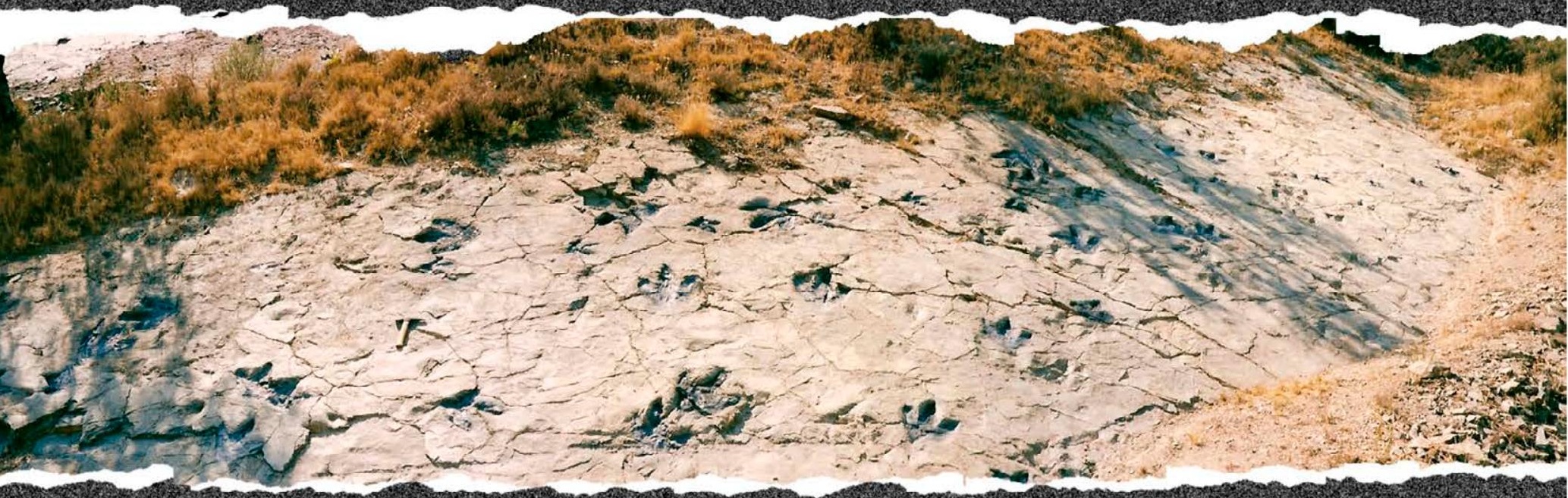




\section{Agradecimientos}

\section{AGRADECIMIENTOS}

Durante muchos (demasiados) años he deseado que llegara el momento de escribir este apartado de agradecimientos para dar las gracias a todo el mundo que, de uno u otro modo, ha hecho posible este trabajo.

El hecho de que por mis venas fluya sangre camerana, un apasionamiento desde mi niñez por los dinosaurios, y una extraña atracción por las piedras, en conjunto, predestinaron y aderezaron desde mi más tierna infancia, estoy seguro, la presente tesis doctoral.

Determinar si una roca recogida en el campo - un caluroso día de verano, allá, a media ladera de una distante y remota montaña riojana con una ancianidad de unos 125 millones de años- fue o no depositada en un lago puede constituir una labor ardua y harto complicada. Un trabajo de estas características abarca datos de multitud de disciplinas y fuentes (estratigráficas, sedimentológicas, paleontológicas, geoquímicas, etc.). Así pues, se necesita la ayuda de otros investigadores ya que hay temas sobre los cuales tengo un conocimiento limitado pero, en otros casos, mi desconocimiento es ilimitado. Por lo tanto, esta tesis nunca podrá ser considerada como el resultado exclusivo de mi trabajo ya que se ha apoyado en multitud de personas que con su ayuda, opinión o, simplemente, con haber estado cuando han sido necesarios han llevado a buen puerto este proyecto.

Durante este tiempo he tenido la suerte de entrar en contacto con investigadores que siempre han tenido a bien ayudarme y, por suerte, nunca he encontrado a ningún profesor Otto Lidenbrock: "un sabio egoísta, un pozo de ciencia pura cuya polea chirriaba cuando se quería sacar de él algún conocimiento" (Viaje al centro de la tierra, J ulio Verne).

En primer lugar, quiero mostrar mi agradecimiento al Dr. D. Trinidad de Torres, director de la tesis doctoral, por su paciencia (infinita según parámetros matemáticos), apoyo incondicional en estos estos años, así como por sus consejos en la supervisión de la memoria. Estaré en deuda siempre por toda su confianza y predisposición a ayudar en las complicaciones (numerosas y abundantes) que han surgido a lo largo de la tesis.

A todo el personal del Departamento de Ingeniería Geológica y Minera de la Escuela Técnica Superior de Ingenieros de Minas y Energía, donde he llevado acabo esta tesis, por haber puesto a mi disposición todos los recursos tanto humanos como técnicos.

A D. Santiago Jiménez por su desinteresada entrega, de la que han hecho gala en todo momento y por todos estos años de amistad. Me has enseñado a amar y respetar la riqueza paleontológica y paleoicnológica de La Rioja.

A D. J oaquín Moratalla, del IGME, por su amistad y ayuda en todo lo referente a las icnitas y cualquier otra marca rara que aparecía en mis columnas. Por contar conmigo en los proyectos que ha desarrollado en el Museo Geominero, ya sea como becario o como investigador: "Los moluscos asociados a las icnitas de dinosaurios de las cuencas de Cameros y VascoCantábrica (J urásico Superior-Cretácico Superior): sistemática, implicaciones paleoambientales y paleobiogeográficas" y "Análisis de la biodiversidad del Cretácico Inferior de la Cuenca de Cameros: Biofacies y Litofacies de los Grupos Urbión y Enciso" (Referencia CGL2006-10380).

Al equipo multidisciplinar PaleoCameros del IGME: Joaquín Moratalla, Graciela Delvene, Rafael Lozano, David Bermúdez-Rochas y Montserrat de la Fuente. Que grandes momentos hemos pasado en el campo y en el despacho, siempre salpicado de algún incidentemás o menos divertido (aún me corre un estremecimiento cuando traigo memoria de la "herida de arma blanca por ataque de garrapata").

Al Museo Geominero (IGME) que puso siempre a mi disposición los efectivos necesarios: en especial a D. Eleuterio Baeza, del laboratorio por estar siempre dispuesto a ayudarme en lo que hiciera falta. 


\section{Agradecimientos}

A D. J osé Arribas, Dña. María Eugenia Arribas, D. Ramón Mas, y Dña. María Isabel Benito, de la Facultad de Geológicas de la Universidad Complutense de Madrid, por su acogida y por permitirme trabajar con ellos en el grupo de Cameros gracias al contrato para el proyecto "Paleogeografía de los intervalos con mayor profusión de huellas de dinosaurios en el registro sedimentario dela cuenca de Cameros: Ambientes de sedimentación, ecologíay clima (Riftibérico mesozoico)" (referencia CGL2008-01648).

A Pepay J osé, dela Facultad de Geológicas, por sus cafés y comidas con sobremesa, y por todos los momentos tan buenos que me hicieron pasar durante mi estancia en Geológicas.

A Inma y Ricardo, de la Casa Rural La Tahona (Enciso), por haberme enseñado multitud de yacimientos y lugares curiosos en los alrededores, y sobre todo, por el trato cercano y familiar que me dispensaron durante mis estancias en el campo.

A los miembros del Hotel Virrey (Arnedo) por hacer siempre muy agradables la estancia en su hotel, sobre todo, después de unajornada dura de campo.

Por último, pero no menos importante, un eterno agradecimiento a toda mi familia, en especial a mi padre Domingo, a mi madre Ana Rosa y a mi hermano Chomi, por haberme acompañado en la realización de este largo viaje. Gracias por haber creído tanto en mí.

A todos, gracias de todo corazón. 


\section{Resumen}

\section{RESUMEN}

Se ha realizado un análisis estratigráfico y sedimentológico completo del Grupo Enciso en la cuenca de Cameros (La Rioja, España) para determinar las relaciones existentes entre las condiciones paleoambientales y los yacimientos paleoichnológicos de dinosaurios.

El relleno Aptiense inferior del Grupo Enciso se depositó en un lago rift localizado en la zona NO del Sistema Rift Mesozoico Ibérico, en un clima (sub)tropical sometido a condiciones de efecto invernadero.

En el Grupo Enciso se han reconocido trece microfacies y veintiuna litofacies. Estas litofacies se han agrupado, a su vez, en doce elementos arquitectónicos. El análisis markoviano permite individualizar nueve ambientes sedimentarios: un depósito fluvial de tipo avulsivo, dos sistemas lacustres siliciclásticos (LS-A y LS-B), tres modelos lacustres mixtos siliciclásticocarbonatado (LM-A, LM-B y LM-C), dos modelos lacustres carbonatados (LC-A y LC-B), y un modelo deltaico lacustre (DL). El Grupo Enciso está compuesto por una secuencia compleja donde aparecen interestratificados los cinturones fluviales avulsivos y los ambientes lacustres someros.

Los depósitos lacustres muestran frecuentes evidencias de exposición subaérea. La ausencia de paleosuelos bien desarrollados implica que los tiempos de exposición fueron cortos. Las evidencias sedimentológicas indican que el paleolago Enciso se caracterizaba por aguas poco profundas y por unos márgenes en rampa de baja energía y que estaba sometido a oscilaciones periódicas en el nivel del lago que resultaban en la exposición subaérea de grandes áreas.

Los datos geoquímicos y de isótopos estables también apuntan hacia un lago con unas aguas sometidas a una gran evaporación, al menos durante la sedimentación de los carbonatos. Los datos paleontológicos y de facies indican que el paleolago Enciso fue principalmente de aguas dulces-oligohalinas con etapas de aguas mesohalinas-polihalinas, y perennes. La sedimentación lacustre parece haber sido continua en el espacio y el tiempo (5,57 Ma).

La ciclicidad estratigráfica estuvo controlada por el clima. En el Grupo Enciso, los análisis espectrales ponen de manifiesto la presencia de periodicidades compatibles con el forzamiento orbital de Milankovitch.

La gran mayoría de los yacimientos icnológicos de dinosaurios aparecen en la parte alta de paquetes asociados a medios deltaicos avulsivos y/ o medios lacustres someros mixtos o carbonatados.

El patrón direccional de los rastros de dinosaurios en el Grupo Enciso es NNE-SSO. Esta orientación sugiere que los dinosaurios, especialmente los terópodos, cruzaron a través de la cubeta del lago, en oposición clara con el patrón direccional observado en otras áreas lacustres donde se observa un movimiento preferencial de los dinosaurio paralelo a la costa/ orilla. 


\title{
Resumen
}

\begin{abstract}
A comprehensive stratigraphic and sedimentological analysis of the Enciso Group in the Cameros basin (La Rioja, Spain) was conducted in order to more completely document the relationships between palaeoenvironmental conditions and dinosaur palaeoichnological sites.

The early Aptian strata of the Enciso Group were deposited in a rift lake that formed in the NW sector of the Mesozoic Iberian Rift System under (sub)tropical greenhouse climate conditions.

Thirteen microfacies and twenty one lithofacies are recognized from the Enciso Group. These lithofacies were further grouped into twelve architectural-elements. Markov chain analysis results in nine sedimentary environments: one fluvial avulsion deposit, two siliciclastic lacustrine systems (LS-A and LS-B), three mixed siliciclastic-carbonate lacustrine models (LM-A, LM-B and LM-C), two carbonate lacustrine environments (LC-A and LC-B), and one lacustrine deltaic model (DL). The deposits of the Enciso Group are composed of a complex sequence of interbedded fluvial avulsion belts and shallow-lacustrine environments.
\end{abstract}

The lacustrine deposits display evidence for frequent subaerial exposure. The lack of welldeveloped paleosoils implies exposure times were short. The sedimentological evidences indicates that Enciso paleolake is best characterized by shallow waters and low-energy ramp-type margins that was subjected to periodic oscillations in lake level resulted in the exposure of large areas.

Stable isotope and geochemical data also point toward evaporated lake waters, at least during carbonate deposition. Paleontological and facies data indicate Enciso paleolake was primarily freshwater-oligohaline with mesohaline-polihaline waters, and was characterized by perennial conditions. Lacustrine deposition appear to have been continuous in space and time $(5,57 \mathrm{Ma})$.

Stratigraphic cyclicity was dominantly controlled by climate fluctuation Spectral analyses generating periodicity ratios compatible with Milankovitch orbital forcing have been well documented for the Enciso Group.

The great majority of dinosaur tracksites occur in the upper units either in fluvio-deltaic environments related to avulsion and shallow mixed-carbonate lacustrine environments.

The dinosaur trackway pattern for the Enciso Group is NNE- SSW. These orientation suggests that dinosaurs, especially theropods, passed through the lake basin in contrast with the orientation pattern observed in other lacustrine areas from which a preferential dinosaur movement parallel to the coast/shore has been observed. 


\section{Índice}

\section{ÍNDICE GENERAL}

CAPÍTULO 1: INTRODUCCIÓN.............................................................................................. 1

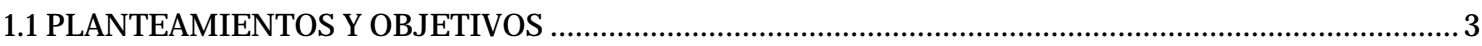

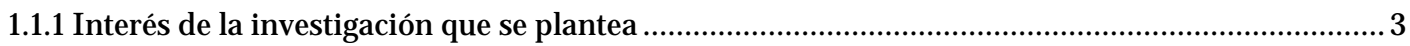

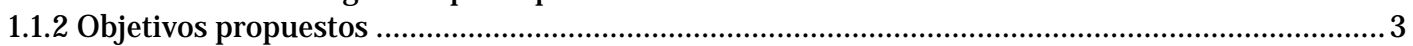

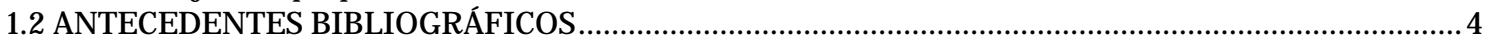

CAPÍTULO 2: METODOLOGÍA.............................................................................9

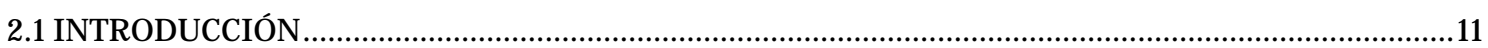

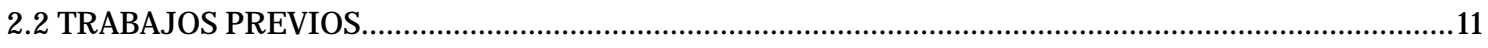

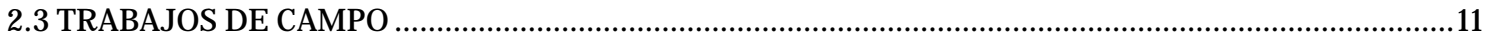

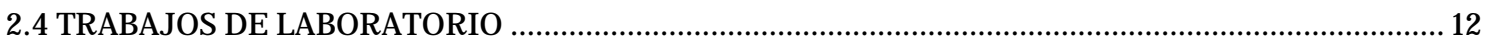

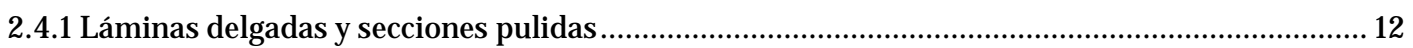

2.4.2 Elementos mayoritarios y traza............................................................................................. 13

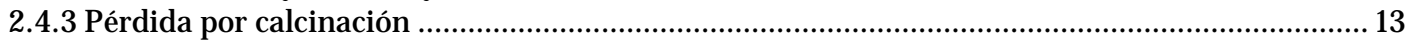

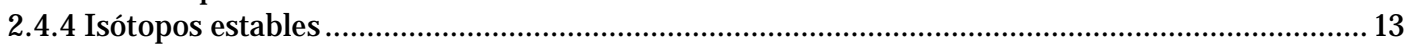

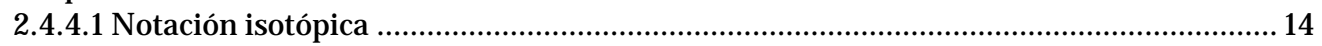

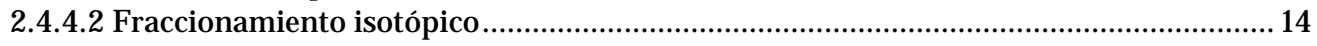

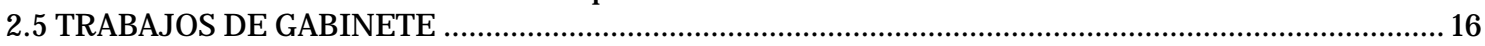

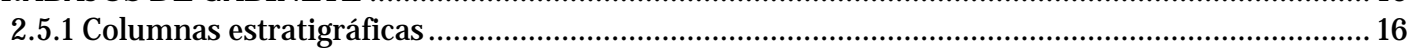

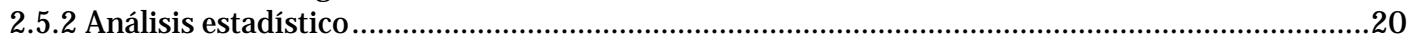

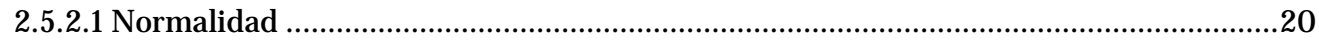

2.5.2.2 Análisis de componentes principales o factores.........................................................20

CAPÍTULO 3: MARCO TECTÓNICO-ESTRATIGRÁFICO DE LA CUENCA DE CAMEROS........23

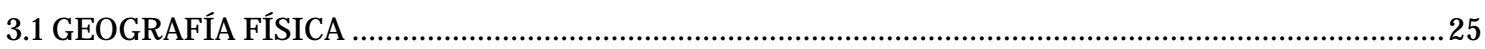

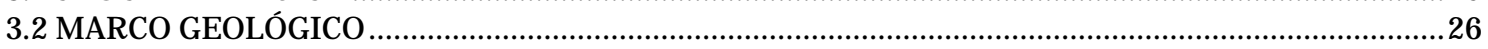

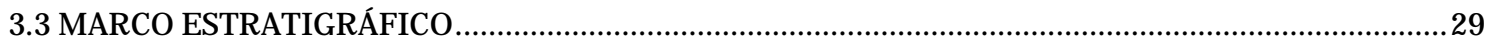

3.3.1 Secuencia Deposicional 1 (SD 1): Titoniense........................................................................... 31

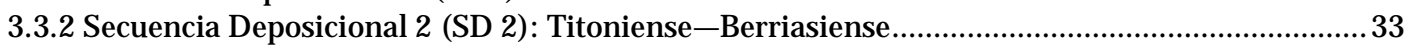

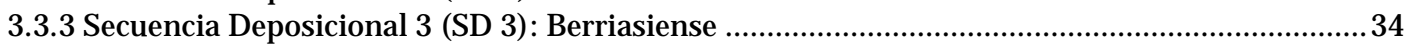

3.3.4 Secuencia Deposicional 4 (SD 4): Berriasiense terminal-Valanginiense basal ........................ 37

3.3.5 Secuencia Deposicional 5 (SD 5): Valanginiense-Hauteriviense ...............................................38

3.3.6 Secuencia Deposicional 6 (SD 6): Hauteriviense terminal-Barremiense ...................................39

3.3.7 Secuencia Deposicional 7 (SD 7): Barremiense superior-Aptiense inferior ..............................40

3.3.8 Secuencia Deposicional 8 (SD 8): Aptiense superior-Albiense...............................................43

CAPÍTULO 4: SISTEMAS LACUSTRES: ESTADO DEL ARTE..........................................45

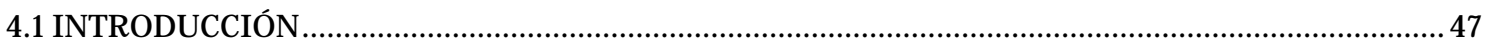

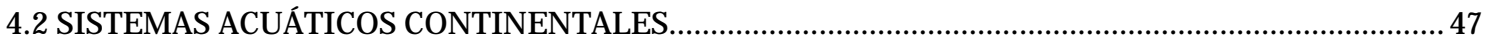

4.2.1 Definición de lago, laguna y charca (ambiente lacustre) ................................................................48

4.2.2 Definición de humedal (ambiente palustre) ……………................................................................49

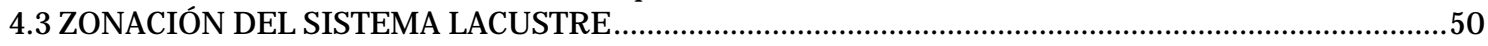

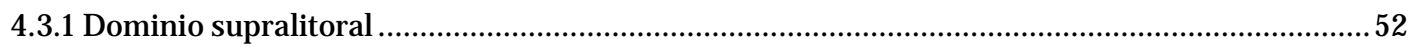

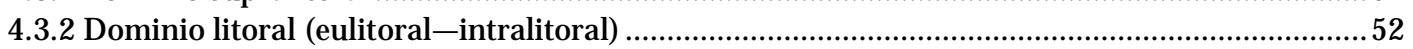

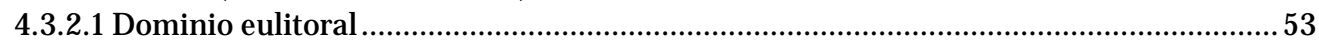

4.3.2.2 Dominio intralitoral ................................................................................................. 54

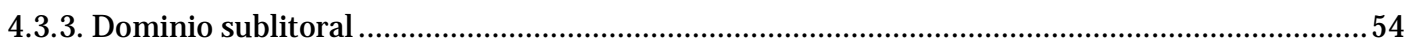

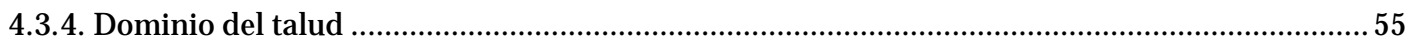

4.3.5. Dominio profundo o abierto ......................................................................................................5 56

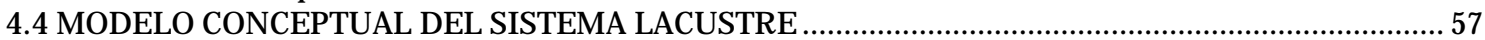

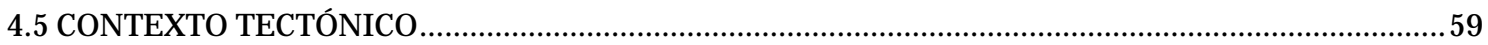

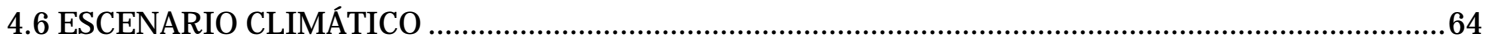

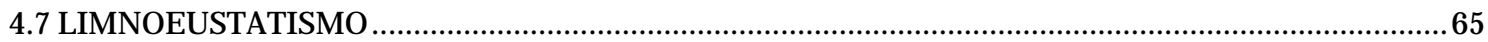

4.8 GEOLOGÍA DE LA CUENCA DE DRENAJE

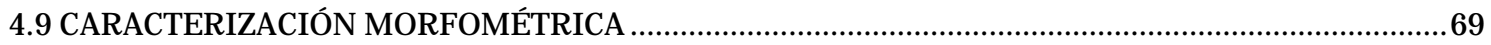

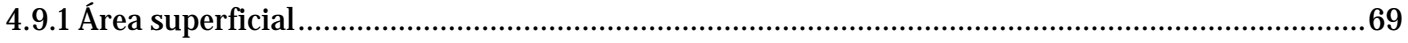

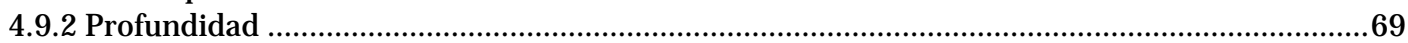

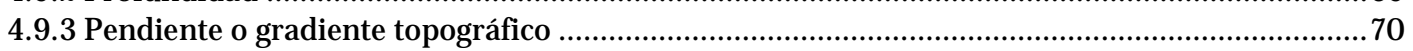

4.10 HIDROLOGÍA DEL LAGO ...........................................................................................................

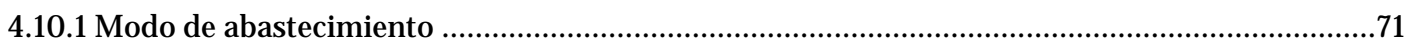

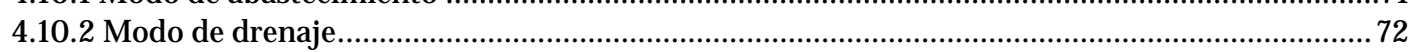

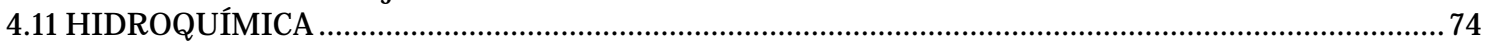




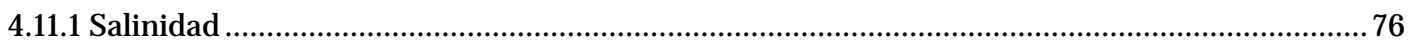

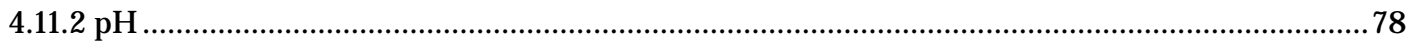

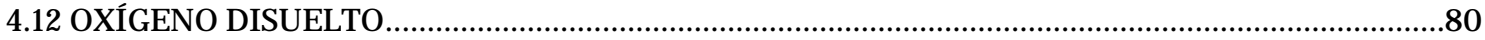

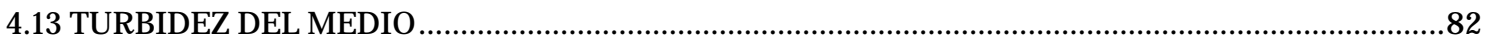

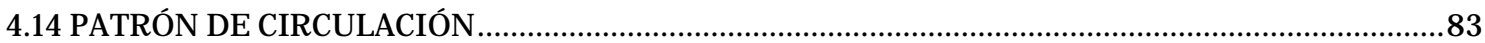

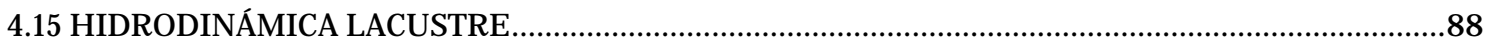

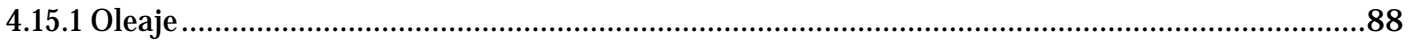

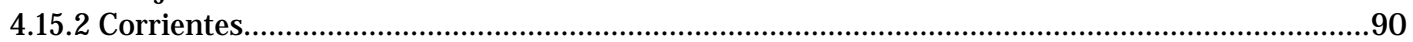

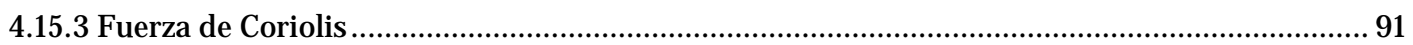

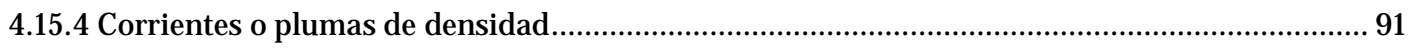

CAPÍTULO 5: ANÁLISIS SEDIMENTOLÓGICO: MICROFACIES Y FACIES..........................95

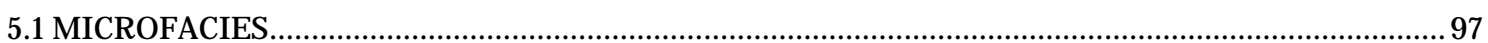

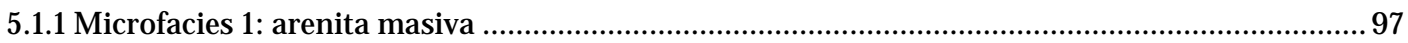

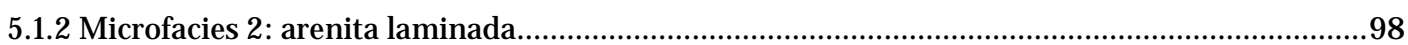

5.1.2.1 Microfacies 2a: arenita con laminación debida a moscovita ........................................98

5.1.2.2 Microfacies 2b: arenita con laminación debida a ostrácodos .......................................99

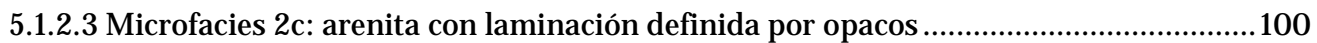

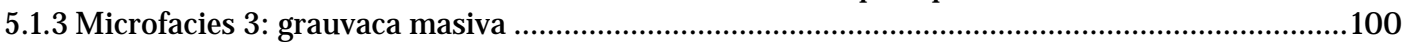

5.1.4 Microfacies 4: arenita -limolita laminada ..........................................................................101

5.1.5 Microfacies 5: limolita masiva............................................................................................... 102

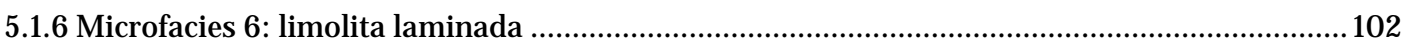

5.1.7 Microfacies 7: caliza bioclástica mudstone-wackestone ........................................................ 104

5.1.7.1 Microfacies 7a: caliza bioclástica de ostrácodos........................................................ 104

5.1.7.2 Microfacies 7b: caliza bioclástica de carófitas.......................................................... 105

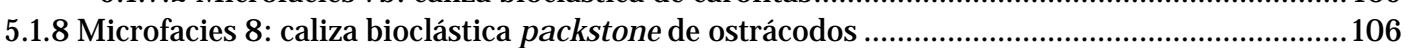

5.1.8.1 Microfacies 8a: packstone de ostrácodos ................................................................... 106

5.1.8.2 Microfacies 8b: packstone de ostrácodos con intraclastos ........................................ 107

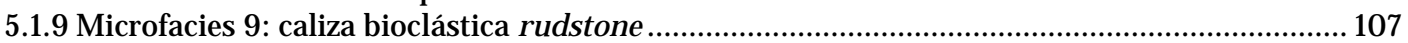

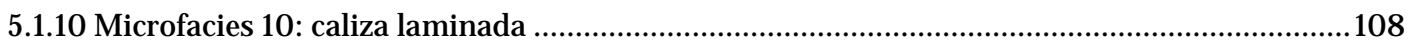

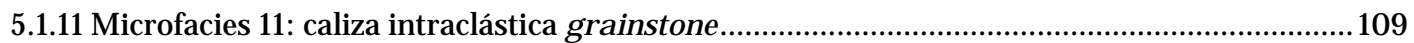

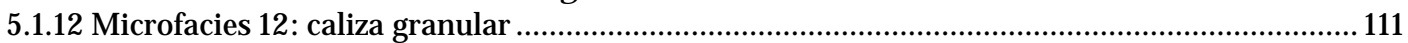

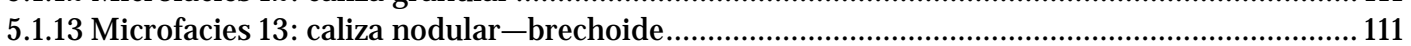

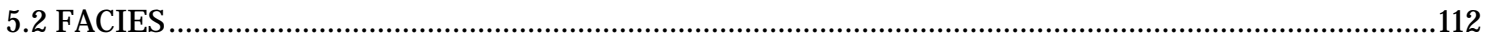

5.2.1 Litofacies As: arenisca con estratificación cruzada en surco a gran escala...............................114

5.2.2 Litofacies Ap: arenisca con estratificación cruzada planar a gran escala ....................................115

5.2.3 Litofacies Ar: arenisca con rizaduras .................................................................................116

5.2.4 Litofacies Ah: arenisca con laminación horizontal ..................................................................118

5.2.4.1 Litofacies $\mathrm{Ah}_{1}$ : arenita con laminación horizontal (paralela) .........................................119

5.2.4.2 Litofacies Ah2: grauvaca con laminación horizontal (paralela) ................................... 120

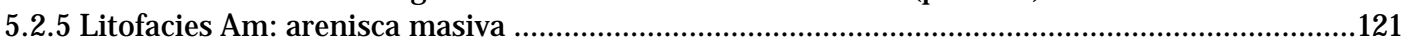

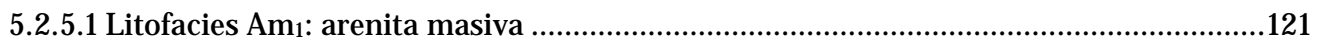

5.2.5.1 Litofacies Am2: grauvaca masiva .......................................................................... 122

5.2.6 Litofacies Lh: lutita con laminación horizontal (paralela) ....................................................... 123

5.2.6.1 Litofacies Lh1: lutita con laminación horizontal (paralela) de color oscuro................. 124

5.2.6.2 Litofacies Lh2: lutita con laminación horizontal (paralela) de color azul, gris o verde 125

5.2.7 Litofacies Lm: lutita masiva............................................................................................... 126

5.2.7.1 Litofacies $\mathrm{Lm}_{1}$ : lutita masiva de color oscuro..............................................................127

5.2.7.2 Litofacies $\mathrm{Lm}_{2}$ : lutita masiva de color azul o gris .....................................................127

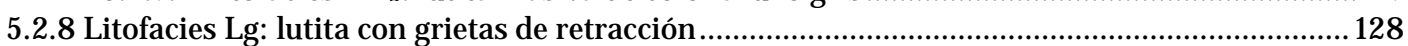

5.2.9 Litofacies LMm: lutita y/ o marga masiva ........................................................................ 130

5.2.10 Litofacies Mm: marga masiva.............................................................................................. 131

5.2.11 Litofacies Ch: caliza con laminación horizontal (paralela) ....................................................... 132

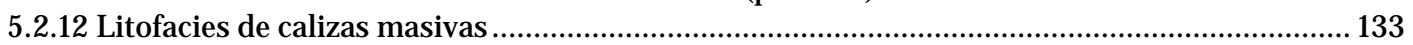

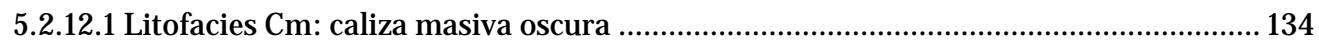

5.2.12.2 Litofacies Cg: caliza masiva con grietas de retracción............................................ 135

5.2.12.3 Litofacies Cn: caliza masiva nodular o con nódulos ................................................. 136

5.2.13 Litofacies CAm: caliza arenosa masiva............................................................................. 136

5.2.14 Litofacies Q: lumaquela con fósiles límnicos .....................................................................137

5.2.14.1 Litofacies Qo: lumaquela de ostrácodos...............................................................137

5.2.14.2 Litofacies Qm: lumaquela de moluscos ................................................................. 139

CAPÍTULO 6: ANÁLISIS SEDIMENTOLÓGICO: ELEMENTOS ARQUITECTÓNICOS Y MEDIOS 


\section{Índice}

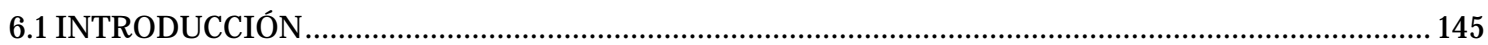

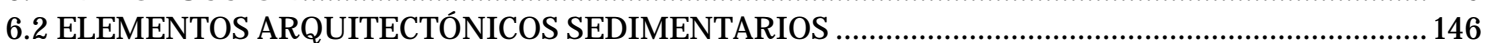

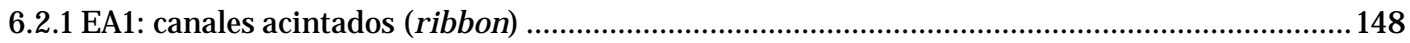

6.2.2 EA2: cuerpos tabulares de areniscas con laminación horizontal............................................. 154

6.2.3 EA3: cuerpos tabulares de areniscas con evidencias de oleaje .................................................155

6.2.4 EA4: cuerpos tabulares de areniscas masivas....................................................................155

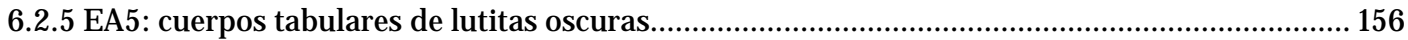

6.2.6 EA6: cuerpos tabulares de lutitas de colores variados .......................................................... 158

6.2.7 EA7: cuerpos tabulares de calizas masivas ......................................................................... 158

6.2.8 EA8: cuerpos tabulares de calizas con evidencias de emersión ................................................. 159

6.2.9 EA9: cuerpos tabulares de calizas con laminación horizontal ................................................... 160

6.2.10 EA10: cuerpos tabulares de margas y/ o lutitas con evidencias de emersión ............................ 160

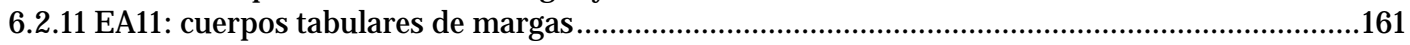

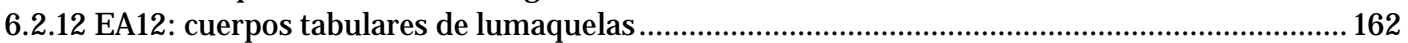

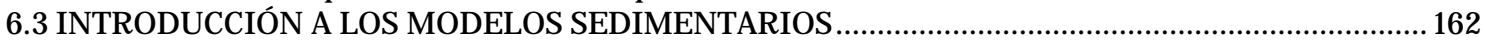

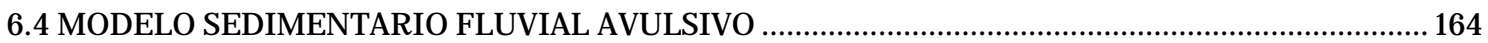

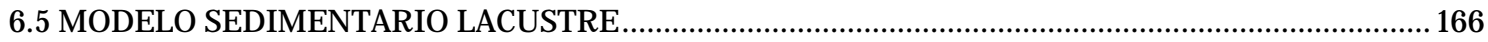

6.5.1 Modelo sedimentario lacustre siliciclástico.........................................................................167

6.5.1.1 Modelo lacustre siliciclástico A (LS-A) ...................................................................167

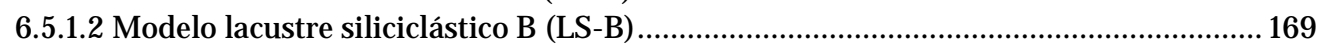

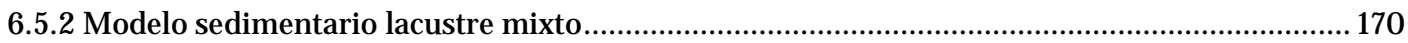

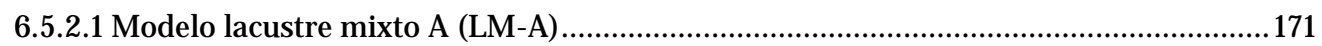

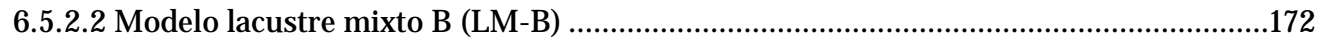

6.5.2.3 Modelo lacustre mixto C (LM-C) ............................................................................173

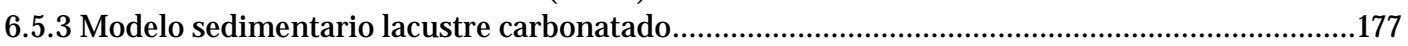

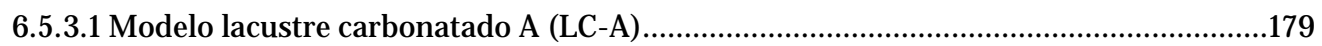

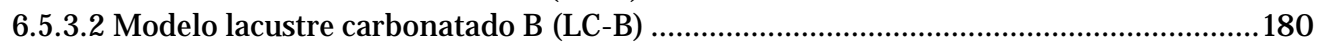

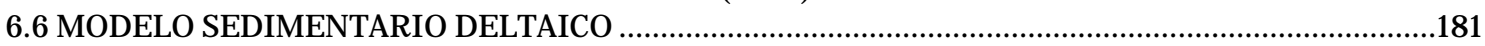

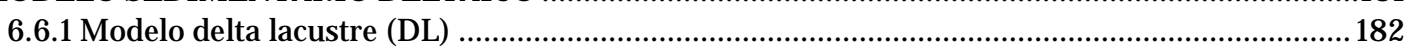

CAPÍTULO 7: ANÁLISIS ISOTÓPICO Y GEOQUÍMICO DEL GRUPO ENCISO..................... 185

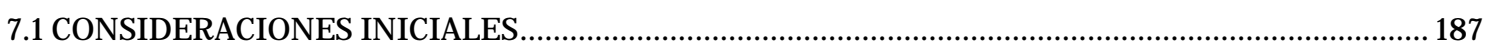

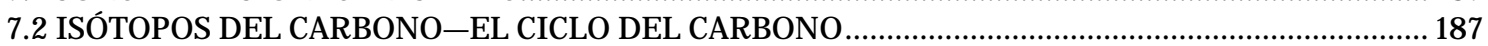

7.2.1 Entrada de carbono desde fuera de la cubeta (carbono alóctono) .......................................... 189

7.2.2 Intercambio de carbono entre el agua y la atmósfera......................................................... 190

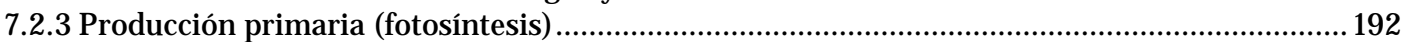

7.2.4 Mineralización del carbono orgánico (oxidación-respiración) ............................................... 193

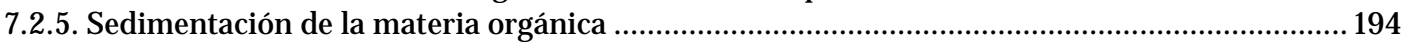

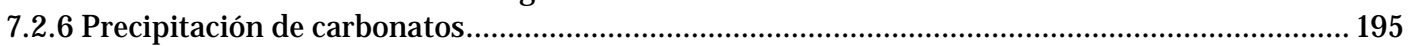

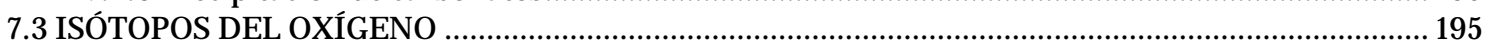

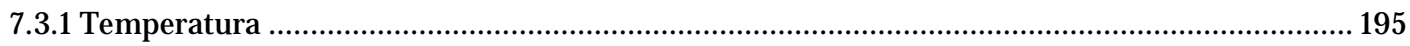

7.3.2 Composición isotópica del agua del lago $\left(\delta_{\mathrm{L}}\right)$ - Balance hídrico............................................. 196

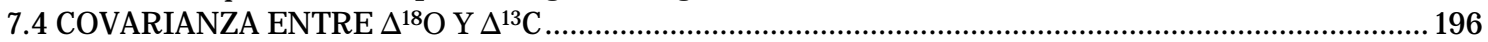

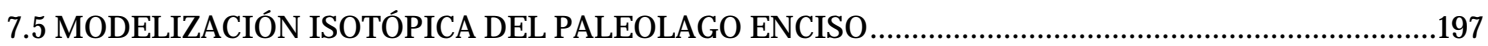

7.5.1 Isotopía del carbono en el paleolago Enciso ....................................................................... 198

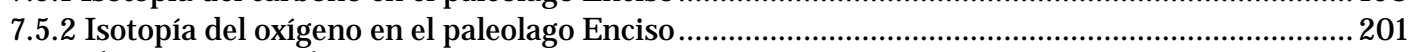

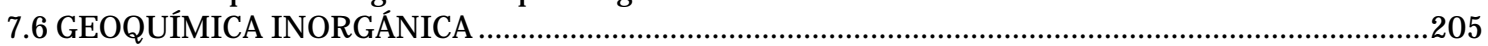

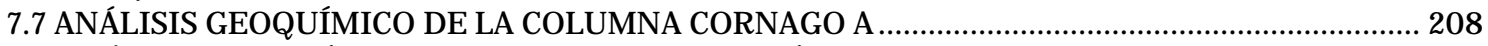

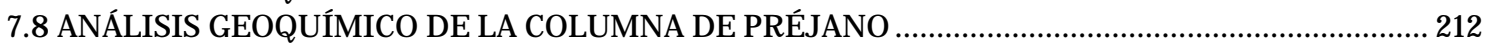

CAPÍTULO 8: ANÁLISIS CICLOESTRATIGRÁFICO DEL GRUPO ENCISO..........................217

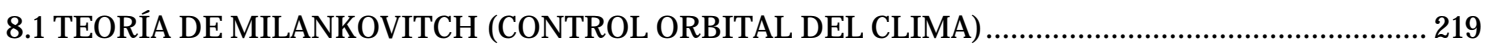

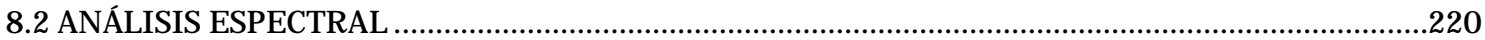

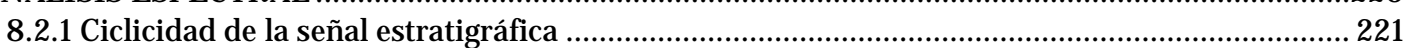

8.2.1.1 Señal estratigráfica de la columna de Enciso ........................................................... 221

8.2.1.2 Señal estratigráfica de la columna de Ambas Aguas .................................................224

8.2.2 Ciclicidad orbital durante el Aptiense inferior .....................................................................224

8.3 COMPARACIÓN DE LA CICLICIDAD ESTRATIGRÁFICA Y ORBITAL .............................................228

8.3.1 Resultados en la columna de Enciso.................................................................................229

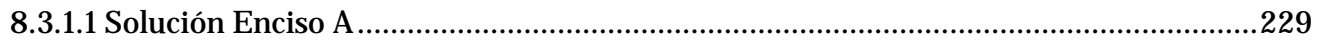

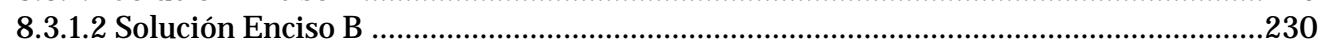

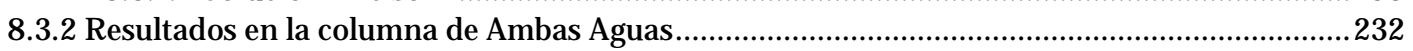

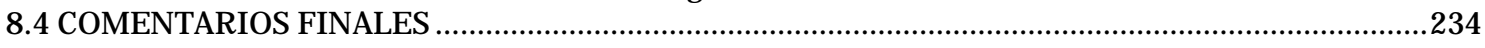

CAPÍTULO 9: MODELO CONCEPTUAL DEL PALEOLAGO ENCISO .............................. 237 


\section{Índice}

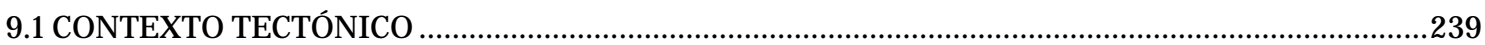

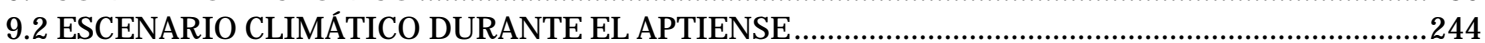

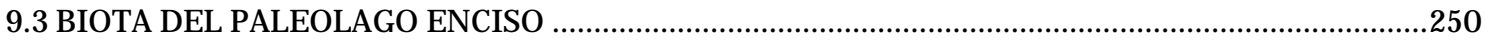

9.4 CARACTERIZACIÓN MORFOMÉTRICA DEL PALEOLAGO ENCISO .............................................. 251

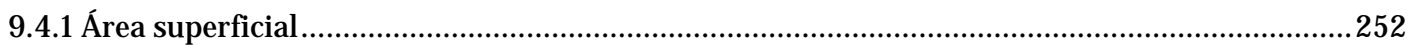

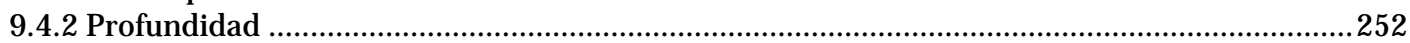

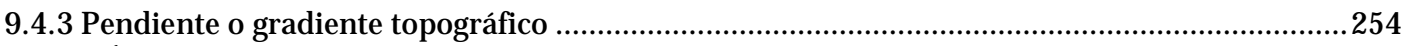

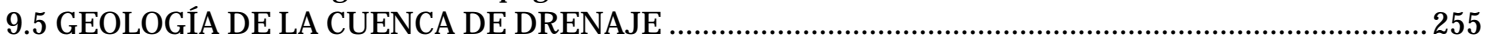

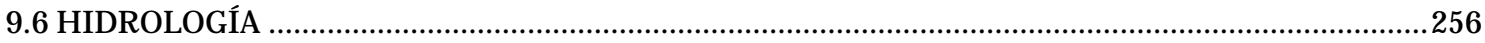

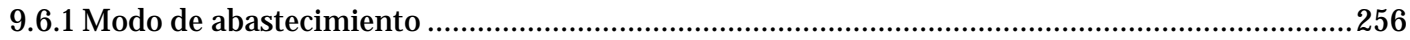

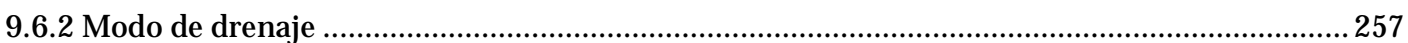

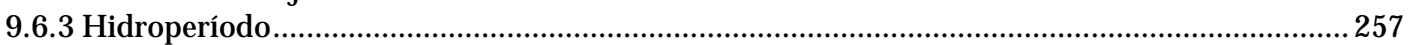

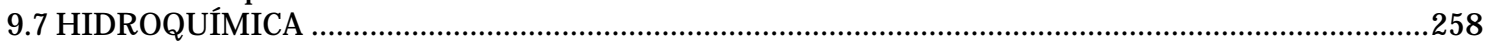

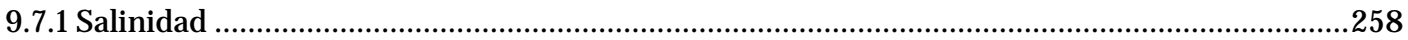

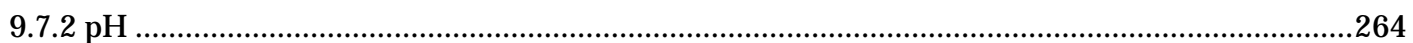

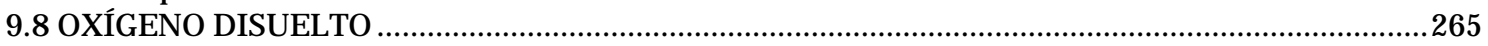

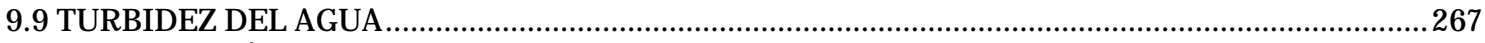

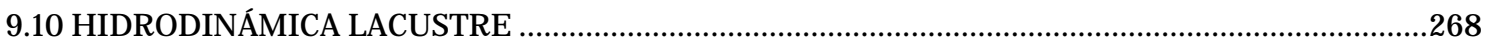

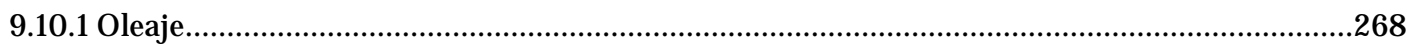

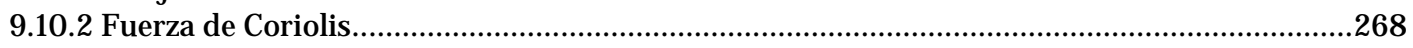

CAPÍTULO 10: YACIMIENTOS ICNOLÓGICOS EN LA ZONA DE ENCISO-AMBAS AGUAS ..271

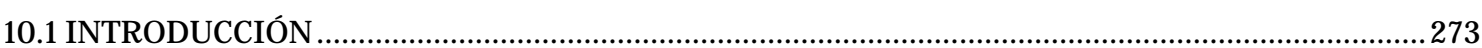

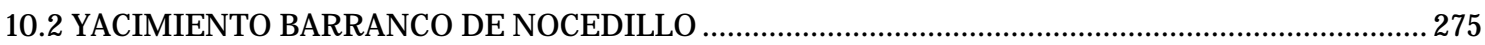

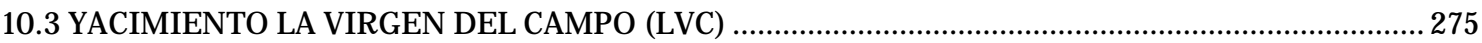

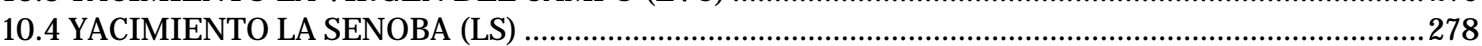

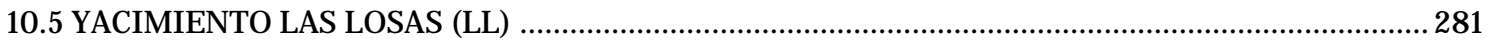

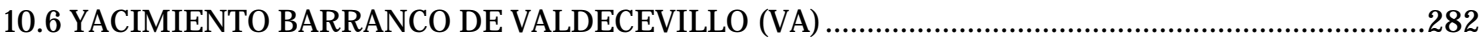

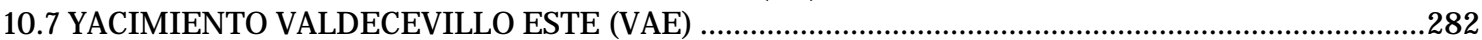

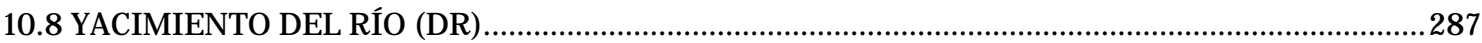

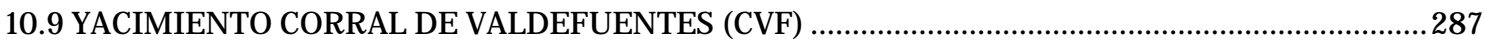

10.10 YACIMIENTO LLANO DEL COJ O (INÉDITO; LLC) ................................................................290

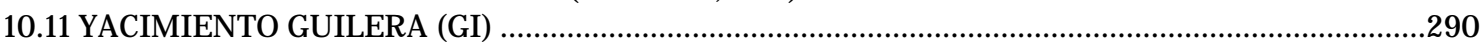

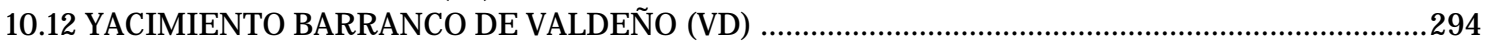

10.13 YACIMIENTO TOMILLAR_VALLECUEVANOS (INÉDITO; TOV) ..............................................294

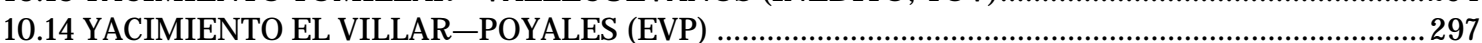

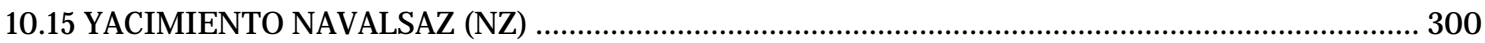

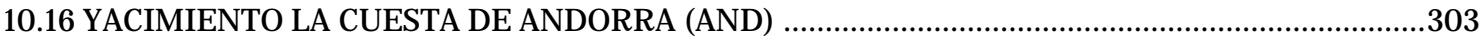

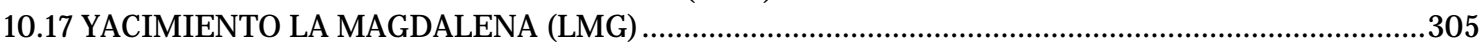

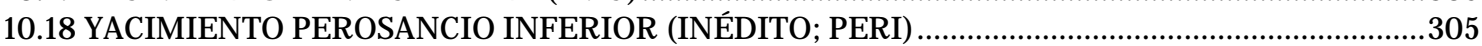

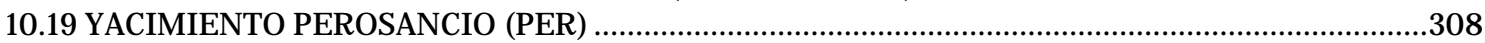

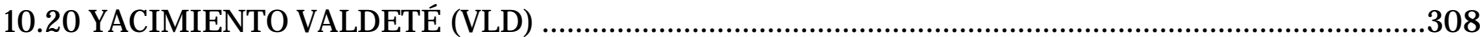

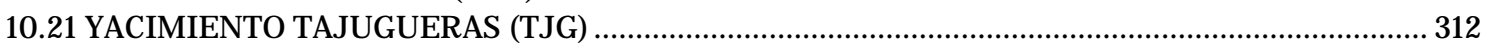

CAPÍTULO 11: YACIMIENTOS ICNOLÓGICOS EN LA ZONA DE MUNILLA....................... 315

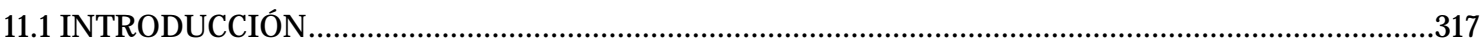

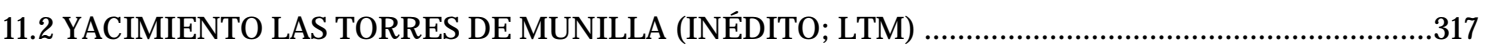

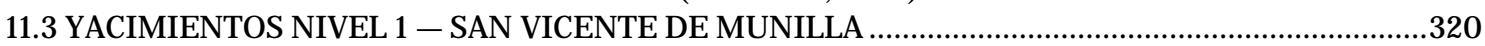

11.3.1 San Vicente de Munilla Nivel 1 Afloramiento 1 o San Vicente I (SVM I) .................................320

11.3.2 San Vicente de Munilla Nivel 1 Afloramiento 2 o San Vicente II (SVM II) ................................ 321

11.3.3 San Vicente de Munilla Nivel 1 Afloramiento 3 o San Vicente III (SVM III) .............................. 321

11.3.4 San Vicente de Munilla Nivel 1 Afloramiento 4 o San Vicente IV (SVM IV) ...............................326

11.3.5 San Vicente de Munilla Nivel 1 Afloramiento 5 o San Vicente V (SVMV) ..............................326

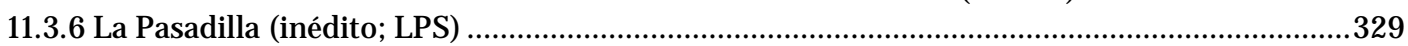

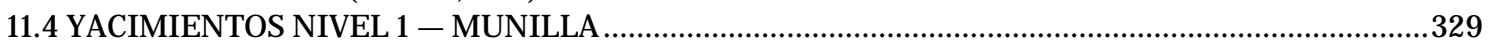

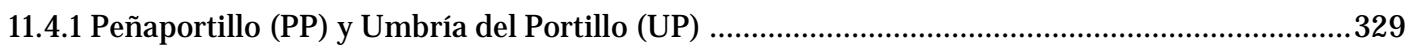

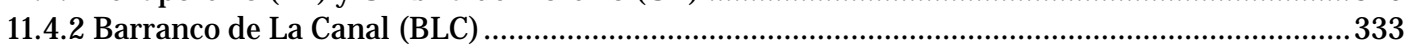

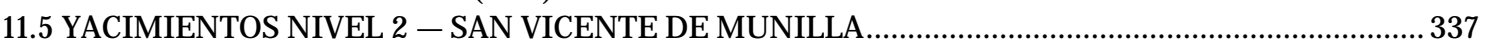

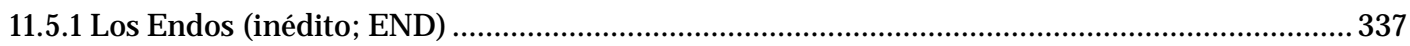

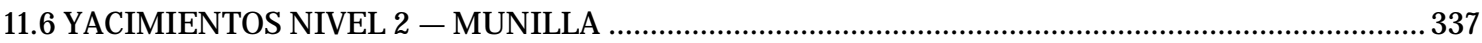

11.6.1 San Vicente de Munilla Nivel 2 Capa 6 - Barranco de La Canal IX (BLC IX) ...........................339

11.7 YACIMIENTOS NIVEL 3 - SAN VICENTE DE MUNILLA..............................................................339

11.7.1 San Vicente de Munilla Nivel 3 Afloramiento 1 o San Vicente VII (SVM VII) ...........................342

11.7.2 San Vicente de Munilla Nivel 3 Afloramiento 4 o San Vicente X (SVM X) ...............................344 


\section{Índice}

11.7.3 San Vicente de Munilla Nivel 3 Afloramiento 5-6 o San Vicente XI-XII (SVM XI-SVM XII).

11.7.4 San Vicente de Munilla Nivel 3 Alloramiento 7 o San Vicente XIII (SVM XIII) ........................348

11.7.5 Umbría Pelilla 1y 2 (inéditos; UPE 1y UPE 2) .........................................................................349

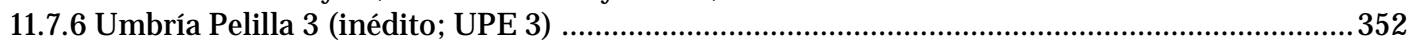

11.8 YACIMIENTOS NIVEL 4 -SAN VICENTE DE MUNILLA ...........................................................352

11.8.1 San Vicente de Munilla Nivel 4 Afloramiento 1 o San Vicente XIV (SVM XIV) ........................352

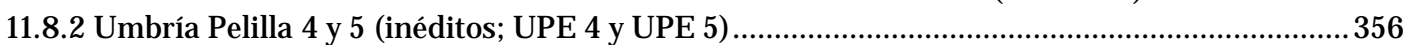

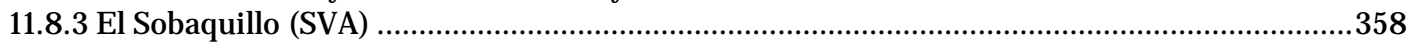

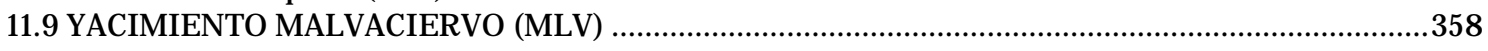

CAPÍTULO 12: YACIMIENTOS ICNOLÓGICOS EN LA ZONA DE CORNAGO ....................... 361

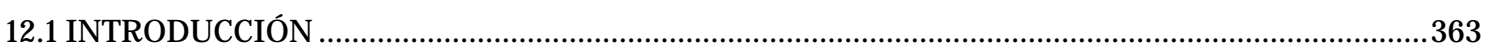

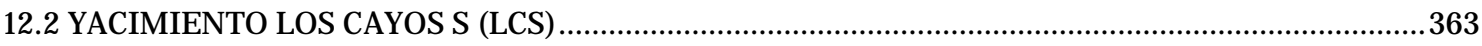

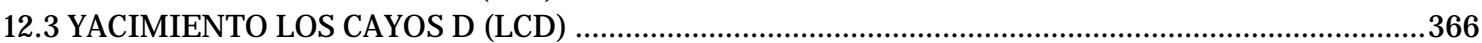

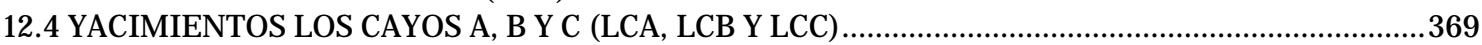

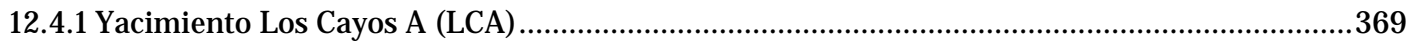

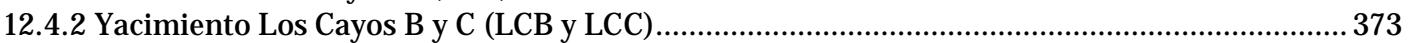

12.4.3 Interpretación del medio deposicional de Los Cayos A, B y C.................................................378

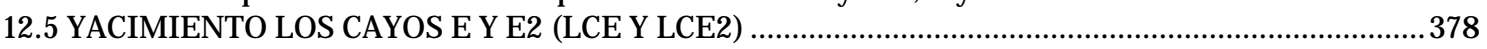

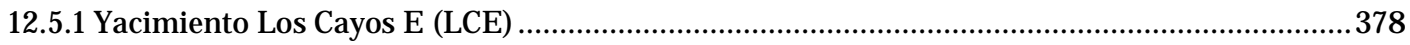

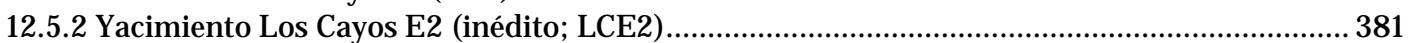

12.5.3 Interpretación del medio deposicional de Los Cayos E y E2 .................................................... 381

CAPÍTULO 13: YACIMIENTOS ICNOLÓGICOS EN LA ZONA DE PRÉJ ANO .....................383

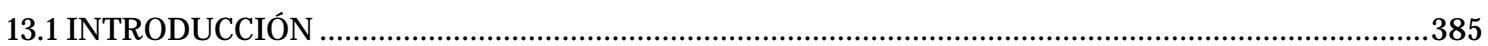

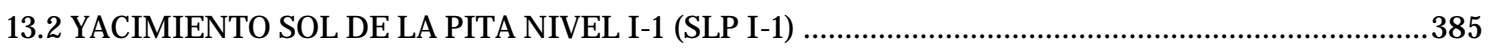

13.3 YACIMIENTO SOL DE LA PITA NIVELES I-2, I-3 E I-4 (SLP I-2, SLP I-3 Y SLP I-4) ......................387

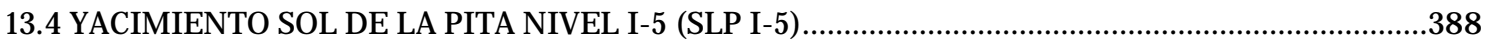

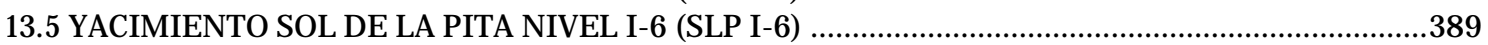

13.6 INTERPRETACIÓN DEL MEDIO DEPOSICIONAL DE SOL DE LA PITA I-2 A I-6..........................390

CAPÍTULO 14: CONTROL PALEOGEOGRÁFICO DE LOS YACIMIENTOS ICNOLÓGICOS .... 391

CAPÍTULO 15: CONCLUSIONES.............................................................................409

CAPÍTULO 16: REFERENCIAS BIBLIOGRÁFICAS ................................................417 


\section{ÍNDICE DE FIGURAS}

Figura 2.1: Modelo de caja utilizado en la elaboración de las columnas estratigráficas............................... 16

Figura 2.2: Tramas y leyenda de las principales litologías utilizadas en las columnas. ...............................17 Figura 2.3: Leyenda de los colores en muestra fresca utilizados en la columna con indicación de las referencias principales a los colores de la tabla de referencia Munsell. .................................................... 18 Figura 2.4: Leyenda de equivalencia entre los colores utilizados en la columna y los elementos

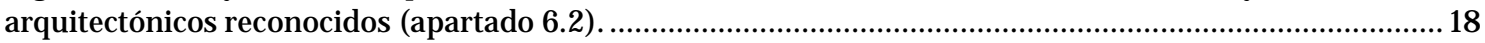

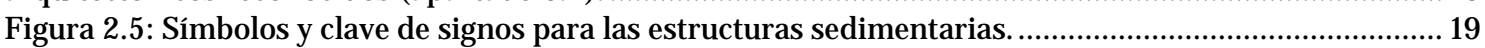
Figura 2.6: Símbolos del contenido paleontológico y restos de actividad orgánica. .................................... 19 Figura 3.1: Mapa físico de la Península Ibérica mostrando la situación de la Unidad de Cameros (en el recuadro), así como las provincias que abarca.................................................................................25 Figura 3.2: Mapa geológico de la Península Ibérica mostrando la localización de la Unidad de Cameros en el

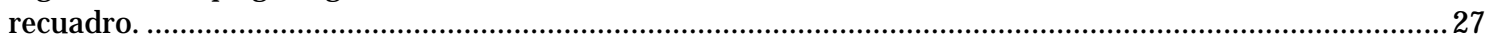
Figura 3.3: Mapa paleogeográfico de la Placa Ibérica durante el Aptiense indicando la posición de los

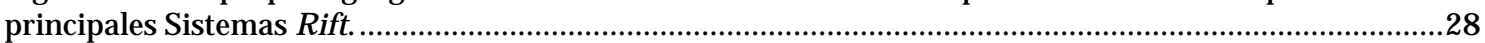
Figura 3.4: Mapa geológico de la cuenca de Cameros mostrando las subcuencas oriental y occidental, y su relleno según secuencias deposicionales. ..........................................................................................29 Figura 3.5: Cuadro litoestratigráfico de la subcuenca Cameros Oriental.................................................. 31

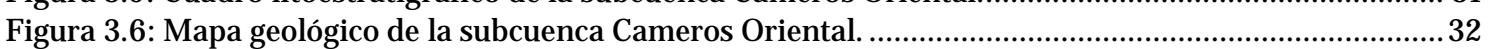
Figura 4.1: Esquema de la zonación presente en un lago, mostrando los diferentes dominios y las principales características sedimentarias y biológicas de cada uno de ellos. ............................................................51 Figura 4.2: Diagrama Erosión-Transporte-Acumulación (líneas continuas) comparado con los valores de la profundidad límite de deposición del fango (líneas punteadas) para diferentes pendientes

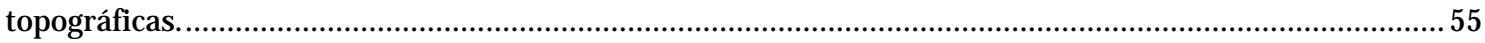
Figura 4.3: Diagrama con los tres tipos de cuencas lacustres en función del espacio de acomodación y la tasa de aportes de sedimento y agua. Modificado y redibujado de BOHACS et al. (2000). P/E representa precipitación/ evaporación.

Figura 4.4: Modelo digital del terreno de la Depresión Nicaragüense (SRTM30) con indicación de los principales lagos (GLWD Global Lake Wetland Database). ..................................................................60 Figura 4.5: Modelo digital del terreno del Sistema Rift Africano Oriental (SRTM30) con indicación de los

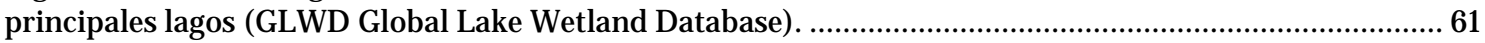
Figura 4.6: Modelo digital del terreno del Sistema Rift Baikal (SRTM30) con indicación de los principales lagos (GLWD Global Lake Wetland Database).................................................................................62 Figura 4.7: Índice de exposición e hidroperíodo. Modificado y redibujado de PLATT Y WRIGHT (1992)........66 Figura 4.8: Ajuste obtenido entre el área de drenaje y el espejo de la cubeta a partir de los datos de 81 lagos localizados en un contexto rift (anexo I). Las líneas discontinuas representan un nivel de confianza del 0,95.

...69

Figura 4.9: Proporción de las diferentes formas en las que se encuentra el carbono disuelto en agua en función del $\mathrm{pH}$. Se ha calculado para un valor de $\mathrm{CO}_{2}$ atmosférico preindustrial (280 ppm), a 25으 y para dos salinidades: limnética (línea discontinua) y marina (línea continua). Para los cálculos realizados véase el anexo II. 79 Figura 4.10: Histograma del rango de variación del pH de los lagos carbonatados actuales. Se han utilizado

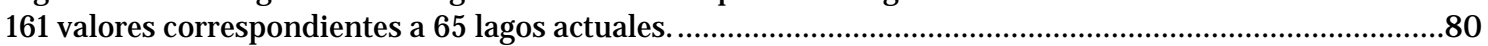
Figura 4.11: Variación de la saturación en oxígeno del agua en función de la temperatura y la salinidad para un valor atmosférico actual del 20,95\%. Las tramas indican salinidad: trama continua (0\%o), trama discontinua (18\%o) y trama a puntos (35\%). Para los cálculos realizados véase anexo III........................... 81 Figura 4.12: Relación entre la densidad y la temperatura a distintas salinidades según la fórmula de CHENY MiLLERO (1986). .84 Figura 4.13: Profundidad teórica de la termoclina y epilimnion en función del espejo de la cubeta lacustre. La trama continua representa la profundidad del epilimnion y la discontinua es para la termoclina. ..........85 Figura 4.14: Patrón de mezcla de los lagos tropicales actuales en función del área del espejo y de la profundidad media. Modificado y redibujado de LEWIS (2000). .............................................................86 Figura 4.15: Mecanismos de distribución de los diferentes tipos de plumas de densidad existentes en un lago.

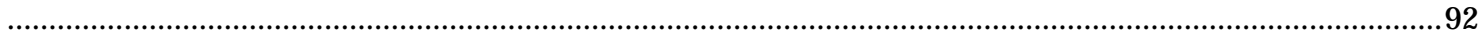

Figura 5.1: Ejemplos de la microfacies 1 bajo el microscopio petrográfico. A) y B) muestran el aspecto general (x2). C) y D) son fotos de detalle (x10). Todas las fotografías han sido tomadas con nícoles cruzados. .......98 Figura 5.2: Ejemplos de la microfacies 2a bajo el microscopio petrográfico. A) Aspecto general de la muestra donde se observa la laminación (x2) y B) detalle de las láminas de moscovita (x10). Ambas fotografías han sido tomadas con nícoles cruzados. ...................................................................................................99 Figura 5.3: Ejemplos de la microfacies $2 \mathrm{~b}$ bajo el microscopio petrográfico. A) Aspecto general de la muestra donde se observan algunos ostrácodos enteros (x2). B) detalle de las láminas de ostrácodos (x10). Ambas fotografías han sido tomadas con nícoles cruzados. .99 


\section{Índice}

Figura 5.4: Ejemplos de la microfacies 2c. A) aspecto general de la muestra donde se observa la laminación definida por opacos (x2). La fotografía ha sido tomada con nícoles cruzados. B) muestra de mano en detalle de las láminas debidas a opacos..........................................................................................................100 Figura 5.5: Ejemplos de la microfacies 3 bajo el microscopio petrográfico. A) aspecto general de la muestra (x2) y B) detalle (x10). Ambas fotografías han sido tomadas con nícoles cruzados. ................................. 100 Figura 5.6: Ejemplos de la microfacies 4. Lámina FC: A) aspecto general de la laminación (x2) y B) detalle del contacto entre láminas (x10). Lámina W10: C) aspecto general de la laminación (x2) y D) detalle del contacto entre láminas. Todas las fotografías han sido tomadas con nícoles cruzados. E) y F) son ejemplos de la laminación en muestras de mano.................................................................................................... 102 Figura 5.7: Ejemplos de la microfacies 5 bajo el microscopio petrográfico. A) aspecto general de la muestra (x2) y B) detalle (x10). Ambas fotografías han sido tomadas con nícoles cruzados. .................................. 102 Figura 5.8: Ejemplos de la microfacies 6 bajo el microscopio petrográfico. A) y B) aspecto general de la laminación (x2). C) muestra de mano de la laminación. D) aspecto general (x2) y E) detalle (x10). Todas las fotografías han sido tomadas con nícoles cruzados. 103 Figura 5.9: Ejemplos de la microfacies 7a bajo el microscopio petrográfico. A) aspecto general de la muestra (x2) y B) detalle de los bioclastos (x10). Ambas fotografías han sido tomadas con nícoles cruzados. C) aspecto general (x2) y D) detalle (x10). Ambas fotografías han sido tomadas sin nícoles. ..................................... 104 Figura 5.10: Ejemplos de la microfacies 7b bajo el microscopio petrográfico. A) aspecto general de la muestra (x2) y B) detalle de las secciones de talos (x10). C) aspecto general (x2) y D) detalle (x10). Todas las fotografías han sido tomadas con nícoles cruzados. .............................................................................. 105 Figura 5.11: Ejemplos de la microfacies 8a bajo el microscopio petrográfico. A) y B) aspecto general de la muestra (x2). Ambas fotografías han sido tomadas con nícoles cruzados. C) y D) aspecto de las muestras de mano....... 106

Figura 5.12: Ejemplos de la microfacies 8b bajo el microscopio petrográfico. A) y B) aspecto general de la muestra (x2) y C) detalle (x10). Todas las fotografías han sido tomadas con nícoles cruzados. D) aspecto de

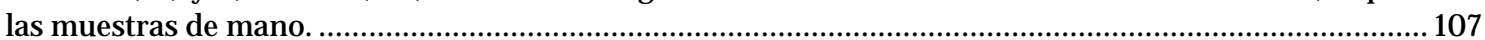
Figura 5.13: Ejemplos de la microfacies 9 bajo el microscopio petrográfico. A) y B) aspecto general de una lumaquela de gasterópodos (x2) y C) aspecto de la muestra de mano. D) aspecto general de la muestra S31 (x2). E) aspecto general de una lumaquela de bivalvos con gasterópodos (x2) y F) muestra de mano. Todas las fotografías han sido tomadas con nícoles cruzados.

108

Figura 5.14: Ejemplos de la microfacies 10 bajo el microscopio petrográfico. A) aspecto general dela muestra P151(x2) y B) detalle (x10). C) aspecto general dela muestra P64 (x2) y D) detalle (x10). Todas las fotografías han sido tomadas con nícoles cruzados.

Figura 5.15: Ejemplos de la microfacies 11 bajo el microscopio petrográfico. A) y B) Aspecto general de la muestra EN519 (x2). C) Detalle de un oncolito (x2). D) Detalle de un oolito (x10). Todas las fotografías han sido tomadas con nícoles cruzados.

.110

Figura 5.16: Ejemplos de la microfacies 12 bajo el microscopio petrográfico. A) y B) aspecto general de la muestra (x2). Todas las fotografías han sido tomadas con nícoles cruzados.....

111 Figura 5.17: Ejemplos de la microfacies 13 bajo el microscopio petrográfico. A) aspecto general de la muestra PR18 (x2). B) aspecto general de la muestra PR17 (x2). Todas las fotografías han sido tomadas con nícoles

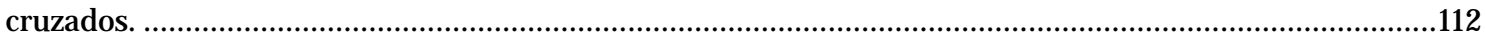
Figura 5.18: Aspecto en campo de las areniscas con estratificación cruzada a gran escala. A) Ejemplo de la facies As correspondiente al tramo 486 de la columna de Enciso. B) Ejemplo de la facies Ap en los tramos 103-105 de la columna de Préjano.

Figura 5.19: Aspecto en campo de las areniscas con rizaduras (facies Ar). A) Rizaduras con estructuras en diapasón (flechas) en el tramo 39 dela columna parcial del yacimiento icnológico San VicenteXI-XII-XIII. B) Rizaduras tipo rolling grain de crestas acuminadas en el tramo 346 de la columna de Munilla. C) Rizaduras tipo vortex de crestas redondeadas en el tramo 346 de la columna de Munilla..........................118 Figura 5.20: Aspecto en campo de las areniscas con laminación horizontal. A) Ejemplo de la facies Ah correspondiente al tramo 498 de la columna de Ambas Aguas. B) Ejemplo de la facies $\mathrm{Ah}_{2}$ en el tramo 306 de la columna de Cornago. 120 Figura 5.21: Aspecto en campo de las areniscas masivas. A) Ejemplo de la facies $\mathrm{Am}_{1}$ correspondiente al tramo 653-657 de la columna de Enciso. B) Ejemplo de la facies $\mathrm{Am}_{2}$ en el tramo 648 de la columna de Enciso. 122

Figura 5.22: Aspecto en campo de las lutitas oscuras con laminación horizontal. A) Ejemplo de la facies $\mathrm{Lh}_{1}$ correspondiente al tramo 34 de la columna de Cornago. B) Ejemplo de la facies Lh 1 en el tramo 491 de la columna de Ambas Aguas. C) Ejemplo de la facies Lh1 localizado en los tramos 276-277 de la columna de Enciso.

125

Figura 5.23: Aspecto en campo de las lutitas con laminación horizontal (facies $L_{2}$ ). A) Ejemplo de la facies Lh2 en el tramo 647 de la columna de Enciso. B) Ejemplo de la facies Lh2 en el tramo 369 de la columna de Ambas Aguas..... 126 Figura 5.24: Aspecto en campo de las lutitas masivas. A) Ejemplo de la facies $\mathrm{Lm}_{1}$ en los tramos 62-75 de la columna de Enciso. B) Ejemplo de la facies Lm1 en el tramo 4 de la columna del yacimiento de Peñaportillo. C) Ejemplo de la facies $\mathrm{Lm}_{2}$ localizado en el tramo 820 de la columna de Enciso. .. 128 


\section{Índice}

Figura 5.25: Aspecto en campo de las lutitas con grietas de retracción. A) Ejemplo de la facies Lg en el yacimiento icnológico de El Sobaquillo (Munilla). B) Ejemplo de la facies Lg en las inmediaciones del barranco de Los Cayos (Cornago). 129 Figura 5.26: Aspecto en campo de las lutitas y/ o margas masivas. A) y B) Ejemplos de la facies LMm en la zona de Los Cayos (Cornago). C) Ejemplo de la facies LMm en los tramos 170_174 de la columna de Ambas Aguas.

Figura 5.27: Aspecto en campo de las margas masivas. A) Ejemplo de la facies Mm en las zonas de Ambas Aguas. B) detalle de un bivalvo en posición de vida en las margas, en la zona de Los Cayos (Cornago). C) Detalle de un nódulo. 132 Figura 5.28: Aspecto en campo de las calizas con laminación horizontal. A) Ejemplo de la facies Ch en el tramo 668 de la columna de Enciso. B) Ejemplo de la facies Ch en los tramos 37-38 de la columna de Préjano. 133

Figura 5.29: Aspecto en campo de las calizas masivas oscuras. A) Ejemplo de la facies Cm en los tramos 257262 de la columna de Ambas Aguas. B) Ejemplo de la facies Cm con morfología de canal laxo (indicado por una flecha) en los tramos 295-297 de la columna de Ambas Aguas.. 134 Figura 5.30: Aspecto en campo de las calizas masivas con grietas de retracción. A) Ejemplo de la facies Cg en el tramo 156 de la columna de Cornago. B) Ejemplo de la facies Cg en las cercanías de yacimiento icnológico de Los Cayos (Cornago).

135 Figura 5.31: Aspecto en campo de las calizas masivas nodulares. A) Ejemplo de la facies Cn en el la zona de la Sierra del Palo (Enciso). B) Ejemplo de la facies Cn en el tramo 317 de la columna de Ambas Aguas.... 136 Figura 5.32: Aspecto en campo de las lumaquelas de ostrácodos. A) Ejemplo de la facies Qo en los tramos 61-67 de la columna de Ambas Aguas. B) Muestra de manos de la facies Qo procedente del tramo 254 de la columna Ambas Aguas.

138

Figura 5.33: Aspecto en campo de las lumaquelas de moluscos. A) y B) Ejemplos de la facies Qm (tipo 1) en la parte superior del Grupo Enciso en la zona de Los Cayos (Cornago). C) Ejemplo de la facies Qm (tipo 1) procedente del tramo 425 de la columna Ambas Aguas. D) Ejemplo de la facies Qm (tipo 3) en el tramo 440 de la columna de Enciso. 140

Figura 6.1: Panel de correlación de las unidades diferenciadas en el Grupo Enciso. Los números indican las columnas utilizadas: 1-Vadillos (DouBLET et al., 2003), 2-Munilla, 3-Enciso, 4-Ambas Aguas, 5-Zona entre Ambas Aguas y Cornago (DuRÁNTEZ et al., 1982), 6-Grávalos (AlONSO-AZCÁRATE, 1997). Se indica la distancia entre columnas...... 146 Figura 6.2: Principales elementos arquitectónicos presentes en el Grupo Enciso. A) EA1 en Ambas Aguas (tramo 59). B) EA1 a techo de la serie de Préjano (tramos 103-105). C) EA1 con acreción lateral en la zona de Rabanera-San Román de Cameros. D) Elemento de areniscas con laminación horizontal (EA2) en Ambas Aguas (tramo 406). E) Elementos de areniscas (EA3) y lutitas (EA6) en Enciso (tramos 817-820). F) Elementos de areniscas (EA3 y EA4) entre paquetes de lutitas EA6 en Enciso (tramos 684-689)............151 Figura 6.3: Principales elementos arquitectónicos presentes en el Grupo Enciso. A) Elementos de areniscas EA4 y de calizas EA7 entre paquetes de lutitas oscuras EA5 en Enciso (tramos 115-125). B) Elementos de areniscas masivas entre EA5 en Enciso (tramos 144-148). C) Elementos EA5, EA2 y EA10 en Enciso (tramos 273-314). D) Detalle del elemento EA5 que aparece en la fotografía anterior. E) Elemento EA10 comprendido entre EA6 en Enciso (tramos 7-13). 152 Figura 6.4: Principales elementos arquitectónicos presentes en el Grupo Enciso. A) Elementos de calizas en Cornago (tramo 70). B) Elementos de margas (EA11) y calizas (EA7 y EA8) con pasadas de EA10 en Ambas Aguas (tramos 124-169). C) Misma sección que la anterior tomada aproximadamente un kilómetro de distancia. El paquete naranja EA7 mantiene su continuidad lateral y potencia (tramo 176). D) Elemento de margas EA11 con intercalaciones de calizas EA7. A techo se observa un elemento EA6. Fotografía tomada en las inmediaciones del pueblo de Enciso (tramos 447-486).

Figura 6.5: Bloque diagrama teórico del medio sedimentario constituido por el cinturón de avulsión del

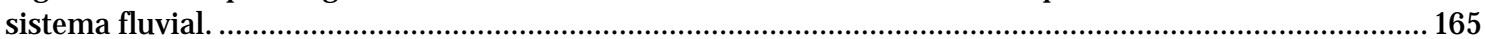
Figura 6.6: Bloque diagrama teórico del modelo lacustre siliciclástico A (LS-A)....................................... 168 Figura 6.7: Secuencia teórica y variaciones litológicas del modelo lacustre siliciclástico A (LS-A)............. 168 Figura 6.8: Bloque diagrama teórico del modelo lacustre siliciclástico B (LS-B)..................................... 169 Figura 6.9: Secuencia teórica y variaciones litológicas del modelo lacustre siliciclástico B (LS-B)............. 170 Figura 6.10: Bloque diagrama teórico del modelo lacustre mixto A (LM-A). ........................................... 171 Figura 6.11: Secuencia teórica y variaciones litológicas del modelo lacustre mixto A (LM-A). ....................172 Figura 6.12: Bloque diagrama teórico del modelo lacustre mixto B (LM-B). .............................................173 Figura 6.13: Secuencia teórica y variaciones litológicas del modelo lacustre mixto B (LM-B)...................173

Figura 6.14: Bloque diagrama teórico del modelo lacustre mixto C (LM-C)...............................................174 Figura 6.15: Secuencia teórica y variaciones litológicas del modelo lacustre mixto C (LM-C). ...................175 Figura 6.16: Bloque diagrama teórico del modelo lacustre mixto C1 (LM-C1) . ...........................................176 Figura 6.17: Secuencia teórica y variaciones litológicas del modelo lacustre mixto C1 (LM-C1). .................176 Figura 6.18: Bloque diagrama teórico del modelo lacustre mixto C2 (LM-C2) ..........................................177 Figura 6.19: Secuencia teórica y variaciones litológicas del modelo lacustre mixto C2 (LM-C2)................177 Figura 6.20: Bloque diagrama teórico del modelo lacustre carbonatado A (LC-A)...................................179 


\section{Índice}

Figura 6.21: Secuencia teórica y variaciones litológicas del modelo lacustre carbonatado A (LC-A).......... 180 Figura 6.22: Bloque diagrama teórico del modelo lacustre carbonatado B (LC-B)................................. 180 Figura 6.23: Secuencia teórica y variaciones litológicas del modelo lacustre carbonatado B (LC-B)........... 181 Figura 6.24: Secuencia teórica y variaciones litológicas del modelo de delta lacustre (DL)...................... 183 Figura 7.1: Ciclo del carbono simplificado en los lagos, con indicación de los procesos de fraccionamiento más comunes..

Figura 7.2: Gráfica de la presión parcial del $\mathrm{CO} 2$ en los lagos en función de la latitud. La línea discontinua horizontal representa la presión parcial media actual de la atmósfera $(\approx 370 \mu \mathrm{atm})$. En la figura se observa claramente la frecuente supersaturación de los lagos actuales. La figura se ha realizado a partir de los datos de MAROTTA et al. (2009).

Figura 7.3: Gráfico mostrando los valores $\delta^{18} \mathrm{O}$ y $\delta^{13} \mathrm{C}$ de los carbonatos precipitados en diversos lagos actuales. En color rojo se representan los lagos cerrados: Turkana $(r=0,85)$ (RICKETTS Y ANDERSON, 1998), Mono (LI Y KU, 1997), Qinghai (Xu et al., 2006), y complejo Greenly ( $r=0,67)$ (DuTKIEWICZ et al., 2000). En color azul se representan los lagos abiertos: Crawford (YU y EICHER, 1998), Elk (SMITH et al., 1997), Twins Pond, Tablas de Daimiel (VAlDEOLMILlos-RodRíGUEZ, 2004), Balatón (CSERNYI et al., 1995), Lawrence $(r=0,84)$ (DRUMMOND et al., 1995), Pretty $(r=0,71)$ (DRUMMOND et al., 1995), Bruin $(r=0,82)$ (DRUMMOND et al., 1995), y Tanganica $(r=0,71)$ (COHEN et al., 1997).

Figura 7.4: Representación $\delta^{18} \mathrm{O}$ y $\delta^{13} \mathrm{C}$ de los valores del Grupo Enciso en su contexto espacial y temporal. En color negro se indican los valores pertenecientes al Grupo Enciso: las series Cornago A-D y Préjano son datos propios, y las series Vadillos y Valdevigas corresponden a la tesis de DouBLET (2004). En verde se señalan los valores de otras formaciones de la cuenca de Cameros: Fm. Rupelo (Berriasiense) (PLATT, 1989b), Fm. Huérteles (Berriasiense) (Alonso-AzCÁRATE et al., 2006), y las formaciones Matute y Magaña (Titoniense) (GONZÁLEZ-ACEBRÓN, 2009). En azul se marcan los valores correspondientes al ámbito marino tetisiano Aptiense: La Bédoule en Francia (KuHNT et al., 1998) y la Fm Almadich en las Béticas (DE GEA et al., 2003). En rojo se presentan valores de sistemas continentales coetáneos: las formaciones Peterson (DRUMMOND et al., 1996) y Cedar Mountain (SHAPIRO et al., 2009) ambas del Aptiense de los Estados Unidos; la Fm Codó (PAZ y RosseTti, 2006) y el Miembro Nova Olinda de la Fm Crato (HeimHOFER et al., 2010), ambas del Aptiense-Albiense de Brasil; la Fm Morrison (DUNAGAN Y TURNER, 2004) del J urásico superior de los Estados Unidos; la Fm Yixian (CHEN et al., 2011) del Aptiense de China; y la Fm Huérguina (PoYATOARIZA et al., 1998) del Barremiense de España.

Figura 7.5: Ajuste obtenido entre la temperatura media del aire y la temperatura media del agua del lago a partir de 669 valores obtenidos en 28 lagos actuales localizados en latitudes tropicales. Los puntos negros hacen referencia a los valores CRU (Climatic Research Unit) y los puntos blancos a NCEP (National Centers for Environmental Prediction). 198 Figura 7.6: En trama transparente aparece el histograma del valor $\delta^{13} \mathrm{C}$ de las plantas terrestres durante el Aptiense $(n=564$; valor medio $-23,15 \pm 1,29 \%$ ). Los datos provienen de la Fm. Wonthaggi en Australia (GRÖCKE, 1998), Grupo Lower Greensand en Gran Bretaña (GRÖCKE, 2002), Grupos Sorachi y Yezo en J apón (ANDO et al., 2003), Fm. Arundel en Estados Unidos (JAHREN et al., 2005), Fm. Bhuj en la India (CHAKRABORTY et al., 2011) y una formación sin nombre en el Aptiense de Colombia (J AHREN et al., 2001). En gris aparece el histograma del valor $\delta^{13} \mathrm{C}$ de las plantas terrestres actuales $(\mathrm{n}=1615$; valor medio $27,82 \pm 2,63 \%$ o) (KoHN, 2010). 200 Figura 7.7: Gráfico $\delta^{18} \mathrm{O}$ y $\delta^{13} \mathrm{C}$ de los carbonatos del Grupo Enciso (Cornago y Préjano) con indicación de los valores $\delta^{13} \mathrm{C}$ teóricos, calculados para una calcita precipitada a una temperatura de $27^{\circ} \mathrm{C}$, en función de los diferentes procesos operantes en un lago. También se han trazado los datos pertenecientes a dos formaciones marinas aptienses: La Bédoule en Francia (KUHNT et al., 1998) y la Fm. Almadich en España (DE GEA et al., 2003).

201

Figura 7.8: Comparación del valor $\delta^{18} \mathrm{O}$ (VSMOW) de la precipitación en función de la latitud. La línea continua negra representa el valor actual (BOWEN Y WILKINSON, 2002). La línea discontinua gris muestra el valor estimado de la paleoprecipitación obtenido a partir del análisis de las esferosideritas (SuAREZ et al., 2011). La línea discontinua negra es el valor de la paleoprecipitación proveniente del Modelo de Circulación General de ZHOU et al. (2008) según la ecuación de SUAREZ et al. (2011)...................................................202 Figura 7.9: A) Histograma de valores $\delta^{18} \mathrm{O}_{\text {calcita }}$ del Grupo Enciso. B) Línea Meteórica de Calcita y ambiente diagenético (filones rellenos de calcita). .203 Figura 7.10: Gráfica que muestra la evolución de los valores $\delta^{18} \mathrm{O}_{\text {calcita }}$ (azul) y $\delta^{18} \mathrm{O}_{\text {dolomita }}$ (rojo), calculados considerando que ambos precipitan en equilibrio en aguas con una composición inicial igual a la de la precipitación, a una temperatura de $27^{\circ} \mathrm{C}$, y en función de la fracción de agua remanente en el lago para diferentes humedades relativas (h). Las líneas horizontales negras marcan los valores máximos $\delta^{18} \mathrm{O}$ de las muestras analizadas en cada columna muestreada. 204 Figura 7.11: Gráfico de los isótopos de las muestras del Grupo Enciso reorganizadas. Los colores son los mismos que para la figura 7.7. Los cuadrados hacen referencia a los valores de los filones rellenos de calcita (diagénesis). Los triángulos representan los valores afectados probablemente por diagénesis. Las cruces marcan la Línea de Meteórica de Calcita. Los círculos corresponden a los valores que guardan su señal isotópica original. .204

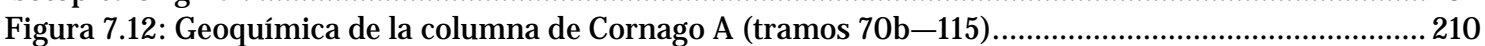




\section{Índice}

Figura 7.13: Geoquímica de la columna de Préjano (tramos 52-69). ....................................................... 214 Figura 8.1: Esquema del movimiento de la órbita terrestre respecto del Sol, mostrando la variación en su

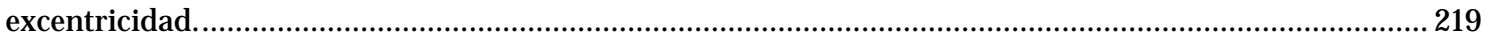
Figura 8.2: Esquema de los movimientos orbitales de la Tierra, mostrando los principales parámetros orbitales; (A) oblicuidad, y (B) precesión. ................................................................................................220 Figura 8.3: Señal estratigráfica obtenida a partir delos rangos de profundidad en las columnas estratigráficas de A) Enciso (1.215 m) y B) Ambas Aguas (636 m).........................................................................222 Figura 8.4: Periodogramas de la señal estratigráfica de las columnas de: A) Enciso y B) Ambas Aguas. Las líneas discontinuas representan los niveles de confianza. Los números marcan los picos de frecuencia y corresponden a los números que aparecen en el texto. ......................................................................223 Figura 8.5: A) Valores de la excentricidad orbital de la Tierra durante el Aptiense inferior basados en la solución nominal La2010. B) Periodograma de Lomb-Scargle de las principales periodicidades de la excentricidad durante el Aptiense inferior. La línea discontinua marca el nivel de confianza del 99,9\%. La numeración de los picos de frecuencia corresponde a los números que aparecen en el texto.....................225 Figura 8.6: A) Valores de la oblicuidad de la Tierra durante el Aptiense inferior obtenidos de la solución nominal La2004. B) Periodograma de Lomb-Scargle de las principales periodicidades de la oblicuidad durante el Aptiense inferior. La línea discontinua marca el nivel de confianza del 99,9\%. La numeración de los picos de frecuencia corresponde a los números que aparecen en el texto............................................226 Figura 8.7: A) Valores de la precesión de la Tierra durante el Aptiense inferior obtenidos de la solución nominal La2004. B) Periodograma de Lomb-Scargle de las principales periodicidades de la precesión durante el Aptiense inferior. La línea discontinua marca el nivel de confianza del 99,9\%. La numeración de los picos de frecuencia corresponde a los números que aparecen en el texto............................................227 Figura 8.8: Posible rango temporal del Grupo Enciso si se asume una duración temporal de 5,57 Ma. Las edades de los pisos y subpisos se han tomado de GTS2012 (OGG et al., 2012) y la biocronozona de RIVELINE et al. (1996)

Figura 9.1: A) Fotografía de uno de los niveles con múltiples volcanes de arena. B) y C) Detalle de los conos delos volcanes dearena, en el segundo ejemplo (C) se aprecia el cráter. D) Volcán de arena donde se observan numerosos caracteres distintivos (1) capa basal sin deformar, (2) capa superior no deformada, (3) preservación de las estructuras sedimentarias dela capa deformada hacia arriba, (4) expulsión del sedimento licuefactado y, (5) fragmentos convolutos transportados por el flujo licuefactado. .....

241 Figura 9.2: A) Nivel con evidencias de laminación convoluta (las flechas indican los niveles no deformados). B) Detalle de la laminación convoluta (corresponde al recuadro de la fotografía anterior). C) Detalle de otra laminación convoluta en el mismo nivel. D) Pseudonódulos asociados a terremotos. E) y F) Detalle de un flujo licuefactado en la superficie del yacimiento paleoicnológico de la Virgen del Campo (Enciso)..........242 Figura 9.3: A) Falla normales sinsedimentarias de escala métrica. B) Nivel con importantes estructuras de carga. C) Posible loop bedding poco desarrollado. D) Posible deslizamiento atribuible a un terremoto. Las siguientes fotos son estructuras creadas por el paso de los dinosaurios que podrían atribuirse a sismitas, tales como pequeñas convoluciones (E), fallas blow-out (F) y estructuras en llama y almohadillas (G y H)......243 Figura 9.4: Mapa paleogeográfico en detalle de la placa Iberia mostrando los aproximadores paleoclimáticos

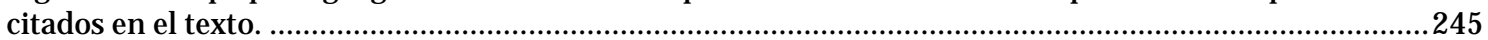

Figura 9.5: Rango de la Temperatura Superficial del Mar a partir de los valores TEX 86 durante el Aptiense. Figura 9.6: Mapa del Aptiense inferior según SCOTESE Y DREHER (2012) ..................................................249 Figura 9.7: Representación del paleolago Enciso estructurado en dos áreas depocentrales bien definidas: la cubeta occidental y la cubeta oriental (o cubeta de Cervera del Río Alhama). Además se esboza la posible extensión del lago durante las etapas de retracción a partir de los yacimientos paleoicnológicos y las evidencias de emersión. .252

Figura 9.8: Correlación entre el valor de $\delta^{18} \mathrm{O}$ y la relación $\mathrm{Mg}^{2+} / \mathrm{Mg}^{2+}+\mathrm{Ca}^{2+}$ en un lago actual tipo playa (lago Greenly en Australia) y dos secciones del paleolago Enciso. Los datos del lago Greenly se han tomado de DuTKIEWICZ et al. (2000). 259

Figura 9.9: Rango de salinidad estimado para los diferentes fósiles encontrados en el paleolago Enciso. La línea negra representa el diagrama de Remane. En gris se indica el rango de paleosalinidades para el océano

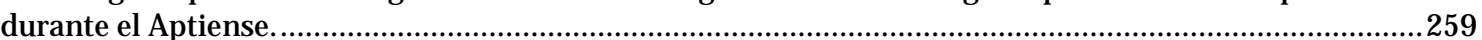
Figura 9.10: Variación de la saturación en oxígeno del agua en función de la temperatura y la salinidad. Las líneas gruesas hacen referencia a valores en el Aptiense $\left(\mathrm{O}_{2}=16 \%\right)$ y las líneas delgadas a valores actuales $\left(\mathrm{O}_{2}=20,95 \%\right)$. Las tramas indican salinidad: trama continua $(0 \%)$, trama discontinua (18\%o) y trama a puntos (35\%o). .266 Figura 9.11: Dirección de los vientos deducida para el lago Enciso a partir del estudio de los trenes de rizaduras en tres áreas muestreadas (Munilla, Enciso y Cornago). .......................................................268 Figura 9.12: Cálculo del número de Burger para diferentes profundidades, en el rango de las previsibles para el paleolago Enciso. 269 Figura 10.1: Composición con ortofoto de la localización de los yacimientos icnológicos en el área EncisoAmbas Aguas. La escala está en metros. 


\section{Índice}

Figura 10.2: A) y B): Aspecto bajo microscopio petrográfico y en campo del yacimiento LVC y 2LVC. C) y D): Aspecto en campo y bajo microscopio del nivel icnológico aflorante en el tramo 17. E) y F) Aspecto en campo y bajo microscopio óptico del yacimiento icnológico que aparece en el tramo 18....................................2276 Figura 10.3: Columna estratigráfica del yacimiento icnológico La Virgen del Campo (LVC)..................... 277 Figura 10.4: Correlación entre la columna de La Virgen del Campo (A) y la columna de Enciso (B). La escala representa $50 \mathrm{~m}$. Los asteriscos indican la posición de los niveles con icnitas..........................................279 Figura 10.5: A) Fotografía de campo del yacimiento icnológico La Senoba. B) y C) Aspecto bajo microscopio petrográfico del nivel con huellas de La Senoba. D) Columna estratigráfica del yacimiento icnológico La

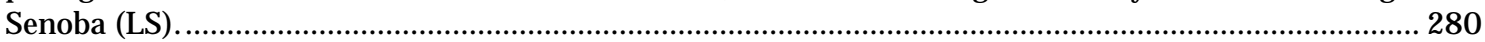
Figura 10.6: A) Aspecto en campo del yacimiento Las Losas. B) y C) Aspecto bajo microscopio petrográfico del nivel con huellas de Las Losas. ... 281 Figura 10.7: A) Fotografía del rastro terópodo VA4. B) y C) Aspecto bajo microscopio petrográfico del nivel icnológico del Barranco de Valdecevillo. D) Columna estratigráfica del yacimiento Barranco de Valdecevillo.

.283

Figura 10.8: Correlación entre la columna parcial de control del Barranco de Valdecevillo (A) y la columna de Enciso (B). Para determinar con mayor exactitud la correspondencia de niveles por debajo del yacimiento se ha utilizado la columna levantada por HERNÁN-MARTíNEZ (1994) en la zona (C). La escala representa 50 m. Los asteriscos indican la posición de los niveles con icnitas. ............................................................284 Figura 10.9: A) Fotografía de un rastro terópodo en el afloramiento Valdecevillo Este. B) y C) Aspecto bajo microscopio petrográfico del estrato con icnitas Valdecevillo Este. D) Columna estratigráfica del yacimiento icnológico Valdecevillo Este. .285 Figura 10.10: Correlación entre la columna del Barranco de Valdecevillo (A) y la columna de Valdecevillo Este (B). La escala representa $20 \mathrm{~m}$. Los asteriscos indican la posición de los niveles con icnitas. .............286 Figura 10.11: A) Fotografía de un rastro ornitópodo. B) Fotografía en detalles de una de las huellas. C) Columna estratigráfica del yacimiento icnológico Del Río (DR) ..............................................................28 Figura 10.12: A) y B) Aspecto en campo del yacimiento icnológico Corral de Valdefuentes. C) y D) Aspecto bajo microscopio petrográfico del estrato con huellas. E) Columna estratigráfica del yacimiento icnológico Corral de Valdefuentes (CVF).

Figura 10.13: Correlación entre la columna del Corral de Valdefuentes (A) y la columna de Enciso (B). La escala representa 50 m. Los asteriscos indican la posición de los niveles con icnitas................................ 291 Figura 10.14: A) Fotografía de campo de una icnita del yacimiento Llano del Cojo. B) Columna estratigráfica del yacimiento icnológico Llano del Cojo. .................................................................................................292 Figura 10.15: Correlación entre la columna del Corral de Valdefuentes (A) y la columna del Llano del Cojo (B). La escala representa 20 m. Los asteriscos indican la posición de los niveles con icnitas. ...................293 Figura 10.16: A) Aspecto en campo del yacimiento icnológico Barranco de Valdeño. B) Huella ornitópoda aislada en el tramo 18 de la columna del yacimiento Barranco de Valdeño. C) Columna estratigráfica del yacimiento icnológico Barranco de Valdeño. 295 Figura 10.17: A) Fotografía de una de las icnitas ornitópodas presentes en el yacimiento. B) Columna estratigráfica del yacimiento icnológico Tomillar-Vallecuevanos. ..........................................................296 Figura 10.18: A) Situación en campo de los yacimientos EVP, 1EVP y 2EVP. B) Aspecto bajo microscopio petrográfico del nivel EVP. C) Fotografía del yacimiento 3EVP. D) Aspecto bajo microscopio petrográfico del nivel 3EVP. E) Fotografía del yacimiento 3I donde se observa su superficiellena de rizaduras de oscilación e icnitas terópodas. F) Aspecto bajo microscopio petrográfico del nivel 3I....................................................298 Figura 10.19: Columna estratigráfica del yacimiento icnológico El Villar-Poyales..................................299 Figura 10.20: A) Aspecto en campo del yacimiento Navalsaz. B) y C) Aspecto bajo microscopio petrográfico del nivel con icnitas de Navalsaz. D) Fotografía del rastro existente en el tramo 4. E) Fotografía del rastro que aparece en el tramo 9. F) Aspecto bajo microscopio petrográfico del nivel icnológico presente en el tramo

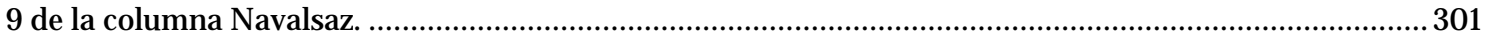
Figura 10.21: Columna estratigráfica del yacimiento icnológico Navalsaz ................................................302 Figura 10.22: A) y B) Fotografías del rastro ornitópodo en el yacimiento AND. C) y D) Aspecto bajo microscopio petrográfico del nivel con icnitas de La Cuesta de Andorra. E) Columna estratigráfica del yacimiento icnológico La Cuesta de Andorra. ........................................................................................304 Figura 10.23: A) Fotografía del rastro ornitópodo en el yacimiento LMG. B) y C) Aspecto bajo microscopio petrográfico del nivel con icnitas de La Magdalena. E) Columna estratigráfica del yacimiento icnológico La Magdalena. 306 Figura 10.24: A) Fotografía del rastro en el yacimiento Perosancio inferior. B) Detalle de una de las icnitas presentes. C) Columna estratigráfica del yacimiento icnológico Perosancio inferior. .................................307 Figura 10.25: A) Aspecto general del yacimiento Perosancio. B) Aspecto bajo microscopio petrográfico del nivel con icnitas. C) Columna estratigráfica del yacimiento icnológico Perosancio...................................309 Figura 10.26: A) y B) Aspecto general del yacimiento Valdeté. C) Aspecto bajo microscopio petrográfico del nivel con huellas. D) Columna estratigráfica del yacimiento icnológico Valdeté. .......................................310 Figura 10.27: Correlación entre la columna de Valdeté (A) y la columna de Ambas Aguas (B). La escala representa $50 \mathrm{~m}$. Los asteriscos indican la posición de los niveles con icnitas.............................................311 


\section{Índice}

Figura 10.28: A) y B) Aspecto bajo microscopio petrográfico del nivel Tajugueras. C) Columna estratigráfica del yacimiento icnológico Tajugueras.................................................................................................. 313 Figura 10.29: Correlación entre la columna de Tajugueras (A), Valdeté (B) y Perosancio (C). La escala representa $20 \mathrm{~m}$. Los asteriscos indican la posición de los niveles con icnitas. ........................................ 314 Figura 11.1: Composición con ortofotos indicando la localización de los yacimientos icnológicos en la zona de Munilla-San Vicente de Munilla. La escala está en metros.......................................................................318 Figura 11.2: A) Fotografía de una icnita presente en el yacimiento icnológico Las Torres de Munilla. B) Columna estratigráfica del yacimiento icnológico Las Torres de Munilla (LTM). ..................................... 319 Figura 11.3: Correlación entre los diferentes yacimientos icnológicos del Nivel 1 en San Vicente de Munilla: SVM I (A), LPS (B), SVM II (C), SVM III (D), SVM IV (E) y SVM V (F). La escala representa 20 m. Los asteriscos indican la posición de los niveles con icnitas. .......................................................................322 Figura 11.4: A) Fotografía del yacimiento San Vicente I. B) Aspecto bajo microscopio petrográfico del nivel con icnitas SVM I. C) Columna estratigráfica del yacimiento icnológico San Vicente I (SVM I).................323 Figura 11.5: A) y B) Fotografías del yacimiento San Vicente II. C) y D) Aspecto bajo microscopio petrográfico de la capa con huellas SVN II. E) Columna estratigráfica del yacimiento icnológico San Vicente II (SVM

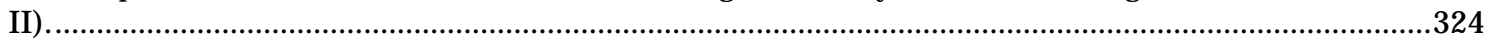
Figura 11.6: A) Fotografía del yacimiento San Vicente III. B) Columna estratigráfica del yacimiento icnológico San Vicente III (SVM III) . ...................................................................................................325 Figura 11.7: A) Fotografía del yacimiento San Vicente IV. B) y C) Aspecto bajo microscopio petrográfico de la capa con huellas SVN IV. E) Columna estratigráfica del yacimiento icnológico San Vicente IV (SVM

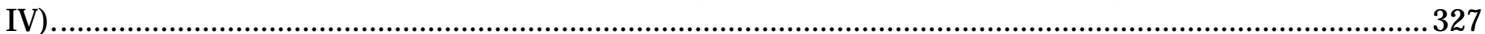
Figura 11.8: A) Fotografía del yacimiento San Vicente V. B) Columna estratigráfica del yacimiento icnológico San Vicente V (SVM V). 328

Figura 11.9: A) Fotografía del yacimiento La Pasadilla. B) Columna estratigráfica del yacimiento icnológico La Pasadilla (LPS). 330 Figura 11.10: Correlación entre la columna de Peñaportillo-Umbría del Portillo (A) y la columna de Munilla (B). La escala representa 50 m. Los asteriscos indican la posición de los niveles con icnitas. .................... 331 Figura 11.11: A) Fotografía del yacimiento Peñaportillo. B) Aspecto bajo microscopio petrográfico de la capa con huellas PP. C) Fotografía del yacimiento Umbría del Portillo. D) Aspecto bajo microscopio petrográfico de la capa con huellas UP. E) Columna estratigráfica del yacimiento icnológico Peñaportillo-Umbría del

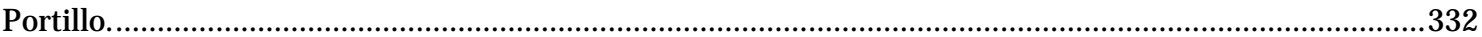
Figura 11.12: Montaje fotográfico con la localización de los yacimientos en la zona de Munilla Nivel 1.....333 Figura 11.13: A) Fotografía del yacimiento Barranco de La Canal. B) Aspecto bajo microscopio petrográfico de la capa con huellas BLC. C) Fotografía de las icnitas presentes en el tramo 5 de la columna. D) Columna estratigráfica del yacimiento icnológico Barranco de La Canal. 335 Figura 11.14: Correlación entre la columna de Peñaportillo-Umbría del Portillo (A) y la columna del Barranco de La Canal (B). La escala representa 20 m. Los asteriscos indican la posición de los niveles con icnitas.

Figura 11.15: A) Fotografía del yacimiento Los Endos. B) Columna estratigráfica del yacimiento icnológico Los Endos (END). ..338 Figura 11.16: A) Fotografía del yacimiento Barranco de La Canal IX. B) Detalle de las icnitas presentes en el afloramiento. C) y D) Aspecto bajo microscopio petrográfico de la capa con huellas BLCIX. E) Columna estratigráfica del yacimiento icnológico Barranco de La Canal IX..........................................................340 Figura 11.17: Correlación entre los diferentes yacimientos icnológicos del Nivel 3 en San Vicente de Munilla: UPE 3 (A), UPE 1-2 (B), SVM VII (C), SVM X (D), y SVM XI-XII-XIII (E). La escala representa 20 m. Los asteriscos indican la posición de los niveles con icnitas. .......................................................................... 341 Figura 11.18: A) Fotografía del yacimiento San Vicente VII. B y C) Aspecto bajo microscopio petrográfico de la capa con huellas SVM VII. D) Columna estratigráfica del yacimiento icnológico San Vicente VII. .........343 Figura 11.19: A) Fotografía de la icnita presente en el tramo 33 de la columna del yacimiento San Vicente VII. B) Fotografía de las dos icnitas aisladas que aparecen en el tramo 37 de la columna San Vicente VII.......344 Figura 11.20: A) Fotografía del yacimiento San VicenteX. B y C) Aspecto bajo microscopio petrográfico de la capa con huellas SVM X. D) Columna estratigráfica del yacimiento icnológico San Vicente X....................345 Figura 11.21: A) Fotografía de las icnitas presentes en el tramo 50 de la columna del yacimiento San Vicente X. B) Fotografía de las dos icnitas que aparecen en el tramo 53 de la columna San Vicente X..................346 Figura 11.22: A) Fotografía del yacimiento Munilla o San Vicente XI-XII. B) Fotografía del yacimiento San Vicente XIII. 346 Figura 11.23: A) y B) Aspecto bajo microscopio petrográfico de la capa con huellas SVM XI-XII. C) y D) Aspecto bajo microscopio petrográfico de la capa con huellas SVM XIII. E) Columna estratigráfica del yacimiento icnológico San Vicente XI-XII-XIII. .............................................................................347 Figura 11.24: A) Fotografía del yacimiento Umbría Pelilla 1. B) y C) Aspecto bajo microscopio petrográfico dela capa con huellas UPE 1. D) Fotografía del yacimiento Umbría Pelilla 2. E) y F) Aspecto bajo microscopio petrográfico de la capa con huellas UPE 2 ...............................................................................................350 Figura 11.25: Columna estratigráfica de los yacimientos icnológicos Umbría Pelilla 1y 2. ........................ 351 


\section{Índice}

Figura 11.26: A) Fotografía de las dos icnitas terópodas aisladas que aparecen en el tramo 7 de la columna UPE 3. B) y C) Fotografías del yacimiento icnológico UPE 3. D) Columna estratigráfica del yacimiento icnológico UPE 3. 353 Figura 11.27: Correlación entre los diferentes yacimientos icnológicos del Nivel 4 en San Vicente de Munilla: SVM XIV (A), UPE 4-5 (B). La escala representa $20 \mathrm{~m}$. Los asteriscos indican la posición de los niveles con icnitas. 354 Figura 11.28: A) Fotografía del yacimiento San Vicente XIV. B) Detalle del rastro presente. C) Columna estratigráfica del yacimiento icnológico San Vicente XIV. 355 Figura 11.29: A) Fotografía del yacimiento Umbría Pelilla 4. B) Fotografía del yacimiento Umbría Pelilla

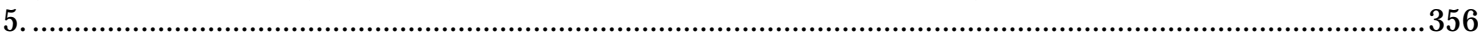
Figura 11.30: A) y B) Aspecto bajo microscopio petrográfico de la capa con huellas UPE 4. C) Columna estratigráfica del yacimiento icnológico Umbría Pelilla 4-5................................................................357 Figura 11.31: A) y B) Fotografías de campo del yacimiento El Sobaquillo. C) y D) Aspecto bajo microscopio petrográfico del nivel con huellas SVA. ................................................................................................359 Figura 11.32: A) Fotografía de campo del yacimiento Malvaciervo. B) Aspecto bajo microscopio petrográfico del nivel con huellas MLV. C) Fotografía de campo de la capa con huellas del tramo 4. D) Columna estratigráfica del yacimiento icnológico MLV. ..........................................................................................360 Figura 12.1: Composición con ortofoto de la localización de los yacimientos icnológicos en el área de Los Cayos (Cornago). La escala está en metros..........................................................................................363 Figura 12.2: A) Columna estratigráfica del yacimiento icnológico Los Cayos S(LCS). B) Detalle de los niveles

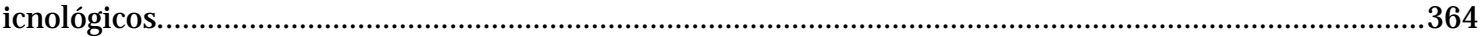
Figura 12.3: A) Fotografía del nivel icnológico S1. B) Fotografía del nivel icnológico S4. C) Fotografía del nivel icnológico S9. D) y E) Aspecto bajo microscopio petrográfico de la capa con huellas S9. F) Fotografía del nivel icnológico S10. .365 Figura 12.4: A) Columna estratigráfica del yacimiento icnológico Los Cayos D (LCD) en el lecho del barranco. B) Columna estratigráfica de Los Cayos D en la zona adyacente, fuera del barranco. .................................367 Figura 12.5: A) Fotografía del nivel icnológico D4 antes de ser destruido. B) Fotografía en detalle de una icnita ornitópoda en el nivel D3. C) Fotografía del nivel icnológico D3 donde se observan las fallas blow-out. D) y E) Fotografías de las icnitas aisladas que se observan en el nivel D5...............................................368 Figura 12.6: Correlación entre los yacimientos icnológicos Los Cayos A (A) y Los Cayos B y C (B). La escala representa $20 \mathrm{~m}$. Los asteriscos indican la posición de los niveles con icnitas. ......................................370 Figura 12.7: A) Columna estratigráfica del yacimiento icnológico Los Cayos A (LCA). B) Detalle delos niveles

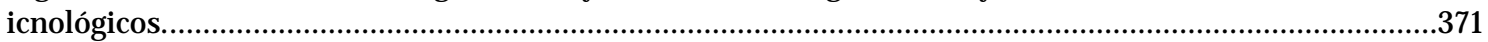
Figura 12.8: A) Fotografía mostrando la situación de los yacimientos LCA y LCB-LCC. B) Fotografía del nivel icnológico A3. C) Fotografía del nivel icnológico A7. D) y E) Aspecto bajo microscopio petrográfico de

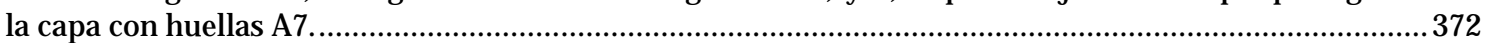
Figura 12.9: A) Columna estratigráfica del yacimiento icnológico Los Cayos B y C (LCB y LCC). B) Detalle de

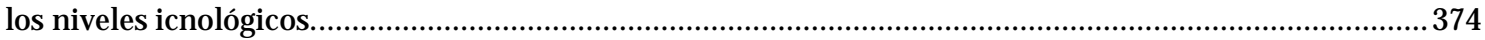
Figura 12.10: A) Fotomontaje mostrando la situación de los yacimientos LCB y LCC. B) Fotografía del nivel icnológico C5. C) Fotografía en detalle de la huella de ave en el nivel icnológico C5. D) y E) Aspecto bajo microscopio petrográfico de la capa con huellas C5. F) y G) Aspecto bajo microscopio petrográfico del nivel icnológico C7. 375 Figura 12.11: A) y B) Aspecto bajo microscopio petrográfico de la capa con huellas B3. C) Fotomontaje del nivel icnológico ¿B3? D) y E) Aspecto bajo microscopio petrográfico del nivel icnológico ¿B3?..................376 Figura 12.12: A) Columna estratigráfica del yacimiento icnológico Los Cayos C en el extremo NO. B) y C) Aspecto bajo microscopio petrográfico de la capa con huellas CC5. C) Fotomontaje de los niveles icnológicos en la zona noroccidental de Los Cayos C. . . .378 Figura 12.13: Correlación entre los yacimientos icnológicos Los Cayos E (A) y Los Cayos E2 (B). La escala representa $20 \mathrm{~m}$. Los asteriscos indican la posición de los niveles con icnitas. ........................................379 Figura 12.14: A) Fotografía del yacimiento Los Cayos E (LCE). B) y C) Aspecto bajo microscopio petrográfico de la capa con huellas LCE. D) Columna estratigráfica del yacimiento icnológico Los Cayos E...................380 Figura 12.15: A) Fotografía del yacimiento Los Cayos E2 (LCE2). B) Fotografía del yacimiento Los Cayos E3 (LCE3). C) Fotografía de campo de la serie granocreciente en la zona de Los Cayos E-Los Cayos E2. D) Columna estratigráfica del yacimiento icnológico Los Cayos E2.

Figura 13.1: Composición con ortofoto de la localización de los yacimientos icnológicos en el área del barranco de Sol de La Pita. La escala está en metros. ................................................................................385 Figura 13.2: Columna estratigráfica del yacimiento icnológico Sol de La Pita. .........................................386 Figura 13.3: A) Fotomontaje del afloramiento Sol de La Pita I-1 (el relieve de la icnita está indicado por el círculo). B) Fotografía de la icnita presente en el nivel icnológico I-1. C) Fotografía del nivel icnológico I-2.

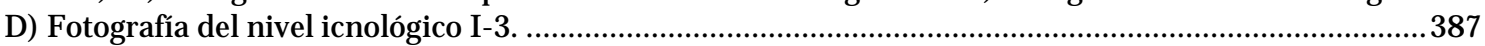
Figura 13.4: A) Fotografía de una de las huellas que aparece en el nivel I-4. C) Aspecto bajo microscopio

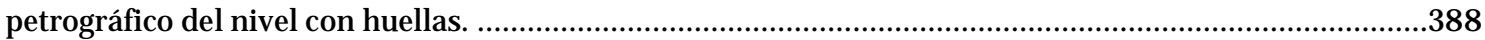
Figura 13.5: A) Aspecto en campo del yacimiento icnológico Sol de La Pita I-5. B) Fotografía en detalle del nivel icnológico. C) y D) Aspecto bajo microscopio petrográfico de la capa con huellas... .389 


\section{Índice}

Figura 13.6: A) Fotografía en detalle de la huella atribuida a la mano de un saurópodo en el nivel icnológico I-6. B) Aspecto bajo microscopio petrográfico del nivel con huellas. .389 


\section{Índice}

\section{ÍNDICE DE TABLAS}

Tabla 6.1: Abundancia relativa de cada facies en las columnas levantadas (\%).

Tabla 6.2: Facies presentes en cada elemento arquitectónico de las cinco columnas muestreadas: Enciso (EN), Ambas Aguas (AA), Cornago (CG), Munilla (MN) y Préjano (PR). En negrita se indican las facies fundamentales de cada elemento. Las dos columnas de la derecha hacen referencia a la potencia $(\mathrm{cm}) \mathrm{y}$ abundancia (\%) de cada elemento.

Tabla 6.3: Niveles de confianza utilizados para el análisis markoviano de Harper [modificado de XU Y MACCARTHY (1998)]. 148

Tabla 6.4: Principales transiciones entre los elementos de las columnas analizadas. En negrita se marcan las transiciones significativas. El resto representan transiciones no significativas. 149 Tabla 7.1: Principales factores en la columna Cornago A (Varimax normalizado). En gris se indican las cargas

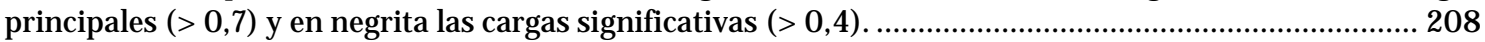
Tabla 7.2: Valores propios y acumulados de los factores extraídos en la columna Cornago A. ...................209 Tabla 7.3: Principales factores en la columna de Préjano (Varimax normalizado). En gris se indican las cargas principales $(>0,7)$ y en negrita las cargas significativas $(>0,4)$....................................................... 213 Tabla 7.4: Valores propios y acumulados de los factores extraídos en la columna Préjano......................... 213 Tabla 8.1: Correlación entre ratios orbitales y estratigráficos en la solución Enciso A1. ...........................2229 Tabla 8.2: Correlación entre ratios orbitales y estratigráficos en la solución Enciso A2 ............................2229 Tabla 8.3: Correlación entre ratios orbitales y estratigráficos de la solución Enciso A3..............................230 Tabla 8.4: Correlación entre ciclos orbitales y estratigráficos comunes a todas las soluciones Enciso A. ..230 Tabla 8.5: Correlación entre ratios orbitales y estratigráficos de la solución Enciso B1. ........................... 231 Tabla 8.6: Correlación entre ratios orbitales y estratigráficos de la solución Enciso B2............................. 231 Tabla 8.7: Correlación entre ratios orbitales y estratigráficos de la solución Enciso B3............................. 231 Tabla 8.8: Correlación entre ciclos orbitales y estratigráficos comunes a todas las soluciones Enciso B. ..232 Tabla 8.9: Correlación entre ratios orbitales y estratigráficos de la solución Ambas Aguas 1. ....................232 Tabla 8.10: Correlación entre ratios orbitales y estratigráficos de la solución Ambas Aguas 2...................233 Tabla 8.11: Correlación entre ratios orbitales y estratigráficos de la solución Ambas Aguas 3....................233 Tabla 8.12: Correlación entre ciclos orbitales y estratigráficos comunes a todas las soluciones en la columna de Ambas Aguas.

Tabla 9.1: Rango de profundidades máximas y mínimas obtenidos a partir del estudio de las rizaduras de oscilación. También se muestra los períodos (T) máximos y mínimos calculados. 
Índice 


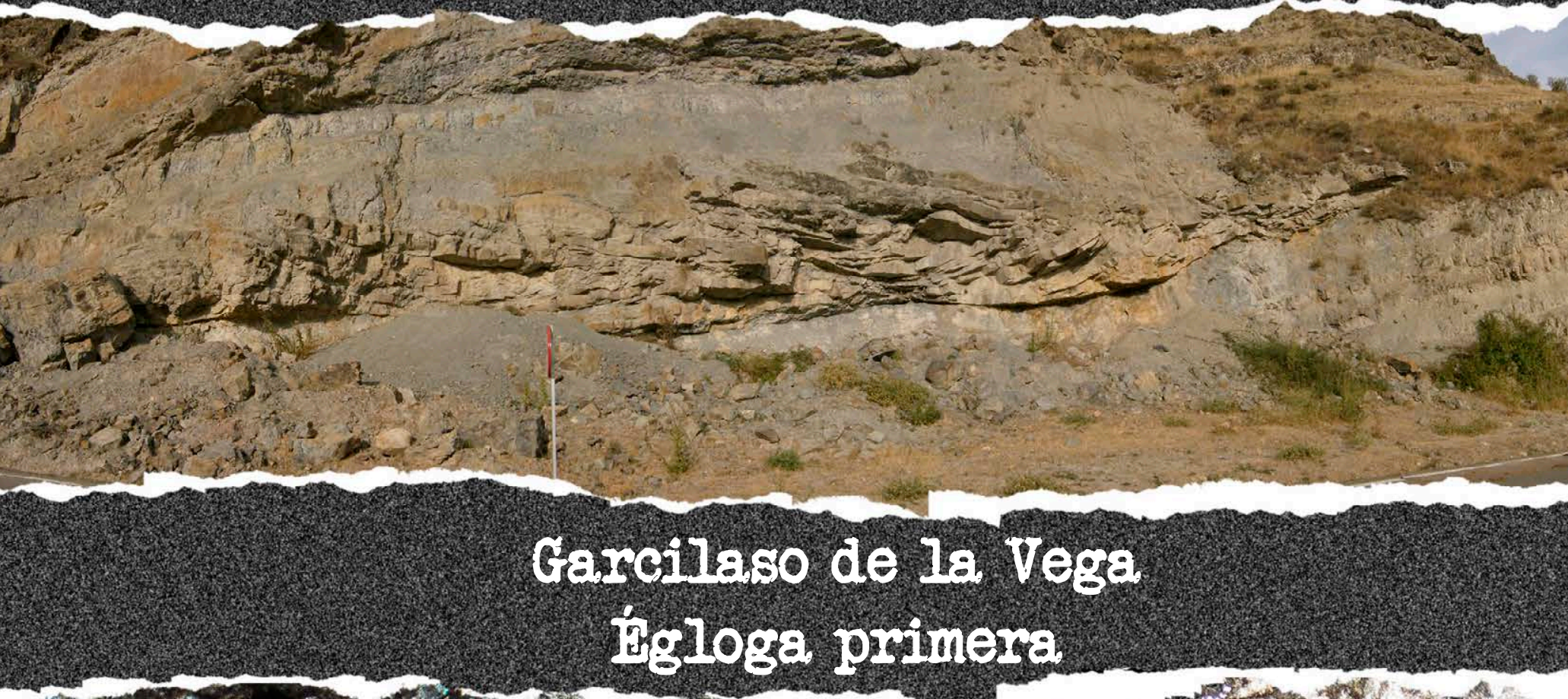

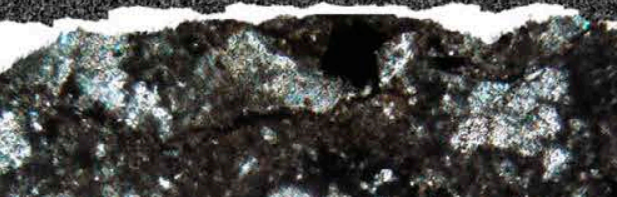

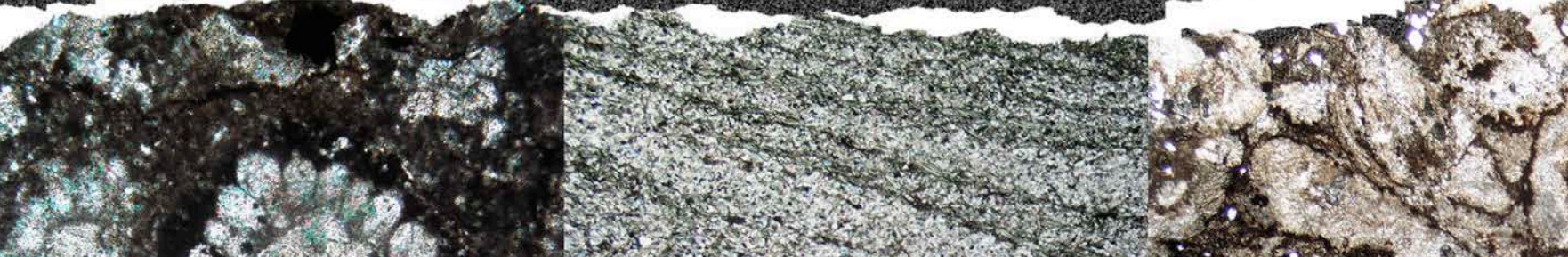

con mi Jomar las piedras entermecen su natumal, dureza $y$ la quebrantan

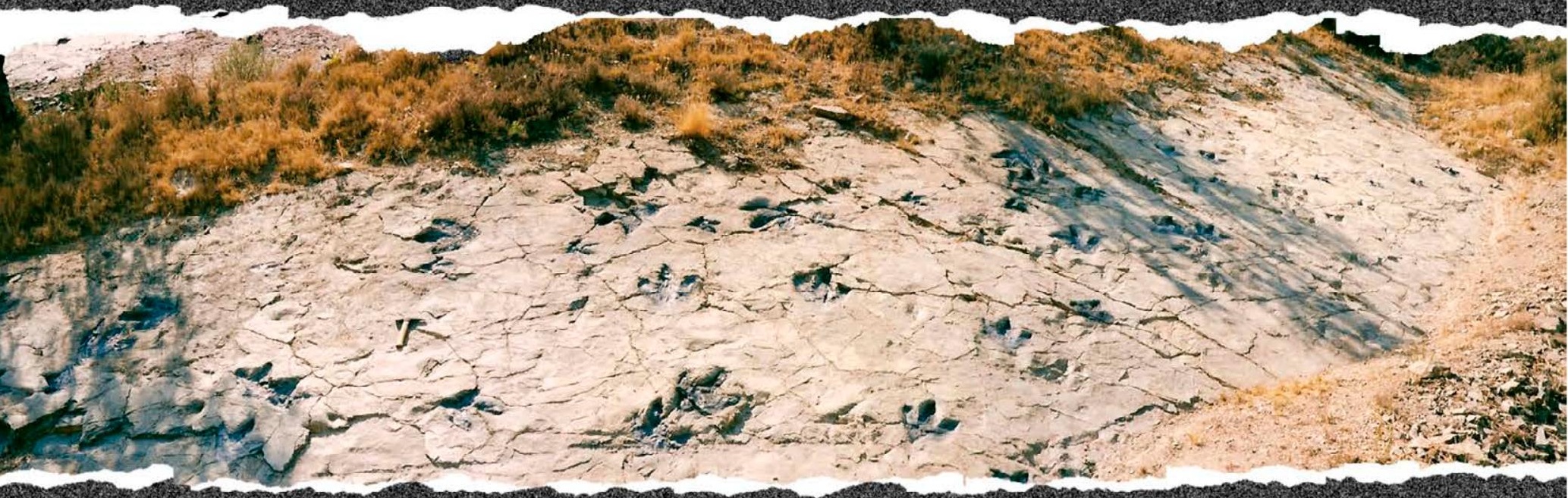




\subsection{PLANTEAMIENTOS Y OBJ ETIVOS}

\subsubsection{Interés de la investigación que se plantea}

El Grupo Enciso y, por extensión, la cuenca de Cameros (La Rioja, España), aglutina un interés considerable entre los investigadores de las diversas especialidades relacionadas con las ciencias de la Tierra. Esta fascinación está motivada, en su mayor parte, por el enorme espesor de su serie continental, así como, por el gran número de yacimientos icnológicos (icnitas de dinosaurios en su mayoría, aunque también aparecen icnitas de aves, tortugas, pterosaurios, y cocodrilos) que aparecen impresos sobre sus sedimentos.

La casi totalidad de los cuantiosos artículos publicados sobre los yacimientos icnológicos del Grupo Enciso han tenido un carácter, predominantemente, paleoicnológico y/o paleobiológico. Es decir, se han concentrado exclusivamente en el estudio de las icnitas y rastros, así como en las interpretaciones que de ellas se pueden extraer (sistemática, tafonomía, morfología, comportamiento, locomoción, etc.). Así pues, no existen estudios que aborden, en detalle, los aspectos sedimentológicos asociados a estos yacimientos icnológicos, siendo muy escasas las contribuciones que se han complementado con información estratigráfica y/o sedimentológica (VIERA Y TORRES, 1979; 1980; VIERA Y AGUIRREZABALA, 1982; VIERA et al., 1984; AGUIRREZABALA et al., 1985; MELÉNDEZY PÉREZ-LORENTE, 1996; EZQUERRA et al., 2007).

En el otro extremo, desde la óptica sedimentológica y/ o estratigráfica, los trabajos que se han publicado son demasiado generales, abarcando gran parte o la totalidad del relleno sedimentario de la cuenca de Cameros. En estos trabajos, los yacimientos icnológicos se reducen a citas o anotaciones marginales que no permiten extraer conclusiones o información relevante.

Así pues, toda esta información, tanto estratigráfica como paleoicnológica, aparece inconexa a pesar de la evidente relación que subsiste entre ellas: existiendo un vacío enorme sobre el conocimiento de los yacimientos icnológicos desde el punto de vista sedimentológico. Este fenómeno no es algo aislado ni característico de los investigadores de esta zona, sino más bien una coyuntura persistente en los estudios icnológicos a nivel mundial. Teniendo en cuenta que la formación de una icnita depende de la interacción, tanto del animal que la origina como de las condiciones del substrato donde queda impresa, es obvio que el estudio de un yacimiento icnológico ha de conjugar ambos aspectos. Es aquí donde se pone de manifiesto el interés y potencial que puede tener la presente tesis doctoral. Supone un primer intento novedoso de investigación multidisciplinar de carácter sedimentológico, geoquímico, paleoecológico y paleoambiental en el área, a fin de aportar una visión conjunta de las relaciones entre yacimientos icnológicos y medios sedimentarios en el Grupo Enciso. Debido al elevado número deyacimientos paleoicnológicos y a la gran variedad de ambientes deposicionales, el Grupo Enciso constituye una zona favorable y adecuada para acometer un estudio bajo esta perspectiva.

Es conveniente señalar que anteriormente realicé un trabajo parecido en mi proyecto Fin de Carrera (HERNÁN-MARTíNEZ, 1994). Dicha investigación se limitaba a unos pocos yacimientos aislados e inconexos entre sí, ni tampoco incluía tantos objetivos como ahora se plantean. Sin embargo, dicho trabajo puso en evidencia el gran interés que puede tener este tipo de estudios, así como su gran potencial. Por tanto, la presente tesis pretende ampliar las zonas y el número de yacimientos, además de realizar una mayor profundización en aspectos estratigráficos y sedimentológicos de cada uno de ellos, los cuales proporcionará información útil para la comprensión de los ecosistemas eocretácicos donde habitaban los dinosaurios

\subsubsection{Objetivos propuestos}

El objetivo o planteamiento general de la presente tesis consiste en la caracterización de los medios sedimentarios del Grupo Enciso, haciendo especial énfasis en sus yacimientos icnológicos, así como en las posibles relaciones entreambos. Bajo este punto devista, los objetivos concretos que se han propuesto para la realización de la presente tesis son: 
a) Establecimiento de los factores que gobiernan la dinámica de los sistemas lacustres actuales y su posible aplicación al registro sedimentario.

b) Definición de las principales microfacies existentes en el Grupo Enciso, sobre todo en los niveles donde aparecen los yacimientos icnológicos.

c) Identificación de las principales (lito)facies, elementos arquitectónicos y medios sedimentarios presentes en el Grupo Enciso.

d) Descripción y reconstrucción de la evolución espacio-temporal de los medios sedimentarios y la arquitectura deposicional del registro sedimentario.

e) Caracterización geolimnológica delos principales factores autocíclicos y/ o alocíclicos que controlaron el relleno del Grupo Enciso.

f) Caracterización geoquímica e isotópica $\left(\delta^{13} \mathrm{C}\right.$ y $\left.\delta^{18} \mathrm{O}\right)$ de los materiales carbonatados.

g) Identificación de la señal climática registrada en los sedimentos del Grupo Enciso.

h) Posicionamiento de los yacimientos icnológicos del Grupo Enciso en las columnas estratigráficas levantadas.

i) Correlación o equivalencia entre los yacimientos icnológicos cercanos entre sí, así como la determinación de su posición relativa y los cambios laterales de facies entre yacimientos y áreas contiguas.

j) Interpretación paleoambiental y paleoecológica del Grupo Enciso, tanto a nivel de la cuenca como a nivel de la placa Ibérica.

k) Integración de los datos sedimentológicos y paleoicnológicos.

l) Establecimiento de posibles relaciones entre la paleogeografía de la placa Ibérica durante el Aptiense y la presencia masiva de icnitas en la cuenca de Cameros.

m) Utilización de los fósiles como marcadores paleoecológicos y paleoambientales, así como indicadores cronológicos.

n) Caracterización de los medios sedimentarios más favorables a la preservación de icnitas a fin de proyectar futuras búsquedas.

\subsection{ANTECEDENTES BIBLIOGRÁFICOS}

Este apartado pretende ser una enumeración lo más completa posible de los estudios existentes sobre el relleno sedimentario J urásico terminal-Cretáceo inferior de la cuenca de Cameros y, en especial, sobre el Grupo Enciso.

El primer estudio del que se tiene constancia fue realizado por VICENTE-PEREDAY AGUIRRE Y MUNIAIN (1793) quienes, al amparo de la corriente de la Ilustración, recorrieron esta zona buscando posibles yacimientos minerales susceptible de ser explotados. Se trata más bien de un libro curioso, más que un estudio geológico-mineralógico del cual puedan extraerse datos interesantes.

Deberá pasar casi un siglo para que los investigadores vuelvan a fijarse en estas sierras. Durante este tiempo solamente se realizan ciertos trabajos de carácter eminentemente minero (MARTíNEZ-AlCIVAR, 1858; DE AYALA, 1862). Este honor corresponde a EGOZCUE (1875) que divulga un pequeño estudio sobre los terrenos existentes en los alrededores del pueblo de Arnedillo.

FERNÁNDEZDE CASTRO (1876) publica una breve reseña bibliográfica acerca delos trabajos geológicos existentes sobre la provincia de Logroño. DE ARANZAZU (1877) realiza la cartografía 1:1.000.000 y un estudio geológico de las provincias de Burgos, Logroño, Soria y Guadalajara. Un año después, URRUTTA (1878) publica un breve artículo sobre la geología, minería y paleontología en la provincia de Logroño.

El primer estudio serio correspondea los ingenieros de minas PALACIOSY SÁNCHEZ (1885) que estudian e identifican por primera vez la formación Wealdense existente en las provincias de Soria y Logroño. Posteriormente, SÁNCHEZ-LOZANO (1894) publica la primera gran síntesis geológica de toda la provincia de Logroño. Modifica la distribución anterior, estableciendo cinco tramos: A, B, C, D y E (A y B Purbeckense; C, D y E Vealdense). Los tramos A, C y E son de naturaleza detrítica, mientras que los tramos $\mathrm{B}$ y $\mathrm{D}$ son de naturaleza predominantemente caliza. 
RoYo-GómEZ (1921) publica un trabajo sobre el Weáldico de la Península Ibérica. En la formación que aparece en las provincias de Burgos, Soria, Logroño y Zaragoza, el autor identifica seis niveles: cinco pertenecientes al Weáldico y otro al Urgo-Aptense. El relleno consta de muro a techo: a) conglomerados y areniscas con margas, b) calizas, c) areniscas, arcillas y pizarras, d) calizas, e) conglomerados, areniscas, arcillas o calizas, y f) lignitos y pudingas.

Posteriormente, Sáenz García retoma el estudio de esta zona, basándose en los trabajos de Palacios y Sánchez, sobre todo en la provincia de Soria. Considera que el relleno está compuesto por tres tramos en vez de cinco, ya que existe una duplicación de tramos: I, de naturaleza detrítica; II, de naturaleza caliza; III, de naturaleza detrítica (I y II Jurásicos, y III Weald) (SÁENZ-GARCÍA, 1932). Publica algunos descubrimientos (SÁENZ-GARCÍA, 1942) y realiza algunas correcciones a los trabajos anteriores denominando al Urgo-Aptense como areniscas Utrillas (SÁENZ-GARCÍA, 1945).

MENDIZÁBAL et al. (1947) publican la hoja geológica de Calahorra. En ella describen un pequeño afloramiento, en el extremo suroccidental, que denominan como Wealdense. En el año 1960 se publican dos mapas geológicos pertenecientes a la primera serie donde ya se ha reconocido el Wealdense: Anguiano (NAVARRO-ALVARGONZÁLEZ et al., 1960) y Logroño (AlVARADO-ARRILLAGA et al., 1960).

En el año 1953, por iniciativa del profesor Brinkmann, un grupo de estudiantes de la Universidad de Bonn estudian la cuenca de Cameros: BEUTHER (1966) el sector occidental, TISCHER (1966b) el sector oriental, y KNEUPER-HAACK (1966) la bioestratigrafía a partir de ostrácodos de las formaciones weáldicas. Sus principales aportaciones son:

a) Dividen el relleno weáldico en cinco grupos litológicamente diferentes: Tera, Oncala, Urbión, Enciso y Oliván. Tres de ellos de naturaleza siliciclástica (Tera, Urbión y Oliván) y los otros dos de naturaleza carbonatada (Oncala y Enciso).

b) Realizan una cartografía de toda la cuenca que hoy en día continúa siendo válida.

c) Por primera vez se lleva a cabo una datación basándose en los ostrácodos y datan el Grupo Enciso como Titoniense-Berriasiense.

Posteriormente, Tischer publica dos artículos de síntesisy resumen en español del trabajo anterior (TISCHER, 1966a; 1968).

JEREZ-MIR y ESNAOLA-GÓMEZ (1969) realizan una exhaustiva cartografía y estudio geológico de la provincia de Logroño para el Instituto Geológico y Minero de España que permanece inédito. Utilizan la división en grupos establecida unos años antes por TISCHER (1966b).

BRENNER Y WIEDMANN (1975) revisan las dataciones existentes fundamentándose en ostrácodos y sitúan el Grupo Enciso en el Hauteriviense-Barremiense. Un año después, BRENNER (1976) realiza un estudio sobre los ostrácodos y carófitas del Weald español, datando el Grupo Enciso como Valanginiense-Barremiense. Ese mismo año se publica el nuevo mapa geológico a escala 1:50.000 de Logroño (CASTIELLA-MURUZÁBAL, 1975). No cambia sustancialmente la cartografía del afloramiento con respecto a la hoja anterior aunque utiliza la división en grupos de TISCHER (1966b) asignando al Grupo Enciso una edad Portlandiense o Berriasiense.

Al año siguiente, CALZADA-BADÍA (1977) publica un artículo sobre un yacimiento defósiles invertebrados en el Grupo Enciso asignándole una edad Barremiense.

A principios de los años ochenta se publican dos nuevos mapas geológico del Plan MAGNA a escala 1:50. 000: Enciso (CÁMARA-RUPELO Y DURÁNTEZ-ROMERO, 1981) y Cervera del Río Alhama (DURÁNTEZ et al., 1982).

SALOMON (1982b) realiza en su tesis doctoral un estudio de toda la cuenca de Cameros (que el autor denomina como cuenca de Soria) estableciendo una nueva estratigrafía más compleja y un nuevo cuadro de edades basándose en los ostrácodos. Describe tres megaciclos que 
corresponden a diferentes momentos de estructuración de la cuenca. El Grupo Enciso lo incluye en el megaciclo III y le asigna una edad Valanginiense inferior. Ese mismo año realiza una descripción formal de todas las unidades existentes en la cuenca (SALOMON, 1982a), manteniendo su cuadro estratigráfico y de edades, haciendo hincapié en las relaciones existentes entre la tectónica y la sedimentación. Un año más tarde publica diversos artículos sobre las etapas estructurales de la cuenca (SALOMON, 1983c; a; b).

Un año después, otro investigador francés realiza su tesis doctoral en sector oriental de la cuenca de Cameros (GUIRAUD, 1983). Estudia aspectos estratigráficos, sedimentológicos, paleontológicos, geoquímicos, tectónicos y metamórficos del Grupo Urbión, Enciso y Oliván. Realiza una nueva cartografía basándose en los mapas MAGNA ya publicados. Posteriormente, publica un artículo basándose en su tesis en el cual realizan un nuevo cuadro estratigráfico y afirman que el Grupo Enciso representa un sistema deltaico depositado en aguas marinas someras (GUIRAUD Y SÉGURET, 1985).

DÍAZ-MARTíNEZ (1988) realiza un estudio estratigráfico y sedimentológico del relleno sedimentario en el borde norte de la cuenca, cerca de J ubera, diferenciando tres ciclos. El ciclo 1 constituido por tres unidades: las unidades 1ay $1 \mathrm{~b}$ corresponden a la Formación J ubera en sentido de ALONSO Y MAS (1993), y la unidad 1c que corresponde a la Formación calizas de Leza en sentido de ALONSO Y MAS (1993). El ciclo 2 presenta dos unidades (2a y 2b) que corresponden al Grupo Enciso (TISCHER, 1966b). Finalmente, el ciclo 3 que corresponde al Grupo Oliván (TisCHER, 1966b).

Martín Closas realiza en su tesis doctoral un estudio bioestratigráfico de las carófitas presentes en la cuenca de Cameros (MARTÍN-ClOSAS, 1989; 2000). Elabora un nuevo cuadro estratigráfico para el sector oriental de la cuenca de Cameros: describe cuatro secuencias deposicionales, aunque mantiene las formaciones definidas por GUIRAUD Y SÉGURET (1985), y cambia las edades hasta entonces establecidas, datando el Grupo Enciso como Hauteriviense terminal-Aptiense.

En el año 1990, la Compañía General de Sondeos publica dos mapas geológicos del Plan MAGNA a escala 1:50.000: Munilla (HERNÁNDEZ-SAMANIEGO et al., 1990a) y Anguiano (RAMÍREZMERINO et al., 1990). Establecen cinco ciclos para el relleno sedimentario J urásico superiorCretácico inferior. El Ciclo III se identifica con el Grupo Enciso al cual asignan una edad Valanginiense-Hauteriviense.

ALONSO et al. (1991) publican un artículo de síntesis sobre el relleno de la cuenca, diferenciando cinco secuencias deposicionales en el sector oriental y seis en el sector oriental, manteniendo las edades de MARTÍN-CLOSAS (1989).

MAS Y ALONSO (1991) y ALONSO y MAS (1993) realizan una descripción formal de la Formación Calizas de Leza ubicándola en seis litosomas. Citan la presencia de algas dasycladáceas: Salpingoporella dinarica y Salpingoporella cemi, le asignan una edad AptienseAlbiense y la constatación de ciertos episodios de transgresión marina en la cuenca de Cameros.

MAS et al. (1993) desarrollan un nuevo cuadro estratigráfico para toda la cuenca de Cameros, estableciendo seis secuencias deposicionales. Posteriormente, MARTíN-CLOSAS Y ALONSO-MILLÁN (1998), con ayuda de datos bioestratigráficos, afinan estos resultados y asignan una edad Barremiense superior-Aptiense al Grupo Enciso. Finalmente, el esquema estratigráfico ha sido revisado y mejorado. En la actualidad se admiten ocho secuencias deposicionales (capítulo 3) (SALAS et al., 2001; MAS et al., 2002; 2003; MAS et al., 2004; MAS et al., 2011).

ALONSO-AZCÁRATE (1997) en su tesis doctoral analiza la mineralogía, sedimentología y condiciones metamórficas del Grupo Enciso. Considera que está constituido por sedimentos depositados en sistemas lacustres someros carbonatados y/o carbonatados-siliciclásticos, y sistemas fluviales meandriformes. 


\section{Introducción}

En 2004, otro investigador francés presenta su tesis doctoral (DOUBLET, 2004). Se trata de una nueva aproximación al Grupo Enciso: analiza los controles tectónicos y climáticos (ciclicidad) y considera que han sido depositados en sistemas lacustres carbonatados y/o siliciclásticos (DOUBLET et al., 2003; DOUBLET Y GARCIA, 2004).

SCHUDACK Y SCHUDACK (2009) realiza una correlación cronoestratigráfica basándose en las asociaciones de ostrácodos en la cadena Ibérica. Considera que el Grupo Enciso es Valanginiense-Barremiense y que la fauna de ostrácodos asociada es típica de aguas dulces.

CLEMENTE (2010) realiza una revisión estratigráfica de toda la cuenca de Cameros. Divide el Grupo Enciso en una parte inferior representada por depósitos fluviales (Formaciones Río Mayor y Río Cidacos) y una parte superior formada por carbonatos lacustres/ costeros (Grupo Enciso). En conjunto lo interpreta como un gran complejo lacustre costero abierto hacia el Golfo de Vizcaya y le asigna una edad Hauteriviense superior-Barremiense.

Recientemente, ANGUlo-MoRENO (2012) realiza un trabajo de fin de máster sobre la cicloestratigrafía del Grupo Enciso en la zona de Munilla, publicando al año siguiente los datos más relevantes (ANGULO Y MUÑOZ, 2013). 


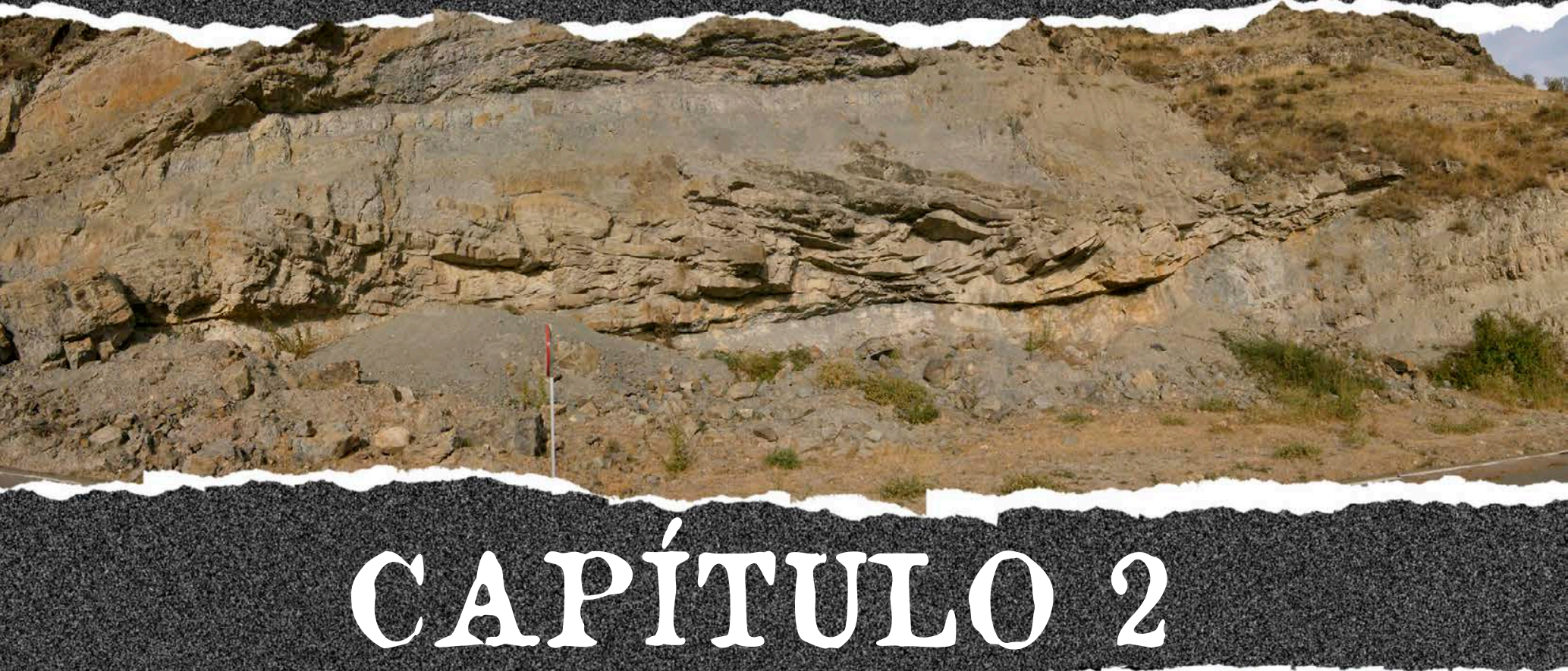

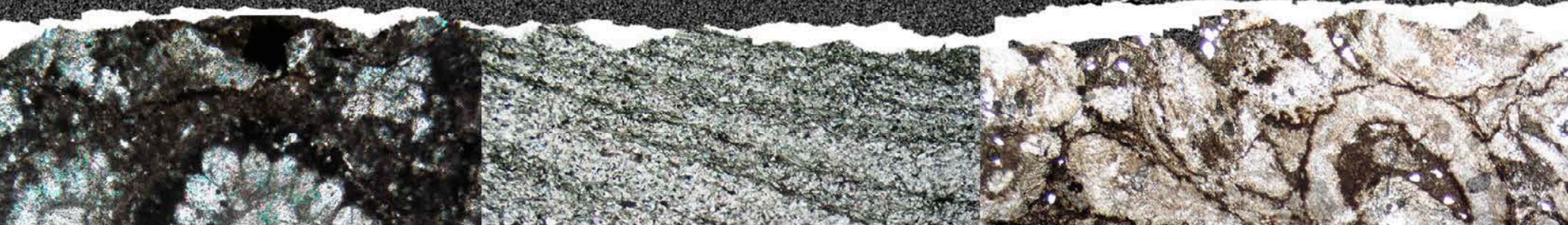

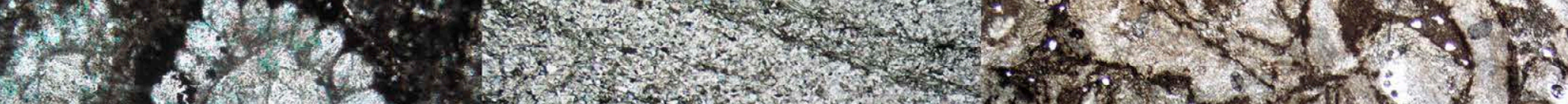

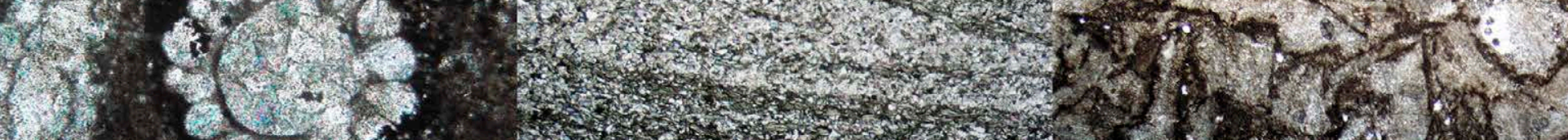

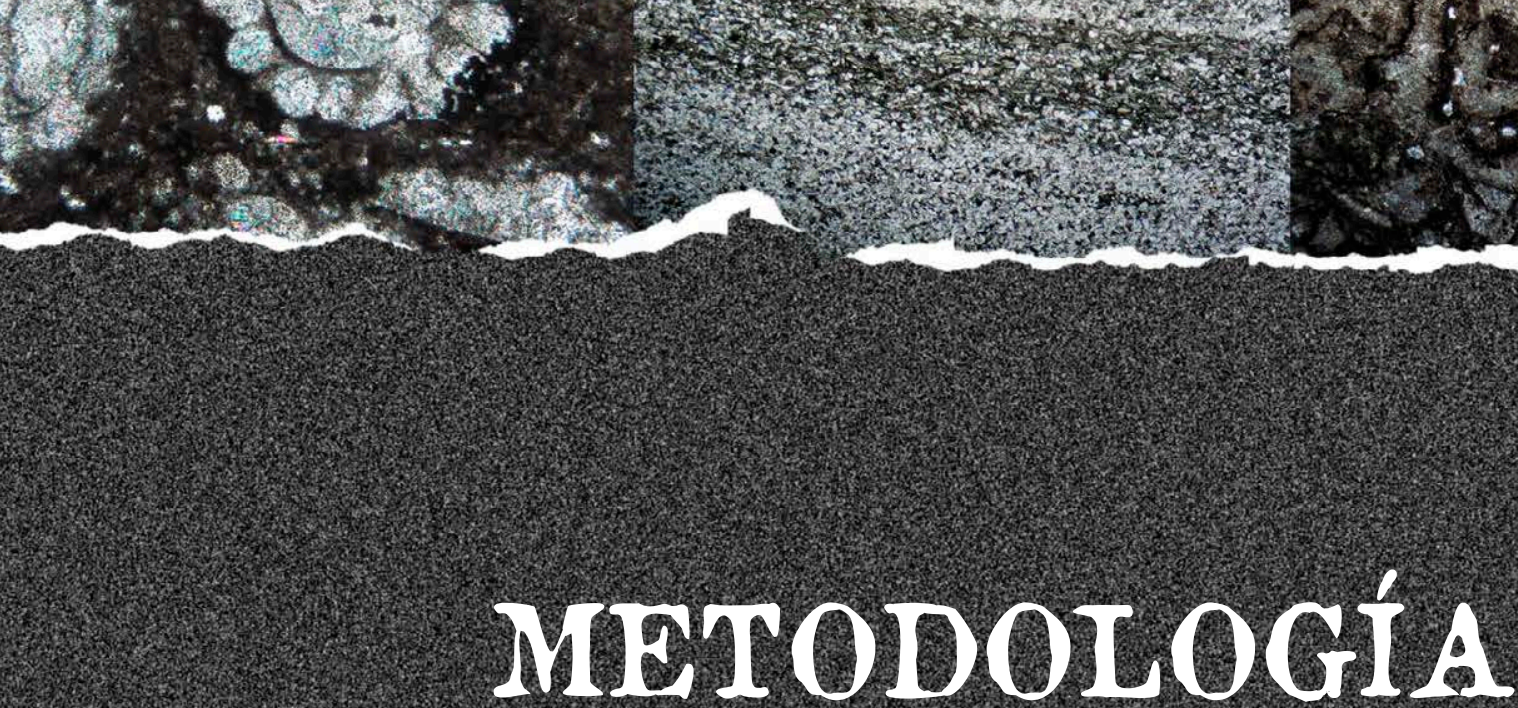

\section{METODOLOGIA}

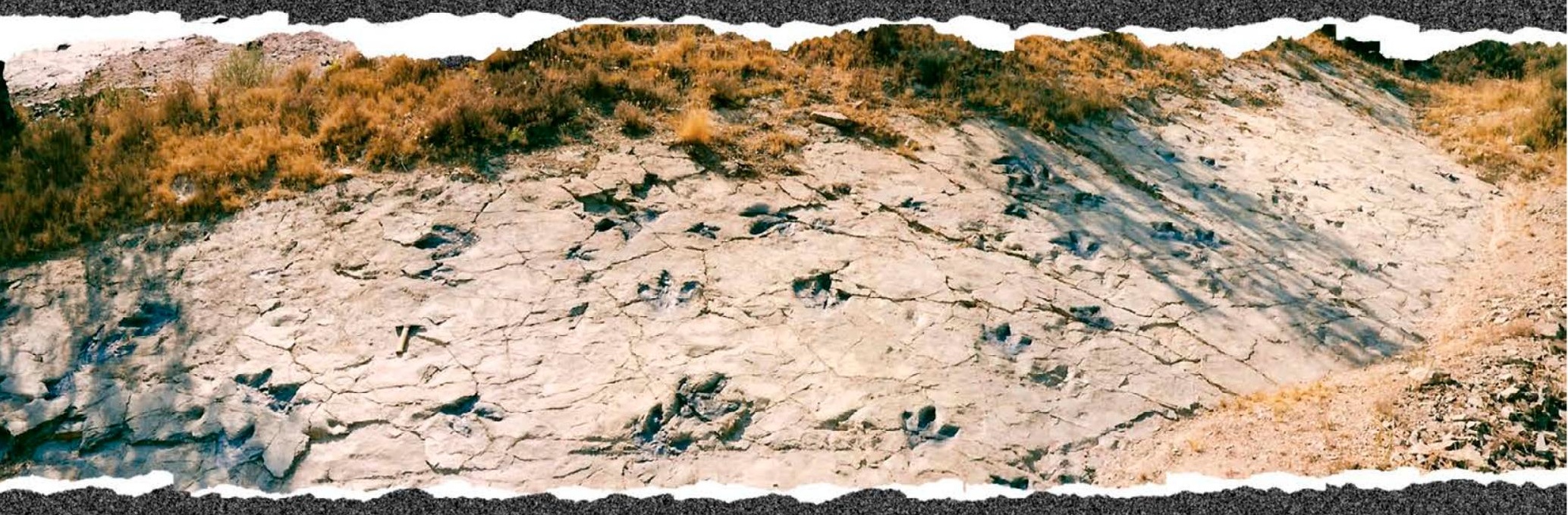




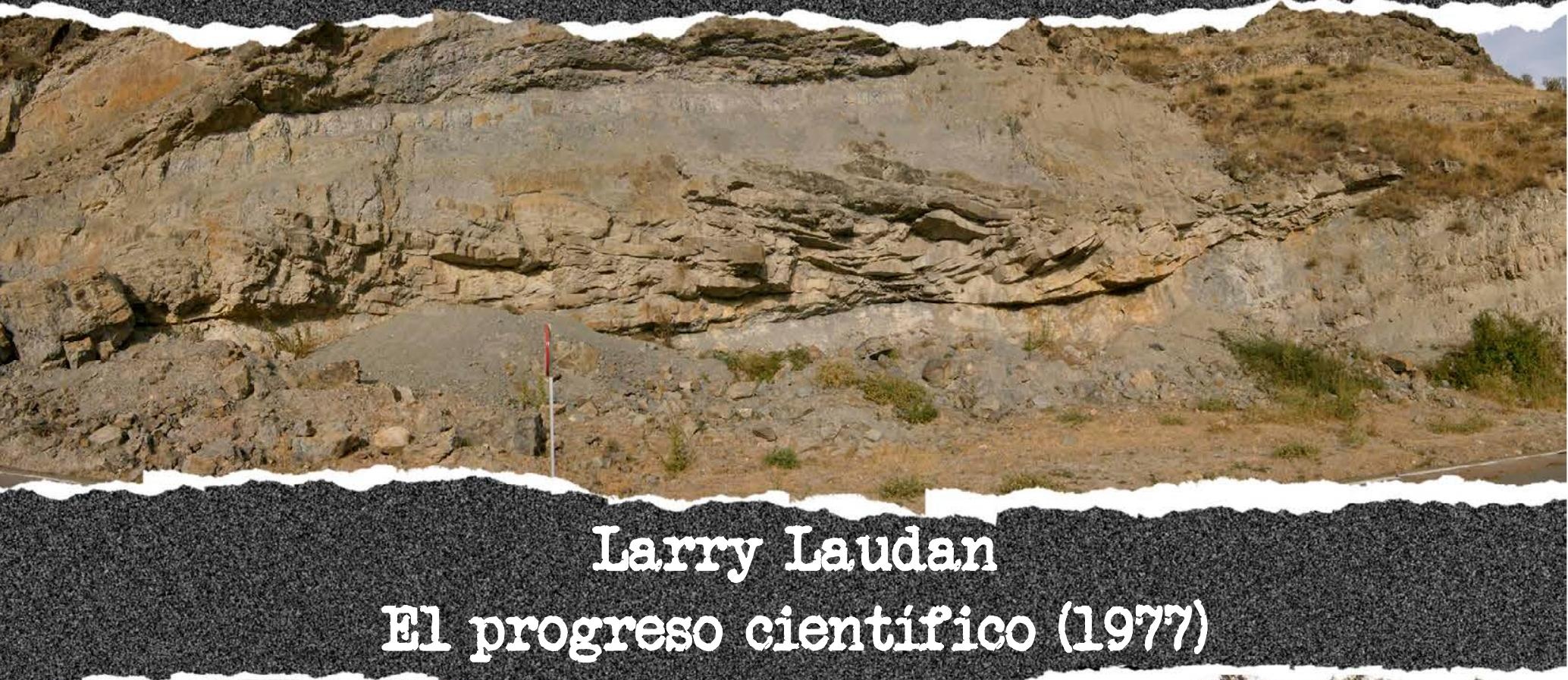

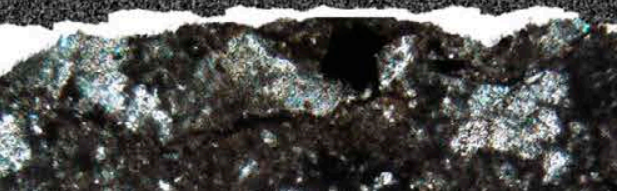

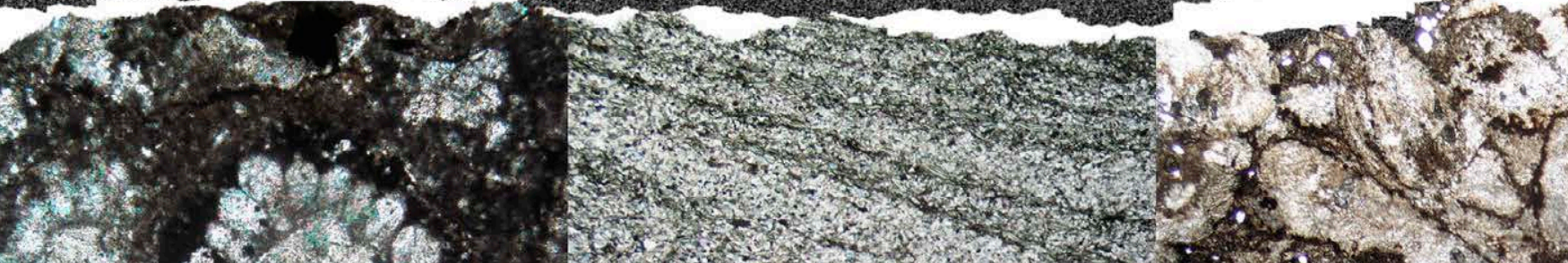

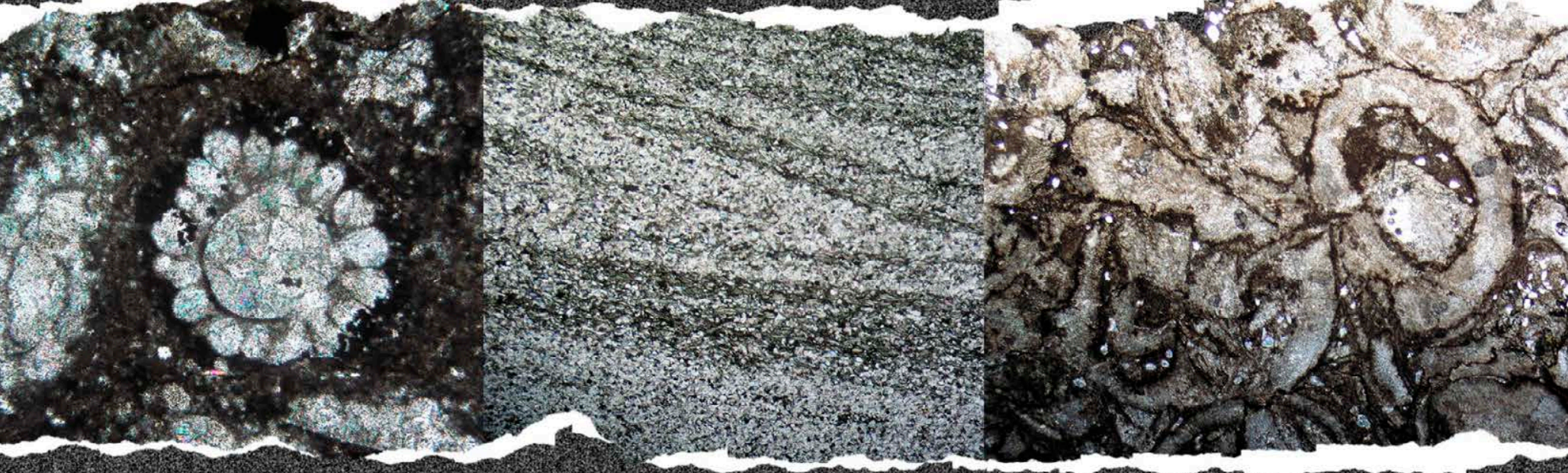

Ia ciencia se propone de manera fundamental la solución de problemas

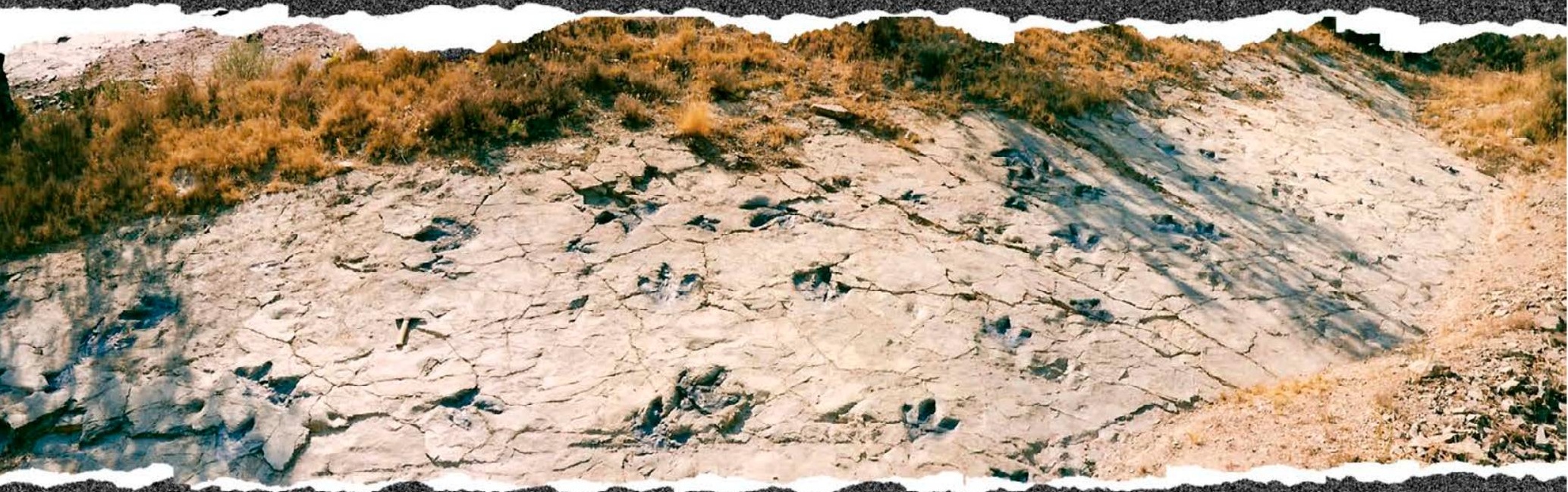




\section{Metodología}

\subsection{INTRODUCCIÓN}

Para alcanzar los objetivos propuestos en el apartado 1.1.2, se han seguido las cuatro etapas inherentes y lógicas al método científico en este tipo de estudios: trabajo previo, campo, laboratorio y gabinete. Este apartado es, pues, una exposición detallada de las metodologías y procedimientos utilizados en cada una de estas etapas.

\subsection{TRABAJ OS PREVIOS}

Durante esta etapa inicial, se han realizado las tareas de recopilación y lectura de la información bibliográfica existente hasta la fecha sobre las materias básicas necesarias para la elaboración de la presente memoria, tales como:

a) Bibliografía concerniente con el contexto geotectónico de la cuenca de Cameros a escala regional, así como en el ámbito del Sistema de Rift Mesozoico Ibérico.

b) Bibliografía de ámbito estratigráfico sobre las unidades que constituyen el relleno sedimentario de la cuenca de Cameros, haciendo especial énfasis en el Grupo Enciso.

c) Bibliografía referente a aspectos paleontológicos y paleoicnológicos del Grupo Enciso y, de manera más secundaria, la cuenca de Cameros.

d) Bibliografía general sobre temas sedimentológicos referidos a sistemas continentales fluviales (avulsión) y lacustres (siliciclásticos y carbonatados), sobre todo en cuencas tipo rift.

e) Recopilación deinformación sobre limnología general y de los factores que gobiernan su dinámica.

f) Recopilación bibliográfica sobre las metodologías de las técnicas a aplicar durante el desarrollo de la tesis (geoquímica, isótopos estables, cicloestratigrafía, estadística, etc.).

Toda esta información bibliográfica será citada en los posteriores apartados y capítulos durante el desarrollo de la presente memoria. Esta labor, aunque es vital en los inicios de la tesis, se ha continuado hasta las etapas finales de la redacción de esta memoria.

A todo esto, se suma la recopilación de la información cartográfica disponible (mapas topográficos, geológicos, fotografías aéreas), tanto en formato papel como digital.

La bibliografía del material paleoicnológico, puso de manifiesto la gran abundancia de yacimientos con icnitas de dinosaurios a lo largo y ancho del Grupo Enciso. Ante la imposibilidad de estudiarlos todos cumpliendo los requisitos y objetivos propuestos, se definieron los principales sectores de interés para el desarrollo de las tareas de campo en función de la bibliografía y cartografía previa. Dicha selección se ha basado en los siguientes aspectos:

a) Criterios paleoicnológicos: se han elegido las zonas con una mayor riqueza icnológica. Así mismo, se ha valorado la presencia en dichas zonas de yacimientos con cierta importancia o relevancia: buen estado de preservación, peculiaridades en la locomoción, presencia de nuevas especies icnológicas, aspectos estratigráficos, hábitos en el comportamiento, volumen icnológico de la zona, etc.

b) Criterios logísticos: es este apartado se han tenido en consideración aspectos referentes a la accesibilidad de los mismos (carreteras, pistas, etc.), infraestructuras delos núcleos rurales cercanos (hoteles, casas rurales, restaurantes, etc.), localización exacta de los yacimientos (lo cual no siempre es posible).

\subsection{TRABAJ OS DE CAMPO}

El trabajo de campo es, sin lugar a dudas, una de las bases fundamentales sobre la que se asienta el presente estudio. Ha consistido básicamente en el levantamiento de las columnas estratigráficas, recogida de muestras para su posterior análisis, y en la realización de fotografías. 
Se han levantado 5 perfiles estratigráficos detallados y representativos del relleno sedimentario del Grupo Enciso a escala 1:250 (anexos IV, V, VI, VII y VIII) en zonas estratégicas y donde las condiciones del afloramiento lo permitían. En la distribución de las columnas se ha intentado cubrir la mayor cantidad posible de yacimientos icnológicos. Por tanto, debido a esta traba inicial, las condiciones de los afloramientos no eran, en algunos casos, las más favorables. Las medidas de potencia se han realizado con cinta métrica y vara de J acob.

Así mismo, se han realizado 44 columnas en detalle, de unos $20 \mathrm{~m}$ de potencia, a escala 1:100 en cada yacimiento icnológico seleccionado (capítulos 10, 11, 12 y 13). En algunos yacimientos no ha podido hacerse debido a las malas condiciones y/o a la escasa serie aflorante.

El levantamiento de las secciones estratigráficas se ha acompañado del mayor número posible de observaciones posibles, así como de una minuciosa descripción de los caracteres litológicos (entre los que se incluyen aspectos dimensionales como el espesor, geometría, forma, textura, granulometría, color en superficie fresca y alterada, etc.), características de la estratificación, geometría de los cuerpos sedimentarios, estructuras sedimentarias, contenido paleontológico, etc., así como cualquier otra cualidad destacable. Además, simultáneamente al levantamiento de perfiles, se ha realizado un muestreo sistemático con el objetivo de efectuar una caracterización petrográfica de los sedimentos tanto de visu como por microscopio petrográfico.

En la presente tesis doctoral, se denomina estrato a cualesquiera capa de roca de litología homogénea o gradacional limitada a techo y muro por superficies de estratificación (erosión, no deposición o cambio brusco en la naturaleza y/o condiciones deposicionales) con un espesor mayor de $10 \mathrm{~mm}$. Por otra parte, se denomina lámina a cualquier capa que manteniendo los mismos requisitos anteriores presenta un espesor menor de $10 \mathrm{~mm}$ (MCKEE Y WEIR, 1953; COLLINSON Y THOMPSON, 1982). La caracterización de los conceptos estratificación y laminación sigue unos razonamientos análogos a los ya expuestos. Así pues, la diferencia entre ambos es una mera cuestión de escala, siendo el valor límite de $10 \mathrm{~mm}$ una elección completamente arbitraria, de forma que una capa puede pasar de estrato a lámina con un simple cambio de espesor lateral (BRIDGE, 1993). Cuando se trabaja con sedimentos laminados lacustres es importante hacer ciertas apreciaciones. El término varva hace referencia a laminaciones depositadas en periodos de tiempo de un año. El término ritmita hace referencia a una laminación de espesor regular en la cual la escala temporal de deposición es desconocida (GLENN Y KELTS, 1991). Por último, el término laminita serefiere a cualquier laminación sea regular o irregular en espesor (GIERLOWSKIKORDESCH, 2010).

Los términos referentes a la geometría de los estratos se basan en los esbozados por BRIDGE (1993) y DABRIO Y HERNANDO-COSTA (2003). Según estos autores las morfologías básicas tridimensionales más características son tabular, cuneiforme, sigmoidal, lobulada, lenticular o acanalada. En dos dimensiones las geometrías más distintivas son rectangular, triangular, trapezoidal, plano-cóncava, plano—convexa, cóncavo—convexa y hollow.

\subsection{TRABAJ OS DE LABORATORIO}

\subsubsection{Láminas delgadas y secciones pulidas}

En este apartado se describe la metodología que se ha utilizado con las muestras de mano para la descripción de las microfacies a partir de secciones (pulidas) y/o láminas delgadas.

Las muestras recolectadas durante las salidas de campo, se han cortado para obtener secciones (algunas se han pulido), que se han utilizado para su posterior examen con una lupa binocular. Cuando se ha considerado necesario por su relevancia, se ha realizado una lámina delgada de la muestra, para su estudio por microscopio petrográfico. Se han hecho unas 160 láminas delgadas. La mayor parte de las láminas se han realizado en los laboratorios del Instituto Geológico y Minero de España y, una pequeña parte, en el Departamento de Ingeniería Geológica de la Escuela Técnica Superior de Ingenieros de Minas y Energía de Madrid. 


\section{Metodología}

En algunas láminas se ha realizado la tinción de media lámina para discernir la composición de los carbonatos con rojo de alizarina y ferricianuro potásico (DICKSON, 1966; LINDHOLM Y FINKELMAN, 1972). El rojo de alizarina tiñe de rojo el calcio por lo que permite diferenciar entre calcita (teñida) y dolomita (sin teñir). El ferricianuro potásico tiñe de azul el hierro distinguiendo cualitativamente el contenido en hierro en estado ferroso de la muestra.

\subsubsection{Elementos mayoritarios y traza}

La determinación delos elementos mayoritariosy traza se ha realizado en los laboratorios del Instituto Geológico y Minero de España. Los elementos mayoritarios $\left(\mathrm{SiO}_{2}, \mathrm{Al}_{2} \mathrm{O}_{3}, \mathrm{Fe}_{2} \mathrm{O}_{3}, \mathrm{CaO}\right.$, $\mathrm{TiO}_{2}, \mathrm{MnO}, \mathrm{K}_{2} \mathrm{O}, \mathrm{MgO}$ y $\mathrm{P}_{2} \mathrm{O}_{5}$ ) se han analizado por fluorescencia de rayos $\mathrm{X}$ mediante fusión con tetraborato de Litio $(0,3: 5,5)$ en una perladora PerlX'3 midiéndose en un equipo MagiX de PANalytical. El contenido en Sodio $\left(\mathrm{Na}_{2} \mathrm{O}\right)$ se ha analizado por Absorción Atómica en un equipo VARIAN FS-220 con fusión con metaborato de litio. Los elementos traza (Ag, As, Ba, Be, Bi, Cd, $\mathrm{Ce}, \mathrm{Co}, \mathrm{Cr}, \mathrm{Cu}, \mathrm{La}, \mathrm{Li}, \mathrm{Mo}, \mathrm{Nb}, \mathrm{Ni}, \mathrm{Pb}, \mathrm{Rb}, \mathrm{Sb}, \mathrm{Sc}, \mathrm{Se}, \mathrm{Sr}, \mathrm{Tl}, \mathrm{V}, \mathrm{W}, \mathrm{Y}, \mathrm{Zn}$ ) se han medido por Espectrofotometría de Plasma Acoplado Inductivamente (ICP-AES) en un equipo Varian VistaMPX previo ataque ácido $\left(\mathrm{HF}+\mathrm{HClO}_{4}+\mathrm{HNO}_{3}\right)$ a sequedad y posterior disolución en ácido clorhídrico al $10 \%$.

\subsubsection{Pérdida por calcinación}

La pérdida por calcinación (loss on ignition) es el método empleado para determinar el contenido en materia orgánica y carbonatos de los sedimentos, al someterlos a un calentamiento secuencial en un horno (DEAN, 1974). Los análisis se han realizado en el laboratorio del Instituto Geológico y Minero de España, siguiendo el procedimiento descrito por HEIRI et al. (2001) con las modificaciones de BENGTSSON Y ENELL (1986). El primer paso es pesar la muestra secada al aire $\left(\mathrm{P}_{\text {muestra }}\right)$. Posteriormente, la muestra se somete a secado a $105^{\circ} \mathrm{C}$ durante $12-24$ horas, se deja enfriar a temperatura ambiente (25-30 minutos), y se pesa $\left(\mathrm{P}_{105}\right)$. Las pérdidas por calcinación a 105으 $\mathrm{C}$ se calculan como:

$$
\mathrm{PPC}_{105}=\frac{\mathrm{P}_{\text {muestra }}-\mathrm{P}_{105}}{\mathrm{P}_{\text {muestra }}} 100
$$

Se calienta de nuevo la muestra durante 4 horas a $550^{\circ} \mathrm{C}$, se dejar enfriar a temperatura ambiente (30-40 minutos), y se pesa ( $\left.\mathrm{P}_{550}\right)$. En esta etapa del proceso se produce la combustión de la materia orgánica que se transforma en $\mathrm{CO}_{2}$ y cenizas. Así pues, esta pérdida de peso es proporcional a la cantidad de carbono orgánico presente en la muestra ( $\mathrm{PPC}_{550}=2,13 \cdot$ Corgánico) (DEAN, 1974; 1999). Las pérdidas por calcinación a 550 $\mathrm{C}$ se calculan mediante la siguiente ecuación:

$$
\mathrm{PPC}_{550}=\frac{\mathrm{P}_{105}-\mathrm{P}_{550}}{\mathrm{P}_{105}} 100
$$

Finalmente se vuelve a calentar durante 2 horas a $950^{\circ} \mathrm{C}$, se enfría a temperatura ambiente y se pesa de nuevo ( $\left.\mathrm{P}_{950}\right)$. En esta nueva fase se produce la extracción del $\mathrm{CO}_{2}$ de los carbonatos y se forman óxidos. La nueva pérdida de peso es, entonces, proporcional al carbonato presente en la muestra (Carbonato =1,36·PPC950) (BENGTSSONY ENELL, 1986):

$$
\mathrm{PPC}_{950}=\frac{\mathrm{P}_{550}-\mathrm{P}_{950}}{\mathrm{P}_{105}} 100
$$

\subsubsection{Isótopos estables}

Los análisis isotópicos se han realizado en el laboratorio de isótopos estables de la Universidad de Michigan en Estados Unidos. Las muestras (peso mínimo de $10 \mu \mathrm{g}$ ) son depositadas en recipientes de acero inoxidable donde se calientan al vacío a $200^{\circ} \mathrm{C}$ durante una hora para eliminar los posibles contaminantes volátiles, así como el contenido en agua. 


\section{Metodología}

Posteriormente se colocan en recipientes de borosilicato donde reaccionan a $76^{\circ}+2^{\circ} \mathrm{C}$ con tres gotas de ácido fosfórico anhidro durante 8 minutos en un equipo Finnigan MAT Kiel I acoplado directamente a un espectrómetro de masas con triple colector Finnigan MAT 251. La corrección por la contribución del isótopo ${ }^{17} \mathrm{O}$ se hace por calibración a partir del mejor ajuste obtenido de la recta de regresión delos estándares NBS-18 y NBS-19. Los datos se dan en notación por mil según el estándar VPDB con una precisión superior al 0,1\%.

\subsubsection{Notación isotópica}

La variación natural de la composición isotópica de los elementos es mínima debido a que los procesos de fraccionamiento asociados son muy pequeños. Por esta razón, MCKINNEY et al. (1950) introdujeron una nueva manera de expresar los valores isotópicos creando la notación delta $(\delta)$. Esta notación refleja la desviación del valor isotópico de una muestra respecto al valor deun material dereferencia o patrón, arbitrariamente seleccionado. Los valores negativos indican una menor abundancia del isótopo ligero en la muestra con respecto al patrón:

$$
\begin{aligned}
& \delta=\frac{R_{\text {muestra }}-R_{\text {patrón }}}{R_{\text {patrón }}} 10^{3}=\left(\frac{R_{\text {muestra }}}{R_{\text {patrón }}}-1\right) 10^{3} \text {, en notación por mil (\%o). } \\
& \delta=\frac{R_{\text {muestra }}-R_{\text {patrón }}}{R_{\text {patrón }}}=\left(\frac{R_{\text {muestra }}}{R_{\text {patrón }}}-1\right) \text {, en notación decimal. }
\end{aligned}
$$

La relación isotópica o abundancia $(\mathrm{R})$ es la razón entre el isótopo menos abundante respecto al isótopo más abundante. En la naturaleza, el carbono presenta dos isótopos estables, ${ }^{12} \mathrm{C}(98,93 \%)$ y ${ }^{13} \mathrm{C}(1,07 \%)$. El oxígeno tiene tres isótopos estables con unas composiciones representativas: ${ }^{16} \mathrm{O}(99,757 \%),{ }^{17} \mathrm{O}(0,038 \%)$ y ${ }^{18} \mathrm{O}(0,205 \%)$ (ROSMANYTAYLOR, 1998; BERGLUND Y WIESER, 2011). Así pues, la abundancia isotópica del oxígeno y del carbono vienen determinadas por:

$$
\begin{aligned}
& { }^{18} \mathrm{R}={ }^{{ }^{18} \mathrm{O}} \\
& { }^{16} \mathrm{O} \\
& { }^{13}={ }^{13} \mathrm{C} \\
& { }^{12} \mathrm{C}
\end{aligned}
$$

Las muestras patrones del $\mathrm{Cy} \mathrm{O}$, tienen dos estándares internacionales de referencia. El primero es el denominado patrón medio del agua del mar conocido por sus siglas en inglés SMOW (Standard Mean Ocean Water). Cuando este patrón se agotó fue reproducido por el Organismo Internacional de la Energía Atómica, con sede en Viena, por lo que se conoce como VSMOW (Viena-SMOW). El segundo es el patrón PDB (Pee Dee Belemnitella) que provenía del $\mathrm{CaCO}_{3}$ del rostro de un Belemnites recolectado en la Formación Pee Dee. Este estándar también se agotó y, en la actualidad, se utiliza la escala VPDB (Vienna-PDB).

La composición isotópica del oxígeno se referencia con respecto a las escalas VSMOW o VPDB, mientras que el carbono utiliza únicamente la escala VPDB. La conversión entre ambos patrones se realiza según las fórmulas de COPLEN (1988):

$$
\begin{aligned}
& \delta^{18} \mathrm{O}_{\text {VSMOW }}=1,03091 \delta^{18} \mathrm{O}_{\text {VPDB }}+30,91 \\
& \delta^{18} \mathrm{O}_{\text {VPDB }}=0,97001 \delta^{18} \mathrm{O}_{\text {VSMOW }}-29,99
\end{aligned}
$$

\subsubsection{Fraccionamiento isotópico}

En una reacción cualquiera entre dos compuestos bien sea en equilibrio $(A \leftrightarrow B)$ o en condiciones irreversibles $(\mathrm{A} \rightarrow \mathrm{B})$, el factor de fraccionamiento isotópico se expresa como el cociente entre la relación isotópica del compuesto final $\mathrm{B}$ respecto del compuesto inicial A: 
$\alpha_{B-A}=\alpha_{A}(B)=\alpha_{B / A}=\frac{R_{B}}{R_{A}}$

El factor de fraccionamiento en la reacción contraria $\mathrm{B} \leftrightarrow \mathrm{A}$ y/ o $\mathrm{B} \rightarrow \mathrm{A}$ queda de la forma:

$\alpha_{A-B}=\alpha_{B}(A)=\alpha_{A / B}=\frac{R_{A}}{R_{B}}$

Ambas ecuaciones están relacionadas entre sí mediante la expresión:

$\alpha_{B-A}=\frac{1}{\alpha_{A-B}}$

Utilizando la escala delta $\delta$ se obtiene por sustitución que:

$a_{\mathrm{B}-\mathrm{A}}=\frac{\delta_{\mathrm{B}}+1}{\delta_{\mathrm{A}}+1} \leftrightarrow \mathrm{a}_{\mathrm{A}-\mathrm{B}}=\frac{\delta_{\mathrm{A}}+1}{\delta_{\mathrm{B}}+1}$, en notación decimal.

$a_{\mathrm{B}-\mathrm{A}}=\frac{\delta_{\mathrm{B}}+1000}{\delta_{\mathrm{A}}+1000} \leftrightarrow \mathrm{a}_{\mathrm{A}-\mathrm{B}}=\frac{\delta_{\mathrm{A}}+1000}{\delta_{\mathrm{B}}+1000}$, en notación por mil (\%o). la forma:

Si se conoce el factor de fraccionamiento, la determinación de uno de los valores $\delta$ es de

$$
\begin{aligned}
& \delta_{\mathrm{B}}=\left[\alpha_{\mathrm{B}-\mathrm{A}}\left(\delta_{\mathrm{A}}+1\right)\right]-1 \leftrightarrow \delta_{\mathrm{A}}=\frac{\delta_{\mathrm{B}}+1}{\alpha_{\mathrm{B}-\mathrm{A}}}-1 \text {, en notación decimal. } \\
& \delta_{\mathrm{B}}=\left[\alpha_{\mathrm{B}-\mathrm{A}}\left(\delta_{\mathrm{A}}+1000\right)\right]-1000 \leftrightarrow \delta_{\mathrm{A}}=\frac{\delta_{\mathrm{B}}+1000}{\alpha_{\mathrm{B}-\mathrm{A}}}-1000 \text {, en notación por mil (\%o). }
\end{aligned}
$$

En los procesos naturales es frecuente que los valores de $\alpha$ sean cercanos a la unidad por lo que se utiliza el fraccionamiento o factor de enriquecimiento definido como:

$$
\begin{aligned}
& \varepsilon_{\mathrm{B}-\mathrm{A}}=\varepsilon_{\mathrm{A}}(\mathrm{B})=\varepsilon_{\mathrm{B} / \mathrm{A}}=\alpha_{\mathrm{B}-\mathrm{A}}-1=\frac{\mathrm{R}_{\mathrm{B}}}{\mathrm{R}_{\mathrm{A}}}-1 \\
& \varepsilon_{\mathrm{A}-\mathrm{B}}=\varepsilon_{\mathrm{B}}(\mathrm{A})=\varepsilon_{\mathrm{A} / \mathrm{B}}=\alpha_{\mathrm{A}-\mathrm{B}}-1=\frac{\mathrm{R}_{\mathrm{A}}}{\mathrm{R}_{\mathrm{B}}}-1
\end{aligned}
$$
expresiones:

En la práctica, el fraccionamiento se utiliza con la escala delta $\delta$ quedando las siguientes

$$
\begin{aligned}
& \varepsilon_{\mathrm{B}-\mathrm{A}}=\frac{\delta_{\mathrm{B}}-\delta_{\mathrm{A}}}{\delta_{\mathrm{A}}+1} \leftrightarrow \varepsilon_{\mathrm{A}-\mathrm{B}}=\frac{\delta_{\mathrm{A}}-\delta_{\mathrm{B}}}{\delta_{\mathrm{B}}+1}, \text { en notación decimal. } \\
& \varepsilon_{\mathrm{B}-\mathrm{A}}=\frac{\delta_{\mathrm{B}}-\delta_{\mathrm{A}}}{\delta_{\mathrm{A}}+1000} \leftrightarrow \varepsilon_{\mathrm{A}-\mathrm{B}}=\frac{\delta_{\mathrm{A}}-\delta_{\mathrm{B}}}{\delta_{\mathrm{B}}+1000} \text {, en notación por mil (\%o). }
\end{aligned}
$$

Como los valores del fraccionamiento suelen ser pequeños, se pueden utilizar ciertas aproximaciones que facilitan los cálculos, aunque sólo son aceptables, siempre y cuando dichos fraccionamientos sean menores de $20 \%$ (FRY, 2003):

$$
\begin{aligned}
& \varepsilon_{\mathrm{B}-\mathrm{A}} \approx-\varepsilon_{\mathrm{A}-\mathrm{B}} \\
& \varepsilon_{\mathrm{B}-\mathrm{A}} \approx 10^{3} \ln \alpha_{\mathrm{B}-\mathrm{A}} \approx \delta_{\mathrm{B}}-\delta_{\mathrm{A}}
\end{aligned}
$$


En la naturaleza existen dos procesos de fraccionamiento isotópico: el fraccionamiento en equilibrio y el cinético (desequilibrio).

El fraccionamiento en equilibrio (o termodinámico) se produce durante un proceso físico o químico reversible $(\varepsilon)$. Por el contrario, el fraccionamiento cinético $\left(\varepsilon_{\mathrm{k}}\right)$ se establece en un proceso irreversible. En estos casos hay que tener en cuenta que:

$$
\begin{aligned}
& \alpha_{\text {total }}=\alpha \alpha_{k} \\
& \varepsilon_{\text {total }}=\varepsilon+\varepsilon_{\mathrm{k}}
\end{aligned}
$$

\subsection{TRABAJ OS DE GABINETE}

En este apartado, se agrupan las tareas que conllevan el procesamiento, análisis e interpretación de los datos obtenidos en campo y laboratorio, culminando en la redacción de esta memoria.

\subsubsection{Columnas estratigráficas}

La elaboración de las secciones estratigráficas ha permitido volcar en forma sinóptica toda la información recolectada en el campo y en el laboratorio. La delineación de los perfiles estratigráficos se ha presentado, para mayor comodidad en el manejo de esta memoria, en tamaño DIN-A4. Para su representación gráfica se ha utilizado el programa CorelDRAW X3, y una caja con la siguiente información (figura 2.1)

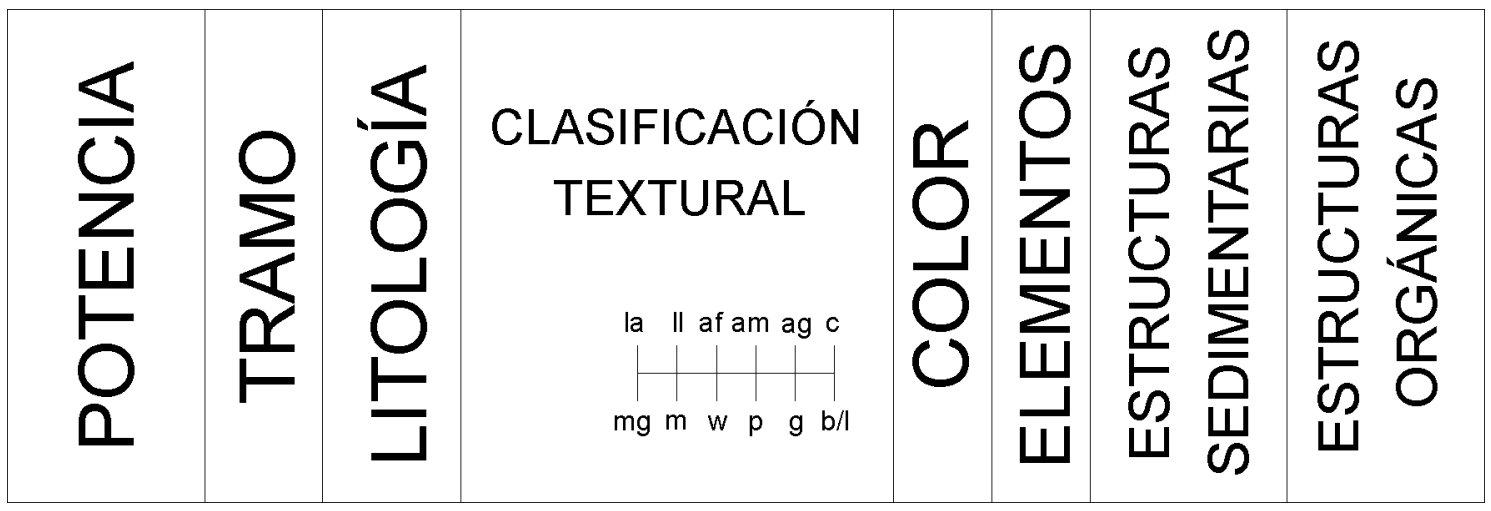

Figura 2.1: Modelo de caja utilizado en la elaboración de las columnas estratigráficas.

La primera columna indica el espesor de la serie levantada. En la segunda columna se marca el número de tramo para facilitar el posicionamiento de fotografías, figuras o descripciones posteriormente.

La tercera columna muestra las tramas utilizadas en las litologías presentes. Las clasificaciones de las rocas sedimentarias son innumerables, y se basan en la naturaleza de los depósitos que abarcan. En caso concreto del Grupo Enciso, aparecen todos los sedimentos intermedios entre carbonatados y siliciclásticos. En la literatura es posible encontrar una amplia gama de nombres para designar las diferentes combinaciones de litologías (así como sus términos intermedios) comprendidas entre estas tres litologías extremas: lutita, arena y caliza (SHEPARD, 1954; LINK, 1966; PICARD, 1971; MOUNT, 1985). Para el reconocimiento de visu, y debido a la idiosincrasia de los sedimentos que aparecen en la zona, se ha elegido la clasificación generalista de las rocas intermedias de VATAN (1967) con las simplificaciones adaptadas a la zona de estudio (figura 2.2).

La cuarta columna hace referencia a la representación de las texturas. La parte superior representa la leyenda de las rocas siliciclásticas: (la) lutita tamaño arcilla, (ll) lutita tamaño limo, (af) arena fina, (am) arena media, (ag) arena gruesa, y (c) conglomerado. La parte inferior hace 
referencia a las rocas carbonatadas según la clasificación clásica de DUNHAM (1962) con las modificaciones de EMBRY Y KLOVAN (1971): (m) mudstone, (w) wackestone, (p) packstone, (g) grainstone, (b) boundstone, y (l) lumaquela.

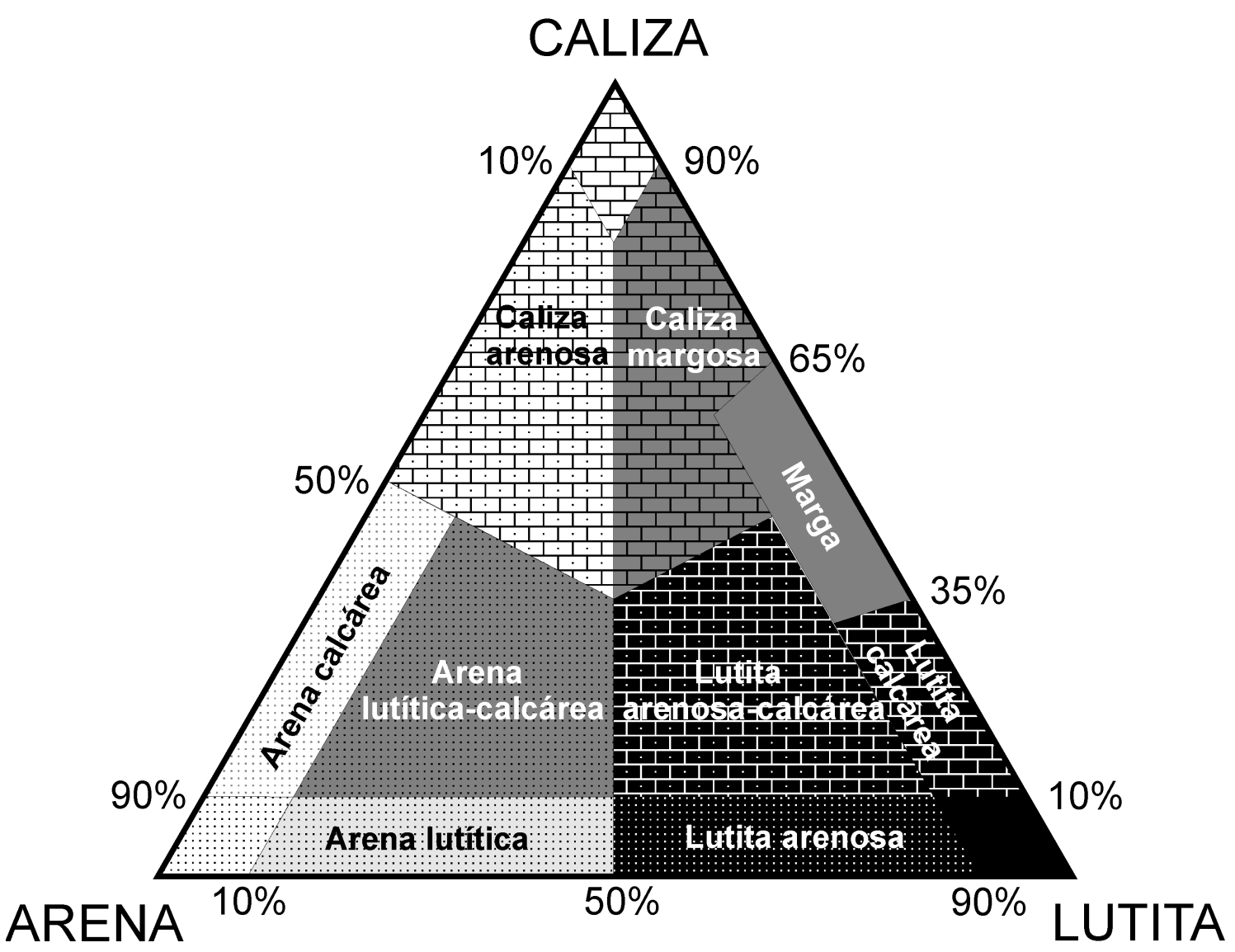

Figura 2.2: Tramas y leyenda de las principales litologías utilizadas en las columnas.

La quinta columna identifica el color en muestra fresca. El color de las rocas se ha obtenido por comparación con las tablas Munsell (figura 2.3). Se denomina moteado (marmorización) a la presencia de puntos, parches o zonaciones que exhiben colores rosados, púrpuras, rojizos y amarillentos debidas a acumulación de hierro férrico. Se origina por la fluctuación del nivel del agua en un sedimento con un contenido en hierro mayor del $2 \%$, ya que el ión ferroso adquiere movilidad y puede fijarse como ión férrico (FREYTETY VERRECCHIA, 2002).

Los colores de las rocas tienen gran interés ya que encierran cierta información sobre las condiciones fisicoquímicas del ambiente sedimentario o diagenético (PANTIN, 1969; GIOSAN et al., 2002). El color en los sedimentos depende de dos factores principales: presencia de materia orgánica y/ o el estado de oxidación del hierro (férrico $\mathrm{Fe}^{3+}$ y ferroso $\mathrm{Fe}^{2+}$ ) y, en menor medida, contenido en carbonato (POTTER et al., 1980; TUCKER, 2003; J IN et al., 2004).

Los colores negros o grises oscuros son debidos a la presencia de materia orgánica o pirita diseminada. El color gris atestigua la ausencia de óxidos de hierro y la presencia de cierta cantidad de materia orgánica (POTTER et al., 1980; TUCKER, 2003; KRAUS Y HASIOTIS, 2006). Los colores verdes indican una relación alta de hierro ferruginoso con respecto al férrico, un bajo contenido en materia orgánica y, condiciones reductoras durante y después de la sedimentación (POTTER et al., 1980). En general, los colores rojos y amarillos-marrones se suele asociar a la presencia de una mezcla de hematites y goetita, siendo más rojizo cuanto mayor sea la proporción de hematites (KRAUS Y HASIOTIS, 2006). El color púrpura suele indicar la presencia de hematites (MCBRIDE, 1974; KRAUSY HASIOTIS, 2006). 


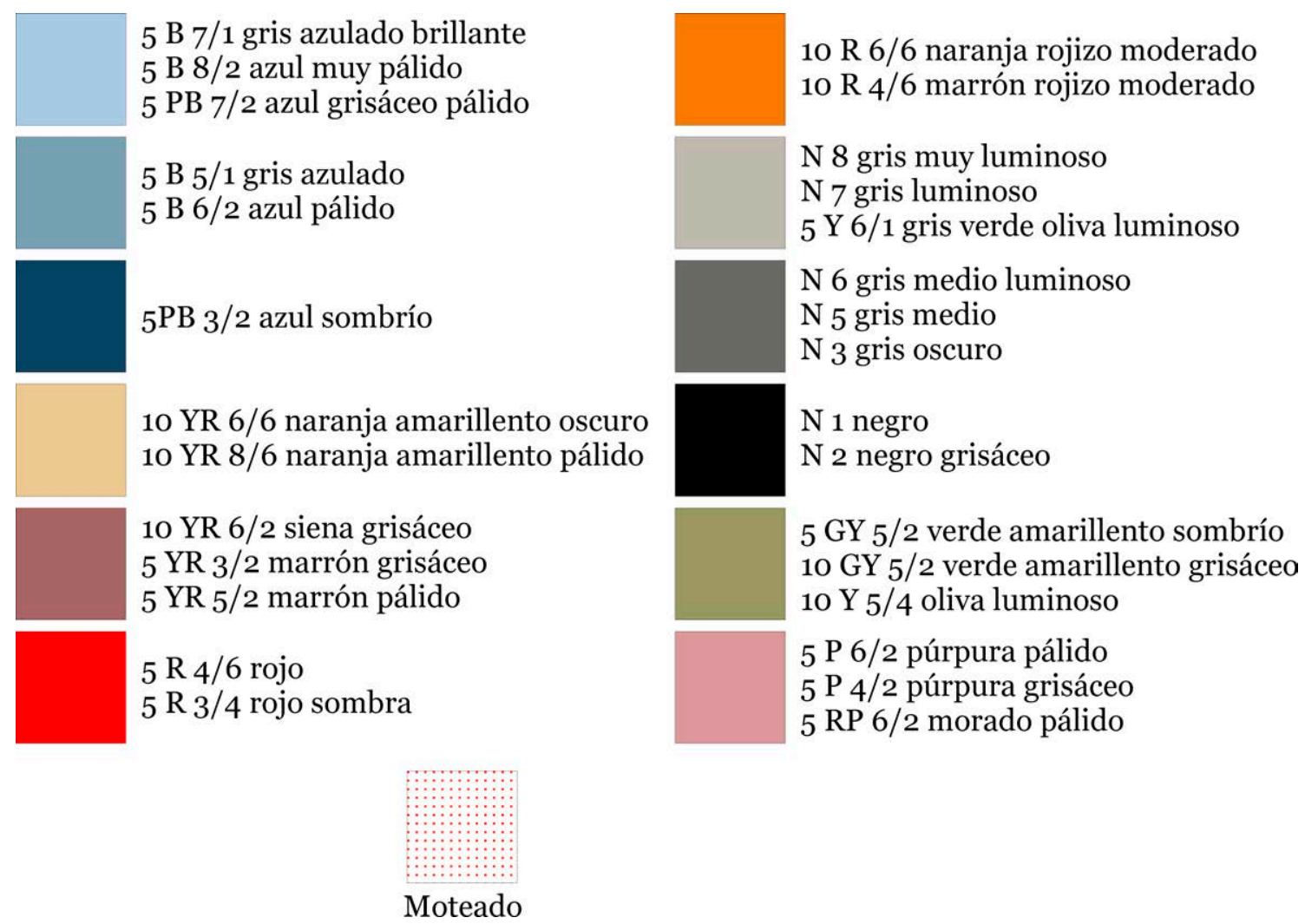

Figura 2.3: Leyenda de los colores en muestra fresca utilizados en la columna con indicación de las referencias principales a los colores dela tabla de referencia Munsell.

La sexta columna, única que no aporta datos descriptivos sino interpretativos, hace referencia a los elementos arquitectónicos descritos en el apartado 6.2 (figura 2.4).
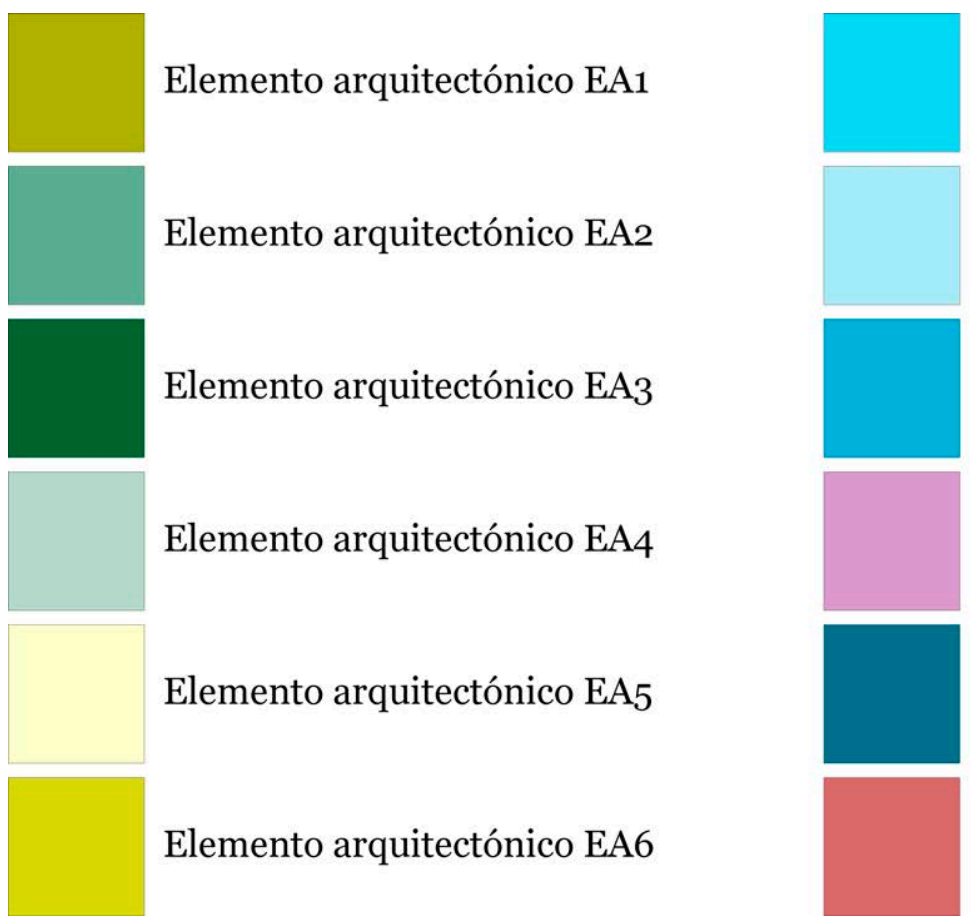

Elemento arquitectónico EA7

Elemento arquitectónico EA8

Elemento arquitectónico EA9

Elemento arquitectónico EA1o

Elemento arquitectónico EA11

Elemento arquitectónico EA12

Figura 2.4: Leyenda de equivalencia entre los colores utilizados en la columna y los elementos arquitectónicos reconocidos (apartado 6.2). 
La séptima columna muestra las estructuras sedimentarias que se han reconocido durante el levantamiento de la serie (figura 2.5).

Estratificación cruzada de surco
Estratificación cruzada planar
Laminación cruzada de surco
Laminación cruzada planar
Laminación paralela
Estratificación nodulosa
Rizadura simétricas
Rizaduras asimétricas
Rizaduras indiferenciadas
Rizaduras ascendentes
Grietas de retracción
Nódulos
Costras de Fe
Pseudomorfos de cristales de yeso
Estructuras de carga
Estructuras de escape de agua
Laminación convoluta
Cristales de pirita
O) Ooides/oolito y pisoides/pisolito
Peloides

Figura 2.5: Símbolos y clave de signos para las estructuras sedimentarias.

La octava columna representa el contenido paleontológico y los restos de actividad orgánica (figura 2.6).

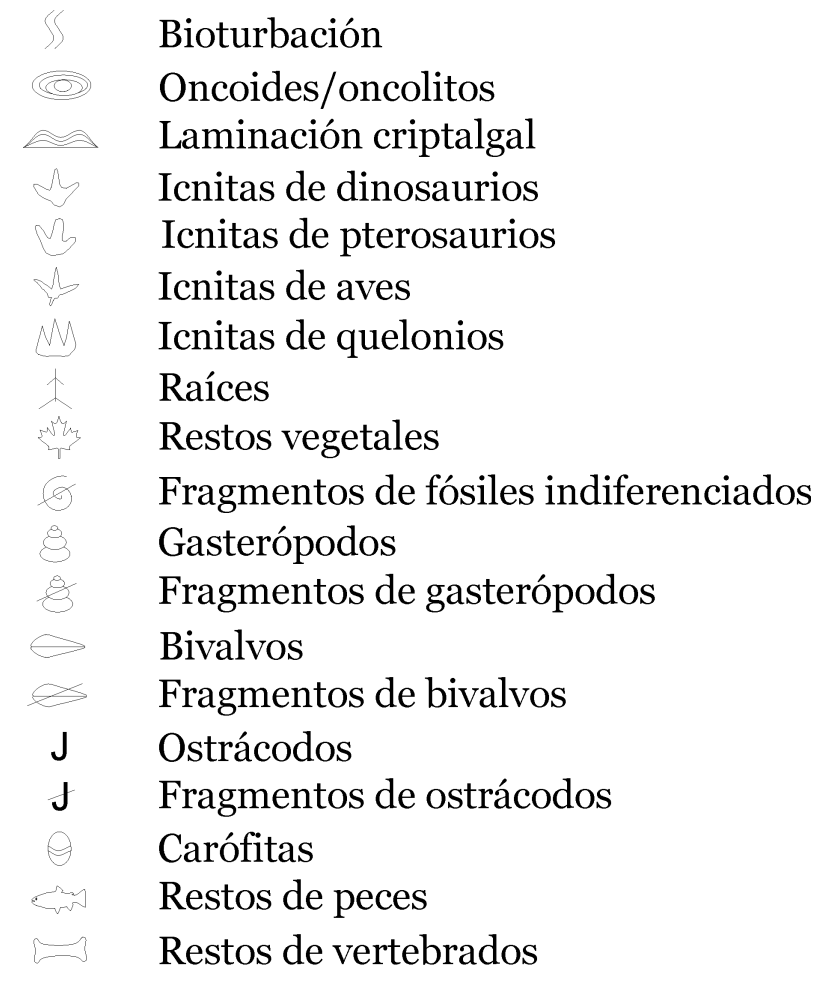

Figura 2.6: Símbolos del contenido paleontológico y restos de actividad orgánica. 


\section{Metodología}

\subsubsection{Análisis estadístico}

En varios apartados de la presente memoria ha sido necesario el manejo de gran número de datos. En estos casos se han utilizado dos técnicas estadísticas básicas que se describen a continuación.

\subsubsection{Normalidad}

El análisis estadístico se inicia siempre con un estudio exploratorio de datos cuya finalidad es examinar los datos antes de aplicar cualquier técnica estadística. Es un método sencillo que permite organizar los datos, detectar fallos en su recogida, identificar casos atípicos, etc.

Lo primero es comprobar si los datos presentan una distribución normal mediante las pruebas de bondad de ajuste. Muchos métodos estadísticos se basan en la hipótesis de normalidad en la variable objeto de estudio, no siendo válidos dichos métodos si la falta de normalidad es suficientemente fuerte.

En la presente tesis se utiliza el test de Shapiro-Wilk para certificar la normalidad de las variables. Este test se utiliza para contrastar la normalidad de un conjunto de datos, sobre todo para muestras de pequeño tamaño comprendidas entre 3 y 50 casos. Se realiza con el programa STATISTICA 7.0 @ StatSoft Inc., que al estar implementado con las modificaciones de ROYSTON (1982) permite su aplicación a muestras de hasta 2.000 observaciones (SHAPIRO Y WILK, 1965; SHAPIRO et al., 1968; ROYSTON, 1982).

Cuando la prueba no cumple el supuesto de normalidad se procederá a realizar una transformación a la variable para que adopte una distribución normal, y se volverá a realizar un análisis de bondad del ajuste.

\subsubsection{Análisis de componentes principales o factores}

El análisis de componentes principales es una técnica estadística que no requiere la suposición de normalidad de los datos, aunque si se cumple esta premisa, el análisis es más riguroso y preciso. Se trata de una técnica de síntesis de la información o reducción del número de variables, perdiendo la menor cantidad de información posible.

Los nuevos componentes principales o factores extraídos son una combinación lineal de las variables originales y, además, son independientes entre sí. Habitualmente se conservan sólo aquellos componentes que recogen la mayor parte de la variabilidad, hecho que permite representar los datos según dos o tres dimensiones pudiéndose entonces identificar grupos naturales entre las observaciones.

De nuevo se utiliza el programa STATISTICA 7.0 (C) StatSoft Inc., que utiliza la metodología descrita en J AMBU (1991). 


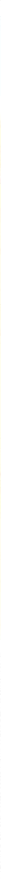

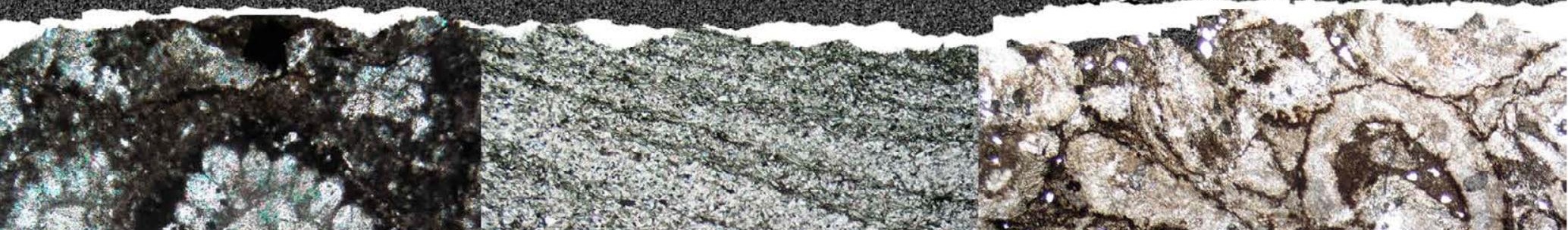

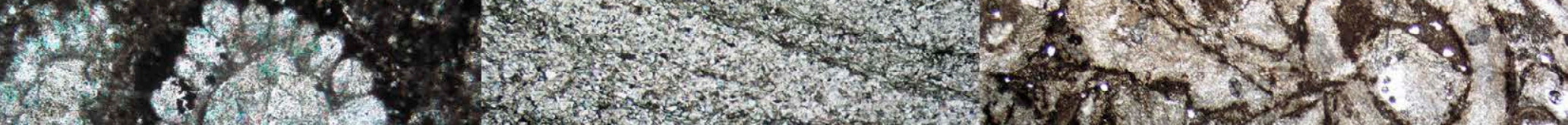

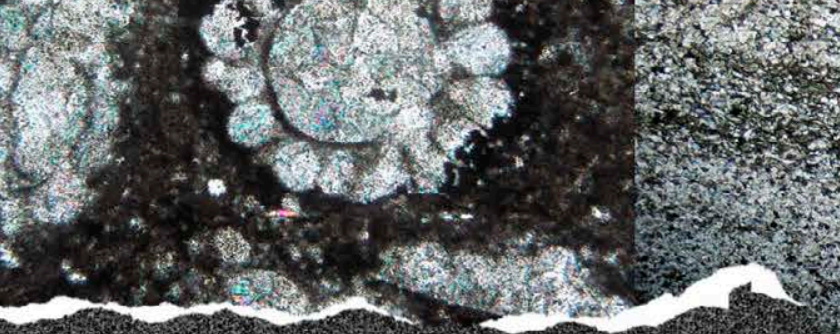

\section{MARCO TECTÓNICO}

ESTRATIGRÁIICO DE LA CUENCA DE CAMIEROS

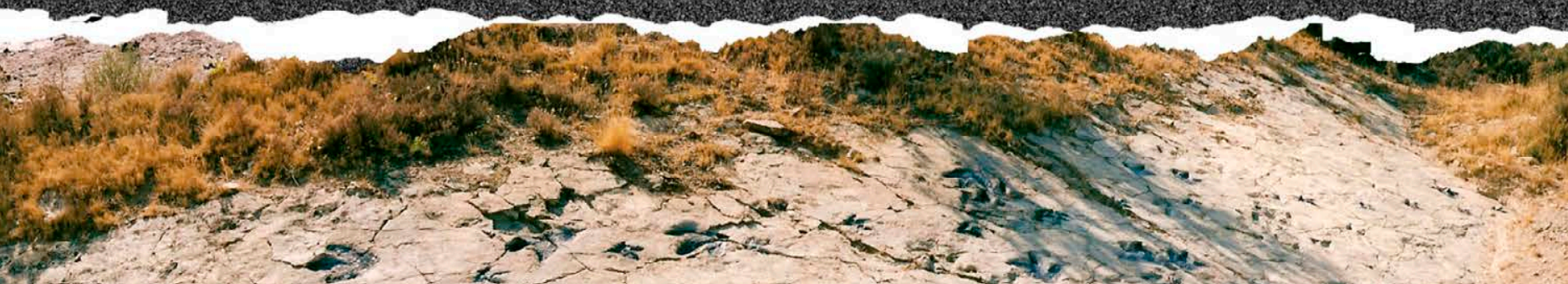

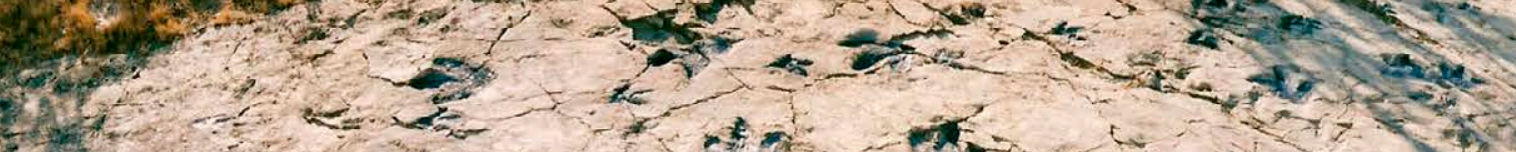

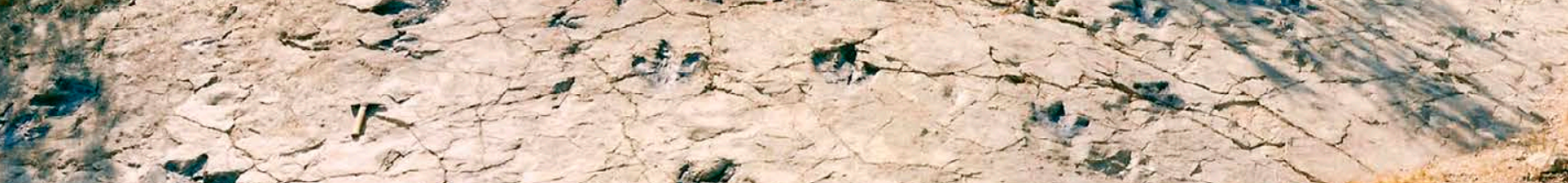

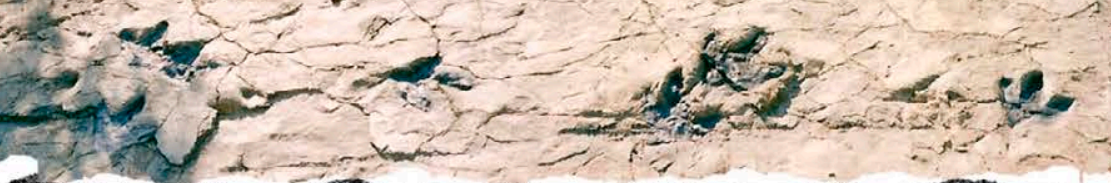


Carta de Charles Darwin a C. Ivell 25 de Noviembre de 1860

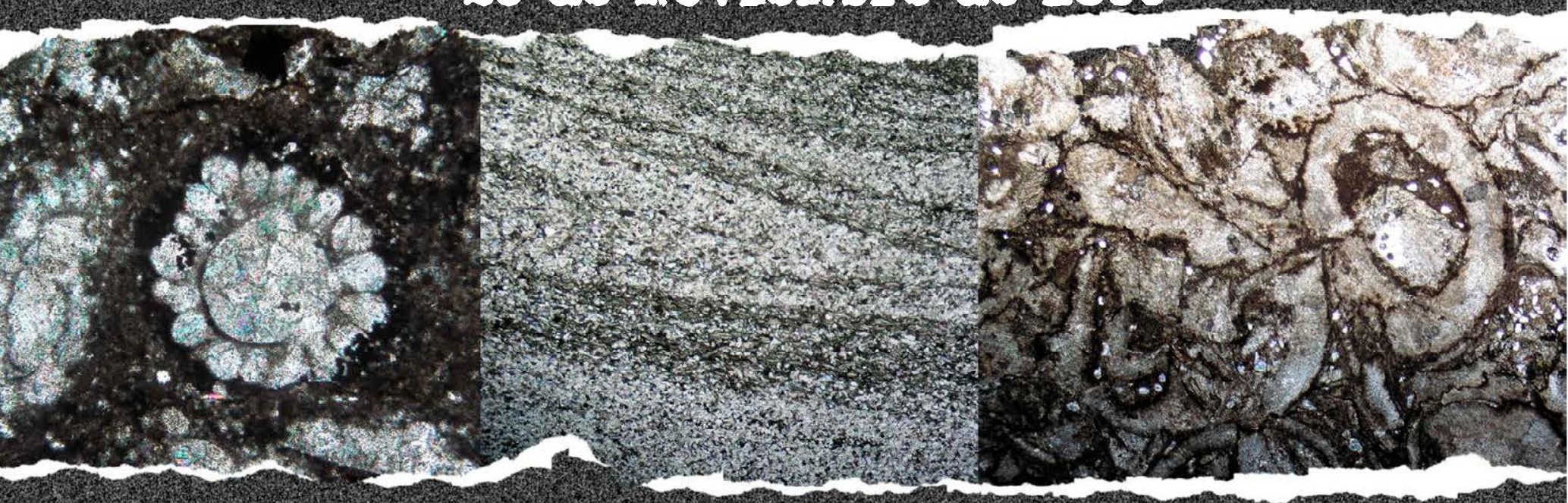

Having burnt my own fingers so consumedly With the Wealden, I an feartul for jou, but I well know how infinitely more cautions, prudent, and far-seeing you are than I an; but for heaven's sake take care of your lingers; to bum them severely, as I have done, is very unpleasant

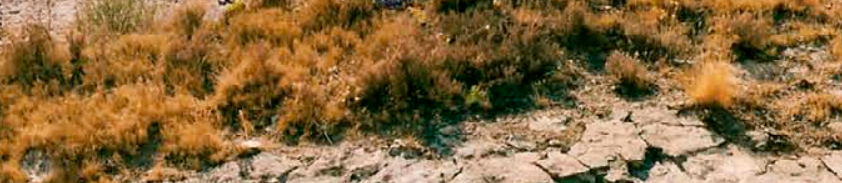

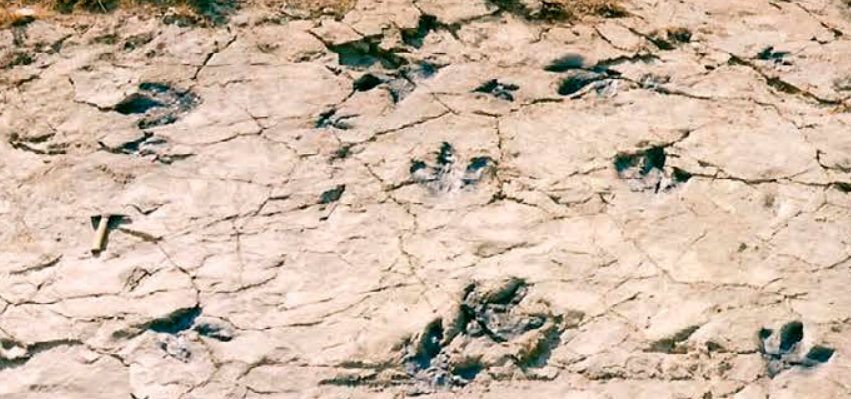




\subsection{GEOGRAFÍA FÍSICA}

La Unidad de Cameros se localiza en la zona más noroccidental de la actual Cadena Ibérica (figura 3.1). Hoy en día constituye un conjunto montañoso situado entre dos grandes afloramientos Paleozoicos: las Sierras de la Demanda y Neila al noroeste (San Lorenzo, $2.262 \mathrm{~m}$ ) y la Sierra del Moncayo al sudeste (Moncayo, $2.315 \mathrm{~m}$ ). Entre ambas, se extiende un conjunto montañoso, de unos $7.500 \mathrm{~km}^{2}$, con una elevada orografía en dirección ONO-ESE y E-O.

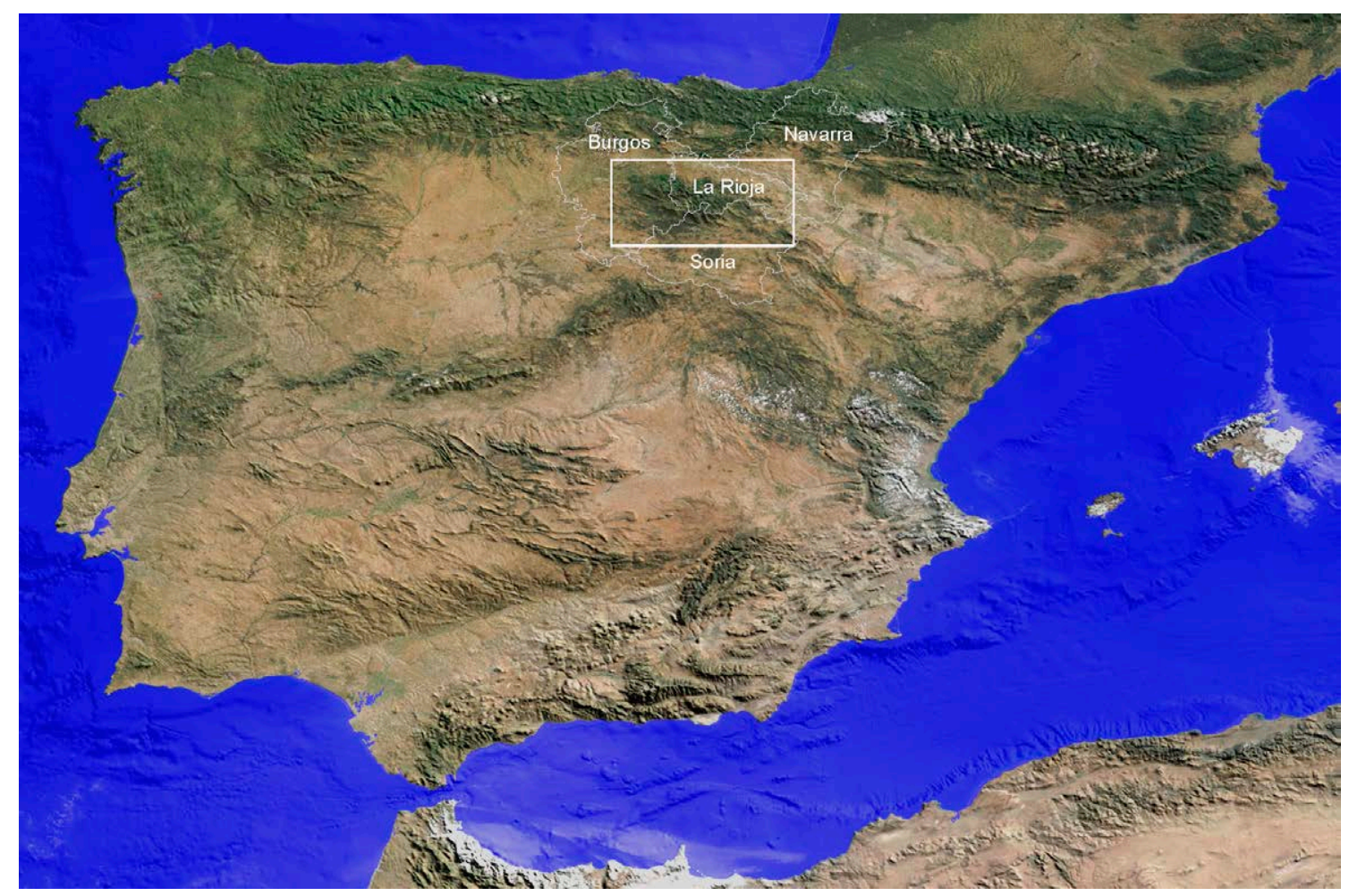

Figura 3.1: Mapa físico dela Península Ibérica mostrando la situación dela Unidad deCameros (en el recuadro), así como las provincias que abarca.

Desde el punto de vista administrativo, los terrenos abarcados por la Unidad de Cameros pertenecen a las provincias de Soria y Burgos (Comunidad Autónoma de Castilla y León), La Rioja (Comunidad Autónoma de La Rioja) y, de manera anecdótica, Navarra (Comunidad Foral de Navarra) (figura 3.1). El Grupo Enciso se localiza, fundamentalmente, en la Comunidad Autónoma de La Rioja, aunque en la provincia de Soria existen algunos afloramientos de poca entidad. Según la comarcalización más conocida y utilizada, incluye las comarcas de Tierra de Cameros o Sierras Centrales (valles del Iregua y del Leza-Jubera) y de las Sierras Orientales (valles del Cidacos y Alhama).

Este terreno se caracteriza por constituir un conjunto montañoso con una línea de cumbres de dirección dominante $\mathrm{E}-\mathrm{O}$. Presenta relieves de origen glaciar que rebasan frecuentemente los $2.000 \mathrm{~m}$ de altitud, y que disminuyen progresivamente hacia el este. Estas cumbres constituyen los límites provinciales entre La Rioja, Burgos y Soria, así como la divisoria hidrográfica de la cuenca del Ebro al norte y de la cuenca del Duero al sur. Según se avanza hacia el este, destacan la Sierra de Urbión o Picos de Urbión (Urbión, 2.228 m), Sierra de (las) Hormazas, Sierra de Castejón, Sierra Fragina, Sierra Cebollera (La Mesa, 2.168 m) y Sierra de Pineda (Puerto de Piqueras, $1.710 \mathrm{~m}$ ). En este momento, toma el relevo un conjunto montuoso cuyas características principales son: un relieve más o menos suave de cumbres alomadas (en el cual, el encajamiento de la red fluvial ha contribuido a incrementar la pendiente de sus laderas, creando desniveles importantes), su modesta altitud que sigue decreciendo hacia el este, sus divisorias de formas redondeadas, y una ausencia clara de orientación. Cabría citar la Sierra de Camero(s) Viejo (Canto Hincado, 1.758 m), Sierra del Hayedo de Santiago, Sierra de San Cristóbal, Sierra del Hayedo de Enciso y Sierra de Achena. 
La red fluvial en la zona de estudio está formada por ríos de sentido norte y noreste como el Iregua, Leza, J ubera, así como por el río Cidacos de curso sensiblemente E-O. Toda la región es tributaria hidrográficamente de la cuenca del Ebro. Los ríos reflejan el carácter climático mediterráneo en un caudal muy irregular con una sequía estival, aunque este rasgo se ve matizado por la alimentación nirval.

Climatológicamente, la zona es de una gran continentalidad, con inviemos de gran crudeza y veranos cálidos suavizados por la altitud de la zona. La pluviosidad es relativamente elevada.

La vegetación natural de la zona de estudio se caracteriza en general por ser un terreno muy deforestado de origen antrópico, vinculado a la creación de pastos de diente y al cultivo de laderas por medio de bancales o terrazas, hoy en día, abandonados. La mayor parte de este terreno se encuentra recubierto por el matorral de sustitución típico mediterráneo: principalmente romeral, tomillar, jaral, aulagar y estepar. En ciertas zonas, aún es posible admirar y disfrutar de algunos buenos reductos de bosques autóctonos en proceso de recuperación: encinar, robledal y hayedo.

La fauna se caracteriza por la presencia de importantes poblaciones de ciervos, corzos y jabalíes. En menor medida, aparecen ciertas especies emblemáticas como el gato montés o la nutria. Los cortados y cañones calizos, muy abundantes en esta zona, constituyen el hábitat ideal para nidificar a ciertas aves rupícolas como el águila perdicera, el buitre leonado, el búho real y el alimoche.

Todas estas características del medio físico tienen su reflejo en la geografía del poblamiento. La zona está dominada por pequeños núcleos rurales cuya economía se basa en la explotación tradicional de los recursos naturales. Su cabaña sigue la estructura tradicional del mundo mediterráneo, destacando la ganadería extensiva del ganado vacuno, ovino y caballar. En ocasiones, los aprovechamientos forestales sirven de complemento. La agricultura es de secano y se basa en el cereal, olivo, almendro y vid, así como pequeñas explotaciones hortofrutícolas (huertos tradicionales) en las zonas de vega de los valles fluviales. La no reconversión de estas actividades y el mantenimiento de estas explotaciones poco rentables constituyen la causa principal de la despoblación actual de este espacio. En los últimos años se ha ido incrementando la importancia del sector servicios asociado a un incipiente turismo rural vinculado al patrimonio cultural y natural: yacimientos de icnitas, yacimientos arqueológicos, senderismo, monumentos, artesanía, etc.

\subsection{MARCO GEOLÓGICO}

La Unidad de Cameros consta, geológicamente, del Basamento Varisco (aflorante en la Sierra de la Demanda y del Moncayo), del substrato mesozoico prerift y, del relleno sinrift y postrift de la cuenca de Cameros. Está situada en el sector noroccidental de la actual Cadena Ibérica, en una posición intermedia entre las dos grandes cadenas alpinas que se desarrollaron en los bordes de la placa ibérica: la Cordillera Bética, al sur, y la Cordillera Cantábrica-Pirineos, al norte (figura 3.2).

Hacia el norte constituye una lámina cabalgante, con implicación del basamento, que se superpone a los sedimentos oligocenos-miocenos de la actual cuenca de antepaís del Ebro por medio del cabalgamiento norte de Cameros (norcamerano o nordibérico), manteniéndose activo al menos hasta el Mioceno superior (CASAS-SAINZ, 1993). Este cabalgamiento, de vergencia hacia el norte y buzamiento uniforme de unos $10^{\circ}$ hacia el sur, tiene una orientación predominante $\mathrm{E}-$ $\mathrm{O}$ en la zona de estudio. Se continúa hacia el sudeste en dirección ONO-ESE donde aparece parcialmente recubierto por los depósitos terciarios de la Cuenca del Ebro, aunque su traza subterránea puede seguirse hasta la Zona de Enlace de la Cadena Ibérica y Costero Catalana (GUIMERÀ et al., 2004). Hacia el oeste, se continúa en la Unidad de La Demanda definiendo un frente continuo de unos 100-120 km de longitud (GUIMERÀ et al., 1995; CASAS-SAINZ et al., 2000). El desplazamiento horizontal estimado de la Unidad de Cameros sobre la cuenca del Ebro es de 
20-30 km (CASAS-SAINZ, 1993), 23-28 km (GUIMERÀ et al., 1995) o 15-25 km (MUÑOZ-J IMÉNEZ y CASAS-SAINZ, 1997). El desplazamiento vertical se estima en más de 4 km (MUÑOZ-J IMÉNEZY CASAS-SAINZ, 1997).

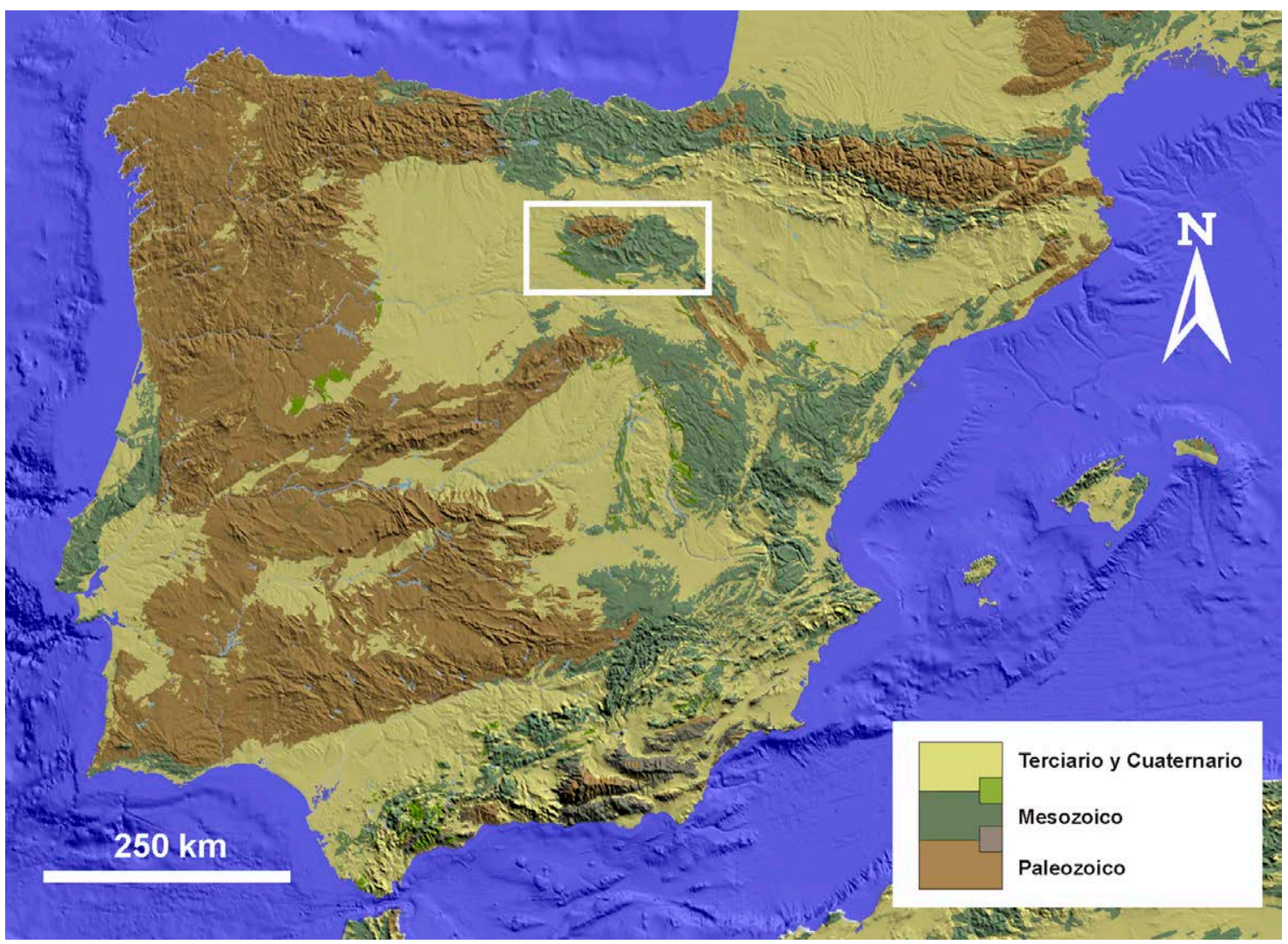

Figura 3.2: Mapa geológico de la Península Ibérica mostrando la localización de la Unidad de Cameros en el recuadro.

El límite sur está constituido por el cabalgamiento sur de Cameros (o surcamerano), con una extensión cartográfica de unos 150 km (GUIMERÀ et al., 1995). En la zona más occidental se estructura en un complejo cinturón de pliegues de propagación, fallas y cabalgamientos imbricados de orientación ONO-ESE y vergencia hacia el sur, que hacen cabalgar la Unidad de Cameros sobre la cuenca terciaria del Duero (MORILlo-VELARDE Y MELÉNDEZ-HEVIA, 1972; PLATT, 1990; MARTÍN-CLOSASY ALONSO-MILLÁN, 1998). En la zona central presentan orientaciones NOSE, E-Oy, en menor medida, NE-SO cabalgando sobre los depósitos Terciarios de la cuenca de Almazán (MIEGEBIELLE et al., 1993; CASAS-SAINZ et al., 2000). Finalmente, desaparece hacia el este en la zona del Moncayo donde se sitúa el límite entre la Unidad de Cameros y la Rama Aragonesa de la Cadena Ibérica (GUIMERÀ, 2004).

En conjunto, esta configuración de sus límites con un desplazamiento mayor de su margen norte con respecto al margen sur, hace que la Unidad de Cameros presente una estructura en pop-up (extrusión tectónica) asimétrica de unos 80 km de anchura (GUIMERÀ et al., 1995; GUIMERÀ, 2004).

Durante el J urásico superior-Cretácico inferior, la Placa Ibérica estuvo sometida a un contexto tectónico distensivo, asociado a la apertura del dominio del Atlántico Norte y al rifting transtensional en el Golfo de Vizcaya (MALOD Y MAUFFRET, 1990; OLIVET, 1996). En respuesta a esta distensión generalizada, la placa se compartimentó en cuatro Sistemas de Rift (figura 3.3):

a) Sistema de Rift Mesozoico Ibérico (SALAS et al., 2001).

b) Sistema de Rift del Margen Nordibérico (PEYBERNĖS, 1982a; VERGÉS Y GARCíA-SENZ, 2001)

c) Sistema de Rift del Margen Ibérico Sur (VERA, 2001). 


\section{Marco tectónico-estratigráfico de la cuenca de Cameros}

d) Sistema de Rift del Margen Ibérico Occidental (PINHEIRO et al., 1996; ALVES et al., 2006).

El Sistema de Rift Mesozoico Ibérico (o cuenca Ibérica) a su vez, se organiza en cuatro cuencas sedimentarias intracratónicas, delimitadas por dos familias de fallas tardihercínicas heredadas de dirección NO—SE y NNE—SSO (CASAS et al., 1995; SALASY GUIMERÀ, 1997):

a) La cuenca de Cameros con dos subcuencas principales denominadas Cameros Oriental y Cameros Occidental, así como varios surcos satélites de menores dimensiones: Bijuesca, Bigornia, Luezas y Rioja (MAS et al., 1993; MAS et al., 2002; 2003).

b) La cuenca del Maestrazgo estructurada en las subcuencas de Peñagolosa, Salzedella, Perelló, Morella, Aliaga, Galve, Oliete y Parras (SALAS Y GUIMERÀ, 1996; 1997; SALAS et al., 2001).

c) La cuenca Sur Ibérica (SALAS et al., 2001).

d) La cuenca de las Columbretes (RocA, 1996).

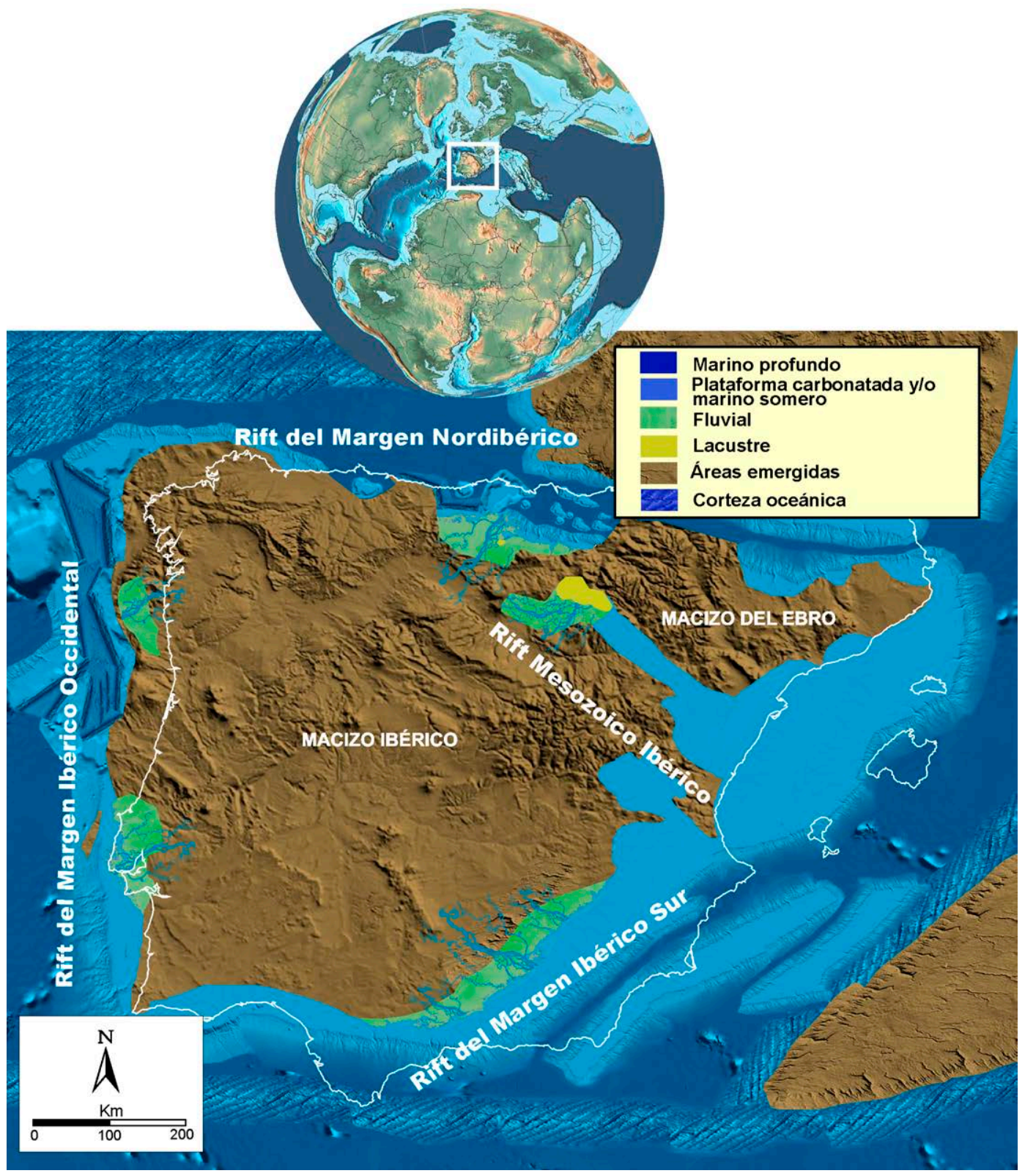

Figura 3.3: Mapa paleogeográfico dela Placa Ibérica durante el Aptiense indicando la posición de los principales Sistemas Rift. 
La cuenca de Cameros presenta una serie de particularidades que la distinguen del resto de cuencas de la Ibérica: un relleno marcadamente continental con escasa influencia marina, una elevada velocidad de subsidencia, una alta tasa de sedimentación y, un evento metamórfico de bajo-muy bajo grado (MAS et al., 1993). Como ya se comentó anteriormente, se estructura en dos subcuencas (Cameros Oriental y Cameros Occidental), cada una de las cuales muestra un marco litoestratigráfico característico (figura 3.4).

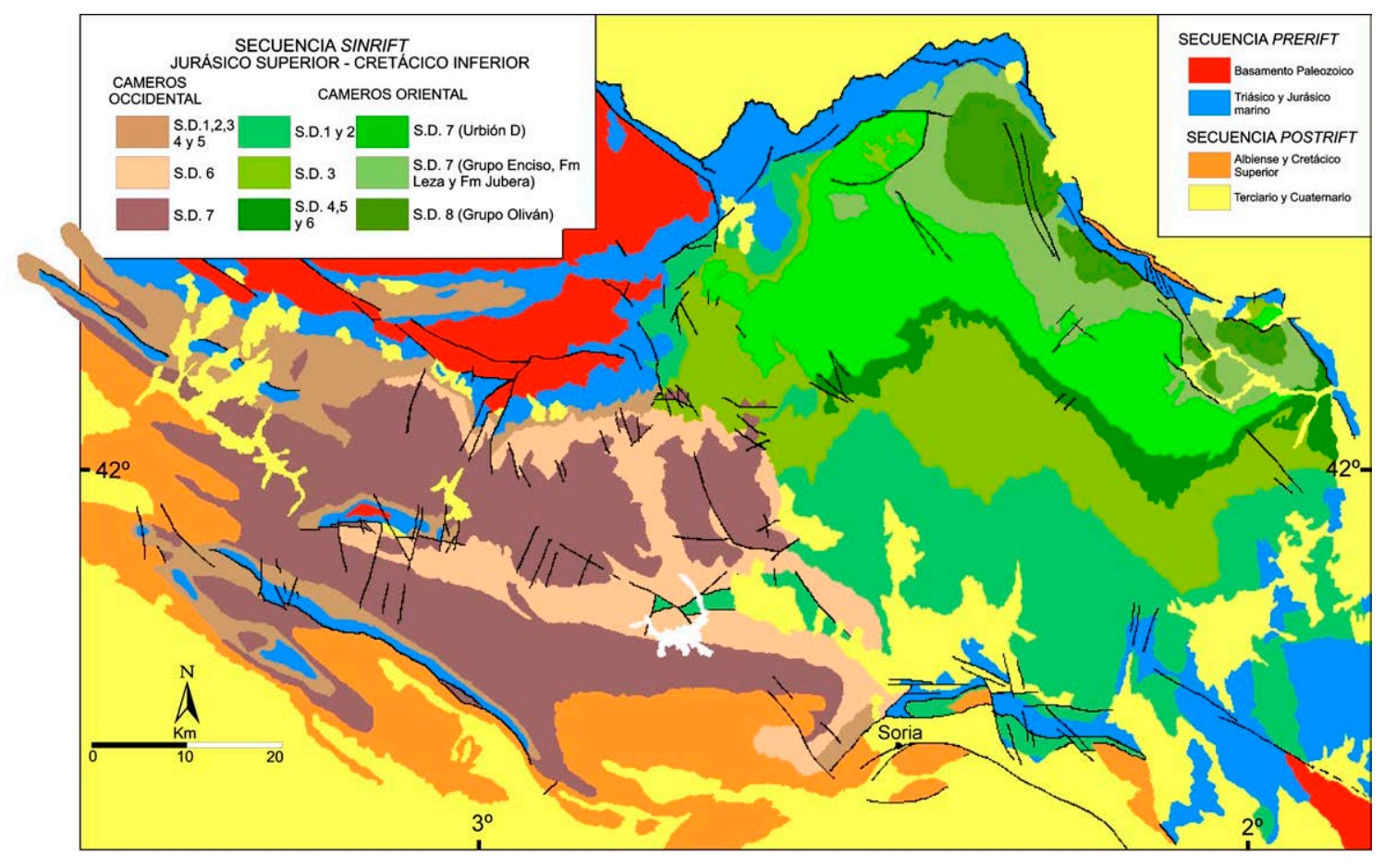

Figura 3.4: Mapa geológico de la cuenca de Cameros mostrando las subcuencas oriental y occidental, y su relleno según secuencias deposicionales.

A escala más regional, y con respecto al marco tectónico de la cuenca de Cameros, existen dos hipótesis. La primera (modelo de cuenca de rampa extensional) considera una cuenca sinclinal emplazada sobre una rampa buzando hacia el sur localizada en el basamento Varisco. Esta rampa está compuesta por dos rellanos subhorizontales a distinta profundidad unidos por un plano intermedio de buzamiento más elevado. El desplazamiento de la rampa provoca la migración progresiva hacia el norte de los depocentros (MAS et al., 1993; MAS et al., 2002). La segunda hipótesis sugiere una cuenca sinclinal tipo semigraben con un importante nivel de despegue en la secuencia prerift por encima de las fallas emplazadas en el basamento (SOTO et al., 2007; CASAS et al., 2009; Sото et al., 2010). En ambos casos, se admite que la cuenca no estuvo limitada por grandes fallas aflorando en superficie, por lo que algunos autores consideran que presenta ciertos caracteres morfológicos de cuenca sag (MAS et al., 2002).

\subsection{MARCO ESTRATIGRÁFICO}

El establecimiento del marco estratigráfico para el relleno sedimentario de la cuenca de Cameros es una cuestión complicada en gran parte, debido a la multiplicidad de ambientes, tectónica compleja, compartimentación diferencial, etc. A día de hoy, permanece como una asignatura pendiente sometida a un debate constante. Reflejo se esta dificultad son los numerosos trabajos existentes al respecto (BEUTHER, 1966; TISCHER, 1966b; SALOMON, 1982b; GUIRAUD, 1983; MAS et al., 1993; MARTÍN-ClOSAS Y ALONSO-MILLÁN, 1998; MAS et al., 2002; 2003; CLEMENTE, 2010). Esta incertidumbre se ve magnificada por la falta de datos fehacientes de edades que, a día de hoy, no son concluyentes, ya que los fósiles existentes poseen un valor cronoestratigráfico muy limitado.

En este apartado se redacta una síntesis, basada en la bibliografía, de las formaciones existentes en el registro sinrift finijurásico-eocretácico de la cuenca de Cameros. En cada formación 
se describen los medios sedimentarios, edades más probables asignadas, contenido paleontológico, contexto paleogeográfico, tectónico, etc.

BEUTHER (1966) y TISCHER (1966b) establecen la primera nomenclatura litoestratigráfica formal para Cameros, definiendo cinco Grupos: Tera, Oncala, Urbión, Enciso y Oliván. Este cuadro litoestratigráfico, debido a su sencillez, fue utilizado como base en la realización de la cartografía MAGNA 1:50.000 y, actualmente, es de uso común aunque con ciertas modificaciones y precisiones.

Con el establecimiento de la Estratigrafía Secuencial como una disciplina científica (PAYTON, 1977), surge un nuevo enfoque en el análisis de cuencas sedimentarias que busca definir unidades caracterizadas por una componente genética y/ o evolutiva a escala de toda la cuenca, o de sectores lo más extensos posibles. En este contexto se define una secuencia deposicional (o secuencia de depósito) como una unidad estratigráfica compuesta por una sucesión relativamente conforme de estratos genéticamente relacionados, limitados a base y a techo por discontinuidades y/ o sus conformidades relativas (MITCHUM et al., 1977). Así pues, dichas discontinuidades reflejan períodos sin deposición, erosión y truncamiento, que separan unidades depositadas en un mismo escenario tectónico y geográfico (VISHER, 2003).

A pesar de que la secuencia deposicional es una unidad aloestratigráfica no formal (NORTH AMERICAN COMMISSION ON STRATIGRAPHIC NOMENCLATURE, 2005), su uso se incorpora al estudio de la cuenca de Cameros tanto a nivel regional como más local (CLEMENTE-VIDAL, 1988; CLEMENTE Y AlONSO, 1990; SALINASY MAS, 1990; ClEMENTE et al., 1991; AlONSO y MAS, 1993; CLEMENTE Y PÉREZARLUCEA, 1993; MAS et al., 1993; MARTÍN-CLOSASY ALONSO-MILLÁN, 1998).

El registro sedimentario sinrift dela cuenca de Cameros (Titoniense-Albienseinferior) está constituido por depósitos de carácter fundamentalmente continental (aluvial y lacustre) con esporádicas incursiones marinas. Esterelleno, en los depocentros, llega a alcanzar un espesor deunos $10.000 \mathrm{~m}$ en la subcuenca oriental y unos $3.000 \mathrm{~m}$ en la subcuenca occidental. Así pues, contiene un registro de medios continentales casi continuo durante aproximadamente unos 42 millones de años. Las líneas sísmicas muestran un relleno bastante asimétrico con un evidente desplazamiento de los depocentros hacia el noreste, así como una disposición de las secuencias deposicionales en claro onlap en la misma dirección (MAS et al., 1993; OMODEO-SALĖ et al., 2014).

Este formidable registro constituye en su totalidad una megasecuencia limitada por dos importantes discordancias reconocibles a escala del Sistema de Rift Mesozoico Ibérico (SALAS et al., 2001). El límiteinferior está constituido por la discontinuidad infra-titoniense, desarrollada sobre el sustrato Jurásico, y que supone la individualización de Cameros como una cuenca con entidad propia. El límite superior es la discontinuidad intra-albiense, que sirve como nivel de base para la posterior sedimentación durante el Cretáceo superior.

El análisis de las discontinuidades, reconocibles a escala de toda la cuenca, ha permitido identificar un total deocho secuencias deposicionales en la cuenca de Cameros (ARRIBAS et al., 2002; MAS et al., 2002; ARRIBAS et al., 2003; MAS et al., 2003), correlacionables con las secuencias determinadas en el resto de cuencas de la Ibérica (SALAS et al., 2001). Cada secuencia deposicional está integrada, a grandes rasgos, por depósitos fluviales que evolucionan lateralmentey/ o hacia techo a depósitos lacustres (figuras 3.5 y 3.6):

i. Secuencia Deposicional 1(SD 1): Titoniense.

ii. Secuencia Deposicional 2 (SD 2): Titoniense-Berriasiense.

iii. Secuencia Deposicional 2 (SD 3): Berriasiense.

iv. Secuencia Deposicional 4 (SD 4): Berriasiense terminal-Valanginiense basal.

v. Secuencia Deposicional 5 (SD 5): Valanginiense-Hauteriviense.

vi. Secuencia Deposicional 6 (SD 6): Hauteriviense terminal-Barremiense.

vii. Secuencia Deposicional 7(SD 7): Barremiense superior-Aptiense inferior.

viii. Secuencia Deposicional 8 (SD 8): Aptiense superior-Albiense. 


\subsubsection{Secuencia Deposicional 1(SD 1): Titoniense}

La propagación del Sistema de Rift Ibérico Mesozoico hacia el noroeste supone el comienzo de la fracturación en el dominio camerano y una nueva configuración paleogeográfica. Comienza la etapa de sedimentación continental, tras el predominio de los ambientes marinos desde el J urásico, así como la individualización de una nueva cuenca sedimentaria con entidad propia que perdurará hasta el Cretácico Inferior, es decir, el nacimiento sensu stricto de la cuenca de Cameros.

En la subcuenca occidental se caracteriza por una configuración espacial en surcos alargados de dirección NO-SE, limitados por fallas de subsidencia variable y, por lo tanto, con importantes variaciones de espesor. Consta de dos unidades litoestratigráficas que constituyen un ciclo aluviallacustre: la Formación Señora deBrezales a muro, quepasa lateralmentey hacia techo ala Formación Boleras. En la subcuenca oriental se forman dos áreas sedimentarias independientes rellenadas por la Formación Ágreda. Esta SD es correlacionable con la secuencia deposicional J 10.1 de la Ibérica (SALAS et al., 2001).

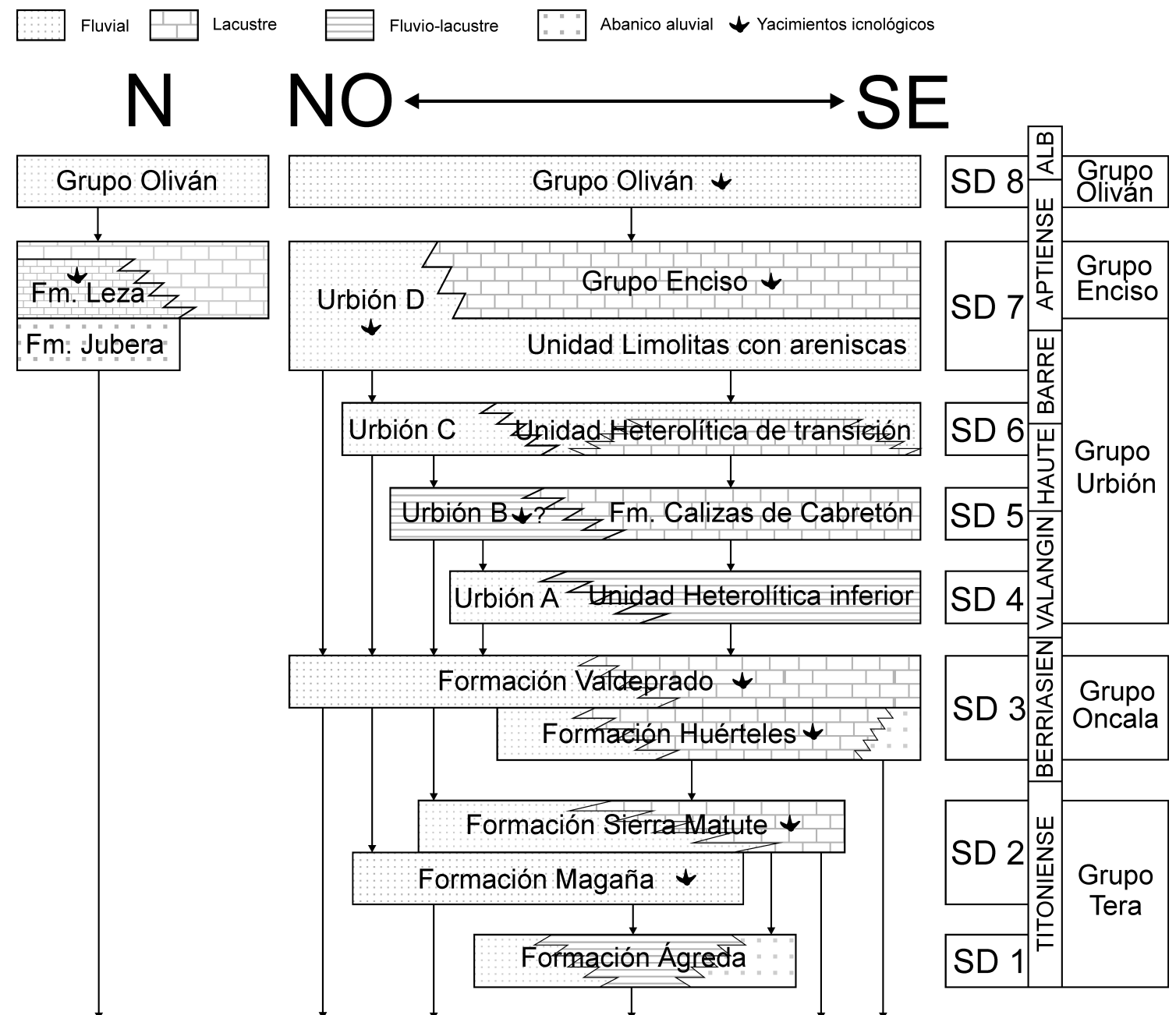

FM. TORReCilla en Cameros y/o Fm. Aldealpozo

Figura 3.5: Cuadro litoestratigráfico de la subcuenca Cameros Oriental.

La Formación Nuestra Señora de Brezales (o Fm. Señora de Brezales, o Fm. Brezales) fue inicialmente definida con este nombre y rango por PLATT (1990). Está constituida por areniscas rojas, conglomerados poligenéticos, lutitas arenosas, calizas arenosas, y paleosuelos calcáreos (WRIGHT et al., 1988; PlatT, 1995; Wright et al., 1995; SACRISTÁN-HORCAJADA et al., 2015). Las areniscas son sedarenitas y cuarzoarenitas con un contenido variable en fragmentos de rocas carbonáticas (ARRIBAS et al., 2002). Representan depósitos de corrientes efímeras depositadas en un clima semiárido (PLATT, 1995). Los conglomerados presentan un predominio en cantos calcáreos 
provenientes del desmantelamiento de los depósitos marinos jurásicos presentes en la cobertera prerift y, en menor medida, clastos de arenisca roja cuyo origen podría estar en el reciclaje de sus propios depósitos o en la erosión de los depósitos del Triásico (PLATT, 1995; ARRIBAS et al., 2002). Estos conglomerados, normalmente siguen las fallas NE-SO (PLATT, 1990), y se interpretan como abanicos aluviales que rellenan los primeros relieves (MARTÍN-CLOSAS Y ALONSO-MILLÁN, 1998). La distribución de las facies (con una fuerte variación lateral) y su potencia (con notables diferencias entre sectores, variando entre la decena de metros hasta un máximo de $75 \mathrm{~m}$ ), indican un fuerte control tectónico (PlatT y PuJalte, 1994; PlatT, 1995). Su contenido paleontológico es escaso: SCHUDACK (1987) cita la presencia de Clavator grovesii var. discordis. Esta carófita es típica de la biocronozona Globator maillardii maillardii, con una edad estimada entre la parte superior del Titoniense superior hasta la parte inferior del Berriasiense medio (RIVELINE et al., 1996).

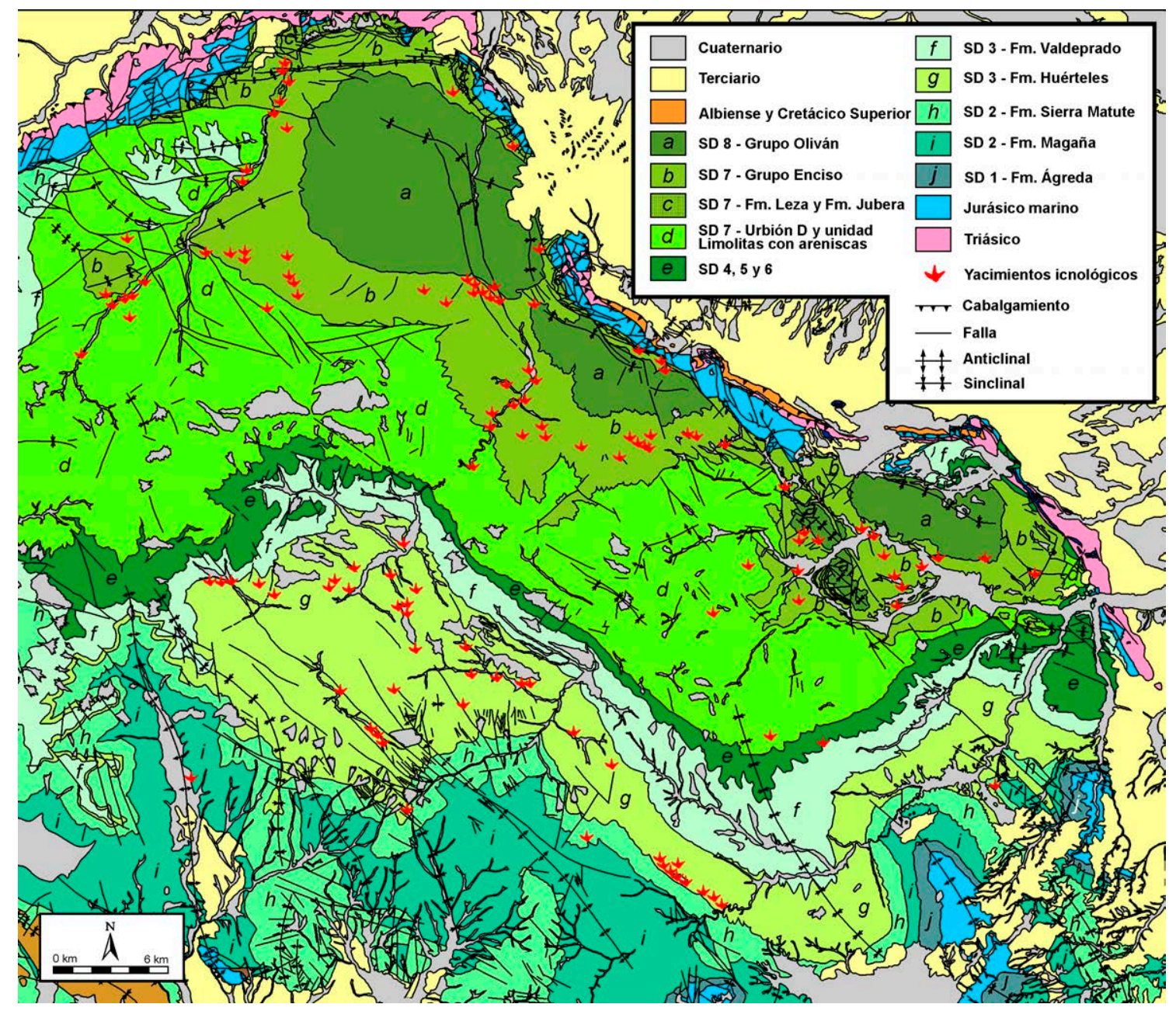

Figura 3.6: Mapa geológico de la subcuenca Cameros Oriental.

La Formación Boleras ha sido definida con este nombre y rango por CLEMENTE Y PÉREZARLUCEA (1993). Es una unidad predominantemente carbonatada, donde aparecen margas y calizas con modificaciones pedogenéticas (MARTÍN-CLOSASY ALONSO-MILLÁN, 1998; SACRISTÁN-HORCAJADA et al., 2015). También es frecuentela presencia depaleosuelos detipo hidromorfo. Seinterpreta como zonas palustres y lacustres someras situadas en zonas distales adyacentes a los abanicos aluviales representados por la Fm. Nuestra Señora de Brezales (MARTíN-ClOSAS y ALONSO-MILLÁN, 1998; SACRISTÁN-HORCAJ ADA et al., 2015). Son frecuentes los restos de carófitas y ostrácodos límnicos. En la serie de Quintanilla de las Viñas, SALOMON (1982b) encuentra Theriosynoecum. forbesii, Perimneste horrida y Nodosoclavator aff. bradleyi. MARTÍN-CLOSAS (1989) identifica Globator maillardii var. maillardii, Atopochara trivolvis var. horrida (con posibletransporte), Clavator reidii var. grovesii, "Mesochara", y "Porochara"). SCHUDACK (1987) describe la presencia de Globator maillardii var. incrassatus. Globator maillardii var. maillardii y Atopochara trivolvis var. horrida son dos carófitas características de la biocronozona Globator maillardii maillardii (zona superior del 
Titoniense superior-zona inferior del Berriasiense medio (RIVELINE et al., 1996). Por otra parte, Globator maillardii var. incrassatus define la biocronozona Globator maillardii. incrassatus de edad Berriasiense medio (parte superior) (RIVELINE et al., 1996).

La Formación Ágreda (o Aloformación Ágreda) fue definida con este nombre y rango de aloformación por MAS et al. (1993) y GÓMEZ-FERNÁNDEZ Y MELÉNDEZ (1994b). Esta sucesión está integrada por sedimentos de naturaleza detrítica: lutitas rojas con nódulos de carbonatos, limolitas verdes, conglomerados polimícticos y areniscas. También aparecen depósitos carbonatados representados por calizas micríticas, litoclásticas y oncolíticas con fósiles límnicos (GÓMEZ-FERNÁNDEZ Y MELÉNDEZ, 1994b). Esta formación se dispone según dos litosomas separados y con sentidos de drenaje contrarios. La cubeta de Torrecilla, con una potencia máxima de $73 \mathrm{~m}$, se sitúa al nonoeste y está rellena por depósitos de sistemas fluviales meandriformes. El surco de Ágreda, situado al sudeste, es el litosoma principal y alcanza hasta $255 \mathrm{~m}$ de potencia, disminuyendo rápidamente su espesor hacia el sudeste. La sedimentación estuvo controlada por un abanico aluvial situado en las zonas más activas y subsidentes, adosadas a las fallas de borde que limitan la cuenca. Hacia el sur, en áreas con menor subsidencia, la sedimentación se produce en unallanura aluvial con canales meandriformes de origen extra eintracuencal. En la zona donde la influencia de ambos sistemas aluviales era menor, aparecen pequeños lagos carbonatados (GÓMEZ-FERNÁNDEZY MELÉNDEZ, 1994b). Estos autores citan la presencia de Dictyoclavator aff. fieri (con caracteres arcaico), Porochara sp., "clavatorites", abundantes ostrácodos y algún fragmento de hueso largo. Pueden aparecer, en casos excepcionales, fragmentos de huesos y troncos ferruginizados dentro de los conglomerados. La presencia de Dictyoclavator aff. fieri (con caracteres arcaicos) sugiere su pertenencia a la biocronozona Dictyoclavator fieri ramalhoi (Kimmeridgiense-Titoniense superior) (RIVELINE et al., 1996).

\subsubsection{Secuencia Deposicional 2 (SD 2): Titoniense-Berriasiense}

Esta secuencia deposicional está constituida, en ambas subcuencas, por un nuevo pulso aluvial-lacustre, compuesto por una unidad basal de carácter aluvial, quelateralmentey hacia techo pasa a una unidad de naturaleza lacustre: la Fm. Jaramillo de la Fuente y Fm. Campolara en la subcuenca occidental y, la Fm. Magaña y Fm. Matute en la subcuenca oriental. Esta SD se correlaciona con la secuencia deposicional J 10.2 de la Ibérica (SALAS et al., 2001).

La Formación J aramillo de la Fuente (o Fm. J aramillo) fue definida con este nombre y rango por CLEMENTE Y PÉREZ-ARLUCEA (1993). Alcanza una potencia máxima de 400 m, y está formada por cuerpos lenticulares de areniscas, lutitas con algunas intercalaciones de calizas (MARTÍN-ClOSAS Y ALONSO-MiLLÁN, 1998). Las areniscas tienen su área fuente en las rocas metamórficas de bajo y medio grado, probablemente, de la Zona Asturoccidental Leonesa del Macizo Hespérico (ARRIBAS et al., 2003). Representa sistemas fluviales con canales meandriformes surcando llanuras aluviales arcillosas, con desarrollo de lagos carbonatados someros y efímeros en las zonas más distales (MARTíN-CLOSAS Y ALONSO-MILLÁN, 1998).

La Formación Campolara ha sido descrita con este nombre y rango por CLEMENTE Y PÉREZARLUCEA (1993). Consta de calizas y margas con carófitas, ostrácodos y gasterópodos. Su potencia máxima es de unos $100 \mathrm{~m}$. Las calizas presentan un elevado contenido en materia orgánica y numerosos niveles edafizados. Se ordenan en secuencias con margas que pasan hacia techo a calizas micríticas nodulizadas. Se interpretan como sistemas lacustres someros lacustres y/ o palustres, de gran entidad, situados en las zonas distales del sistema fluvial correspondiente a la Fm. J aramillo de la Fuente (MARTÍN-CLOSAS Y ALONSO-MILLÁN, 1998). Recientemente se han descubierto numerosos yacimientos icnológicos: Las Sereas 1-14, la mayoría de los cuales están todavía sin describir (TORCIDA-FERNÁNDEZ-BALDOR et al., 2010b; TORCIDA FERNÁNDEZ-BALDOR et al., 2015).

La Formación (de) Magaña (o Aloformación de Magaña) fue inicialmente descrita con este nombre y rango por GUIRAUD Y SÉGURET (1985) y, con rango dealoformación por GÓMEZ-FERNÁNDEZ Y MELÉNDEZ (1994b). Se trata de una unidad de naturaleza predominantemente detrítica (potencia máxima $695 \mathrm{~m}$ ) constituida por lutitas rojas y verdosas, areniscas y conglomerados, localmente, calizas micríticas negras. Se interpreta como un medio fluvial, con el área madre hacia el oeste. En esta zona aparecen los ambientes fluviales más proximales, caracterizados por canales 
entrelazados de gravas a arenosos. Hacia el centro se produce el paso de canales entrelazados a meandriformes $\mathrm{y}$, finalmente, hacia el este pasan a ambientes fluviales meandriformes de material fino, surcando una llanura de inundación muy amplia y con poca pendiente (GóMEZFERNÁNDEZ, 1992; GÓMEZ-FERNÁNDEZ Y MELÉNDEZ, 1994b). El contenido paleontológico es muy escaso. En las calizas aparecen bivalvos y gasterópodos en mal estado de conservación, así como restos de troncos ferruginizados en los conglomerados y areniscas (GóMEZ-FERNÁNDEZ Y MELÉNDEZ, 1994b). Se ha encontrado un fémur perteneciente a un dinosaurio Titanosauriforme (BAQUEDANO, 1981; CANUDO et al., 2010). Existen algunos yacimientos icnológicos, todos ellos inéditos y sin estudiar: un yacimiento en la columna de Montenegro-Villoslada (Montenegro de Cameros) (GONZÁLEZ-ACEBRÓN, 2009), la Dehesa del Gallinero (Almarza) (BOLETín OFICIAL DEL ESTADO, 2003) y Molino del tío Manuel (Almarza) (PASCUAL-ARRIBAS et al., 2009). También aparecen icnitas de pterosaurios (HERNÁNDEZ-MEDRANO et al., 2017).Según GÓMEZ-FERNÁNDEZ (1992), los restos vegetales estudiados por DEPAPE Y DOUBINGER (1956-1960) pertenecen a esta formación.

La Formación (de la) Sierra Matute (o Fm. Matute o Aloformación de la Sierra de Matute) fue referida con este nombre y rango por GUIRAUD Y SÉGURET (1985), y rango de aloformación por GÓMEZ-FERNÁNDEZ Y MELÉNDEZ (1994b). Se trata de una unidad de carácter mixto detríticocarbonatado, alcanzando $646 \mathrm{~m}$ de potencia máxima. Predominan las margas, calizas y dolomías micríticas (a veces brechificadas o nodulizadas) con trazas de raíces, marmorización, oncolitos, moldes de yeso y nódulos de sílex. También aparecen lutitas, areniscas tabulares y/ o en cuerpos de base erosiva y, conglomerados. Representa un mosaico complejo de sistemas fluvio-lacustres con etapas de intrusión marina. Hacia el norte predominan los medios fluviales (área madre en el Macizo de la Demanda), que pasan de ser trenzados a meandriformes hacia de sudeste (GóMEZFERNÁNDEZ, 1992). En el suroeste predominan los ambientes lacustres y palustres (NORMATI Y SALOMON, 1989; GÓMEZ-FERNÁNDEZ Y MELÉNDEZ, 1994b). En estas áreas lacustres, topográficamente más deprimidas, se producen frecuentes intrusiones marinas desde el sudeste, en donde estaría el mar (SCHUDACK Y SCHUDACK, 1989; GÓMEZ-FERNÁNDEZ, 1992). Aparecen gran cantidad de organismos límnicos: carófitas, ostrácodos, gasterópodos, bivalvos y peces. Se han identificado oogonios de Mesochara harrisii, Porochara sp. y "clavatorites", y destaca la presencia relativamente abundante de foraminíferos (miliólidos) en la zona sur, demostrando ocasionales intrusiones marinas en la formación (GÓMEZ-FERNÁNDEZ Y MELÉNDEZ, 1994b). Son escasos los yacimientos icnológicos: La Callejuela (Valtajeros) (BOLETín OfICIAL DEL ESTADO, 2003), El Encinar (Villanueva de Cameros) (Moratalla et al., 1996), Virgen del Prado (Aguilar del Río Alhama) (MORATALLA etal., 1993), y un yacimiento localizado en la columna deAlmarza deCameros levantada por GÓMEZ-FERNÁNDEZ (1992). Recientemente se ha descrito un nuevo género de pez Camerichthys lunae(BERMÚDEZ-ROCHASY POYATO-ARIZA, 2015).

\subsubsection{Secuencia Deposicional 3 (SD 3): Berriasiense}

Durante el depósito de esta SD, las subcuencas oriental y occidental se han diferenciado de forma clara. De nuevo, en ambas subcuencas, la secuencia está conformada por un sistema fluvial que lateral y verticalmente evoluciona a medios lacustres carbonatados de cierta entidad. Sin embargo, el aislamiento paleogeográfico se manifiesta en la instauración de dos sistemas lacustres con grandes diferencias en cuanto a extensión y salinidad. En Cameros occidental aparece la Formación Salcedal y Formación San Marcos. En Cameros oriental está la Formación Huérteles y Formación Valdeprado. Se corresponde con la secuencia deposicional J 10.3 de la Ibérica (SALAS et al., 2001).

La Formación Río del Salcedal (o Fm. Salcedal) fue definida con este nombrey rango por CLEMENTE Y PÉREZ-ARLUCEA (1993). Consta delutitas y areniscas en cuerpos de geometríalenticular con algunas intercalaciones de calizas. Su potencia máxima es de $400 \mathrm{~m}$. Esta formación pasa lateralmentey hacia techo a la Fm. San Marcos (MARTíN-CLOSASY ALONSO-MILLÁN, 1998). El estudio petrográfico de areniscas, sugiere un área madre en los materiales metamórficos pertenecientes a la Zona Asturoccidental Leonesa del Macizo Hespérico (ARRIBAS et al., 2003). Representa un sistema fluvial de carácter meandriforme instaurado en una llanura aluvial lutítica (MARTíN-CLOSAS Y ALONSO-MILLÁN, 1998). 
La Formación Río de San Marcos (o Fm. San Marcos) fue descrita con este nombre y rango por CLEMENTE Y PÉREZ-ARLUCEA (1993). Está compuesta por calizas pedogenetizadas (mudstonewackestone) con carófitas, ostrácodos y gasterópodos depositadas en un medio lacustre litoralpalustre (SACRISTÁN-HORCAJADA et al., 2012). También aparece una alternancia de margas oscuras y calizas margosas con ostrácodos y foraminíferos. La abundante presencia de foraminíferos (miliólidos) indica una influencia marina continua, y se interpreta como un ambiente lacustrelagoon somero (SACRISTÁN-HORCAJADA et al., 2012). Se ha citado la presencia de Globator maillardii var. maillardii, Nodosoclavator bradleyi, Clavator grovesii var. grovesii (MARTíN-CLOSASY ALONSOMILLÁN, 1998). Aunque estos autores dicen que existen huellas de dinosaurios a techo de la unidad (sin especificar), sólo se puede situar, de manera tentativa, el yacimiento icnológico de La Pedraja (Mambrillas de Lara) (PLATTY MEYER, 1991; TORCIDA et al., 2001) y algunos huesos de saurópodos (PlatT Y MEYER, 1991). La presencia de Globator maillardii var. maillardii demuestra su pertenencia a la biocronozona Globator maillardii maillardii cuyo rango de edad va desde el Titoniense superior (parte superior) hasta el Berriasiense medio (parte inferior) (RIVELINE et al., 1996). La presencia de Clavator grovesii var. grovesii permite una datación más precisa como Berriasiense (MARTÍN-CLOSAS, 2000).

La Formación (de) Huérteles (o Aloformación de Huérteles) fueinicialmente definida con este nombre y rango por GUIRAUD Y SÉGURET (1985), y con el rango de aloformación por GóMEZFERNÁNDEZ Y MELÉNDEZ (1994b). Tiene un carácter mixto, aumentando su contenido en carbonatos hacia el este, donde alcanza un espesor de $1.050 \mathrm{~m}$ en la zona depocentral. La cubeta muestra una distribución asimétrica según un surco muy subsidente de dirección NO-SE, el cual condicionó la distribución de los ambientes sedimentarios. Al oeste aparecen limolitas, areniscas (tabulares y canalizadas), conglomeradosy algunas calizas micríticas, pertenecientes a un sistema fluvial entrelazado-meandriforme (los sedimentos proceden de la erosión de los materiales depositados en etapas anteriores). Hacia el esteafloran limolitas, calizas micríticas con moldes de cristales de yeso y areniscas tabulares depositadas en una llanura fangosa con lagos efímeros carbonatados. Gradualmente pasa a un ambiente de lago playa (calizas y dolomías con yesos, y brechas calcáreas con estructuras de deslizamiento). Adosado al extremo nordeste de la cuenca, con el área madre en el Macizo del Ebro, se instaura un dispositivo de abanicos deltaicos constituido por limolitas, areniscas y conglomerados (GÓMEZ-FERNÁNDEZY MELÉNDEZ, 1994b; a). Su contenido paleontológico es escaso, constando de ostrácodos, carófitas, Unio sp., restos vegetales y escamas de Lepidotes sp. (AGUIRREZABALA Y VIERA, 1980; 1983; GÓMEZ-FERNÁNDEZ Y MELÉNDEZ, 1994b; FUENTES-VIDARTE Y MEIJ IDE-CALVO, 1996). Existen dos yacimientos con restos de huesos atribuidos a Pterosauria indet.: Río Ventosa y Valduérteles (FUENTES-VIDARTE Y MEIJ IDE-CALVO, 1996). Esta formación es especialmenteimportante por la multitud de yacimientos paleoicnológicos que atesora (MORATALLA Y HERNÁN, 2010).

- Valdecantos (Santa Cruz de Yanguas): icnitas de dinosaurios (omitópodos y terópodos) y pterosaurios (AgUIRREZABALA Y VIERA, 1983; PASCUAL-ARRIBAS Y SANZ-PÉREZ, 2000a; PASCUALARRIBAS et al., 2015).

- Los Tormos o Santa Cruz 0-4 (Santa Cruz de Yanguas): icnitas de dinosaurios (terópodos y ornitópodos) y pterosaurios (AGUIRREZABALA Y VIERA, 1983; PASCUAL-ARRIBAS Y SANZ-PÉREZ, 2000a; CAMPAÑA-LOZANO et al., 2010; PASCUAL-ARRIBAS Y HERNÁNDEZ-MEDRANO, 2012; PASCUAL-ARRIBAS et al., 2015).

- El Prao Caído o Santa Cruz 5 (Santa Cruz de Yanguas): icnitas de terópodos (AgURRREZABALA Y VIERA, 1983).

- Las Cuestas (Santa Cruz de Yanguas): icnitas de dinosaurios (ornitópodos, terópodos y saurópodos) y posibles cocodrilos (AGUIRREZABALA YVIERA, 1983; PASCUAL-ARRIBAS et al., 2008; 2009; PASCUAL-ARRIBAS Y HERNÁNDEZ-MEDRANO, 2010).

- La Matecasa, La Peña, y El Corral de la Peña (Villar del Río): icnitas de dinosaurios terópodos y omitópodos (AGUIRREZABALA Y VIERA, 1980; CASTANERA et al., 2015).

- Fuente Lacorte (Villar del Río): icnitas de dinosaurios (terópodos y ornitópodos) y cocodrilos (AgUIRREZABALA YVIERA, 1980; PASCUAL-ARRIBAS et al., 2005a).

- El Frontal (Villar del Río): icnitas de dinosaurios (terópodos y ornitópodos) y pterosaurios (AgUiRREZABALA YVIERA, 1980; PASCUAL-ARRIBAS Y SANZ-PÉREZ, 2000a). 
- Santa Cristina I y II (Villar del Río): icnitas de dinosaurios terópodos (FUENTES-VIDARTE Y MEIJ IDE-CALVO, 1998; FUENTES-VIDARTE et al., 2005b; CASTANERA et al., 2015).

- Barranco de Serrantes (Villar del Río): icnitas de dinosaurios (terópodos y ornitópodos), aves y pterosaurios (FUENTES-VIDARTE, 1996; FUENTES-VIDARTE et al., 2004a; FUENTES-VIDARTE et al., 2004b; PASCUAL-ARRIBAS et al., 2015).

- Valdegén I (Villar del Río): icnitas de dinosaurios terópodos y pterosaurios (HERNÁNDEZMEDRANO et al., 2006; PASCUAL-ARRIBAS et al., 2015).

- Fuentesalvo (Villar del Río): icnitas de dinosaurios terópodos (BARCO et al., 2006).

- La Dehesa (Villar del Río): icnitas de dinosaurios terópodos (SANZ et al., 1997).

- En el término de Villar del Río aparecen numerosos yacimientos no estudiados todavía: La Laguna I, La Calavera, Villaseca 32, Fuente La Dehesa, La Ventizuela y Las Palomeras (BOLETíN OFICIAL DEL ESTADO, 2003; 2005), Revilla de Cidacos (CASTANERA et al., 2015), y un yacimiento en la columna de Valdehuérteles de GÓMEZ-FERNÁNDEZ (1992).

- Valloria (Las Aldehuelas): icnitas de dinosaurios (terópodos, ornitópodos, saurópodos y estegosaurios), aves y pterosaurios (PASCUAL-ARRIBAS Y SANZ-PÉREZ, 2000a; FUENTES-VIDARTE, 2001; MEIJ IDE-CALVO Y FUENTES-VIDARTE, 2001; FUENTES-VIDARTE et al., 2004b; PASCUAL et al., 2012).

- Salgar de Sillas o Los Campos (Las Aldehuelas): icnitas de saurópodos y pterosaurios (PASCUALARRIBAS Y SANZ-PÉREZ, 2000a; MEIJ IDE-FUENTES et al., 2001a).

- Las Aldehuelas II (Las Aldehuelas): icnitas de pterosaurios (FUENTES-VIDARTE et al., 2004b).

- La Revilleja (Las Aldehuelas): icnitas de saurópodos (MEIJ IDE-FUENTES et al., 2001b; MEIJIDEFUENTES et al., 2004).

- San Roque (San Pedro Manrique): icnitas de dinosaurios terópodos (SANZ et al., 1997).

- La Hoyuela (San Pedro Manrique): icnitas de dinosaurios omitópodos (PASCUAL et al., 2002).

- Barranco de Valdelavilla o valles de Valdelalosa (San Pedro Manrique): icnitas de dinosaurios (saurópodos, ornitópodos y terópodos), pterosaurios, tortugas y cocodrilos (PASCUAL-ARRIBASY SANZ-PÉREZ, 2000a; b; FUENTES-VIDARTE et al., 2004a; FUENTES-VIDARTE et al., 2004b; PASCUAL-ARRIBAS et al., 2005a; FUENTES-VIDARTE et al., 2008b; PASCUAL-ARRIBAS et al., 2015).

- Matasejún (San Pedro Manrique): icnitas de pterosaurios (FUENTES-VIDARTE et al., 2004b)

- Las Adoberas (San Pedro Manrique): icnitas de dinosaurios terópodos (SANZ et al., 1997; CASTANERA et al., 2015).

- Sierray Fuente de la Haya (San Pedro Manrique): icnitas terópodas y ornitópodas (SANZ-PÉREZ, 1993).

- El Castillejo (San Pedro Manrique): icnitas dedinosaurios terópodosy ornitópodos (SANZ-PÉREZ, 1993) y pterosaurios (PASCUAL-ARRIBAS Y SANZ-PÉREZ, 2000a).

- La Losa I-II y Las Costanillas (San Pedro Manrique): yacimientos sin estudiar (BOLETínOfiCIAL DELESTADO, 2003).

- Arroyo de Miraflores (Fuentes de Magaña-Cerbón-Magaña) donde aparecen 24 yacimientos con huellas de dinosaurios (terópodos, ornitópodos y saurópodos), pterosaurios y otros reptiles tetrápodos (PASCUAL-ARRIBAS Y SANZ-PÉREZ, 2000a; PASCUAL-ARRIBAS et al., 2005b; LATORREMACARRÓN et al., 2006; PASCUAL-ARRIBAS et al., 2015): Miraflores I-IV, Umbría del Sastre, Vallejuelo III, Camino de las M. M. I-II, Fuente Cazo, Barranco Malo, El J uncal I-IV, Solanilla I, Solana del Cerro Alto, Cerro Alto I-III, Malvalvao I-II, Vallejuelo II, y Goncala I. En un arroyo cercano, GÓMEZ-FERNÁNDEZ (1992) cita icnitas, sin especificar, en la columna del Corral de la Severa (Cerbón).

- Valdehijuelos (La Laguna): icnitas de dinosaurios terópodos (PASCUAL-ARRIBAS y HERNÁNDEZMEDRANO, 2011; CASTANERA et al., 2015).

- Arévalo (Oncala): yacimientos sin estudiar (BOLETíN OFICIAL DEL ESTADO, 2003; 2005)

- Barranco del Cuenco (Cigudosa): icnitas de terópodos y ornitópodos (HERNÁNDEZ-MEDRANO et al., 2014).

- Arroyo Calderón (Cigudosa): icnitas de terópodos y pterosaurios (HERNÁNDEZ-MEDRANO et al., 2014).

- Camino de Castilruiz (Cigudosa): icnitas omitópodas (HERNÁNDEZ-MEDRANO et al., 2014).

- Pinchano (Cigudosa): icnitas de pterosaurios y una marca de pisada que podría haber sido producida por un cocodrilo (HERNÁNDEZ-MEDRANO et al., 2014).

- Los Barranquillos (Fuentestrún): icnitas de terópodos (CASTANERA et al., 2015). 
- Río Ventosa (Ventosa de San Pedro): icnitas de terópodos (CASTANERA et al., 2015)

- Las Villasecas (Villaseca Somera): icnitas terópodas (CASTANERA et al., 2015).

- Valduérteles (Valduérteles): icnitas de terópodos (CASTANERA et al., 2015).

La Formación (de) Valdeprado (o Aloformación de Valdeprado) fue descrita con este nombre y rango por GUIRAUD Y SÉGURET (1985), y con rango de aloformación por GÓMEZFERNÁNDEZ Y MELÉNDEZ (1994b). Es una unidad de naturaleza mixta (espesor máximo de 1164 $\mathrm{m})$, predominando los siliciclásticos hacia el oeste y norte, y los carbonatos hacia el este. Consta de lutitas, areniscas (en cuerpos tabulares y canalizados), conglomerados (canalizados), calizas micríticas negras, calizas oncolíticas, calizas laminadas y margas. Las directrices tectónicas, NOSE y NE-SO, influyen en la distribución de ambientes sedimentarios y, favorecen una dirección de transporte general de oeste a este. Hacia el oeste aparecen ríos de canales entrelazados que pasan progresivamente a meandriformes para, finalmente, desembocar en un lago localizado al este. El lago carbonatado, con condiciones de alta energía y sin la influencia de los ríos, desarrolla en el litoral extensas plataformas progradantes dondeabundan los oncolitos (GÓMEZ-FERNÁNDEZ, 1992; GÓMEZ-FERNÁNDEZ Y MELÉNDEZ, 1994b). Los restos de fósiles límnicos son poco abundantes, limitándose a ostrácodos, carófitas y gasterópodos. Además, aparecen fósiles marinos tales como foraminíferos (miliólidos) y posibles restos de dasycladáceas, probando la existencia de esporádicas intrusiones marinas de escasa envergadura. En el norte abundan los restos vegetales (GÓMEZ-FERNÁNDEZ Y MELÉNDEZ, 1994b). En el yacimiento de La Cuesta (Villar del Río) ha aparecido un ejemplar casi completo de Lepidotes sp. (ROMERO-MARíN, 1994; PASCUAL-ARRIBAS et al., 2007). Los yacimientos icnológicos son escasos:

- La Cuesta (Villar del Río): icnitas de pterosaurios (PASCUAL-ARRIBAS y SANZ-PÉREZ, 2000a).

- Río Maguillo (Villoslada de Cameros): ocho icnitas de dinosaurios ornitópodos (CARO et al., 2001).

- La Moga 1-3 (Villoslada de Cameros): icnitas de dinosaurios saurópodos y terópodos (CARO et al., 2001).

- San Prudencio (Villoslada de Cameros): nueve icnitas de dinosaurios ornitópodos (CARO et al., 2001).

- Los Colmenares (Villanueva de Cameros): icnitas terópodas (Moratalda et al., 1996).

- Curva del Manzano (Villanueva de Cameros).

- Dos yacimientos, sin estudiar, en la columna estratigráfica de Montenegro-Villoslada (Villoslada de Cameros), y un yacimiento en la columna de Almarza de Cameros (Almarza de Cameros) (GóMEZ-FERNÁNDEZ, 1992).

\subsubsection{Secuencia Deposicional 4 (SD 4): Berriasiense terminal-Valanginiense basal}

La sedimentación en esta SD queda registrada en el sector oriental de la cuenca. Comprende dos unidades relacionadas lateralmente entre sí: Urbión A de carácter fluvial y, Unidad Heterolítica inferior de naturaleza fluvio-lacustre. Se correlaciona con la secuencia deposicional K1.1 de la cuenca Ibérica (SALAS et al., 2001).

La unidad Urbión A (o Unidad A) ha sido definida informalmente con este nombre por FERNÁNDEZ-BARRENECHEA (1993). A grandes rasgos corresponde a la parte más inferior del Grupo Urbión (TisCHER, 1966b). Alcanza un espesor máximo de 200 m, acuñándose hacia el oeste hasta desaparecer. Hacia el este pasa lateralmente a la Unidad Heterolítica inferior. Está constituida por areniscas y, en menor proporción, lutitas verdosas y areniscas conglomeráticas. En el sector suroriental, la proporción de cuerpos canalizados respecto a los paquetes lutíticos va descendiendo paulatinamente, hasta aparecer un conjunto fundamentalmente lutítico, con abundantes niveles ricos en materia orgánica, frecuentes bioturbaciones por raíces y zonas muy ferruginizadas. En conjunto, representa la sedimentación acontecida en un sistema fluvial meandriforme con un importante desarrollo de la llanura de inundación en las zonas distales hacia el sudeste (FERNÁNDEZ-BARRENECHEA, 1993).

La Unidad Heterolítica inferior, unidad informal, ha sido descrita con este nombre por SALINAS Y MAS (1990). Aflora en la zona más oriental de la cuenca, restringida a la cubeta de 
Cervera del Río Alhama. Está formada por calizas, areniscas y limolitas depositados en un sistema fluvio-lacustre distal y muy limitado espacialmente. Aparecen fragmentos de moluscos, carófitas, fitoclastos, y ostrácodos (SALINAS Y MAS, 1989; 1990). MARTíN-CLOSAS (2000) cita la presencia de Globator maillardii var. nurrensis. Esta canófita permite datar la unidad como Berriasiense terminal (biocronozona Globator maillardii nurrensis) (RIVELINE et al., 1996)).

\subsubsection{Secuencia Deposicional 5 (SD 5): Valanginiense-Hauteriviense}

En la subcuenca occidental, la sedimentación se circunscribe a una unidad lacustre que aparece en el extremo más occidental dela cuenca, la Formación Peñacoba. En la subcuenca oriental está constituida por una unidad siliciclástica fluvial, Urbión B, y una unidad lacustre carbonatada, la Formación Cabretón. Esta SD se correlaciona con las secuencias deposicionales K1.2 y K1.3 de la cuenca Ibérica (SALAS et al., 2001).

La Formación Calizas de Peñacoba (o Fm. Peñacoba) fue definida informalmente por BEUTHER (1966) como "serie de Peñacoba" (Grupo Tera). Con este nombre y rango de formación es descrita por primera vez por CLEMENTE Y PÉREZ-ARLUCEA (1993). Aparece sólo en una pequeña cubeta al sur de Cameros Occidental donde presenta una potencia comprendida entre 50-300 m (MAS et al., 1993; MARTÍN-ClOSAS Y ALONSO-MILLÁN, 1998). Está formada por calizas en niveles discontinuos, areniscas en cuerpos lenticulares de base erosiva, margas y arcillas. El techo de la formación muestra un importante nivel carstificado y edafizado (MARTÍN-CLOSASY ALONSO-MILLÁN, 1998). Se interpretan como depósitos de origen lacustre somero (ALONSO et al., 1991; MAS et al., 1993). MARTíN-CLOSAS (1989) encuentra Atopochara trivolvis var. micrandra, Atopochara trivolvis var. ancora, Pseudoglobator adnatus, Clavator harrisii var. jiuquanensis, Clavator harrisii, "Porochara" gr. Kimmeridgensis, Lamprothamnium polyspiratum, "Mesochara", y ostrácodos y gasterópodos límnicos. MARTÍN-ClOSAS Y ALONSO-MILLÁN (1998) citan, en la localidad tipo, Hemiclavator adnatus, Clavator harrisii y poblaciones mixtas de Atopochara trivolvis var. micrandra y Atopochara trivolvis var. ancora. Estos mismos autores también citan la presencia de restos de dinosaurios, sin especificar. Esta asociación de carófitas caracteriza la biocronozona Globator maillardii steinhauseri cuya edad abarca desde la parte superior del Berriasiense superior hasta el Hauteriviense superior (RIVELINE et al., 1996).

La unidad Urbión B (o unidad B) ha sido descrita informalmente por FERNÁNDEZBARRENECHEA (1993). Aparece distribuida en la zona central donde alcanza los $500 \mathrm{~m}$ de espesor. Es más extensiva hacia el oeste que la "unidad A", sin embargo, también se acuña hasta desaparecer hacia la parte occidental. Hacia el este, pasa lateralmente a la Fm. Calizas de Cabretón. Está compuesta por lutitas con intercalaciones decimétricas de areniscas. Aparecen también calizas bioturbadas, que ocasionalmente incluyen gasterópodos y bivalvos. Se trata de una unidad generada en una llanura de inundación de un sistema fluvial meandriforme, en la que hacia el sector oriental tendría lugar un proceso de encharcamiento progresivo, con el desarrollo de lagos someros carbonatados (FERNÁNDEZ-BARRENECHEA, 1993). En el yacimiento de Valdehierro (Navajún) se han citado Margaritifera (Pseudunio) idubedae, así como escamas aisladas y en conexión anatómica atribuibles a peces Semionotiformes (BERMÚDEZ-ROCHAS et al., 2006). Aparecen algunos yacimientos icnológicos, sin especificar, en la zona de Yanguas (FERNÁNDEZ-BARRENECHEA, 1993) y probablemente pueda ser asignado a esta unidad el yacimiento de Solana del Chorrón y Mina Victoria (ANSORENA et al., 2007-2008).

La Formación Calizas de Cabretón (o Fm. Cabretón) fue informalmente descrita como "Calizas de Cabretón" por TisCHER (1966b). Posteriormente es redefinida con este nombre y rango por SALINAS Y MAS (1990). Aflora únicamente en la zona más oriental de la cuenca. Su potencia es variable con un valor aproximado comprendido entre $20-35 \mathrm{~m}$. Se trata de una unidad fundamentalmente calcárea, que en las zonas más periféricas muestra un aumento de la influencia clástica, y una disminución del espesor. Está constituida por calizas micríticas, calizas arenosas, calizas oncolíticas, margas y, en menor proporción, areniscas y lutitas. Representa la sedimentación de carbonatos en un sistema lacustre implantado en las zonas distales de un sistema aluvial, con cierta influencia siliciclástica procedentes del sector occidental (SALINASY MAS, 1990). Se ha citado la presencia de fitoclastos, carófitas, ostrácodos y restos de moluscos (SALINAS Y MAS, 1990). MARTÍN-CLOSAS (1989), en la muestras CER1-7, cita la presencia de Atopochara trivolvis 
var. ancora, Atopochara trivolvis var. micrandra, Clavator harrisii, Clavator reidii var. grovesii, "Mesochara", "Porochara", Globator maillardii var. nurrensis., Estas carófitas definen la biocronozona Globator maillardii steinhauseri de edad Berriasiense superior-Hauteriviense superior (RIVELINE et al., 1996).

\subsubsection{Secuencia Deposicional 6 (SD 6): Hauteriviense terminal-Barremiense}

Esta secuencia deposicional supone un nuevo cambio en la configuración general de la cuenca, debido a una importante reactivación tectónica. Esto conlleva la llegada de terrígenos gruesos desde el margen meridional, así como una migración de la zona depocentral hacia el NE. Está ampliamente representada en toda la cuenca de Cameros. En la subcuenca occidental está constituida por la Fm. Cuerda del Pozo, Fm. Golmayo, Fm. Hortigüela y Fm. Pinilla de los Moros. En la subcuenca oriental comprende a una formación siliciclástica de carácter aluvial Urbión Cy la Unidad Heterolítica de transición, de origen fluvial-lacustre. Se correlaciona con las secuencias deposicionales K1.4, K1.5 y K1.6 de la Ibérica (SALAS et al., 2001).

La Formación Areniscas y arcillas del pantano de la Cuerda del Pozo (o Fm. Cuerda del Pozo), fue inicialmente definida con este nombre y rango por ClEMENTE y ALONSO (1990). Anteriormente aparecía en la bibliografía como Miembro Pantano (ClEMENTE y AlONSO, 1988). La unidad consta de 800-1200 m de conglomerados, areniscas conglomeráticas, areniscas, y lutitas. Se interpreta como depósitos proximales-medios de un sistema aluvial complejo, con múltiples canales no confinados, que se desarrollaban sobre una gran llanura de inundación. La actividad de la falla de San Leonardo condicionó la distribución de ambientes, forzando una dirección del drenaje casi paralela a dicha falla (CLEMENTE Y ALONSO, 1988; CLEMENTE Y ALONSO, 1990; ClemeNTE y PÉREZ-ARLUCEA, 1993). ClEMENTE y AlONSO (1990) citan la presencia de abundantes troncos ferruginizados y otros restos vegetales sin especificar. MARTíN-CLOSASYALONSOMILLÁN (1998) identifican Patellasporites distaverrucosus f. tavaredensis, una espora típica de edad Barremiense.

La Formación Areniscas, arcillas y calizas de Golmayo (o Fm. Golmayo) es una unidad informal ya que no presenta base visible (CLEMENTE Y ALONSO, 1990). Inicialmente fue designada como Miembro Golmayo por CLEMENTE Y ALONSO (1988). Su presencia se restringe únicamente al sector de Soria y no aflora la base ya que esta unidad aparece fallada. Está formada por unos $700 \mathrm{~m}$ de areniscas, arcillas, calizas, margas y, de manera subordinada y hacia techo, conglomerados silíceos y calcáreos. Representa un sistema fluvial meandriforme con un importante desarrollo de zonas lacustres-palustres sobre la llanura de inundación. Su arquitectura deposicional, elevada subsidencia y gran potencia indican un origen tectónico, probablemente relacionado con la falla de Las Cuevas de Soria. Se pueden reconocer dos pulsos de reactivación que originan dos ciclos sedimentarlos. A muro predominan los ambientes lacustres, que van desapareciendo progresivamente hacia techo, donde predominan los depósitos terrígenos de ambientes fluviales (ClEMENTE-VIDAL, 1988; CleMENTE Y AlONSO, 1988; ClEMENTE y AlONSO, 1990). Se ha citado la presencia de dasycladáceas (MARTíN-CLOSAS, 1989), restos de peces, ostrácodos, carófitas, gasterópodos, moluscos de agua dulce(Unio sp), restos de troncos ferruginizados, restos vegetales carbonizados, polen y numerosos coprolitos atribuidos a cocodrilos (CLEMENTE Y ALONSO, 1990; FUENTES-VIDARTE et al., 2005a; FUENTES-VIDARTE et al., 2008a). Las carófitas están representadas por Atopochara trivolvis var. triquetra (primitiva típica), Clavator harrisii, "Mesochara", Pseudoglobator adnatus (Hemiclavator adnatus) y Nodosoclavator adnatus (CLEMENTE Y ALONSO, 1990). La presencia de la forma primitiva de Atopochara trivolvis var. triquetra indica su pertenencia a la biocronozona Atopochara trivolvis triquetra de edad Barremiense inferior-Barremiense superior (parte inferior) (RIVELINE et al., 1996). Aparecen dos importantes yacimientos con restos óseos de vertebrados:

- Zorralbo I (Golmayo): restos de un quelonio Chelonii indet., un cocodrilo Goniophilidae indet., y varios dinosaurios: Polacanthus sp., Hypsilophodontidae indet., Allosauroidea indet. y Dromaeosauridae indet. (FUENTES-VIDARTE et al., 2005a; PEREDA-SUBERBIOLA et al., 2007). Recientemente se han descrito dos nuevos géneros de dinosaurios: un iguanodóntido, Magnamanus soriaensis (FUENTES VIDARTE et al., 2016) y un saurópodo, Soriatitan golmayensis (ROYO-TORRES et al., 2017). 
- Los Caños (Golmayo): restos de tortugas (Hylaeochelys aff. latiscutata), cocodrilos (Goniopholis sp.), peces (Lepidotes mantelli), y dinosaurios (Dinosauria indet., Hypsilophodon sp. y Dromeosauridae indet.) (FUENTES-VIDARTE et al., 2003).

La Formación Pinilla de los Moros (o Fm. Pinilla) ha sido definida con estenombrey rango por CLEMENTE Y PÉREZ-ARLUCEA (1993). Está constituida por unos $450 \mathrm{~m}$ de areniscas canalizadas y lutitas rojas interpretadas como sistemas fluviales que lateralmente pasan a los medios lacustres y palustres de la Fm. Hortigüela (MARTíN-CLOSAS Y ALONSO-MILLÁN, 1998). MARTÍN-CLOSAS (1989) identifica Atopochara trivolvis var. triquetra (típica), Pseudoglobator adnatus (Hemiclavator adnatus), Clavator harrisii, Lamprothamnium polyspiratum, "Mesochara" y ostrácodos límnicos. Se asignan a la biocronozona Atopochara trivolvis triquetra de edad Barremiense inferiorBarremiense superior (RIVELINE et al., 1996). Aparecen yacimientos paleontológicos:

- Tenadas de Costalomo o Cuestalomo: 239 icnitas de dinosaurios terópodos, saurópodos, ornitópodos (de andar cuadrúpedo) y terópodos avianos (PLATT Y MEYER, 1991; TORCIDAFERNÁNDEZ-BALDOR et al., 2006c; HUERTA et al., 2012), así como dos rastros de artrópodos quelicerados (TORCIDA-FERNÁNDEZ-BALDOR et al., 2006c).

- La Tejera-Valdesancho: fragmentos óseos de cocodrilos, coprolitos, restos postcraneales desarticulados de un dinosaurio "iguanodóntido", y un diente identificado como cf. Baryonyx (TORCIDA-FERNÁNDEZ-BALDOR et al., 2006b).

- Monte Puente Ballesta (Salas de los Infantes): restos óseos de una tortuga Larachelus morla (PÉREZ-GARCÍA Y MuRELAGA, 2012).

La Formación Hortigüela fue definida con este nombrey rango por PLATT (1989a). Aflora en el sector norte (60-100 m de potencia) y se subdivide en dos unidades: Miembro de San Martín y Miembro deZurramujeres. El Miembro de San Martín (30 m) consta de margas, lutitas, areniscas y escasos conglomerados. El Miembro de Zurramujeres $(70 \mathrm{~m})$ está formado por areniscas, lutitas, margas, calizas nodulares y calizas oncoidales. Ambos miembros representan ambientes lacustres carbonatados sometidos a frecuentes entradas de material detrítico terrígeno, con evidencias de etapas transgresivas y de somerización progresiva (PLATT, 1989a). MARTÍN-CLOSAS Y ALONSOMiLLÁN (1998) citan la presencia de ostrácodos, restos de dinosaurios, carófitas y laminaciones de cianobacterias. MARTÍN-CLOSAS (1989) encuentra Atopochara trivolvis var. triquetra (típica) y Clavator harrisii (con posible transporte de Clavator harrisii) que permite datar esta formación como Barremiense (biocronozona Atopochara trivolvis triquetra) (RIVELINE et al., 1996).

La unidad Urbión C o Unidad C ha sido definida informalmente con este nombre por FERNÁNDEZ-BARRENECHEA (1993). Aparece en la parte central de la subcuenca oriental llegando a alcanzar un espesor máximo de $900 \mathrm{~m}$, siendo más extensiva hacia el oeste que las unidades Urbión A y B. No obstante, al igual que éstas, se acuña hacia la parte occidental dela cuenca hasta desaparecer. Hacia el este, es el equivalente de la Unidad Heterolítica de transición. Está constituida por una alternancia de areniscas de grano fino y lutitas, con una arquitectura dominada por una elevada proporción de cuerpos canalizados. Estos depósitos son el resultado de la sedimentación dentro de un sistema fluvial meandriforme con términos característicos de la llanura de inundación hacia el este (FERNÁNDEZ-BARRENECHEA, 1993).

La Unidad Heterolítica de transición fue inicialmente descrita con este nombre y rango por SALINAS Y MAS (1990). Esta unidad está representada únicamente en la zona oriental de Cameros. Está formada por calizas, areniscas y limolitas, predominando estas últimas, con un espesor de unos $100 \mathrm{~m}$. Es sensiblemente más calcárea hacia base, perdiendo carbonatos paulatinamente hacia techo. Representa la transición entre un sistema lacustre a otro fluvial, por colmatación del primero. Se ha citado la presencia de restos de gasterópodos, carófitas y ostrácodos, sin especificar (SALINAS Y MAS, 1989; 1990).

\subsubsection{Secuencia Deposicional 7 (SD 7): Barremiense superior-Aptiense inferior}

Esta SD supone un cambio drástico en la paleogeografía que provocó una expansión de la sedimentación abarcando a la totalidad de la cuenca. Se correlaciona con un pulso tectónico muy importante del rifting, no solo reconocible en Cameros (MAS et al., 1993), sino también presente en 
otros dominios del resto de la placa Ibérica: cuenca Vasco-Cantábrica (GARCíA-MONDÉjAR et al., 2005), cuencas pirenaicas (VERGÉSY GARCíA-SENZ, 2001) y, cuencas del Maestrazgo y Sur Ibérica (VANWEES et al., 1998).

En el dominio occidental está constituida por dos formaciones: la Formación Castrillo de La Reina, y Formación Conglomerados y arenas de Abejar. En el dominio oriental consta de cinco unidades: en el sector más meridional aparece Urbión D y la Unidad Limolitas con areniscas, ambas de carácter aluvial. En el borde nororiental de la cuenca, el relleno está representado por la Formación J ubera y la Formación Calizas de Leza. Por último, en el sector central aparece el Grupo Enciso. Se correlaciona con las secuencias deposicionales K1.7 y K1.8 presentes en la cuenca Ibérica (SALAS et al., 2001).

La Formación Castrillo de la Reina fue inicialmente definida con este nombre y rango por CLEMENTE Y PÉREZ-ARLUCEA (1993), aunque hasta la fecha no se ha realizado una descripción formal de la misma. Es un cambio lateral de facies de la Fm. Abejar hacia el norte. Según MARTÍN-CLOSASY ALONSO-MILLÁN (1998), se interpreta como un sistema fluvial, distal, de canales meandriformes sobre una extensa de llanura de inundación Se trata de una formación rica en restos óseos de vertebrados, con gran número de yacimientos:

- Tenadas de los Vallejos II (La Revilla-Ahedo, Burgos): restos de un nuevo rebaquisáurido Demandasaurus darwini, así como dos vértebras cervicales de un terópodos espinosáurido (PEREDA-SUBERBIOLA et al., 2003; TORCIDA-FERNÁNDEZ-BALDOR et al., 2003; TORCIDAFERNÁNDEZ-BALDOR et al., 2010a; TORCIDA FERNÁNDEZ-BALDOR et al., 2011).

- La Solana A y B (Cabezón de la Sierra, Burgos): dientes de terópodos identificados como Dromaeosauridae indet. y cf. Baryonyx (TORCIDA-FERNÁNDEZ et al., 2003). También se ha encontrado material perteneciente a dinosaurios ornitópodos: Hypsilophodon sp., cf. Hypsilophodon sp. (IZQUIERDO et al., 2005), e "Iguanodontidae" indet. (TORCIDA-FERNÁNDEZBALDOR, 1996; RUIZ-OMEÑACA, 2001).

- Tenadas de Costalomo IV: una espina ósea de Ankylosauria indet., restos óseos indeterminados y bivalvos uniónidos (IZQUIERDO-MONTERO et al., 2004).

- El Oterillo II (Salas de los Infantes, Burgos): restos de un nuevo género de saurópodo Europatitan eastwoodi, Iguanodontoidea sp., hipsilofodóntidos, tres terópodos distintos, dientes de cocodrilos y peces óseos (Osteichtyes) (TORCIDA-FERNÁNDEZ-BALDOR et al., 2006a; CONTRERAS et al., 2007; CONIRERAS-IZQUIERDO et al., 2009; TORCIDA-FERNÁNDEZ-BALDOR et al., 2009; ALONSO et al., 2017; TORCIDA FERNÁNDEZ-BALDOR et al., 2017).

- Vegagete: restos incompletos de Rhabdodontomorpha (DIEUDONNÉ et al., 2016).

La Formación Conglomerados y arenas de Abejar (o Fm. Abejar) fue inicialmente descrita con este nombre y rango por CLEMENTE Y ALONSO (1990), aunque anteriormente había sido citada como Grupo Abejar (CLEMENTE-VIDAL, 1988; CLEMENTE y ALONSO, 1988; CLEMENTE, 1989). Está formada por unos $1.300 \mathrm{~m}$ de conglomerados y gravas, arenas silíceas, limos y arcillas. Esta formación, básicamente, es una potente serie de conglomerados y arenas. Se distinguen tres ciclos sedimentarios con tendencia granodecreciente. Cada ciclo consta de una base conglomerática que hacia techo pasa a ser más arenosa. Se depositó en zonas medias y distales de abanicos aluviales húmedos, relacionados con el borde fracturado de San Leonardo, de tal manera, que cada ciclo representa una etapa de reactivación de la falla de San Leonardo, atenuándose hacia techo. Las direcciones de paleocorrientes son de SO a NE, con el área fuente en la zona de San Leonardo (CLEMENTE, 1989; CLEMENTE Y ALONSO, 1990). MARTÍN-ClOSAS Y AlONSO-MiLLÁN (1998) le asignan una edad Barremiense superior en función de la siguiente palinoflora: Cicatricosisporites, Patellasporites distaverrucosus, Equinatisporites longechinus y Distaltriangulisporites irregularis.

La unidad Urbión D o Unidad D ha sido definida informalmente con este nombre por FERNÁNDEZ-BARRENECHEA (1993). Es equivalente a la parte superior del Grupo Urbión de TISCHER (1966b). Aparece ampliamente representada en toda la subcuenca oriental. Hacia el este pasa a la Unidad Limolitas con areniscas. Está formada por conglomerados, areniscas y lutitas que corresponden a un sistema fluvial entrelazado que pasa a meandriforme con un gran desarrollo de los depósitos de llanura de inundación (FERNÁNDEZ-BARRENECHEA, 1993). En el yacimiento de Valdeperillo aparece una fauna malacológica constituida por gasterópodos asignables al género 
Viviparus y bivalvos uniónidos identificados como Protopleurobema numantina (BERMÚDEZROCHAS et al., 2006; DELVENE Y ARAUJ O, 2009b), muchos de ellos con daños en las conchas infligidos por vertebrados, probablemente cocodrilos (BERMúDEZ-ROCHAS et al., 2013). Los restos de vertebrados son escasos. En la Aguzadera (San Román de Cameros) se ha encontrado un cráneo prácticamente completo de un cocodrilo identificado como Goniopholis sp. (ORTEGA et al., 1996). En el yacimiento Valdeperillo en Cornago aparecen escamas ganoideas asignables a peces Semionotiformes (BERMúdEZ-ROCHAS et al., 2006). Por último, las citas de restos de peces y reptiles en el yacimiento Mojón Alto en Ortigosa de Cameros (BATALLER, 1960), podrían asignarse, con ciertas dudas, a la unidad Urbión D. También aparecen numerosos yacimientos icnológicos: La Cela A, B, C y D en Muro de Cameros (CASANOVAS et al., 1995e); El Robledo, Barranco de Valdaedo, Camino de la Nevera 1-2 y Los Chopos en Cabezón de Cameros (DIAZMARTíNEZ et al., 2007); La Rueda en Laguna de Cameros (DíAZ-MARTíNEZ et al., 2015); La Ilaga (HERNÁNDEZ-MEDRANO Y PÉREZ-LORENTE, 2003) y Camino a Treguajantes en Terroba (CASANOVAS et al., 1995f); La Aguzadera en San Román de Cameros (MORATALLA-GARCía et al., 1997); Barranco deAcrijos (CASANOVAS et al., 1995c), Barranco La Solana, Valdeperillo (ANSORENA et al., 2007-2008) y Cabezuelos (MORATALLA, 1993) en Cornago; El Majadal (SANZ et al., 1997) y Carretera de Soria (CASANOVAS et al., 1995b) en Yanguas; y Las Adoberas en San Pedro Manrique (SANZ et al., 1997).

La Unidad Limolitas con areniscas fue descrita con este nombre y rango por SALINAS Y MAS (1990). Esta unidad sólo aflora en la cubeta de Cervera del Río Alhama, pasando lateralmente a la Unidad D por cambio lateral de facies hacia el oeste. Presenta una potencia de unos $100 \mathrm{~m}$, con un paulatino aumento de potencia hacia el oeste. Está compuesta mayoritariamente por limolitas, con delgadas intercalaciones de areniscas que se disponen en una única asociación de facies. Representa un sistema fluvial meandriforme con predominio de llanura de inundación (SALINAS Y MAS, 1989; 1990).

La Formación J ubera fue definida con este nombre y rango por ALONSO Y MAS (1993). Se acuña lateralmente hacia el sur, reconociéndose únicamente en los sectores del bondenororiental de la cuenca. Su potencia es muy variable según las zonas. Está comprendida entre $25 \mathrm{~m}$ (zonas de Préjano y Arnedillo), 160 m (en la zona de Jubera), y 315 m (zona de Leza) (HERNÁNDEZ-SAMANIEGO et al., 1990b). Consta de conglomerados, areniscas, limolitas y arcillas con intensas tonalidades rojizas. Los conglomerados predominan hacia la base dela sucesión, mientras que hacia el techo son más frecuentes las areniscas y arcillas (HERNÁNDEZ-SAMANIEGO et al., 1990b). Los conglomerados tienen su área madre en el Paleozoico (DíAZ-MARTíNEZ, 1988), y en los carbonatos J urásicos (DíAzMARTÍNEZ, 1988; ALONSO Y MAS, 1993). El medio de sedimentación se interpreta como depósitos distales de abanicos aluviales adosados al margen nororiental de la cuenca. Están dominados por canales posiblemente de baja sinuosidad que, lateralmente, evolucionan a zonas de llanura de inundación con desarrollo de episodios de encharcamiento que dan lugar zonas palustres y lacustres en la zona más distal (DÍAZ-MARTíNEZ, 1988; HERNÁNDEZ-SAMANIEGO et al., 1990b; ALONSO Y MAS, 1993).

La Formación Calizas de Leza (o Formación Leza) fue inicialmente definida con este rango por MAS Y ALONSO (1991). Sin embargo, la descripción formal con este nombre y rango corresponde a ALONSO Y MAS (1993). Es equivalente a la "facies a" del Grupo Enciso de TISCHER (1966b). Aflora al norte-nordeste de la subcuenca oriental de Cameros, constituyendo una banda alargada y discontinua en dirección paralela al cabalgamiento (en origen, a la falla de borde de cuenca). Es un cambio de facies gradual vertical y lateral con la Fm. J ubera. Está constituida por seis litosomas (Leza-J ubera; San Vicente; Arnedillo I; Arnedillo II; Peñalmonte; y Préjano) limitados por paleofracturas, de espesores variables entre 100 y $400 \mathrm{~m}$. Todos los litosomas están adosados al margen nororiental y tienen muy poca una extensión hacia el sudoeste. Consta básicamente de calizas micríticas, estromatolíticas y oncolíticas, con escasas intercalaciones siliciclásticas. Se han interpretado como un sistema carbonatado de humedales costeros (SUÁREZGONZÁLEZ et al., 2013; SUÁREZ-GONZALEZ et al., 2015). En general, el contenido fosilífero se reduce a carófitas, ostrácodos, gasterópodos, algas dasycladáceas, foraminíferos bentónicos, miliólidos y fragmentos de equinodermos (HERNÁNDEZ-SAMANIEGO et al., 1990b; MASY ALONSO, 1991; ALONSO Y MAS, 1993; SUÁREZ-GONZÁLEZ et al., 2010; SUÁREZ-GONZÁLEZ et al., 2013; SUÁREZ-GONZALEZ et al., 2015). ALONSO Y MAS (1993) citan la presencia de dos algas dasycladáceas: Salpingoporella 
cemi y Salpingoporella dinarica. DOUBLET (2004) en su tesis doctoral, y SUÁREZ-GONZÁLEZ et al. (2010) señalan la presencia de Salpingoporella urladanasi. Esta asociación permite determinar las incursiones marinas y asignar una edad Barremiense-Aptiense a esta formación. Salpingoporella cemi tiene un rango cronoestratigráfico que abarca desde el Hauteriviense superior hasta el Barremiense (CARRAS et al., 2006). Salpingoporella dinarica comprende desde el Berriasiense hasta el Albiense (CARRAS et al., 2006). Salpingoporella urladanasi presenta un rango Barremiense-Albiense (CARRAS et al., 2006). Se han encontrado algunos restos óseos de pterosaurios en Sol de la Pita 2 (MORATALLA et al., 1999) y un ejemplar casi completo en Préjano (FUENTES-VIDARTE Y MEIJ IDE-CALVO, 2010; PEREDA-SUBERBIOlA et al., 2012). También existen algunas huellas aisladas en Sol de La Pita 2. Según la cartografía recientemente presentada por SUÁREZ-GONZÁLEZ (2015), los yacimientos Soto 2 (CASANOVAS et al., 1992a) y Trevijano 1-2 (MORATALIA-GARCía et al., 1997) pertenecerían a la Formación Leza.

El Grupo Enciso fue definido con este nombre y rango por TiSCHER (1966b). Con una superficie de unos $245 \mathrm{~km}^{2}$, se dispone formando un sinclinorio asimétrico con un gran desarrollo longitudinal de su traza axial $(\approx 50 \mathrm{~km}$ ) de orientación preferente NO-SE (paralela a la traza del cabalgamiento) (figura 3.6). El flanco meridional presenta buzamientos suaves, una gran superficie aflorante, y una potente serie que alcanza más de $1.400 \mathrm{~m}$ en el depocentro. Por el contrario, el flanco septentrional muestra buzamientos elevados, poca superficie, un menor espesor de la serie, así como un elevado grado de fracturación y complejidad tectónica debido a que la mayor parte de la compresión terciaria se acomoda en esta zona. El Grupo Enciso es mundialmente conocido por su riqueza icnológica compuesta por multitud de yacimientos, principalmente huellas de dinosaurios aunque también aparecen icnitas de aves, quelonios, y pterosaurios. La descripción de los sedimentos, facies, medios sedimentarios y contenido paleontológico serán tratados en detalle en los siguientes capítulos de la presente memoria.

\subsubsection{Secuencia Deposicional 8 (SD 8): Aptiense superior-Albiense}

Aparece solamente en la subcuenca oriental y no tiene equivalente en el sector occidental. Representa una reactivación general dela cuenca que origina una nueva llegada de terrígenos gruesos a la cuenca. Está compuesta exclusivamente por el Grupo Oliván, de carácter aluvial. Se correlaciona con las secuencias deposicionales K1.9 y K1.10 de la cuenca Ibérica (SALAS et al., 2001).

El Grupo Oliván fue definido con este nombre y rango por TisCHER (1966b). Su potencia varía entre 800-2000 m. Está formado básicamente por areniscas que alternan con lutitas y, en menor medida, margas arenosas. Correspondea un medio fluvial con amplias llanuras deinundación surcadas por canales meandriformes de alta sinuosidad (TISCHER, 1966b; DURÁNTEZ et al., 1982; GUIRAUDY SÉGURET, 1985; HERNÁNDEZ-SAMANIEGO etal., 1990b). En el yacimiento dePico Quemado (Igea) se han encontrado restos óseos de un dinosaurio cf. Hypsilophodon sp. (TORRESYVIERA, 1994). 


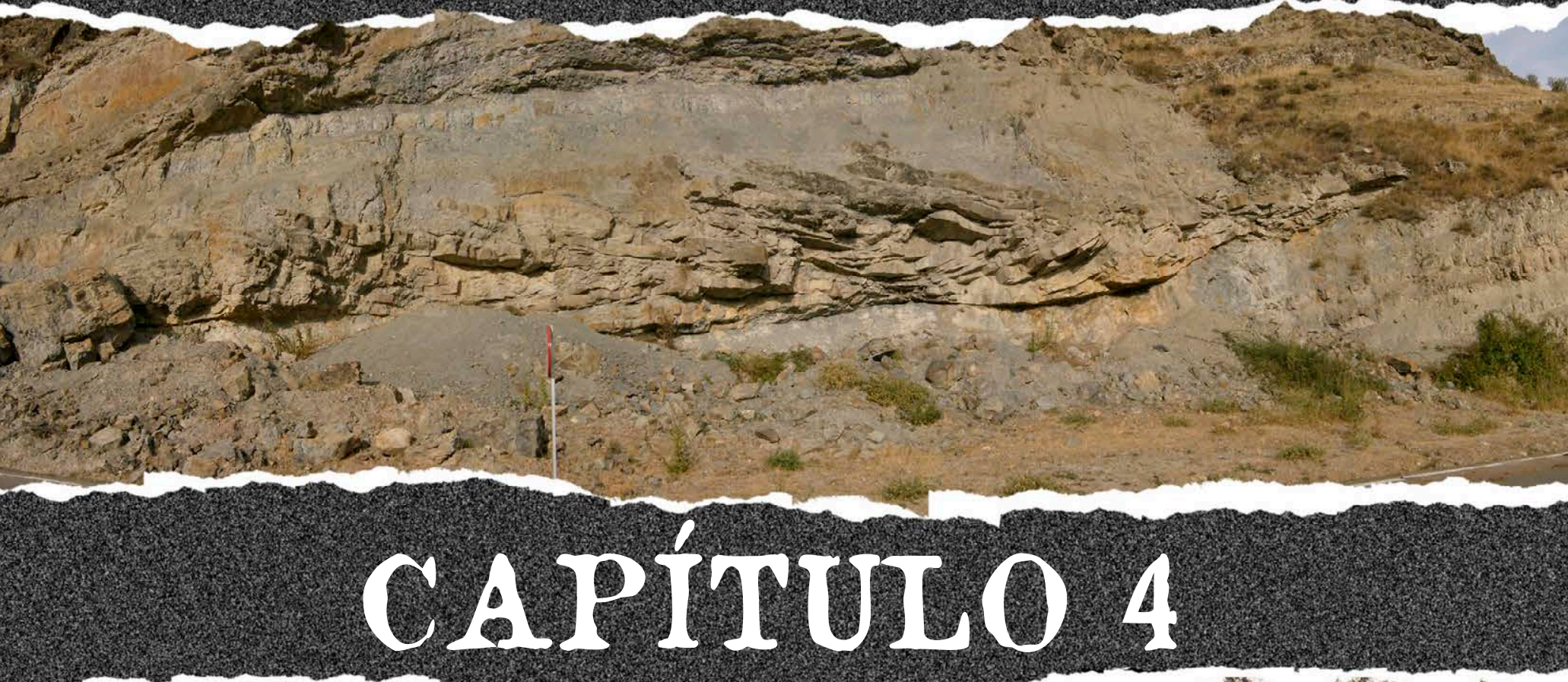
17. $17.5 \%$

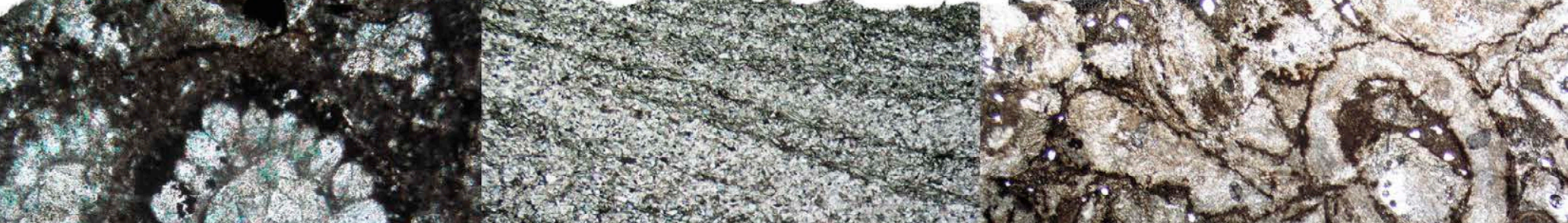

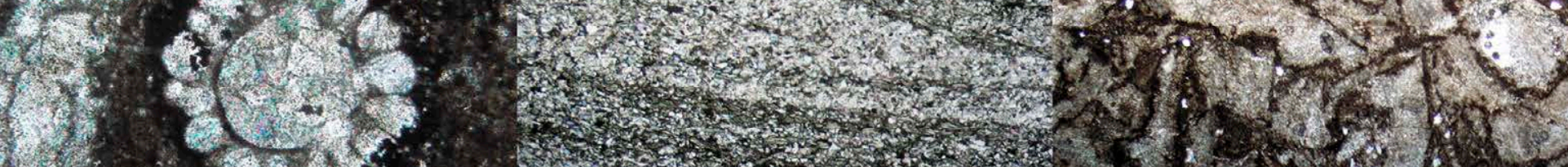

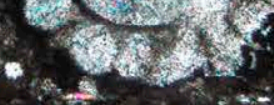

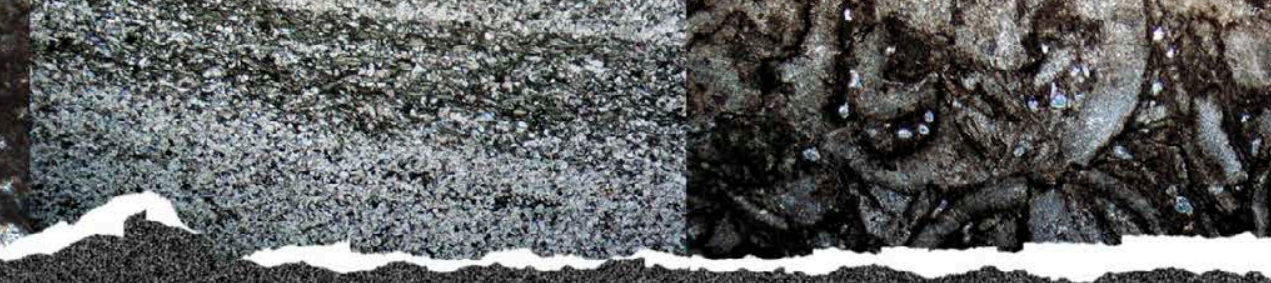

\section{SISTEMAS LACUSTRES: ESTADO DEL ARTE}

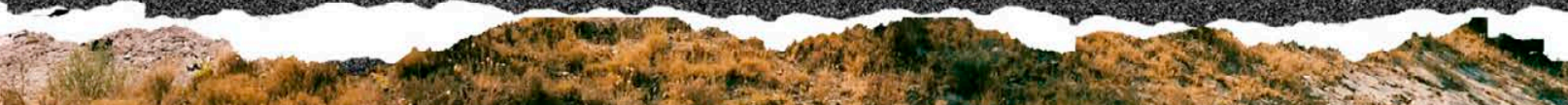

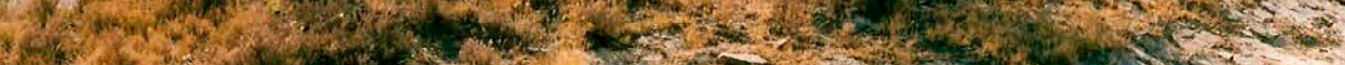

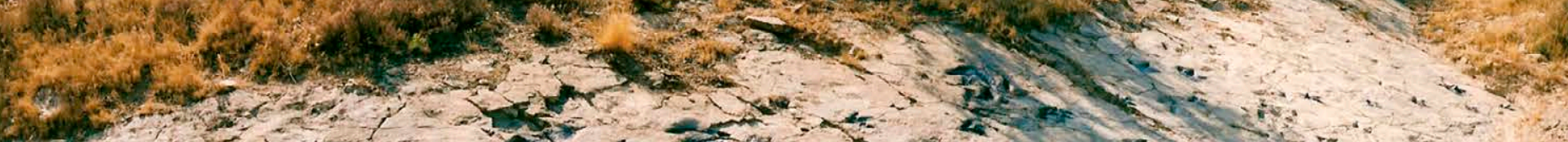

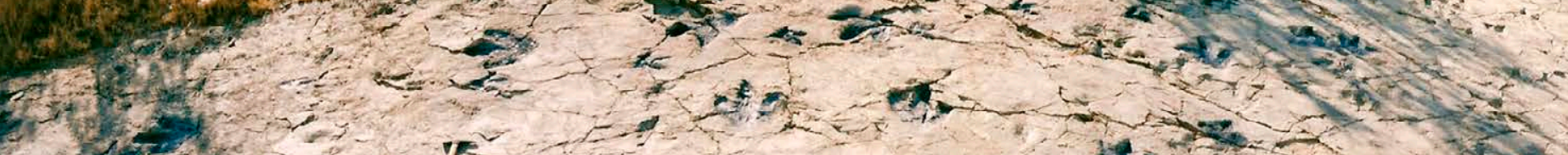

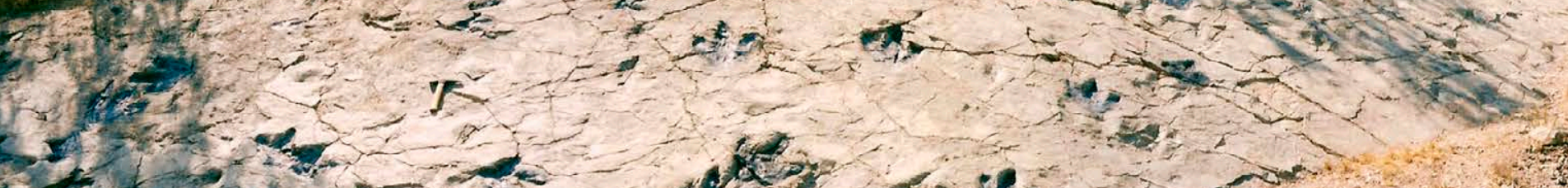
$5-2,-2<-1 x^{2}-4$ 


\section{Portey Richard}

\section{Ia vida. Una biografia no autorizada}

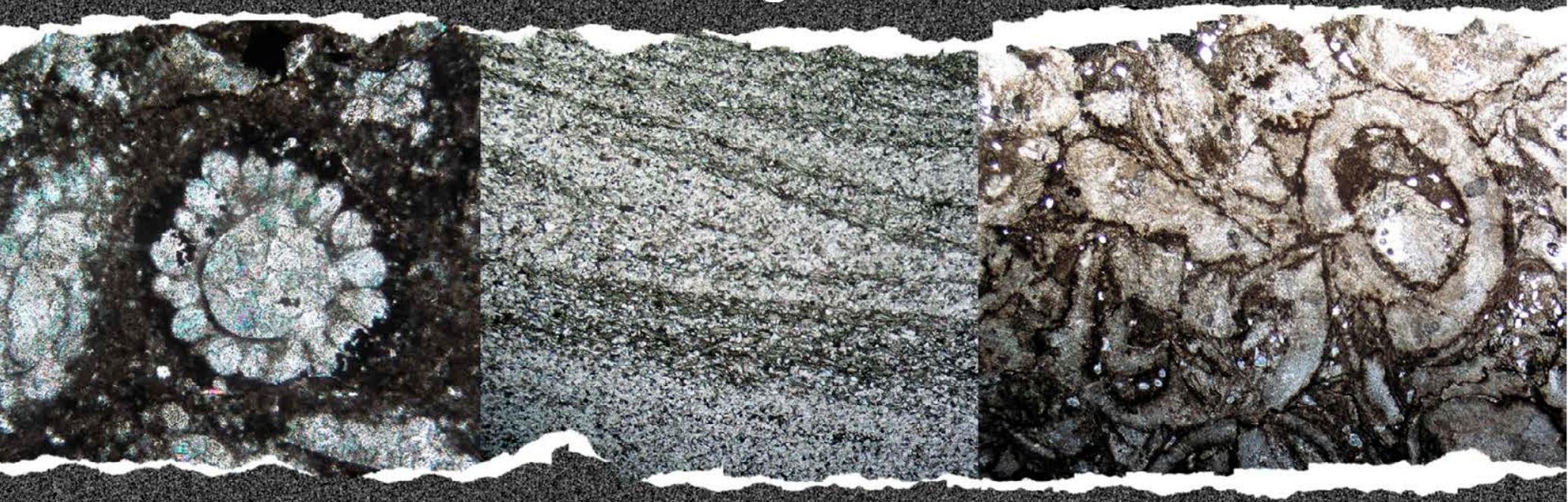

en obasiones es tentador emplear nás tiempo especulando acerca de 10 que podmia haber ahi fuera que apormeando de hecho las duras rocas bajo el abrasador sol del nediodía

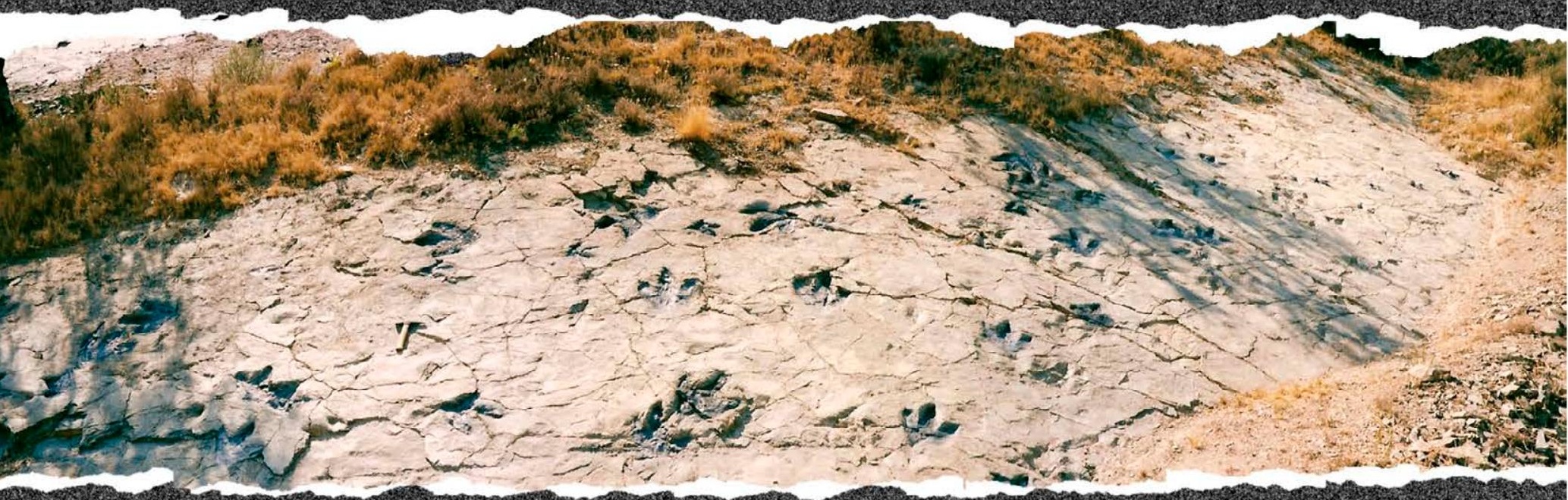




\subsection{INTRODUCCIÓN}

Este capítulo, de naturaleza fundamentalmente teórica, pretende ser una visión actualizada del estado del arte en el ámbito de los medios sedimentarios vinculados a masas de aguas continentales. Esta exposición incluye una descripción de los mecanismos y procesos básicos que operan en estos medios, e incorpora contribuciones y perspectivas procedentes de diferentes disciplinas. No se pretende que esta puesta a día sea una mera recopilación documental de carácter general y, por esta razón, se ha hecho especial hincapié en aquellos ambientes sedimentarios bajo unas condiciones climáticas (subtropical-tropical) y tectónicas (cuenca rift) similares a las existentes en la cuenca de Cameros durante el Aptiense. Todos estos principios operantes serán los fundamentos a la hora de abordar el análisis e interpretación del registro sedimentario y, en consecuencia, ocupan una extensión importante.

Los sistemas lacustres actuales son elementos del paisaje muy heterogéneos en términos de su origen, modo de abastecimiento, hidrología, dinámica, hidroquímica, patrón decirculación, contexto climático, etc. Esta diversidad añade cierto grado de dificultad a la hora de abordar su estudio desde un enfoque puramente sedimentológico. Por esta razón, en los últimos años ha surgido una nueva disciplina, con una metodología propia, denominada geolimnología. Según LAST (2002), la geolimnología se define como el "estudio e interpretación de los procesos físicos, biológicos, geoquímicos e hidrológicos que ocurren en los lagos y en el registro sedimentario de las cubetas lacustres". A pesar de esta diversidad, muchos de estos procesos limnológicos muestran un comportamiento latitudinal que se pueden predecir de manera rigurosa.

Por desgracia, todos estos inconvenientes se agigantan al abordar el estudio de los sistemas lacustres fósiles. Así pues, bajo esta perspectiva (paleo)geolimnológica, se pretende alcanzar una aproximación inicial o punto de partida, que permita acotar los procesos que teóricamente pudieron gobernar la dinámica sedimentaria en el paleolago Enciso y que, hoy en día, hayan podido quedar registrados en sus sedimentos. Con posterioridad, se proyecta utilizarlos como un elemento básico en la interpretación sedimentaria. Por esta razón se desarrollan en este capítulo, evitando ser repetitivo en las explicaciones en el resto de capítulos de la presente tesis.

\subsection{SISTEMAS ACUÁTICOS CONTINENTALES}

En este apartado, únicamente, se ambiciona clarificar la terminología referente a los cuerpos de agua existentes sobre la superficie terrestre. A tal fin, se intenta caracterizar, con cierta exactitud y precisión, los conceptos de uso común utilizados por los diferentes investigadores referentes a los ambientes lacustres y palustres. De tal modo, que se obtenga una armonización de la terminología utilizada para su posterior uso en el desarrollo de la presente tesis.

Una aproximación inicial a las aguas epicontinentales permite categorizarlas según la presencia o ausencia de un flujo importante en la masa de agua. Así se dividen en:

a) La aguas leníticas (estancadas o remansadas) abarcan a todas las masas de aguas sin corriente continua, tales como lagos, lagunas, charcas y humedales. En esta categoría se aceptan ciertos movimientos del agua como consecuencia del oleaje, viento, etc., constituyendo lo que en sedimentología se denomina como sistemas lacustres y palustres.

b) Las aguas lóticas (o corrientes) engloban a las masas de aguas en movimiento continuo en una dirección determinada o preferente tales como ríos, manantiales, riachuelos, etc., comprendiendo los sistemas aluviales.

Incluso en esta clasificación relativamente sencilla y categórica, existen límites poco claros donde un mismo sistema puede funcionar estacionalmente como lótico o lenítico: lagos situados en llanuras de inundación (VEGAS-VILARRÚBIA Y HERRERA, 1993), tablas de agua o de río (e.g. las Tablas de Daimiel), o waterholes que son canales con aguas más o menos permanentes aunque no siempre fluyendo (KNIGHTONY NANSON, 1994; GIBLING et al., 1998). 
Desde una perspectiva geomorfológica, considerándolos como simples manifestaciones paisajísticas, los sistemas leníticos se clasifican tradicionalmente en lagos, lagunas y charcas, recurriendo al tamaño como el criterio discriminatorio más habitual. El término lago hace referencia a cuerpos de aguas remansadas de centenares metros de longitud. La charca constituye una masa de agua con una longitud menor de $50 \mathrm{~m}$. Finalmente, la laguna es cualquier masa de agua comprendida entre ambos. Sin embargo, la utilización del tamaño como descriptor discriminatorio para tipificar los ambientes deposicionales genera una gran cantidad de imprecisiones en su uso que lo invalida para su identificación en el registro geológico. Otros autores consideran que la profundidad es el factor de discriminación básico ya que estructura la cubeta en unos gradientes tanto ecológicos como sedimentarios. Sin embargo, este valor límite de compromiso para cada categoría se fija de forma arbitraria (apartado 4.9.2). Desde un enfoque geolimnológico, la importancia estriba en el tiempo de residencia del agua en cada uno de estos medios. De tal manera, los sistemas leníticos, por tener tiempos de residencia mayores, se comportan como áreas de deposición y acumulación de la casi totalidad de los sedimentos transportados por las aguas.

\subsubsection{Definición de lago, laguna y charca (ambiente lacustre)}

Hoy en día, los lagos cubren aproximadamente 2-3 millones de $\mathrm{km}^{2}$, representando el 1,3-1,8\% de la superficie terrestre. A pesar de su abundancia, sólo existen 3.067 lagos con un espejo mayor de $50 \mathrm{~km}^{2}$ (DoWNING et al., 2006). Los lagos son elementos privilegiados del paisaje que desde tiempos lejanos han fascinado y cautivado la imaginación de los hombres, bien como morada de enigmáticas criaturas, bien como lugares sagrados o mitológicos, todos ellos impregnados de leyendas o maldiciones (HEATH, 1975; SHANKLIN, 1989; 2007). En los últimos años, los lagos han seguido sorprendiendo a la comunidad científica con asombrosos hallazgos. Así, en la década de los años noventa, cubierto por unos $4 \mathrm{~km}$ de hielo antártico, se descubrió uno de los lagos más extensos de la Tierra (aproximadamente unos $14.000 \mathrm{~km}^{2}$ ), hasta entonces desconocido para la ciencia: el lago Vostok (KAPITSA et al., 1996; ZOTIKOV, 2006). Con posterioridad, los investigadores han descubierto multitud de lagos bajo el manto helado antártico (WRIGHT Y SIEGERT, 2012). Fuera de la propia Tierra, llaman la atención los numerosos lagos extintos en la superficie de Marte (CABROL Y GRIN, 2005; 2010) o los insólitos lagos de hidrocarburos en Titán, una de las lunas de Saturno (MITRI et al., 2007; STOFAN et al., 2007).

Los lagos constituyen elementos paisajísticos cuya modelización es bastante compleja. Así pues, el primer reto que se plantea es acordar la definición del término lago. Estas definiciones son muy abundantes en la literatura, por lo que es complicado encontrar una válida que acepte todo el mundo. Esta variabilidad es el resultado del enfoque que cada investigador le otorga de acuerdo al campo de estudio y de su disciplina. Así pues, la definición varía en función de su utilización desde un punto de vista limnológico, ecológico, geográfico, geomorfológico, geológico, e incluso legislativo.

REEVES J R. (1968) caracteriza un lago como "un cuerpo de agua que es lo bastante profundo como para no permitir que la vegetación arraigue completamente a lo largo de su extensión".

MARGALEF (1983) considera que "el lago, prototipo deecosistema acuático epicontinental, presupone una extensión y una profundidad mínimas. El fondo de un verdadero lago no recibe luz suficiente para estar todo él cubierto de vegetación. Esta profundidad mínima hace inevitable que, por lo menos, en algún momento del ciclo estacional, se forme una termoclina y se manifieste un aislamiento relativo de las capas profundas, -y del sedimento-".

NEUENDORF et al. (2005) definen un lago como "cualquier masa de agua lenítica continental que ocupa una depresión sobre la superficie terrestre, comúnmente de un tamaño apreciable (mayor que una laguna) y lo suficientemente profundo como para no permitir que la vegetación arraigue completamente en toda la amplitud del agua (exceptuando la vegetación subacuática); el agua puede ser dulce o salina". 
Según NEUENDORF et al. (2005) una laguna (pond) es "una masa de agua lenítica de origen natural que ocupa una pequeña depresión del terreno, generalmente de tamaño menor que un lago y mayor que una charca". Sin embargo, PLATTY WRIGHT (1992) consideran que una laguna se define mejor como un lago estacional o somero.

Por último, una charca (pool) es "una pequeña masa de agua lenítica de origen natural, generalmente de agua dulce" (NEUENDORF et al., 2005).

En general, todas estas definiciones, al no basarse en descriptores sedimentológicos y asentarse sobre caracteres con connotaciones paisajística o ecológica, hacen que su distinción en el registro geológico sea bastante problemático.

La voz lacustre tiene dos connotaciones: "perteneciente, producido o formado en un lago o lagos" o "creciendo o habitando en los lagos" (NEUENDORF et al., 2005).

\subsubsection{Definición de humedal (ambiente palustre)}

De manera análoga a la discusión anterior, tampoco existe una definición consensuada del vocablo humedal. Como en el caso anterior, las definiciones que existen están muy condicionadas, bien por los objetivos a desarrollar (investigación, legislación, restauración, conservación, etc.), bien por el campo profesional de los investigadores (hidrología, geología, geografía, botánica, zoología, ecología, etc.).

El párrafo 1 del artículo 1 de la Convención sobre los Humedales (Convenio de Ramsar), define los humedales como "las extensiones de marismas, pantanos y turberas, o superficies cubiertas de aguas, sean éstas de régimen natural o artificial, permanentes o temporales, estancadas o corrientes, dulces, salobres o saladas, incluidas las extensiones de agua marina cuya profundidad en marea baja no exceda deseis metros". El problema de esta definición es que utiliza como elementos de la definición términos subjetivos, ambiguos y demasiado generalistas, produciendo cierta confusión, lo cual limita considerablemente su uso.

NEUENDORF et al. (2005) considera un humedal "un área que está húmeda o inundada de manera regular, y que tiene un nivel freático que permanece a nivel o por encima de la superficie del terreno al menos parte del año".

GONZÁLEZ-BERNÁLDEZ (1992) califica un humedal como "una unidad funcional del paisaje que no siendo un río, ni un lago ni el medio marino, constituye en el espacio y en el tiempo una anomalía hídrica positiva respecto a su entorno más seco. El exceso de humedad debe ser lo suficientemente importante para afectar a los procesos físicos, químicos y biológicos del área en cuestión. Estas unidades territoriales se caracterizan básicamente por contener suelos hídricos y vegetación hidrófila, además de poseer una fauna, microorganismos y unos usos humanos diferentes a la de los espacios adyacentes".

Así pues, generalizando, se pueden convenir que los humedales se localizan entre dos entidades antagónicas: en un lado los sistemas acuáticos (marino, fluvial y lacustre) y, en el otro extremo, los sistemas terrestres. El problema surge cuando se pretende concretar unos límites precisos al segmento, más o menos amplio, situado entre ambos extremos. Es en esta zona fronteriza e imprecisa es donde se emplazan los humedales, formando la transición de los sistemas acuáticos y los terrestres adyacentes emergidos. Por esta razón, suelen constituir medios muy heterogéneos con unas características propias, así como otras derivadas de los medios contiguos (terrestres y/o acuáticos). Según su posición relativa respecto de dichos extremos tendremos humedales influenciados por los océanos como las marismas (MACNEIL Y J ONES, 2006), ríos (GARCÍA-RODRÍGUEZ, 2003) o lagos (HERDENDORF, 2004; MAYER et al., 2004). Esta dificultad se agudiza en el registro geológico y, como prueba de esta dualidad, se puede citar a la Formación Morrison (J urásico, Estados Unidos), interpretada tradicionalmente como lacustrey, hoy en día, entendida como un humedal (DUNAGANY TURNER, 2004). 
En sedimentología, está muy extendido el uso del término palustre. En general, existen dos formas de pensamiento o nociones sobre dichos depósitos.

Por un lado, tal como fue definida ab initio por los investigadores franceses (FREYTET, 1973; FREYTETY PLAZIAT, 1982; FREYTET, 1984), los depósitos palustres sensu stricto son depósitos lacustres dulceacuícolas (marginales o someros) que han sufrido posteriores transformaciones por fenómenos de emersión y pedogénesis. De tal modo, que un sedimento palustre debe mostrar ambos caracteres en conjunción: es decir, tanto las propias del sedimento lacustre primario como las debidas a su posterior transformación. En esta línea se adscribe la definición de ESTEBAN Y KLAPPA (1983): "áreas donde los carbonatos lacustres (o suelos subaéreos relictos) están sujetos a procesos incipientes de suelos (colonización por plantas terrestres, formación de glaébulos, agrietamiento circumgranular) pero todavía saturados con agua del lago (por esta razón son también denominados suelos hidromórficos)". Estos ambientes lacustres-palustres aparecen estrechamente conectados entre sí, tanto lateral (espacio) como verticalmente (tiempo). De tal forma que a medida que un lago somero se deseca, pasa inevitablemente a convertirse en un área pantanosa (DJ AMALI et al., 2006). En este caso, a cada facies lacustre le corresponde una facies palustre equivalente (FREYTET Y VERRECCHIA, 2002).

La otra concepción de la expresión palustre es menos restrictiva y más abierta. A grandes rasgos, considera que un depósito palustre corresponde a cualquier depósito de ambientes someros que exhiba evidencias de modificación pedogenética y/ o por emersión (PLATT Y WRIGHT, 1992; WRIGHT Y PLATT, 1995). Por tanto, no corresponde necesariamente a los depósitos lacustres marginales previos, aunque sí los incluiría. Bajo esta nueva visión, los medios palustres se consideran un producto pedogenético de:

a) Ambientes lacustres marginales con poca pendiente y con fluctuaciones del nivel del lago (FREYTET, 1973; FREYTET Y PlAZIAT, 1982; FREYTET, 1984). El único sistema análogo actual lo constituye la zona marginal del Lago Balatón en Hungría (ALONSOZARZA, 2003).

b) Áreas pantanosas y/o cenagosas (FREYTET, 1973; NEUENDORF et al., 2005) y humedales estacionales (WRIGHT Y PLATT, 1995). Los análogos modernos son Las Tablas de Daimiel en España (DoRADO-VALIÑO et al., 2002; ALONSO-ZARZA, 2003; ALONSO-ZARZA et al., 2006), la zona pantanosa de la Baja Mesopotamia en Irán (BALTZER Y PURSER, 1990; AQRAWI Y EVANS, 1994; PLAZIATYYOUNIS, 2005), el Pantano Ruby (DEAN Y FOUCH, 1983) y, las Everglades en Estados Unidos (PlatT Y WRIGHT, 1992).

c) Lagos someros y efímeros desarrollados sobre las llanuras de inundación de sistemas fluviales (TOOTH et al., 2002; HUERTA Y ARMENTEROS, 2005).

d) Ambientes marinos perimareales (WRIGHT Y PlatT, 1995; MACNEIL Y J ONES, 2006).

\subsection{ZONACIÓN DEL SISTEMA LACUSTRE}

Los sistemas lacustres presentan múltiples compartimentos espaciales, generados por procesos químicos, físicos y/ o bióticos, tanto en la horizontal como en la vertical. Aunque algunas de estas segmentaciones pueden ser específicas para determinados tipos de lagos, en general son comunes para la mayoría de ellos. Por tanto, la existencia de esta organización espacial común en todos ellos ha desembocado en la descripción de unos dominios o cinturones distintivos (LEWIS, 2009).

Esta idea de la compartimentación en dominios, reconocida desde antiguo en los estudios limnológicos, se puede aplicar con ciertas modificaciones, a los estudios sedimentológicos. En teoría, estos cinturones se pueden determinar a partir ciertos descriptores procedentes de caracteres que puedan ser observables a nivel del afloramiento. En cada dominio concreto, el descriptor presenta un modelo de distribución determinado, así como un grado de desarrollo característico (VALERO et al., 1992; GIERLOWSKI-KORDESCH Y KELTS, 1994).

Así pues, se ha de buscar límites con objeto de obtener unas unidades operativas útiles que faciliten su estudio. De esta forma, al delimitar unos dominios, más o menos discretos, se 
puede obtener una herramienta universal y de gran utilidad en la interpretación de los sedimentos lacustres. La consecuencia más importante de conceptuar los sistemas lacustres en cinturones sedimentarios, organizados jerárquicamente y relacionados entre sí, es que cada dominio exhibe unas peculiaridades únicas (asociadas a unas condiciones hidrodinámicas, tectónicas, climáticas, fisicoquímicas, de transporte, deposicionales y/ o post-deposicionales) que dejan su impronta en las facies.

Otro aspecto a tener en cuenta es que los medios lacustres se caracterizan por un gran dinamismo, en el cual el factor tiempo juega un papel significativo. Según CECIL (2003), las modificaciones temporales en los sedimentos se pueden catalogar en: instantáneas ( $10^{2}$ años), muy corto plazo ( $10^{3}$ años), corto plazo ( $10^{4}$ años), medio plazo ( $10^{5}$ años) y largo plazo ( $10^{5}-10^{8}$ años). Por todo ello, resulta difícil demarcar en el registro fósil el momento en que las propiedades que definen un determinado cinturón dan paso a otro o viceversa. Además, que un determinado dominio no quede registrado en el sedimento no implica, a priori, que no existiera, ya que las fluctuaciones del nivel del lago pueden erosionar sus propios depósitos (canibalismo) o modificarlos hasta hacerlo irreconocible en el registro geológico. Por este motivo, es importante la determinación de unos descriptores prefijados y reglados que caractericen dichos dominios.

Desde un enfoque geolimnológico se puede asumir que los dominios lacustres constituyen subdivisiones fundamentales en un lago, exhibiendo en cada caso concreto una distribución particular así como un grado de desarrollo característico. En general el esquema básico más ampliamente utilizado es: supralitoral, litoral (eulitoral-intralitoral), sublitoral, talud y profundo (figura 4.1).
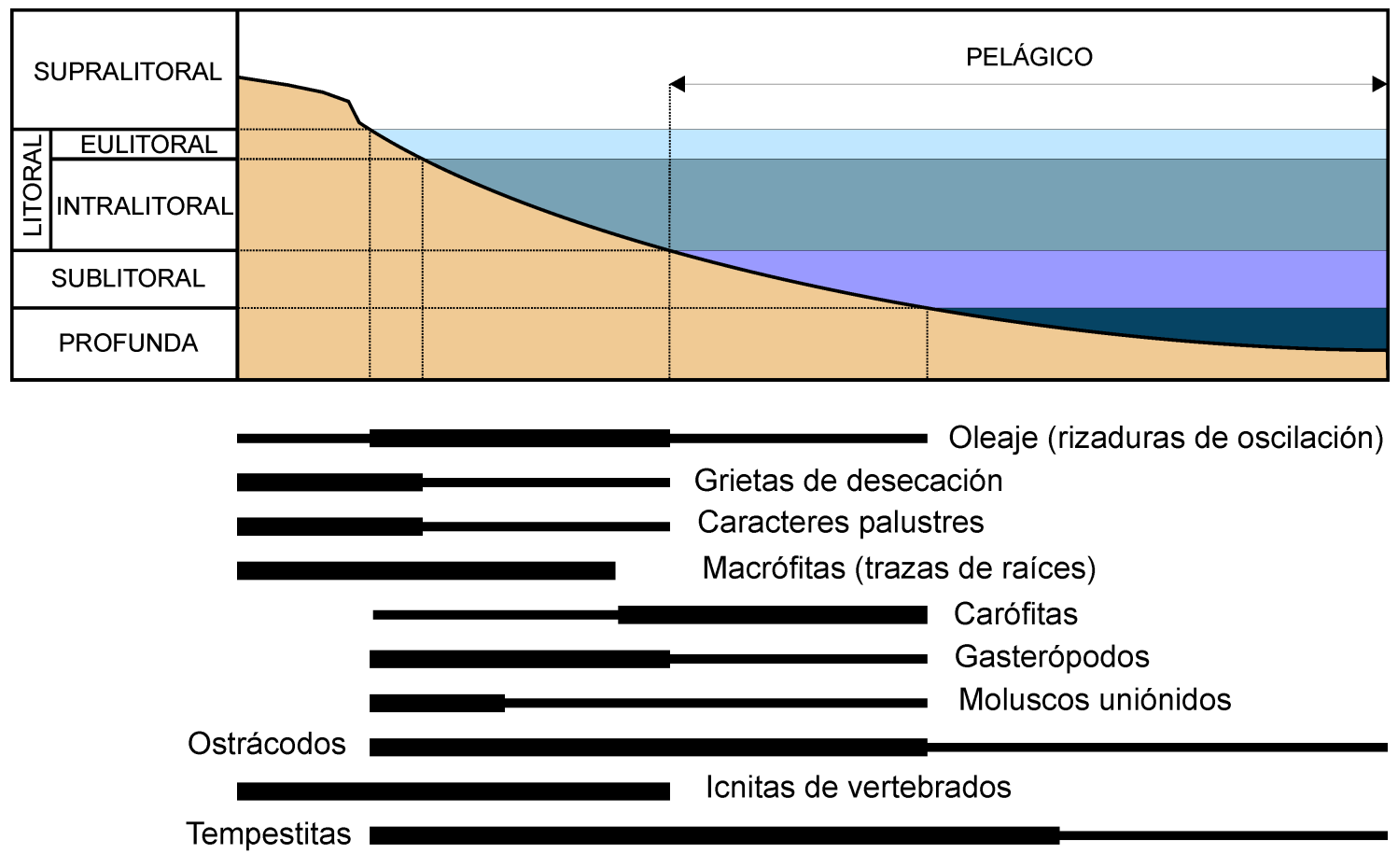

Lumaquelas (concentraciones biológicas)

Lumaquelas (concentraciones sedimentarias)

Flujos gravitatorios de sedimentos

Figura 4.1: Esquema de la zonación presente en un lago, mostrando los diferentes dominios y las principales características sedimentarias y biológicas de cada uno de ellos.

Estos subambientes derivan de las clásicas divisiones observadas en los estudios limnológicos (HUTCHINSON, 1967; WETZEL, 2001), que posteriormente se aplicaron a la 
geolimnología de manera general (KELTS, 1988; VALERO et al., 1992; GIERLOWSKI-KORDESCH Y KELTS, 1994). De esta manera, la cubeta lacustre queda compartimentada en cinturones o franjas, más o menos concéntricas, en función de:

a) Un gradiente horizontal en dirección orilla-centro del lago.

b) Un gradiente vertical basado en tres descriptores básicos delimitados por la energía (oleaje y corrientes), la penetración de la luz (biota) y la temperatura.

Además, esta zonación está muy influenciada por la geomorfología del lago de tal forma que, por ejemplo, los lagos poco profundos pueden ser monozonales o, según la pendiente, un dominio puede mostrar un mayor o menor desarrollo respecto al resto o, incluso, no existir.

Es difícil que una zonación tan detallada pueda reconocerse en el registro estratigráfico, aunque existen algunos ejemplos destacables en la literatura paleolimnológica consultada (CARBALleira-CuETO Y Pol-MÉNDEZ, 1986; ARP, 1995; FerBer y Wells, 1995; Bustillo et al., 2002; CABALERI Y ARMELLA, 2005). En general, son más numerosos los trabajos paleolimnológicos donde se distingue entre: lacustre marginal o litoral (incluyendo los dominios supralitoral, eulitoral e intralitoral) y lacustre abierto o profundo (englobando los dominios sublitoral, talud y profundo) (RYDER et al., 1976; BUCHHEIM Y SURDAM, 1981).

\subsubsection{Dominio supralitoral}

El dominio supralitoral corresponde a la banda que bordea el lago por encima del límite del agua (figura 4.1). Esta zona no se encuentra sumergida, sin embargo, puede estar expuesta a la acción del oleaje (batida) en días ventosos (HUTCHINSON, 1967; WETZEL, 2001). Debido a que la mayor parte del tiempo está por encima del nivel freático se considera un dominio totalmente terrestre (HASIOTIS, 2007). Se sitúa por encima de la línea de costa y soporta una cobertera vegetal importante, así como numerosos invertebrados excavadores, exhibiendo una gran icnodiversidad (HASIOTIS, 2007; HAMER Y SHELDON, 2010).

Los sedimentos característicos de este dominio muestran evidencias de enraizamiento por vegetación y/o de pedogénesis por las fluctuaciones del nivel freático (ALONSO-ZARZA, 2003). Litológicamente muestran texturas típicas de medios de poca o nula energía tales como siliciclásticos de grano fino (LAST, 1989b; HAMER Y SHELDON, 2010) o carbonatos fangosoportados con abundante matriz (ARP, 1995; CABALERI Y ARMELLA, 2005). La intensa bioturbación junto a la emersión, elimina a posteriori casi todos los rasgos primarios de los sedimentos.

Los ambientes sedimentarios característicos de este dominio están constituidos por llanuras fluvio-deltaicas, llanuras fangosas/arenosas y áreas pantanosas-cenagosas (medios palustres) adosadas a los lagos (FERBER YWELLS, 1995). El término llanura fangosa (mudflat) hace referencia a una: "superficie plana bajo agua somera o bajo condiciones subaéreas con una sedimentación de baja energía" (CASTLE, 1990). Algunos buenos ejemplos de llanuras fangosas actuales, todos ellos exhibiendo caracteres de emersión, son el lago Freefight (LAST, 1993b) y el lago Caylon (LAST, 1989b). Con un significado parecido se utilizan términos como llanura fangosa carbonatada (carbonate mudflat) (SURDAM Y STANLEY, 1979) y llanura carbonatada lacustre marginal (lake-margin carbonate-flat environment) (RYDER et al., 1976).

\subsubsection{Dominio litoral (eulitoral-intralitoral)}

El dominio litoral se extiende desde la línea de costa hasta la profundidad donde llega el $1 \%$ de la luz solar, siendo de vital importancia en la dinámica y vida del lago. La morfología de la cubeta regula, en gran medida, la extensión de la zona litoral. En lagos someros o con poco gradiente topográfico domina el hábitat físico existente, constituyendo un porcentaje significativo del área total del lago. En algunos casos puede llegar a componer la mayor parte del fondo de la cubeta lacustre (PETERS Y LODGE, 2009). En lagos con mayores pendientes, la franja litoral es menos extensa, pudiendo constituir un porcentaje mínimo del área respecto al dominio profundo (VADEBONCOEUR et al., 2011). Tanto la biota como los sedimentos del dominio litoral exhiben una 
distribución heterogénea, en contraposición con la homogeneidad característica en el dominio profundo (PETERS Y LODGE, 2009).

Desde una perspectiva biótica, es el dominio donde habitan la mayoría de los organismos acuáticos (VADEBONCOEUR et al., 2011) y que presenta la mayor diversidad de hábitats para los mismos (PETERS y LODGE, 2009). Por un lado, constituye la franja de la cubeta donde las condiciones deluzy la presión hidrostática permiten la colonización por macrófitos. Por otro, son abundantes los invertebrados dominados por los filtradores suspensívoros (WHITE Y MILLER, 2008). Así pues, los sedimentos presentan trazas de raíces, gran contenido en bioclastos y fósiles (carófitas, ostrácodos, bivalvos y gasterópodos), granos revestidosy, una icnofauna rica en huellas de animales terrestres y acuáticos (HASIOTIS, 2004). En el registro geológico la profusión de raíces de macrófitos acuáticos puede malinterpretarse como depósitos subaéreos con raíces. Además, un crecimiento excesivo de plantas puedebloquear el desarrollo de una icnofauna litoral distintiva y reemplazarla por trazas de raíces (MILLER Y WHITE, 2007).

Los procesos hidrodinámicos dominantes son: la acción del viento (olas, corrientes y secas superficiales), la dinámica de los flujos que vierten en la cubeta (aportes por escorrentía o subterráneos) y, las corrientes de convección causadas por calentamiento diferencial. La zona más cercana a la costa está afectada de manera continua por el oleaje, mientras que la zona cercana al límite con el dominio sublitoral está sometida a resuspensiones ocasionales inducidas por las tormentas (WHITE Y MILLER, 2008). En los lagos de tamaño considerable o con un gran alcance, la acción de las olas puede limitar el crecimiento de macrófitos. Por el contrario, los lagos pequeños, comúnmente, están dominado por macrófitos que amortiguan la acción del oleaje, permitiendo a los sedimentos finos depositarse y aportándoles abundante materia orgánica (WETZEL, 2001; KALFF, 2002).

El tipo de sedimento presente está influenciado por la morfología del lago y por la acción del viento (PETERS Y LODGE, 2009). El sedimento está sometido a la resuspensión inducida por el viento (TALLING, 1992; ARFI Y BOUVY, 1995) y/ o por las tormentas (BRYDSTEN, 1992; RITZRAU Y GRAF, 1992) y, en menor medida, por las secas que eliminan los finos de las zonas someras (NEWELL, 1960; SCHOLZ et al., 1990b). Por ejemplo, en el lago Malaui, el oleaje y las corrientes inducidas por el viento eliminan los sedimentos finos hasta una profundidad de unos $100 \mathrm{~m}$ (J OHNSON Y NG'ANG'A, 1990). Los sedimentos litorales generalmente contienen una mayor contenido en carbonato que los sedimentos en zonas más profundas (DEAN, 1981).

El dominio litoral, se subdivide en dos cinturones: eulitoral e intralitoral (HUTCHINSON, 1967; WETZEL, 2001).

\subsubsection{Dominio eulitoral}

El dominio eulitoral constituye la zona de transición entre el lago y los terrenos colindantes emergidos. Está delimitada por las fluctuaciones del nivel de la lámina de agua a escala anual y, a menudo, está influenciada por la acción de las olas rompientes (HuTCHINSON, 1967; ARP, 1995; WETZEL, 2001) (figura 4.1). En lagos con poca pendiente esta zona puede tener una extensión considerable. En el lago Poopó (Bolivia) existe una zona periférica de carácter temporal, con profundidades menores de $0,5 \mathrm{~m}$, que se deseca durante la estación seca y se extiende unos $1.000 \mathrm{~km}^{2}$ (CARMOUZE et al., 1978). Se caracteriza por la presencia de plantas emergentes (si las hubiera).

Debido a las caídas de la lámina de agua anuales, son frecuentes las grietas de retracción y las huellas de vertebrados (HAMER Y SHELDON, 2010).

Se interpretan como pertenecientes a este cinturón, todos los sedimentos litorales exhibiendo evidencias de emersión que modifiquen su estructura original. En este sentido, es un claro sinónimo de palustre asociado a lagos someros (DUNAGAN Y DRIESE, 1999; TANNER, 2000; BustiLlo et al., 2002). 


\subsubsection{Dominio intralitoral}

El dominio intralitoral (o infralitoral) está constituido por la franja costera que está permanentemente inundada a escala anual (figura 4.1), aunque puede sufrir etapas de exposición subaérea de manera ocasional durante grandes caídas del nivel del lago.

En función de la vegetación existente se subdivide en superior (vegetación enraizada y macrófitos emergentes), media (macrófitos de hojas flotantes) e inferior (macrófitos sumergidos como las carófitas) (HUTCHINSON, 1967; WETZEL, 2001). En general, es muy problemático (casi imposible) el reconocimiento de estas subdivisiones en el registro geológico.

Sedimentológicamente se caracteriza por: a) exhibir secuencias transgresivas-regresivas (EUGSTER Y KELTS, 1983), b) presencia de raíces, c) estructuras de tracción (oleaje y/o unidireccionales), d) abundancia de restos fósiles (bioclastos), e) oogonios o fragmentos de talos de carófitasy, f) ausencias de emersión o pedogénesis (ARP, 1995). La presencia deuna vegetación abundante contribuye a atrapar gran cantidad de sedimentos.

\subsubsection{Dominio sublitoral}

El dominio sublitoral (o litoriprofundo) es un cinturón que permanece inundado de manera permanente, y por consiguiente, no muestra rasgos de exposición subaérea (figura 4.1). Su límite inferior con la zona profunda es difícil de determinar ya que se trata de una zona de transición (HUTCHINSON, 1967; WETZEL, 2001). En ciertos lagos coincide con la profundidad límite de vida para los moluscos (J ÓNASSON, 2004). En caso de existir estratificación térmica, este dominio aparece en el metalimnion (HUTCHINSON, 1967; WETZEL, 2001), y suele coincidir con la termoclina en muchos lagos (J ÓNASSON, 2004; WHITE Y MILLER, 2008). Su límite superior se corresponde con la profundidad de la zona fótica ( $1 \%$ de penetración de la luz solar) permitiendo la existencia de algunos organismos fotosintéticos, principalmente algas y cianobacterias (WHITE Y MILLER, 2008).

Presenta una gran diversidad y densidad en invertebrados bentónicos, en algunos casos exhibiendo gran abundancia de conchas denominándose entonces como zona de concentración (J ÓNASSON, 2004; WHITE Y MILLER, 2008). Otra característica fundamental es la colonización por macrófitos sumergidos, esencialmente carófitas (HANNON Y GAILLARD, 1997; COLLADO et al., 1999).

Así pues, el dominio sublitoral se puede definir como una zona que mantiene características sedimentarias propias de la zona profunda (pero todavía fótica) y con presencia de vida, especialmente organismos zoobentónicos. Su extensión varía en función de la topografía y profundidad de la cubeta, estando ausente en lagos someros con escaso gradiente topográfico. Si el lago presenta estratificación, los sedimentos de este dominio pueden verse afectados por la acción de olas baroclínicas (apartado 4.15.1) (SAKAI et al., 2002), como por ejemplo, las secas internas (BOEGMAN, 2009).

Desde el punto de vista sedimentológico, en muchos lagos actuales se equipara con la zona donde se produce el cambio abrupto de tamaño del sedimento de grueso a fino (KALFF, 2002). Esta transición coincide con el nivel de base de las tormentas, siendo entonces equivalente a la profundidad crítica (HÅKANSON, 1982) o a la profundidad límite de deposición del fango (ROWAN et al., 1992).

Una de las formas de calcular este límite es a partir del diagrama ETA (ErosiónTransporte-Acumulación) (figura 4.2). El área de erosión corresponde a la zona donde no se produce la deposición del material fino ya que es resuspendido y eliminado. El área de transporte se refiere a la región donde los materiales finos se depositan periódicamente y está influenciada por la dinámica del oleaje. El área de acumulación es la zona donde el sedimento fino se deposita

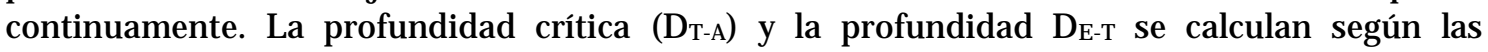
siguientes fórmulas (HÅKANSON, 1977; 1981b; HÅKANSON, 1982): 


$$
\begin{aligned}
& \mathrm{D}_{\mathrm{T}-\mathrm{A}}=\frac{45,7 \mathrm{~F}}{\mathrm{~F}+21,4} \\
& \mathrm{D}_{\mathrm{E}-\mathrm{T}}=\frac{30,4 \mathrm{~F}}{\mathrm{~F}+34,2}
\end{aligned}
$$

Donde $\mathrm{D}_{\mathrm{T}-\mathrm{A}} \mathrm{y}$ D $\mathrm{D}_{\mathrm{E}-\mathrm{T}}$ son las profundidades que separan la zona de transporte-acumulación y erosión-transporte respectivamente $(\mathrm{m}) \mathrm{y}$, F es el alcance $(\mathrm{km})$.

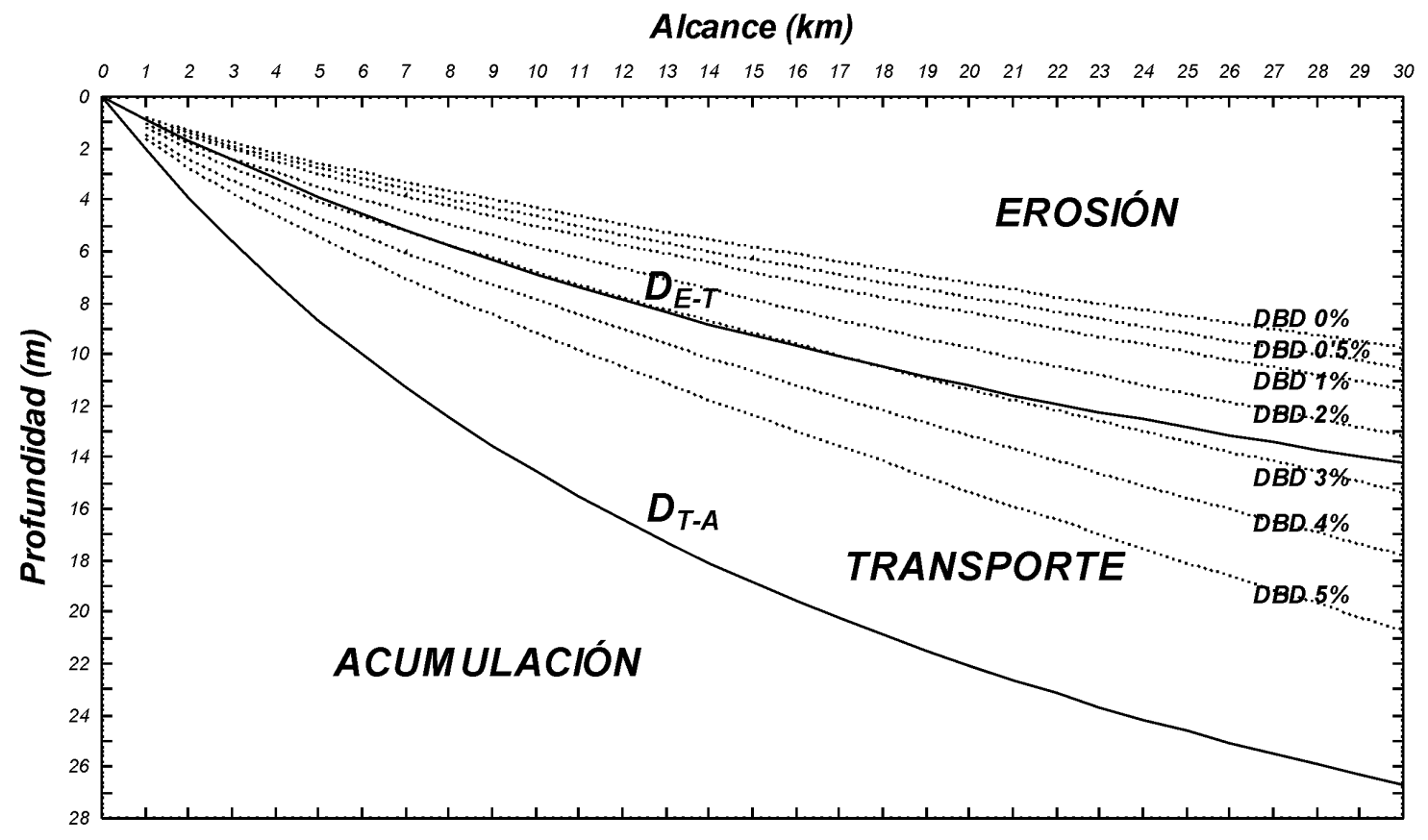

Figura 4.2: Diagrama Erosión-Transporte-Acumulación (líneas continuas) comparado con los valores de la profundidad límite de deposición del fango (líneas punteadas) para diferentes pendientes topográficas.

Otro método de calcular esta frontera es mediante la profundidad límite de deposición del fango (mud deposition boundary depth DBD). Según RowAN et al. (1992) se define como la profundidad a la cual se produce una transición abrupta entre ambientes erosivos de alta energía (sedimentos no cohesivos de tamaño de grano grueso) y, ambientes de deposición de baja energía donde tiene lugar la acumulación de sedimento fino cohesivo (figura 4.2).

Esta profundidad es aplicable solamente a lagos donde la distribución de los sedimentos está controlada por la energía del oleaje. Así pues, su aplicación a sistemas lacustres donde esta distribución puede estar controlada por otros factores, aparte del oleaje, es más controvertida. Tales casos se dan en lagos con tasas de aportes de sedimentos extremadamente altas, lagos extremadamente someros con tiempos de residencia altos dondela resuspensión del material fino no se elimina por los desagües y, lagos con ambientes dominados por macrófitos acuáticos que amortiguan la acción del oleaje (RoWAN et al., 1992):

$$
\log \mathrm{DBD}=-0,107+0,742 \log \mathrm{F}+0,0653 \mathrm{P}
$$

Donde F es el alcance máximo (km) y P es la pendiente (\%).

\subsubsection{Dominio del talud}

El dominio del talud se manifiesta por una ruptura perceptible de la pendiente. No siempre está presente y, en caso de existir, muestra el mayor gradiente topográfico de todos los dominios presentes en la cubeta. Si los flancos del lago son muy escarpados los sedimentos no se depositan sino que se produce un bypass, como ocurre en el lago Walen de Suiza (LAMBERTY HSÜ, 
1979). En algunos lagos, las secas internas pueden inducir la resuspensión y transporte de material en zonas del talud hipolimnéticas (HORPPILA Y NIEMISTÖ, 2008).

\subsubsection{Dominio profundo o abierto}

El dominio profundo (abierto, offshore, limnético o de cuenca según otros autores) hace referencia a la zona central y de mayor profundidad relativa dentro de la cubeta lacustre (figura 4.1). Aunque es la zona más profunda, esto no implica necesariamente una batimetría elevada. $\mathrm{Si}$ el lago presenta estratificación térmica, aunque no siempre, se desarrolla por debajo de la termoclina (hipolimnion) y en condiciones afóticas. Si el lago es meromíctico, una gran parte o su totalidad, se localiza en el monimolimnion.

En lagos someros la zona sublitoral y profunda pueden formar un único cinturón sin diferenciación o puede que la zona profunda no exista como tal.

La biota es insignificante. No existe ninguna clase de vegetación (HUTCHINSON, 1967; WETZEL, 2001), aunque pueden aparecer restos vegetales transportados delas zonas más someras o, incluso, procedentes de fuera de la cubeta lacustre (alóctono). Los macroinvertebrados bentónicos son escasos, ya que pocos son capaces de soportar condiciones anóxicas, aunque sólo sea durante periodos de tiempo cortos. Aun así se puede esperar que existan ciertas trazas de actividad bentónica en el sedimento.

Este dominio puede exhibir todos los términos intermedios comprendidos entre los límites de condiciones oxigenadas hasta anóxicas.

Se caracteriza porque se encuentra por debajo del nivel de base del oleaje y, en general, fuera del radio de influencia de los aportes fluviales. Por tanto, desde una perspectiva sedimentaria, se identifica por una sedimentación bajo condiciones poco energéticas, fundamentalmente por decantación desde la zona pelágica, en muchos casos, procedente de supraflujos (algunos autores la denominan "lluvia" pelágica). Las partículas depositadas provienen de la decantación de los minerales carbonatados precipitados en la zona epilimnética de la columna de agua o bien de partículas siliciclásticas finas (o una mezcla de ambos).

Además, de manera ocasional existe cierto grado de aporte por fenómenos tales como turbiditas-infraflujos, interflujos y slumps (PHARO Y CARMACK, 1979; HALFMAN Y SCHOLZ, 1993; LAST, 1993a; CHEN et al., 2006b; MCCUlLOUGH Y BARBER, 2007; MCCULlOUGH et al., 2007).

Una vez que el sedimento se ha depositado, la resuspensión o erosión del mismo es difícil. De manera esporádica puede verse afectado durante grandes tormentas (HALFMAN et al., 2009), por eventos físicos anómalos tales como el hundimiento de barreras térmicas (WETZEL, 2001; WhitE y MiLLER, 2008), y/ o por secas internas (GLOOR et al., 1994; SHTEINMAN et al., 1997; HORPPILA Y NIEMISTÖ, 2008).

El contenido en carbonatos es menor que el de las zonas más someras. Las temperaturas más bajas y la descomposición de la materia orgánica favorecen la disolución parcial de los minerales carbonatados (DEAN Y GORHAM, 1976; MURPHY Y WILKINSON, 1980). En algunos casos inhibe totalmente su sedimentación. Sin embargo, algunos carbonatos litorales pueden ser redepositados en la región profunda. Una de las maneras más comunes es por corrientes de turbidez asociadas a slumping en los márgenes abruptos de ciertos lagos, como por ejemplo los lagos Fayettteville Green y Round (LUDLAM, 1974; DEANY FOUCH, 1983) o el lago Freefight (LAST, 1993a). Estos depósitos son fáciles de reconocer puesto que suelen exhibir un color, una textura y una granulometría diferente, así como restos de faunísticos propios de la zona litoral. Otra forma de sedimentación es por transporte de los carbonatos en suspensión hasta el centro del lago, para posteriormente ser depositados por decantación como sedimentos profundos, siendo más difíciles de reconocer en el registro sedimentario (DEAN Y FOUCH, 1983). Finalmente, el procedimiento menos común es por medio de interflujos (LAST, 1993a). 


\subsection{MODELO CONCEPTUAL DEL SISTEMA LACUSTRE}

Todo estudio paleogeolimnológico conlleva, ab inicio, un desconocimiento significativo del funcionamiento del medio lacustre a estudiar. Sin embargo, su comparación con medios actuales enclavados en un contexto similar (tectónico, climático, etc.) permitiría, en teoría, reconocer ciertas generalizaciones de los procesos aplicables al registro sedimentario.

La sedimentación acaecida en una cuenca queda delimitada por un complejo entramado de agentes de forzamiento auto- y/o alocíclicos, que en cada momento concreto producen una sedimentación característica. A grosso modo se puede afirmar que los factores que controlan el patrón de la sedimentación a gran escala en un medio fluvio-lacustre son (OLSEN, 1990; GLENN Y KELTS, 1991; SCHUMM, 1993; GIERLOWSKI-KORDESCH Y KELTS, 1994; SLADEN, 1997; CECIL et al., 2003; COHEN, 2003; ETHRIDGE Y SCHUMM, 2007):
a) El contexto tectónico.
b) El escenario climático.
c) El eustatismo y/o limnoeustatismo.
d) La cuenca de drenaje.
e) La morfometría del lago.
f) La hidrología.
g) La hidroquímica.
h) La hidrodinámica.
i) La biota.

Un análisis geolimnológico debe tener en consideración los múltiples acoplamientos y retroalimentaciones entre estos factores, así como el modo en que interactúan para interpretar el registro sedimentario observable en el campo. Así pues, en teoría, si se determinan o aproximan de modo riguroso, se podría obtener un fundamento básico de los procesos y mecanismos operantes más significativos que permitiesen el desarrollo de un modelo sedimentario preconcebido. Así, se podrían obtener unas pautas generales que faciliten su interpretación, las cuales deberán ser verificadas en el estudio de las asociaciones de facies a posteriori. En ciertos casos, esta aproximación permite por un lado, caracterizar dichos sistemas de manera más o menos unívoca. Por otro lado, permite determinar lo que no son, excluyendo en las interpretaciones posteriores los mecanismos sedimentarios poco o nada probables.

A pesar de la complejidad indicada, los factores que de manera más significativa y universal gobiernan la distribución y arquitectura de las facies sedimentarias en medios fluviolacustres son la tectónica, el clima y el eustatismo, restringiéndose al clima y la tectónica en cuencas continentales (LEEDER Y GAWTHORPE, 1987; LAMBIASE, 1990; OLSEN, 1990; GAWTHORPE et al., 1994; LAMBIASE Y BOSWORTH, 1995; SLADEN, 1997; NICHOLSYWATCHORN, 1998; GAWTHORPE Y LEEDER, 2000; WiTHJACK et al., 2002; NiCHOLS Y UTTAMO, 2005). Todos ellos están interrelacionados entre sí de manera compleja (HAY, 1996). De su combinación o derivados de su acción a distintas escalas temporales depende, en mayor o menor medida, el resto de factores que afectan a la dinámica sedimentaria. Esta incertidumbre se traslada a la documentación científica de tal manera quealgunos autores consideran la tectónica como el factor fundamental (LAMBIASE, 1990; LAMBIASE Y BOSWORTH, 1995) mientras que, por el contrario, otros asumen un predominio del clima (OlSEN, 1986; FROSTICK Y REID, 1989). Además, hay que considerar ciertos factores de control locales que causan una importante variabilidad en el tipo de sedimento.

Todas las combinaciones factibles entre los factores de forzamiento originan un espectro amplio de posibles ambientes lacustres y, en consecuencia, de asociaciones de facies que no pueden ser abarcados por el reducido número de modelos de facies existentes. A grandes rasgos, a pesar de la complejidad inherente, el estudio del registro fósil de sistemas lacustres no muestra tanta multiplicidad. Se ha observado una recurrencia de tres modelos en posiciones extremas que permiten caracterizar la mayoría de los rellenos en cubetas lacustres fósiles (CARROLL Y BOHACS, 1999; BOHACS et al., 2000) (figura 4.3). Cada tipología delago puede ser reconocida en el registro geológico (ya que utiliza parámetros que pueden ser reconocidos en las rocas) a partir de las secuencias estratigráficas preservadas en el relleno de la cuenca. Según estos autores, los factores 
de forzamiento esenciales que gobiernan la disposición de las secuencias lacustres son el balance entre la tasa del aporte de agua y sedimento (relacionados con el clima), y la potencial tasa de creación del espacio de acomodación (dependiente de la tectónica). La profundidad del agua constituye un tercer factor de forzamiento, si bien su importancia es menor ya que no controla los atributos básicos de los tipos de cuencas lacustres. No obstante, influye en otros caracteres más secundarios como el espesor de la secuencia, extensión, tipo de costa, etc. (BOHACS et al., 2000).

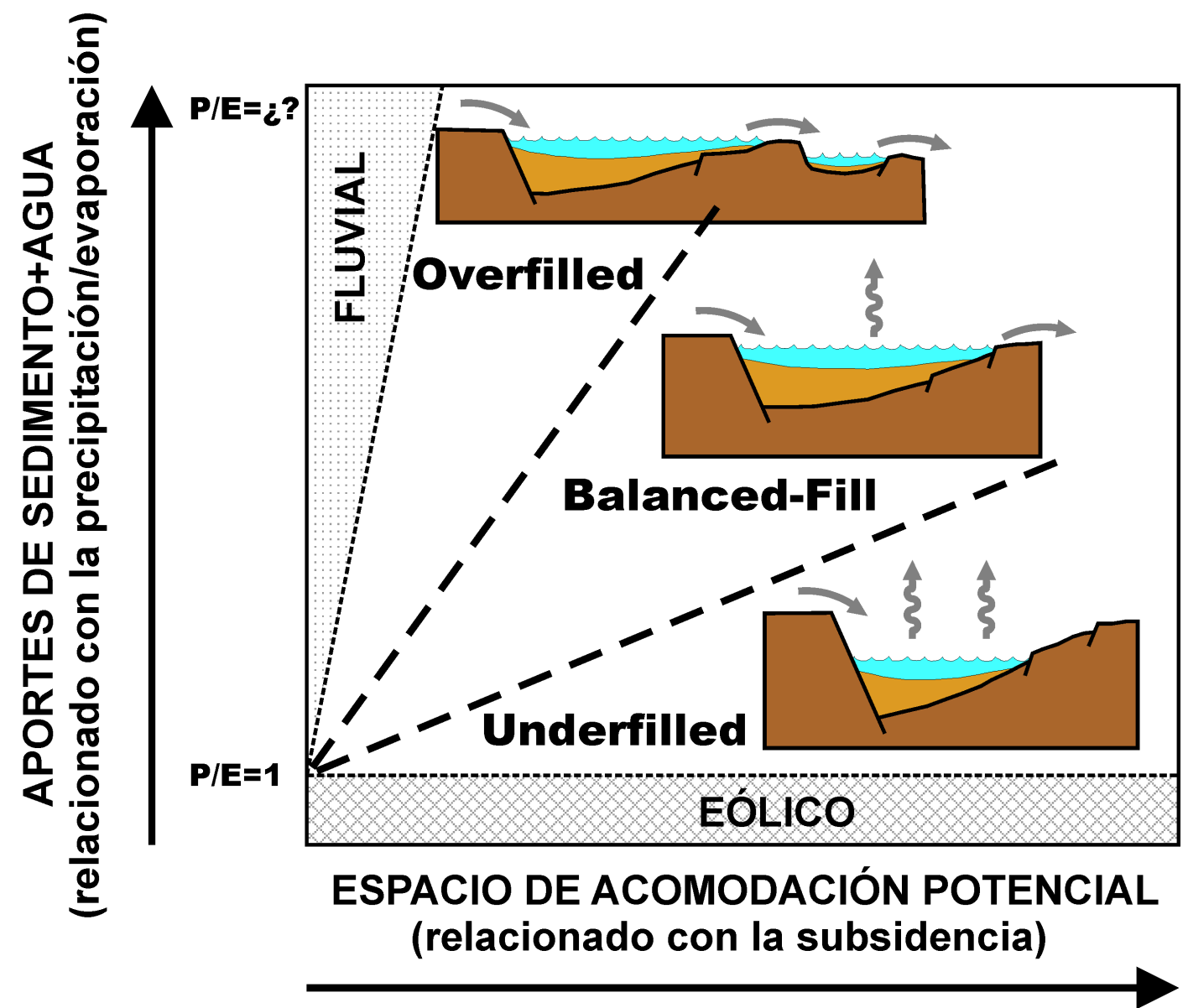

Figura 4.3: Diagrama con los tres tipos de cuencas lacustres en función del espacio de acomodación y la tasa de aportes de sedimento y agua. Modificado y redibujado de BOHACS et al. (2000). P/ E representa precipitación/ evaporación.

Las cuencas lacustres overfilled (figura 4.3) se originan cuando la tasa de aportes de sedimento y agua, en general, excede el espacio de acomodación disponible, bien sea porque la relación precipitación/ evaporación es muy alta o porque la tasa de subsidencia tectónica es baja:

a) Se produce un registro progradante con una influencia significativa de los aportes fluviales y deltaicos. Las secuencias deposicionales tienden a estar dominadas por asociaciones de facies fluvio-lacustres, que aparecen interestratificadas con facies fluviales o carbón. Es equivalente al complejo de facies lacustres tipo Richmond de OLSEN (1990). La parasecuencia está determinada, predominantemente, por la progradación de la línea de costa, así como por los fenómenos de avulsión tanto de deltas como de los canales fluviales.

b) Son típicas de sistemas hidrológicamente abiertos permanentemente o durante la mayor parte del tiempo de sedimentación. Las fluctuaciones del nivel del lago ocasionadas por el clima son mínimas. Suelen corresponder a lagos de agua dulce (someros o profundos) conectados a sistemas fluviales perennes. 
Las cuencas lacustres balanced-fill (figura 4.3) ocurren cuando el potencial de acomodación está equilibrado con el aporte de agua y sedimento. Durante la etapa de sedimentación de la secuencia:

a) Se origina un registro agradacional y progradante. La secuencia deposicional registra una combinación de la progradación de los siliciclásticos y de la agradación de los sedimentos químicos durantela desecación. La asociación de facies profunda domina el relleno sedimentario y aparecen ciclos de somerización. La entrada se sedimentos fluviales es posible. Corresponden al complejo de facies lacustres tipo Newark de OLSEN (1990).

b) Se producen en cuencas hidrológicamente mixtas, con etapas abiertas durante las fases de nivel alto de agua, y etapas cerradas durante las fases de bajo nivel del agua. Es habitual que sufran importantes fluctuaciones del nivel del lago forzadas por el clima.

Las cuencas lacustres underfilled (figura 4.3) se producen cuando el potencial de acomodación siempre supera a los aportes de agua y sedimento:

a) La disposición de la parasecuencia registra de manera predominante la agradación vertical de los depósitos evaporíticos debido a los ciclos de desecación. Son muy frecuentes las fluctuaciones del nivel del lago y los ciclos de inundación-desecación. Equivalen al complejo de facies lacustres tipo Fundy de OLSEN (1990). Como los lagos tienen una persistencia temporal reducida, las secuencias y parasecuencias son poco potentes (escala decimétrica). El relleno está formado por facies evaporíticas con una entrada fluvial mínima: depósitos de lagos efímeros o charcas salobres y lagos-playa interestratificados con sedimentos de lagos perennes.

b) Se forman en cuencas hidrológicamente cerradas permanentes, aunque pueden existir etapas abiertas poco significativas.

Las cuencas no marinas pueden evolucionar de un tipo a otro a diversas escalas temporales debido a modificaciones del clima y/ o de la subsidencia tectónica, según trayectorias verticales u horizontales en el diagrama (figura 4.3) (BOHACs et al., 2000).

\subsection{CONTEXTO TECTÓNICO}

La tectónica actúa a dos escalas espaciales diferenciables: a nivel de la cuenca de drenaje y/ o sedimentaria y, a una escala menor, dentro de la propia cubeta lacustre. Esta influencia tectónica puede quedar registrada en los sedimentos de manera evidente o, estar enmascarada debido a la interacción con otros factores de forzamiento auto- y/ o aloctocíclicos. A grandes rasgos regula:

a) El modelo de cuenca o del sistema.

b) El origen de la cubeta lacustre.

c) El relieve circundante (el levantamiento o hundimiento del área madre) que afecta a la tasa de producción de sedimento.

d) La pendiente o gradiente deposicional.

e) La tasa de subsidencia (espacio de acomodación).

f) Los parámetros morfométricos de la cubeta lacustre (que se analizan con más detalle en un apartado posterior).

g) El desplazamiento de umbrales en zonas de desagüe.

h) El patrón de drenaje.

i) Los aportes de agua y sedimento.

A escala de la cuenca, la evolución tectónica pre- y sinsedimentaria controla la formación, geometría y estilo tectónico de la cuenca sedimentaria, influyendo de manera importante en la sedimentación (acumulación, distribución, naturaleza, etc.) y en el mecanismo de subsidencia. 
Las cuencas sedimentarias se pueden clasificar en función de tres criterios: tipo de corteza sobre el cual se emplaza, posición de la cuenca respecto a los márgenes de las placas y, tipo de interacción entre el margen de placa y cuenca durante la sedimentación (MIALL, 2000). Aunque existen multitud de clasificaciones, bajo estas premisa se identifican cinco grandes categorías: cuencas ligadas a márgenes divergentes, cuencas ligadas a márgenes convergentes, cuencas ligadas a fallas transcurrentes y transformantes, cuencas desarrolladas durante colisión continental y, cuencas intraplaca (MIALL, 2000).

Por consideraciones de espacio y concisión, se hace especial hincapié en los sistemas tectónicos ligados a márgenes divergentes tipo rift. Esta decisión se ha tomado basándose en el contexto tectónico de la cuenca de Cameros (apartado 3.2).

Por último, se ha creído conveniente hacer ciertas consideraciones iniciales. Así por ejemplo, las cuencas rift son "depresiones de la corteza alongadas limitadas en uno o ambos extremos por fallas normales que involucran al basamento" (WITHJ ACK et al., 2002). Este tipo de cuencas no aparecen aisladas, sino que forman parte de estructuras más extensas denominadas sistemas rift. Un sistema rift se define como "colecciones de cuencas rift que se disponen escalonadas, entrecortándose y/ o paralelas entre sí" (WITHJ ACK et al., 2002).

Los sistemas rift son áreas favorables al establecimiento de lagos, tanto en extensión como en cantidad. Existen ejemplos destacables como la Depresión Nicaragüense (figura 4.4), aunque los paradigmas actuales son el Sistema Rift Africano Oriental (figura 4.5) y, en menor consideración, el Sistema Rift Baikal (figura 4.6):

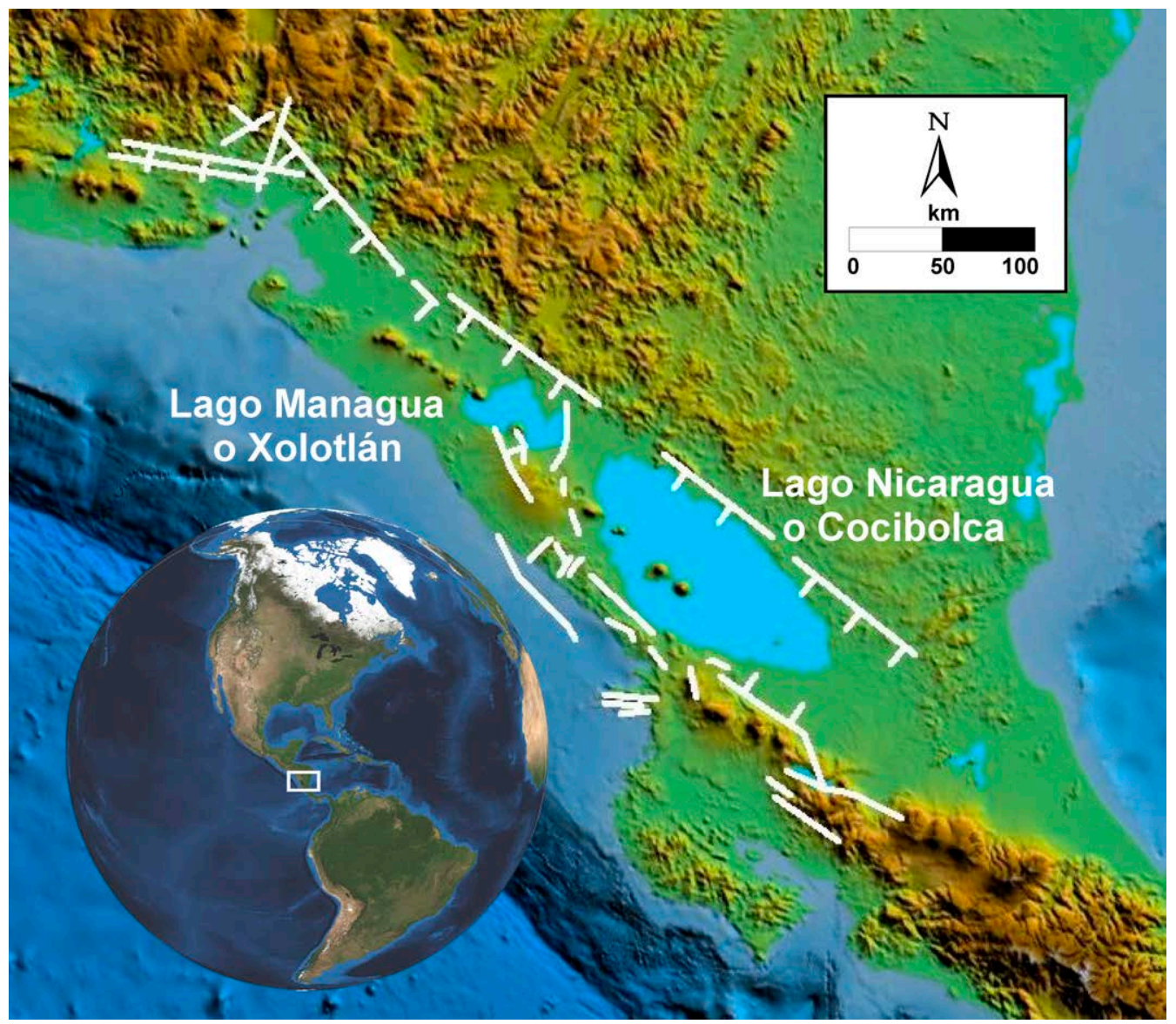

Figura 4.4: Modelo digital del terreno de la Depresión Nicaragüense (SRTM30) con indicación de los principales lagos (GLWD Global Lake Wetland Database). 


\section{Sistemas lacustres: estado del arte}

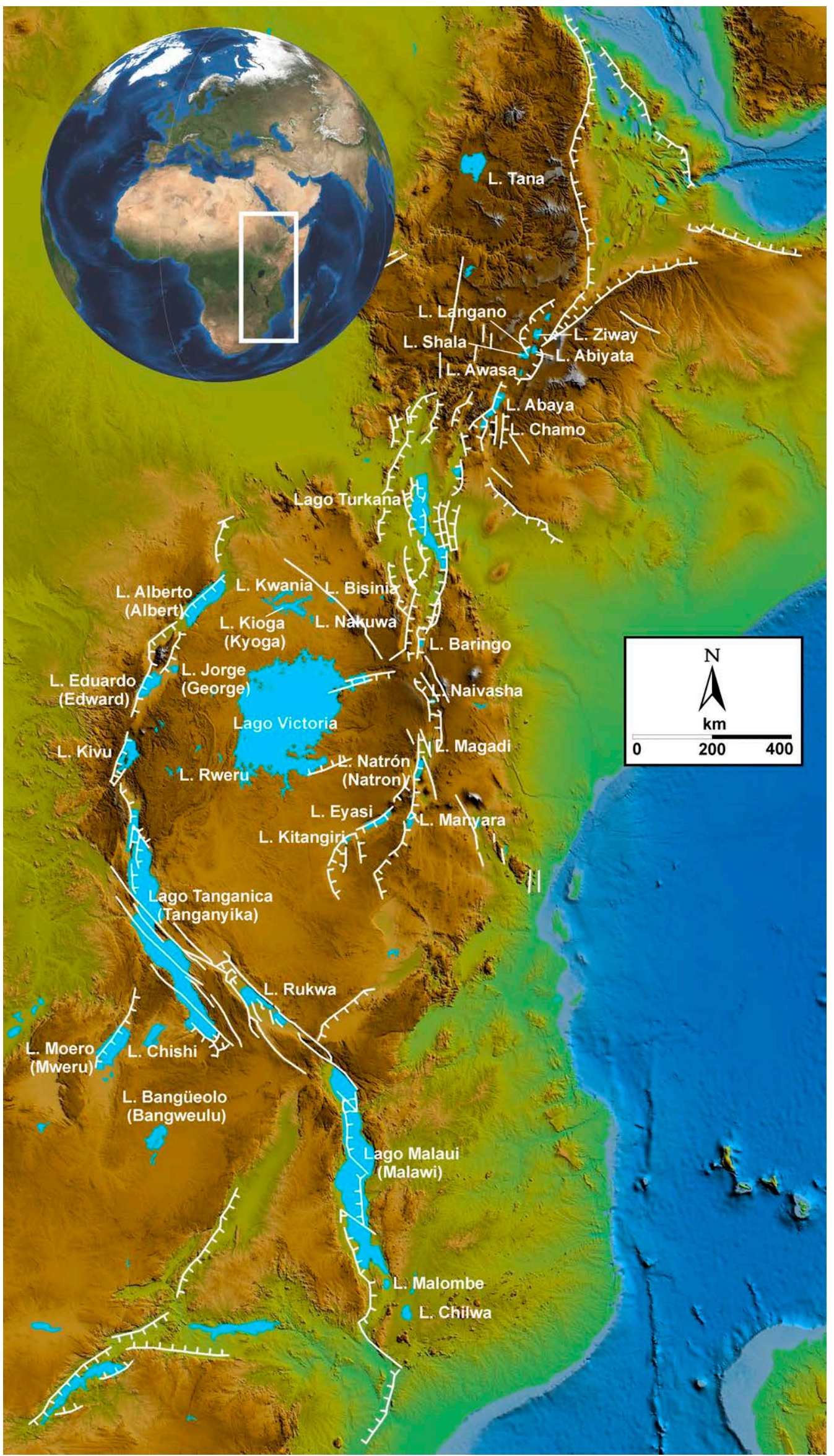

Figura 4.5: Modelo digital del terreno del Sistema Rift Africano Oriental (SRTM30) con indicación de los principales lagos (GLWD Global Lake Wetland Database). 


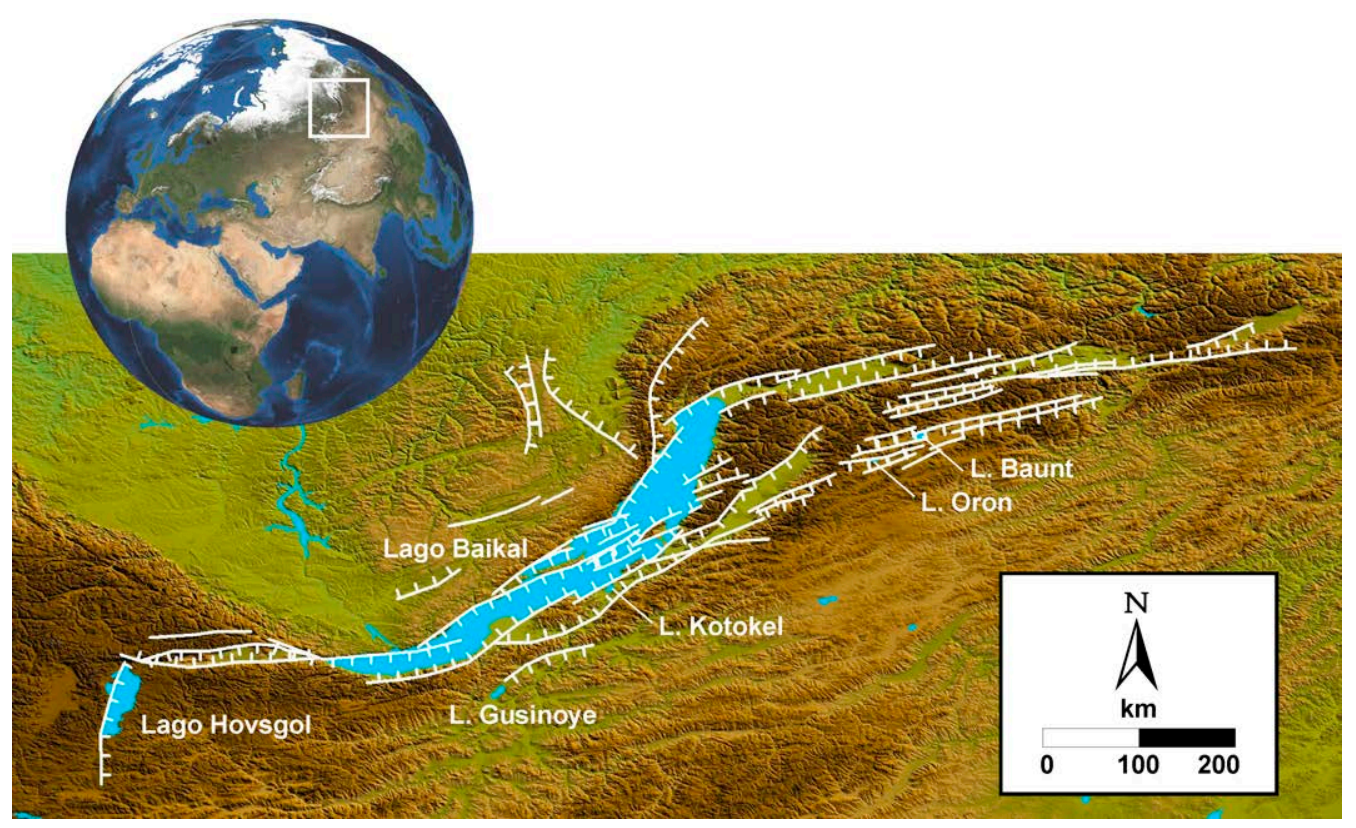

Figura 4.6: Modelo digital del terreno del Sistema Rift Baikal (SRTM30) con indicación de los principales lagos (GLWD Global Lake Wetland Database).

A nivel de la cubeta lacustre, muchas de las diferencias sedimentológicas entre lagos se pueden relacionar con el origen del lago, en conexión con los procesos formadores de la cubeta (COHEN, 2003). Los lagos se clasifican según su origen en: lagos glaciales y periglaciales, tectónicos, asociados a sistemas fluviales, costeros, volcánicos, formados por deflación (eólicos), cársticos o debidos a procesos de disolución, asociados a deslizamientos de laderas, por impacto meteórico y, formados por barreras de plantas o por la acción de animales (HUTCHINSON, 1957; COHEN, 2003; LÖFFLER, 2004). Los lagos tectónicos, a su vez, se clasifican igual que las cuencas sedimentarias vistas anteriormente (COHEN, 2003). La cubeta de un lago rift puede ocupar total o parcialmente una única cuenca rift o, en algunos casos, extenderse mucho más einundar varias cuencas. Aunque la categorización entre cuencas sedimentarias y lacustres pueda parecer una reiteración innecesaria, es oportuna ya que no siempre ambos orígenes coinciden, aunque lo normal es que así sea. Por ejemplo, dentro del Sistema Rift Africano Oriental (figura 4.5) existen lagos de origen volcánico como el lago Kivu (BRANSTRATOR, 2009), formados por inversión del drenaje fluvial como el lago Victoria y Kioga (BRANSTRATOR, 2009), o asociados a sistemas fluviales como el lago Moero (Bos et al., 2006).

Los lagos tectónicos tipo rift presentan numerosas características propias, que se comentan brevemente a continuación, tales como:

a) En la actualidad, el área ocupada por los lagos tectónicos ( $\approx 40 \%)$ es menor quela de los lagos glaciales, sin embargo, su elevada profundidad media hace que acumulen la mayor parte del volumen total de agua ( $\approx 75 \%$ ) (HERDENDORF, 1982; MEYBECK, 1995; COHEN, 2003).

b) La composición del sedimento está a menudo ligada a contextos estructurales específicos de la cubeta lacustre (SOREGHANY COHEN, 1996).

c) La tasa de acumulación de sedimento a largo plazo está controlada por el movimiento de las fallas y la subsidencia (COHEN, 2003).

d) Los lagos actuales en sistemas rift están gobernados por los mismos factores de forzamiento ya mencionados (tectónica y clima básicamente), aunque en ciertos sistemas el vulcanismo es muy importante (OWENY CROSSLEY, 1989; FROSTICKY REID, 1990; TIERCELIN, 1990; LETURDU et al., 1999).

e) La disposición cíclica de depósitos lacustres y fluviales es muy típica en este contexto tectónico (FROSTICK Y REID, 1989; LAMBIASE, 1990; SCHLISCHE Y OLSEN, 1990).

f) Están bien representados en el registro estratigráfico en comparación con otros tipos de lagos. En la vida de un lago, los procesos más trascendentales se relacionan con 
los fenómenos de somerización-profundización y la extensión del espejo del lago. Así, los eventos que favorecen la profundización y/o aumento del espejo del lago se consideran elementos rejuvenecedores. Por el contrario, los sucesos que promueven una somerización paulatina y/o disminución de la superficie aceleran la dinámica destructiva del lago. SCHÖN Y MARTENS (2004) consideran que "los lagos son esencialmente suicidas, ya que sus cubetas tienden a rellenarse por los aportes del sedimento". Esta afirmación implica que, debido a su dinámica, los lagos son elementos de vida corta a escala geológica salvo que existan procesos de rejuvenecimiento. Sin embargo, cuando están ubicados en un contexto rift se caracterizan por ser perdurables en el tiempo a escala de millones de años. El lago Baikal tiene una edad estimada de 11-25 Ma (CoLMAN et al., 2003). El lago Tanganica 9-12 Ma (COHEN et al., 1993), el lago Malui 5 Ma (SCHOLZ Y FINNEY, 1994), el lago Turkana 4,3 Ma (MCDOUGALL, 1985) y el lago Matano 2-4 Ma (RoY et al., 2007).

g) Los lagos rift longevos (más de $10^{6}$ años) exhiben un endemismo característico a nivel de especies. Este fenómeno es observable tanto en lagos actuales (COHEN, 1995; SCHÖN Y MARTENS, 2004; MATZINGER et al., 2007) como fósiles (GIERLOWSKIKORDESCH Y PARK, 2004).

h) Debido a su longevidad, el relleno sinrift presenta espesores muy potentes. El lago Baikal tiene espesores de 4,4-7,5 km (HUTCHINSON et al., 1992). El lago Malaui, según los autores, presenta potencias de más de 4,5 km (J OHNSONY NG'ANG'A, 1990) o entre 2,5-4 km (SPECHT Y ROSENDAHL, 1989). El lago Tanganica unos 4 km (COHEN et al., 1993).

i) Alta tasa de sedimentación lineal. Los lagos, en general, muestran una tasa comprendida entre 0,04-1 mm/año (J OHNSON, 1984; EINSELE, 1992), con un valor medio en torno a 0,7 mm/ año en el caso delagos tectónicos rift (HINDERER Y EINSELE, 2001). En el lago Chapala la sedimentación está comprendida entre $1-2 \mathrm{~mm} /$ año, aunque se incrementa hasta 3,5-5 mm/año en la zona con influencia deltaica (FERNEX et al., 2001). En el lago Turkana está entre 3-5 mm/año en los deltas y en el dominio profundo debido a la focalización del sedimento (J OHNSON et al., 1987). En el lago Tanganica los valores en áreas deltaica son del orden de 1,1-3,5 mm/ año (MCKEE et al., 2005), mientras que en el dominio profundo pasan a $0,1-0,2 \mathrm{~mm} /$ año (MCGLUE et al., 2008) y a 0,4-12 mm/año en zonas intermedias (ALIN Y COHEN, 2003). En el lago Malaui, la zona profunda anóxica tiene tasas de 1,5 mm/año (CROSSLEY Y OWEN, 1988; OWEN et al., 1990), 0,3-1,4 mm/año (FINNEY Y J OHNSON, 1991; PILSKALN Y J OHNSON, 1991), y 0,9-3,6 mm/ año (J OHNSON Y NG'ANG'A, 1990). Existen algunos ejemplos de lagos tectónicos con una tasa de sedimentación excepcionalmente alta: en el lago Naivasha, la zona central tiene una sedimentación de $10 \mathrm{~mm} /$ año, incrementándose hasta $30 \mathrm{~mm} /$ año en las zonas someras protegidas (TARRAS-WAHLBERG et al., 2002).

La subsidencia gobierna la creación y disposición del espacio de acomodación para la sedimentación (DE WET et al., 1998; CARROLL Y BOHACS, 1999; BOHACS et al., 2000). También afecta a la tasa de deposición así como al potencial de preservación de las facies en el registro sedimentario (PARRISH et al., 1993). A escala de la cuenca de drenaje, los movimientos tectónicos pueden ejercer un control importante levantando o hundiendo el terreno, y provocando modificaciones en el nivel de base o incluso una reorganización de la red fluvial. A nivel de la cubeta lacustre incrementa la capacidad de la cubeta atenuando los efectos colmatadores de la sedimentación. El equilibrio de ambos permite que no se produzca una modificación sustancial de la capacidad de la cubeta y favorece la acumulación de gran cantidad de sedimentos, que conlleva, a su vez, una subsidencia por compactación. Las cuencas rift activas muestran tasas de subsidencia de 100-300 mm/ka y los sags continentales de 10-20 mm/ ka (EINSELE, 1992).

A menor escala, la dinámica tectónica se manifiesta en terremotos. Es bien sabido que las zonas rifts muestran una elevada sismicidad (GANGOPADHYAY Y TALWANI, 2003; SCHULTE Y MOONEY, 2005), donde los grandes terremotos se producen con recurrencia (BEGIN et al., 2005). Como dato curioso, un reciente estudio afirma que, cerca de o en los entornos rifts, existe una probabilidad importante de que dichos terremotos vayan asociados a ciertos fenómenos luminosos aéreos denominados "luces de terremotos" (THÉRIAULT et al., 2014). Además de la 
sismicidad asociada al contexto rift, existe una sismicidad ligada con la propia presencia de la masa de agua (sistema lacustre). La construcción y llenado de una presa favorece la sismicidad en la región, ya sea incrementando la frecuencia de los mismos o, incluso, provocando terremotos en áreas que con anterioridad eran asísmicas. Estos son los denominados "terremotos inducidos por presas" (GUPTA et al., 1972; GUPTA, 2002). Un caso trágico fue el terremoto del 12 de Mayo del 2008 en Wenchuan (China) que causo la muerte a cerca de 90.000 personas, y pudo ser originado por el llenado de la presa de Zipingpu (GE et al., 2009).

En algunas ocasiones, los movimientos sísmicos afectan a la biota del lago. El terremoto en Agosto de 1912 en el lago Baikal, liberó gran cantidad de metano a sus aguas causando una muerte en masa de la fauna (RADZIMINOVICH et al., 2010). En otros casos, se especula con la formación de una capa de aguas desoxigenadas que modifica temporalmente el hábitat de los peces como en el lago Malaui (TWEDDLE Y CROSSLEY, 1991), o incluso provocando su muerte en masa en el lago Alberto (ECCLES, 1976).

La sacudida sísmica fomenta numerosos procesos gravitatorios del sedimento. Fuera de la cubeta lacustre, puede crear nuevos lagos por el embalsamiento ocasionado por la caída gravitacional (deslizamientos deladera y avalanchas derocas). Un ejemplo extremo es el ya citado terremoto del 12 de Mayo de 2008 en Wenchuan (China), que creó hasta 257 nuevos lagos (CuI et al., 2009). Dentro de la cubeta lacustre, modifican la sedimentación acontecida de múltiples maneras. Ocasionan la resedimentación de material en las partes más profundas del lago (DoIG, 1991). Son una causa frecuente de secas (BARBEROPOULOU, 2008): el gran terremoto de Alaska en 1964 causó secas en masas de agua repartidas a lo largo de todos los Estados Unidos (MCGARR Y VORHIS, 1968). También causan deslizamientos (SCHNELLMANN et al., 2002; 2004; GIBERT et al., 2005), que al producirse en condiciones subacuáticas, pueden originar grandes tsunamis (SCHNELLMANN et al., 2002). Estos fenómenos son reconocibles en el registro geológico ya que originan dos tipos de depósitos característicos: homogenitas (CHAPRON et al., 1999) y (seismo)turbiditas (MUTTI et al., 1984; INOUCHI et al., 1996).

El nivel del lago y su topografía también se ven afectados por los terremotos ya que pueden causar subsidencias instantáneas significativas. El terremoto del 17 de Agosto de 1959 originó un basculamiento de la cubeta del lago Hebgen (E.E.U.U.), hundiendo e inundando el margen norte $(\approx 6 \mathrm{~m})$ y emergiendo el margen sur (STEINBRUGGE Y CLOUD, 1962; MYERS Y HAMILTON, 1964). DUMONT (1992) comenta que un basculamiento del lago Moero-Bangüeolo provocó un incremento de la lámina de agua de unos 2 m. RuSs (1979; 1982) considera que durante los terremotos de 1811-1812 en el área de Nuevo Madrid (E.E.U.U.), el lago Reelfoot se extendió a consecuencia de la compactación inducida. El terremoto Tsagan que ocurrió el 12 de Enero de 1862, ocasionó el hundimiento y la inundación catastrófica de un área de $230 \mathrm{~km}^{2}$ cercana al delta de río Selenga. La subsidencia acontecida fue de unos $4 \mathrm{~m}$, alcanzando en algunas zonas hasta 9 m, y formó una nueva bahía (bahía Proval) en el lago Baikal (VOLOGiNA et al., 2010; SHCHETNIKOV et al., 2012).

Además, una actividad tectónica concretada en terremotos constituye un mecanismo causante de avulsiones y migraciones de la red fluvial (MORSE, 1941; COLEMAN, 1969; PEAKALL, 1998; HolbROOK y SCHUMM, 1999; PeAKAll et al., 2000). En el delta de Okavango, la red de drenaje del río cambia continuamente debido a los seísmos (DUMONT, 1992).

\subsection{ESCENARIO CLIMÁTICO}

El clima se define como el tiempo característico de una región, particularmente respecto a la temperatura y precipitación medida en un intervalo de tiempo significativo (NEUENDORF et al., 2005).

Los sistemas lacustres son especialmente sensibles al escenario climático en el cual se sitúan. Su respuesta a las variaciones de las condiciones climáticas es prácticamente inmediata, quedando registrada en los sedimentos depositados: de ahí su amplia utilización y reconocimiento como una herramienta trascendental en las reconstrucciones paleoclimáticas. Los depósitos sedimentarios lacustres localizados en cuencas rift son especialmente útiles en los estudios 
(paleo)climáticos tanto en lagos actuales (FELTON et al., 2007; MURAKAMI et al., 2010) como fósiles (OLSEN, 1986; OLSENY KENT, 1999). Es tal su influencia quelos lagos se pueden clasificar en función del clima en el cual están enclavados: lagos tropicales, templados (subárticos) y polares (árticos y antárticos) (AGRAWAL, 1999). De tal manera que, dos lagos de características idénticas situados en diferentes cinturones climáticos, presentan un comportamiento y una dinámica totalmente desigual, originando dos registros sedimentarios completamente distintos.

De manera general, se puede afirmar que las variables climáticas que mayor influencia ejercen sobre la sedimentación fluvio-lacustre son la temperatura, la pluviosidad y la estacionalidad de la precipitación (PARRISH et al., 1993). En el caso particular de los sistemas lacustres, el régimen de los vientos ejerce un control, en algunos casos, muy relevante. Sin embargo, no existe una correlación entre la humedad $\left(\frac{\text { precipitación }}{\text { evaporación }}=\frac{\mathrm{P}}{\mathrm{E}}\right)$ y los factores morfométricos de los lagos (tamaño, profundidad, volumen, etc.) tanto actuales como fósiles (CARROLL Y BOHACS, 1999; BOHACS et al., 2000), ni tampoco explica la salinidad (dulceacuícola a salino) o litología (siliciclástico versus carbonatado) de los lagos actuales. Por consiguiente, las asociaciones de facies en un sistema lacustre no pueden adscribirse de manera unívoca a un régimen climático (BOHACS et al., 2000; BOHACS et al., 2003).

El clima es uno de los factores más citados en la literatura, con una influencia determinante en la dinámica fluvio-lacustre afectando de manera directa o indirecta a (PARRISH et al., 1993; HASIOTIS et al., 2007):

a) La biota.

b) La tasa, extensión e intensidad de la meteorización fisicoquímica y, en consecuencia, a la tasa de erosión y/o transporte.

c) El balance hidrológico (aportes y salidas de agua).

d) La hidroquímica de las aguas continentales.

e) El modo de drenaje.

f) El patrón de circulación del lago, sobre todo en lo referente a los ciclos de estratificación térmica.

g) El hidroperíodo (permanencia de las aguas en la cubeta y patrón de llenadovaciado).

h) La cobertera vegetal.

i) El grado de desarrollo de los fenómenos pedogenéticos postdeposicionales.

j) Las características fisicoquímicas del agua (densidad, oxígeno disuelto, etc.), y a las reacciones que se dan en su seno o en la interfase agua-sedimento.

k) La estacionalidad del clima que afecta a los procesos de mezcla de la columna de agua.

l) La composición de los sedimentos y su textura, que afecta a la carga de fondo de los ríos y en consecuencia al estilo fluvial.

m) La deposición de sedimentos químicos.

n) La escorrentía superficial (ríos versus flujos no canalizados).

o) La hidrodinámica.

Todas estas características se describen con más detalle en los apartados posteriores de la presente tesis.

\subsection{LIMNOEUSTATISMO}

El término limnoeustasia hace referencia a las fluctuaciones del nivel de la columna de agua del lago a escala de toda la cubeta lacustre, definiendo la extensión y alcance de la superficie expuesta o inundada durante dichas perturbaciones (LEMONS Y CHAN, 1999).

Las fluctuaciones del nivel del lago están forzadas principalmente por cambios en el clima a escala regional o global, reflejando las variaciones entre el agua que entra (precipitación y escorrentía) y el agua que sale (desagüe y evaporación) tanto del lago como de su cuenca de drenaje. Sin embargo, a una escala menor, en muchos lagos de manera no perceptible por su escasa magnitud, existen otros mecanismos capaces de modificar el nivel del lago (MERCIER et al., 
2002): cambios de la temperatura o composición del agua (e.g. entrada de aguas geotérmicas), variaciones en la presión superficial, procesos en la circulación del agua, eventos originados por el viento (e.g. secas) y, mareas. Los efectos de las variaciones del nivel del agua afectan, sobre todo, al dominio litoral y dependen de la amplitud, sentido (inundación o desecación), frecuencia y duración de dicha fluctuación (GASITH Y GAFNY, 1990).

El hidroperíodo hace referencia a la duración (persistencia) y frecuencia (periodicidad) de la presencia de agua en la cubeta lacustre. Todos los lagos se localizan en algún término intermedio comprendido entre las masas de aguas efímeras (temporales) y perennes (permanentes). Los lagos temporales pueden ser salinos o de aguas dulces (aunque predominan los salinos con cambios de la salinidad muy pronunciados), y están muy influenciados por la precipitación. Estos sistemas temporales se catalogan en intermitentes o episódicos (WILLIAMS, 2000). Las masas de aguas intermitentes poseen agua durante una parte del año y muestran un patrón de llenado-secado predecible, frecuentemente conectado al régimen de lluvias. Por el contrario, los lagos episódicos están secos durante largos periodos de tiempo y su llenado se produce de manera impredecible. Son muy comunes en zonas áridas de Australia, como el lago Eyre (WILLIAMS Y KOKKINN, 1988), el lago Wyara (TIMMS, 1998a) o el lago Torrens (WILLIAMS et al., 1998). Desde el punto de vista sedimentológico, el hidroperíodo se puede calcular de manera aproximada a partir del índice de exposición (PlATT Y WRIGHT, 1992) (figura 4.7).

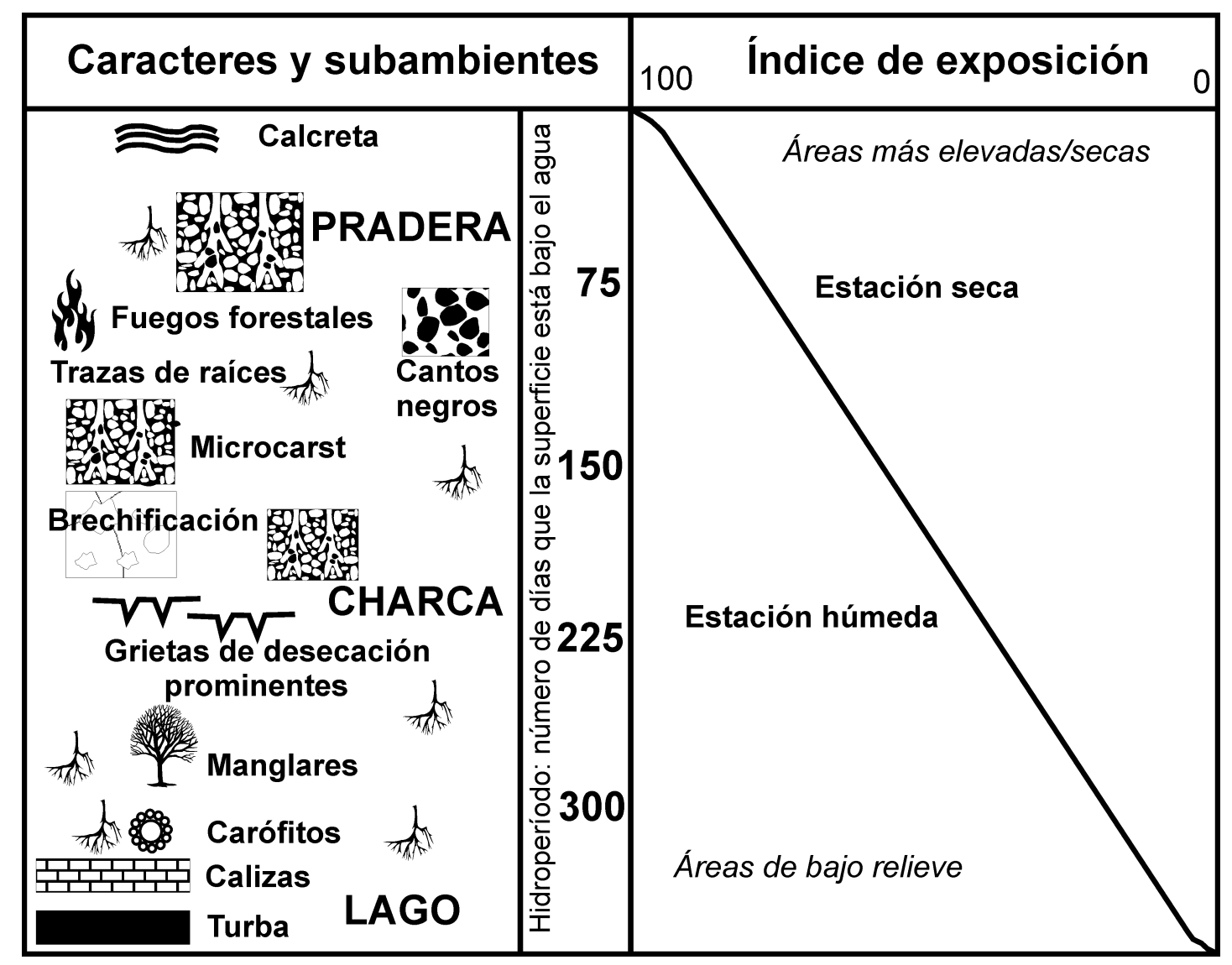

Figura 4.7: Índice de exposición e hidroperíodo. Modificado y redibujado de PLATT Y WRIGHT (1992).

Estas fluctuaciones del nivel del agua no sólo afecta a parámetros obvios como el área, volumen y profundidad del lago sino que su influencia se deja notar en la calidad del agua (GASITH Y GAFNY, 1990), biota (GASITH Y GAFNY, 1990), condiciones dinámicas del fondo (HÅKANSON et al., 2000) y, tasa de sedimentación (GIBSONY GUILLOT, 1997).

La profundidad de la cubeta influye en la permanencia de la masa de agua: a mayor profundidad, mayor será la inercia del sistema, aunque presente caídas importantes del nivel de agua. Sin embargo, uno de los aspectos fisiográficos más significativos es la pendiente de la cubeta 
lacustre que, a su vez, está muy influenciada por la tectónica (FROSTICK y REID, 1989). Los lagos con poca pendiente sufren mayores desplazamientos dela línea de costa debido a las fluctuaciones de la lámina de agua. El lago Chad se puede considerar un modelo paradigmático y, a la vez, un caso extremo: desde los años sesenta hasta la actualidad el área cubierta por sus aguas ha pasado de $23.000 \mathrm{~km}^{2}$ hasta $1.350 \mathrm{~km}^{2}$. Una caída de la lámina de agua de $3 \mathrm{~m}$ ha ocasionado una regresión de la línea de costa de unos $18 \mathrm{~km}$ (MOHLER et al., 1995). El lago Poopó (Bolivia) presenta una zona inundable de carácter temporal de unos $1.000 \mathrm{~km}^{2}$ (CARMOUZE et al., 1978). En el Sistema Rift Africano Oriental (figura 4.5) existen numerosos ejemplos. El lago Rukwa ha sufrido una recesión de la línea de costa de unos $7 \mathrm{~km}$ en los últimos 50 años (MUYUNGI, 2007) y, desde 1780 hasta 1840, estuvo completamente seco (DELVAUX et al., 1998). El lago Chilwa, de unos $700 \mathrm{~km}^{2}$ de superficie, sufre fluctuaciones periódicas y ocasionalmente se ha desecado totalmente (CANTRELL, 1988). El lago Malombe se secó casi completamente en 1924, para un año después volverse a llenar debido a las fuertes lluvias (HARA YJ UL-LARSEN, 2003).

La composición de la fauna está también influenciada por la persistencia del agua. La temporalidad de las aguas restringe la biota a aquellos organismos con adaptaciones que les permiten sobrevivir a los períodos secos, así como soportar amplias fluctuaciones ambientales. Por el contrario, en las aguas permanentes los organismos se adaptan a otros factores no relacionados con la persistencia del agua tales como la temperatura, salinidad, etc. Las fluctuaciones del nivel del lago tienden a causar una reducción en la abundancia y diversidad de especies de los invertebrados litorales, sobre todo los que tienen una movilidad reducida (GASITH Y GAFNY, 1990).

\subsection{GEOLOGÍA DE LA CUENCA DE DRENAJ E}

La geología de la cuenca de drenaje (o hidrográfica) engloba características geomorfológicas, tales como el relieve, la naturaleza litológica de la roca madre, la relación entre el área de la cubeta y la cuenca de drenaje, los aportes y la estructura (COHEN, 2003). Tiene una gran importancia en la sedimentación, así por ejemplo, a pesar de que los lagos Malombey Chiuta (figura 4.5) tienen el mismo forzamiento climático, las características individuales de cada cuenca originan una respuesta que muestra diferencias en la amplificación de dicha señal climática (DULANYA et al., 2013).

El relieve topográfico gobierna el régimen erosivo predominante en la cuenca (HINDERER Y EINSELE, 2002). En las cuencas rift, la zona de mayor relieve se localiza en el escarpe de falla del bloque levantado. Esta zona se caracteriza por un área de drenaje con mucho desnivel (hasta varios kilómetros) y poca extensión. El resto del bloque levantado se bascula hacia el exterior de la cuenca de drenaje, por lo que no se depositan sedimentos dentro de la cuenca (COHEN, 1990).

A grandes rasgos, la naturaleza de los sedimentos depositados en un lago es un claro reflejo de la litología presente en el área madre. Aunque este aspecto se desarrolla con más detalle en el apartado de la hidroquímica (apartado 4.11), influye en la química de sus aguas (la salinidad, alcalinidad y pH están directamente relacionados con la composición dela roca madre). También, acoplado con el clima, regula la tasa de aportes superficiales versus subterráneos (permeabilidad, porosidad y meteorización del terreno) (REID Y FROSTICK, 1986).

En cuencas con áreas madre que presentan litologias muy heterogéneas, los cambios entre etapas con sedimentación siliciclástica o carbonatada, tienen su origen en desplazamientos del área fuente. Son numerosos los ejemplos en los cuales una sutil actividad tectónica puede ejercer un control importante en la cuenca de drenaje (KOWALEWSKA Y COHEN, 1998; MAY et al., 1999; SÁEZ et al., 1999).

La presencia de un área madre carbonatada favorece la precipitación y deposición de sedimentos carbonatados sobre los siliciclásticos en los sistemas lacustres, de dos maneras:

a) Proporcionan aguas cargadas en iones $\mathrm{Ca}^{2+}$ (GIERLOWSKI-KORDESCH, 1998) y disminuyen el aporte de siliciclásticos (COHEN, 1989a), incrementando la precipitación de carbonatos en la cubeta lacustre. Los granitos suele suministrar 
aguas ricas en sílice disuelto con relaciones molares altas de $\mathrm{SiO}_{2} / \mathrm{HCO}_{3}^{-}$y bajas de $(\mathrm{Ca}+\mathrm{Mg}) / \mathrm{HCO}_{3}^{-}<0,5$. Por el contrario, la meteorización de rocas sedimentarias carbonatadas facilita aguas con poca sílice disuelta y relaciones molares extremadamente bajas de $\mathrm{SiO}_{2} / \mathrm{HCO}_{3}^{-}$y altas de $(\mathrm{Ca}+\mathrm{Mg}) / \mathrm{HCO}_{3}^{-}>0,5$ (YAN et al., 2002). En el lago Kelly (Canadá), los carbonatos se depositan únicamente en la zona de entrada de ríos que drenan el área madre carbonatada pérmica (RENAUT, 1990; FERRIS et al., 1997).

b) Entrada de carbonato clástico procedente del desmantelamiento y transporte de las rocas carbonatadas existentes en la cuenca de drenaje. Constituyen los denominados carbonatos alogénicos (J ONES Y BOWSER, 1978), alóctonos (DEAN Y FOUCH, 1983) o detríticos-clásticos (KELTS Y HSÜ, 1978). No son fáciles de reconocer en el registro geológico ya que sus texturas son fácilmente eliminadas por los procesos sinsedimentarios y diagenéticos tempranos (FREYTETY PLAZIAT, 1982; ARRIBAS, 1986; GIERLOWSKI-KORDESCH et al., 1991). Constituyen una proporción importante del total de los carbonatos sedimentados en lagos con áreas madres carbonatadas (MÜLLER, 1966; 1969; LAMBERT et al., 1976), o lagos de origen glacial con tillitas carbonatadas (TREESE Y WILKINSON, 1982; BROWN et al., 1992).

Otro aspecto interesante es la relación entre el área de la cuenca de drenaje (Adrenaje) y el

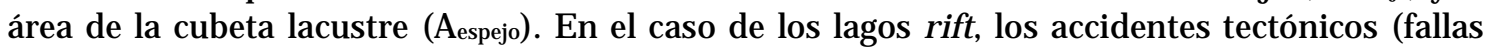
principalmente) que los delimitan tiene un mismo origen (orientación, características, etc.), por lo que la morfología de la cubeta lacustre se relaciona con la de la cuenca de drenaje. A partir del estudio de una población de 81 lagos rift (anexo I), 16 de ellos con dos valores del espejo máximo y mínimo (n=97), se ha obtenido una relación:

$$
\frac{A_{\text {drenaje }}}{A_{\text {espejo }}}=20,0 \pm 2,4 \leftrightarrow \ln \frac{A_{\text {drenaje }}}{A_{\text {espejo }}}=2,5 \pm 0,1
$$

El primer valor está un poco alejado de la estimación de 13 obtenido por HINDERER Y EINSELE (2001). Como la distribución de valores iniciales (Adrenaje Y Aespejo) no muestra normalidad, se han sometido a una transformación logarítmica. El ajuste lineal entre ambos queda de la forma (figura 4.8):

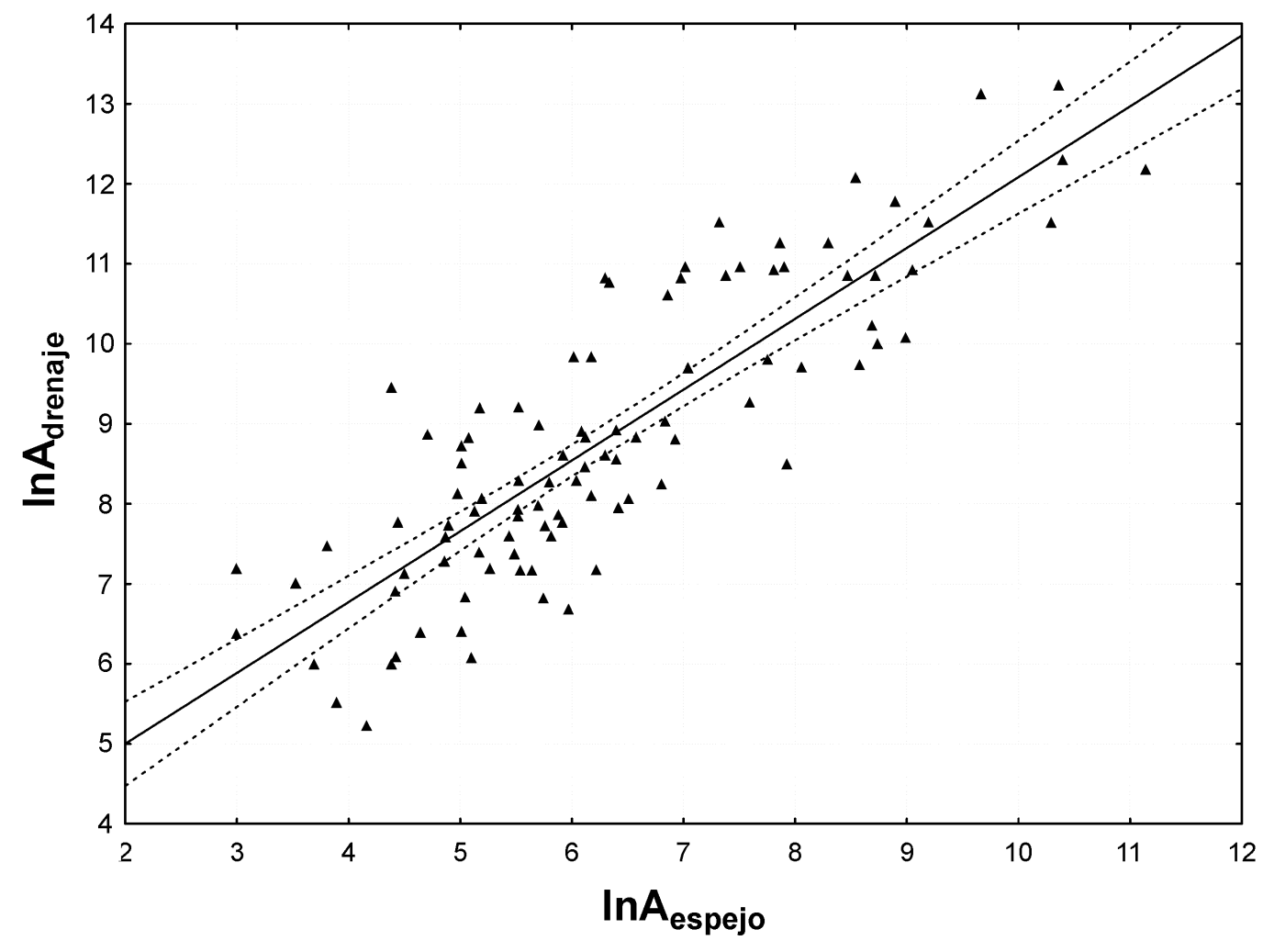


Figura 4.8: Ajuste obtenido entre el área de drenajey el espejo de la cubeta a partir de los datos de81lagos localizados en un contexto rift (anexo I). Las líneas discontinuas representan un nivel de confianza del 0,95.

$$
\ln \mathrm{A}_{\text {drenaje }}=3,2311+0,88528 \ln \mathrm{A}_{\text {espejo }}
$$

Los valores de las áreas ( $\mathrm{A}_{\text {drenaje }} \mathrm{y} \mathrm{A}_{\text {espejo }}$ ) están en $\mathrm{km}^{2}$, y el ajuste presenta una buena correlación $\left(r=0,84664 ; r^{2}=0,7168\right)$.

\subsection{CARACTERIZACIÓN MORFOMÉTRICA}

La morfometría cuantifica los elementos relacionados con la forma o parámetros morfométricos de la cubeta (o álveo) del lago. Es una práctica frecuente en los estudios limnológicos ya que conlleva implicaciones notables en su dinámica. Desde una perspectiva (paleo)geolimnológica, esta información es útil para conjeturar sobre los fenómenos que afectan a la sedimentación (HÅKANSON, 1977; 1981b). Estos parámetros morfológicos ejercen un papel trascendental en numerosas propiedades físicas, químicas y biológicas del sistema lacustre. Los lagos pueden exhibir diferentes morfologías a lo largo de su vida como consecuencia de las fluctuaciones de la columna de agua, perturbaciones en el suministro hídrico o del sedimento, control tectónico, etc.

\subsection{1Área superficial}

El área superficial hace referencia a la superficie del espejo del lago, estando directamente relacionado con el alcance. El alcance se define como la distancia de una masa de agua, lago u océano, uniformemente afectada en dirección y fuerza por el viento (HÅKANSON, 1977). Demanera aislada o conjunta, constituyen dos de los parámetros morfométricos más importantes, y se utilizan para calcular los efectos potenciales del viento sobre el lago, tales como:

a) La profundidad de la termoclina (KLING, 1988; FEE et al., 1996; J OHANSSON et al., 2007).

b) La sedimentación y las condiciones dinámicas del fondo (HÅKANSON, 1977; RowAN et al., 1992; J OHANSSON et al., 2007).

c) La resuspensión (HAMILTONY MiTCHELL, 1996; 1997).

d) La concentración de materia particulada en suspensión (LINDSTRÖM et al., 1999).

\subsubsection{Profundidad}

La profundidad del lago constituye otro parámetro muy importante, no sólo por su implicación en la propia definición de lago, sino también por su influencia sobre aspectos tales como la sedimentación (LARSEN Y MACDONALD, 1993; LARSEN et al., 1998), el oleaje (KOMAR, 1998), o la productividad (RAWSON, 1952; 1955; FEE, 1979). Sin embargo, la profundidad no es un parámetro constante, ya que fluctúa según diversas escalas temporales (HOFMANN et al., 2008). Así por ejemplo, en el lago Baringo, la profundidad del lago ha pasado de unos 9 metros a mediados de la década de los años setenta a unos 2 metros en la actualidad (ILEC, 2007).

Los lagos someros (rasos) constituyen un estadio intermedio del gradiente batimétrico continuo comprendido entre un lago y un humedal. De ahí, su dificultad a la hora de establecer unos valores límites de discriminación. Aunque la determinación de un lago somero en función de su profundidad presenta graves inconvenientes (PADISÁK Y REYNOLDS, 2003), la comunidad científica acepta que los lagos someros se caracterizan por tener una profundidad media menor de 3 metros (MOsS et al., 1994; SCHEFFER, 2004). Sin embargo, esta profundidad característica es variable y arbitraria según otros investigadores, de tal manera que se pueden encontrar valores límites de 10 m (HigLER Y STATZNER, 1988) o de 8-10 m (CASADO DE OTAOLA Y MONTES DEL OLMO, 1995), mientras que para los lagos tropicales se considera que la profundidad límite es $5 \mathrm{~m}$ (TALLING, 2001). Otro criterio propuesto para la caracterización de una masa de agua como somera es la ausencia de estratificación térmica (Moss et al., 1994). El problema que conlleva este criterio es que el establecimiento de la estratificación es un mecanismo complejo, que depende de 
muchos factores (clima, morfología, vientos, etc.) y muestra poca correlación con la profundidad. Bajo esta perspectiva se puede llegar al absurdo de afirmar que el lago Balatón (Hungría), con una profundidad media de 3,2 m y sin estratificación (LUETTICH et al., 1990), sería somero; mientras que el lago Óhalász (Hungría) con una profundidad media de 2,8 m y estratificado (TESZÁRNÉNAGY et al., 2003), debería ser considerado como un lago profundo.

La someridad en un sistema lacustre conlleva unas consecuencias y comportamientos característicos:

a) Una resuspensión continua del material fino (HILTON, 1985), ya sea por la acción de las olas rompientes (NIXON, 1988) o por la tensión de corte transmitida por el oleaje (Bloesch, 1995). Por tanto, sus aguas contienen gran cantidad de material en suspensión y en disolución. La focalización del sedimento (sediment focussing) es un mecanismo importante para que este material sea finalmente depositado en las áreas más profundas.

b) Una relación elevada entre la superficie del espejo en relación al volumen de la masa de agua.

c) Una gran sensibilidad ante cualquier modificación en el balance hidrológico, precipitación y escorrentía principalmente (TALLING, 2001).

d) El escaso volumen de agua no permite mantener el calor residual en sus aguas por lo cual, la diferencia de temperatura es una causa frecuente en la creación de diferencias de densidad en la columna de agua (TALLING, 2001).

e) Gran desarrollo del dominio litoral abarcando gran parte de la extensión de la cubeta lacustre. Además, muestra una ausencia total o un escaso desarrollo del dominio profundo.

Los lagos profundos se caracterizan por un predominio del dominio profundo sobre el dominio litoral. Así pues, desde un punto de vista sedimentológico, un lago profundo se caracterizaría por una preponderancia de facies típicas del dominio abierto (deposición en un medio de poca energía, anoxia, ausencia de bioturbación, etc.) respecto a las facies litorales. Sin embargo, muchos lagos profundos con una cubeta tipo semigraben poseen, en el lado menos basculado, extensas áreas protegidas (bahías) o zonas de poca pendiente que se comportan como lagos someros desde el punto de vista sedimentológico.

\subsubsection{Pendiente o gradiente topográfico}

La pendiente de la cubeta lacustre es otro parámetro morfométrico que influye en numerosos procesos, tales como:

a) La limnoeustasia (apartado 4.7).

b) La dinámica del oleaje.

c) La distribución de los sedimentos.

d) La extensión y desarrollo de los dominios lacustres.

e) La biota.

La pendiente influye en la extensión superficial de las áreas sometidas a la acción de las olas (HÅKANSON, 1981b; HÅKANSON, 1982), reduciendo la velocidad umbral de las partículas así como la estabilidad del sedimento e, incrementando la interacción del oleaje con el fondo del lago (RowAN et al., 1992).

El gradiente topográfico de la cubeta lacustre también modifica de manera significativa la distribución de los sedimentos en un lago (HÅKANSON, 1977; 1981b; ROWAN et al., 1992), la zona de acumulación del sedimento (BLAIS Y KALFF, 1995), la composición de las arenas depositadas (SOREGHAN Y COHEN, 1993; 1996), y la arquitectura de los deltas (SCHOLZ Y ROSENDAHL, 1990; SCHOLZ et al., 1990a; LEMONS Y CHAN, 1999). Las pendientes mayores de 4-5o facilitan la formación de corrientes turbidíticas que transportan sedimentos a la zona profunda (HÅKANSON, 1977; 1981b; HÅKANSON, 1982). Por el contrario, pendientes menores del 3\% tienen efectos 
mínimos o prácticamente nulos en la distribución del sedimento, mientras que los sedimentos finos son escasos en pendientes mayores del 10\% (RowAN et al., 1992).

La distribución de los dominios está también afectada por la pendiente. Así, el dominio litoral puede estar ausente o ser mínimo en lagos que exhiben grandes pendientes (por ejemplo los lagos instalados en cráteres volcánicos o lagos maar) o bien extenderse cientos de kilómetros en lagos de bajo gradiente (e.g. lago Poopó y Victoria). En general, los lagos someros de pendientes suaves poseen una extensa banda litoral.

La pendiente asimismo afecta a la biota influyendo en la presencia de macrófitos (DUARTE y KALFF, 1986) y de fauna zoobentónica (RASMUSSENY KALFF, 1987; RASMUSSEN, 1988).

Los lagos tectónicos con pendientes suaves suelen instalarse en dos tipos de estructuras. En primer lugar, los lagos en cuencas tipo sag como el lago Chad (SERVANT, 1983), Mar Caspio (OvEREEM et al., 2003), o lago Victoria (TALBOT Y LÆRDAL, 2000). En segundo lugar, los lagos rift con cubetas de morfología semigraben que presentan diferentes pendientes según estén adosados al escarpe de falla o no. En estos lagos existe un lado de pendientes suaves que recibe diferentes denominaciones según los autores consultados: margen flexural (SCHOLZ, 1995a) o margen en rampa o plataforma (COHEN, 1990; SCHOLZY ROSENDAHL, 1990).

Los lagos con poca pendiente muestran una elevada relación entre su superficie respecto al volumen de sus aguas, lo cual implica que sean sistemas muy dinámicos. Reaccionan rápidamente frente a pequeñas fluctuaciones de cualquier factor que modifique su régimen hidrológico: el Lago Victoria frente a las precipitaciones (YIN Y NICHOLSON, 2002; AWANGE et al., 2008). Este dinamismo se concreta en marcadas oscilaciones del nivel de la lámina de agua y, en sus patrones de vaciado-llenado. Asimismo, los organismos que habitan estos lagos se deben adaptar a la variabilidad de dichas fluctuaciones de la lámina de agua.

\subsection{HIDROLOGÍA DEL LAGO}

Las condiciones hidrológicas del lago gobiernan tanto la naturaleza y disposición de las facies sedimentarias, como el patrón delas secuencias en la vertical. Así pues, su importancia hace que deban ser consideradas en cualquier estudio de secuencias lacustres antiguas (GORE, 1988a; b; 1989).

Los dos aspectos más relevantes de esta componente hidrológica, discernibles en el registro estratigráfico, hacen referencia al modo de abastecimiento y al estilo de drenaje.

\subsubsection{Modo de abastecimiento}

El abastecimiento de agua en los lagos se produce por aguas subterráneas (hipogénico) y/o por aguas superficiales (epigénico). Los sistemas epigénicos se alimentan de los aportes superficiales procedentes del agua meteórica (lluvia, nieve, hielo, niebla), agua de escorrentía (ríos, arroyadas o flujos vadosos) y/ o agua de mar (mareas o tempestades ocasionales). Lo normal es que un determinado sistema lacustre se alimente tanto de aportes superficiales como subterráneos, en muchos casos, no mostrando un evidente predominio de una u otra fuente (mixtos). Sin embargo, algunos sistemas lacustres, que en circunstancias habituales son mixtos, pueden comportarse temporalmente como hipogénicos o epigénicos en escenarios o bajo condiciones especiales.

Los lagos (sub)tropicales suelen presentar una componente epigénica muy elevada debido a numerosos factores:

a) Un clima caracterizado por abundantes precipitaciones.

b) Los lagos asociados a ríos son los más abundantes, así pues, la hidrología fluvial está muy relacionada con la hidrología lacustre (LEWIS, 2000).

c) La escorrentía constituye aproximadamente un $60 \%$ de la precipitación en zonas tropicales húmedas actuales (LEWIS et al., 1995; LEWIS, 2008). 
El abastecimiento por aguas subterráneas puede ser muy importante en la regulación de los niveles del lago. Minimizan las fluctuaciones estacionales de entrada de agua, aunque, son sensibles a cambios a largo plazo en la precipitación y evaporación. En general, los lagos situados en zonas topográficamente deprimidas son más propensos a recibir entradas de aguas subterráneas (WINTER, 2004).

Aunque no existe una metodología axiomática capaz de diferenciar en el registro sedimentario entre ambos tipos de abastecimiento, existen algunas claves que permiten intuir o hacerse una idea del tipo de abastecimiento del sistema lacustre objeto de estudio.

a) En un reciente estudio sobre la Formación Morrison (E.E.U.U.), se ha sugerido que la ausencia o escasez de depósitos deltaicos y costeros podría indicar un predominio del aporte hipogénico sobre el epigénico (DUNAGAN Y TURNER, 2004). Sin embargo, en la actualidad, el Lago Victoria no presenta evidencias de canales o deltas en los perfiles sísmicos (STAGER Y J OHNSON, 2008) y su modo de abastecimiento no es hipogénico, más bien se trata de un lago pluvial que recibe el $80 \%$ de su abastecimiento por precipitación directa sobre la superficie del lago (AWANGE et al., 2008).

b) El dominio profundo lacustre suele estar constituido por sedimentos finos con abundante materia orgánica. Estos materiales son poco permeables y dificultan los aportes hipogénicos en esta zona. Por el contrario, el dominio litoral es más heterogéneo, con menos depósitos finos, y se favorecen los intercambios con las aguas subterráneas (WINTER, 2004).

c) La falta de covarianza entre $\delta^{18} \mathrm{O}$ y $\delta^{13} \mathrm{C}$ ha sido interpretada por algunos autores como indicador válido de entrada de aguas subterráneas (QUADE et al., 1995; DUNAGANY TURNER, 2004).

d) La ausencia de minerales evaporíticos en un lago con grandes fluctuaciones de la lámina de agua es un indicio de la existencia de una componente importante en los aportes subterráneos (WOOD Y SANFORD, 1990; SANFORD Y WOOD, 1991).

\subsubsection{Modo de drenaje}

El modo de drenaje del lago controla de manera relevante la naturaleza, disposición, y desarrollo de las facies sedimentarias encontradas en el registro sedimentario (EUGSTER Y KELTS, 1983; GORE, 1989; PLATT Y WRIGHT, 1991). Según el drenaje que presentan, los sistemas lacustres se categorizan en lagos (hidrológicamente) abiertos y lagos (hidrológicamente) cerrados.

Los lagos (hidrológicamente) abiertos, o de drenaje abierto, poseen uno o varios conductos de desagüe (emisarios) y se localizan en cuencas exorreicas. El balance hidrológico del lago está en equilibrio igualando la entrada de aguas (precipitación, escorrentía, y recarga subterránea) y la salida de aguas (evaporación, infiltración, desagüe). Los lagos (hidrológicamente) cerrados no tienen emisarios, así pues, la descarga se produce exclusivamente por medio de la evaporación y la infiltración. Se sitúan en cuencas endorreicas o arreicas. La presencia o ausencia de un aliviadero (vertedero de aguas sobrantes) determina la extensión hasta la cual puede fluctuar el nivel del lago en una cubeta (COHEN, 2003).

Esta categorización sencilla puede complicarse. Un caso típico son los lagos (abiertos o cerrados) con morfometrías complejas, es decir, constituidos por varias subcubetas separadas por altos topográficos. Cuando se produce una caída importante en la lámina de agua, el lago se compartimenta en varias cubetas independientes, alguna de las cuales puede comportarse como un lago abierto y otras como un lago cerrado. Un ejemplo es el Gran Lago Salado de Utah (SPENCER et al., 1984; KELTS, 1988). Así pues, ante un mismo fenómeno (variación del nivel del lago), un sistema lacustre podría mostrar registros sedimentarios completamente opuestos en diferentes zonas de la cubeta. Otro ejemplo más raro es el lago Ichkeul, donde el río Tindja se comporta como un emisario durante la estación lluviosa y, como un afluente en la estación seca (LÖFFLER, 2004). 
En los lagos abiertos, tanto la lámina de agua (área superficial y profundidad) como la línea de costa permanecen casi constantes en el transcurso del tiempo (EUGSTER Y KELTS, 1983; KELTS, 1988; PLATT Y WRIGHT, 1991). De tal forma que si se produce un incremento en la entrada de agua, ésta es compensada con un aumento en la descarga por los desagües, y los niveles del lago permanecen significativamente constantes, aunque puede dar lugar a un incremento de las tasas de sedimentación (KEIGHLEY et al., 2003).

Los lagos abiertos se caracterizan por una ausencia generalizada de evaporitas y, generalmente, son de aguas dulces o tienen una salinidad baja, excepto en aquellos lagos alimentados por aguas subterráneas salinas (GORE, 1989; COHEN, 2003). Aunque hay que tener en cuenta que algunas evaporitas pueden formarse en ciertos subambientes aislados de lagos dulceacuícolas (EUGSTER Y HARDIE, 1978). Como presentan aguas diluidas y ratios Mg/ Ca bajos, suelen precipitar calcita de bajo contenido en magnesio (MÜLLER et al., 1972; EUGSTER Y KELTS, 1983), aunque la calcita con alto contenido en magnesio puede también aparecer (LAST, 1982; COHEN Y THOUIN, 1987). Dependiendo del tiempo de residencia, los sedimentos que entran pueden depositarse en la cubeta o bien ser evacuados junto con el agua por los desagües.

En los lagos cerrados, las fluctuaciones del balance hidrológico causan variaciones significativas espaciales y temporales: nivel del lago, espejo o superficie, límites entre dominios y tasas de acumulación del sedimento. Todo esto favorece que las líneas de costa puedan desplazarse de manera rápida y frecuente (EUGSTER Y KELTS, 1983; COHEN, 2003). La frecuencia de estas fluctuaciones del nivel del agua puede abarcar desde unos segundos hasta centenares de años. La amplitud de estas oscilaciones comprende desde unos pocos centímetros hasta centenares de metros (HOFMANN et al., 2008). Los depósitos característicos están constituidos por una mezcla compleja (sedimentos derivados de medios fluviales, sedimentos intracuencales retrabajados y depósitos bioquímicos y/ o químicos), que se dispone en secuencias sedimentarias transgresivas-regresivas. La intercalación frecuente entre depósitos lacustres y fluviales se considera una prueba incuestionable de un sistema hidrológicamente cerrado (endorreísmo). En consecuencia, el registro fósil de este tipo de cuencas lacustres se caracteriza por frecuentes y rápidos cambios de facies tanto lateral como verticalmente (EUGSTER Y KELTS, 1983). GORE (1989) admite que la presencia de evaporitas y de secuencias transgresivas-regresivas que a techo muestren superficies de exposición subaérea cerca del centro de la cuenca, son los mejores indicadores una cuenca cerrada. Los deltas experimentan notables cambios de su posición en respuesta a las oscilaciones del nivel del lago (KROONENBERG et al., 1997). Durante las épocas de nivel bajo, los depósitos previamente acumulados a lo largo de las zonas marginales pueden ser erosionados y depositados en las partes más profundas de la cubeta (COHEN, 2003). En un lago cerrado, la cubeta lacustre actúa como un sumidero para todos los sedimentos que entran. La agradación de este sedimento depositado en el lecho del lago desplaza hacia arriba la masa de agua existente, de tal forma que, durante periodos sin cambios en el aporte de agua se puede observar un incremento del nivel del lago (EINSELE Y HINDERER, 1997; EINSELE Y HINDERER, 1998). Los lagos cerrados pueden, a su vez, dividirse en tres categorías (YAN et al., 2002):

a) Lagos efímeros que fluctúan en intervalos de tiempo muy cortos debido a una intensa evaporación de la lámina de agua.

b) Lagos perennes que fluctúan en intervalos de tiempo mayores.

c) Lagos perennes de gran tamaño que pueden mantener un volumen de aguas más o menos constante.

Aparte de las consecuencias físicas por el cierre del lago, se producen también profundos cambios químicos y biológicos. El cierre hidrológico permite que la concentración iónica se incremente con el paso del tiempo, produciendo depósitos evaporíticos y de manera más indirecta, determinando la biota potencial afectando a la sedimentación (extensión de la bioturbación, concentración de lumaquelas, etc.) (COHEN, 2003). Por esta razón, suelen tener una salinidad elevada (WILLIAMS, 1998a), aunque no es una regla universal ya que existen multitud de lagos cerrados de aguas dulces: Chad (ROCHE, 1977), Naivasha (GAUDETY MELACK, 1981), Turkana (HALFMAN et al., 1989), etc. De hecho, el lago Notaza, considerado en la actualidad como uno de los lagos más diluidos del mundo, no presenta desagües permanentes (EILERS et al., 1990). 
VERSCHUREN et al. (2000) afirma que la fauna que habita un lago fluctuante muestra adaptaciones a un amplio rango de salinidades.

La covarianza entre los valores de $\delta^{18} \mathrm{O}$ y $\delta^{13} \mathrm{C}$ es muy común en lagos cerrados (TALBOT, 1990; TALBOT Y KeLTS, 1990; LI Y KU, 1997), aunque también se han descrito en lagos abiertos (DRUMMOND et al., 1995; COHEN et al., 1997).

A partir de las icnofaunas es posible, a grandes rasgos, discernir entre lagos cerrados y abiertos (BUATOIS Y MANGANO, 2004). Los lagos cerrados se caracterizan por una baja icnodiversidad que se asocia con estructuras sedimentarias indicadoras de exposición subaérea. Las trazas fósiles se restringen a los depósitos sedimentados durante etapas de estrés hidrológico bajo. Por el contrario, los lagos abiertos exhiben una icnofauna más diversa y abundante (BUATOIS Y MANGANO, 2004).

Las cuencas cerradas pueden comportarse como abiertas a resultas de las pérdidas por infiltración a los acuíferos subterráneos, afectando al cortejo de minerales precipitados (WOOD Y SANFORD, 1990; SANFORD Y WOOD, 1991). Es un mecanismo común que permite el escape de solutos y, favorecen el establecimiento de unas condiciones de equilibrio antes de alcanzar los niveles de concentración necesarios para la precipitación de ciertos minerales evaporíticos, que pueden, por tanto, no llegar a precipitar nunca. Cuando las condiciones de equilibrio ocurren, sólo precipitan los minerales que estén en equilibrio con la disolución en ese preciso momento. Así pues, según WOOD Y SANFORD (1990), la tasa de infiltración determina hasta donde llegará la salmuera en su evolución dentro de las rutas propuestas por HARDIE et al. (1978) y EUGSTER (1980).

Los cambios temporales en el régimen hidrológico conllevan una nueva dificultad: un lago, con una vida relativamente larga a escala geológica, puede fluctuar entre etapas abiertas y cerrada a lo largo de su historia evolutiva. Los principales ejemplos se encuentran en el Sistema Rift Africano Oriental (figura 4.5): lago Tanganica y Kivu (HABERYAN Y HECKY, 1987), Malaui (FINNEY Y J OHNSON, 1991) y Turkana (COHEN, 1981). Son el resultado de modificaciones en las condiciones climáticas, eventos tectónicos, cambios en el patrón de drenaje de los ríos que desaguan en la cubeta, etc. (GORE, 1989).

\subsection{HIDROQUÍMICA}

La hidroquímica hace referencia a los valores característicos de la salinidad o mineralización del agua, así como la variación espacio-temporal de la misma. Las aguas continentales (leníticas y lóticas) están dominadas por cuatro cationes (calcio, magnesio, sodio y potasio) y cuatro aniones (bicarbonato, carbonato, sulfato y cloruro). El resto de los elementos pueden estar presentes en forma no iónica (como la sílice) o iónica en cantidades tan pequeñas que tienen un efecto mínimo en la salinidad aunque sean importantes en ciertas reacciones biológicas (WETZEL, 2001).

La mineralización presente en las aguas continentales es muy variable. Inicialmente, las proporciones relativas de cada ión están gobernadas por las contribuciones procedentes de fuera de la cubeta:

a) La naturaleza litológica del área madre (cuenca de drenaje) o dominio de la roca (GIBBS, 1970; KILHAM, 1990; GIBBS, 1992). Afecta de manera directa a la composición química de las aguas de escorrentía y subterráneas (HARDIE et al., 1978; HEM, 1989), dejando su impronta tanto en los ríos (PETERS, 1984; BLUTH Y KUMP, 1994) como en los lagos (BRAKKE Y LORANGER, 1986; EILERS et al., 1992). Al fin y al cabo, debido a que el agua es un solvente universal, es lógico que la química de un cuerpo de agua refleje, en gran parte, la naturaleza geoquímica del terreno que lo contiene. Un ejemplo actual muy ilustrativo es el lago Bear (E.E.U.U.). Este lago siempre ha precipitado aragonito hasta que entre los años 1911 y 1918 se desvió parte del curso de río Bear a fin de utilizar el lago como un embalse. Como consecuencia de ello, en 
la actualidad el río Bear drena carbonatos paleozoicos y se ha producido un incremento significativo de la precipitación de calcita (DEAN et al., 2007).

b) Los aspectos climáticos que controlan la meteorización acontecida, principalmente la precipitación (cantidad y distribución) y, en menor medida, la temperatura en la cuenca hidrográfica (MEYBECK, 1983; HEM, 1989). En general, los lagos salados tienden a localizarse en zonas áridas mientras que los lagos de agua dulce abundan en zonas de gran pluviosidad. Sin embargo, esto no siempre es así: en zonas áridas de Australia existen numerosos lagos de aguas dulces (TIMMS, 2001) y, por el contrario, en áreas húmedas de Canadá son muy abundantes los lagos salinos (LAST, 1989a; 2002; LAST Y GINN, 2005). Uno de los procesos más importante de abastecimiento de iones a la cuenca lacustre es la precipitación atmosférica (GIBBS, 1970; KILHAM, 1990; GiBBS, 1992). La mayoría de los elementos atmosféricos tienen su fuente en los océanos, donde el oleaje rompiente en la orilla del mar facilita el paso de gran cantidad de sustancias a la atmósfera. Estas sales pueden ser transportadas grandes distancias tierra adentro aunque la mayoría cae con la lluvia en las regiones costeras. Esta influencia oceánica de la precipitación decrece con la distancia tierra adentro (continentalidad) hasta prácticamente desaparecer a unos $100 \mathrm{~km}$ de distancia. Sobre los océanos y en las regiones costeras, la composición de la precipitación es diferente que la del agua del mar (valores normalizados a Cl-). Los iones $\mathrm{Ca}^{2+}, \mathrm{SO}_{4}^{2+}, \mathrm{K}^{+}$y $\mathrm{HCO}_{3}^{-}$están enriquecidos, mientras que el $\mathrm{Mg}^{2+}$ y Na+ están casi en la misma proporción que en el agua marina (MEYBECK, 1983).

c) Las contribuciones atmosféricas mediante el viento (STUMM, 2004).

d) Los aportes marinos directos.

Posteriormente, los iones que han entrado en la cubeta lacustre sufren una serie de procesos fisicoquímicos y biológicos dentro dela columna de agua, como consecuencia delos altos tiempos de residencia (HEM, 1989). El tiempo de residencia en los lagos salinos es un factor de vital importancia en la composición química del sedimento precipitado (VERRECCHIA, 2008). Todos estos procesos modifican las proporciones iniciales, mediante mecanismos tales como:

a) La concentración delas especies disueltas a consecuencia de la evaporación (EUGSTER Y HARDIE, 1978; EUGSTER, 1980). En el registro geológico, un rango amplio en la variación de los valores $\delta^{18} \mathrm{O}$ se considera un indicador de la evaporación ocurrida en la masa de agua (TALBOT Y KELTS, 1990).

b) Las reacciones químicas relacionadas con procesos biológicos (HEM, 1989). En el caso concreto de los carbonatos existen dos mecanismos básicos. Primero, producción de carbonato procedente de restos de organismos: carbonatos biogénicos (DEAN Y FOUCH, 1983) o bioclásticos (KeLTS Y HSÜ, 1978). Los principales organismos acuáticos lacustres productores de carbonatos son zooplancton, ostrácodos, cocolitofóridos, fitoplancton (algunas algas clorofíceas), gasterópodos, bivalvos, huesos de oído interno de muchos peces, y oogonios de carófitas (KELTSY HSÜ, 1978). Segundo, la precipitación inorgánica de carbonato inducida por la actividad fotosintética de ciertos organismos: carbonatos bioinducidos (DEANY FOUCH, 1983). Ocurre a consecuencia de la utilización del $\mathrm{CO}_{2}$ y del bicarbonato durante la fotosíntesis por carófitas, fitoplancton y picoplancton (THOMPSON Y FERRIS, 1990; THIEL et al., 1997; THOMPSON et al., 1997; DiTTRICH et al., 2003).

c) La dinámica propia del lago (HEM, 1989).

d) La eliminación selectiva de las especies disueltas. Los principales procesos de eliminación selectiva comprenden la precipitación de minerales evaporíticos, la "meteorización inversa" de minerales arcillosos y la reducción del sulfato (YAN et al., 2002). La precipitación inorgánica de carbonato, inducida por procesos fisicoquímicos, disminuye la salinidad de las aguas: en el lago Powell en Arizona (E.E.U.U.) se calcula una pérdida de salinidad de 19-29 ppm por esta causa (REYNOLDS, 1978). Esta precipitación depende de multitud de factores: cambios notables de temperatura que afectan a la solubilidad de Ca y a la concentración de $\mathrm{CO}_{2}$, pérdidas mecánicas de $\mathrm{CO}_{2}$, y mezcla de aguas de diferente composición. La precipitación inducida por la temperatura es más intensa en la zona litoral de lagos con variaciones grandes diurnas y estacionales (TUCKER Y WRIGHT, 1990). La pérdida 
de $\mathrm{CO}_{2}$ a la atmósfera es un proceso tan lento que tiene poca o nula influencia, aunque, puede incrementase en zonas litorales agitadas por el oleaje (TUCKER Y WRIGHT, 1990). Sin embargo, a veces, la acción del oleaje puede inhibir su deposición como ocurre en el lago Pretty en los Estados Unidos (WETZEL, 1970). La mezcla de aguas ricas en $\mathrm{Ca}$ con aguas ricas en $\mathrm{CO}_{3}$ suele producir la deposición de carbonatos (WIGLEY Y PLUMMER, 1976; WHITICAR Y SUESS, 1998). Aunque hay que tener cuidado ya que la mezcla de soluciones de diferente composición química producen efectos no lineales, pudiendo darse el caso de que la mezcla de dos aguas saturadas con respecto a la calcita originen una mezcla no saturada, o viceversa (WIGLEY Y PLUMMER, 1976).

e) La infiltración no selectiva: la mayoría de los lagos experimentan pérdidas de solutos debido a este mecanismo (WOOD Y SANFORD, 1990; SANFORD Y WOOD, 1991).

Uno de los fenómenos naturales más espectaculares son los eventos whiting, en los cuales, tiene lugar una precipitación masiva de carbonato que dota de una apariencia lechosa a una gran extensión de las aguas epilimnéticas. Estos eventos son relativamente frecuentes en ambientes marinos someros. En medios lacustres se han citado en el lago Ontario (STRONG Y EADIE, 1978; HodELl et al., 1998), Erie (STRONG Y EADIE, 1978), Michigan (STRONG Y EADIE, 1978), Pyramid (Galat y J acobsen, 1985), Fayetteville Green (THOMPSON et al., 1997), Finger (LAJEWSKI et al., 2003), La Cruz (ROMERo-VIANA et al., 2008) y en el Mar Muerto (BlOCH et al., 1944). Se produce por un incremento en la temperatura de las aguas del lago que conlleva una disminución de la solubilidad del $\mathrm{CaCO}_{3} \mathrm{y}$, en menor medida, aunque también importante, la presencia de picoplancton que actúa aumentando el pH por fijación fotosintética del $\mathrm{HCO}_{3}{ }^{-} \mathrm{y}$, constituyendo puntos preferentes de nucleación para la cristalización de carbonato (STABEL, 1986; THOMPSON et al., 1997; HODELL et al., 1998).

En general, en una cubeta cerrada, la disminución del nivel de agua conlleva invariablemente un incremento de la salinidad, así como la sedimentación de un cortejo de minerales evaporíticos característicos (EUGSTER Y KELTS, 1983). Sin embargo, en algunas cubetas cerradas donde la tasa de infiltración es mayor que la tasa de evaporación, la salinidad del lago no se incrementa significativamente a medida que cae el nivel del agua (OSTERKAMP Y WOOD, 1987). Un caso curioso es el Lago Chad, que a pesar de ser un lago terminal con significativas fluctuaciones del nivel del agua y unas pérdidas por evaporación estimadas entre el 93-96\%, no muestra una gran mineralización (salinidad). Este lago presenta un control selectivo de la salinidad por medio de tres mecanismos: 1) "meteorización inversa", es decir, la precipitación química y bioquímica que convierte los solutos disueltos en partículas sólidas, reduciendo la salinidad dentro del lago, 2) infiltración no selectiva y, 3) eliminación de sales en las salinas que se forman en la zona litoral durante las fluctuaciones del nivel del lago (ROCHE, 1977; CARMOUZE, 1979; TALLING, 2001). Otros ejemplos de lagos someros cerrados con salinidad baja debido a una infiltración no selectiva son los lagos Awasa y Naivasha (TALLING, 2001).

\subsubsection{Salinidad}

En limnología, la salinidad se define como la concentración de todas las sales disueltas, es decir, la suma total de todas las concentraciones iónicas o composición iónica total. Como se comentó anteriormente, los principales iones presentes en la salinidad son: los cationes monovalentes $\mathrm{Na}^{+} \mathrm{y} \mathrm{K}+$, los cationes divalentes $\mathrm{Ca}^{2+} \mathrm{y} \mathrm{Mg}^{2+}$, y los aniones $\mathrm{Cl}^{-}, \mathrm{SO}_{4}^{2-}, \mathrm{HCO}_{3}^{-}$y CO${ }_{3}^{2-}$. El resto de elementos están presentes en cantidades tan pequeñas que no afectan a la salinidad aunque localmente pueden ser importantes $\mathrm{NO}_{3}^{-}$y $\mathrm{PO}_{4}^{2-}$.

A efectos de la presente tesis, la caracterización de la salinidad de las masas de aguas superficiales se hace de conformidad con los descriptores del sistema de Venecia (ANONYMOUS, 1958; The Venice System FOR the ClasSificAtion of MARINE WATERS ACCORDING TO SALINITY, 1958):

a) Limnética o agua dulce $(<0,5 \%$ o).

b) Oligohalino $(0,5 \%$ a $<5 \%$ o $)$.

c) Mesohalino $(5 \%$ a $<18 \%$ o $)$. 
d) Polihalino (18\% a $<30 \%$ o).

e) Euhalino (30\%o a $<40 \%$ ).

f) Hiperhalino $(>40 \%$ o).

A grandes rasgos, se puede distinguir entre la salinidad de las aguas continentales y la de las aguas marinas, con diferencias muy importantes entre ambas. Por un lado, las aguas marinas se caracterizan por una notable uniformidad tanto en su composición como en su concentración, aproximadamente un 34,72\%o según HAY et al. (2006). Por el contrario, en el extremo opuesto, las aguas continentales exhiben composiciones químicas más heterogéneas, así como unos rangos muy amplios en su concentración.

En relación con la composición iónica, las masas de aguas continentales se pueden catalogar como talásicas o atalásicas. Las aguas talásicas (o talasohalinas) presentan una composición parecida y/o derivada de la del mar, con un predominio de los iones $\mathrm{Na}^{+}$y Cl . Las aguas atalásicas (o atalasohalinas) son aguas con una composición diferente a la del mar que resulta de la disolución de depósitos de origen continental, y están dominadas por los cationes divalentes y los carbonatos (WILLIAMS Y SHERWOOD, 1994; WILLIAMS, 1998a).

Respecto a la concentración, las aguas continentales presentan unos rangos de salinidad comprendidos entre prácticamente $0 \%$ hasta más de $400 \%$. En la actualidad, algunas delas citas de las masas de aguas más salinas son el lago Patience en Canadá con 428\% (HAMMER Y PARKER, 1984; HAMMER, 1986) y el lago Rosa (Retba) en Senegal con aproximadamente 363\%o (BETTAREL et al., 2006; 2007). Uno de los ejemplos más curiosos es la charca Don J uan en la Antártida: con una salinidad de 338\% (HAMMER, 1986) fue descubierta durante un vuelo de reconocimiento al llamar la atención de los pilotos debido a que no estaba congelada, a pesar de que había una temperatura de $-24^{\circ} \mathrm{C}$ en el exterior (MEYER et al., 1962). Se ha estimado que puede permanecer sin congelarse con temperaturas por debajo de -50ㄷ (MARION, 1997). En el otro extremo del espectro se sitúan los lagos con aguas muy diluidas, puras, casi destiladas. El lago Notasha en E.E.U.U. presenta una salinidad de 1,3 $\mu \mathrm{S} / \mathrm{cm}(0,8 \%$ ) (EILERS et al., 1990). Esta extraordinaria diversidad se relaciona con la disparidad litológica del área madre, la composición de las aguas que entran y salen tanto superficiales como subterráneas, así como por las múltiples y variadas reacciones que tienen lugar en la columna de agua dentro de la cubeta lacustre.

Otra diferencia importante entre las aguas marinas y continentales hace referencia a la estabilidad temporal de la salinidad. La salinidad del mar es más o menos estable en el tiempo a corto plazo ya que a escala geológica su variación es significativa (LOWENSTEIN et al., 2003; BERNER, 2004; HAY et al., 2006). Por el contrario, ciertos sistemas lacustres pueden mostrar grandes fluctuaciones de salinidad en cortos espacios de tiempo. Existen diversos patrones en la fluctuación de la salinidad (WILLIAMS, 1998a; b). En los lagos permanentes de gran extensión, la salinidad puede ser más o menos constante durante períodos de tiempo largos y, cambiar en respuesta a modificaciones regionales del clima. Los lagos permanentes pequeños muestran fluctuaciones estacionales. Los lagos temporales intermitentes muestran oscilaciones significativas de carácter estacional, con un mínimo de salinidad después de la entrada de los afluentes y un máximo de salinidad poco antes de que el lago se seque, como el lago Eurack en Australia (WILLIAMS, 1984). Los lagos temporales episódicos muestran unas fluctuaciones más pronunciadas relacionadas con el patrón dellenado-secado (desde pocas semanas hasta un año) de la cubeta. Esta pauta es semejante a la descrita en los lagos intermitentes, sin embargo, en algunos casos la salinidad puede ser muy elevada inmediatamente después del llenado de la cubeta debido a la disolución de las costras de sales. Este fenómeno es muy común en muchos lagos australianos: la salinidad del lago Wyara (1987-1996) fluctuó desde2,8\% a 350\% (TIMMS, 1998b), el lago Torrens (1989-1990) entre <40\%o hasta >200\%o (WILLIAMS et al., 1998), y el lago Eyre (1984-1985) entre 25\%o hasta >270\%o (WILLIAMS Y KOKKINN, 1988).

Aparte de esta variación temporal, dentro de la propia cubeta lacustre puede existir una diferenciación espacial de la salinidad bien sea según un gradiente horizontal como en el lago Poopó de Bolivia (ILTIS, 1993) o el lago Niriz (o Neiriz) en Irán (LÖFFLER, 1981), o según un gradiente vertical sobre todo en etapas de meromixis. El lago Freefight (Canadá) presenta una diferencia de salinidad del 70\%o entre el mixo- y monimolimnion (LAST, 1993b). 
La salinidad es un factor importante que afecta a la biota existente, turbidez, patrón térmico, profundidad del epi- e hipolimnion y, a la capacidad para disolver oxígeno (WILLIAMS, 1998a; JEPPESEN et al., 2007). Como los cuatro últimos aspectos se tratan en posteriores apartados del presente capítulo, a continuación, sólo se va a describir su influencia en la biota.

Como se comentó anteriormente, uno de los factores abióticos que más influye en la estructura de las comunidades biológicas (composición, riqueza de especies y diversidad) es la salinidad del medio, ya que para muchos organismos acuáticos, la regulación de la concentración de los solutos es un proceso de importancia vital (WILLIAMS, 1998b). En el caso de lagos del pasado, la interpretación de la salinidad de los fósiles se realiza a partir de los requerimientos ecológicos de los organismos actuales emparentados y de las asociaciones de fósiles. El conocimiento de dichos requerimientos es fundamental tanto en cuanto permiten extraer una información valiosa desde el punto de vista de la paleosalinidad siempre que sean extrapolables a los organismos del pasado. Así pues, ciertos organismos poseen una gran utilidad como testimonios dela salinidad imperante en un momento dado o de las fluctuaciones experimentadas a lo largo del tiempo. La biota de los lagos con una salinidad moderada $(<10 \%$ o) está compuesta fundamentalmente por taxones dulceacuícolas halotolerantes. A medida que la salinidad aumenta, éstos desaparecen y son reemplazados por taxones típicos de aguas saladas (HAMMER, 1986).

\subsection{2 pH}

El rango devariación del pH en los lagos actuales es muy amplio. En un extremo se sitúan los lagos extremadamente alcalinos (básicos), con valores altos del pH, que suelen localizarse en cuencas cerradas. Los ejemplos más clásicos son los numerosos lagos salinos del Sistema Rift Africano Oriental con valores comprendidos entre 9,5-10,5 (TALLING Y TALLING, 1965; HECKY Y KILHAM, 1973). En el otro extremo se encuentran los lagos extremadamente ácidos que suelen ubicarse en regiones volcánicas o en el interior de cráteres volcánicos (VAREKAMP et al., 2000), destacando por su acidez el lago Yugama en J apón con un pH de 0,9-1,3 (OHBA et al., 2008). También, los lagos muy ricos en materia orgánica disuelta muestran un $\mathrm{pH}$ muy bajo (TALBOT Y ALLEN, 1996).

El pH de las aguas continentales está controlado, en gran medida, por la meteorización de la litología de la roca madre (BRAKKE Y LORANGER, 1986; BAILEY et al., 2005) y el intercambio de $\mathrm{CO}_{2}$ con la atmósfera (figura 4.9).

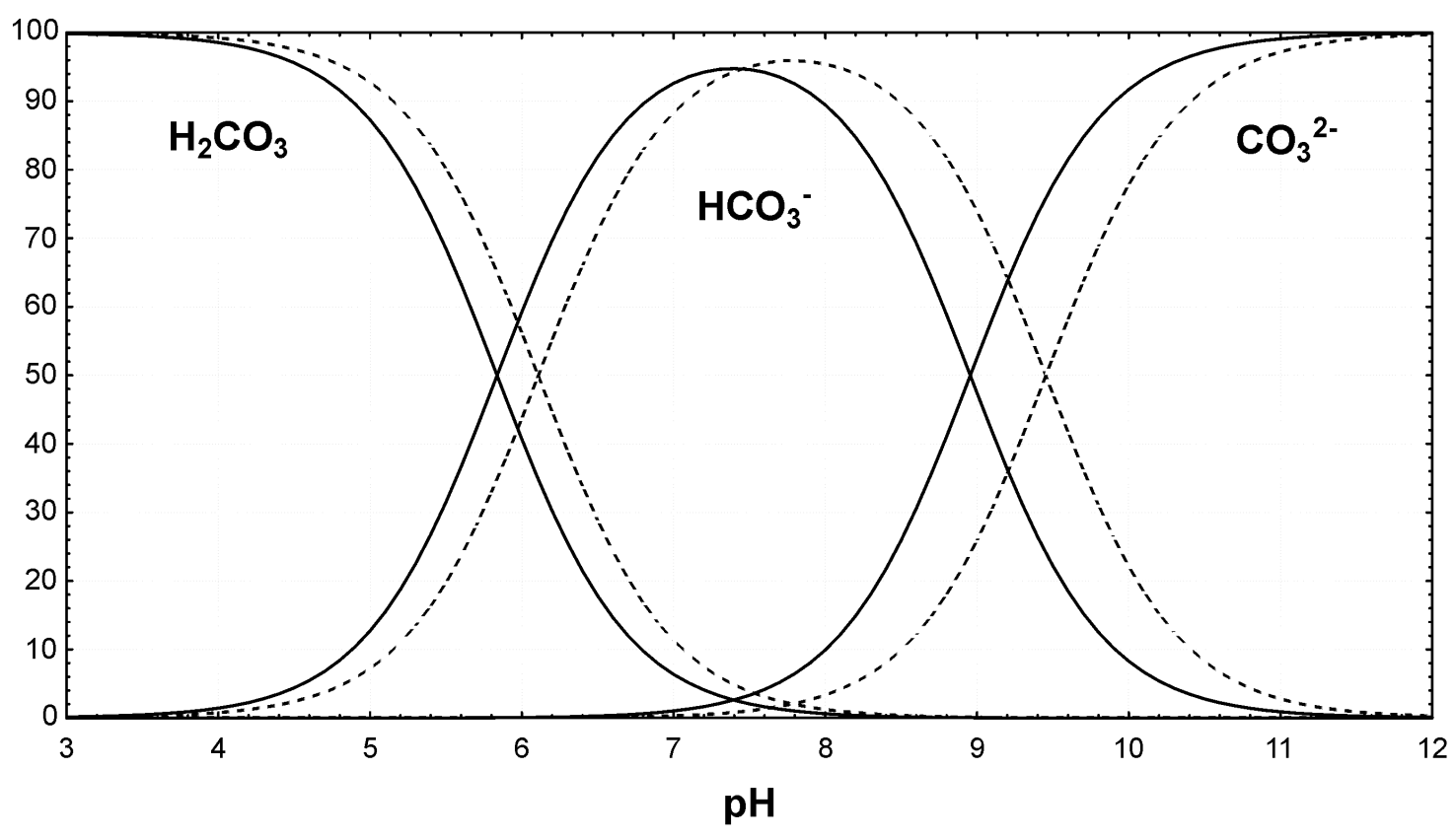


Figura 4.9: Proporción de las diferentes formas en las que se encuentra el carbono disuelto en agua en función del $\mathrm{pH}$. Se ha calculado para un valor de $\mathrm{CO}_{2}$ atmosférico preindustrial (280 ppm), a $25^{\circ} \mathrm{C}$ y para dos salinidades: limnética (línea discontinua) y marina (línea continua). Para los cálculos realizados véase el anexo II.

El dióxido de carbono atmosférico $\left(\mathrm{CO}_{2}\right)$ se combina con el agua formando ácido carbónico $\left(\mathrm{H}_{2} \mathrm{CO}_{3}\right)$. Este ácido débil se disocia en los iones bicarbonato $\left(\mathrm{HCO}_{3}^{-}\right)$y carbonato $\left(\mathrm{CO}_{3}^{2-}\right)$ según las siguientes reacciones (figura 4.9):

$$
\begin{aligned}
& \mathrm{CO}_{2 \text { (gas) }}+\mathrm{H}_{2} \mathrm{O}_{\text {(líquido) }} \leftrightarrow \mathrm{H}_{2} \mathrm{CO}_{3 \text { (acu) }} \\
& \mathrm{H}_{2} \mathrm{CO}_{3(\text { acu) }} \leftrightarrow \mathrm{H}^{+}+\mathrm{HCO}_{3}^{-} \\
& \mathrm{CO}_{3}^{2-}+\mathrm{H}^{+} \leftrightarrow \mathrm{HCO}_{3}^{-}
\end{aligned}
$$

La disociación del ácido carbónico genera un ión hidrógeno $\left(\mathrm{H}^{+}\right)$que tiendeaincrementar la acidez (reducción del pH) del agua a medida que el $\mathrm{CO}_{2}$ atmosférico se disuelve. Esta tendencia es compensada por la tercera reacción que consume $\mathrm{H}^{+}$. Así pues, en la medida que estas dos reacciones estén equilibradas, no se produce un cambio significativo en el $\mathrm{pH}$ ya que el ión carbonato actúa como un tampón. Sin embargo, en la naturaleza el aporte de $\mathrm{CO}_{3}^{2-}$ a las aguas es limitado, así que cuanto más $\mathrm{CO}_{2}$ es asimilado, mayor es la concentración de $\mathrm{H}^{+}$, y se produce la acidificación de las aguas.

La concentración de bicarbonato disuelto en el agua es un componente importante en la precipitación de carbonatos:

$$
\mathrm{Ca}^{2+}+2 \mathrm{HCO}_{3}^{-} \leftrightarrow \mathrm{CaCO}_{3}+\mathrm{CO}_{2}+\mathrm{H}_{2} \mathrm{O}
$$

A pesar de la dificultad, existen algunas pautas que permiten hacerse una idea del $\mathrm{pH}$ existente en el registro sedimentario de un paleolago.

a) Los lagos actuales en los cuales se producela precipitación y sedimentación de calcita (marl lakes) tienen un $\mathrm{pH}$ comprendido entre 7y 11, con un rango preferente de 88,6, y un valor medio de 8,5 $\pm 0,1$ (figura 4.10).

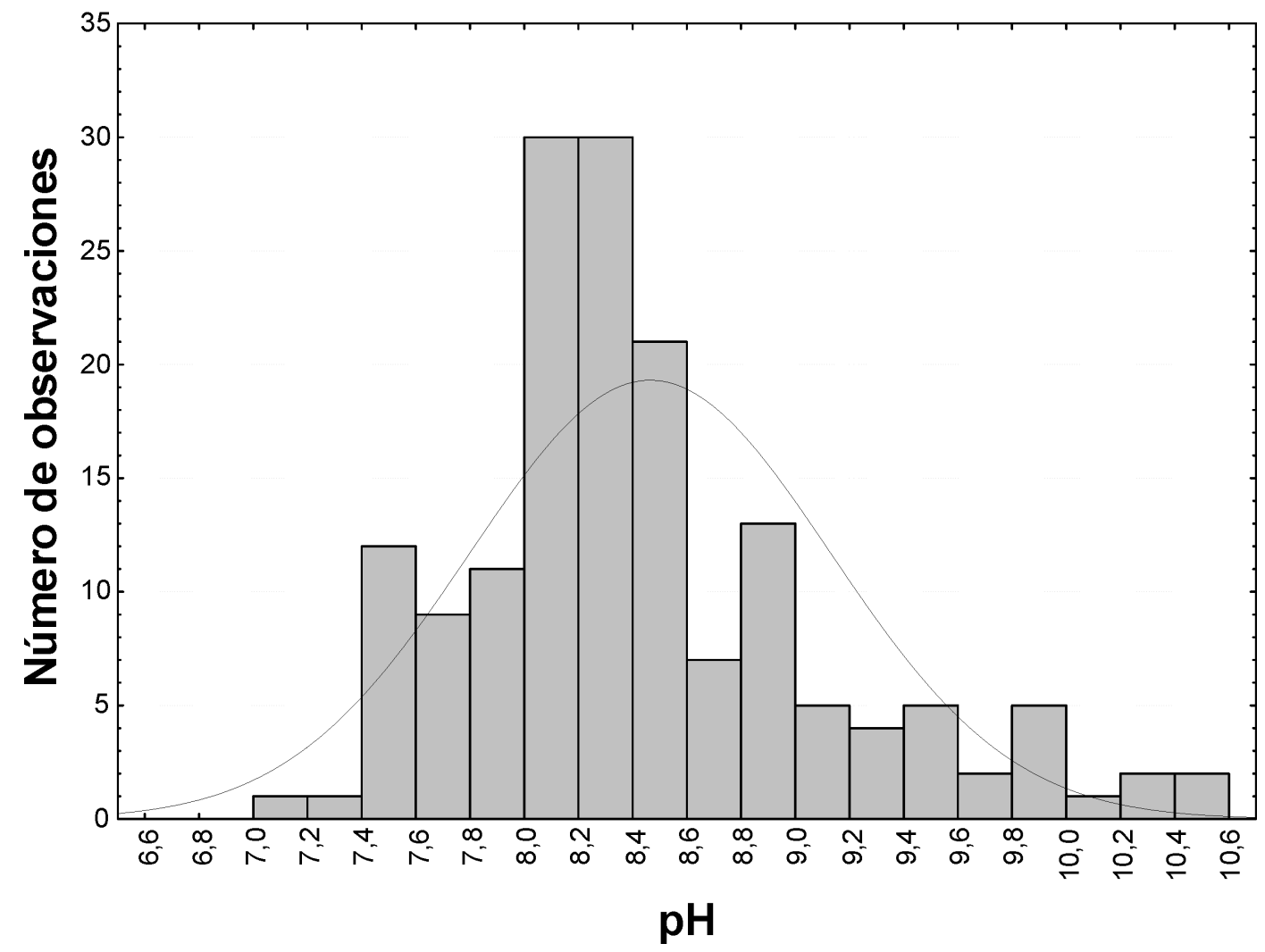


Figura 4.10: Histograma del rango de variación del $\mathrm{pH}$ de los lagos carbonatados actuales. Se han utilizado 161 valores correspondientes a 65 lagos actuales.

b) Los organismos con conchas calcáreas no toleran aguas con un $\mathrm{pH}$ bajo ya que, en general, son pobres en calcio y los ácidos acaban por disolver la concha provocando una mortalidad considerable (KAT, 1982). Además, hay que tener en cuenta que un hábitat de aguas ácidas disminuye la diversidad de especies.

c) Las especies actuales de carófitas calcificadoras habitan únicamente masas de aguas alcalinas (GARCía, 1994).

d) Los medios acidificados tienden a disolver los fósiles carbonatados (BAILEY et al., 2005), por lo cual, la abundancia y buena conservación de ostrácodos se utiliza como un indicador fiable de un medio de aguas alcalinas (LÖFFLER, 1997).

e) Ciertas especies de ostrácodos modernos muestran una significativa correlación con los principales solutos disueltos en las aguas del medio que habitan (FORESTER, 1986; SMTTH, 1993).

\subsection{OXÍGENO DISUELTO}

El oxígeno disponible juega un papel importante en los numerosos procesos que ocurren en el seno de la masa de agua tales como: las reacciones redox (oxidación-reducción), la fotosíntesis, la descomposición de la materia orgánica y la biota acuática. La cantidad de oxígeno disuelto en un lago depende principalmente del intercambio gaseoso en la interfase aguaatmósfera en la superficie del lago y del equilibrio entre producción por la actividad de organismos fotosintéticos versus consumo por respiración.

En menor medida, también puede verse afectada por fenómenos turbidíticos, estratificación, viento, factores morfométricos de la cubeta, etc. En general, las turbiditas suministran cantidades importantes de oxígeno aunque también puede favorecer la pérdida de $\mathrm{O}_{2}$ por la gran cantidad de partículas en suspensión que disminuyen la solubilidad. En el lago Issyk-Kul en Kirguistán, las plumas de densidad aportan abundante $\mathrm{O}_{2}$ a las zonas más profundas del lago (PEETERS et al., 2003; PEETERS Y KIPFER, 2009).

Por otro lado, la agitación producida por la acción del viento favorece la homogeneización del contenido en oxígeno de la columna de agua. La poca profundidad del lago favorece la oxigenación de sus aguas por la acción del viento y de la mezcla. Sin embargo, la anoxia en un lago no requiere de grandes profundidades y/ o del establecimiento de etapas meromícticas (aunque ambos la favorecen), existiendo numerosos ejemplos delagos anóxicos someros no estratificados (J EWELL, 1992). Por ejemplo, los lagos someros con aguas cálidas y una productividad extrema, presentan extensas zonas de la columna de agua en condiciones anaerobias, sobre todo en áreas donde las plantas emergentes son abundantes (COHEN, 2003). Otro aspecto morfométrico importante es la relación entre la superficie de la interfase agua-sedimento y el volumen total de agua en la cubeta lacustre. Cuanto mayor es estevalor, más importante es la tendencia a presentar un déficit en oxígeno debido a los procesos de descomposición de la materia orgánica que se producen en el interior del sedimento depositándose en el fondo (LAMPERT Y SOMMER, 1997).

El proceso de intercambio gaseoso atmósfera-agua es una fuente fundamental de oxígeno. Aunque el $\mathrm{O}_{2}$ es un elemento abundante en la atmósfera, debido a su baja solubilidad es muy escaso en el agua. La solubilidad es función de:

a) La presión parcial del $\mathrm{O}_{2}$ en la atmósfera.

b) La temperatura del agua: las aguas cálidas contienen menos oxígeno disuelto que las aguas frías (figura 4.11).

c) La concentración de impurezas tales como la salinidad (muy importante en medios hiperhalinos) o sólidos en suspensión que reducen el espacio intermolecular disponible para el oxígeno (figura 4.11).

d) La presión atmosférica-altitud. La concentración del oxígeno disminuye al aumentar la altitud (menor presión atmosférica). 


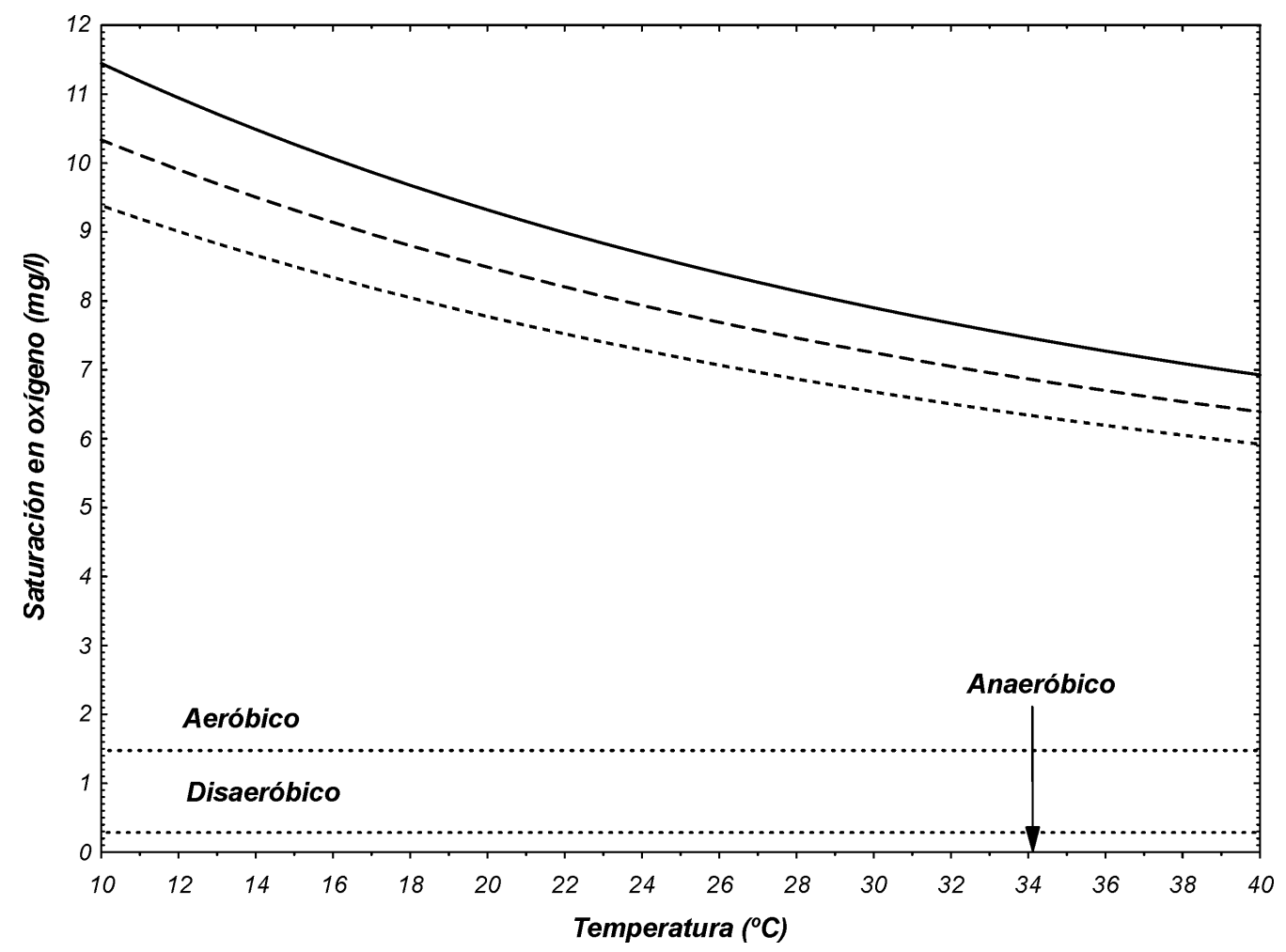

Figura 4.11: Variación de la saturación en oxígeno del agua en función de la temperatura y la salinidad para un valor atmosférico actual del 20,95\%. Las tramas indican salinidad: trama continua (0\%), trama discontinua (18\%o) y trama a puntos (35\%o). Para los cálculos realizados véase anexo III.

Como este intercambio se produce en la superficie del cuerpo de agua y, además, la fotosíntesis depende de la luz, la casi totalidad del aporte de oxígeno se produce en la parte alta (somera) de la columna de agua. En las aguas epilimnéticas se produce la fijación del carbono por los organismos fotosintéticos. Esta fijación elimina $\mathrm{CO}_{2}$ del medio disminuyendo la acidez (incrementa el pH) y oxigenando las aguas (aumenta el contenido en $\mathrm{O}_{2}$ ). Por el contrario, la descomposición de la materia orgánica en las aguas hipolimnéticas favorece tanto la anoxia, debido al consumo el $\mathrm{O}_{2}$, como la acidez del medio como consecuencia de la producción de $\mathrm{CO}_{2}$. La tasa de consumo del oxígeno varía, aparte de por el nivel trófico, por parámetros tales como el espesor de la capa hipolimnética (CHARLTON, 1980), la profundidad media (WALKER, 1979), y la forma del hipolimnion (CORNETT, 1989).

Respecto a los lagos situados en regiones tropicales, hay que señalar su predisposición al desarrollo de aguas anóxicas debido a factores tales como:

a) Las altas temperaturas epilimnéticas favorecen una mayor fotosíntesis, mientras que las altas temperaturas hipolimnéticas aumentan la tasa de eliminación del oxígeno por metabolismo microbiano (LEWIS, 2000). La tasa de descomposición de materia orgánica en un lago tropical puede ser del orden de cuatro a nueve veces mayor que en un lago situado en regiones templadas (ROLDÁN-PÉREZ Y RAMÍREZ-RESTREPO, 2008).

b) Las elevadas temperatura de la columna de agua disminuyen la solubilidad del oxígeno (BENSONY KRAUSE, 1984).

c) Débil circulación geostrófica (apartado 4.15.3).

d) La historia de las aguas que alcanzan la cubeta lacustre. El contacto de las aguas de escorrentía con un área de drenaje muy vegetada, típica de zonas tropicales, resulta en la pérdida del $\mathrm{O}_{2}$ disuelto antes de alcanzar la cubeta lacustre, como ocurre en la actualidad en el Pantanal en Brasil (HAMILTON et al., 1997) o en ciertos lagos costarricenses (HABERYAN et al., 2003). 
Los métodos paleoecológicos, sedimentarios, paleoicnológicosy/ o geoquímicos permiten discernir, de manera general, entre ambientes aeróbicos (el contenido en oxígeno disuelto en el agua es $>1 \mathrm{ml} / \mathrm{l})$, disaeróbico $(0,1-1 \mathrm{ml} / \mathrm{l})$ y anaeróbicos (<0,1 ml/l) (CLUFF, 1980).

Los modelos paleoecológicos (o de biofacies) se fundamentan en que una reducción del oxígeno disponible se refleja en una evidente disminución de la diversidad de especies bentónicas (WigNALl Y HALLAM, 1991; WigNALL, 1994). La biota está afectada por la disponibilidad de oxígeno, con un valor crítico (donde comienzan los fallos en la regulación respiratoria) para la mayoría de los invertebrados acuáticos de 2 mg/l (WILLIAMS, 1998b).

Otro método de cálculo son los modelos paleoicnológicos. Se fundan en dos evidencias actualistas, según las cuales un bajo contenido en oxígeno:

a) Reduce la actividad biológica de los organismos y disminuye la diversidad, el diámetro dela perforación y la profundidad depenetración de los icnofósiles (SAVRDA Y BOTTJ ER, 1986).

b) Permite el desarrollo de ciertas asociaciones etológicas de los icnofósiles. Las facies más desoxigenadas están dominadas por Fodinichnia o ausencia total de bioturbaciones.

Los modelos sedimentarios para la determinación del oxígeno se basan en la fábrica del sedimento, la cual permite discernir entre medios anaeróbicos (caracterizados por fábricas laminadas y sin bioturbación) y aeróbicos (caracterizados por fábricas masivas y/ o bioturbadas).

Los modelos geoquímicos son tratados en mayor detalle en el capítulo 7 de la presente tesis doctoral.

\subsection{TURBIDEZ DEL MEDIO}

La turbidez del agua está causada por la cantidad de sustancias en suspensión en la masa de agua, las cuales pueden ser de origen inorgánico u orgánico. Esta turbidez, permanente o temporal, depende básicamente dela acción del viento y dela presencia de macrófitos. De manera menos significativa, también influyen los ritmos anuales de inundación (LOVERDE-OLIVEIRA et al., 2009), las fluctuaciones del nivel del lago (BEKLIOGLU et al., 2006), la salinidad (J EPPESEN et al., 2007), y la naturaleza del sedimento (HÂKANSON, 1977).

La turbidez inducida por el viento es promovida por las olas que ponen en suspensión sedimento y, en muchos casos, es compensada por los macrófitos (SCHELSKE et al., 1995). En zonas tropicales, los huracanes son una causa frecuente de estadios de alta turbidez en los lagos. En general, el paso del huracán genera un incremento temporal del sedimento en suspensión, como en el lago Okeechobee de los E.E.U.U. (HAVENS et al., 2001). En casos extremos, modifica de manera permanente y drástica el estado del lago. En 1947, el paso de un huracán hizo que el lago Apopka (E.E.U.U.) pasara de ser un lago de aguas claras con abundantes macrófitos a ser, hasta el día de hoy, un lago de aguas turbias (BACHMANN et al., 2000; HAVENS et al., 2001).

En la propia cubeta lacustre, los macrófitos reducen la turbidez controlando el desarrollo excesivo del fitoplancton (SCHEFFER Y VAN NES, 2007) y atenuando la energía del oleaje o la velocidad de las corrientes en áreas litorales (LOSEE YWETZEL, 1988; LOSEE Y WETZEL, 1993). Este efecto pantalla evita la resuspensión del sedimento por el oleaje (SCHEFFER Y VAN NES, 2007) e incrementa la tasa de sedimentación (PETTICREW Y KALFF, 1992). Además, los macrófitos localizados en los alrededores del lago actúan como filtros para el material transportado hacia la cubeta lacustre. Este efecto filtro es importante en lagos (sub)tropicales ya que durante la etapa anual de inundación, las aguas fluviales decantan casi todo el material en suspensión durante su paso por estas llanuras densamente vegetadas (LOVERDE-OLIVEIRA et al., 2009).

Los lagos someros suelen presentar dos estadios alternativos con desplazamientos rápidos entre ambos: aguas turbias con pocas plantas sumergidas y aguas claras con abundantes 
macrófitos sumergidos (SCHEFFER et al., 1993). En estos ecosistemas poco profundos los niveles altos de agua pueden ocasionar una pérdida de macrófitos y la instauración de un estadio de turbidez (WALLSTENY FORSGREN, 1989; ENGEL Y NiCHOLS, 1994). Por el contrario, los niveles bajos de agua favorecen un estadio de aguas claras.

La cuantificación de la turbidez en el registro sedimentario es problemática, aunque existen ciertos indicadores cualitativos:

a) La abundancia de partículas finas, tamaño arcilla y/ o limo, puede ser indicativa, a priori, de cierto grado de turbidez (FÜRSICH, 1995).

b) Los bivalvos fósiles pueden ser indicadores útiles, ya que una turbidez elevada tiende a no permitir el desarrollo de organismos filtradores (FÜRSICH, 1995).

c) Las carófitas suelen vivir en aguas claras y transparentes (TORN et al., 2004).

\subsection{PATRÓN DE CIRCULACIÓN}

La regulación de la dinámica física y química de las aguas continentales está gobernada en gran medida por las diferencias de densidad generadas en el seno de la masa de agua. Debido a este gradiente vertical de densidad, la columna de agua se compartimenta en capas o estratos con condiciones físicas, químicas y biológicas diferentes. Este fenómeno recibe el nombre de estratificación y está inducido por diferencias de temperaturas, contrastes de salinidades (material en disolución) y/o turbidez diferencial (material en suspensión). Cuando la estratificación térmica se ha establecido, la columna de agua se divide en tres capas:

a) Una capa superior, menos densa y más cálida denominada epilimnion.

b) Una capa intermedia donde se produce un cambio apreciable del rango de temperaturas llamada metalimnion.

c) Una capa inferior, más densa y fría designada como el hipolimnion.

Dentro del metalimnion se forma la termoclina, definida por el máximo gradientevertical de temperatura. La instauración de la termoclina dificulta la interacción entre el hipolimnion y epilimnion, constituyendo una barrera que impide el intercambio de gases y sustancias disueltas, aunque permite el paso del material particulado.

La estratificación es consecuencia directa del comportamiento de la densidad del agua en función de la temperatura y, por tanto, está muy influenciada por el escenario climático en el cual se enclava el lago. Como la relación densidad-temperatura no es uniforme (CHEN Y MILLERO, 1986) (figura 4.12), las diferencias de densidad se incrementan con la temperatura de manera no lineal, lo cual tiene efectos significativos en la dinámica lacustre.

Así pues, por ejemplo, la diferencia de densidad entre dos masas de agua limnéticas estratificadas a $4^{\circ} \mathrm{C}$ y $5^{\circ} \mathrm{C}$ es $0,0000081 \mathrm{gr} / \mathrm{cm}^{3}$, mientras que entre $24^{\circ} \mathrm{C}$ y $25^{\circ} \mathrm{C}$ es 0,0002516 $\mathrm{gr} / \mathrm{cm}^{3}$. En el segundo caso, la cantidad de trabajo requerido para su mezcla es aproximadamente 31 veces mayor que respecto al primero. Por esta razón, los lagos situados en zonas cálidas (tropicales y subtropicales) no requieren de un gran gradiente térmico (una diferencia mínima de la temperatura es suficiente) para que se origine la estratificación térmica. La termoclina en los lagos tropicales se define como la zona del metalimnion donde existe un gradiente térmico de $0,2-0,5$ - $C$. Por el contrario, los lagos situados en regiones templadas necesitan por lo menos una diferencia de $1^{\circ} \mathrm{C}$. Por esta razón, la estratificación térmica en los lagos tropicales es menos estable que la de los lagos situados en latitudes mayores ya que, como se ha visto, la cantidad de calor requerido para destruirla es también menor (LEWIS, 1973; LEWIS, 1996).

Si la turbulencia creada por los agentes desestabilizadores (principalmente la convección térmica y/ o la acción del viento) no es lo suficientemente intensa como para vencer a las fuerzas estabilizadoras (densidad), se promueve la estratificación. Si por el contrario, la turbulencia es suficiente, se origina la mezcla que uniformiza y homogeniza las propiedades de toda la columna de agua. 


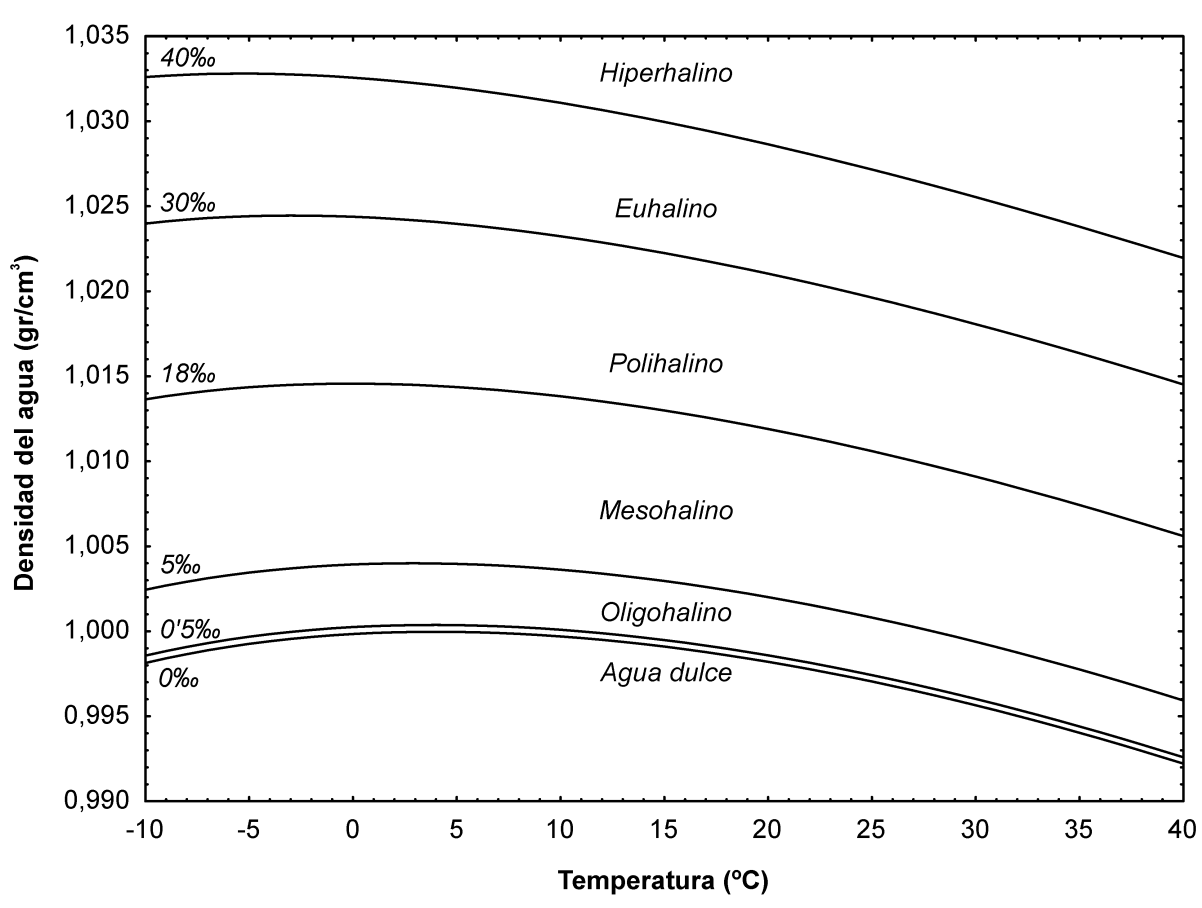

Figura 4.12: Relación entre la densidad y la temperatura a distintas salinidades según la fórmula de CHENY MILLERO (1986).

El climay la morfometría de la cubeta son los factores que más influyen en los fenómenos de estratificación - mezcla. La efectividad del viento como agente detonante de la mezcla depende de la velocidad, dirección respecto a la orientación del lago, topografía o vegetación circundante (que puede exponerlo o protegerlo de la acción de los vientos dominantes), superficie del espejo, alcance y la profundidad del lago. Sin embargo, la reacción del lago a la acción del viento, o cualquier otro agente favorecedor de la mezcla, depende en gran medida de la intensidad de la estratificación presente (SPIGEL Y IMBERGER, 1987).

La profundidad de la termoclina (zt) y del epilimnion (ze) se puede calcular en función del área de la cubeta lacustre (A $\mathrm{A}_{\text {espejo }}$ ). En la figura 4.13 se puede observar una selección de las numerosas fórmulas existentes en la literatura (ARAI, 1981; PATALAS, 1984; DAVIES-COLLEY, 1988; KuING, 1988; HANNA, 1990; FEE et al., 1996).

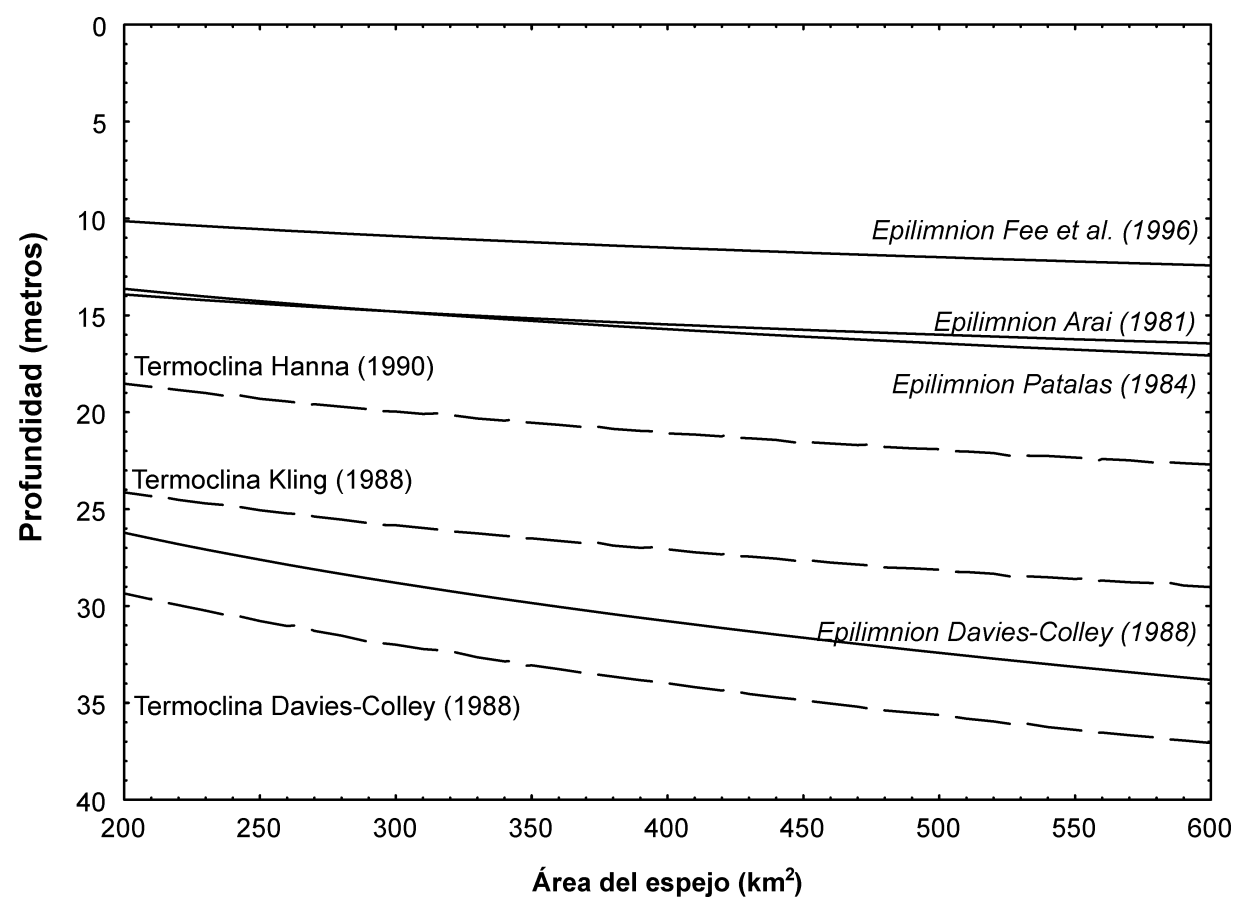


Figura 4.13: Profundidad teórica dela termoclina y epilimnion en función del espejo dela cubeta lacustre. La trama continua representa la profundidad del epilimnion y la discontinua es para la termoclina.

La acción de todos estos agentes origina un patrón de circulación del agua en etapas de estratificación y mezcla. Este patrón influye considerablemente en la sedimentación, sobre todo en los precipitados, y en los ciclos fisicoquímicos. Los lagos se pueden clasificar, de inicio, en tres grandes categorías (LAMPERT Y SOMMER, 1997):

a) Amícticos: lagos permanentemente cubiertos de hielo cuyas aguas no se mezclan nunca. Se localizan en las regiones árticas, antárticas y de alta montaña.

b) Meromícticos: lagos que se mezclan sólo parcialmente, ya que sus aguas profundas nunca sufren una mezcla completa.

c) Holomícticos: lagos cuyas aguas se mezclan completamente. Pueden ser categorizados de acuerdo al grado y frecuencia de sus modelos de circulación (LEWIS, 1983; LAMPERT Y SOMMER, 1997):

- Oligomícticos: lagos que se mezclan completamente, aunque no todos los años.

- Monomícticos fríos: lagos con una cubierta de hielo la mayor parte del año y cuya temperatura nunca (o raramente) sobrepasa los $4^{\circ} \mathrm{C}$. Las aguas se mezclan una vez al año durante la época estival del deshielo.

- Monomícticos cálidos: lagos que nunca están cubiertos de hielo, exhiben estratificación estable la mayor parte del año y, se mezclan una vez al año en invierno.

- Dimícticos: lagos cuyas aguas se mezclan dos veces al año. Las etapas de estratificación son durante el invierno (capa de hielo) y el verano (estratificación térmica estable). La mezcla se produce durante las transiciones entre estos dos estadios (otoño y primavera).

- Polimícticos fríos continuos: lagos con cubierta de hielo parte del año que durante la estación cálida se deshielan permitiendo la formación de una estratificación casi diariamente.

- Polimícticos cálidos continuos: lagos que nunca se hielan y que se estratifican a lo sumo unas pocas horas cada vez.

- Polimícticos fríos discontinuos: lagos con una capa de hielo parte del año que se deshielan cuando la temperatura está por encima de $4^{\circ} \mathrm{C}$. Durante la estación cálida se estratifican durante días o semanas pero con etapas de interrupción por mezcla.

- Polimícticos cálidos discontinuos: nunca se hielan y presentan estratificaciones durante días o semanas cada vez, aunque mezclándose más de una vez al año.

Existe, además, otro patrón de mezcla, más desconocido y raro, pero muy importante en lagos tropicales. La atelomixis se define como la estratificación y mezcla diaria de las aguas del lago. Esta mezcla puede ser completa si afecta a todo la columna de agua, o parcial si la mezcla se restringe a las aguas epilimnéticas (LEWIS, 1973; ROLDÁN-PÉREZ Y RAMÍREZ-RESTREPO, 2008). La atelomixis ocurre durante el invierno tropical cuando la variación de la temperatura diurna es mayor que la variación anual (LEWIS, 1973; BARBOSA Y PADISÁK, 2002).

Dos de los factores que influyen de manera cuantificable en el patrón de mezcla de los lagos es el área del espejo y la profundidad media (figura 4.14). En función de este par de parámetros morfométricos, los lagos tropicales actuales tienen una tendencia muy significativa a ser monomícticos cálidos o polimícticos (LEWIS, 2000).

Los lagos meromícticos poseen masas de agua permanentemente estratificadas y muestran un patrón de circulación incompleto, es decir, sus aguas se mezclan sólo de manera parcial. La columna de agua está compartimentada en dos capas separadas por un gradiente de densidad denominado quimioclina o termoclina, según sea su origen. Los intercambios entre 
ambas capas son nulos o muy pequeños. El mixolimnion es el estrato superior que sufre circulación periódica. El monimolimnion es el estrato más profundo que nunca se mezcla, bien sea por la alta densidad del agua causada por sustancias disueltas y/ o en suspensión, o porque el lago está muy protegido de los efectos del viento. Permanece aislado de los intercambios gaseosos con la atmósfera durante temporadas prolongadas y, en la mayoría de los casos, la anoxia se establece después de un período de tiempo suficiente. Como además, está permanentemente sometido a la presión hidrostática de la columna de agua suprayacente, los gases $\left(\mathrm{CO}_{2}, \mathrm{H}_{2} \mathrm{~S}\right.$ y otros) se pueden acumular en grandes concentraciones.

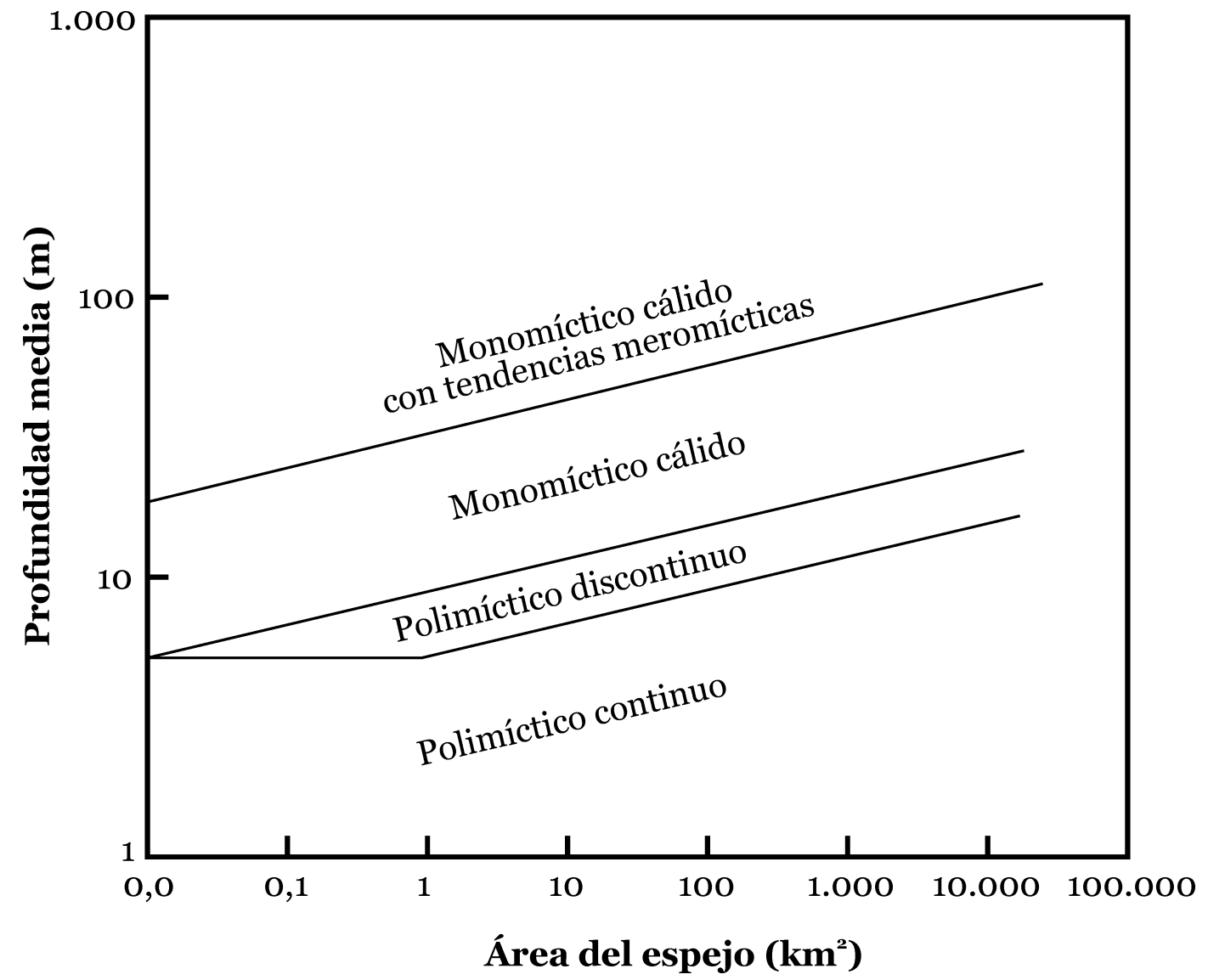

Figura 4.14: Patrón de mezcla de los lagos tropicales actuales en función del área del espejo y dela profundidad media. Modificado y redibujado de LEWIS (2000).

La meromixis sensu stricto requiere que nunca se produzca la mezcla completa en la masa de agua, sin embargo, el término meromíctico sensu lato (de uso más pragmático) admite periodos irregulares de estratificación y mezcla. En estalínea, WALKER Y LIKENS (1975) consideran que los lagos meromícticos deben desarrollan una estratificación permanente duranteun período de tiempo que sea mayor que la mitad de la vida del propio lago. BOEHRER y SCHULTZE (2008) estiman que el lago debe permanecer estable durante al menos un ciclo anual. Así pues, la meromixis no es una estado permanente en la vida del lago. El Mar Muerto, considerado como un ejemplo clásico y paradigmático de lago meromíctico, ha sufrido etapas de mezcla completa (STEINHORN, 1985).

Existen tres tipos básicos de meromixis que se catalogan en función del origen de las sustancias que crean el gradiente de densidad: ectogénica, crenogénica y biogénica.

La meromixis ectogénica se inicia cuando un evento externo, actuando durante un periodo de tiempo limitado, induce una estratificación permanente en el cuerpo de agua. Aunque no es fácil, en el registro geológico se han reconocido etapas de meromixis ectogénica en el Grupo Purbeck Limestones (Berriasiense) asociadas a grandes acumulaciones de materia orgánica (SCHNYDER et al., 2009). En la actualidad, la meromixis ectogénica puede ocurrir como consecuencia de la entrada de pulsos de aguas salobres en una masa de agua dulce. De tal forma 
que las aguas salobres más densas constituyen el monimolimnion, mientras que el mixolimnion está compuesto por las aguas más dulces y menos densas procedentes de la cuenca hidrográfica y la precipitación (HAKALA, 2004). Se localiza con frecuencia en regiones costeras marinas donde se produce la entrada de agua salada de origen marino de manera estacional (KING Y TYLER, 1981; LUDLAM Y DUVAL, 2001) o durante grandes tormentas (HUTCHINSON, 1957). Menos frecuente es el caso de la entrada de ríos levemente salinos (SCHMID y DORJ I, 2008). Estos aportes salinos no necesitan ser muy importantes y, en la actualidad, existen numerosos ejemplos de lagos que sufren meromixis por la entrada de las sales que se vierten en las carreteras para evitar la formación de hielo (SCHARF Y OEHMS, 1992). Otro posible mecanismo de meromixis ectogénica sería el caso contrario, es decir, la entrada de agua dulce en un lago salino (J ELLISON et al., 1998). Suele ocurrir en lagos salinos de poca profundidad localizados en regiones áridas que reciben la entrada ocasional de grandes cantidades de agua dulce. En el lago Mono (E.E.U.U.), la implantación de eventos meromícticos por la entrada de agua dulce es más estables y permanentes cuando el lago está en etapas regresivas. Por el contrario, los niveles altos del lago disminuyen la estabilidad y duración de la meromixis (ROMERO Y MELACK, 1996). Finalmente, la meromixis ectogénica puede originarse cuando el gradiente de densidad es causado por la entrada deaguas con una alta concentración de sedimento en suspensión (FREY, 1955; LARSON, 1979). Este último tipo de meromixis es importante en lagos glaciales (GUSTAVSON, 1975). Los lagos heliotérmicos, también denominados charcas solares (solar ponds), son un caso raro de meromixis ectogénica, ya que el monimolimnion presenta una temperatura mucho más elevada que la existente en la superficie del lago (hasta $70^{\circ} \mathrm{C}$ ). Este fenómeno necesita, en general, una diferencia de densidad mínima de $15 \mathrm{~g} / \mathrm{l}$. Por consiguiente, sólo se produce en lagos estratificados con salmueras de cloruro y sulfato, siendo imposible en lagos con carbonatos y bicarbonatos (SONNENFELD Y HUDEC, 1980; WILLIAMS, 1998a).

La meromixis crenogénica es provocada por la entrada de aguas subterráneas (DEL DON et al., 2001) y, en ocasiones, es posible reconocerla en el registro fósil (LÖFFLER, 1977; BOYER, 1981). En el lago Sonachi (Kenia), períodos de elevada pluviosidad incrementan la entrada de las aguas subterráneas que disuelven las evaporitas existentes en el lecho del lago, reforzando y/o favoreciendo la meromixis (MACINTYRE Y MELACK, 1982). Uno de los ejemplos más extremos y espectaculares de meromixis crenogénica se produce en ciertas áreas volcánicas donde componen un escenario anómalo de riesgo natural: la erupción límnica de gases. Debido a su poder catastrófico se les denomina como "lagos asesinos" (SCHMID et al., 2006) y suelen estar rodeados de leyendas que les atribuyen comportamientos malignos (SHANKLIN, 1989; 2007). El aporte de gases a las aguas profundas se produce a través de grietas y originan una densidad suficiente como para establecer una estratificación estable. Estos gases disueltos (principalmente $\mathrm{CO}_{2}$ y en menor medida $\mathrm{CH}_{4}$ ) se acumulan en el monimolimnion hasta que la presión parcial supera a la presión hidrostática y es, en ese momento, cuando se produce una desgasificación masiva. Curiosamente, sólo se tiene constancia de dos erupciones límnicas ocurridas en Camerún en los años ochenta: en 1984 en el lago Monoun con 37 víctimas (SIGURDSSON et al., 1987), y en 1986 en el lago Nyos con unas 1.700 víctimas (KLING et al., 1987). El lago Kivu (Ruanda, Congo) es un ejemplo de "presunto" lago asesino con grandes acumulaciones de $\mathrm{CH}_{4}$ debido a la entrada profunda deaguas termales (STOFFERS Y HECKY, 1978). En el registro geológico, sólo se han reconocido dos erupciones fósiles, una en el lago Kivu (HABERYANY HECKY, 1987) y otra en el lago Barombi Mbo de Camerún (MALEY et al., 1990).

La meromixis biogénica es originada por la descomposición de la materia orgánica. Las elevadas concentraciones de $\mathrm{CO}_{2}$ como consecuencia de la descomposición de la materia orgánica en el sedimento, causan la disolución parcial de ciertos elementos que se acumulan en el monimolimnion, creando el gradiente de densidad necesario. Los solutos más comunes capaces de estabilizar este tipo de estratificación son $\mathrm{Ca}^{2+}$ y $\mathrm{HCO}_{3}^{-}$(WÜEST et al., 1992; RODRIGO et al., 2001), $\mathrm{Fe}^{2+}$ (KJ ENSMO, 1967; KJ ENSMO, 1968; MERILÄINEN, 1970; CAMPBELL YTORGERSEN, 1980) y $\mathrm{Mn}^{2+}$ (HONGVE, 1997). Se ha descrito un ejemplo fósil de meromixis por hierro en el paleolago Tubutulik del Eoceno de Alaska (DICKINSON, 1988).

La meromixis termogénica es un término propuesto hace pocos años para designar a la meromixis originada y mantenida, únicamente, por un gradiente de temperatura (KATSEV et al., 2010). Por desgracia, los lagos estratificados de manera permanente por un gradiente térmico son 
muy escasos (CRAWFORD Y COLLIER, 2007; BOEHRER et al., 2008). Las aguas ricas en ácidos húmicos mejoran la absorción de la energía solar en las capas superficiales, favorecen la estratificación térmica y, en consecuencia, la instauración de condiciones meromícticas (J ONESY ARVOLA, 1984).

Como se comentó con anterioridad, la meromixis no es un estado permanente en la vida de un lago, sino que más bien constituye un período de tiempo corto a escala geológica, años a decenas de años en los casos más prolongados. Por consiguiente, su reconocimiento en el registro sedimentario puede ser complicado o incluso no quedar registrado. TRACEY et al. (1996) consideran que los tres indicadores de meromixis son la presencia de laminación, cambios en la relación hierro-manganeso y las diatomeas. Otros autores postulan que el tamaño de la calcita puede dar información sobre la disolución parcial, e indicar una posible etapa de meromixis (LOTTER et al., 1997; RAMISCH et al., 1999).

En general, si el aislamiento del monimolimnion se prolonga el tiempo suficiente se puede llegar al establecimiento de unas condiciones anóxicas. Esta carencia de oxígeno comporta una escasez o ausencia de organismos bentónicos y, por lo tanto, de bioturbación. Es por esto que las varvas o ritmitas constituyen los sedimentos paradigmáticos de los lagos meromícticos (ANDERSON et al., 1985; ANDERSON Y DEAN, 1988). Por desgracia, no constituyen una evidencia unívoca, ya que son numerosos los ejemplos de sedimentos laminados en lagos holomícticos (LUDLAM, 1976) o dimícticos (O'SULLIVAN, 1983). De hecho, en ciertos lagos, se ha observado que la formación de ritmitas precede a la instauración de la meromixis (HODGSON, 1999). Por otro lado, la ausencia de depósitos laminados no debería, a priori, eliminar la posibilidad un lago meromíctico. En muchos lagos meromícticos se producen ciertos eventos ocasionales de oxigenación que permiten, durante un corto espacio de tiempo, el desarrollo de una bioturbación suficiente para destruir la laminación (MARTIN, 2004).

\subsection{HIDRODINÁMICA LACUSTRE}

Las mareas en los lagos son insignificantes por lo que no se tienen en consideración. En los Grandes Lagos de E.E.U.U. y Canadá son menores de $10 \mathrm{~cm}$ (SCHWAB, 1992) y en el lago Constance no alcanza $1 \mathrm{~mm}$ de amplitud (HAMBLIN et al., 1977).

Las olas y las corrientes son los dos movimientos fundamentales que se producen en la columna de agua de un lago. Además, si tienen gran extensión, esta dinámica puede ser modificada por el efecto de la rotación de la Tierra. En general, las olas y corrientes coexisten, y constituyen los principales mecanismos de transporte y distribución del sedimento en la cubeta. Así pues, es fundamental conocer los mecanismos que gobiernan dicho transporte para comprender einterpretar las facies encontradas en el registro geológico (COHEN, 2003). El viento $\mathrm{y}$, en menor medida, el intercambio calórico son los principales agentes causantes de ambos movimientos.

El viento es un importante agente de forzamiento en los lagos. Actúa sobre la superficie libre del lago aportando la energía cinética (tensión de corte) necesaria para generar los procesos de mezcla, las olas (superficiales e internas) y las corrientes, que impulsan el movimiento y la circulación en la masa de agua. La efectividad del viento como agente de forzamiento depende de la velocidad, la orientación existente entre el viento dominante y la masa de agua, el grado de protección o exposición a dicha acción (cobertera vegetal o relieve circundante), la dimensión del espejo del lago y, la relación entre el alcance y la profundidad.

\subsubsection{Oleaje}

Las olas se definen como oscilaciones periódicas que se propagan por las interfases existentes en la masa de agua. $\mathrm{Si}$ la interfase es agua-aire se producen olas superficiales (o barotrópicas). $\mathrm{Si}$ por el contrario la interfase se encuentra dentro de la columna de agua (termoclina, quimioclina, picnoclina, etc.) se originan olas internas (o baroclínicas). A su vez, las olas se denominan progresivas si existe desplazamiento horizontal, o estacionarias en caso contrario. En la cubeta lacustre existe una gran diversidad de olas abarcando multitud de escalas 
espaciales y temporales (IMBODEN Y WÜEST, 1995). De todas ellas, por su importancia sedimentaria, destacan las olas de gravedad superficiales y las secas.

Las olas de gravedad superficiales son olas progresivas generadas por el viento. Comprenden todas las olas que normalmente se observan en la superficie del lago, siendo el mecanismo dominante (LUETTICH et al., 1990; HAWLEY Y LESHT, 1992). Desde una perspectiva sedimentológica tienen gran importancia en las zonas más someras, ya que inducen la resuspensión de los sedimentos litorales (BLOESCH, 1995; BLOESCH, 2004). La tensión de corte sobre el sedimento y su resuspensión dependen dela velocidad del viento, la dirección, el alcance y la profundidad del agua (BENGTSSON et al., 1990; BLOM et al., 1992). En función de la profundidad (calado) las olas presentan diferentes comportamientos y se distinguen tres dominios: aguas profundas, aguas intermedias y aguas someras (US ARMY CORPS OF ENGINEERS Y COASTAL ENGINEERING RESEARCH CENTER, 1984; KOMAR, 1998).

a) En el dominio de aguas profundas, las olas no están afectadas por el fondo. Las partículas del agua describen trayectorias circulares de diámetros decrecientes exponencialmente con la profundidad. La velocidad del oleaje (celeridad) depende de la longitud de onda.

b) En el dominio de aguas intermedias, el oleaje se ve influenciado por el fondo. Las partículas se desplazan según trayectorias elípticas de ejes decrecientes exponencialmente con la profundidad y con el eje mayor siempre paralelo a la superficie de nivel del fondo.

c) En el dominio de aguas someras, las olas están muy afectadas por el fondo. Las olas sufren una gran transformación como consecuencia de la gran disipación (por rotura o fricción) de energía que sufren. Las trayectorias de las partículas son elipses con el eje mayor independiente de la profundidad y su velocidad está limitada por la profundidad.

Cuando las olas comienzan a verse afectadas por el fondo (aguas intermedias y someras) se produce la formación de rizaduras en el lecho de la cubeta. Sin embargo, durante la propagación desde las aguas profundas hasta el litoral (aguas someras), las olas sufren multitud de transformaciones tales como difracciones, reflexiones, refracciones y asomeramientos (US ARMY CORPS OF ENGINEERS Y COASTAL ENGINEERING RESEARCH CENTER, 1984; KOMAR, 1998). Las tres últimas son las más importantes, desde el punto de vista sedimentológico, por lo que se van a explicar con más detalle.

La reflexión consiste en un cambio brusco en la dirección de propagación de las olas debido a la presencia de un obstáculo. La cantidad de energía reflejada depende de la pendiente de la barrera u obstáculo. Así, una zona costera muy plana refleja poca energía ya que la mayor parte de esa energía se disipa durante la rotura.

El asomeramiento (shoaling) de la ola comprende su transformación por la influencia tanto de la pendiente (topografía) como de la rugosidad del fondo en la zona litoral. Como consecuencia de la pérdida de profundidad, se produce una disminución dela velocidad del oleaje y un aumento del peralte (H/L) de la ola (aumento dela altura y disminución de la longitud) hasta alcanzar las condiciones de inestabilidad (o rotura).

La refracción consiste en una cambio en la dirección de propagación de la ola debido a la disminución de la profundidad, de tal modo, quelas crestas de las olas muestran una tendencia a disponerse paralelas a las isobatas, es decir, al contorno de la costa. Así pues, cuando una ola se aproxima oblicuamente a la costa, la región de la cresta que se propaga por la zona de mayor profundidad se desplaza con mayor velocidad que la región de la cresta que lo hace por la zona de profundidad menor, haciendo que las crestas giren y se orienten paralelas a las isobatas. Este fenómeno es muy importante en el análisis de las rizaduras de oscilación actuales y/ o fósiles. La realidad es que los trenes de olas (rizaduras) siempre se disponen perpendiculares a la dirección del viento y, solamente en ciertas ocasiones, sufren refracción y se disponen paralelos a la línea de costa. Por lo tanto, la determinación en el registro geológico de la dirección de la línea de costa a partir del análisis de rizaduras debe hacerse con sumo cuidado (DAVISJ R., 1965). 
Las secas (seiches) son ondas estacionarias que afectan a la totalidad de la masa del lago. Se originan cuando una fuerza externa provoca un basculamiento en alguna de las interfases existentes en la cubeta. Lo normal es que se formen cuando el viento sopla de manera prolongada y constante, y la oscilación se inicia en el momento que el viento cesa de manera súbita o cambia de dirección. Sin embargo, las secas pueden también ser provocadas por el paso de huracanes (CHIMNEY, 2005), cambios en la presión atmosférica, terremotos (ICHINOSE et al., 2000), etc.

a) Las olas de gravedad superficiales estacionarias (secas superficiales) son olas que pasan de un extremo a otro de la cubeta. En algunos casos el movimiento de la seca es tan llamativo que, en el lago Wakatipu de Nueva Zelanda, las tribus maorís lo atribuyeron a los latidos de un gigante que habitaba en el fondo del lago (HEATH, 1975).

b) Las olas internas de gravedad (secas internas) se forman si el lago está estratificado y pueden llegar a tener hasta $10 \mathrm{~m}$ de altura. Inducen la resuspensión de los sedimentos profundos (BLOESCH, 1995; BLOESCH, 2004), alcanzando incluso a los materiales depositados en el hipolimnion (HORPPILA Y NIEMISTÖ, 2008).

Existen otros dos tipos de olas internas que están muy influenciadas por la morfometría del lago y por la rotación terrestre. Estos dos forzamientos hacen que las olas se propaguen alrededor de los límites de la cubeta, en lugar de hacerlo a través del centro del lago como ocurre en el caso de no estar influenciados por la rotación. La fuerza de Coriolis es vital para su mantenimiento, así pues, sólo se observan en grandes lagos. Se denominan como olas de Kelvin y olas de Poincaré, y pueden producir corrientes importantes en el hipolimnion de grandes lagos.

Las espirales o franjas de Langmuir son corrientes verticales helicoidales que se forman en la parte superficial del lago, disponiéndose paralelas a la dirección del viento. Se originan por la interacción entre las olas superficiales y las corrientes inducidas por el viento. No tienen importancia en la distribución del sedimento en un lago.

\subsubsection{Corrientes}

Las corrientes son movimientos de agua no periódicos. Los agentes más importantes generadores de corrientes en un lago son el viento (en muchos casos es el principal aporte de energía), cambios asociados a la presión atmosférica, gradientes de densidad causados por el calentamiento-enfriamiento diferencial o sustancias disueltas, y la entrada-salida de ríos (HORNE Y GOLDMAN, 1994; WETZEL, 2001). Las corrientes inducidas por el viento pueden causar la resuspensión del sedimento, aunque no es un fenómeno frecuente en sistemas lacustres (BENGTSSON et al., 1990).

Las corrientes superficiales inducidas por el viendo se originan por la transferencia de energía debido al esfuerzo de fricción del aire sobre la masa de agua. Su relación con el viento dominante se define como el factor del viento (wind factor) que representa la velocidad de la corriente como una fracción de la velocidad del viento. En general, aunque variable, una buena aproximación es aproximadamente un 2-3\% de la velocidad del viento que la ha generado. Cuando se alcanza el equilibrio, la tensión de corte del aire sobre el agua ( $\tau_{\text {aire }}$ ) se iguala a la tensión de corte del agua sobre el aire ( Tagua :

$$
\begin{aligned}
& \tau_{\text {aire }}=\rho_{\text {aire }} u_{* \text { aire }}^{2}=\rho_{\text {agua }} u_{* \text { agua }}^{2}=\tau_{\text {agua }} \text {, donde } u_{*} \text { es la velocidad de corte } \\
& \frac{u_{* \text { agua }}}{u_{* \text { aire }}}=\sqrt{\frac{\rho_{\text {aire }}}{\rho_{\text {agua }}}}=\sqrt{\frac{1,23}{1000}}=0,035 \rightarrow u_{* \text { agua }}=0,035 u_{* \text { aire }}
\end{aligned}
$$

El viento al actuar sobre la superficie libre del lago transfiere energía en forma de una tensión de corte. La presencia de la orilla lacustre condiciona este comportamiento y genera la inclinación dela superficie libre. La interfase aire-agua se eleva a sotavento creando un gradiente 
de presión en la horizontal. Para compensar este desequilibrio se generan unas corrientes en profundidad en sentido contrario a las corrientes superficiales y, además, se produce la inclinación de la interfase de densidad en sentido contrario, es decir, se eleva a barlovento (zona de donde viene el viento). Esta inclinación presenta una pendiente más pronunciada que la superficial debido a que la diferencia de densidades es menor que en el caso aire-agua. El aumento de la velocidad del viento hace que las interfases se inclinen aún más. En algunos casos puede ocurrir que la capa inferior aflore en superficie, fenómeno conocido como surgencia (upwelling). Cuando la presión hidrostática equilibra la tensión de corte en la superficie, la recirculación neta desaparece y se forman dos recirculaciones independientes, una en el epilimnion y otra en el hipolimnion (más tenue).

Las corrientes superficiales en lagos de tamaño considerable tienden a moverse componiendo grandes remolinos o giros a escala de la cubeta (EMERY Y CSANADY, 1973). Aunque están forzados por la rotación dela Tierra, la trayectoria final de los giros está también modificada por otros factores como los vientos, parámetros morfométricos de la cubeta, etc.

\subsubsection{Fuerza de Coriolis}

La fuerza de Coriolis actúa sobre cualquier masa que se desplaza sobre la superficie de la Tierra a consecuencia de su rotación, desviándolas hacia la derecha en el hemisferio norte y hacia la izquierda en el sur. Este efecto se transmite a las capas inferiores dela masa de agua (transporte de Ekmann) y conlleva una pérdida de velocidad de la corriente. Aunque tradicionalmente se considera solamente su efecto sobre las corrientes, también influye en la profundidad de la capa epilimnética, de tal modo que, la profundidad de mezcla varía inversamente con la latitud (LEWIS, 1987).

El efecto de Coriolis influye únicamente en la dinámica de grandes masas de agua, es decir, grandes lagos con dimensiones ( $\mathrm{L}$ ) similares al radio de de formación de Rossby (R). Su posible incidencia en un cuerpo de agua se evalúa con el número de Burger (adimensional). $\mathrm{Si}$ este valor es menor o igual que la unidad, el efecto de Coriolis es relevante y, por consiguiente, se puede afirmar que la hidrodinámica del lago está dominada por la rotación. El número de Burger se define como:

$$
\mathrm{B}=\frac{\mathrm{R}}{\mathrm{L}}
$$

Donde $\mathrm{R}$ es el radio de deformación de Rossby y L es una longitud que caracteriza la dimensión del lago. En la práctica, si la cubeta lacustre presenta una morfología circular, L se considera el radio, y si es elíptica se utiliza la mitad del eje mayor (ANTENUCCI Y IMBERGER, 2001). El radio de deformación de Rossby se calcula como:

$$
\mathrm{R}=\frac{\mathrm{C}}{\mathrm{f}}
$$

Siendo c la celeridad de la corriente en la masa de agua y f el parámetro de Coriolis. Dicho parámetro de Coriolis viene dado por la ecuación:

$$
f=2 \Omega \operatorname{sen} \varphi=\frac{4 \Pi}{T} \operatorname{sen} \varphi
$$
la latitud.

Donde T es el período de rotación de la Tierra, $\Omega$ la velocidad angular de la Tierra, y $\varphi$ es

\subsubsection{Corrientes o plumas de densidad}

Las corrientes de densidad se originan cuando en la masa de agua existe una diferencia de densidad a consecuencia de un gradiente en la temperatura, salinidad, sustancias disueltas, partículas en suspensión o presión. Estas plumas de densidad pueden ser generadas por agentes 
externos (entrada de agua de escorrentía o subterránea) o internos (enfriamiento diferencial, barrera térmica, baricidad térmica u oleaje).

La pluma de densidad clásica y con mayor influencia en la sedimentación, es la producida por la entrada de un flujo al lago. Cuando una corriente cargada de sedimento (densidad $\rho_{c}$ ) entra en un lago o en una masa de aguas estancadas (densidad $\rho_{\mathrm{a}}$ ), la diferencia de densidad existente condiciona la mezcla pudiéndose dar los siguientes casos (figura 4.15):

a) Si $\rho_{c}<\rho_{a}$, el flujo se mueve por la superficie constituyendo un flujo hipopicnal (BATES, 1953) o supraflujo (STURM Y MATTER, 1978). Estas plumas superficiales se ven afectadas por el oleaje y las corrientes generadas por el viento (HALFMAN Y SCHOLZ, 1993). Son fenómenos muy significativos en las desembocaduras (NEMEC, 1995).

b) Si $\rho_{\mathrm{c}}>\rho_{\mathrm{a}}$, el flujo se desliza por el fondo formando un flujo hiperpicnal (BATES, 1953) o infraflujo (STURM Y MATTER, 1978), constituyendo una parte de los flujos gravitatorios subacuosos. Desdeuna perspectiva geolimnológica un flujo gravitatorio subacuoso sólo se considera hiperpicnal (hiperpicnita) sensu stricto si su origen está en una corriente efluente, descartando los flujos originados en el interior dela cubeta por otros fenómenos tales como terremotos (INOUCHI et al., 1996; SHIKI et al., 2000), deslizamientos o slumping (STURM Y MATTER, 1978; KELTS Y HSÜ, 1980), tormentas (SHIKI et al., 2000), etc. Los flujos hiperpicnales generadores de corrientes turbidíticas son eventos frecuentes en lagos lacustres templados y glaciares (GUSTAVSON, 1975; LAMBERT et al., 1976; LAMBERTY HSÜ, 1979; LAMBERTY GIOVANOLI, 1988), y relativamente menos comunes en los lagos tropicales y subtropicales (TIERCELINY MONDEGUER, 1991; TIERCELIN et al., 1992).

c) Si el lago está estratificado y $\rho_{a}$ (hipolimnion) $>\rho_{c}>\rho_{\text {a(epilimnion), el flujo se desplaza por el }}$ fondo hasta que alcanza la picnoclina (termoclina o quimioclina) creando un flujo mesopicnal (BATES, 1953; MULDER Y ALEXANDER, 2001) o interflujo (STURMY MATTER, 1978). En los lagos de agua dulce, los interflujos tienden a quedar confinados en la termoclina, ya que, por definición, ésta exhibe un amplio gradiente de temperatura (y por tanto de densidad) (PEETERS Y KIPFER, 2009). A medida que pierden partículas por decantación y se mezclan con el agua, los interflujos pueden varían su profundidad (HALFMANY SCHOLZ, 1993).

d) Si $\rho_{\mathrm{c}}=\rho_{\mathrm{a}}$, el flujo de dispersa de forma homogénea en la columna de agua formando un flujo homopicnal (BATES, 1953).

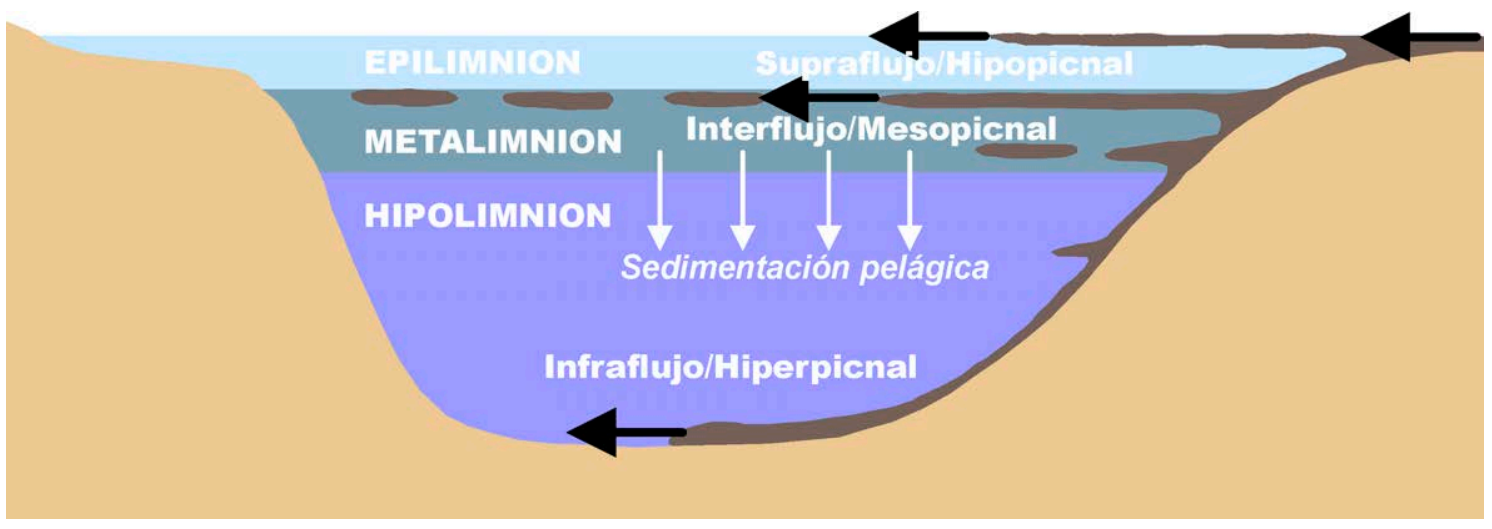

Figura 4.15: Mecanismos dedistribución delos diferentes tipos de plumas dedensidad existentes en un lago.

Otras veces, el enfriamiento diferencial entre las aguas someras y las profundas es el encargado de producir el gradiente de temperatura necesario para generar la corriente de densidad. Esta pluma se mueve por el fondo pudiendo alcanzar grandes profundidades. Para generar este tipo de plumas de densidad es necesario que las aguas estén a una temperatura superior a la temperatura de máxima densidad ( $\left.\mathrm{T}_{\rho \max }\right)$. 
Las barreras térmicas son un caso particular del fenómeno denominado cabbeling. El cabbeling se origina por la mezcla de dos masas de agua de igual densidad pero con diferente temperatura y salinidad. Debido a la dependencia no linear de la densidad con la temperatura y la salinidad, el agua resultante siempre tiene una densidad mayor y se hunde. Las barreras térmicas se forman paralelas a la línea de costa cuando se mezclan dos masas de aguas, una con una temperatura mayor y la otra menor que $T_{\rho \operatorname{smax}}$. Esta agua de mezcla presenta una temperatura muy cerca de la $T_{\text {pmax }} \mathrm{y}$ por tanto se hunde como una pluma térmica (RAO Y SCHWAB, 2007; RAOY MURTHY, 2008).

La baricidad térmica se produce por el efecto termobárico (decrecimiento de la $\mathrm{T}_{\text {pmax }} \mathrm{al}$ aumentar la presión). Requiere de unas condiciones tan específicas que hacen que sea un fenómeno raro (MCDOUGALL, 1987).

Tanto las barreras térmicas como la baricidad térmica son fenómenos queno se producen en los lagos tropicales ya que la temperatura de sus aguas siempre está por encima de $\mathrm{T}_{\text {pmax }}$. Por el contrario, las corrientes de densidad debida a fenómenos de enfriamiento diferencial y entrada de flujos son muy importantes (PEETERS Y KIPFER, 2009). 
Sistemas lacustres: estado del arte 


\section{Análisis sedimentológico: microfacies y facies}

En este capítulo se aborda el estudio sedimentológico de los materiales presentes en el Grupo Enciso. Como ya se ha comentado en el apartado sobre la metodología, el presente estudio sedimentológico incluye la descripción pormenorizada de las facies reconocidas durante el muestreo de las cinco columnas estratigráficas levantadas: Enciso, Munilla, Cornago, Ambas Aguas y Préjano (anexos IV, V, VI, VII y VIII). La individualización se inicia con la caracterización de las microfacies, para posteriormente abordar el estudio de las litofacies.

\subsection{MICROFACIES}

Una microfacies se define como el conjunto de aspectos distintivos y característicos de una roca sedimentaria que son únicamente observables bajo el microscopio (BROWN, 1943; NEUENDORF et al., 2005). Sin embargo, la definición de FLÜGEL (2010) es menos restrictiva y de un uso más amplio y engloba a todos los datos sedimentológicos y paleontológicos que pueden ser descritos e identificados a partir de láminas delgadas, réplicas y muestras pulidas o de mano

Para la descripción de las microfacies siliciclásticas por microscopio petrográfico se ha utilizado la tradicional clasificación de PETTIJ OHN et al. (1987). Los parámetros morfológicos referentes a la esfericidad y redondez de los granos detríticos se han obtenido por comparación visual con la tabla patrón de los mismos autores (PETTiJ OHN et al., 1987). El grado de selección de los elementos siliciclásticos se ha estimado por comparación con la tabla de referencia de COMPTON (1962).

Para la caracterización de las microfacies carbonatadas se ha usado la clasificación de DUNHAM (1962), con las modificaciones de EMBRY Y KLOVAN (1971). Sin embargo, para una descripción más detallada, se han utilizado términos de la clasificación de FOLK (1959; 1962) y FLÜGEL (2010), así como de cierta terminología típica del estudio de medios lacustres-palustres (ARMENTEROS et al., 1997; FREYTET Y VERRECCHIA, 2002; ALONSO-ZARZA YWRIGHT, 2010).

La identificación de las principales microfacies se ha realizado a partir del estudio de 160 láminas delgadas que abarcan la mayor diversidad posible observada en campo. Se han diferenciado 13 microfacies cuya descripción es del siguiente modo:

\subsubsection{Microfacies 1: arenita masiva}

En esta microfacies se agrupan todas las muestras pertenecientes a la familia de las arenitas. La mayoría se clasifican como cuarzoarenitas y, de manera anecdótica, aparecen sublitarenitas. Exhiben un esqueleto constituido dominantemente por clastos de cuarzo y, en algunas muestras, moscovita y/o fragmentos de roca. Como accesorios aparecen plagioclasa (exhibiendo maclado polisintético), moscovita (con cierto grado de deformación por la compactación), biotita, feldespato (en general muy alterado), óxidos de hierro, fragmentos de rocas lutíticas, turmalina, circón y materia orgánica (figura 5.1).

Los granos de cuarzo son monocristalinos, con un tamaño comprendido entre arena muy fina-fina, a veces arena media (figuras 5.1A y B), formando un armazón equigranular bien seleccionado. Los granos varían desde subredondeados hasta angulosos con una baja esfericidad. Debido a la compactación, los granos muestran contactos largos, cóncavo-convexos y sobre todo suturados, así como puntos triples (figuras 5.1C y D). Muchos muestran grados variables de corrosión por cemento de calcita.

La matriz es una arcillolita muy rica en materia orgánica que puede, localmente, coexistir con una matriz micrítica. En ocasiones, seobservan zonas con matriz clorítica de colores verdosos. El cemento mayoritario es esparítico, forma un mosaico equidimensional que ocupa el espacio intergranular, y corroe los bordes de los componentes del esqueleto. También se ha observado algo de cemento de cuarzo y cemento pelicular ferruginoso. 


\section{Análisis sedimentológico: microfacies y facies}
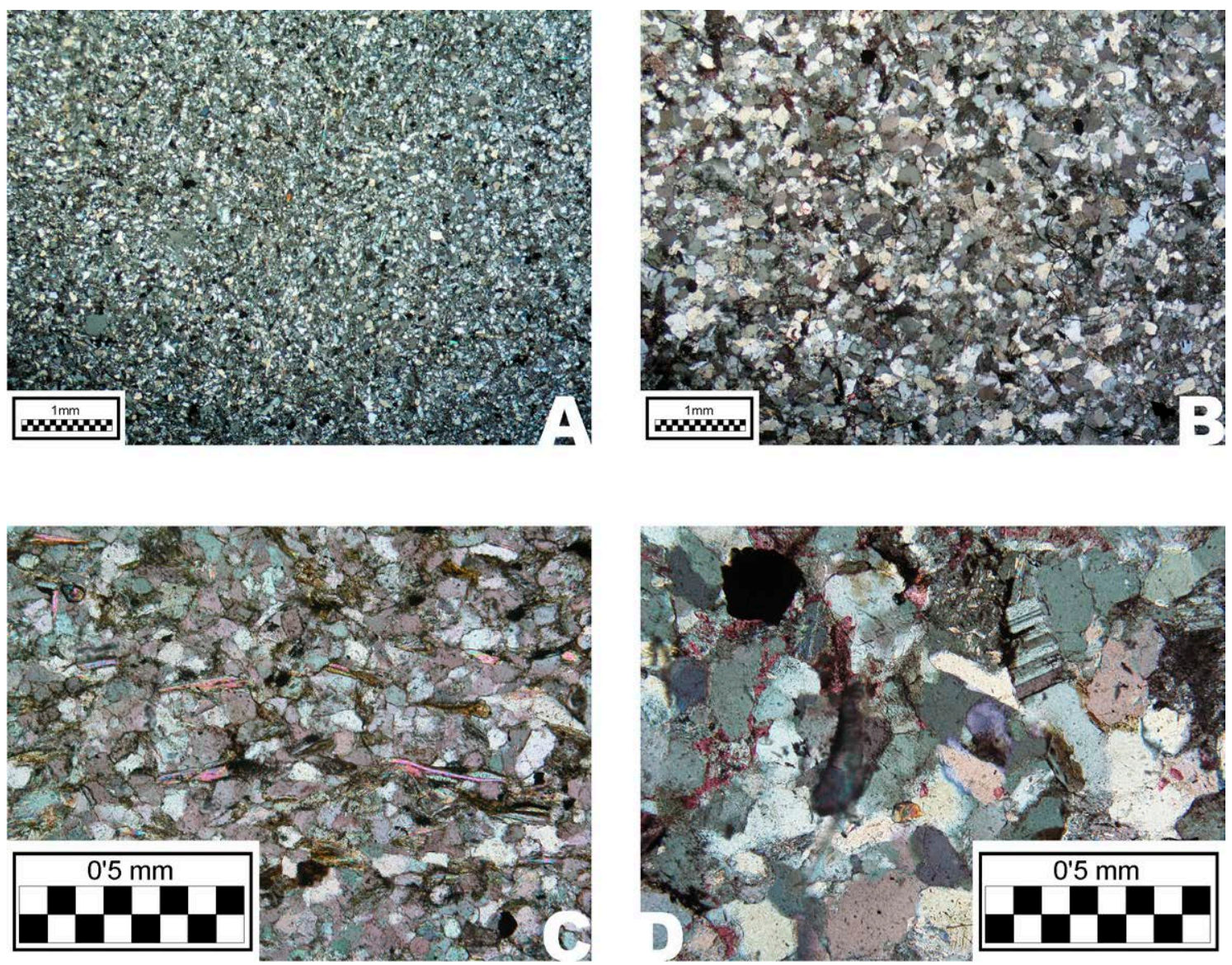

Figura 5.1: Ejemplos de la microfacies 1 bajo el microscopio petrográfico. A) y B) muestran el aspecto general (x2). C) y D) son fotos de detalle (x10). Todas las fotografías han sido tomadas con nícoles cruzados.

\subsubsection{Microfacies 2: arenita laminada}

Según el tipo de laminación existente se subdivide en 3 microfacies: microfacies 2a (laminación debida a moscovita), microfacies $2 \mathrm{~b}$ (laminación debida a ostrácodos) y microfacies 2c (laminación definida por opacos).

\subsubsection{Microfacies 2a: arenita con laminación debida a moscovita}

La lámina clara ( $2-5 \mathrm{~mm}$ ) es una cuarzoarenita o grauvaca que en algunas muestras es muy carbonatada. Está constituida mayoritariamente por granos de cuarzo. Como accesorios aparecen plagioclasa, óxidos de hierro, feldespato y materia orgánica. Los granos de cuarzo (monocristalinos, en menor proporción policristalinos), constituyen un armazón con buena selección y un tamaño comprendido entre arena muy fina-arena fina (figura 5.2A). Los granos varían entre subangulosos - angulosos de baja esfericidad y gran cantidad de contactos largos, cóncavo-convexos y suturados (figura 5.2B). Muestran un proceso variable de corrosión por el cemento esparítico. La matriz es arcillosa-micrítica y, según la muestra analizada, puede variar entre abundante (20\%) a casi nulo (2\%). El cemento es calcítico, silíceo y/ o ferruginoso (muy raro).

La lámina más oscura presenta espesores de unos 300-500 $\mu \mathrm{m}$. En general muestra una composición parecida a la lámina clara con un mayor desarrollo de la matriz y, sobre todo, se distingue por la gran abundancia en moscovita que se dispone paralela a los límites de la laminación (figura 5.2B). En algunos casos puede ser más abundante que el cuarzo. 

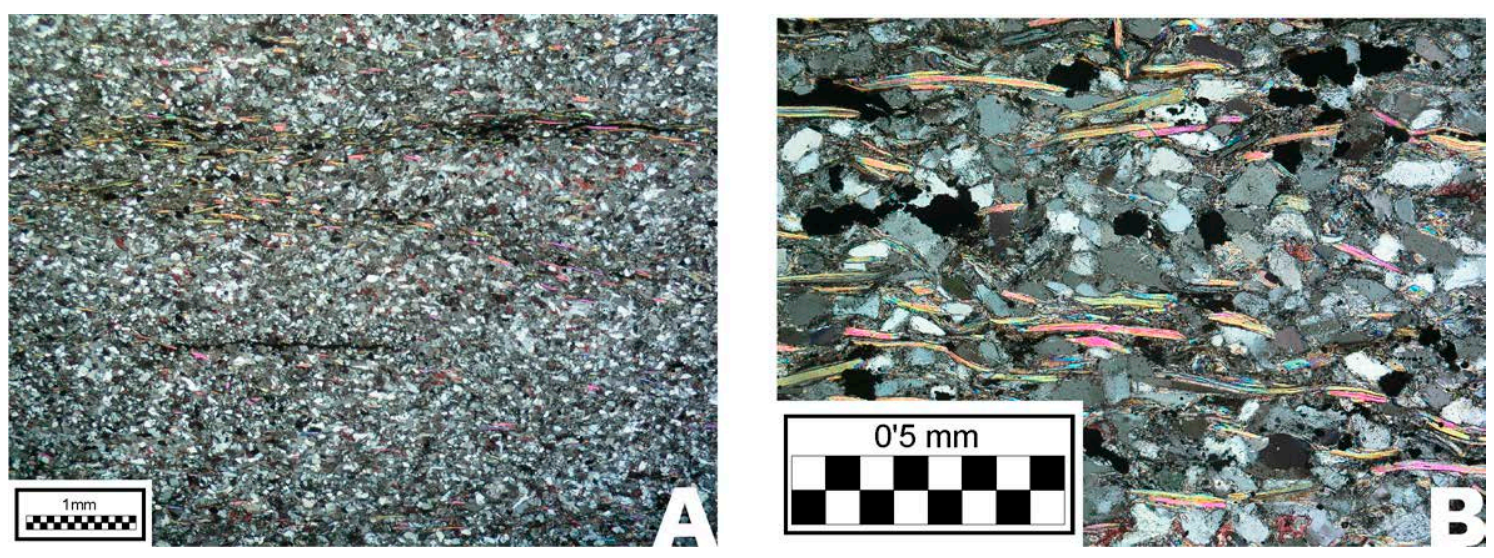

Figura 5.2: Ejemplos de la microfacies 2a bajo el microscopio petrográfico. A) Aspecto general dela muestra donde se observa la laminación (x2) y B) detalle delas láminas demoscovita (x10). Ambas fotografías han sido tomadas con nícoles cruzados.

\subsubsection{Microfacies $2 b$ : arenita con laminación debida a ostrácodos}

Las láminas muestran límites poco nítidos, a veces, con muy poca continuidad lateral. La lámina clara presenta espesores entre 3-5 $\mathrm{mm}$. Consta de un esqueleto homométrico, con buena clasificación, de granos de cuarzo tamaño arena muy fina y limo grueso (figura 5.3A). Los granos monocristalinos son subangulosos-angulosos de baja esfericidad y, con contactos largos y/o cóncavo-convexos (figura 5.3B). Los accesorios están formados por fragmentos de roca lutítica, moscovita (localmente se presenta en proporciones altas), feldespato y plagioclasa. La matriz es arcillosa-micrítica. El cemento calcítico es abundantey suele corroer los granos del armazón. Se observa, también, algo de cemento ferruginoso.
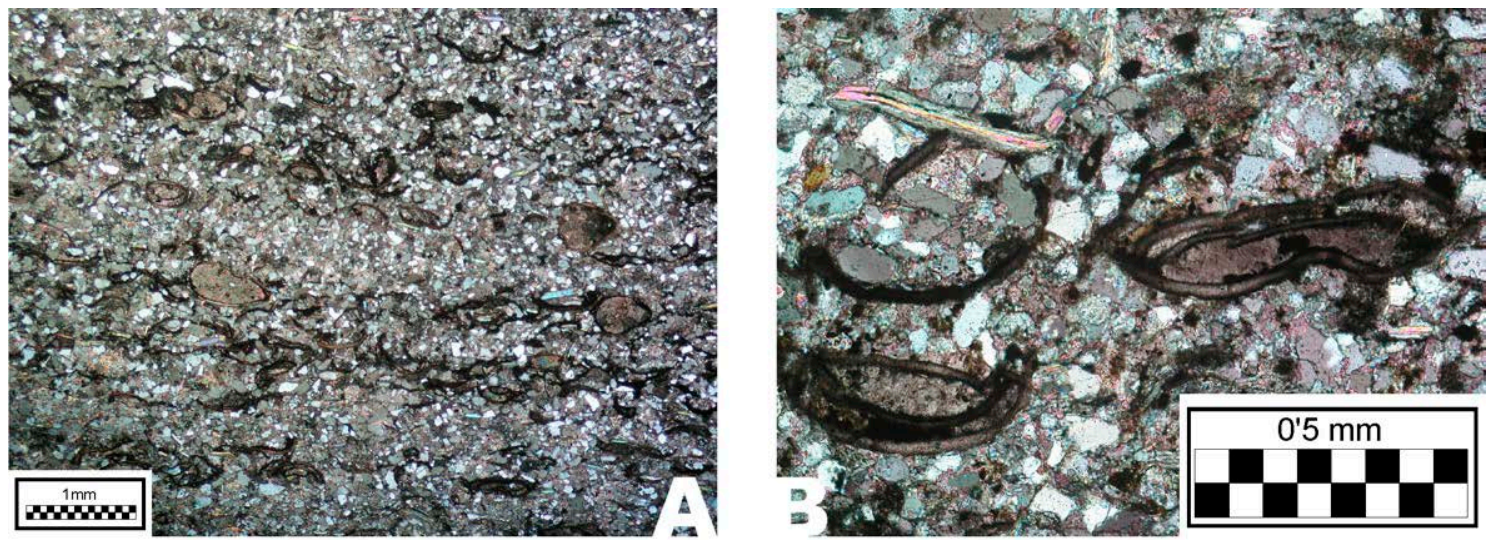

Figura 5.3: Ejemplos de la microfacies 2b bajo el microscopio petrográfico. A) Aspecto general de la muestra donde se observan algunos ostrácodos enteros (x2). B) detalle de las láminas de ostrácodos (x10). Ambas fotografías han sido tomadas con nícoles cruzados.

La lámina oscura tiene un espesor irregular comprendido entre $400-700 \mu \mathrm{m}$. Está formada por una acumulación de ostrácodos y granos de cuarzo como componentes principales. Los restos de ostrácodos se componen de valvas desarticuladas y escasos caparazones enteros articulados, algunos de ellos aplastados (figuras 5.3A y B). Las valvas desarticuladas se acomodan paralelas a la laminación, sin una disposición preferente en la orientación de su concavidad. Los caparazones enteros están rellenos de un mosaico de esparita o micrita. El tamaño en los granos de cuarzo es ligeramente inferior al que aparece en las láminas claras. Presentan una mayor proporción de granos tamaño limo que, además, exhiben más esfericidad. La moscovita está en proporciones accesorias y tiende a orientarse paralela a la laminación, aunque también aparece oblicua o subperpendicular. Se observa un mayor contenido en cemento esparítico en mosaico 


\section{Análisis sedimentológico: microfacies y facies}

equidimensional que corroe los granos de cuarzo monocristalino y de moscovita. El contenido en matriz arcillosa es también superior.

\subsubsection{Microfacies 2c: arenita con laminación definida por opacos}

La lámina de color claro presenta espesores comprendidos entre 3-4 $\mathrm{mm}$. Es una cuarzarenita homométrica de cuarzo monocristalino, tamaño arena fina (en menor medida limo y arena muy fina) y, buena clasificación. Los granos varían entre subangulosos-angulosos de baja esfericidad, presentando puntos triples y, contactos largos y cóncavo-convexos (figura 5.4A). Como accesorios aparecen fragmentos de roca de naturaleza lutítica y carbonatada, anfíbol, moscovita, biotita, feldespato y plagioclasa. La matriz es arcillosa. El cemento es calcítico (corroe los bordes de los granos de cuarzo) y ferruginoso.

La lámina de color oscuro $(100-300 \mu \mathrm{m})$ presenta límites nítidos e irregulares. Está formada por acumulaciones de opacos que, debido al aspecto moteado-ferruginizado de la muestra de mano, se asocian a óxidos de hierro (figuras 5.4A y B).
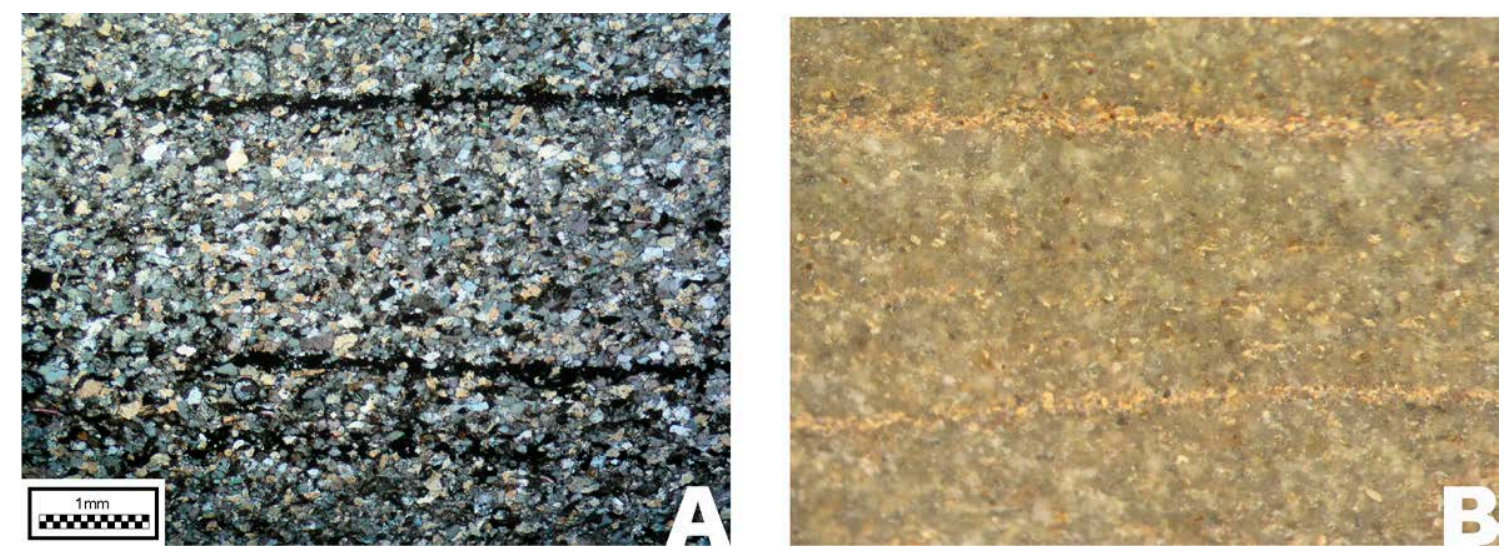

Figura 5.4: Ejemplos dela microfacies 2c. A) aspecto general dela muestra donde se observa la laminación definida por opacos (x2). La fotografía ha sido tomada con nícoles cruzados. B) muestra de mano en detalle de las láminas debidas a opacos.

\subsubsection{Microfacies 3: grauvaca masiva}

Esta microfacies engloba las muestras pertenecientes a la familia de las grauvacas. Todas las láminas analizadas se clasifican como grauvacas cuarzosas no habiéndose reconocido ni grauvacas feldespáticas ni líticas. En general, representan rocas inmaduras con una selección buena-moderada. El esqueleto está formado básicamente por granos de cuarzo homométrico y moscovita como componentes principales. Como accesorios aparecen feldespato, biotita, fragmentos de roca (lutíticosy carbonatados), plagioclasa (con maclas polisintéticas) y glauconita.
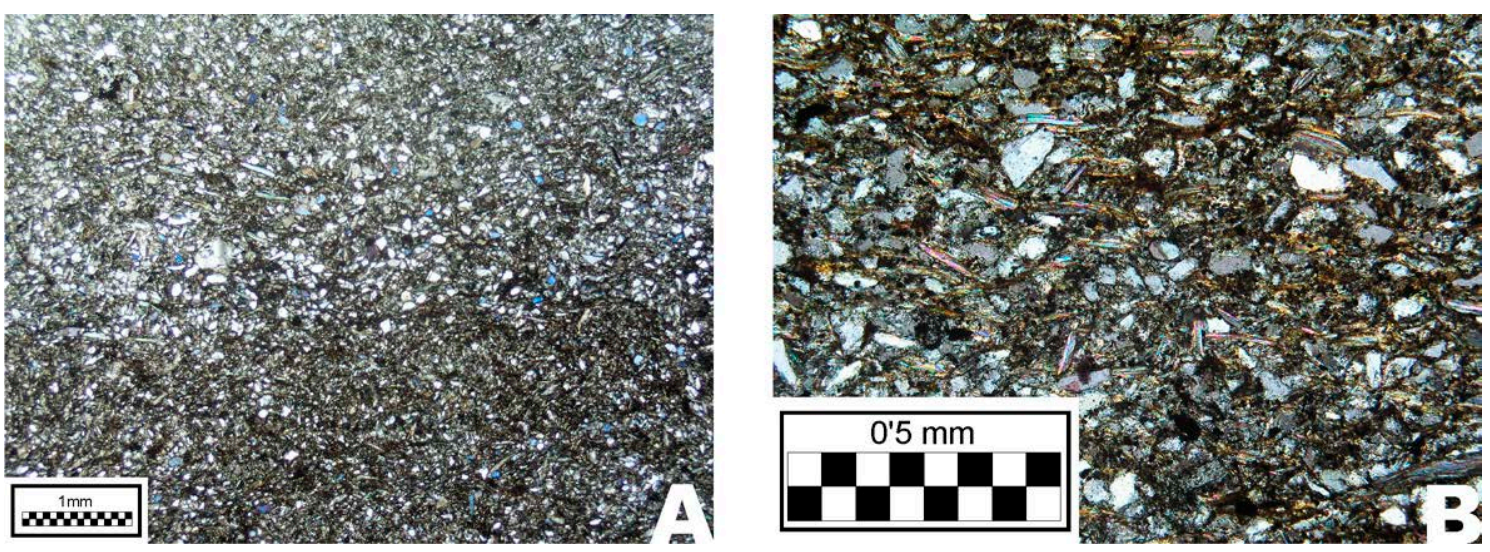

Figura 5.5: Ejemplos dela microfacies 3 bajo el microscopio petrográfico. A) aspecto general de la muestra (x2) y B) detalle (x10). Ambas fotografías han sido tomadas con nícoles cruzados. 


\section{Análisis sedimentológico: microfacies y facies}

El cuarzo es de tamaño arena muy fina con escaso tamaño limo (figura 5.5A), aunque en ciertas muestras los granos tamaño arena fina pueden ser importantes. Los contactos son de tipo puntual y largo, en ocasiones, cóncavo-convexo y, raramente, suturado. La granos son equigranulares, con morfología de baja-alta esfericidad y, subredondeados-angulosos. La moscovita no presenta orientación preferente. Localmente puede ser muy abundante (hasta un 15\%) haciendo que la muestra sea muy moscovítica (figura 5.5B).

La matriz, muy abundante, es de naturaleza arcillosa y procede de la meteorización de los silicatos (epimatriz). En algunas muestras, presenta un elevado contenido en materia orgánica. Localmente, aparece escaso cemento de calcita.

\subsubsection{Microfacies 4: arenita-limolita laminada}

La lámina oscura presenta un espesor comprendidos entre 120 y $1500 \mu \mathrm{m}$ (figuras 5.6A, C, E y F). Está formada por una limolita de granos de cuarzo monocristalino y abundante moscovita. Los granos son subredondeados a subangulares, de tamaño limo grueso y, en menor cuantía, arena muy fina. Los clastos de cuarzo aparecen flotando en la matriz arcillosa aunque, en ocasiones, se observan contactos puntuales y largos. La moscovita es muy abundante y muestra una clara orientación paralela a la laminación. La matriz es arcillosa con un alto contenido en materia orgánica y, en ocasiones, puede ser muy carbonatada. Aparece escaso cemento calcítico (figuras 5.6B y D).
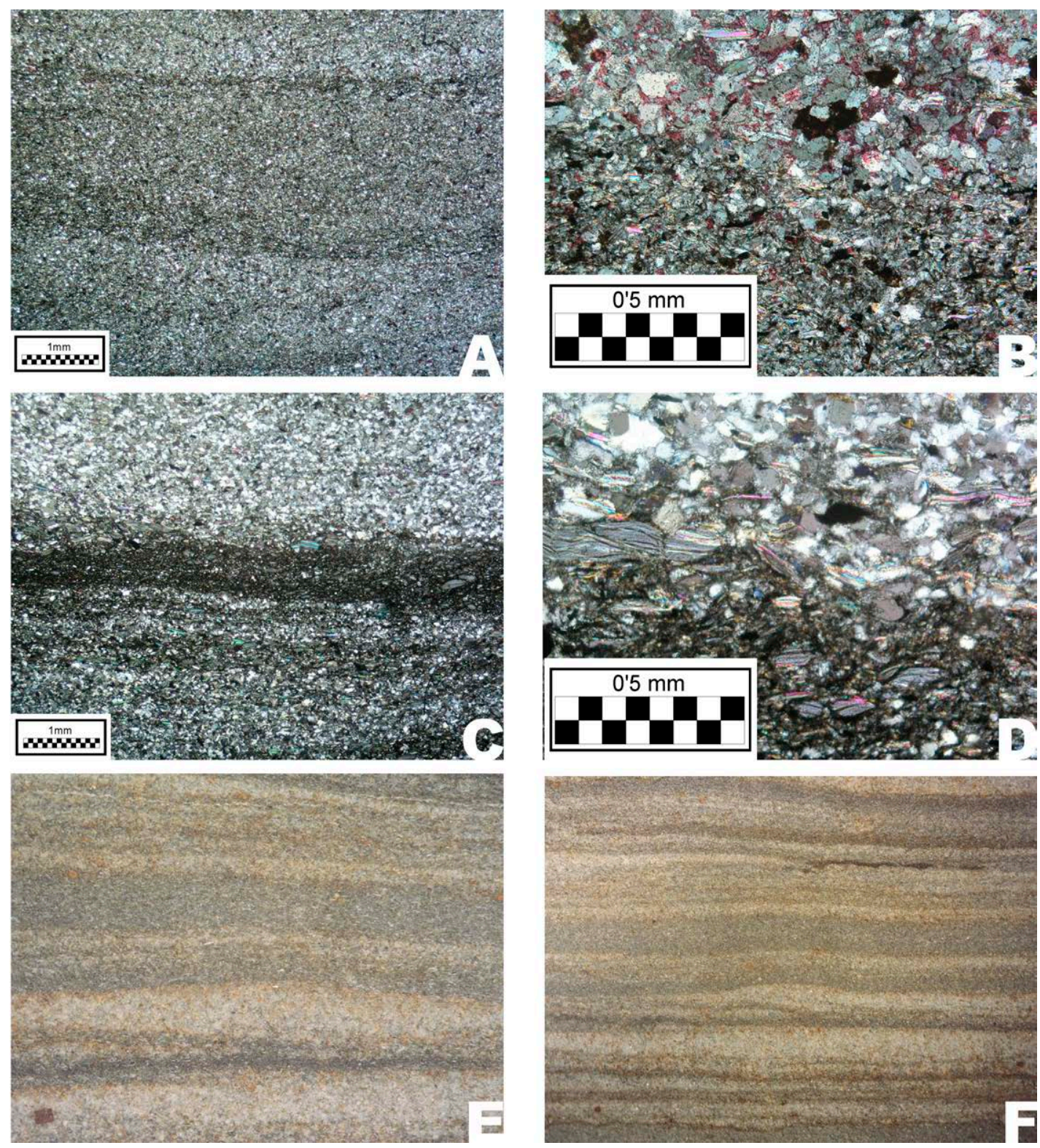
Figura 5.6: Ejemplos de la microfacies 4. Lámina FC: A) aspecto general de la laminación (x2) y B) detalle del contacto entre láminas (x10). Lámina W10: C) aspecto general de la laminación (x2) y D) detalle del contacto entre láminas. Todas las fotografías han sido tomadas con nícoles cruzados. E) y F) son ejemplos de la laminación en muestras de mano.

La lámina clara tiene espesores comprendidos entre 300-1500 $\mu \mathrm{m}$ (figuras 5.6A, C, E y F). Consta de un esqueleto de granos de cuarzo monocristalino de tamaño arena fina (el tamaño limo grueso puede abarcar un porcentaje importante en algunas muestras) y de morfología angulosa-subangulosa (raramente redondeada). Los contactos son de tipo largo y cóncavoconvexo. El contenido en moscovita es menor que el observado en las láminas oscuras, aunque sigue apareciendo en cantidades principales y muestra una orientación preferente paralela a la laminación. Localmente son abundantes los óxidos de hierro. La matriz es arcillosa y con un menor contenido en materia orgánica. El cemento calcítico corroe algunos granos del esqueleto (figuras 5.6B y D).

\subsubsection{Microfacies 5: limolita masiva}

Está constituida por una matriz arcillosa o limosa con abundante materia orgánica donde flotan los terrígenos con contactos puntuales. Los componentes principales del esqueleto son cuarzo y moscovita (figuras 5.7A y B). El cuarzo es siempre de tamaño limo grueso y varía entre subanguloso a subredondeado. La moscovita suele aparecer orientada. Los componentes accesorios son muy variables: calcita, óxidos de hierro y feldespato. En algunas muestras la cantidad de cemento calcítico es significativa. Los ostrácodos (caparazones articulados y valvas aisladas), cuando aparecen, son siempre accesorios y suelen estar silicificados.
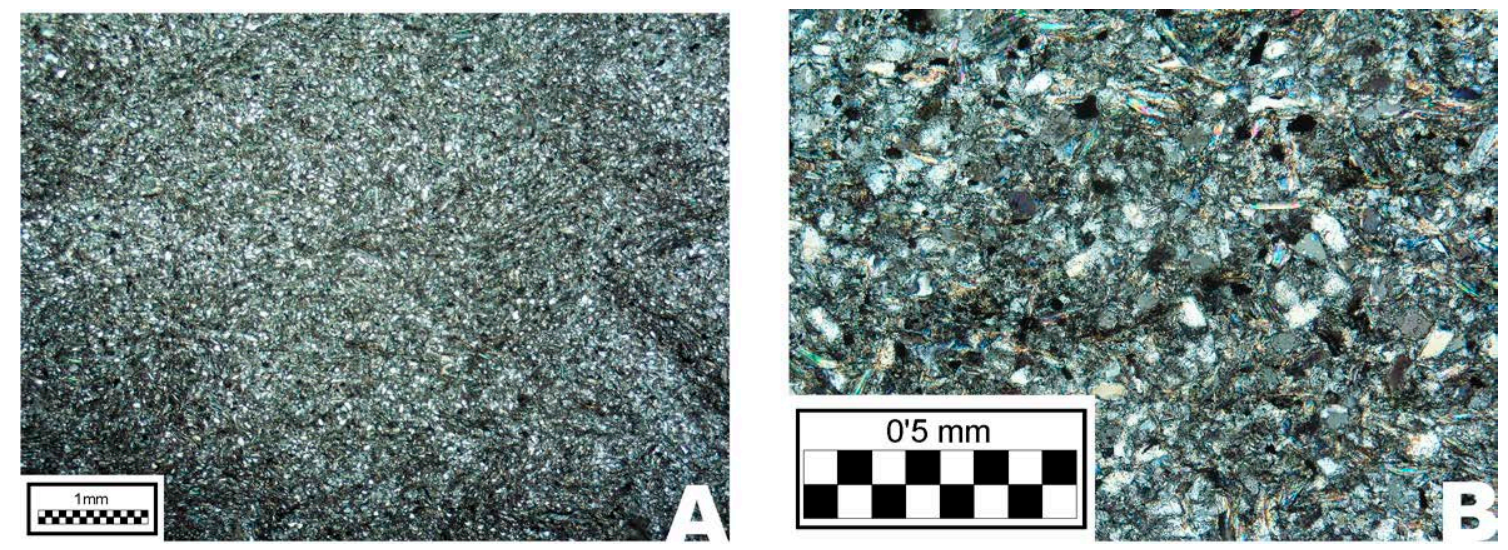

Figura 5.7: Ejemplos dela microfacies 5 bajo el microscopio petrográfico. A) aspecto general de la muestra (x2) y B) detalle (x10). Ambas fotografías han sido tomadas con nícoles cruzados.

\subsubsection{Microfacies 6: limolita laminada}

Son limolitas-arcillolitas que exhiben una laminación con espesores comprendidos entre 0,1-1 mm (lámina oscura) y 0,2-2 mm (lámina clara) (figuras 5.8A, By D). Dentro de una misma muestra los espesores son muy variables. En ocasiones, la laminación está levemente afectada por bioturbaciones o muestra evidencias de perturbaciones tales como convoluciones, microfallas, rizaduras, y convoluciones (loop bedding), lo cual le confieren un aspecto difuso y con poca continuidad lateral (figura 5.8C).

La lámina oscura es una arcillita con un elevado contenido en materia orgánica. Otros componentes principales que parecen son: cuarzo tamaño limo grueso y moscovita con una selección moderada - pobre. Los granos de cuarzo monocristalinos (subredondeados-angulosos) aparecen flotando en la matriz arcillosa rica en materia orgánica o mostrando contactos puntuales y largos. Debido a su baja esfericidad tienden a orientarse con el eje mayor paralelo a la laminación. La moscovita, que en ocasiones está en proporciones accesorias, exhibe siempre una clara orientación paralela a los límites definidos por la laminación. 


\section{Análisis sedimentológico: microfacies y facies}
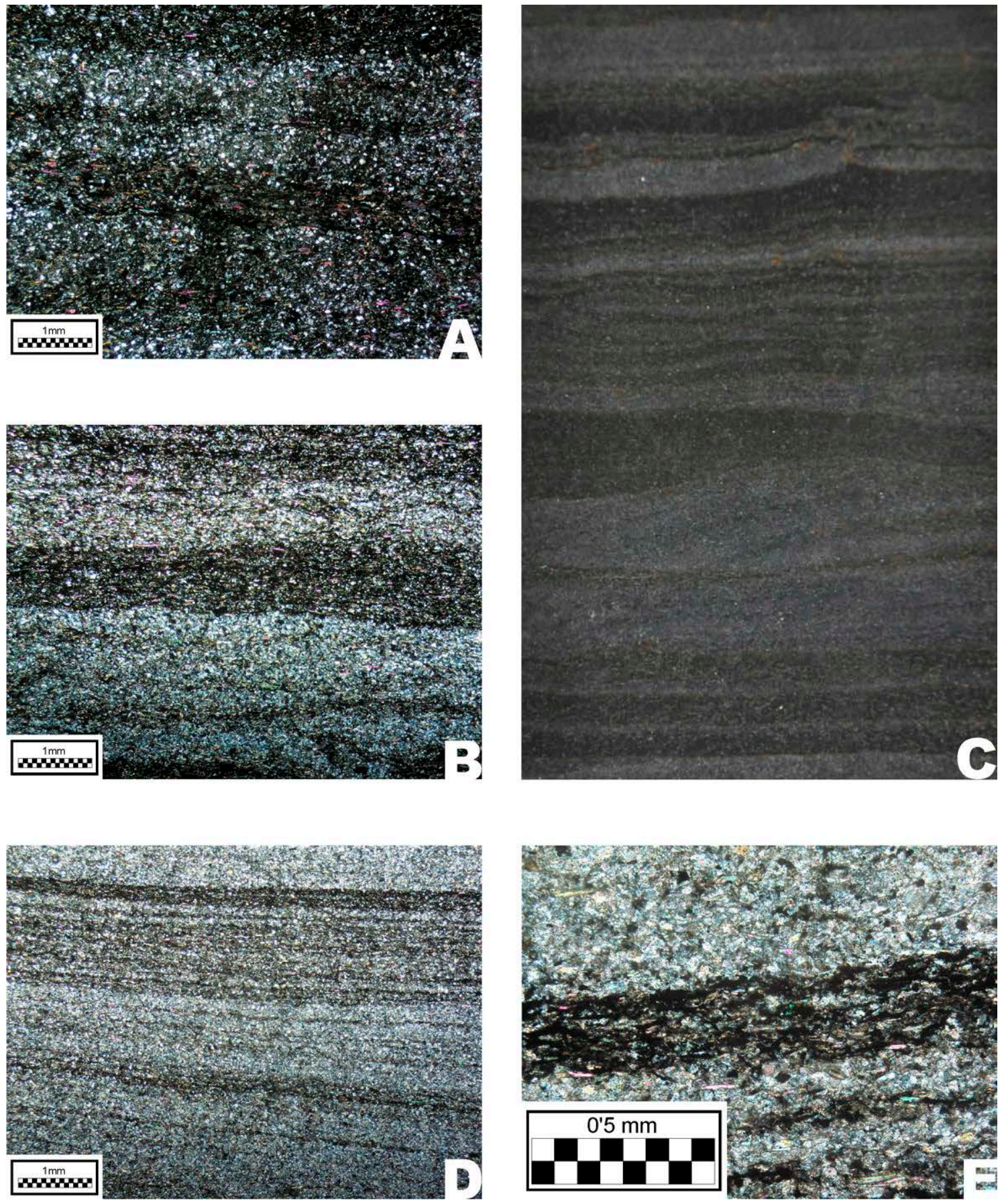

Figura 5.8: Ejemplos de la microfacies 6 bajo el microscopio petrográfico. A) y B) aspecto general de la laminación (x2). C) muestra de mano de la laminación. D) aspecto general (x2) y E) detalle (x10). Todas las fotografías han sido tomadas con nícoles cruzados.

La lámina clara muestra una selección entre buena y moderada. Está conformada por abundantes granos de cuarzo tamaño limo grueso (en proporciones accesorias, tamaño arena fina). Los granos varían de subredondeados a subangulosos con contactos largos, cóncavoconvexos y suturados. No se observa orientación, aunque en las láminas de menor espesor existe cierta tendencia a disponerse con el eje mayor subparalelo a la laminación. Los granos pueden mostrar cierta corrosión por el cemento calcítico. La moscovita es abundante, constituyendo un componente principal, y aparece orientada a favor de la laminación. El esqueleto se dispone en una matriz de naturaleza arcillosa (clorítica) y/ o carbonatada. Aparece cemento silíceo, calcítico (microesparítico y esparítico) y ferruginoso (figura 5.8E). 


\section{Análisis sedimentológico: microfacies y facies}

\subsubsection{Microfacies 7: caliza bioclástica mudstone-wackestone}

En términos de abundancia, es la microfacies más representativa del conjunto de calizas en el Grupo Enciso. Son rocas matriz-soportadas con una proporción importante en bioclastos. En función del tipo de bioclasto dominante se han reconocido dos microfacies: microfacies 7a (ostrácodos) y microfacies 7b (carófitas).

\subsubsection{Microfacies 7a: caliza bioclástica de ostrácodos}

Es una biomicrita con textura mudstone-wackestone cuyo componente aloquímico principal son los ostrácodos (figuras 5.9A y C). El espectro de bioclastos comprende, en orden decreciente de abundancia: ostrácodos, fragmentos de moluscos, oogonios de carófitas y restos vegetales. Los ostrácodos pueden ser los únicos bioclastos existentes, y el resto siempre aparece en proporciones accesorias. Los ostrácodos preservados presentan diferentes grados de conservación (caparazones articulados, caparazones aplastados, caparazones fragmentados, valvas enteras, valvas fracturadas) y no muestran una orientación o disposición preferente en la matriz micrítica. Los caparazones aparecen rellenos por un mosaico drúsico o granular de esparita o microesparita (figuras 5.9B y D), por una matriz micrítica de características iguales a la matriz donde se encuentran englobados y/o, en algunos casos, por una matriz micrítica de naturaleza diferente a la englobante sugiriendo cierto retrabajamiento. En algunas zonas la acumulación preferente de ostrácodos genera texturas packstone.
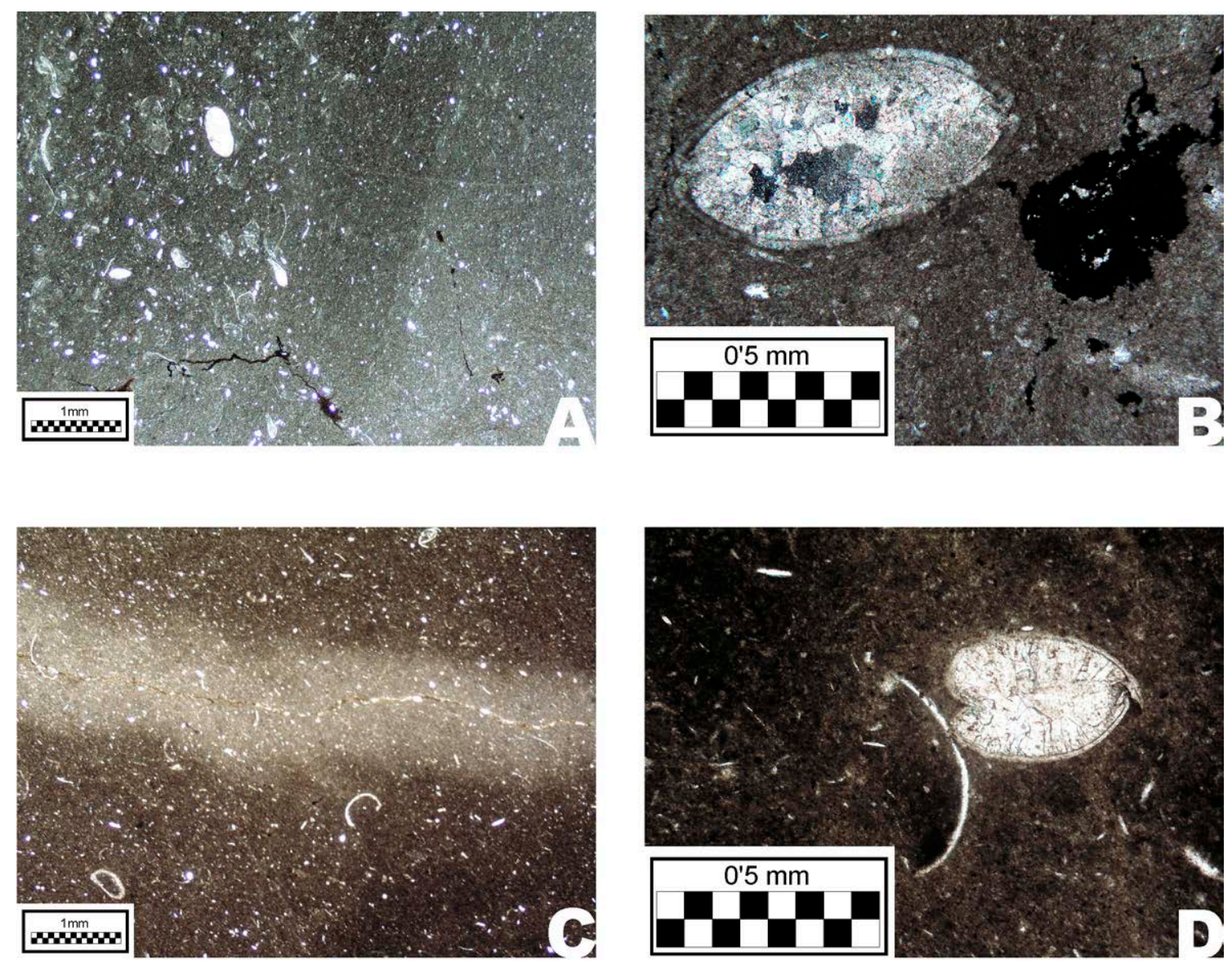

Figura 5.9: Ejemplos de la microfacies 7a bajo el microscopio petrográfico. A) aspecto general de la muestra (x2) y B) detalle de los bioclastos (x10). Ambas fotografías han sido tomadas con nícoles cruzados. C) aspecto general (x2) y D) detalle (x10). Ambas fotografías han sido tomadas sin nícoles.

Los terrígenos (cuarzo, moscovita, feldespato y opacos) son minoritarios o accesorios y se disponen flotando dentro de la matriz micrítica. Suelen mostrar evidencias de corrosión por el 


\section{Análisis sedimentológico: microfacies y facies}

cemento esparítico. Los granos de cuarzo son subredondeados con un tamaño comprendido entre limo y arena fina.

La matriz es masiva y de naturaleza micríticas aunque, a veces, aparece esparita. En algunas muestras la proporción de arcilla en la matriz puede ser importante. El contenido en materia orgánica es siempre muy importante. Algunas láminas muestran una matriz micrítica de diferentes tonalidades separadas por límites irregulares.

La porosidad es baja y se asocia al contenido en bioclastos (tipo móldica). También aparecen estructuras fenestrales, microfracturas y trazas de raíces rellenas por un mosaico esparítico (figura 5.9C).

\subsubsection{Microfacies 7b: caliza bioclástica de carófitas}

Se trata de una biomicrita con textura wackestone (localmente puede constituir un floatstone) formada básicamente por acumulaciones de restos de carófitas: dominan los fragmentos de talos y, en menor cuantía, los oogonios (figuras 5.10A y C). Las secciones transversales de talos son abundantes y muestran su estructura típica: una célula axial de unos 200-300 $\mu \mathrm{m}$ de diámetro rodeada de un anillo externo conteniendo entre 12 y 18 células corticales con un tamaño aproximado de $60 \mu \mathrm{m}$ (figuras 5.10B y D). También son abundantes las secciones longitudinales (sin orientación preferente) de hasta varios milímetros de longitud. Los talos suelen estar rellenos por un mosaico blocky o drúsico de cemento esparítico euhedral. Otros están recubiertos por una película micrítica de distinto color al de la micrita de la matriz. Como accesorios aparecen cuarzo, ostrácodos y óxidos de hierro. El contenido en terrígenos es escaso o nulo: pudiendo aparecer algún grano de cuarzo tamaño limo flotando en la matriz micrítica. Ocasionalmente se distinguen algunas valvas desarticuladas de ostrácodos ( $<2 \%)$.
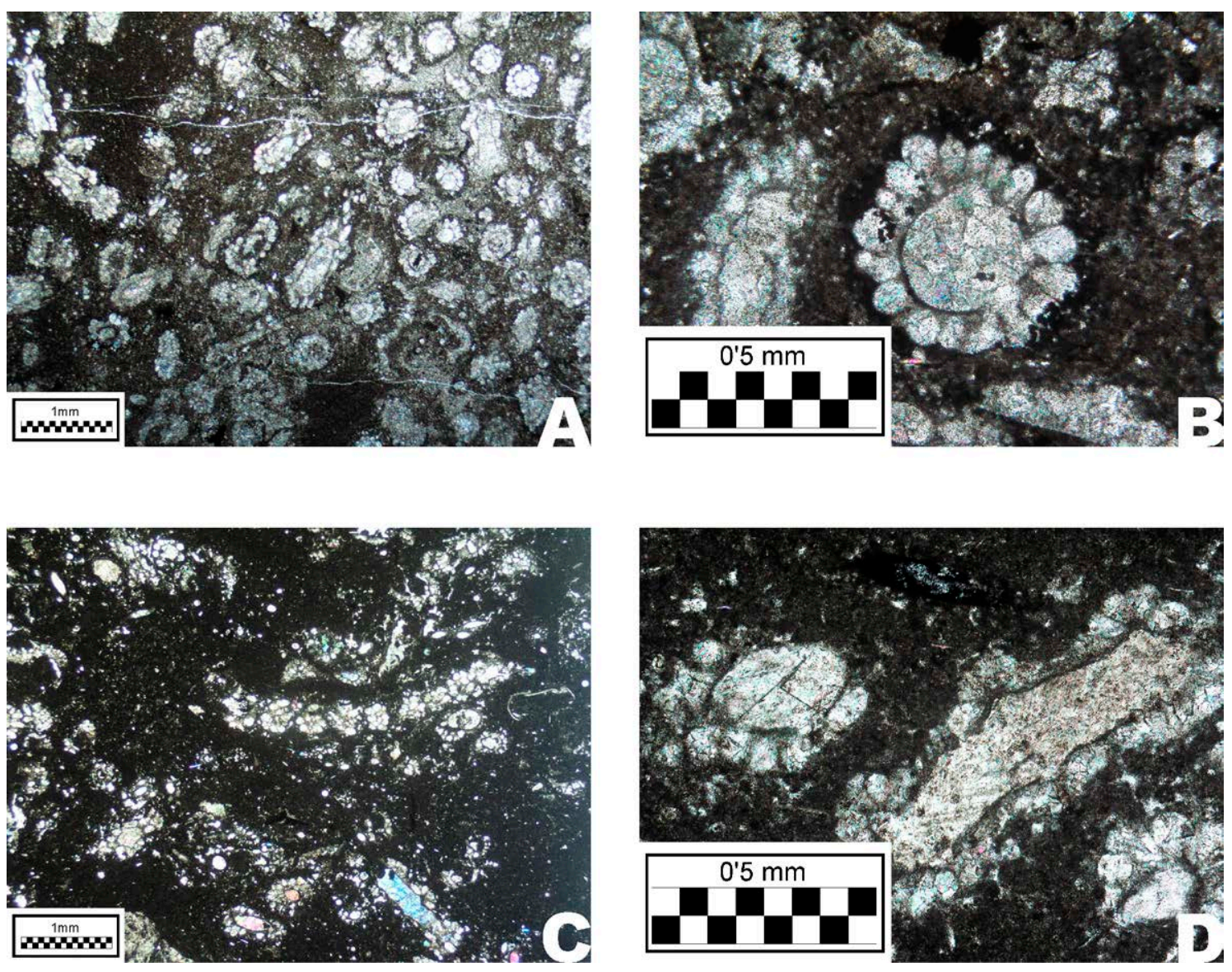

Figura 5.10: Ejemplos de la microfacies 7b bajo el microscopio petrográfico. A) aspecto general dela muestra (x2) y B) detalle delas secciones detalos (x10). C) aspecto general (x2) y D) detalle (x10). Todas las fotografías han sido tomadas con nícoles cruzados. 


\section{Análisis sedimentológico: microfacies y facies}

La matriz es micrítica, de color oscuro y con zonas donde muestra una ligera recristalización a microesparita. Presenta porosidad selectiva (fenestral y móldica), y no-selectiva originada por grietas poco desarrolladas que podrían corresponder a trazas de raíces. Todos los poros están rellenos por un mosaico de cemento esparítico. También se observan huecos rellenos de micrita, de otro color al de la matriz, que se interpretan como bioturbaciones.

\subsubsection{Microfacies 8: caliza bioclástica packstone de ostrácodos}

Esta microfacies está formada por ostracoditas. En función de los caracteres observados en el estudio petrográfico se han diferenciado dos microfacies: microfacies 8a (packstone de ostrácodos) y microfacies $8 \mathrm{~b}$ (packstone de ostrácodos con intraclastos).

\subsubsection{Microfacies 8a: packstone de ostrácodos}

Se trata de una biomicrita packstone compuesta en su totalidad por bioclastos de ostrácodos: caparazones articulados, caparazones aplastados, caparazones fragmentados, valvas enteras y valvas fracturadas (figuras 5.11A, B, C y D). Los caparazones $(800-300 \mu \mathrm{m})$ pueden estar rellenos por la propia matriz micrítica, o bien por un mosaico granular o drúsico de cemento microesparítico-esparítico. Las valvas presentan imbricación concordante (con algunos bioclastos perpendiculares y oblicuos) con una densidad de empaquetamiento elevada. La matriz micrítica muestra poros y huecos fenestrales vacíos o rellenos de cemento esparítico. La bioturbación existente puede llegar a fragmentar algunos bioclastos. En cantidades siempre accesorias aparece moscovita y cuarzo (tamaño arena fina), que puede mostrar evidencias de corrosión por el cemento calcítico.
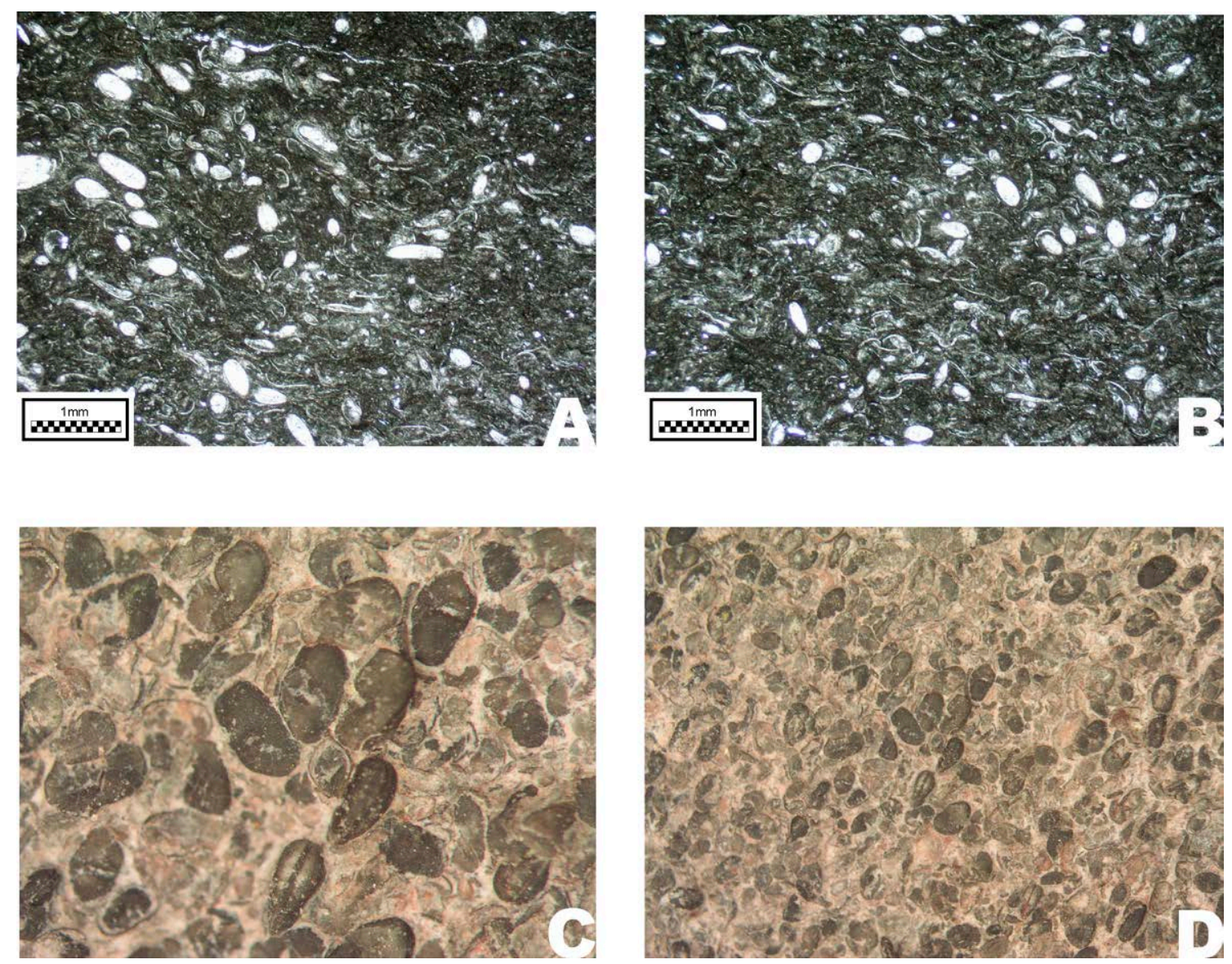

Figura 5.11: Ejemplos de la microfacies 8a bajo el microscopio petrográfico. A) y B) aspecto general de la muestra (x2). Ambas fotografías han sido tomadas con nícoles cruzados. C) y D) aspecto de las muestras de mano. 


\section{Análisis sedimentológico: microfacies y facies}

\subsubsection{Microfacies 8b: packstone de ostrácodos con intraclastos}

Esta microfacies mantiene todas las características de la microfacies 8a, diferenciándose por la presencia de numerosos intraclastos elipsoidales (longitud del eje mayor entre 1-4 mm) de límites netos e irregulares, que se disponen más o menos paralelos a la estratificación. Estos intraclastos están compuestos de micrita mudstone-wackestone oscura con escasos bioclastos de ostrácodos (figuras 5.12A, B, Cy D).
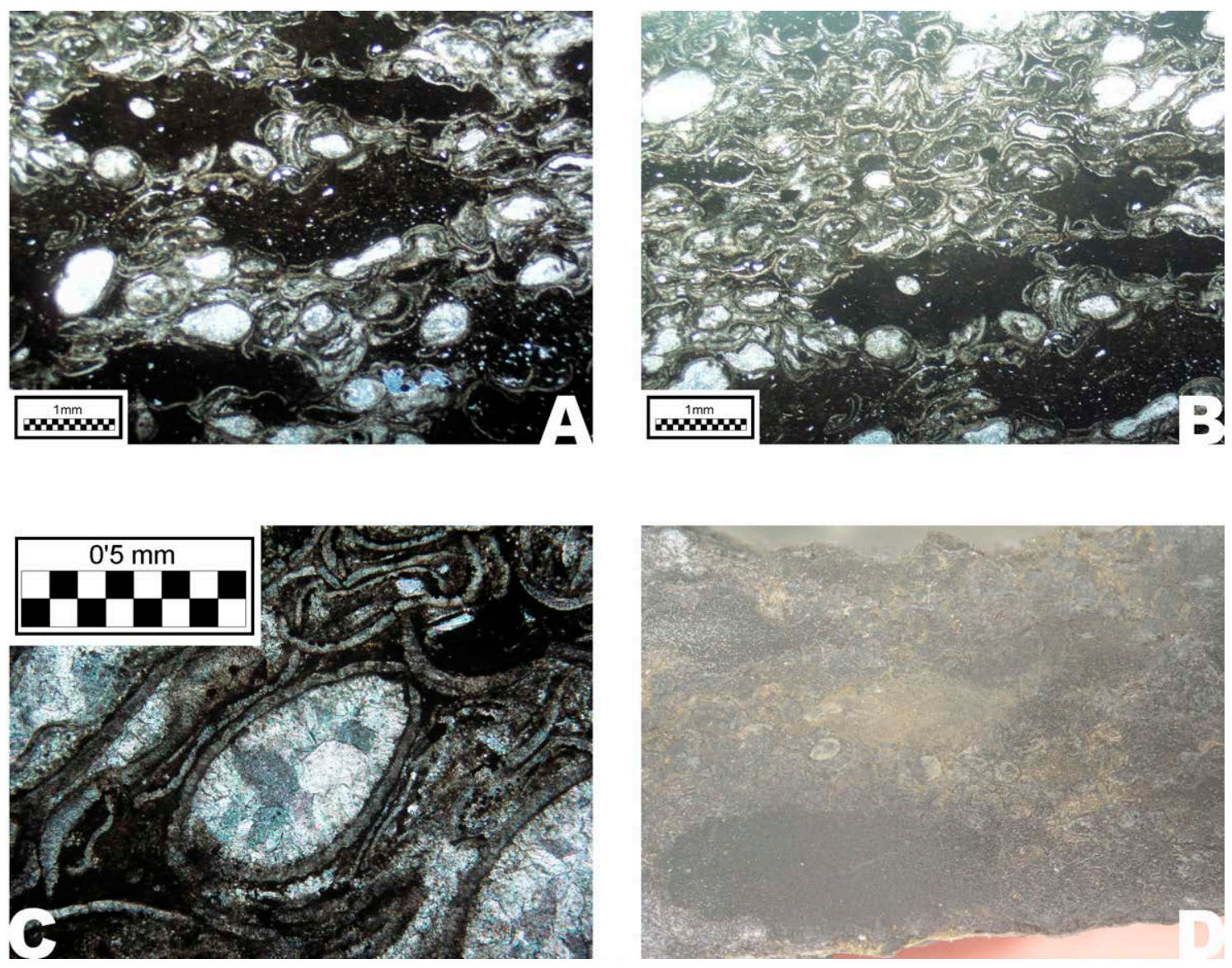

Figura 5.12: Ejemplos de la microfacies 8b bajo el microscopio petrográfico. A) y B) aspecto general de la muestra (x2) y C) detalle (x10). Todas las fotografías han sido tomadas con nícoles cruzados. D) aspecto delas muestras de mano.

\subsubsection{Microfacies 9: caliza bioclástica rudstone}

Esta microfacies agrupa a todos los depósitos que comprenden las lumaquelas de moluscos. Es una biomicrita rudstone de bioclastos de bivalvos, gasterópodos o una mezcla de ambos. Los bioclastos de gasterópodos aparecen enteros (secciones transversales y longitudinales) y/o fragmentados (figuras 5.13A, B, C, D y F). Los restos de bivalvos están compuestos por conchas enteras (articuladas, fragmentadas y/o aplastadas) y conchas aisladas (fragmentadas y/o enteras) (figuras 5.13E y F).

No se observan bioclastos que conserven su fábrica original, de tal manera que todos los restos esqueléticos se preservan como moldes. Las conchas de gasterópodos están constituidas fundamentalmente por aragonito. Las conchas de bivalvos son también de naturaleza aragonítica (aunque algunas especies son calcíticas-aragoníticas y, en menor medida, totalmente calcíticas). Así pues, debido a la diagénesis, la composición aragonítica original se disuelve originando moldes que posteriormente son rellenados.

En las láminas estudiadas, los moldes están rellenos por un mosaico de cemento esparítico granular o blocky (figuras 5.13A y B). Algunos bioclastos están recubiertos 


\section{Análisis sedimentológico: microfacies y facies}

externamente por una delgada capa de micrita que es el resultado dela acción de algas endolíticas. A veces presentan un color marrón oscuro debido a la presencia de materia orgánica. La matriz está constituida por micrítica. En cantidades accesorias aparece cuarzo con evidencias de corrosión por el cemento calcítico (figura 5.13A y B). En una muestra, la abundancia de cuarzo resulta en una biomicrita arenosa con textura floatstone (figura 5.13D).
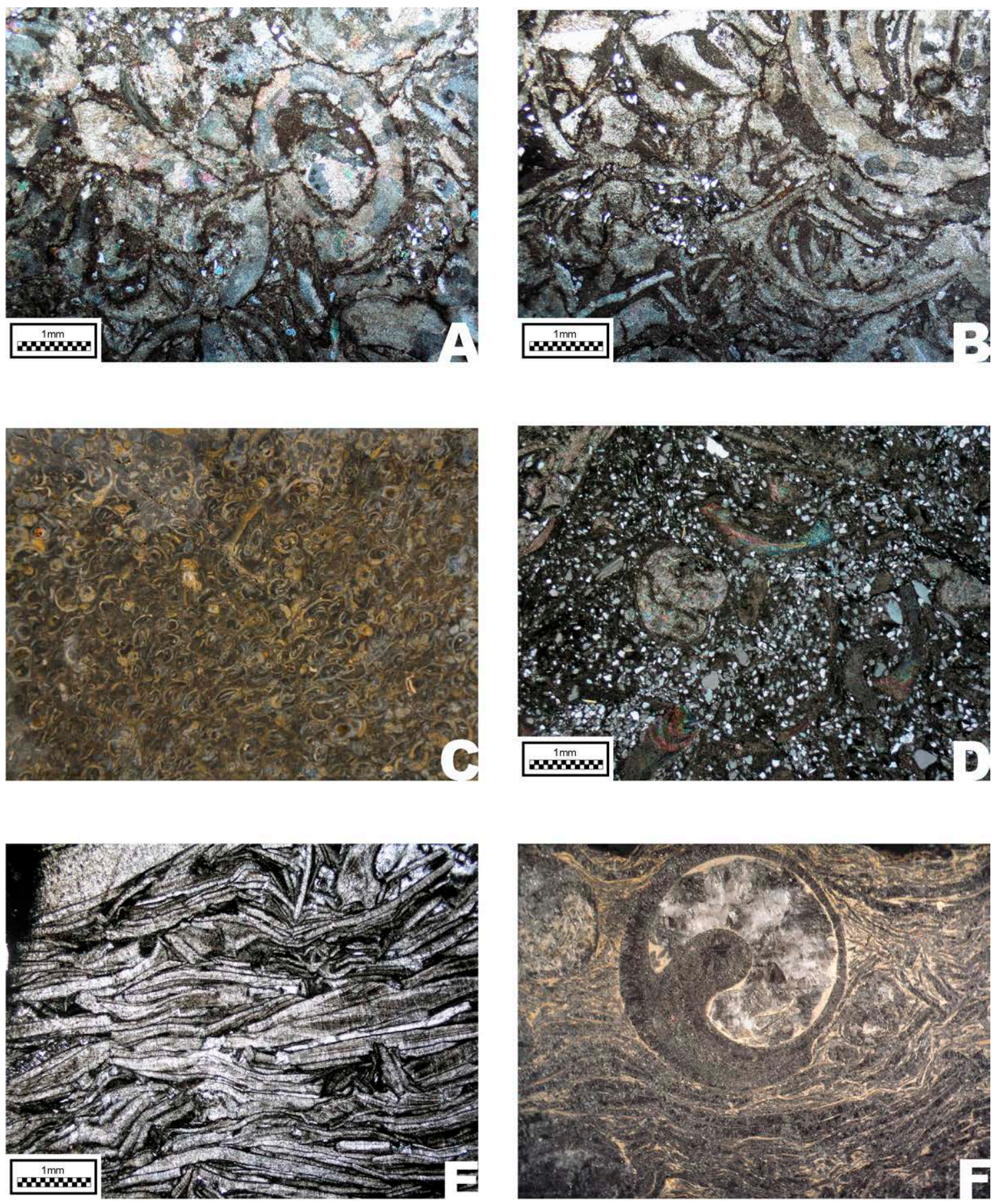

Figura 5.13: Ejemplos de la microfacies 9 bajo el microscopio petrográfico. A) y B) aspecto general de una lumaquela de gasterópodos (x2) y C) aspecto de la muestra de mano. D) aspecto general de la muestra S31 (x2). E) aspecto general de una lumaquela de bivalvos con gasterópodos (x2) y F) muestra de mano. Todas las fotografías han sido tomadas con nícoles cruzados.

\subsubsection{Microfacies 10: caliza laminada}

Petrográficamente, esta microfacies está configurada por una alternancia de láminas de biomicrita packstone de ostrácodos y, láminas de biomicrita mudstone-wackestone. La 


\section{Análisis sedimentológico: microfacies y facies}

laminación es bastante irregular, con límites neto o difusos y, espesores comprendidos entre 0,5 y $2 \mathrm{~mm}$ (figuras 5.14A y C).
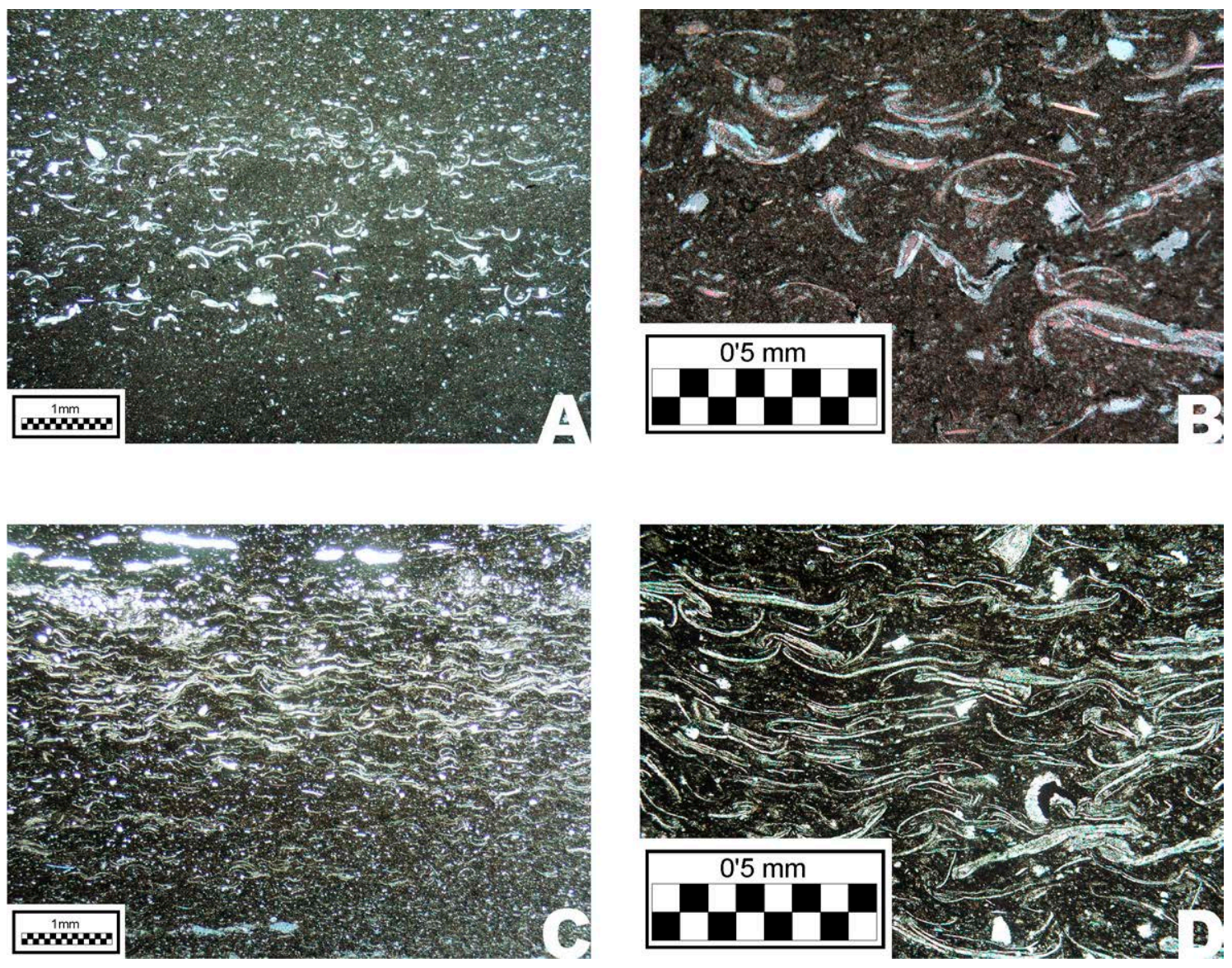

Figura 5.14: Ejemplos de la microfacies 10 bajo el microscopio petrográfico. A) aspecto general dela muestra P151 (x2) y B) detalle (x10). C) aspecto general dela muestra P64 (x2) y D) detalle (x10). Todas las fotografías han sido tomadas con nícoles cruzados.

La lámina grano-soportada (biomicrita packstone) está constituida por acumulaciones de ostrácodos: caparazones enteros y/ o aplastados por la compactación, así como numerosas valvas desarticuladas. Muestran una orientación paralela a la laminación pero no se advierte tendencias en la disposición de la convexidad de las valvas. Aparecen escasos granos cuarzos tamaño limo y algo de moscovita (figuras 5.14B y D).

La lámina matriz-soportada es una biomicrita mudstone-wackestone muy rica en materia orgánica en la cual aparecen dispersos fragmentos de ostrácodos y algunos detríticos (cuarzo tamaño limo y moscovita). Las valvas de ostrácodos y las micas se disponen orientadas.

\subsubsection{Microfacies 11: caliza intraclástica grainstone}

Se trata de una microfacies muy pobremente seleccionada, exhibiendo una fábrica grano-soportada donde los componentes principales son intraclastos, cuarzo, oolitos y oncolitos (enteros o fragmentados). Los accesorios están formados por peloides y cortoides. No se observa la presencia de ostrácodos que son casi omnipresentes en el resto de microfacies (figuras 5.15A y B).

Petrográficamente, los elementos más importantes son los intraclastos. Presentan una mala selección con morfologías subredondeadas a redondeadas y tamaños no superiores a $2 \mathrm{~mm}$. Existen dos tipos de intraclastos: los más abundantes están formados por micrita oscura y, en menor proporción, los fragmentos redondeados de oncolitos. 

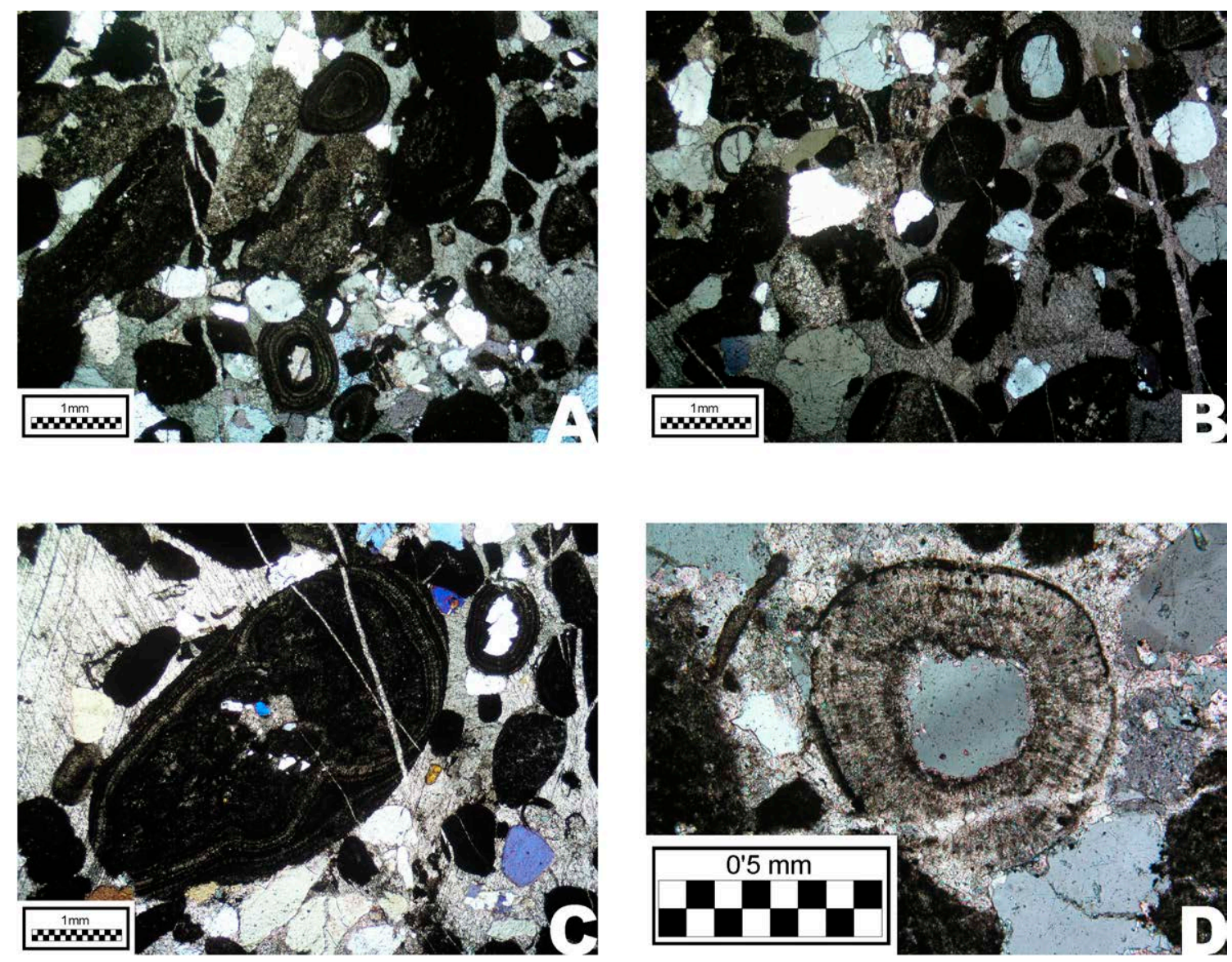

Figura 5.15: Ejemplos de la microfacies 11 bajo el microscopio petrográfico. A) y B) Aspecto general de la muestra EN519 (x2). C) Detalle de un oncolito (x2). D) Detalle de un oolito (x10). Todas las fotografías han sido tomadas con nícoles cruzados.

Los granos de cuarzo son heterométricos, con tamaños comprendidos entre limo y arena media, y con morfologías que varían entre subredondeadas hasta angulosas de baja-alta esfericidad. La mayoría está formado por cuarzo monocristalino aunque aparecen escasos granos redondeados de cuarzo policristalino. Frecuentemente presentan corrosión por cemento esparítico.

Los oolitos exhiben morfologías redondeadas o levemente ovaladas con tamaños inferiores a $1 \mathrm{~mm}$. Están constituidos por una alternancia de envueltas concéntricas de color claro y oscuro alrededor del núcleo. Las láminas corticales son continuas, lisas y no presentan variaciones de espesor en cada envuelta. La lámina oscura presenta una fábrica concéntrica tangencial (espesor $<10 \mu \mathrm{m}$ ). La lámina clara exhibe una fábrica radial fibrosa (espesor $<60 \mu \mathrm{m}$ ). El núcleo de los oolitos es cuarzo monocristalino, tamaño arena fina y media que presentan cierta esfericidad, y con los bordes corroídos por cemento esparítico (figura 5.15D).

Los oncolitos están formados por envueltas claras $(10-60 \mu \mathrm{m})$ y oscuras $(60-180 \mu \mathrm{m})$. Uno de ellos $(\approx 5 \mathrm{~mm})$ presenta un núcleo formado por un gasterópodo. A su alrededor se produce el crecimiento de las láminas: se observa como las primeras envueltas se adaptan a la forma del núcleo, lo cual le confiere una cierta asimetría en el crecimiento. Las láminas son continuas (no muestran variaciones de espesor, a excepción de las que se encuentran más cerca del núcleo) y en general lisas. No se observan cicatrices o discontinuidades que sugieran la interrupción en su crecimiento (figura 5.15C).

Los escasos cortoides que aparecen son granos de cuarzo cubiertos de una película de micrita. Todos estos elementos del esqueleto se disponen sobre un cemento calcítico poiquilotópico. Los contactos entre los componentes mayoritarios varían desde puntuales a suturados. 


\subsubsection{Microfacies 12: caliza granular}

Esta microfacies muestra claras evidencias de pedogénesis. La característica más destacable es la presencia de una fábrica granular en la matriz micríticas (también aparece en la literatura bajo denominaciones tales como fábrica clotted-peloidal, grumelar o grumosa). Esta textura de aspecto brechoide es debida a la formación de abundantes grietas irregulares (en ocasiones con bifurcaciones) o circumgranulares que se disponen alrededor de los gránulos, aislándolos en agregados de micrita. Estas grietas están rellenas de un mosaico de cemento esparítico y se interpretan como grietas de desecación y/ o trazas de raíces (figuras 5.16A y B). En general no presenta terrígenos o aparecen en cantidades accesorias granos de cuarzo subangulosos y tamaño limo ( $<2 \%$ ). También como accesorios aparecen algunas valvas desarticuladas de ostrácodos.

Las estructuras fenestrales y alveolares son abundantes y muestran cierto alineamiento preferente. Están rellenas de un mosaico granular, blocky o drúsico de esparita. Algunas muestran cementos poiquilotópicos.

También son frecuentes unas estructuras ovaladas con tamaños comprendidos entre 100-300 $\mu \mathrm{m}$ (según el eje mayor) rellenas de cemento esparítico. En ocasiones muestran un recubrimiento formado por una delgada película micrítica oscuray, otras veces, presentan límites difusos respecto a la matriz que los engloba. Se interpretan como fantasmas de peloides o trazas de raíces.
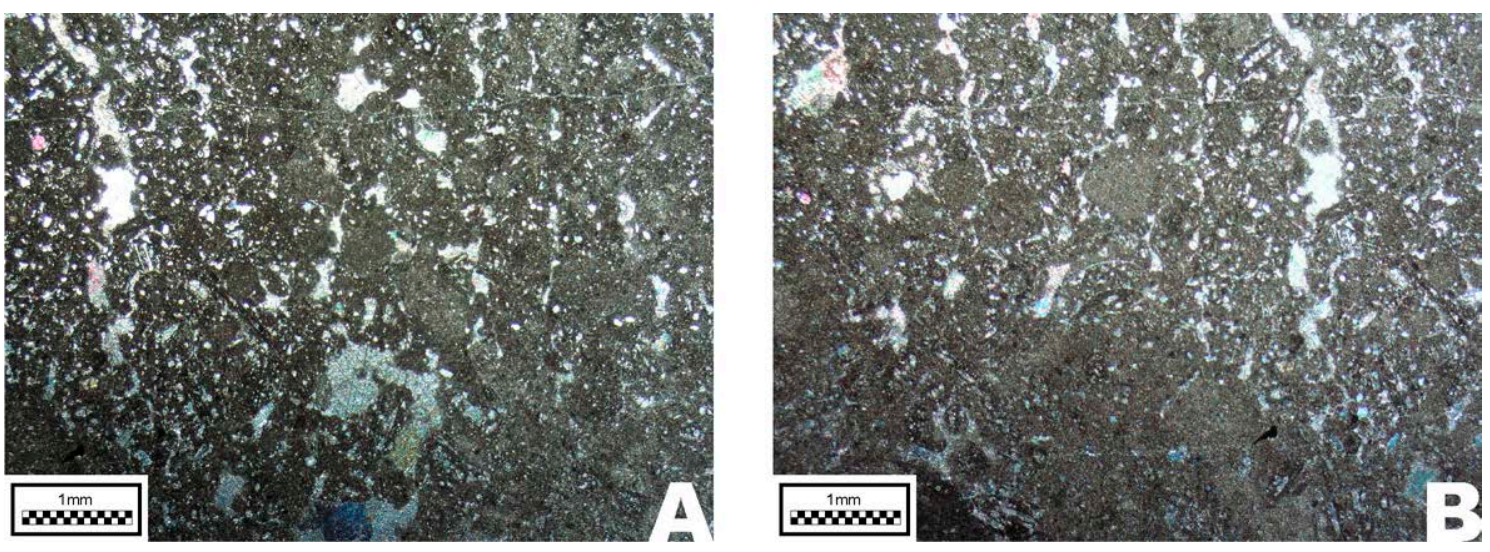

Figura 5.16: Ejemplos de la microfacies 12 bajo el microscopio petrográfico. A) y B) aspecto general de la muestra (x2). Todas las fotografías han sido tomadas con nícoles cruzados.

\subsubsection{Microfacies 13: caliza nodular-brechoide}

Se trata de una microfacies que exhibe un marcado aspecto brechoide--nodular y una textura packstone y floatstone-rudstone debido a procesos de nodulización incipiente. La muestra está formada por nódulos (milimétricos hasta centimétricos) que, según las muestras analizadas, varían entre ovalados-redondeados (figura 5.17A), hasta formas irregulares angulosas (figura 5.17B). Cada muestra exhibe un tipo de morfología y no coexisten en una misma lámina. Muestran una gran diversidad de tamaños dentro de la misma lámina, variando desde centimétricos hasta milimétricos.

Los nódulos están constituidos por micrita con escasos bioclastos dispersos en la matriz: algún ostrácodo aplastado o fragmentos de valvas desarticuladas. Otros nódulos pueden estar enriquecidos en terrígenos, apareciendo moscovita y granos de cuarzo tamaño limo flotando desordenadamente en la matriz micrítica, llegando a alcanzar cantidades principales. Las grietas o espacios internodulares que separan los clastos están constituidos por biomicrita-micrita con terrígenos mudstone - wackestone, intramicrita, o biomicrita packstone de ostrácodos. Parte del fango micrítico puede estar recristalizado a microesparita. La matriz pueden mostrar halos de 


\section{Análisis sedimentológico: microfacies y facies}

límites difusos en una tonalidad más oscura, que se interpretan como moteado debido a la marmorización.
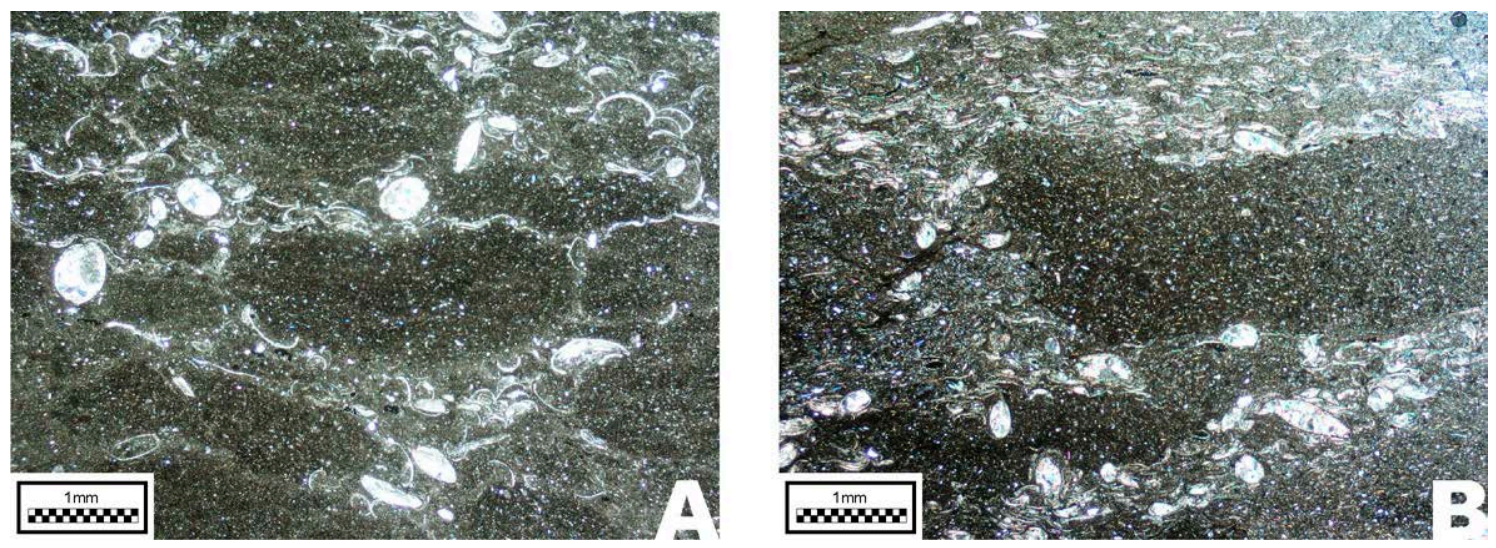

Figura 5.17: Ejemplos de la microfacies 13 bajo el microscopio petrográfico. A) aspecto general de la muestra PR18 (x2). B) aspecto general de la muestra PR17 (x2). Todas las fotografías han sido tomadas con nícoles cruzados.

\subsection{FACIES}

La correcta descripción de las facies es una delas etapas más trascendentales en el estudio estratigráfico-sedimentológico, constituyendo una herramienta fundamental, así como una fuente indispensable de información en la que se puede basar cualquier tipo de interpretación posterior (MIALL, 1999).

Se ha estimado conveniente realizar ciertas apreciaciones y puntualizaciones previas sobre el concepto de facies, para un mejor desarrollo y comprensión de los apartados posteriores. El problema no estriba en el concepto o definición de facies, sobre el cual hay un consenso generalizado, sino más bien en su aplicación práctica, es decir, en su uso. Existen multitud de definiciones (SELLEY, 1970; WALKER, 1984; READING, 1989) que, a grandes rasgos, caracterizan una facies como "un cuerpo rocoso con unas características específicas que las diferencian de los adyacentes basándose en el color, la estratificación, la composición, la textura, los fósiles y las estructuras sedimentarias". Por tanto, idealmente, debería ser una roca distintiva formada bajo determinadas condiciones sedimentarias y, por consiguiente, reflejando un proceso o un ambiente particular. Sin embargo, la selección de los rasgos para definir las facies y el peso dado a cada una de ellas depende de una evaluación subjetiva personal, basada en el material muestreado, el tipo de afloramiento, el tiempo disponible y los objetivos a alcanzar (READING, 1989).

En este trabajo, siguiendo este axioma, las facies serán definidas objetivamente, basándose en caracteres observables y medibles. Cada facies presenta una serie de características propias que permiten deducir su significado genético. Sin embargo, también se ha de asumir que una facies individual puede variar en su valor interpretativo en función de su contexto deposicional: por tanto se ha de admitir también grandes limitaciones de las facies individuales tomadas aisladamente (READING, 1989). Por lo tanto, se va a evitar la utilización de término facies en sentido interpretativo: tanto genético (e.g. facies turbidítica), como ambiental o deposicional (e.g. facies lacustre), como tectónico (e.g. facies de molasas), ya que en todos estos casos se introduce un factor de subjetividad. Asimismo, se va a eludir en la medida de lo posible el uso de facies en sentido cronoestratigráfico, aunque históricamente, los materiales presentes en la zona estudiada se han denominado facies Purbeck-Weald.

Con todo esto en mente, se pretende diferenciar claramente entre los datos objetivos observables y sus interpretaciones. Los primeros no cambian con el tiempo sin embargo sus interpretaciones sí. En algunos casos basta con comparar estudios realizados en las mismas áreas en diferentes épocas para darse cuenta de esta realidad. Al mejorar el conocimiento de los medios sedimentarios actuales se produce irremediablemente una variación en sus posibles interpretaciones. 
Un análisis sedimentológico riguroso requiere un conocimiento preciso de las facies más representativas y/o significativas. La caracterización de estas facies se fundamenta en los datos y observaciones obtenidos en la columna de Enciso (la cual se considera como "estratotipo" y se utiliza como patrón de comparación por la calidad de sus afloramientos), complementadas con los datos adquiridos en el resto de las columnas levantadas en Munilla, Cornago, Ambas Aguas y Préjano (las cuales se establecen como secciones de referencia). Las razones por las cuales se ha optado por esta decisión son variadas destacando tres sobre el resto. La primera hace referencia a la concisión y clarificación de la presente memoria: una descripción de todas las facies en cada una de las columnas daría lugar a un apartado, en muchos casos y cuando menos, repetitivo y enrevesado. La segunda, la serie de Enciso constituye el registro más completo al estar en un área depocentral abarcando la serie más potente con mínimas pérdidas por erosión, aunque las discontinuidades son inherentes al propio registro (AGER, 1973). Por lo tanto, a priori, existe una gran probabilidad de que cualquiera de las facies existentes en otros sectores esté registrada 0 presente un equivalente en la de Enciso. Por último, la tercera es porque las obras de la nueva carretera por la construcción del embalse de Enciso han expuesto de manera óptima gran parte del registro sedimentario permitiendo unas condiciones idóneas de observación.

La abundancia de las diferentes facies se presenta en porcentajes en tanto por ciento respecto del total de la columna muestreada. Además, se utiliza la siguiente terminología: escaso $(<5 \%)$, frecuente $(<15 \%)$, común $(<25 \%)$, abundante $(<40 \%)$ y, muy abundante $(>40 \%)$.

Antes de continuar es conveniente aclarar que es (muy) posible que todas las columnasy, en consecuencia, todas las facies reconocidas muestren cierto sesgo hacia medios fluviolacustres de baja energía o someros. Esto es debido a que todas las columnas se han realizado intentando incorporar el mayor número posible de yacimientos icnológicos, los cuales muestran una preferencia por los mecanismos genéticos y de preservación, hacia este tipo de medios.

La individualización de las facies se ha realizado con la aplicación de métodos estadísticos a los datos adquiridos durante las campañas de campo. Para la descripción de las facies se han diferenciado dos categorías básicas: facies de naturaleza siliciclástica y facies de naturaleza carbonatada (química), aunque las facies intermedias son también abundantes. Las facies siliciclásticas predominan en los dos tercios inferiores del Grupo Enciso, mientras que las facies carbonatadas son dominantes en el tercio superior. Algunas facies descritas muestran un desarrollo espacial muy limitado, estando su presencia restringida a zonas muy concretas.

Para la designación nominal de las facies se ha utilizado un código de notación abreviada semejante a otros existentes en la literatura geológica (WILSON, 1975; MIALL, 1985; PICKERING et al., 1986; GHIBAUdO, 1992; MiALL, 2000; 2006; FLÜGEL, 2010). Por su simplicidad y alta aceptación por la comunidad científica, se utiliza el esquema jerarquizado propuesto por MIALL (1985; 2000; 2006), aunque solamente con un sentido estrictamente descriptivo, a fin de evitar la confusión por la cual un código concreto se asocie a un ambiente específico (BRIDGE, 1993). Esta notación presenta algunas modificaciones a fin de acomodarlas y ajustarlas a los materiales presentes en la zona de estudio, ya que estas litofacies fueron descritas para depósitos fluvialesaluviales, aunque su uso en medios lacustres también se ha generalizado. En el presente esquema, la primera letra se escribe en mayúscula y hace mención a la litología fundamental: (A) arenisca, (L) lutita, (C) caliza y, (M) marga. Cuando la facies descrita está formada por una mezcla de dos litologías, se utilizan dos letras en mayúsculas que hacen referencia a las litologías registradas: (CA) caliza arenosa y (LM) lutita-marga. A continuación se añade una letra en minúscula, la cual hace referencia al tipo de estructura sedimentaria más característica: (s) estratificación cruzada en surco, (p) estratificación cruzada planar, (r) rizaduras, (h) laminación horizontal, (m) masiva, (g) grietas de retracción y, (n) nódulos-nodular. No obstante, en ciertas facies se ha considerado conveniente incluir alguna indicación, relevante desde una perspectiva interpretativa o de abundancia, y aparecen apuntadas con los subíndices 1 y 2 . En las areniscas permite diferenciar entre (1) arenita y (2) grauvaca. En las lutitas distingue el color característico, (1) negro u oscuro y (2) azul, gris o verde. De manera excepcional, fuera de estas normas establecidas, se utiliza la letra mayúscula (Q) para designar la facies de lumaquela de fósiles, sin importar la litología que la alberga. A continuación se añade una letra minúscula que indica su contenido paleontológico: 


\section{Análisis sedimentológico: microfacies y facies}

(m) moluscos y, (o) ostrácodos. Con estas premisas se han definido y caracterizado 21 facies diferentes, cuya notación queda del siguiente modo:

As: arenisca con estratificación cruzada en surco a gran escala.

Ap: arenisca con estratificación cruzada planar a gran escala.

Ar: arenisca con rizaduras.

Ah1: arenita con laminación horizontal (paralela).

$\mathrm{Ah}_{2}$ : grauvaca con laminación horizontal (paralela).

$\mathrm{Am}_{1}$ : arenita masiva.

$\mathrm{Am}_{2}$ : grauvaca masiva.

Lh: lutita con laminación horizontal (paralela) de color oscuro.

Lh2: lutita con laminación horizontal (paralela) de color azul, gris o verde.

$\mathrm{Lm}_{1}$ : lutita masiva de color oscuro.

$\mathrm{Lm}_{2}$ : lutita masiva de color azul o gris.

Lg: lutita con grietas de retracción.

LMm: lutita y/ o marga masiva.

Mm: marga masiva.

Ch: caliza con laminación horizontal (paralela).

Cm: caliza masiva oscura.

Cg: caliza masiva con grietas de retracción.

Cn: caliza masiva nodular o con nódulos.

CAm: caliza arenosa masiva.

Qm: lumaquela de moluscos.

Qo: lumaquela de ostrácodos.

La diversidad de facies individualizables no es más que un reflejo de la amplia variedad y complejidad de (sub)ambientes de sedimentación presentes en el área de estudio. La información que se deriva de una facies aislada es limitaday nunca unívoca, sin embargo, ésta aumenta cuando se establecen las relaciones verticales y laterales dentro del cuerpo sedimentario (asociaciones de facies). De aquí la necesidad de contextualizar dichas facies para la validación de su interpretación.

Cada facies descrita, se va a interpretar desde una perspectiva hidrodinámica y de disponibilidad de sedimento, en relación a uno o varios procesos deposicionales, a su vez, indicativos de un mecanismo de transporte, para después describir los ambientes sedimentarios más viables (actuales o en el registro fósil).

\subsubsection{Litofacies As: arenisca con estratificación cruzada en surco a gran escala}

Esta facies es equivalente, en conjunto, a la litofacies St de MiALL (2006) (figura 5.18A). Está compuesta por arenitas o grauvacas cuya característica fundamental es la presencia de estratificación cruzada en surco (festoneada o en artesa) a gran escala. En todas las series muestreadas presenta una abundancia escasa: 2\% en Enciso, 0,8\% en Ambas Aguas y Munilla, $0,9 \%$ en Cornago y 0,6\% en Préjano. Su abundancia real es mayor, ya que en muchos paquetes siliciclásticos siempre aparecelateralmente, aunque no quede registrado en la columna levantada.

Mayoritariamente consta de cuarzoareniscas $(\approx 76 \%)$, grauvacas $(\approx 22 \%) \mathrm{y}$, de forma anecdótica, lutitas $(\approx 2 \%)$. En muestra fresca, los colores predominantes son: azul claro $(\approx 69 \%)$ (5B 5/ 1 gris azulado; 5 B 7/ 1 gris azulado brillante; 5 B 6/ 2 azul pálido y; 5 B 8/ 2 azul muy pálido), azul oscuro $(\approx 17 \%)$ (5PB $3 / 2$ azul oscuro) y gris $(\approx 8 \%)$ ( $\mathrm{N} 8$ gris muy luminoso; $\mathrm{N} 7$ gris luminoso $\mathrm{y} ; \mathrm{N} 6$ gris medio luminoso). Cuando la oxidación es importante, aparecen totalmente ferruginizadas mostrando colores rojizos y/o anaranjados $(\approx 4 \%)$ (10 $\mathrm{R} 6 / 6$ naranja rojizo moderado; 10 R 4/ 6 marrón rojizo moderado y; 10 YR 6/ 6 naranja amarillento oscuro).

Se presenta en sets lenticulares con muro y techo netos-erosivos de geometría cóncava o levemente convexa, sigmoidal y espesores variables de valor medio $\approx 31 \mathrm{~cm}$ (valores comprendidos entre 4-170 cm), llegando a alcanzar hasta decenas de metros de extensión lateral. La estratificación cruzada es, predominantemente, de bajo ángulo y más rara de alto ángulo. De 


\section{Análisis sedimentológico: microfacies y facies}

manera más local se ha observado estratificación cruzada tipo hummocky y sigmoidal. Aparecen agrupados en cosets de potencia métrica en paquetes acanalados o tabulares. A veces se observan finas capas lutíticas interestratificadas que se asemejan a cicatrices que fosilizan tanto episodios de acreción lateral como de abandono del canal. Los sets son mayoritariamente masivos $(\approx 73 \%)$, aunque no es infrecuente que presente laminación horizontal $(\approx 20 \%)$ o laminación cruzada producida por rizaduras $(\approx 12 \%)$. También es muy habitual la presencia de moteados por óxidos de hierro $(\approx 72 \%)$, así como de costras ferruginosas $(\approx 93 \%)$. Sin embargo, estos son los únicos caracteres indicativos de emersión ya que no se han observado rizolitos, nódulos ni grietas de retracción.
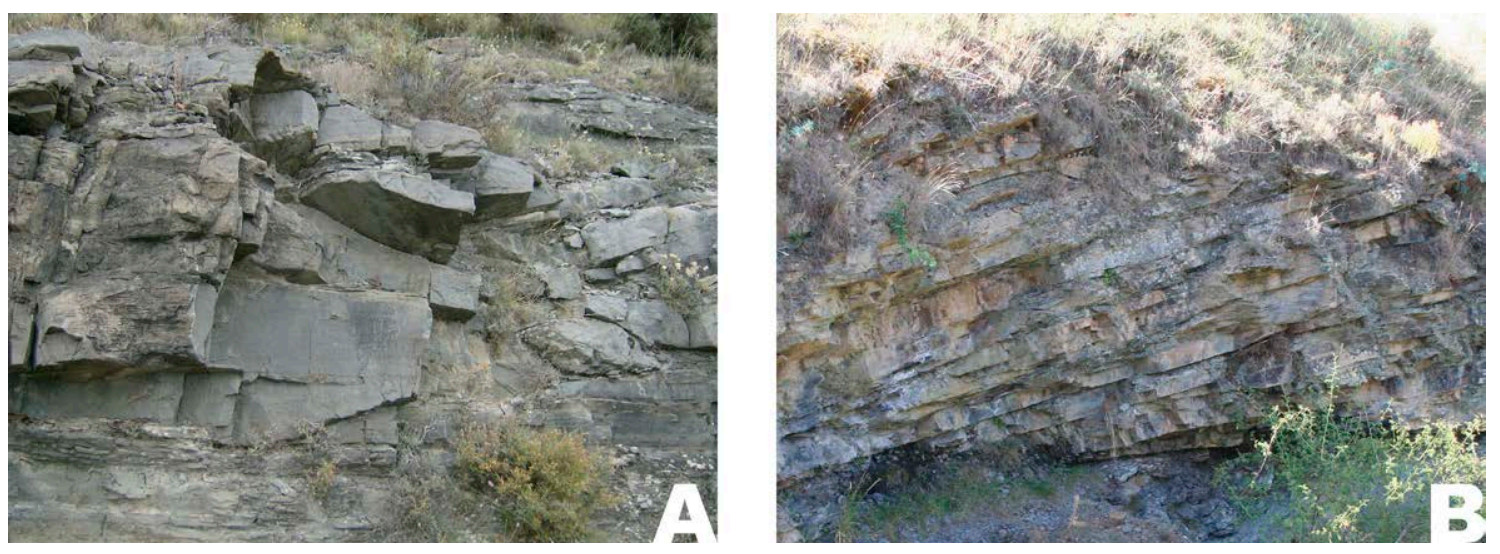

Figura 5.18: Aspecto en campo de las areniscas con estratificación cruzada a gran escala. A) Ejemplo de la facies As correspondiente al tramo 486 de la columna de Enciso. B) Ejemplo de la facies Ap en los tramos 103-105 de la columna de Préjano.

Su contenido paleontológico es prácticamentenulo, apareciendo muy localmentealgunos fósiles fragmentados $(\approx 10 \%)$ y, en menor medida, ostrácodos $(<1 \%)$. Abundanes huellas de bioturbación $(\approx 56 \%)$.

Desde una perspectiva hidrodinámica, la estratificación cruzada en surco es el resultado de la migración de dunas 3D de cresta sinuosa en la parte alta del régimen de flujo bajo (HARMS et al., 1975; HARMS, 1979). A medida que aumenta la profundidad del flujo, las dunas resultantes incrementan su campo de estabilidad, así como el rango de velocidades requeridas (SOUTHARD, 1991). Estas dunas se forman siempre bajo flujos unidireccionales o combinados, pero nunca bajo la acción de flujos oscilatorios puros. La estratificación hummocky se origina por la acción conjunta del oleaje y las corrientes durante tormentas (DUMAS Y ARNOTT, 2006).

Desde una perspectiva geomorfológica, se consideran el producto de la migración de dunas (barras) en el fondo de canales de corrientes tanto efímeras (WILLIAMS, 1971) como permanentes (CANT Y WALKER, 1976). Por esta razón es la facies predominante en el relleno arenoso de multitud de tipos de canales asociados a sistemas fluvio-lacustres: anastomosados (PÉREZ-ARLUCEA Y SMITH, 1999), distributarios (TYE y COLEMAN, 1989b; a; FARRELL, 2001), o derrames deltaicos (SMITH Y PÉREZ-ARLUCEA, 1994). Asimismo, se han citado en corrientes no canalizadas asociadas a mantos de arroyada (KARCZ, 1972), debidas a la migración de dunas lunadas-linguoides durante etapas de inundación (SINGH Y KUMAR, 1974), o en llanuras arenosas (CANT Y WALKER, 1978). En los deltas lacustres aparece principalmente en las barras de desembocadura (HYNE et al., 1979b; WeLLS et al., 1994).

\subsubsection{Litofacies Ap: arenisca con estratificación cruzada planar a gran escala}

Equivale en su totalidad a la litofacies Sp y, quizás, a parte de la litofacies Sl de MIALL (2006) (figura 5.18B). Son areniscas con estratificación cruzada planar de gran escala. Se trata de una facies con escasa presencia, constituyendo sólo un 1,7\% en la serie de Enciso, 0,6\% en Ambas Aguas, $1 \%$ en Munilla y 2,9\% en Préjano. No aparece registrada en la columna de Cornago. 


\section{Análisis sedimentológico: microfacies y facies}

Consta básicamente de arenitas $(\approx 84 \%)$ y grauvacas $(\approx 8 \%)$, apareciendo de forma subordinada lutitas $(\approx 8 \%)$. En muestra fresca exhiben únicamente dos colores muy característicos: azul ( $\approx 49 \%$ ) (5 B 5/ 1 gris azulado; 5 B 7/ 1 gris azulado brillante; 5 B 6/2 azul pálido y; 5 B $8 / 2$ azul muy pálido) y gris $(\approx 51 \%$ ) (N 8 gris muy luminoso; $\mathrm{N} 7$ gris luminoso $\mathrm{y} ; \mathrm{N}$ 6 gris medio luminoso).

Los sets pueden aparecer aislados o asociados en cosets. El tamaño medio de los sets se sitúa entre 4-75 cm de potencia (espesor medio $21 \mathrm{~cm}$ ), de geometría cuneiforme o lenticular. Los cosets alcanzan potencias máximas de algunos metros. Constituyen cuerpos de geometría acanalada o tabular de algunas decenas de metros de extensión lateral. En general, internamente los sets son masivos (69\%), aunque también muestran laminación horizontal (20\%) y cruzada (18\%). Es relativamente frecuente la presencia de óxidos de hierro, en forma de costras (56\%) y/o de moteado interno (46\%), con un grado muy variable de desarrollo.

El contenido paleontológico es prácticamente nuloy, los escasos ostrácodos queaparecen (7\%) se asocian a niveles lutíticos. Sin embargo, es frecuente encontrar gran abundancia de bioturbaciones de orientación vertical y, en menor medida, horizontal (71\%).

Según la bibliografía consultada, la estratificación cruzada planar a gran escala se interpreta como el producto dela migración de formas de lecho tipo duna de crestas rectas (dunas 2D) bajo flujos unidireccionales (HARMS et al., 1975; HARMS, 1979), en un régimen energético más bajo que el requerido para la formación de la facies As. Por consiguiente, es típica de canales fluviales permanentes o efímeros (WILLIAMS, 1971).

\subsubsection{Litofacies Ar: arenisca con rizaduras}

Corresponde en su totalidad a las litofacies Sr y parte de Fl de Miall (2006). Son mayoritariamente estratos de naturaleza arenosa cuya característica más destacable es la presencia de rizaduras a techo y/ o laminación cruzada (surco y/o planar) a pequeña escala, originada por la migración de rizaduras. Es una facies con un escaso desarrollo en la columna de Enciso $(1,9 \%)$ y Ambas Aguas $(0,1 \%)$, aunque es más frecuente en las columnas de Cornago (5,7\%), Munilla (8,8\%) y Préjano (5\%).

Está constituida por arenitas $(\approx 60 \%)$, grauvacas $(\approx 29 \%)$, calizas arenosas $(\approx 9 \%)$ y lutitas $(\approx 2 \%)$. En muestra fresca, las areniscas son de color azul claro $(\approx 51 \%)$ (5 B 5/1 gris azulado; 5 B 7/ 1 gris azulado brillante; 5 B 6/2 azul pálido y; 5 B 8/2 azul muy pálido) o gris ( $\approx$ 23\%) (N 8 gris muy luminoso; N 7 gris luminoso; N 6 gris medio luminoso; N 5 gris medio; $5 \mathrm{Y}$ $6 / 1$ gris verde oliva luminoso y; $5 \mathrm{G} 4 / 1$ gris verdoso moderado). Localmente pueden ser de color marrón $(\approx 2 \%)$ (10 YR 6/2 siena grisáceo), azul oscuro $(\approx 2 \%)$ (5PB $3 / 2$ azul oscuro) o verde $(\approx$ 1\%) (5 GY 5/ 2 verde amarillento sombrío; 10 GY 5/ 2 verde amarillento grisáceo y; 10 Y 5/ 4 oliva luminoso). Cuando los fenómenos de oxidación son importantes, muestra colores rojizosanaranjados ( $\approx 11 \%$ ) (10 R 6/6 naranja rojizo moderado; $10 \mathrm{R}$ 4/6 marrón rojizo moderado y; 10 YR 6/ 6 naranja amarillento oscuro). Las calizas arenosas son siempre negras (N 1 negro y N 2 negro grisáceo) y las lutitas azules (5 B 7/ 1 gris azulado brillante).

Aflora en estratos de geometría tabular o ligeramentecuneiforme, lateralmente continuos a escala del afloramiento, con espesores comprendidos entre 3-110 cm (valor medio $14 \mathrm{~cm}$ ). Internamente muestran laminación cruzada planar y/o en surco $(\approx 73 \%)$, o bien son masivas $(\approx$ $16 \%)$. En este último caso, siempre presenta rizaduras a techo de los estratos. Es frecuente que muestre moteado $(\approx 41 \%)$. A techo de algunas capas aparecen costras ferruginosas $(\approx 73 \%)$, bioturbación $(\approx 21 \%)$ y grietas de retracción $(\approx 2 \%)$.

El contenido fosilífero es escaso y se reduce a fragmentos de fósiles inidentificables $(\approx$ $7 \%)$ y ostrácodos $(\approx 4 \%)$.

En campo, esta facies presenta tres morfotipos representativos: a) estratos (cosets) tabulares masivos de muro neto y plano, y techo con rizaduras; b) estratos tabulares, con 


\section{Análisis sedimentológico: microfacies y facies}

laminación cruzada, de muro plano-neto y/o transicional, y techo con rizaduras y; c) estratos tabulares, con laminación cruzada, de muro y techo plano, sin rizaduras.

Las rizaduras son las formas de lecho típicas de un régimen hidrodinámico bajo. Se originan por la interacción entre un fluido en movimiento (aire y/o agua) y un sedimento no cohesivo (arena y/o limo). A grandes rasgos, se pueden catalogar atendiendo a criterios puramente morfológicos o bien genéticos. En el primer supuesto, según su aspecto en sección transversal, se dividen en simétricas o asimétricas. En el segundo supuesto, según el tipo de flujo que los origina, se clasifican en rizaduras de corriente o de oscilación. Sin embargo, en la naturaleza puede acontecer una concurrencia de ambos flujos, en el espacio y en el tiempo, originándose rizaduras de flujos combinados, con un amplio abanico de posibilidades intermedias. Asimismo, esta concurrencia puede ser espacial pero no temporal (flujos no simultáneos), apareciendo estructuras típicas de una clase de flujo que son posteriormente modificadas por el otro flujo (rizaduras de corrientes que con posterioridad son retrabajadas por las corrientes oscilatorias o viceversa).

Los experimentos de laboratorio demuestran que las rizaduras asimétricas (2D y 3D) se originan bajo flujos unidireccionales (ASHLEY, 1990), combinados (DUMAS et al., 2005), y oscilatorios puros (ALLEN, 1984; SOUTHARD, 1991). También se ha observado experimentalmente la imposibilidad de generar rizaduras en arenas con un tamaño de grano mayor de 0,6 mm (SOUTHARD Y BOGUCHWAL, 1990). Las rizaduras simétricas (2D y 3D) se ha obtenido experimentalmente a partir de flujos oscilatorios puros (ALLEN, 1984) o combinados con una pequeña, casi nula, componente unidireccional (DUMAS et al., 2005). Los flujos oscilatorios puros no producen rizaduras 2D de gran tamaño (ARNOTT Y SOUTHARD, 1990; SOUTHARD Y BOGUCHWAL, 1990). Las rizaduras de corriente tipo washed-out son generadas por flujos unidireccionales y debido a que presentan una mayor simetría, en ciertos casos podrían confundirse con las rizaduras de oscilación (BAAS Y DE KONING, 1995).

Para el trabajo en campo, es más útil la primera clasificación, basada en criterios morfológicos y más descriptivos. Sin embargo, para la interpretación es necesario diferenciar entre rizaduras generadas por corrientes u oleaje. Los caracteres diagnósticos que permiten distinguirlas se detallan a continuación. Las rizaduras de corriente producen siempre crestas asimétricas con una pendiente suave a barlovento, y más empinada a sotavento. Basándose en la naturaleza de sus crestas se pueden clasificar de multitud de tipologías. Las rizaduras de corriente de crestas rectilíneas, las más comunes en la zona de estudio, originan laminación cruzada planar, por consiguiente, la coexistencia de ambos caracteres es un criterio válido de reconocimiento. Las rizaduras de oscilación se producen bajo la acción de un flujo oscilatorio y, morfológicamente, pueden ser tanto simétricas como asimétricas. Aunque las rizaduras de oscilación no son necesariamente simétricas, en general, exhiben una mayor simetría que las de corriente (EVANS, 1941). La presencia de laminación cruzada en surco con estructuras típicas en haz (o manojo) y off-shoots es otro carácter distintivo. Las líneas de crestas bifurcadas (estructura en diapasón) en las rizaduras $2 \mathrm{D}$ se forman bajo flujos en los que intervienen movimientos oscilatorios tanto puros como combinados (HARMS, 1969; DUMAS et al., 2005). Según REINECK y SiNGH (1980), la estructura en diapasón no se origina bajo corrientes unidireccionales y puede considerarse como un criterio típico de que en su formación ha tomado parte un flujo oscilatorio (figura 5.19A).

La mayor parte de las rizaduras observadas en el Grupo Enciso se identifican como de oscilación. En muchos afloramientos, la presencia de trenes de rizaduras con bifurcaciones corrobora la acción del oleaje (figura 5.19A). En secciones transversales presentan una gran simetría apareciendo tanto rizaduras simétricas tipo rolling grain de crestas acuminadas y baja energía (figura 5.19B), como rizaduras tipo vortex que muestran crestas redondeadas e indican una mayor energía (figura 5.19C). Cuando en el afloramiento se conservan conjuntamente las rizaduras y la laminación cruzada se observa la concurrencia de rizaduras simétricas con laminación bidireccional (flujo oscilatorio puro o predominante) o unidireccional (flujo combinados o flujos unidireccionales que posteriormente son retrabajados por bajo la acción de un flujo oscilatorio). 


\section{Análisis sedimentológico: microfacies y facies}
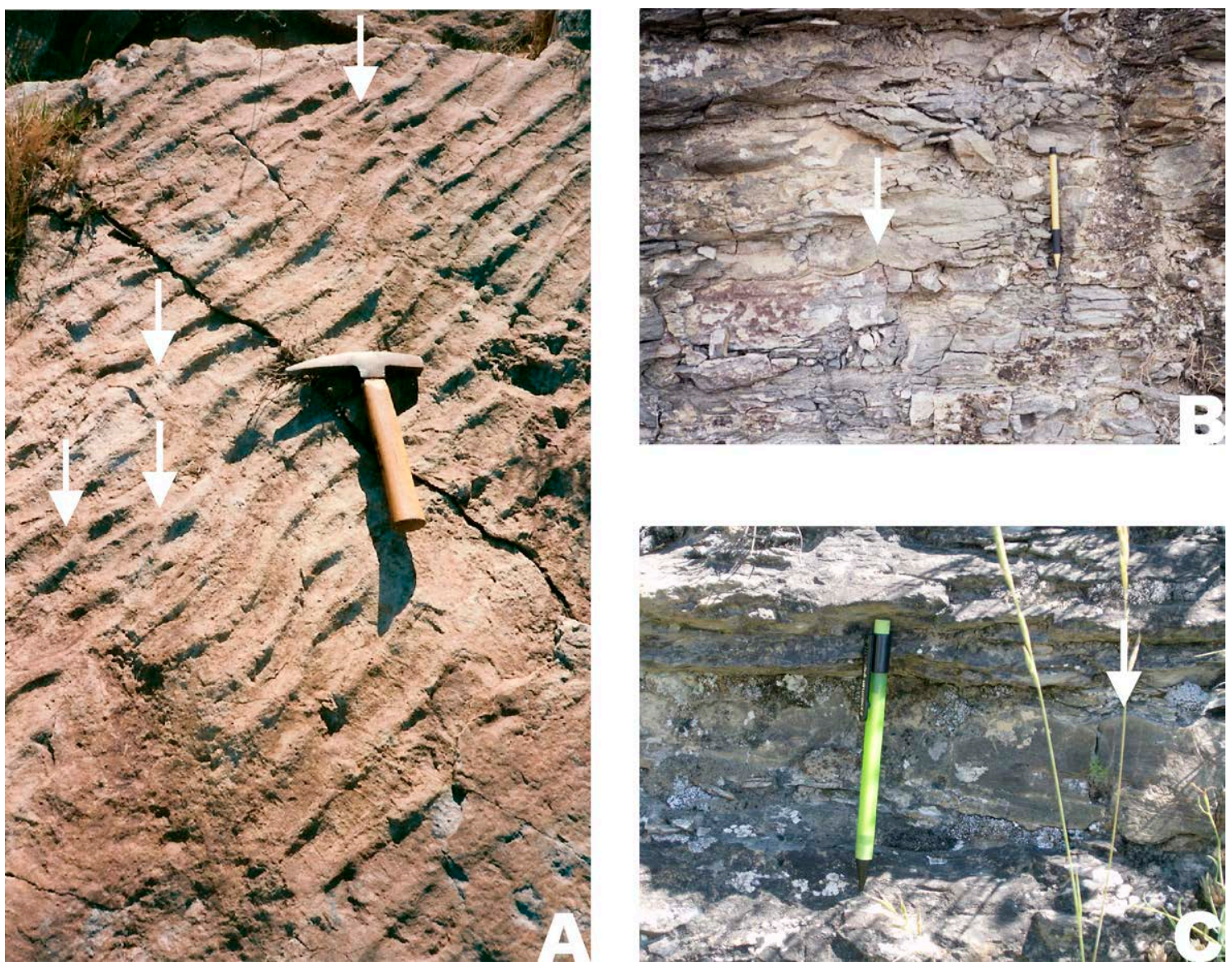

Figura 5.19: Aspecto en campo de las areniscas con rizaduras (facies Ar). A) Rizaduras con estructuras en diapasón (flechas) en el tramo 39 dela columna parcial del yacimiento icnológico San Vicente XI-XII-XIII. B) Rizaduras tipo rolling grain de crestas acuminadas en el tramo 346 de la columna de Munilla. C) Rizaduras tipo vortex de crestas redondeadas en el tramo 346 de la columna de Munilla.

Las rizaduras de oscilación aparecen en un amplio espectro de ambientes, tanto fluviales como lacustres. En los medios fluviales, se circunscriben a zonas inundadas o áreas del canal con aguas remansadas (BENTTO et al., 2003). En medios lacustres, la presencia de rizaduras se restringe a la zona litoral, aunque durante las tormentas pueden desarrollarse a mayores profundidades, en la zona sublitoral e incluso profunda (KOMAR, 1974; ALLEN, 1982b). En los lagos, la ausencia de mareas hace que la acción del oleaje esté limitada a una estrecha franja litoral. No obstante, las variaciones de la lámina de agua pueden extender dicha acción sobre una gran área (TALBOT Y ALLEN, 1996). En los deltas lacustres actuales se han citado en el canal distributario, la barra de desembocadura, el prodelta, el frente deltaico, la bahía interdistributarios y los derrames (HYNE et al., 1979b; TYE Y COLEMAN, 1989b; a; SMITH Y PÉREZARLUCEA, 1994).

\subsubsection{Litofacies Ah: arenisca con laminación horizontal}

Es equivalente a la litofacies Sh de MiaLl (2006). Se han diferenciado dos subfacies en función de su madurez composicional y textural, reflejando distintos procesos de sedimentación $\mathrm{y}$, posiblemente, diferentes ambientes sedimentarios: arenitas $\left(\mathrm{Ah}_{1}\right)$ y grauvacas $\left(\mathrm{Ah}_{2}\right)$ con laminación horizontal. Ambas facies, en conjunto, son muy escasas, representando sólo el 1,6\% del total de la serie de Enciso, 2,1\% en Ambas Aguas, 2,9\% en Cornago, 4,1\% en Munilla y 3,2\% en Préjano.

Desde una perspectiva hidrodinámica la laminación horizontal en areniscas se puede originar a partir de multitud de procesos: 


\section{Análisis sedimentológico: microfacies y facies}

a) Flujo unidireccional. Se forma sobre un lecho plano bajo un régimen hidráulico tanto de alta energía como de baja energía. En el primer caso, la laminación horizontal se produce por la migración de formas de lecho de poco relieve (rizaduras, dunas o antidunas) en aguas someras (BEST Y BRIDGE, 1992). Por lo tanto, son frecuentes en etapas de avenida o inundación de carácter efímero, confinadas en canales o bien como corrientes no confinadas que se extiende sobre amplias áreas (mantos de arroyada) (MCKEE et al., 1967; WILLIAMS, 1971; FROSTICK Y REID, 1977). También aparecen en ríos someros entrelazados con flujos fluctuantes como Medano Creek (LANGFORDY BRACKEN, 1987; LORENZY NADON, 2002). Esta laminación horizontal en régimen de flujo alto aparece asociada, distintivamente, con laminación primaria de corriente (HARMS et al., 1975). En el segundo caso (régimen de baja energía) se forma también por la migración de formas de lecho en aguas someras (SMITH, 1971; MCBRIDE et al., 1975). En este contexto se requiere un aporte suficiente de sedimento para la creación de laminación horizontal (GuY et al., 1966). Son típicas de diques, de prodeltay de barras de desembocadura en los deltas lacustres (SMITH Y PÉREZ-ARLUCEA, 1994; WELLS et al., 1994).

b) Flujo oscilatorio puro. La laminación horizontal se origina por dos mecanismos hidrodinámicamente diferentes. El primer mecanismo tiene lugar bajo la acción de un flujo oscilatorio puro de alta energía, formándose una mezcla de agua y sedimento con un movimiento de vaivén constante. A este fenómeno se le denomina flujo en capas (sheet flow) y es el equivalente al régimen alto en los flujos unidireccionales (CLIFTON, 1976; ALLEN, 1984). La presencia de concentraciones de láminas de micas se considera un criterio específico de sedimentación por flujos oscilatorios en capas (CLIFTON, 1976). La formación de esta laminación requiere unas velocidades orbitales relativamente elevadas: como los medios lacustres se caracterizan por oleajes de períodos cortos, sólo se originan en áreas costeras bajo una intensa actividad del oleaje (CLIFTON, 1976). Esta laminación también se origina bajo la acción de flujos combinados: en estas circunstancias, cualquier pequeña corriente unidireccional disminuye el umbral de velocidad necesario para la formación del flujo en capas (ARNOTT Y SOUTHARD, 1990). El segundo mecanismo se produce por la migración de las rizaduras en ambientes con poca tasa de acumulación (NEWTON, 1968).

c) Decantación. En experimentos de laboratorio se ha observado que la laminación se origina por decantación del sedimento en suspensión (sin necesidad o con una mínima tracción) en masas de aguas estancadas o con poco movimiento. En la naturaleza se asocia a plumas de sedimento en suspensión como consecuencia de tormentas, huracanes, fuerte oleaje, inundaciones (REINECK Y SINGH, 1972; SINGH, 1972).

d) Flujos gravitatorios de sedimento debidos a corrientes de turbidez (LOWE, 1982; EYLES et al., 1987; BAAS, 2004).

\subsubsection{Litofacies $A h_{1}$ : arenita con laminación horizontal (paralela)}

Se trata de una arenita que manifiesta, como carácter destacado, laminación horizontal (paralela) (figura 5.20A). Es una facies escasa en las series muestreadas: 07\% en Enciso, 1,8\% en Ambas Aguas, 1,9\% en Cornago, 2\% en Munilla y, 0,9\% en Préjano. Sin embargo, se ha individualizado como una subfacies porque muestra unos indicadores deposicionales muy característicos.

Consta de cuarzoareniscas y areniscas cuarzosas, que en ocasiones presentan un contenido variable de cemento calcítico $(\approx 20 \%)$. Habitualmente el color de la muestra fresca es azul claro $(\approx 65 \%)$ ( 5 B 5/1 gris azulado; 5 B 7/1 gris azulado brillante; 5 B 6/2 azul pálido y; 5 B $8 / 2$ azul muy pálido) o gris ( $\approx 25 \%$ ) (N 8 gris muy luminoso; $\mathrm{N} 7$ gris luminoso; $\mathrm{N} 6$ gris medio luminoso; $N$ gris medio; 5 Y 6/ 1 gris verde oliva luminoso y; 5 G 4/ 1 gris verdoso moderado). En menor medida, pueden ser marrón medio $(\approx 4 \%)$ (5 YR 6/4 marrón tenue y 5 YR 5/6 marrón brillante), azul oscuro ( $\approx 2 \%$ ) (5PB $3 / 2$ azul oscuro) o, cuando los fenómenos oxidantes son muy importantes, anaranjados (10 R 6/ 6 naranja rojizo moderado; 10 R 4/ 6 marrón rojizo moderado y; 10 YR 6/ 6 naranja amarillento oscuro).

Se presenta en estratos de morfología tabular o levemente cuneiforme de escasa potencia (espesor varía entre 3-61 cm), y una relativa continuidad lateral a escala del afloramiento 
(decenas hasta algunas centenas de metros). El techo es plano y neto, el muro suele ser plano, no erosivo y neto, aunque en ciertas ocasiones se han observado bases irregulares de naturaleza erosiva (escasos gutter cast). En algunos estratos, la laminación horizontal no es muy clara (menos perceptibley visible), apareciendo en estos casos asociada lateralmentea cierta masividad $(\approx 13 \%)$ y/o bioturbación $(\approx 6 \%)$. Asimismo es muy frecuente la presencia de óxidos de hierro, bien sea formando externamente costras o películas $(\approx 93 \%)$ o bien internamente por un moteado evidente $(\approx 69 \%)$. A muro pueden aparecer estructuras de carga $(\approx 5 \%)$, aunque no es habitual. La presencia de pirita es casi anecdótica $(\approx 13 \%)$. No se observa superficies de acreción ni laminación primaria de corriente.
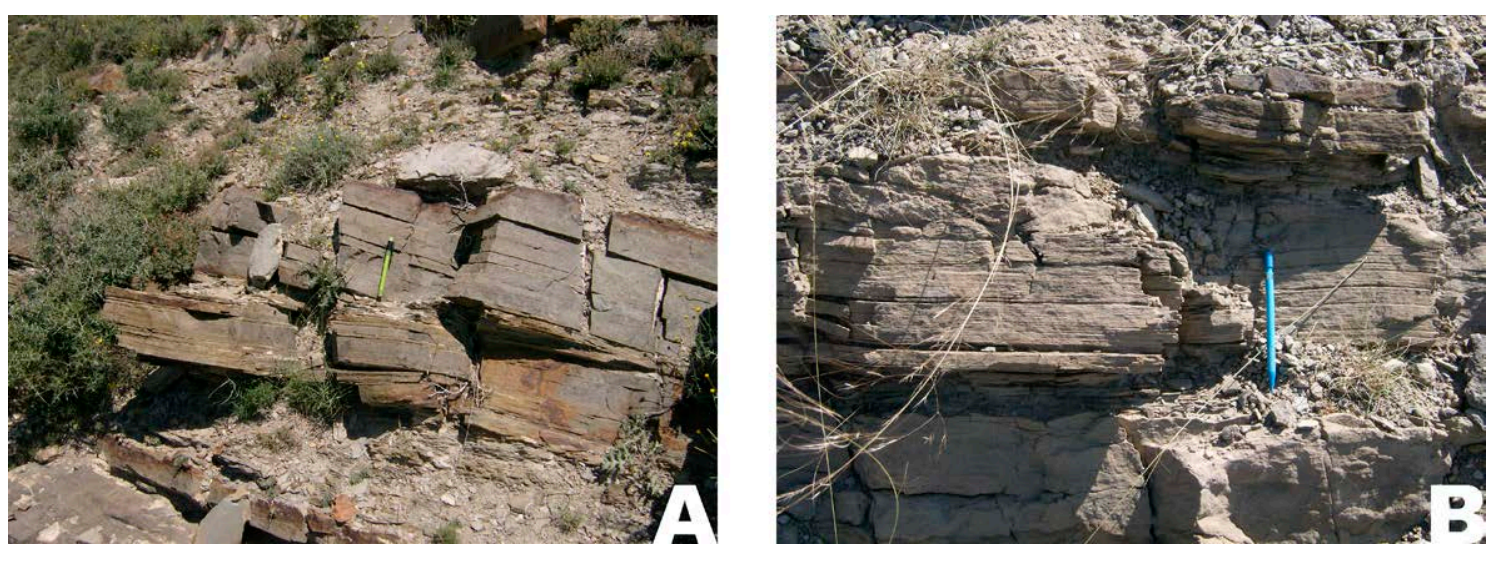

Figura 5.20: Aspecto en campo de las areniscas con laminación horizontal. A) Ejemplo de la facies $\mathrm{Ah}_{1}$ correspondiente al tramo 498 de la columna deAmbas Aguas. B) Ejemplo dela facies $\mathrm{Ah}_{2}$ en el tramo 306 de la columna de Cornago.

Su contenido paleontológico es prácticamente nulo apareciendo escasos ostrácodos $(\approx$ $2 \%)$ y fragmentos de moluscos no identificables $(\approx 2 \%)$.

\subsubsection{Litofacies $\mathrm{Ah}_{2}$ : grauvaca con laminación horizontal (paralela)}

Son grauvacas con laminación horizontal. Al igual que la facies Ah 1 no es muy abundante en proporción: 0,8\% en Enciso, 0,2\% en Ambas Aguas, 1\% en Cornago, 2,1\% en Munilla y 2,3\% en Préjano.

Está formada por grauvacas, a veces, muy carbonatadas $(\approx 8 \%)$. En muestra fresca es de color gris $(\approx 49 \%$ ) (N 8 gris muy luminoso; $N 7$ gris luminoso; $N 6$ gris medio luminoso y N 5 gris medio), azul ( $\approx 30 \%$ ) (5 B 5/1 gris azulado y 5 B 6/2 azul pálido), o verde ( $\approx 17 \%$ ) (10 Y 5/4 oliva luminoso y 5 GY $5 / 2$ verde amarillento sombrío). Raramente, aparece totalmente ferruginizada, mostrando un color rojo y/ o naranja (4\%) (10 R 6/ 6 naranja rojizo moderado; 10 R 4/ 6 marrón rojizo moderado y; 10 YR 6/ 6 naranja amarillento oscuro).

Se presenta en estratos de morfología tabular o cuneiforme con potencias comprendidas entre 4-60 cm, y continuos lateralmente a escala del afloramiento (decenas a veces centenares de metros). El techo es neto y plano-irregular. El muro es también neto, más o menos plano y no erosivo (figura 5.20B).

Internamente, además de la laminación horizontal, puede intercalarse con zonas masivas $(\approx 4 \%)$ y con un cierto moteado $(\approx 70 \%)$. A techo de los estratos es muy abundante la presencia de costras ferruginosas $(\approx 90 \%)$ y de bioturbación $(\approx 66 \%)$, en diversos grados de desarrollo. A muro pueden aparecer escasas estructuras de carga $(\approx 2 \%)$.

Su contenido paleontológico es mayor que en la facies anterior: abundantes ostrácodos $(\approx 26 \%$ ), pero siempre en cantidades queno alcanzan el $3 \%$ dela muestra, y frecuentes fragmentos de fósiles indiferenciados $(\approx 8 \%)$. 


\section{Análisis sedimentológico: microfacies y facies}

\subsubsection{Litofacies Am: arenisca masiva}

Se corresponde con la litofacies Sm de MiALL (2006) y consta de areniscas sin estructuras sedimentarias de ordenamiento interno observable. Algunos autores consideran que todas las rocas exhiben un ordenamiento y que su ausencia es, simplemente, una cuestión de la metodología aplicada. En función de su madurez litológica y textural se han definido dos sublitofacies: arenita masiva $\left(\mathrm{Am}_{1}\right)$ y grauvaca masiva $\left(\mathrm{Am}_{2}\right)$. En conjunto, es una facies frecuente, en términos de abundancia, en las columnas: 6,7\% en Enciso, 5,5\% en Ambas Aguas, 5,9\% en Cornago, 8,9\% en Munilla y 7,3 en Préjano.

La interpretación de esta facies es problemática. Por un lado se puede asumir que es una estructura sedimentaria primaria asociada a unas condiciones hidrodinámicas y procesos deposicionales determinados. Por otro lado, se puede considerar que es una estructura secundaria, es decir, un producto postdeposicional debido a fenómenos biológicos (bioturbación) o fisicoquímicos (pedogénesis, diagénesis, etc.) que la homogeneizan.

Los principales mecanismos deposicionales que pueden resultar en la sedimentación de una arenisca masiva en un medio fluvio-lacustre son:

a) Corrientes fuertemente cargadas en sedimentos que sufren una desaceleración rápida debido a la elevada concentración de carga en suspensión. Este hecho inhibe su capacidad de transporte de la carga de fondo por tracción, y favorece una decantación rápida (LOWE, 1988; ARNOTT Y HAND, 1989). Es típica de turbiditas (PICKERING et al., 1986), inundaciones-avenidas (MAIZELS, 1993), flujos hiperconcentrados (MARTINYTURNER, 1998), y mantos de tracción (SOHN, 1997).

b) Presencia de sedimento bien clasificado, homogranular y con un estrecho margen de variación de tamaño de grano. En este caso es posible que se produzca una sedimentación, tanto por decantación como por tracción, con una apariencia masiva (BAAS, 2004).

c) Flujos licuefactados o flujos gravitatorios de sedimentos, tanto granulares como de derrubios sin cohesión (STAUFFER, 1967; MIDDLETONY HAMPTON, 1976).

Por otra parte, el aspecto masivo puede deberse a fenómenos postdeposicionales de origen biológico o puramente fisicoquímicos:

a) $\mathrm{Si}$ el ritmo de retrabajamiento del sedimento por los organismos zoobentónicos excede a la tasa de sedimentación, se produce una homogeneización de los sedimentos en su totalidad.

b) Bioturbación por raíces en zonas vegetadas.

c) Fenómenos de licuefacción asociados a terremotos o a la carga debida a una rápida deposición (LOWE, 1975).

d) Resuspensión del material en medios lacustres (LiCK, 1982; HiLTON, 1985).

\subsubsection{Litofacies Amı: arenita masiva}

Esta facies equivale a parte de la litofacies Sm de Miall (2006) (figura 5.21A). Son cuarzoareniscas o areniscas cuarzosas en estratos tabulares que se distinguen por su marcado carácter masivo. En ocasiones se observa cierta gradación interna en los estratos. En términos de abundancia varía entre escasa (4\% en Enciso, 4,8\% en Ambas Aguas y Préjano, 2,8 en Cornago) y frecuente (7\% en Munilla).

Consta de cuarzoareniscas y areniscas cuarzosas que pueden tener cierto contenido en carbonatos en forma de cemento (41\%), aunque lo normal es que presente cemento silíceo (59\%). En muestra fresca el color dominante y más característico es el azul $(\approx 75 \%)(5 \mathrm{~B} 5 / 1$ gris azulado; 5 B 7/ 1 gris azulado brillante; 5 B 6/ 2 azul pálido y; 5 B 8/ 2 azul muy pálido) y, menos abundante, el gris $(\approx 10 \%)$ (N 8 gris muy luminoso; $\mathrm{N} 7$ gris luminoso; $\mathrm{N} 6$ gris medio luminoso; y N 5 gris medio), azul oscuro ( $\approx 3 \%$ ) (5PB $3 / 2$ azul oscuro), verde ( $\approx 2 \%$ ) (10 Y 5/4 oliva luminoso; $10 \mathrm{Y}$ 4/2 oliva grisáceo, $5 \mathrm{G} 3 / 2$ verde oscuro y; 5 GY $5 / 2$ verde amarillento sombrío) y marrón ( $\approx 1 \%$ ) 


\section{Análisis sedimentológico: microfacies y facies}

(5YR 6/ 4 marrón tenuey 5YR 5/ 6 marrón brillante). Las muestras muy ferruginizadas presentan colores anaranjados $(\approx 9 \%)$ (10 R 6/6 naranja rojizo moderado; $10 \mathrm{R}$ 4/6 marrón rojizo moderado y; 10 YR 6/ 6 naranja amarillento oscuro).
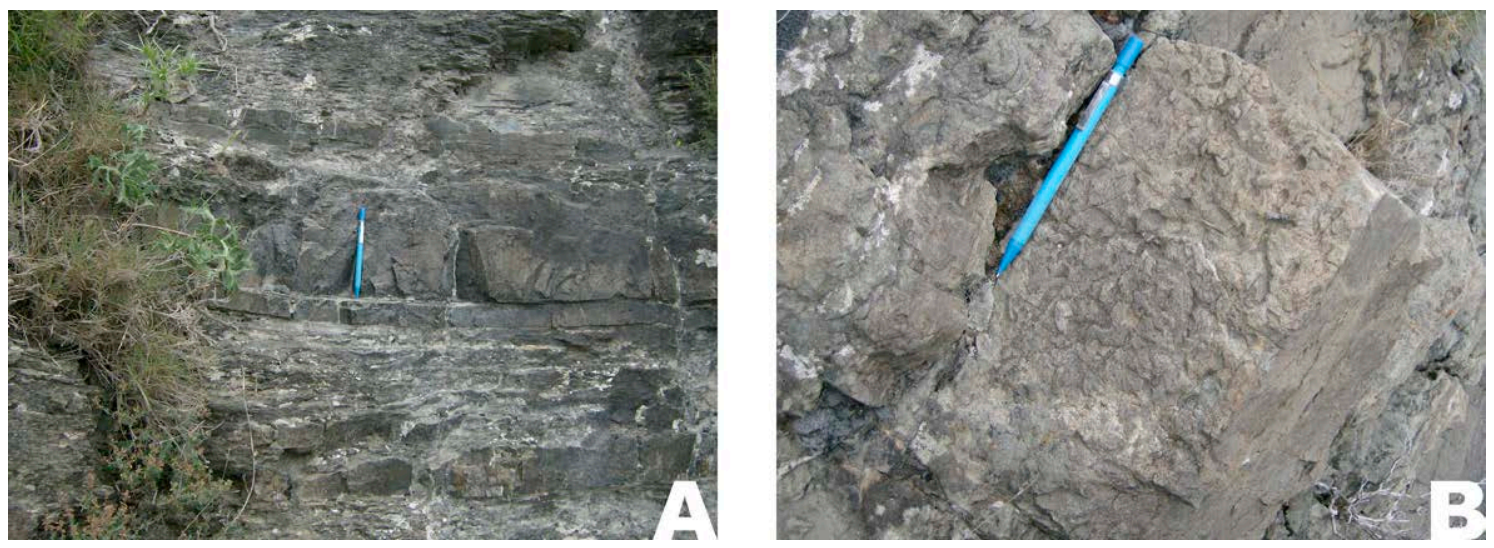

Figura 5.21: Aspecto en campo de las areniscas masivas. A) Ejemplo de la facies $\mathrm{Am}_{1}$ correspondiente al tramo 653-657 de la columna de Enciso. B) Ejemplo de la facies $\mathrm{Am}_{2}$ en el tramo 648 dela columna de Enciso.

El espesor medio es $20 \mathrm{~cm}$ aunque su rango de variación es amplio, entre 4-92 cm. Se presenta en estratos con techos y muros planos o irregulares de morfología tabular y gran extensión lateral. En campo puede aparecer como estratos aislados estratificado entre sedimentos de naturaleza diferente o constituyendo apilamientos de varios estratos de orden decimétrico hasta métrico generados por acreción vertical. La presencia de óxidos de hierro en forma de costras o películas superficiales $(\approx 89 \%)$ o de moteado $(\approx 64 \%)$ es muy abundante. De manera más esporádica aparece pirita $(\approx 3 \%)$. Se observa una importante bioturbación de hábito horizontal $(\approx 40 \%)$, la presencia de rizolitos $(\approx 3 \%)$, nódulos $(\approx 4 \%)$, grietas de retracción $(\approx 1 \%)$ y estructuras de escape de agua $(\approx 1 \%)$. A muro se pueden observar frecuentes estructuras de carga $(\approx 8 \%)$.

Su contenido paleontológico a nivel de cada muestra es insignificante, aunque es frecuente la presencia de ostrácodos $(\approx 13 \%)$ y de fragmentos de fósiles no identificables $(\approx 11 \%)$.

\subsubsection{Litofacies $\mathrm{Am}_{2}$ : grauvaca masiva}

Corresponde a parte de la facies Sm de MiALL (2006) (figura 5.21B). Se caracteriza por estar constituida por estratos tabulares de grauvacas con abundante matriz limosa - arcillosa que internamenteno presenta ningún tipo de estructura primaria. Es una facies escasa en abundancia en todas las series muestreadas: 2,6\% en Enciso, 0,7\% en Ambas Aguas, 3,1\% en Cornago, 1,9\% en Munilla y, 2,5\% en Préjano.

En ocasiones presenta matriz o cemento levemente carbonatado $(\approx 26 \%)$. En fractura exhiben multitud de colores, probablemente, reflejando multitud de estadios fisicoquímicos. Predomina el color azul claro ( $\approx 38 \%$ ) ( 5 B 5/1 gris azulado; 5 B 7/1 gris azulado brillante; 5 B 6/2 azul pálido y; $5 \mathrm{~B} 8 / 2$ azul muy pálido), gris $(\approx 22 \%)$ ( $\mathrm{N} 8$ gris muy luminoso; $\mathrm{N} 7$ gris luminoso; N 6 gris medio luminoso; y N 5 gris medio), y verde ( $\approx 17 \%$ ) (10 Y 5/4 oliva luminoso y; 5 GY 5/2 verde amarillento sombrío). También, aunque con un desarrollo mínimo, aparecen muestras de color negro ( $\approx 2 \%$ ) ( $\mathrm{N} 1$ negro y $\mathrm{N} 2$ negro grisáceo) y azul oscuro $(2 \%)$ (5PB $3 / 2$ azul oscuro). Finalmente, es relativamente importante el desarrollo de rubefacción $(\approx 19 \%)$ (10 R 6/6 naranja rojizo moderado; 10 R 4/ 6 marrón rojizo moderado y; 10 YR 6/ 6 naranja amarillento oscuro).

Los límites de los estratos son netos y no erosivos, aunque no es infrecuente que puedan ser graduales o levemente erosivos. Aflora en estratos tabulares o cuneiformes con espesores comprendidos entre 2 y $250 \mathrm{~cm}$. 


\section{Análisis sedimentológico: microfacies y facies}

En campo, es muy abundante la presencia de cierto grado de ferruginización en forma de pátinas de hierro $(\approx 80 \%)$ y/o moteado $(\approx 71 \%)$. La bioturbación es también muy abundante $(\approx$ $63 \%$ ), variando desde levey poco penetrativa hasta totalmente bioturbadas. Localmente aparecen nódulos $(\approx 4 \%)$ y alguna estructura de escape de agua $(\approx 3 \%)$. Los nódulos son de tamaño centimétrico a decimétrico y están compuestos de limolita, arcillita y, a veces, micrítica. A muro son escasas las estructuras de carga ( $\approx 2 \%)$.

El contenido paleontológico es escaso y se restringe a ostrácodos $(\approx 3 \%)$ en proporciones menores del 3\% y a fragmentos de moluscos $(\approx 7 \%)$.

\subsubsection{Litofacies Lh: lutita con laminación horizontal (paralela)}

Esta facies no tiene correspondencia clara con ninguna de las litofacies de MIALL (2006). Se ha subdividido en dos sublitofacies en función de los colores que presenta en roca fresca: $\mathrm{Lh}_{1}$ (color negro-oscuro) y Lh 2 (color azul, gris o verde). A pesar de esta distinción, la laminación presente en ambas subfacies es muy parecida, por lo que se asume una génesis hidrodinámica y deposicional semejante, siendo las condiciones fisicoquímicas o diagenéticas (representadas por el color) las que dan los caracteres diferenciales. En conjunto es una facies frecuente en todas las columnas levantadas: 12\% en Enciso, 6,2\% en Ambas Aguas, 15,3\% en Cornago, 10,5\% en Munilla y, 10,3\% en Préjano.

Los principales procesos sedimentarios implicados en la formación de laminación horizontal en materiales de naturaleza lutítica son:

a) Decantación del sedimento en suspensión (supra o intraflujos).

b) Infraflujos (corrientes de turbidezy/o flujos hiperpícnicos).

c) Tracción (corrientes de fondo o contornitas).

Estos procesos constituyen los términos extremos (cuando actúan aislados) de un espectro continuo con multitud de términos intermedios. En teoría, cada uno de estos mecanismos resulta en unas configuraciones específicas (formas de lecho, textura, etc.) reconocibles en el sedimento y, por extrapolación, en las facies. Además de los procesos sedimentarios, una (pseudo)laminación puede originarse como consecuencia de la diagénesis, principalmente por compactación (HAWLEY, 1981; LASH Y BLOOD, 2004).

La laminación por decantación refleja fluctuaciones en el aporte del sedimento en suspensión (naturaleza del sedimento y/o del mecanismo de transporte). Estas diferencias originan los límites de separación entre láminas. En el lago Turkana (figura 4.5), la laminación se origina por la decantación de las plumas de sedimento en suspensión que se forman durante la estación húmeda (YuRETICH, 1979). En el lago Malaui (figura 4.5) se asocia a intraflujos que pierden el sedimento por decantación (J OHNSON Y MCCAVE, 2008). También se producen por la decantación del material fino resuspendido por tormentas u otros agentes (REINECK Y SINGH, 1972; DE RAAF et al., 1977). Otro de los mecanismos más citados es el cambios en el régimen de la estratificación del lago y/ o el aporte del sedimento (STURM, 1979).

Las corrientes de turbidez son otro gran mecanismo formador de laminación horizontal como se ha comprobado experimentalmente (PASIERBIEWICZ Y KOTLARCZYK, 1997; LECLAIR Y ARNOTT, 2005). En algunos lagos son frecuentes los infraflujos turbidíticos episódicos (no anuales) relacionados con la entrada cíclica en el lago de aguas cargadas en sedimentos (LUDLAM, 1969; STURMY MATTER, 1978; LAMBERT Y HSÜ, 1979).

Por último, esta facies se puede originar por un flujo de aguas claras sobre un lecho plano en un régimen hidráulico de alta energía (SOUTHARD, 1991).

Sin embargo, la presencia de laminación horizontal en el registro geológico requiere, además de los procesos generadores ya descritos, la concurrencia de unas condiciones óptimas de preservación que no alteren la fábrica original. Los principales mecanismos favorables (o que aumentan la probabilidad de preservación) son los siguientes: 
a) Ausencia de organismos bioturbadores del fondo (bentónicos) cuya actividad tiende a homogeneizar el sedimento (DAVIS, 1974). Los organismos perforadores pueden desarrollarse en zonas lacustres profundas, incluso en aquellos que sufren mezclas esporádicas o con poco oxígeno hipolímnico (CARR y HILTUNEN, 1965). Estos organismos suelen desarrollar su actividad hasta una profundidad de unos $16 \mathrm{~cm}$, aunque pueden llegar hasta los 40-50 cm (DAVIS, 1974). Generalmente una anoxia permanente, o durante un periodo de tiempo suficientemente largo, es un requisito aunque no es esencial. Otras veces, la poca disponibilidad de nutrientes (COHEN, 1984) o la salinidad puede ser suficiente para excluir a los organismos bentónicos (GIERLOWSKI-KORDESCH Y RUST, 1994), de manera que, sedimentos laminados pueden aparecer en lagos someros salinos (RENAUT, 1990).

b) Ausencia o escasa actividad de corrientes de fondo que destruyan o modifiquen la laminación debido a la resuspensión del material previamente depositado (LARSENY MACDONALD, 1993; EVANS, 1994; LARSEN et al., 1998).

c) Una tasa de sedimentación lo bastante elevada como para que los organismos bentónicos no puedan retrabajarla totalmente, pero no tanto como para diluir o eliminar la deposición cíclica (SIMOLA et al., 1981; RIPPEY, 1982).

d) Una cubeta con el fondo lo suficientemente plano o con poca pendiente para que el sedimento no se deslice (O'SULLIVAN, 1983).

Todos o gran parte de estos factores confluyen en los lagos meromícticos. Por consiguiente, es normal que en el hipolimnion se depositen sedimentos laminados (ANDERSON et al., 1985; ANDERSONY DEAN, 1988), aunque no todos los depósitos laminados apuntan de manera unívoca a etapas de meromixis. Las laminaciones también aparecen en lagos holomícticos (LUDLAM, 1976) y dimícticos (O'SULLIVAN, 1983).

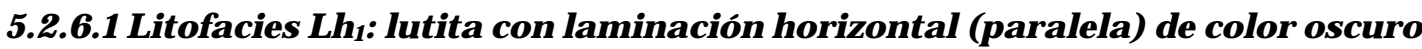

Constituye una subfacies de la litofacies Lh, cuya característica distintiva es la presencia de laminación horizontal asociada a muestras de color negro-oscuro debido al alto contenido en materia orgánica (figuras 5.22A, By C). Su abundancia varía entre escasa en Ambas Aguas (2,6\%) y Munilla (5\%), hasta frecuente en Enciso (7,1\%), Cornago (8,5\%) y Préjano (10,3\%).

Aparece en estratos o paquetes sin estratificación clara de 10-70 cm de potencia. En campo algunas pueden exhibir una evidente pizarrosidad (hojosidad) lo cual les da apariencia de pizarras negras (black shales) (figuras 5.22A y B). También pueden presentar cierto desarrollo de esquistosidad de fractura.

Esta facies contiene esencialmente lutitas $(95 \%)$, abundando las de cemento silíceo $(\approx$ $79 \%)$ sobre las de cemento carbonatado $(\approx 16 \%)$. La presencia de lutitas arenosas $(\approx 4 \%)$ y lutitas arenosas carbonatadas $(\approx 1 \%)$ es escasa. Los colores son siempre oscuros con un claro predominio del negro $(\approx 92 \%)$ ( $\mathrm{N} 1$ negro y $\mathrm{N} 2$ negro grisáceo) sobre el azul oscuro $(\approx 8 \%)$ (5 $\mathrm{PB} 3 / 2$ azul oscuro). El color oscuro refleja un alto contenido en materia orgánica y/ o piritización.

La laminación horizontal de los estratos suele ser la única estructura presente, aunque en ocasiones coexiste, lateralmente, con cierta masividad $(\approx 40 \%)$ o laminación cruzada por rizaduras $(\approx 3 \%)$. A techo es muy abundante la presencia de bioturbación muy tenue $(\approx 56 \%)$ y de escasas rizaduras simétricas $(\approx 2 \%)$. También pueden aparecer nódulos de naturaleza silícea 0 carbonatada $(\approx 12 \%)$ (figuras $5.22 \mathrm{~A}$ y B). Es normal que aparezcan pátinas ferruginosas muy poco desarrolladas $(\approx 65 \%)$ y más ocasionalmente, un leve moteado $(\approx 5 \%)$. La bioturbación es nula (grado 0), y cuando existe es muy leve y poco penetrativa (grado 1). Su escaso o nulo desarrollo asociado a sedimentos ricos en materia orgánica parecen indicar que se tratan de trazas de organismos anaerobios (condiciones anóxicas) o disaerobios (BROMLEYY EKDALE, 1984; EKDALEY MASON, 1988).

El contenido paleontológico tiene escasa entidad y se limita a fósiles límnicos: abundan los ostrácodos $(\approx 42 \%)$ y, en menor proporción, los bivalvos $(\approx 1 \%)$ y fragmentos indiferenciados 


\section{Análisis sedimentológico: microfacies y facies}

de moluscos $(\approx 18 \%)$. La presencia en algunos afloramientos con ejemplares de la familia Unionidae en posición mariposa sugiere la instalación de etapas de anoxia.
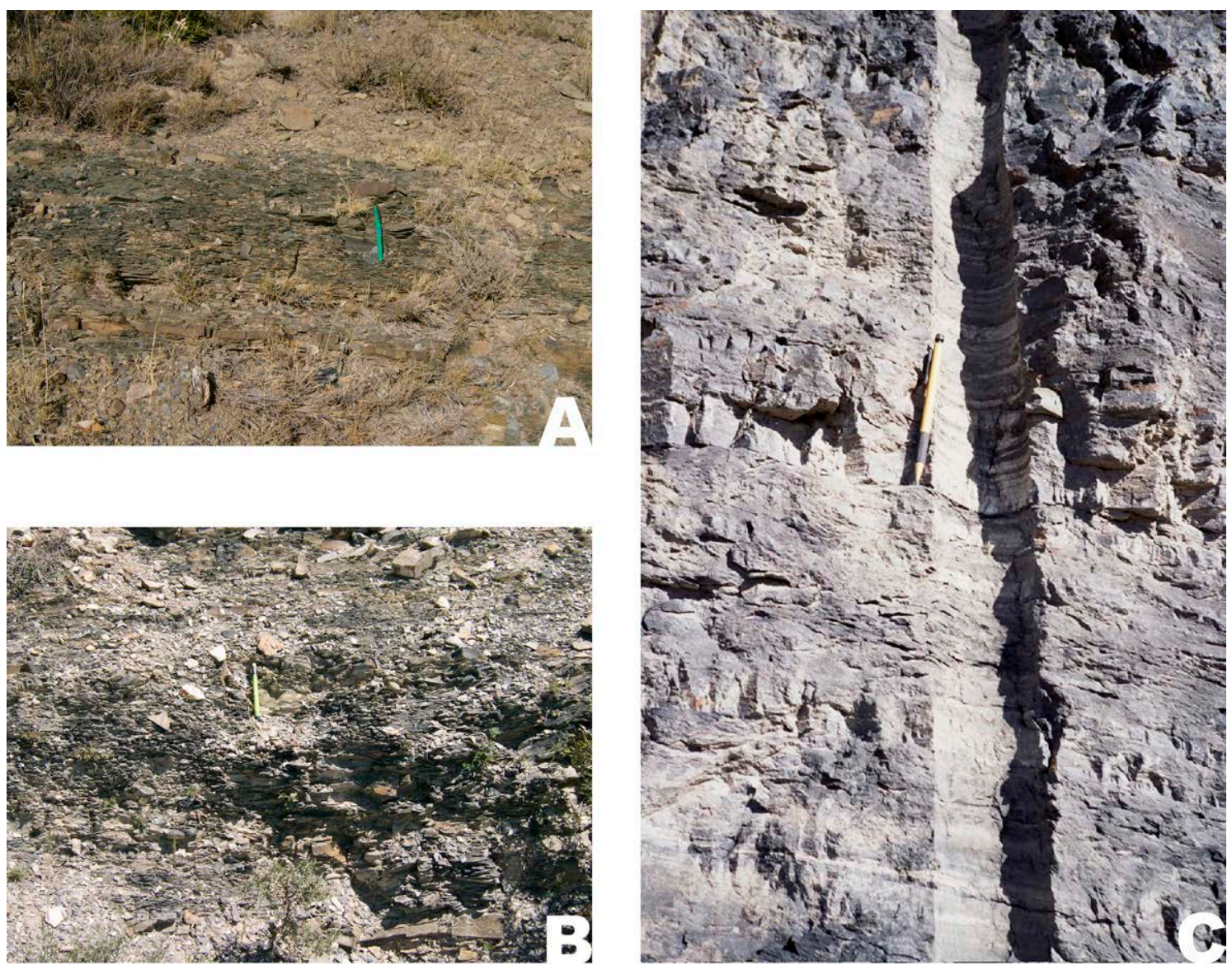

Figura 5.22: Aspecto en campo de las lutitas oscuras con laminación horizontal. A) Ejemplo de la facies $\mathrm{Lh}_{1}$ correspondiente al tramo 34 de la columna de Cornago. B) Ejemplo de la facies $\mathrm{Lh}_{1}$ en el tramo 491 de la columna de Ambas Aguas. C) Ejemplo de la facies $\mathrm{Lh}_{1}$ localizado en los tramos 276-277 de la columna de Enciso.

En la actualidad las lutitas negras con laminación horizontal son características de lagos tanto someros como profundos, así como del prodelta en deltas lacustres (SMITH et al., 1986b; TYE Y COLEMAN, 1989b; a).

\subsubsection{Litofacies $\mathrm{Lh}_{2}$ : lutita con laminación horizontal (paralela) de color azul, gris o verde}

Está constituida por lutitas que internamente exhiben una clara laminación horizontal milimétrica. En ocasiones, en el campo muestran un aspecto pizarroso o lajoso (figuras 5.23A y B). Son siempre de color azul, gris o verde, nunca de colores oscuros. Su desarrollo varía desde escaso en Enciso (4,9\%) y Ambas Aguas (3,6\%) hasta frecuente en Cornago (6,8\%) y Munilla $(5,4 \%)$. En la columna de Préjano, esta facies es inexistente.

Consta de lutitas $(\approx 53 \%)$, lutitas carbonatadas $(\approx 4 \%)$, lutitas arenosas $(\approx 40 \%)$ y lutitas arenosas carbonatadas $(\approx 3 \%)$. En muestra fresca predomina el color azul ( $\approx 46 \%)$ (5 B 5/1 gris azulado; 5 B 7/1 gris azulado brillante; 5 B 6/2 azul pálido y; 5 B 8/2 azul muy pálido), gris ( $\approx$ 44\%) (N 8 gris muy luminoso; N 7 gris luminoso; N 6 gris medio luminoso; y N 5 gris medio) $\mathrm{y}$, verde ( $\approx 10 \%$ ) (10 Y 5/4 oliva luminoso y; 5 GY 5/ 2 verde amarillento sombrío).

Afloran en estratos tabulares o niveles levemente lenticulares de potencia comprendida entre 9-210 cm, de gran extensión lateral a escala del afloramiento (alcanzando centenares de metros). Los estratos puede mostrar, asociados a la laminación horizontal, cierta masividad $(\approx$ 


\section{Análisis sedimentológico: microfacies y facies}

$10 \%$ ) o laminación cruzada por rizaduras $(\approx 5 \%)$. Es habitual que a techo de los mismos aparezca una tenue bioturbación $(\approx 63 \%)$. Más inusual es la presencia de nódulos ovalados, decimétricos, de naturaleza silícea o micrítica $(\approx 10 \%)$. En ocasiones aparecen cubos milimétricoscentimétrico de pirita $(\approx 3 \%)$, estructuras de escape de agua $(\approx 1 \%)$ y, estructuras de carga $(\approx 1 \%)$. Cuando la muestra ha sufrido cierta ferruginización, ésta se manifiesta superficialmentemediante pequeñas pátinas de óxidos de hierro $(\approx 61 \%)$ e internamente con un moteado evidente $(\approx 35 \%)$.
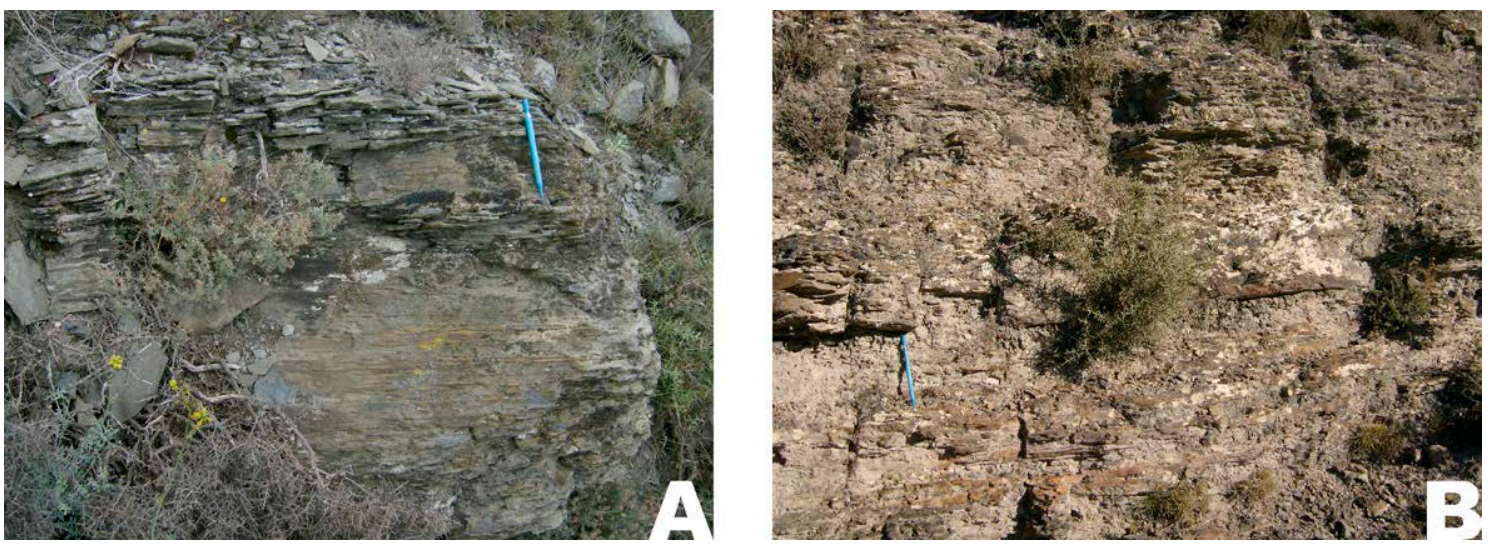

Figura 5.23: Aspecto en campo de las lutitas con laminación horizontal (facies $\mathrm{Lh}_{2}$ ). A) Ejemplo dela facies $\mathrm{Lh}_{2}$ en el tramo 647 dela columna de Enciso. B) Ejemplo de la facies $\mathrm{Lh}_{2}$ en el tramo 369 de la columna de Ambas Aguas.

El contenido paleontológico consta, básicamente, de ostrácodos $(\approx 19 \%)$, gasterópodos $(\approx 4 \%)$ y restos fragmentados inidentificables $(\approx 8 \%)$.

En los deltas lacustres actuales, es una facies característica del prodelta (HYNE et al., 1979b; TYE Y COLEMAN, 1989b; a; SMITH Y PÉREZ-ARLUCEA, 1994). En menor medida aparece en diques naturales (WELLS et al., 1994) y en ambientes de bahía interdistributarios y derrames (HYNE et al., 1979b). También es característica de lagos someros localizados en llanuras de inundación donde se asocia a episodios periódicos de inundación del río (HYNE et al., 1979b; YURETICH, 1979; ASLANY AUTIN, 1999).

\subsubsection{Litofacies Lm: lutita masiva}

Corresponde a parte de la litofacies Fsc y Fcf de Miall (2006). Esta facies pasa de ser abundante en la columna de Enciso (28,9\%) a común en Munilla $(19,8 \%)$ y, escasa en Ambas Aguas (4,2\%). En el resto es una facies frecuente: Cornago (10,2\%) y Préjano (10,5\%). La masividad en esta facies conlleva una gran ambigüedad interpretativa, que sejunta a su extensa distribución, indicativa de una amplio abanico de ambientes deposicionales. Así pues, se ha creído conveniente formalizar ciertas subdivisiones que faciliten su interpretación. En los estudios paleolimnológicos consultados, esta diferenciación en subfacies se fundamenta en el color, así como, en la presencia de ciertas estructuras postdeposicionales que evidencien procesos de interés en la interpretación (KEIGHLEY et al., 2003; RigSBY et al., 2005). El contenido paleontológico también puede ser un carácter significativo. Un ejemplo clásico de la ambigüedad y diversidad de esta facies, en medios fluvio-lacustres asociados a cuencas rift, lo constituye el Supergrupo Newark (SMOOT y OLSEN, 1985; SMOOT y OLSEN, 1988). En este caso se han diferenciado dos sublitofacies basándose en el color: Lm1 (color negro—oscuro) y Lm2 (color azul o gris).

$\mathrm{Al}$ igual que ocurre con la litofacies de areniscas masivas, su masividad puede deberse a la ausencia original de laminación durante la deposición (un ambiente inmutable desde una perspectiva sedimentaria), o bien la destrucción post-sedimentaria de las estructuras primarias.

Sin embargo, esta facies puede depositarse bajo la acción de flujos unidireccionales y, en este contexto, se asocia a: 
a) Etapas finales de baja energía durante las avenidas (MIALL, 1977).

b) Etapas finales de corrientes turbidíticas de baja densidad (HORTONY SCHMITT, 1996).

c) Deposición en masa a partir de corrientes de turbidez lutíticas de alta concentración (PICKERING et al., 1986).

La decantación del material en suspensión en zonas poco energéticas es uno de los mecanismos más citados en la literatura. Así pues aparece en un amplio abanico de ambientes. En los deltas lacustres se han citado como características en el frente deltaico (HYNE et al., 1979b). En pequeños deltas por derrame son representativas del prodelta y de las barras de desembocadura limosas (SMITH Y PÉREZ-ARLUCEA, 1994). También se ha descrito como la facies característica de lagos someros emplazados en las cubetas de inundación (SMITH Y PÉREZARLUCEA, 1994; PÉREZ-ARLUCEA Y SMITH, 1999; MOROZOVA Y SMITH, 2000). Porúltimo, son típicas de humedales (ASLANy Autin, 1999; PÉREZ-ARLUCEA Y SMITH, 1999; DORADO-VALIÑO et al., 2002).

En ciertos sistemas lacustres es frecuente que el material decantado proceda de la resuspensión provocada por terremotos: lago Lucerna (SIEGENTHALER et al., 1987), lago Tadoussac (DOIG, 1990; 1991), lago Washington (KARLIN Y ABELLA, 1992), y lago Le Bourget (CHAPRON et al., 1999). Este fenómeno produce un depósito de material fino, masivo y muy homogéneo denominado homogenita (homogenite), con un espesor que varía entre unos pocos centímetros (CHAPRON et al., 1999) hasta varios metros (SIEGENTHALER et al., 1987).

Además, una bioturbación intensa o los fenómenos pedogenéticos asociados a la emersión pueden destruir la estratificación y las estructuras sedimentarias, dotando a cualquier sedimento lutítico de una apariencia masiva y homogénea.

\subsubsection{Litofacies Lm1: lutita masiva de color oscuro}

Consta de lutitas en estratos de geometría tabular sin estructura sedimentaria visible, y cuya característica diferencial es un significativo color oscuro en muestra fresca (figuras 5.24A y B). Esta facies muestra un desarrollo muy diverso. En la sección de Enciso es abundante (21,7\%) y pasa a escaso en las series de Ambas Aguas (1,7\%) y Cornago (4\%). En el resto de columnas tiene una abundancia común: Munilla (8,4\%) y Préjano (10,5\%).

Se presenta en estratos o paquetes tabulares sin estratificación clara o aparente con potencias que varían desde unos pocos centímetros $(4 \mathrm{~cm})$ hasta varios metros $(610 \mathrm{~cm})$. El techo y muro suele ser plano y no erosivo, aunque en ocasiones aparece rellenando paleorrelieves y/o amoldándose a la morfología preexistente.

Esta litofacies consta en su mayor parte de lutitas ( $\approx 83 \%$ ), aunque en porcentajes mucho menos importantes, aparecen lutitas carbonatadas $(\approx 10 \%)$, lutitas arenosas $(\approx 6 \%)$ y lutitas arenosas carbonatadas $(\approx 1 \%)$. Los colores en fractura, específicos de esta subfacies, son el negro $(\approx 78 \%)$ ( $\mathrm{N} 1$ negro y $\mathrm{N} 2$ negro grisáceo) y el azul oscuro ( $\approx 22 \%)$ (5PB $3 / 2$ azul oscuro).

Esta facies usualmente exhibe una intensa bioturbación ( $\approx$ 93\%) (figura 5.24B), así como costras de hierro $(\approx 52 \%)$, mientras que la aparición de nódulos $(\approx 10 \%)$ y moteado por óxidos de hierro $(\approx 10 \%)$ es más esporádica. Es rara la presencia de estructuras de carga $(\approx 1 \%)$ o de escape de agua $(\approx 1 \%)$. En las mismas proporciones, algunos afloramientos muestran piritas $(\approx 1 \%)$ o pseudomorfos de yeso $(\approx 1 \%)$.

El contenido paleontológico consta de fósiles límnicos (en ocasiones piritizados): ostrácodos $(\approx 51 \%)$, bivalvos $(\approx 1 \%)$, gasterópodos $(\approx 6 \%)$ y fragmentos $(\approx 36 \%)$.

\subsubsection{Litofacies $\mathrm{Lm}_{2}$ : lutita masiva de color azul o gris}

Se define como unas lutitas en estratos tabulares de aspecto masivo y/ o homogéneo de color azul o gris. Esta facies muestra un desarrollo desigual según la zona, pasando de ser frecuente en Enciso (7,2\%), Cornago (6,2\%) y Munilla (11,3\%), hasta escaso en Ambas Aguas $(2,5 \%)$, hasta no estar presente en la columna de Préjano. 


\section{Análisis sedimentológico: microfacies y facies}
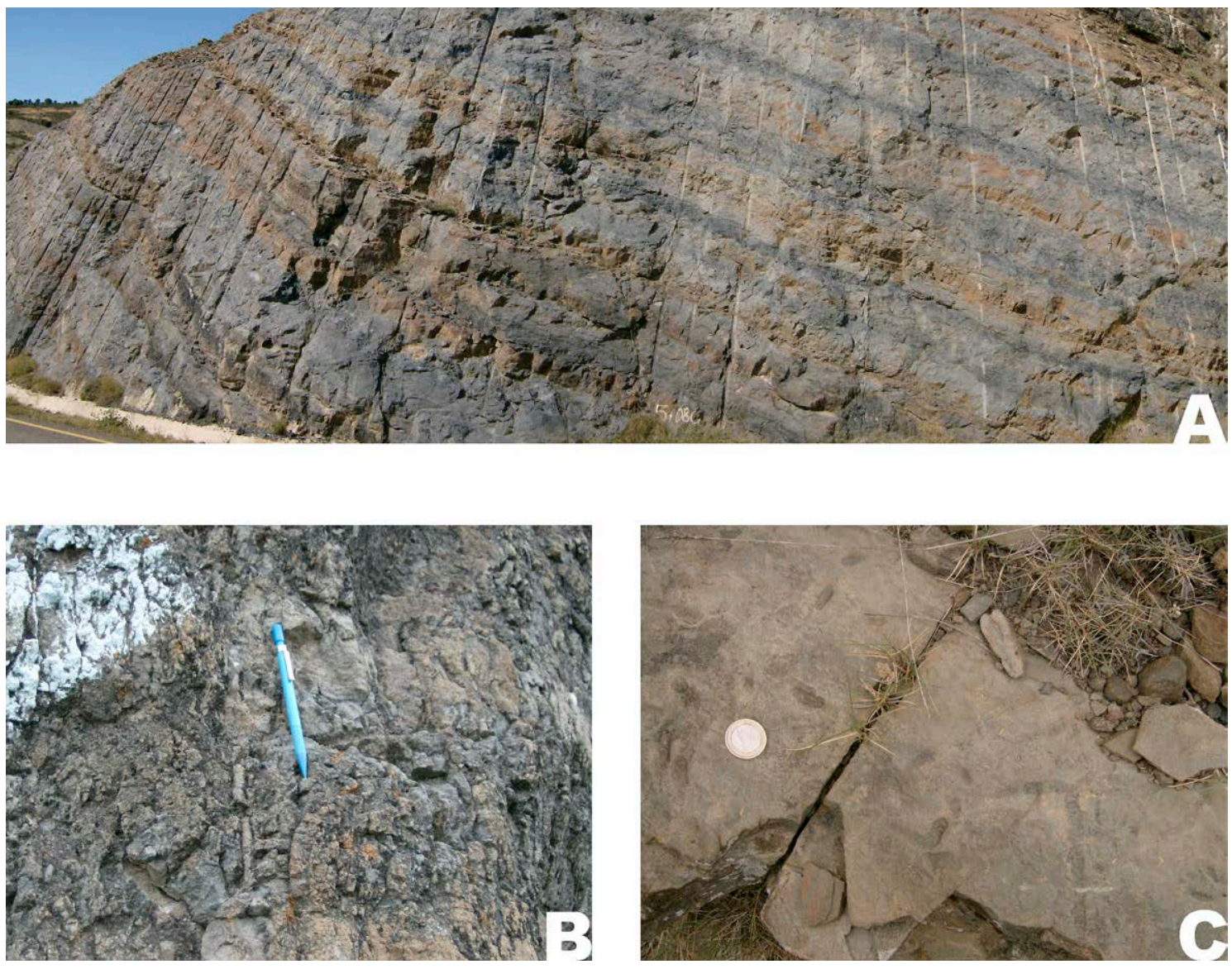

Figura 5.24: Aspecto en campo de las lutitas masivas. A) Ejemplo dela facies $\mathrm{Lm}_{1}$ en los tramos 62-75 de la columna de Enciso. B) Ejemplo de la facies $\mathrm{Lm}_{1}$ en el tramo 4 de la columna del yacimiento de Peñaportillo. C) Ejemplo de la facies $\mathrm{Lm}_{2}$ localizado en el tramo 820 de la columna de Enciso.

Comprende fundamentalmente lutitas $(\approx 52 \%)$ y lutitas arenosas $(\approx 29 \%)$, en menor proporción, aparecen lutitas carbonatadas $(\approx 12 \%)$ y lutitas arenosas carbonatadas $(\approx 7 \%)$. Los colores básicos en muestra fresca son el azul $(\approx 48 \%)$ (5 B 5/1 gris azulado y 5 B $6 / 2$ azul pálido) y el gris $(\approx 45 \%$ ) (N 8 gris muy luminoso; $\mathrm{N} 7$ gris luminoso; $\mathrm{N} 6$ gris medio luminoso; y $\mathrm{N} 5$ gris medio). Más inusual es la presencia de muestras de color marrón ( $\approx 6 \%)$ (5 YR 6/4 marrón tenue y 5 YR $5 / 6$ marrón brillante) y verde ( $\approx 1 \%$ ) (10 Y $5 / 4$ oliva luminoso y; 5 GY 5/ 2 verdeamarillento sombrío).

Se presentan en estratos o niveles de geometría tabular o ligeramente lenticular con gran continuidad lateral, que a menudo excede las dimensiones del afloramiento, y espesores comprendidos entre 7-120 cm. Aparte de su característica masividad y color, se asocia con una importante bioturbación $(\approx 89 \%)$ (figura $5.24 \mathrm{C}$ ) variando entre completa (grado 6) hasta moderada (grado 3), y numerosas costras de hierro $(\approx 79 \%)$. Más dispersa es la presencia de moteado por óxidos ferruginosos $(\approx 40 \%)$, nódulos carbonatados o arcillíticos $(\approx 11 \%) \mathrm{y}$, estructuras de carga $(\approx 4 \%)$. De forma anecdótica pueden aparecer cubos y dodecaedros milimétricos de pirita $(\approx 1 \%)$.

El contenido paleontológico consiste en ostrácodos $(\approx 21 \%)$, bivalvos $(\approx 2 \%)$, gasterópodos $(\approx 2 \%)$ y fragmentos no identificables $(\approx 28 \%)$.

\subsubsection{Litofacies Lg: lutita con grietas de retracción}

Corresponde en su totalidad a la litofacies Fm de MiaLL (2006). Se describe como lutitas masivas en estratos tabulares o lenticulares con grietas de retracción a techo (figuras 5.25A y B). 


\section{Análisis sedimentológico: microfacies y facies}

Es una facies escasa en todas las secciones muestreadas: Enciso (0,7\%), Ambas Aguas (0\%), Cornago (1,5\%), Munilla (2\%) y, Préjano (0,6\%).

Está compuesto de lutitas $(\approx 68 \%)$ y lutitas arenosas $(\approx 32 \%)$ de color azul (5 B 5/1 gris azulado y 5 B 6/ 2 azul pálido).

Los estratos son tabulares, a veces ligeramente lentejonares, con techos y muros netos, no erosivos, y espesores que varían entre 8 y $330 \mathrm{~cm}$. Son lateralmente continuos a escala del afloramiento (decenas de metros). Se caracterizan por su masividad interna y por la presencia de grietas de retracción en superficie. Normalmente también aparece asociado a una importante bioturbación $(\approx 98 \%)$, costras de hierro $(\approx 79 \%)$ y nódulos $(\approx 56 \%)$. No se ha observado contenido paleontológico alguno. Las grietas son ortogonales (hexagonal y pentagonal) y no ortogonales, tanto completas como incompletas, dispuestas de manera aleatoria o con una ligera orientación. En algunos ejemplos, las grietas aparecen rellenas de ostrácodos, interpretándose como acumulaciones generadas por la acción del viento.
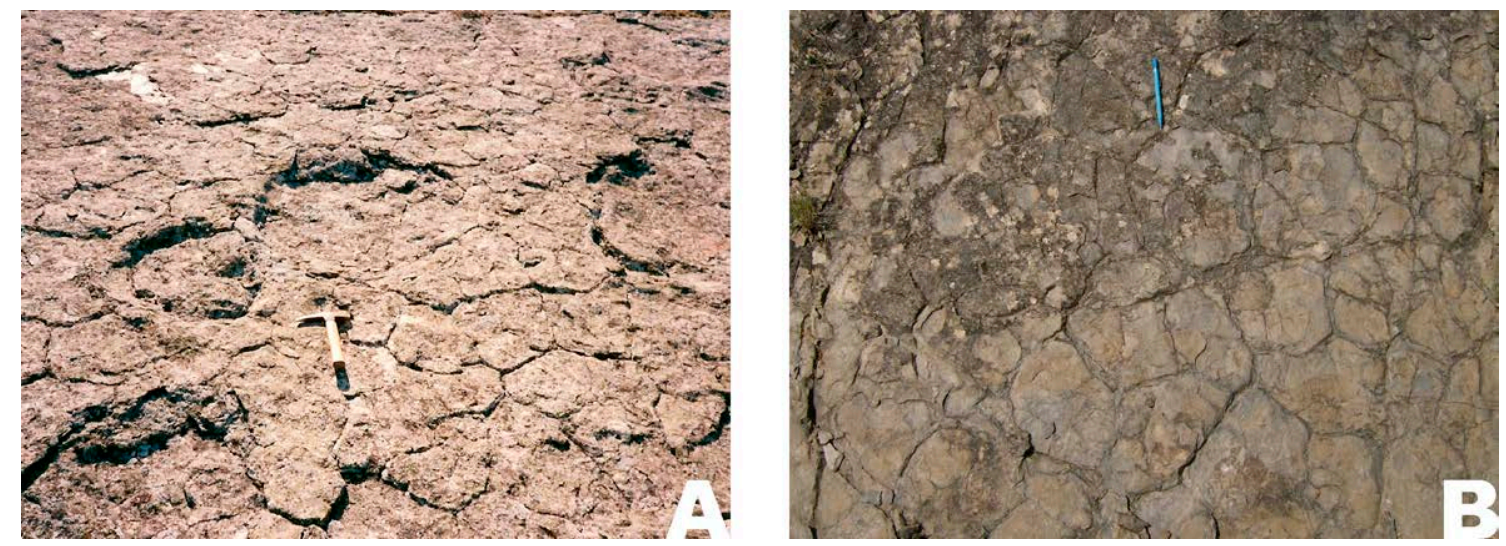

Figura 5.25: Aspecto en campo de las lutitas con grietas de retracción. A) Ejemplo de la facies Lg en el yacimiento icnológico de El Sobaquillo (Munilla). B) Ejemplo de la facies Lg en las inmediaciones del barranco de Los Cayos (Cornago).

Las grietas de retracción (mud cracks en la literatura anglosajona), son unas estructuras sedimentarias relativamente abundantes y fáciles de reconocer en campo, aunque pueden dar lugar a interpretaciones erróneas en el registro geológico. Habitualmente, se han considerado como un elemento diagnóstico de un ambiente deposicional periódicamente sujeto a exposición subaérea. No obstante, y aunque es cierto en la mayoría de los casos, éstas también pueden originarse bajo el agua sin necesidad de emersión, por cambios de salinidad, terremotos, etc. Por consiguiente, su presencia no debe aceptarse, a primera vista, como evidencia indiscutible de emersión.

A esto, hay que añadir una cierta confusión en la terminología existente (NEAL, 1978; ALLEN, 1982a). Así pues las grietas de retracción, también denominadas grietas de desecación (dessication cracks) y grietas de contracción (shrinkage cracks), se originan por una pérdida de volumen debido a la desecación y compactación de sedimentos de grano fino saturados en agua. Hay que diferenciarlo de otras grietas de morfología parecida, las grietas de sinéresis (synaeresis cracks), que tienen un origen y génesis muy diferente, pudiéndose formar subacuáticamente (NEAL, 1978). Estos términos son muy difíciles de diferenciar y reconocer en campo, por consiguiente, en el presente trabajo se considera grieta de retracción a cualquier fractura poligonal conectada, completamente o incompletamente, que se forma perpendicularmente a la superficie de una capa (ALLEN, 1982a). Esta definición es muy descriptiva y de fácil reconocimiento en campo.

Durante el levantamiento de las columnas estratigráficas, se han observados grietas de retracción en sedimentos tanto de naturaleza detrítica como carbonatada. Normalmente, las grietas de retracción se originan en sedimentos de granulometría fina, como arcillas y limos, no 


\section{Análisis sedimentológico: microfacies y facies}

apareciendo en arenas ya que no se produce reducción volumétrica alguna durante la desecación (NEAL, 1978).

El desarrollo de las grietas está controlados por una amplia gama de factores (PLUMMER Y GOSTIN, 1981; ALLEN, 1982a). Cualquier fisura o hendidura sobre la superficie de una capa puede controlar la configuración inicial en el patrón delas grietas de retracción. Esta rotura inicial puede tener un origen orgánico o inorgánico. Entre las primeras, cabe citarse las marcas del paso de gasterópodos (BALDWIN, 1974), larvas de escarabajos (METZ, 1980), gusanos (SOLEILHAVOUP Y BERTOUILLE, 1976), y aves (MASONY VON BRUNN, 1978), así como la simple presencia de bivalvos (KUES Y SIEMERS, 1977). En el registro fósil, también se han atribuido al paso de dinosaurios, actuando las icnitas como puntos de inicio del agrietamiento (THULBORN, 1990).

Los sitios más favorables al desarrollo de grietas de retracción son las superficies de sedimentos saturados en agua que sufre exposición subaérea: charcas, lagos, lagunas, deltas lacustres, canales fluviales abandonados, llanuras de inundación, etc. Cuando estos rasgos aparecen combinados, se está en presencia de un indicador claro de exposición subaérea del sedimento (REINECK Y SINGH, 1980). En la zona estudiada, se puede asumir que la mayor parte de la grietas de retracción existentes se han formado por emersión, ya que suelen aparecer acompañadas de estructuras pedogenéticas, nodulización, costras ferruginosas, bioturbación, icnitas de vertebrados, etc.

\subsubsection{Litofacies LMm: lutita y/o marga masiva}

Se define como margas y/o lutitas masivas (en ocasiones laminadas) en estratos o paquetes tabulares que exhiben colores púrpuras, rojizos y/ o anaranjados muy característicos en fractura (figuras 5.26A, B y C). En general presenta una abundancia frecuente en las secciones de Enciso (6,2\%), Ambas Aguas (8,3\%) y Cornago (19,3\%). Por el contrario, en Munilla es escasa $(1,1 \%)$ y no está presente en la columna de Préjano.
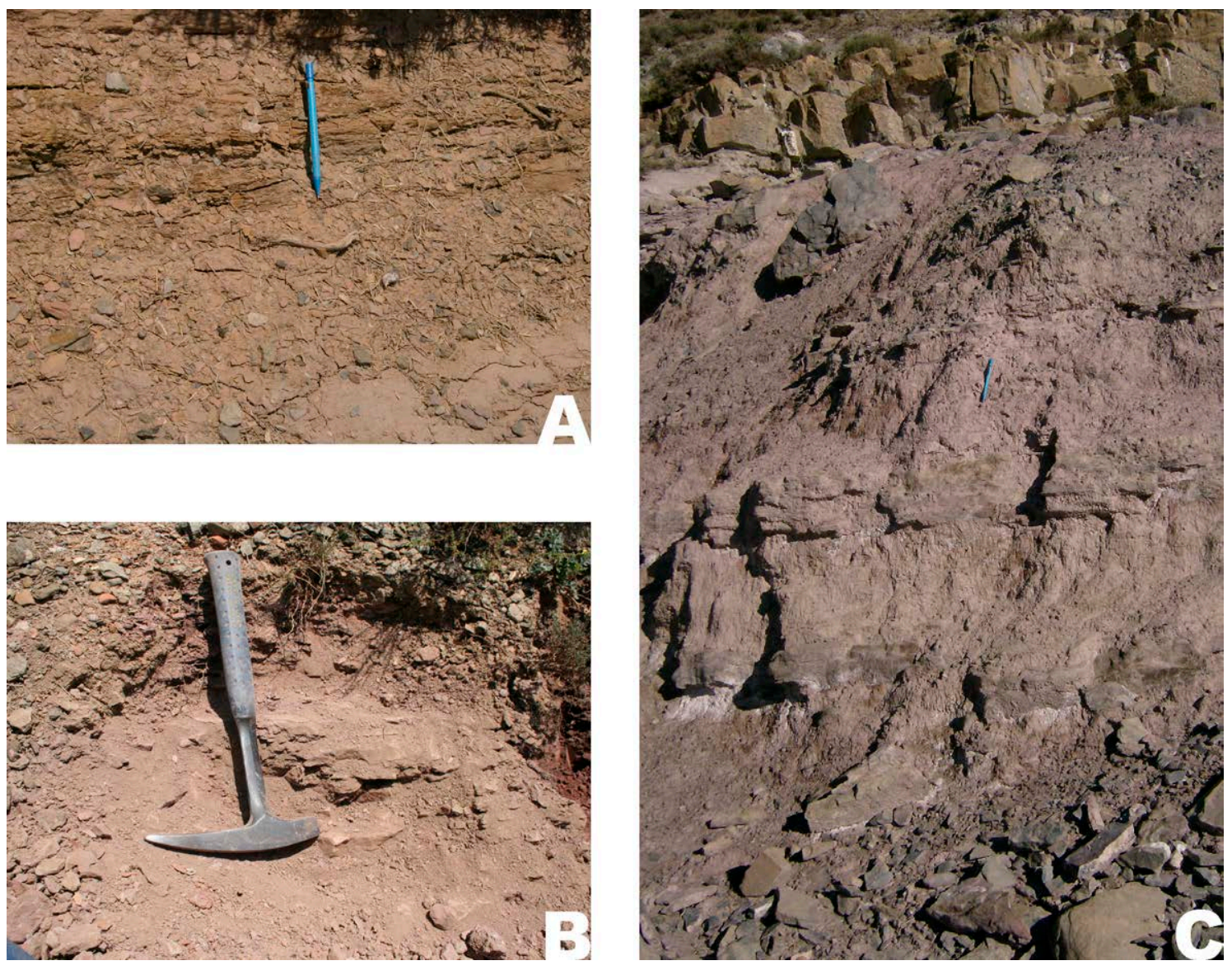


\section{Análisis sedimentológico: microfacies y facies}

Figura 5.26: Aspecto en campo de las lutitas y/ o margas masivas. A) y B) Ejemplos de la facies LMm en la zona de Los Cayos (Cornago). C) Ejemplo de la facies LMm en los tramos 170-174 dela columna de Ambas Aguas.

Esta facies consta fundamentalmente de margas $(\approx 65 \%)$ y lutitas $(31 \%)$, constituyendo las lutitas carbonatadas $(\approx 1 \%)$ y las lutitas arenosas carbonatadas $(\approx 3 \%)$ una fracción ínfima. En muestra fresca exhiben un color marrón anaranjado $(\approx 60 \%)(5$ YR 7/2 marrón anaranjado grisáceo y 5 YR 8/4 marrón anaranjado moderado), naranja ( $\approx 15 \%)$ (10 R 6/6 naranja rojizo moderado y 10 YR 6/6 naranja amarillento oscuro) y, púrpura ( $\approx 25 \%)$ (5 $\mathrm{P} 6 / 2$ púrpura pálido, $5 \mathrm{P}$ 4/ 2 púrpura grisáceo y $5 \mathrm{RP} 6 / 2$ morado pálido).

Es habitual que esta facies muestre el desarrollo de otros procesos pedogenéticos concurrentes: intensa bioturbación $(\approx 74 \%)$, fenómenos de ferruginización atestiguados por pátinas superficiales ( $80 \%$ ) y/ o moteados (40\%) y, en menor proporción, la presencia de nódulos centimétricos de naturaleza micrítica $(\approx 8 \%)$.

El contenido paleontológico tiene cierta entidad estando formado básicamente por abundantes ostrácodos $(\approx 90 \%)$, así como escasos bivalvos $(\approx 2 \%)$ y gasterópodos $(\approx 4 \%)$. También son abundantes los fragmentos de fósiles no identificables $(\approx 26 \%)$.

Su génesis es muy similar a la descrita para las litofacies Lm o Mm. Se deposita por decantación de material fino en un cuerpo de agua, a la que se superponen fenómenos de oxidación-ferruginización asociadas a emersiones.

\subsubsection{Litofacies Mm: marga masiva}

Se trata de margas carentes de estructuras sedimentarias y, en general, de aspecto no consolidado (raramente presenta laminación). En casi todas las series levantadas constituye una facies volumétricamente importante en la parte superior del Grupo Enciso. Es muy abundante en Ambas Aguas (41,7\%), común en Enciso (18,9\%) y Cornago (22,3\%), frecuente en Munilla (10,7\%) y, finalmente, escasa en Préjano (0,9\%).

Son margas con un contenido en arcillas variable, mayoritariamente de color gris ( $\approx 97 \%$ ) (N 8 gris muy luminoso; 7 gris luminoso; N 6 gris medio luminoso; y N 5 gris medio). De forma más dispersa puede ser de color verde $(\approx 2 \%)$ ( 10 Y $5 / 4$ oliva luminoso; 10 Y 4/2 oliva grisáceo, 5 G 3/2 verde oscuro y; 5 GY 5/2 verde amarillento sombrío) o negro ( $\approx 1 \%$ ) (N 1 negro y N 2 negro grisáceo) cuando la cantidad de materia orgánica es importante.

Se presenta en estratos o en paquetes incompetentes con potencias comprendidas entre unos pocos centímetros hasta varios metros (valores máximos de $6 \mathrm{~m}$ ), en este último caso con continuidades laterales de escala kilométrica (figura 5.27A). En campo puede también presentar un aspecto pizarroso y/o lajoso. En general son muy deleznables y se disgregan con facilidad (aspecto pulverulento). Forman cuerpos tabulares de muro neto-no erosivo y techo neto, aunque con las lutitas el contacto es más gradual y difuso. Cuando los espesores son pequeños pueden mostrar una geometría lenticular.

Es habitual que muestren cierta bioturbación $(\approx 54 \%)$ y, menos comúnmente, costras de hierro $(\approx 9 \%)$ y leve moteado $(\approx 1 \%)$. Aparecen nódulos centimétricos-decimétricos dispuestos de manera dispersa ( $\approx 4 \%$ ) (figura $5.27 \mathrm{~B}$ ). Pueden presentar intercalaciones finas muy ricas en materia orgánica y/ o hiladas de lignito.

El contenido paleontológico consta substancialmente de ostrácodos $(\approx 95 \%)$ y en menor medida restos malacológicos, bivalvos $(\approx 2 \%)$, gasterópodos $(\approx 1 \%) \mathrm{y}$, fragmentos de difícil atribución $(\approx 9 \%)$. Los fósiles límnicos principales son los ostrácodos, pudiendo aparecer tanto sueltos como formando lumaquelas de potencia milimétrica hasta centimétrica. La determinación de la fauna malacológica muestra la presencia de bivalvos infaunales subacuáticos (Unio, Margaritifera, Neomiodon) y gasterópodos (Paraglauconia, Viviparus). En ambos casos, pueden aparecer en posición de vida, aunque no es lo más normal (figura 5.27C). 


\section{Análisis sedimentológico: microfacies y facies}
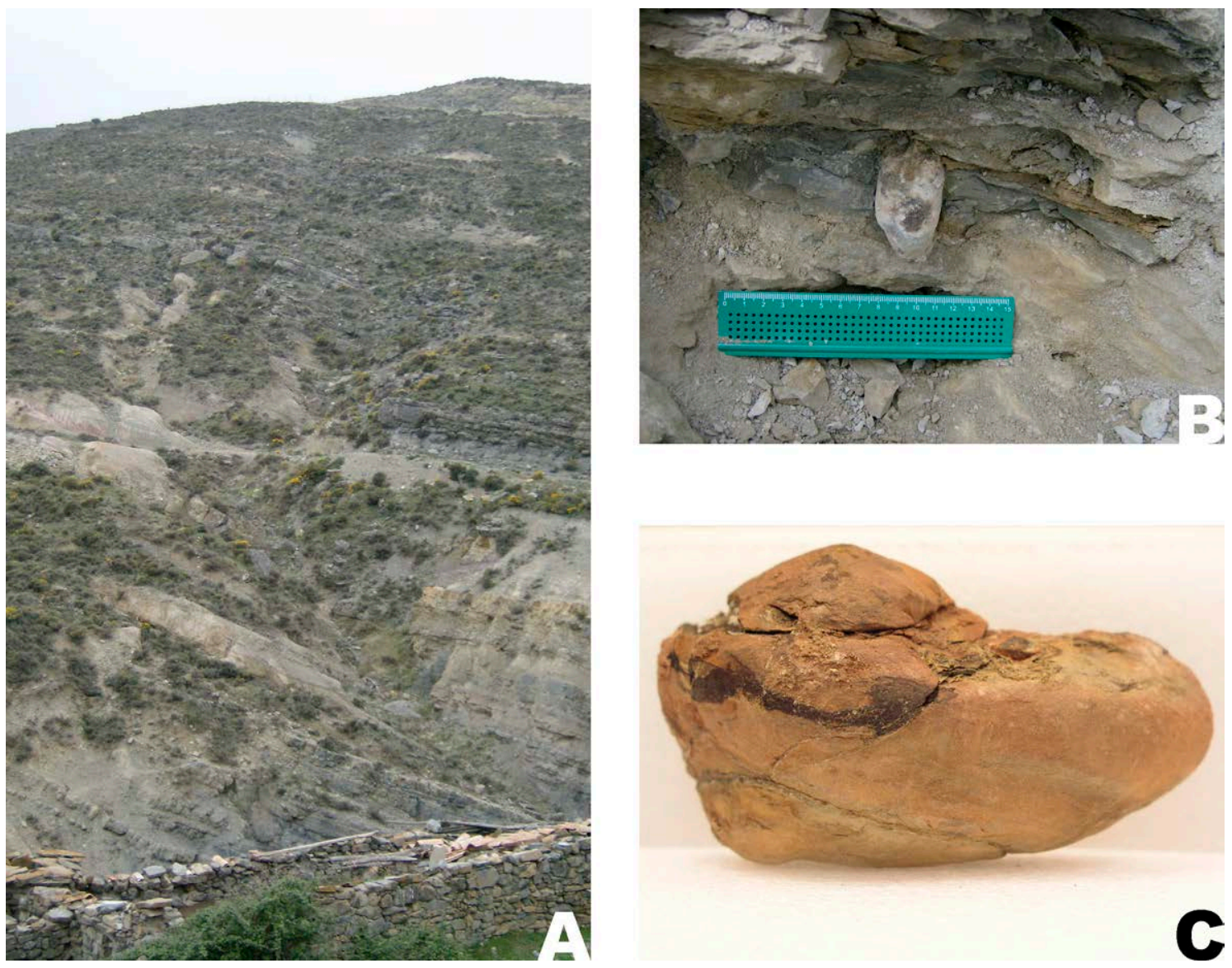

Figura 5.27: Aspecto en campo de las margas masivas. A) Ejemplo dela facies Mm en las zonas de Ambas Aguas. B) detalle de un bivalvo en posición de vida en las margas, en la zona de Los Cayos (Cornago). C) Detalle de un nódulo.

Representa una sedimentación subacuática por decantación de la carga en suspensión en cuerpos de aguas estancadas, en zonas ricas en producción de carbonatos. Dentro de la cubeta lacustre, esta facies se deposita tanto en sectores litorales (someros), sublitorales, como más profundos. En el lago Bear (Estados Unidos), las margas grises se depositan en la zona profunda, desapareciendo por encima de $30 \mathrm{~m}$ de profundidad (COLMAN, 2006). También puede depositarse en lagunas (STREET-PERROTT et al., 1993; HOLMES et al., 1995) o pequeños lagos instaurados sobre la llanura de inundación (FRIEND Y MOODY-STUART, 1970). Las margas orgánicas negras se forman bajo densas praderas de macrófitos (HOLMES et al., 1995).

\subsubsection{Litofacies Ch: caliza con laminación horizontal (paralela)}

Esta facies se caracteriza por incluir todos los depósitos carbonatados que muestran en campo laminación horizontal (figuras 5.28A y B). Se presenta en bancos o estratos tabulares de techo y muro plano, no erosivo y neto, con bastante continuidad lateral a escala del afloramiento. Se trata de una facies escasa, en términos de abundancia: Enciso (1,1\%), Ambas Aguas (1,7\%), Cornago $(0,3 \%)$ y Munilla (1,2\%). Sin embargo, en la columna de Préjano constituye una facies abundante (38,3\%).

Está compuesta básicamente por calizas puras $(\approx 84 \%)$, calizas margosas $(\approx 13 \%)$ y calizas arenosas $(\approx 3 \%)$. En fractura exhiben únicamente dos colores: negro $(\approx 78 \%)$ (N 1 negro y N 2 negro grisáceo) y gris $(\approx 22 \%$ ) (N 8 gris muy luminoso; N 7 gris luminoso; N 6 gris medio luminoso; y N 5 gris medio). El color oscuro es debido al alto contenido en materia orgánica.

Suele estar asociada con una leve bioturbación poco penetrativa $(\approx 31 \%)$ y escasas costras de hierro $(\approx 11 \%)$. 


\section{Análisis sedimentológico: microfacies y facies}

El contenido paleontológico consta de abundantes ostrácodos (aproximadamente el 67\% de las muestras como componente accesorio y el $28 \%$ como principal), bivalvos $(\approx 9 \%)$, gasterópodos $(\approx 8 \%)$ y, fragmentos de moluscos $(\approx 4 \%)$.
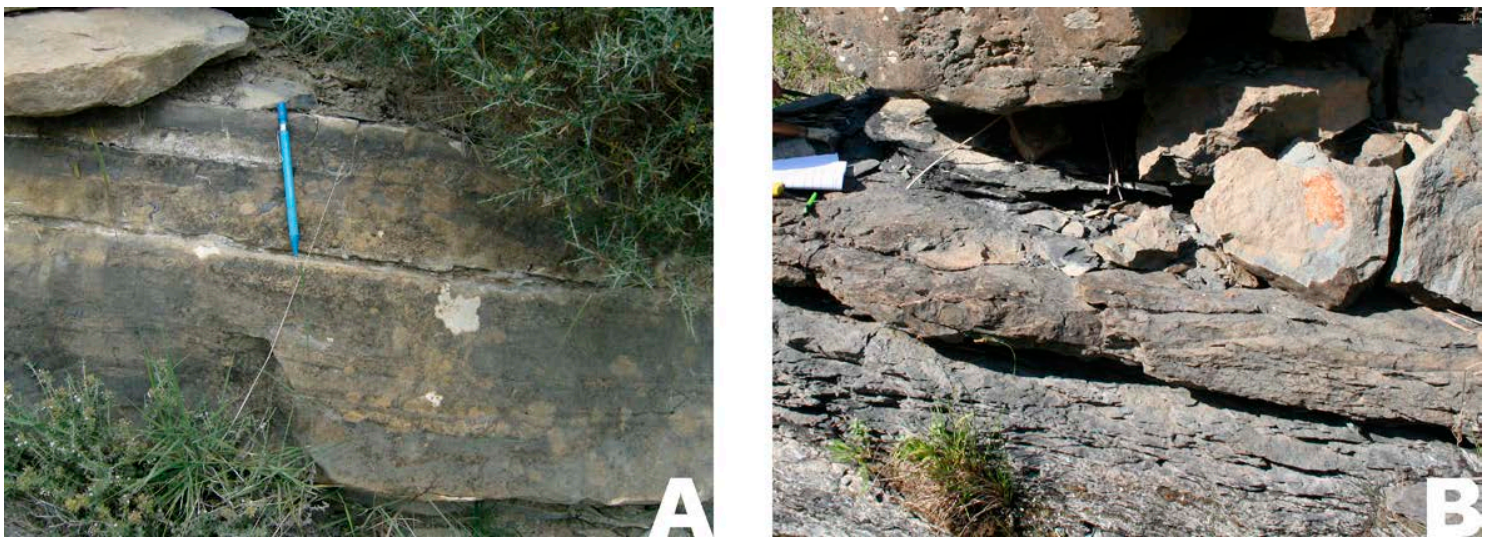

Figura 5.28: Aspecto en campo de las calizas con laminación horizontal. A) Ejemplo de la facies Ch en el tramo 668 de la columna de Enciso. B) Ejemplo de la facies Ch en los tramos 37-38 de la columna de Préjano.

La laminación es un carácter muy común en los carbonatos lacustres, aunque su origen es variado y complejo (KELTS Y HSÜ, 1978; TUCKER Y WRIGHT, 1990). En la literatura se suelen interpretan como sedimentos típicos de la zona abierta profunda (PLATT Y WRIGHT, 1991; GIERLOWSKI-KORDESCH, 2010). Por desgracia, no es frecuente la presencia en lagos actuales con facies laminadas ricas en ostrácodos (HALFMANYJ OHNSON, 1988) como la que aparece en la zona estudiada. En el registro geológico, facies similares a estas se han interpretado como acumulaciones mecánicas por corrientes tractivas (ANADÓN et al., 1988; BELLANCA et al., 1992; PLATT, 1992). En algunos aspectos, esta laminación presenta ciertas semejanzas con las shelly laminites descritas por HALLAM (1987). Se acumulan en ambientes marinos exaeróbicos (límite entre disaeróbico - anaeróbico) donde se producen unas laminaciones cuya característica más destacable es la presencia anómala de abundantes conchas (TYSONY PEARSON, 1991).

\subsubsection{Litofacies de calizas masivas}

Destaca esta facies por su inherente ausencia de rasgos (estructuras) de ordenamiento interno aunque algunos términos presentan estructuras postdeposicionales. Dentro del conjunto de las calizas masivas se han diferenciado tres sublitofacies: caliza masiva oscura $(\mathrm{Cm})$, caliza masiva con grietas de retracción $(\mathrm{Cg})$ y, caliza masiva nodular o con nódulos $(\mathrm{Cg})$.

Poseen una amplia representación y variabilidad textural en todas las series muestreadas. Las características comunes a todas ellas son: aspecto masivo, predominio de los colores oscuros, presencia de una fauna límnica (moluscos, ostrácodos y carófitas) y, bajo contenido en terrígenos.

Presentan un característico color negro (oscuro) como consecuencia del alto contenido en materia orgánica y/o pirita. La preponderancia de texturas mudstone y wackestone, así como la ausencia total de estructuras de tracción indican una sedimentación bajo lámina de agua en cuerpos de aguas estancadas (con poca o nula energía). El predominio de colores reducidos (negro, gris y azul) parece indicar áreas poco o nada oxigenadas favoreciendo la producción, deposición y preservación de un gran contenido en materia orgánica. En ocasiones, estas masas de agua pudieron presentar un mayor contenido en oxígeno, lo que permitió el desarrollo de fenómenos de oxidación que se manifiestan en los colores rojizos asociados a óxidos e hidróxidos de hierro (moteado y/o pátinas). La ausencia de estructuras sedimentarias en los carbonatos lacustres se atribuye, normalmente, a una intensa bioturbación en aguas oxigenadas (GIERLOWSKI-KORDESCH, 2010). Sin embargo, una fábrica masiva puede originarse también por un incremento en la tasa de sedimentación (VERRECCHIA, 2008). El bajo contenido en terrígenos (<10\%) sugiere una entrada mínima de siliciclásticos (zonas protegidas de dichos aportes o zonas 


\section{Análisis sedimentológico: microfacies y facies}

muy distales) o etapas de bypass siliciclástico en la cubeta lacustre. A veces, la presencia de grandes praderas vegetadas funciona como un filtro para la entrada de terrígenos (FREYTET Y PLAZIAT, 1982).

La gran continuidad y extensión lateral de estos cuerpos, los cuales se pueden seguir en campo durante kilómetros con variaciones mínimas de su espesor, sugiere un área deposicional con poca o nula pendiente, hecho que se refuerza por la casi total ausencia de estructuras slump. Esta continuidad del espesor también sugiere una ausencia de los fenómenos de focalización característicos de muchos lagos actuales.

\subsubsection{Litofacies Cm: caliza masiva oscura}

Esta facies consta de calizas y calizas margosas que afloran en estratos tabulares o potentes niveles sin estratificación visible, cuyo único carácter observable en campo es un marcado aspecto masivo (ausencia de estructuras sedimentarias). Esta facies, en términos de abundancia, varía entre común en Ambas Aguas (21,5\%) y Munilla (20,2\%), hasta frecuente en las series de Enciso (14,7\%), Cornago (9,5\%) y Préjano $(10,5)$.

De visu, las litologías dominantes son las calizas puras $(\approx 67 \%)$ aunque también aparecen calizas margosas $(\approx 33 \%)$, a veces con un característico olor fétido. Las calizas micríticas de gran pureza pueden llegar a dar fractura concoidea. Predomina el color negro $(\approx 61 \%)$ ( $\mathrm{N} 1$ negro y $\mathrm{N}$ 2 negro grisáceo) o gris ( $\approx 30 \%$ ) (N 8 gris muy luminoso; N 7 gris luminoso; $\mathrm{N} 6$ gris medio luminoso; y N 5 gris medio), si bien esporádicamente son de color azul ( $\approx 4 \%$ ) (5 B 5/1 gris azulado; 5 B 7/ 1 gris azulado brillante; 5 B $6 / 2$ azul pálido y; $5 \mathrm{~B} 8 / 2$ azul muy pálido) o verde ( $\approx$ $2 \%$ ) (10 Y 5/ 4 oliva luminoso y; 5 GY 5/ 2 verde amarillento sombrío). Cuando los fenómenos de rubefacción son evidentes, la muestra es de color marrón anaranjado $(\approx 1 \%)(5 \mathrm{YR} 7 / 2$ marrón anaranjado grisáceo y 5 YR 8/4 marrón anaranjado moderado), naranja ( $\approx 1 \%$ ) (10 R 6/6 naranja rojizo moderado y 10 YR 6/6 naranja amarillento oscuro) o púrpura ( $\approx 1 \%)$ (5 $\mathrm{P} 6 / 2$ púrpura pálido, $5 \mathrm{P} 4 / 2$ púrpura grisáceo y $5 \mathrm{RP} 6 / 2$ morado pálido). Estos niveles rubefactados se generan por procesos edáficos (marmorización).

El espesor medio de los estratos se sitúa entre 3 y $420 \mathrm{~cm}$. Se presentan en bancos de morfología tabular de techo y muro planos o ligeramente irregulares, de gran continuidad lateral (figura 5.29A). En ocasiones, pueden presentar una morfología de canal laxo levemente erosivo (figura 5.29B). A veces, pueden aparecer como paquetes lajosos como consecuencia de la esquistosidad de fractura, donde es difícil o no se observa una estratificación clara. Suelen aparecer intercaladas entre las facies margosas.
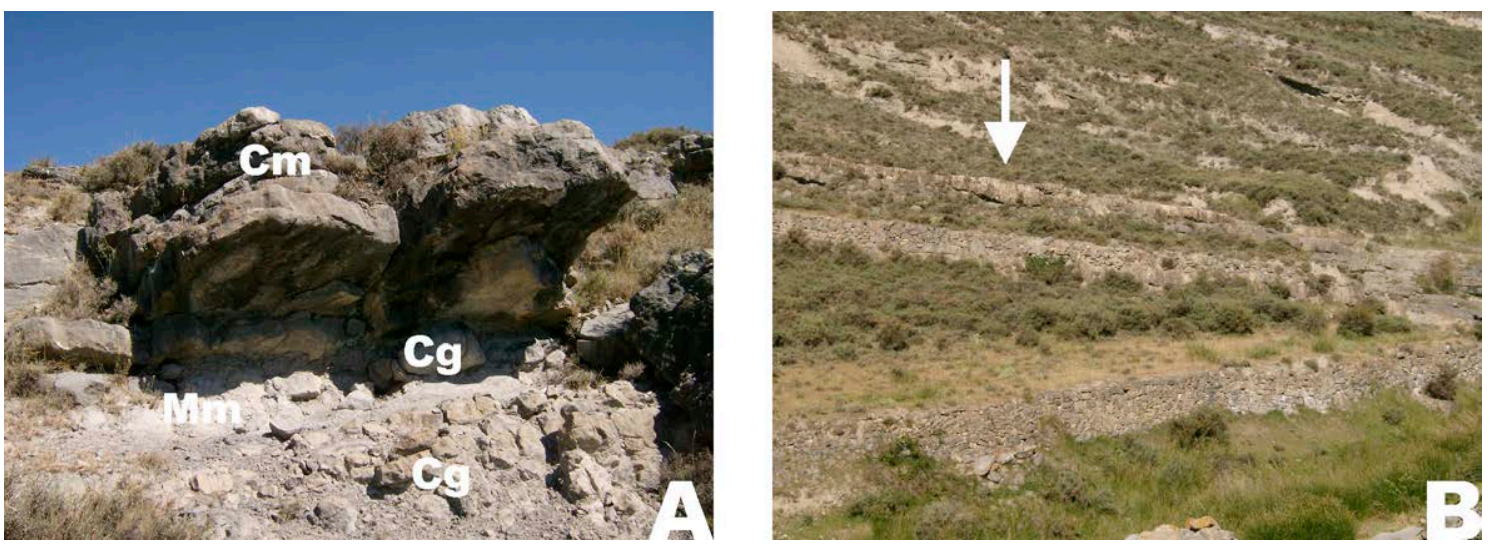

Figura 5.29: Aspecto en campo de las calizas masivas oscuras. A) Ejemplo de la facies Cm en los tramos 257-262 de la columna de Ambas Aguas. B) Ejemplo de la facies Cm con morfología de canal laxo (indicado por una flecha) en los tramos 295-297 dela columna de Ambas Aguas.

En superficie se observa cierta bioturbación $(\approx 39 \%)$ con un desarrollo muy variable (grado 0 hasta 6 ), óxidos e hidróxidos de hierro en forma de costras ( $\approx 4 \%$ ) o de moteado $(\approx 7 \%)$, 


\section{Análisis sedimentológico: microfacies y facies}

rizolitos $(\approx 1 \%)$, icnitas de dinosaurios $(\approx 1 \%)$ y estructuras de carga $(\approx 3 \%)$. A veces aparecen cubos o piritoedros de pirita $(\approx 2 \%)$ y pseudomorfos de yeso $(\approx 1 \%)$. Pueden presentar algunos procesos diagenéticos tempranos como un ligero moteado.

El contenido fósil presente es típicamente límnico: ostrácodos ( $\approx 89 \%)$, bivalvos $(\approx 2 \%)$, gasterópodos $(\approx 3 \%)$ y fragmentos indiferenciados $(\approx 19 \%)$. A veces, a techo aparecen acumulaciones de poca extensión y muy localizadas de grainstone o lumaquelas de ostrácodos que se asocian a procesos tractivos.

Constituyen un grupo que caracteriza la sedimentación acontecida en medios lacustres litorales-sublitorales. La ausencia de rasgos de exposición subaérea (grietas de desecación) sugiere un ambiente de deposición subacuático. Los intraclastos micríticos, en cantidades siempre accesorias (diferente color que la matriz micrítica), parecen indicar un leve y localizado retrabajamiento de materiales no litificados procedentes de áreas más someras (FREYTET Y PLAZIAT, 1982).

\subsubsection{Litofacies Cg: caliza masiva con grietas de retracción}

Esta subfacies se presenta en estratos de geometría tabular que internamente carecen de estructuras sedimentarias primarias (son de apariencia masiva en campo), y que a techo contienen grietas de retracción (figuras 5.30A y B). No constituye una facies con una gran distribución, siendo escasa en Enciso (0,1\%), Ambas Aguas $(0,1 \%)$, Cornago $(1,7 \%)$ y Munilla $(1,8 \%)$, aunque presenta un mayor desarrollo e importancia volumétrica en el sector de Préjano $(5,5 \%)$.
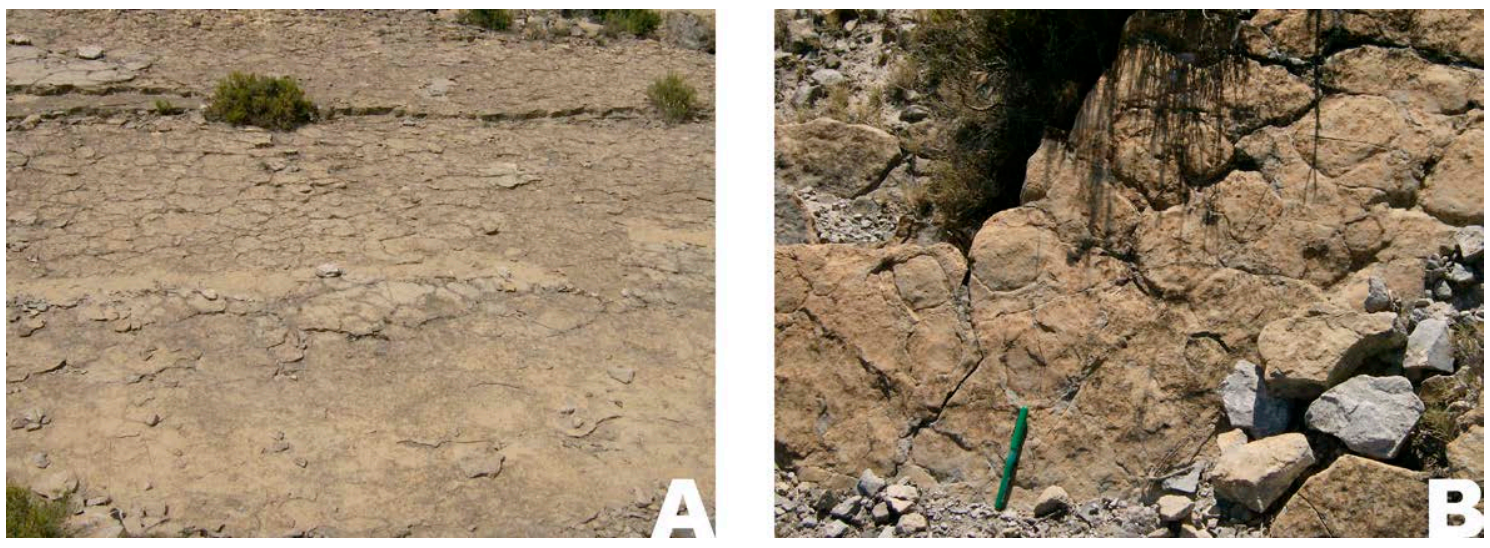

Figura 5.30: Aspecto en campo de las calizas masivas con grietas de retracción. A) Ejemplo de la facies $\mathrm{Cg}$ en el tramo 156 dela columna deCornago. B) Ejemplo dela facies Cg en las cercanías deyacimiento icnológico de Los Cayos (Cornago).

Incluye calizas $(\approx 87 \%)$, calizas arenosas $(\approx 9 \%)$ y calizas margosas $(\approx 4 \%)$. Constituye una subfacies que muestra un color negro muy monótono $(\approx 96 \%)$ ( $\mathrm{N} 1$ negro y $\mathrm{N} 2$ negro grisáceo) y, sólo en zonas donde la ferruginización es importante, púrpura ( $\approx 4 \%$ ) (5 P 6/2 púrpura pálido, 5 P 4/ 2 púrpura grisáceo y 5 RP 6/ 2 morado pálido).

En la superficie de estos estratos, en general, se observa bioturbación vertical y/o horizontal $(\approx 83 \%)$ e icnitas de dinosaurios. Aunque no es un carácter habitual, puede mostrar moteado por óxidos de hierro $(\approx 9 \%)$.

El contenido paleontológico consiste en ostrácodos $(100 \%)$ y fragmentos de fósiles $(\approx$ $4 \%)$. Algunas grietas aparecen rellenas de ostrácodos como por ejemplo en el yacimiento icnológico de La Era del Peladillo (Igea).

Aunque la génesis de las grietas de retracción se ha explicado ampliamente al describir la facies Lg (apartado 5.2.8), es conveniente subrayar que la formación de grietas de retracción en 
sedimentos carbonatados, puede estar controlada por la salinidad, con un mayor desarrollo cuanto más menor es la salinidad del medio (BARIA, 1977). Sin embargo, la presencia de numerosos rasgos asociados a procesos típicos de exposición subaérea, sugiere que en las series estudiadas, la formación de estas grietas de retracción apunta a lagos con fluctuaciones en la lámina de agua y a períodos de emersión. Esta facies es típica de áreas lacustres emergidas desarrolladas en la orla eulitoral (DE DECKKER, 1988b; HAMER Y SHELDON, 2010), así como de zonas palustres poco evolucionadas, indicando etapas subaéreas con poco tiempo de residencia (ALONSO-ZARZA Y WRIGHT, 2010).

\subsubsection{Litofacies $\mathrm{Cn}$ : caliza masiva nodular o con nódulos}

Se describe esta facies como cualquier estrato de naturaleza carbonatada que presenta nódulos o una estratificación nodular claramente visible (figuras 5.31A y B). Constituye una facies volumétricamente escasa en todas las columnas muestreadas: Enciso (1,1\%), Ambas Aguas $(4,5 \%)$, Cornago (1,9\%), Munilla (4,7\%) y, Préjano (3,5\%). A veces los nódulos pueden coalescer y formar niveles paralelos a la estratificación.
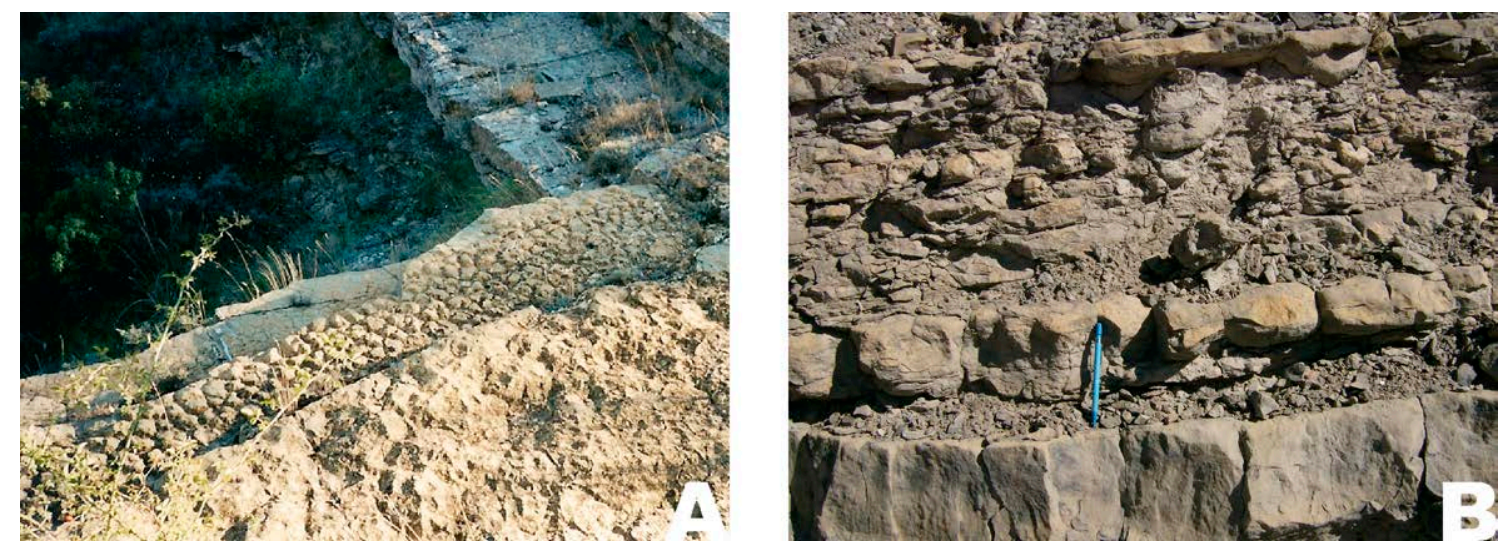

Figura 5.31: Aspecto en campo de las calizas masivas nodulares. A) Ejemplo de la facies Cn en el la zona dela Sierra del Palo (Enciso). B) Ejemplo de la facies Cn en el tramo 317 de la columna de Ambas Aguas.

Está formada por calizas $(\approx 72 \%)$ y/o calizas margosas $(28 \%)$ con un claro predominio, en muestra fresca, del color negro $(\approx 52 \%)$ ( 1 negro y $\mathrm{N} 2$ negro grisáceo) o gris $(\approx 44 \%)$ (N 8 gris muy luminoso; $\mathrm{N} 7$ gris luminoso; $\mathrm{N} 6$ gris medio luminoso; y $\mathrm{N} 5$ gris medio). De forma más ocasional pueden ser de color verde $(\approx 2 \%)$ (10 Y $5 / 4$ oliva luminoso y; $5 \mathrm{GY} 5 / 2$ verde amarillento sombrío) o marrón anaranjado $(\approx 2 \%)$ (5 YR 7/2 marrón anaranjado grisáceo y 5 YR 8/4 marrón anaranjado moderado).

Esta facies puede mostrar también bioturbación $(\approx 75 \%)$ y, en menor proporción, costras de hierro $(\approx 3 \%)$, estructuras de carga $(\approx 14 \%)$ y moteado $(\approx 1 \%)$.

Asociada a esta facies, se reconoce una rica fauna de ostrácodos $(\approx 93 \%)$, bivalvos no fragmentados $(\approx 5 \%$ ) (algunos de los cuales se identifican como Uniónidos), y restos de fósiles fragmentados de asignación dudosa $(\approx 13 \%)$.

La nodulización se origina por la desecación del material inicialmente sedimentado (FREYTET, 1973). Son comunes en zonas lacustres y palustres que han sido sometidas a períodos de exposición subaérea, aunque con unos períodos de residencia mayores que para la facies $\mathrm{Cg}$ (ALONSO-ZARZA Y WRIGHT, 2010).

\subsubsection{Litofacies CAm: caliza arenosa masiva}

Son calizas arenosas de apariencia masiva que se presentan en estratos tabulares de potencia decimétrica con contactos netos y gran continuidad lateral a escala del afloramiento. Es 


\section{Análisis sedimentológico: microfacies y facies}

una facies poco desarrollada en todas las columnas levantadas, con un porcentaje escaso en abundancia: Enciso (1\%), Ambas Aguas (1,2\%), Comago (1\%), Munilla (3,8\%) y, Préjano (0,4\%).

En fractura, la mayoría es de color negro $(\approx 66 \%)$ (N1 negro y N2 negro grisáceo), azul oscuro $(\approx 24 \%)$ (5PB $3 / 2$ azul oscuro), o gris $(\approx 8 \%)$ ( $\mathrm{N} 6$ gris medio luminoso y $\mathrm{N} 5$ gris medio). De forma esporádica, cuando los fenómenos de rubefacción son importantes la muestra exhibe colores anaranjados $(\approx 2 \%$ ) (10 R 6/6 naranja rojizo moderado y 10 YR 6/ 6 naranja amarillento oscuro).

La apariencia masiva suele estar asociada a una bioturbación preferentemente de hábito vertical $(\approx 85 \%)$. No es inusual la presencia de óxidos de hierro en forma de pátinas $(\approx 49 \%)$ y/o moteado $(\approx 17 \%)$. De modo más ocasional muestra cubos milimétricos de pirita $(\approx 4 \%)$, estructuras de carga $(\approx 5 \%)$ y, estructuras convolutas $(\approx 4 \%)$.

El contenido paleontológico se circunscribe a ostrácodos $(\approx 74 \%)$ y fragmentos de moluscos indiferenciados $(\approx 32 \%)$.

El significativo contenido en siliciclásticos pone de manifiesto etapas con aporte de terrígenos o áreas cercanas a la entrada de detríticos en el lago. Esta facies se interpreta como depositada en zonas lacustres someras marginales que corresponden a etapas de expansión lacustre en donde existe un mayor aporte de terrígenos o a la reactivación de los sistemas fluviales (GLASS Y WILKINSON, 1980; ARRIBAS, 1986).

\subsubsection{Litofacies Q: lumaquela con fósiles límnicos}

Las lumaquelas constituyen niveles de concentraciones fosilíferas (o esqueléticas). Según KIDWELL et al. (1986) una concentración fósil se define como "cualquier acumulación relativamente densa de las partes duras biológicas, independientemente de la composición taxonómica, estado de preservación o grado de modificación postmortem". En la literatura pueden aparecer bajo denominaciones tales como coquinas, biocalciruditas, pavimentos, calizas conchíferas, etc. Son importantes ya que permiten extraer datos paleoecológicos significativos, así como información de los factores que afectan a la composición de las comunidades observadas en el registro geológico. Todos estos aspectos se deben interpretar teniendo en cuenta lainfluencia de la dinámica sedimentaria en la cual se hayan depositado.

Conceptualmente, las concentraciones fósiles pueden originarse por la acción de tres procesos, o una combinación de ellos (KIDWELL et al., 1986): biológicos, sedimentarios y diagenéticos. Las concentraciones biológicas pueden deberse al modo de vida de los organismos que producen los fósiles (concentración biogénica intrínseca) o bien por la acción de otros organismos que interactúan con los restos esqueléticos (concentración biogénica extrínseca). Las concentraciones sedimentarias resultan del transporte físico (generalmente por corrientes newtonianas o gravitacionales) en la que los restos se comportan como partículas sedimentarias. Por último, las concentraciones diagenéticas se originan por procesos fisicoquímicos que actúan durante el enterramiento de los restos, sobre todo la compactación que incrementa el empaquetamiento.

Para la descripción de las lumaquelas se va a seguir la nomenclatura propuesta por KIDWELL et al. (1986), GOLDRING (1991) y KIDWELL Y HOLLAND (1991).

Esta facies se ha subdividido en dos en función del contenido fosilífero: la subfacies Qo es una lumaquela de ostrácodos, y la subfacies Qm es una lumaquela de moluscos con escasa diversidad (mono o bigenérica). El estado de conservación de los individuos es variable, desde lumaquelas con conchas muy bien conservadas a completamente fracturadas.

\subsubsection{Litofacies Qo: lumaquela de ostrácodos}

Está constituida por acumulaciones de caparazones y valvas de ostrácodos (figuras 5.32A y B; figuras 5.11C y D). En los depósitos recientes se denominan lags o arenas de ostrácodos 


\section{Análisis sedimentológico: microfacies y facies}

(COHEN, 1987). En los sedimentos fósiles se conocen como ostracoditas o grainstone de ostrácodos. Constituye niveles de textura packstone de muy poca potencia $(3-15 \mathrm{~cm})$ y escasa continuidad lateral. A pesar de ser una facies muy habitual, su poca potencia hace que volumétricamente sea escasa con respecto del total de la columna muestreada: Enciso $(0,3 \%)$, Ambas Aguas (0,9\%), Cornago (0,2\%), Munilla (0,8\%) y, Préjano (0\%). Las lumaquelas de ostrácodos pueden aparecer como:

a) Delgados niveles individualizados con contactos netos formando lentejones de longitud decimétrica hasta métrica.

b) A techo de los estratos carbonatados donde aparecen como mantos relativamente extensos, agrupamientos aislados sin orden evidente, o bien rellenando cualquier tipo de irregularidad a techo de la capa (grietas de retracción, trazas de raíces o incluso, de manera anecdótica, icnitas de dinosaurios).
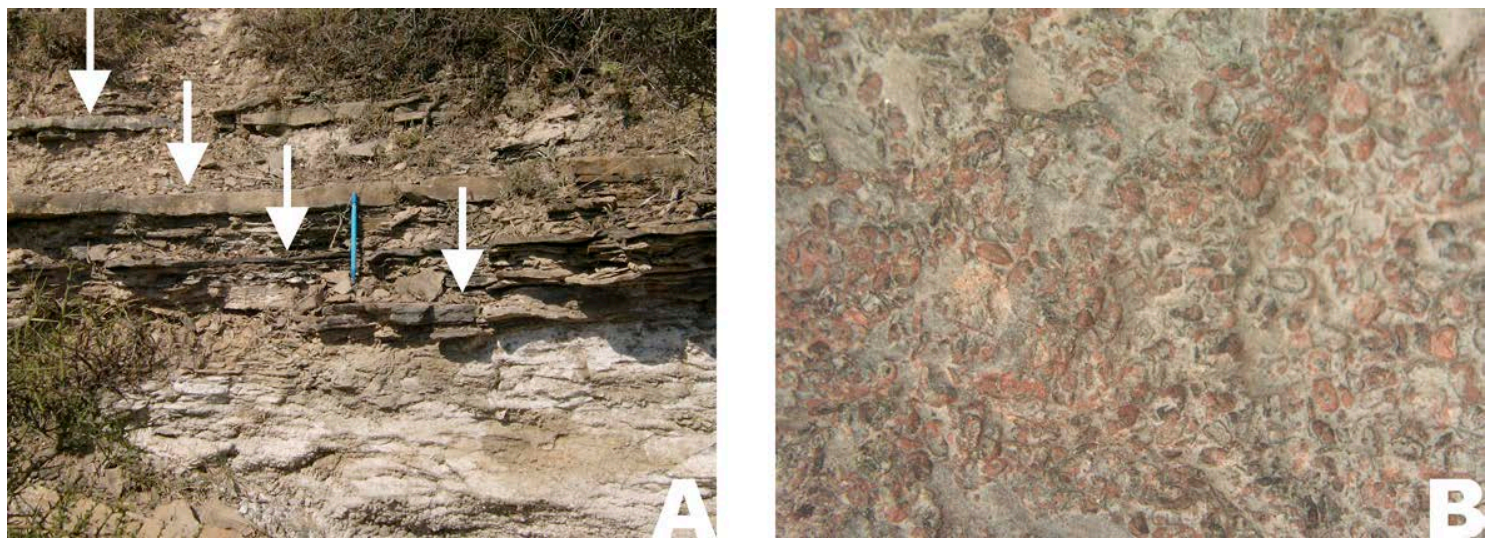

Figura 5.32: Aspecto en campo de las lumaquelas de ostrácodos. A) Ejemplo de la facies Qo en los tramos 61-67 de la columna de Ambas Aguas. B) Muestra de manos de la facies Qo procedente del tramo 254 de la columna Ambas Aguas.

Cuando los ostrácodos mueren, sus valvas se abren y, en cuestión de horas o días, se desarticulan totalmente (DE DECKKER, 1988a). En consecuencia la presencia de caparazones articulados se considera una evidencia de sedimentación rápida, con muy poco o nulo transporte.

En la actualidad, las acumulaciones biológicas de ostrácodos se originan por el comportamiento masificado (crowding) de algunas especies, bajo condiciones ambientales óptimas persistentes (CARBONEL et al., 1988). Así, por ejemplo, en la zona litoral del lago Pääjärvi (Finlandia) se han encontrado concentraciones máximas de 160.000 individuos/ $\mathrm{m}^{2}$ y mínimas de 30.000 individuos/ $\mathrm{m}^{2}$ de Darwinula stevensoni (RANTA, 1979). También se han interpretado como etapas de alta mortalidad cuando se significan por la presencia de caparazones articulados de individuos adultos y juveniles, sin evidencias de transporte tractivo (PAZ Y ROSSETTI, 2005).

Las acumulaciones sedimentarias pueden tener múltiples orígenes y aparecen en todos los cinturones lacustres. En la zona eulitoral se depositan por la agitación del oleaje (ARP, 1995). En la zona litoral, sobre todo en lagos con fluctuaciones rápidas del nivel de agua o lagos efímeros, se originan por la acción del oleaje dando un conjunto de fragmentos corroídos de valvas fracturadas con selección de tamaños (DE DECKKER, 1988a). En el registro fósil, los ejemplos de ostracoditas en zonas someras litorales son abundantes (COLE, 1985; CERLING et al., 1988). En la Formación Codó de Brasil (Aptiense), las acumulaciones litorales se interpretan como eventos de mortalidad en masa durante las bajadas del nivel del lago (PAZ Y ROSSETTI, 2005). En la zona sublitoral del lago Turkana se forman finos y extensos mantos de valvas, intactas y en conexión, por debajo del nivel de base del oleaje. Estas agrupaciones experimentan un transporte mínimo y se producen por lavado de finos (COHEN, 1987). En la zona profunda del lago Mobutu son frecuentes las acumulaciones de ostrácodos desarticulados y con evidencias de abrasión a consecuencia de corrientes de fondo o turbidíticas (COHEN, 1987). 
A veces, en los lagos actuales, es posible observar acumulaciones mixtas biológicassedimentarias originadas por una muerte en masa, lavado y enterramiento rápido. Se caracterizan por la presencia de caparazones articulados y completos en zonas litorales (DE DECKKER, 1988a). En los lagos australianos, los ostrácodos que aparecen rellenando las grietas de desecación son transportados por el viento o lavados durante una etapa de aguas someras (DE DECKKER, 1988a; b).

\subsubsection{Litofacies Qm: lumaquela de moluscos}

Corresponde a lo que en la literatura se ha venido denominando como una típica caliza conchífera o coquina. Se presentan en capas o lentejones negros, bioturbados, y de potencia centimétrica a decimétrica (hasta $0,3 \mathrm{~m}$ ). Aparecen aislados o constituyendo cosets decimétricos. Ocasionalmente pueden presentar restos vegetales, ostrácodos y escamas de Lepidotes. En términos de abundancia es una facies escasa: Enciso (1\%), Ambas Aguas (0,2\%), Cornago (1,4\%), Munilla (0,1\%) y, Préjano (0,1\%).

En relación al taxón preponderante se pueden establecer cuatro tipos básicos: niveles de Eomiodon, niveles de Paraglauconias, niveles de mezcla Eomiodon-Paraglauconia, niveles de Viviparus. Todos estos moluscos se consideran organismos infaunales y epifaunales, lo cual los hace susceptibles de retrabajamiento postmortem (TANABE Y ARIMURA, 1987). En campo, se reconocen tres tipos básicos de lumaquelas:

Las lumaquelas tipo 1 están constituidas por niveles de color negro, con techo y muro neto, aunque en algunas es posible observar a muro estructuras erosivas. Constituyen mantos plano-paralelos lateralmente extensos a nivel del afloramiento (figuras 5.33A y B), aunque de manera local, pueden presentar una estratificación levemente ondulada (figura 5.33C). Pueden aparecer formando capas de poco espesor (una a dos conchas de potencia) mostrando una disposición en pavimento sin observarse ninguna orientación clara (polimodal), aunque muy localmente se han observado pequeñas zonas con gasterópodos mostrando una orientación unimodal poco clara. Son más frecuentes las capas de mayor potencia (más de dos conchas de potencia). En este caso, en sección los fragmentos muestran un apilamiento concordante. En ningún caso se ha observado variaciones en su estructura interna pudiéndose asegurar que constituyen concentraciones esqueléticas simples (simple skeletal concentrations). Los bioclastos muestran un fuerte empaquetamiento con gran cantidad de contactos directos. Los gasterópodos aparecen completos. Los bivalvos aparecen como conchas enteras articuladas bien conservadas, conchas enteras fragmentadas por procesos de compactación y, otras veces, como fragmentos de valvas. No se observa presencia de siliciclásticos. Se caracterizan por su baja diversidad (uno o dos géneros) y el elevado número de individuos. Los contactos netos de estas coquinas sugieren una concentración hidráulica. La fábrica (conchas apiladas, nested e imbricados) sin orientación preferente sugiere procesos de transporte de las conchas en suspensión y una deposición rápida (KIDWELL Y HOLLAND, 1991; ANDERSONY MCBRIDE, 1996). Algunas lumaquelas son muy parecidas, a nivel de taxón y tipología sedimentaria, a las coquinas de tormentas encontradas en la Formación Vectis de Inglaterra (RADLEY Y BARKER, 2000b). La presencia de conchas articuladas indica que han sufrido poco transporte. Suelen aparecen intercaladas entre margas y lutitas, es decir, asociadas a ambientes poco energéticos. A veces los depósitos finos infra- y suprayacentes contienen los mismos fósiles de manera dispersa. En este caso se interpretan como depositadas por tormentas o por eliminación de los finos. Cuando aparecen a techo de estratos de caliza se pueden interpretar como concentraciones por el oleaje.

Las lumaquelas tipo 2 son una mezcla de bioclastos y terrígenos con un pobre empaquetamiento y con algunos bioclastos con contactos directos. Se asemejan a ciertas coquinas descritas en la Formación Lagoa Feira de Brasil, que han sido interpretadas como depositadas en una playa de sedimentación siliciclástica que se mezcla con las conchas transportadas por corrientes inducidas por las tormentas (DE CARVALHO et al., 2000).

Las lumaquelas tipo 3 están formadas por concentraciones de gasterópodos Viviparus (figura 5.33D) o Paraglauconia que no llegan a constituir verdaderos estratos y se interpretan como acumulaciones biológicas o sedimentarias en las zonas litorales. 


\section{Análisis sedimentológico: microfacies y facies}

Algunas de las formas actuales emparentadas con los gasterópodos identificados en las lumaquelas (Viviparus), presentan hábitos de vida constituyendo densas agrupaciones en la zona litoral, que favorecen la formación de acumulaciones biológicas. Estas densidades elevadas son típicas de los vivipáridos actuales: Viviparus viviparus puede exceder los 800 individuos $/ \mathrm{m}^{2}$ (J AKUBIK, 2003), V. georgianus más de 200 individuos/ $\mathrm{m}^{2}$ (BROWNE, 1978), V. ater llega a los 1.500 individuos/ $\mathrm{m}^{2}$ (DE BERNARDI et al., 1976) y V. subpurpureus más de 1.500 individuos/ $\mathrm{m}^{2}$ (BROWN et al., 1989). Otro mecanismo de acumulación biológica es la utilización de conchas de gasterópodos para la construcción de nidos por ciertas especies de cangrejos y peces (COHEN, 1989b).
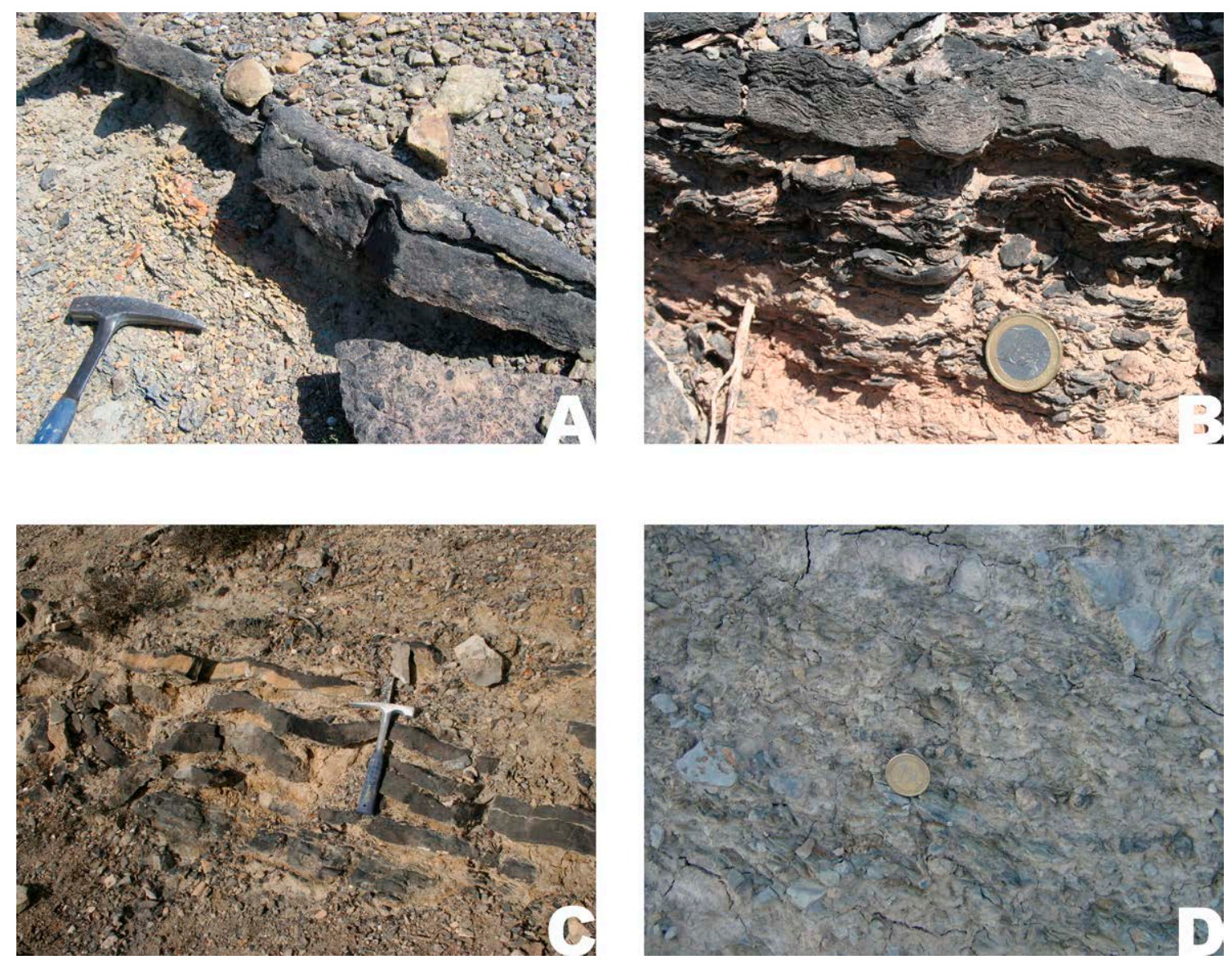

Figura 5.33: Aspecto en campo de las lumaquelas de moluscos. A) y B) Ejemplos de la facies Qm (tipo 1) en la parte superior del Grupo Enciso en la zona de Los Cayos (Cornago). C) Ejemplo de la facies Qm (tipo 1) procedente del tramo 425 de la columna Ambas Aguas. D) Ejemplo de la facies Qm (tipo 3) en el tramo 440 dela columna de Enciso.

Otras acumulaciones biológicas se producen por eventos de mortalidad en masa, los cuales pueden originarse por uno o varios de los siguientes procesos (DUMONT, 1992):

a) Cambios bruscos de salinidad que afectan la regulación osmótica de los organismos. En medios con salinidades elevadas, se producen problemas de flotabilidad y concentraciones de elementos traza en cantidades tóxicas.

b) Mezcla de aguas anóxicas profundas con aguas superficiales más oxigenadas.

c) Entrada en la cubeta de aguas de escorrentía desoxigenadas como consecuencia de su paso por zonas densamente vegetadas.

d) Turbidez excesiva de las aguas.

Las concentraciones sedimentarias pueden producirse por la acción de huracanes (LIU Y FEARN, 1993), o tormentas que acumulan los bioclastos en la zona litoral o en plataformas deltaicas (McGluE et al., 2010). En el delta del río Catatumbo (Venezuela) aparecen capas de 


\section{Análisis sedimentológico: microfacies y facies}

conchas de moluscos, probablemente depositadas durante las tormentas (HYNE et al., 1979b). En áreas abiertas, durante las tormentas, se crea una corriente fluyendo hacia el interior del lago que tiende a compensar el set-up en la zona costera. Así que el efecto combinado de la concentración por tracción y la eliminación del material más fino (arena y/ o lutita), origina concentraciones de conchas (DAVIES et al., 1989, Boyajian, 1995 \#1847).

Otras acumulaciones de bioclastos se suelen interpretar ligadas a procesos tractivos que los trasladan desde su área de producción (litoral) a las zonas profundas (J OHNSON Y GRAHAM, 2004). En la actualidad, estos depósitos se han citado abundantemente en los ambientes deltaicos lacustres. En el lago Bosumtwi (Ghana) aparecen carbonatos conchíferos (shell carbonate) casi exclusivamente en las secuencias deltaicas (TALBOT Y DELIBRIAS, 1980).

En la zona litoral, la acción del oleaje y las corrientes es un mecanismo importante en la formación de lumaquelas (RENAUT Y OWEN, 1991; MCGLUE et al., 2010). Desde una perspectiva hidrodinámica, las conchas de gasterópodos exhiben unas condiciones favorables de flotabilidad. En el momento de morir, debido los gases en el interior de su concha originados por la descomposición, son transportados fácilmente hacia las zonas litorales (DE DECKKER, 1988b). Las conchas vacías también exhiben una gran flotabilidad. En los lagos y humedales de Mesopotamia, las concentraciones de gasterópodos se forman durante las inundaciones haciendo que las conchas vacías floten y se acumulen en la zona litoral emergida, marcando los niveles altos alcanzados por el agua. También se observan acumulaciones de conchas de gasterópodos que flotan, así como conchas de gasterópodos y bivalvos que son transportados por las corrientes y el oleaje (TYE Y COLEMAN, 1989b; a; PlAZIAT Y YoUnIS, 2005).

Otro de los mecanismos de acumulación sedimentaria está ligado al descenso del nivel del lago: en función del gradiente topográfico origina diferentes tipos de lumaquelas. En zonas con poco gradiente topográfico, el descenso del nivel del agua permite que extensas áreas, antes en zonas sublitorales protegidas, queden expuestas a la acción del viento y del oleaje lo cual permite la eliminación de los sedimentos finos y facilita la acumulación. El ejemplo actual más estudiado son las lumaquelas del lago Tanganica donde aparecen extensos mantos tabulares (de hasta $200 \mathrm{~km}^{2}$ ) en la zona sublitoral (COHEN, 1989b). Otras veces, en zonas con un elevado gradiente topográfico, la regresión favorece la acumulación de restos en la zona litoral por procesos de transporte en masa desde zonas más someras (MCGLUE et al., 2010). Las subidas del nivel del lago también originan acumulaciones por acción del oleaje (MCGLUE et al., 2010). 
Análisis sedimentológico: microfacies y facies 


\section{Clemente Saenz Garcia}

\section{Historia geologica del Solar Numantino (1957)}

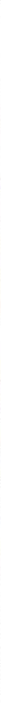

tal y como nos las naman las pajginas de un $110 \mathrm{br}$ inpreso con earacteres indelebles por el dedo de 1 . Providencia. Mstas páginas son las capas de piedra formadas en el curso de 10 s nilenilos sobre el nismo lugar. Su lectura, escuita en un illoma nada turbio para el especialista geb10go, puede sesultar en algunos nonentos amena y distratida, y esta irecuentenente ilustrada por el grabado de unas extranas tormas de vida, nuchas hor desconobidas, que son $10 \mathrm{~s}$ fosilies

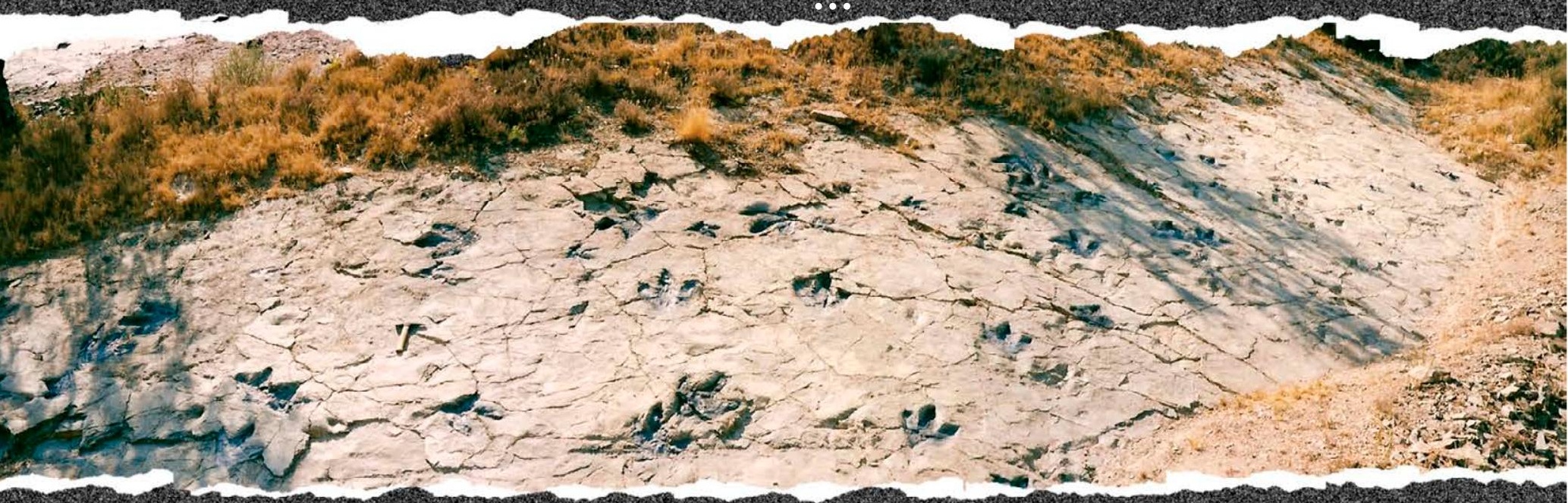




\subsection{INTRODUCCIÓN}

En este capítulo se estudian las relaciones verticales, laterales y secuenciales de las facies descritas en el capítulo anterior, las cuales se agrupan en elementos arquitectónicos. A grandes rasgos, las cinco columnas levantadas (anexos IV, V, VI, VII y VIII) muestran las mismas facies aunque, por supuesto, con variaciones en cuanto a abundancia y desarrollo de las mismas (tabla $6.1)$.

\begin{tabular}{|c|c|c|c|c|c|c|c|c|c|c|}
\hline & \multicolumn{2}{|c|}{ Enciso } & \multicolumn{2}{|c|}{ Ambas Aguas } & \multicolumn{2}{|c|}{ Cornago } & \multicolumn{2}{|c|}{ Munilla } & \multicolumn{2}{|c|}{ Préjano } \\
\hline As & 2,0 & \multirow{7}{*}{13,8} & 0,8 & \multirow{7}{*}{9,2} & 0,9 & \multirow{7}{*}{15,3} & 0,8 & \multirow{7}{*}{23,6} & 0,6 & \multirow{7}{*}{19,0} \\
\hline$A p$ & 1,7 & & 0,6 & & $x$ & & 1,0 & & 2,9 & \\
\hline Ar & 1,9 & & 0,1 & & 5,7 & & 8,8 & & 5,0 & \\
\hline $\mathbf{A} \mathbf{h}_{1}$ & 0,7 & & 1,8 & & 1,9 & & 2,0 & & 0,9 & \\
\hline $\mathrm{Ah}_{2}$ & 0,8 & & 0,2 & & 1,0 & & 2,1 & & 2,3 & \\
\hline$A m_{1}$ & 4,0 & & 4,8 & & 2,8 & & 7,0 & & 4,8 & \\
\hline $\mathrm{Am}_{2}$ & 2,6 & & 0,7 & & 3,1 & & 1,9 & & 2,5 & \\
\hline $\mathrm{Lh}_{1}$ & 7,1 & \multirow{6}{*}{47,7} & 2,6 & \multirow{6}{*}{18,6} & 8,5 & \multirow{6}{*}{46,3} & 5,0 & \multirow{6}{*}{33,3} & 10,3 & \multirow{6}{*}{21,4} \\
\hline $\mathrm{Lh}_{2}$ & 4,9 & & 3,6 & & 6,8 & & 5,4 & & $x$ & \\
\hline $\mathrm{Lm}_{1}$ & 21,7 & & 1,7 & & 4,0 & & 8,4 & & 10,5 & \\
\hline $\mathrm{Lm}_{2}$ & 7,2 & & 2,5 & & 6,2 & & 11,3 & & $x$ & \\
\hline $\mathrm{Lg}$ & 0,7 & & $x$ & & 1,5 & & 2,0 & & 0,6 & \\
\hline LMm & 6,2 & & 8,3 & & 19,3 & & 1,1 & & $x$ & \\
\hline $\mathrm{Mm}$ & 18,9 & \multirow{8}{*}{38,4} & 41,7 & \multirow{8}{*}{72,2} & 22,3 & \multirow{8}{*}{38,4} & 10,7 & \multirow{8}{*}{43,1} & 0,9 & \multirow{8}{*}{59,6} \\
\hline $\mathrm{Ch}$ & 1,1 & & 1,7 & & 0,3 & & 1,2 & & 38,3 & \\
\hline $\mathrm{Cm}$ & 14,7 & & 21,5 & & 9,5 & & 20,2 & & 10,5 & \\
\hline $\mathrm{Cg}$ & 0,1 & & 0,1 & & 1,7 & & 1,8 & & 5,5 & \\
\hline$C_{n}$ & 1,1 & & 4,5 & & 1,9 & & 4,7 & & 3,5 & \\
\hline CAm & 1,0 & & 1,2 & & 1,0 & & 3,8 & & 0,4 & \\
\hline Qm & 1,0 & & 0,2 & & 1,4 & & 0,1 & & 0,1 & \\
\hline Qo & 0,3 & & 0,9 & & 0,2 & & 0,8 & & $x$ & \\
\hline
\end{tabular}

Tabla 6.1: Abundancia relativa de cada facies en las columnas levantadas (\%).

Las tres columnas que representan a la totalidad del registro del Grupo Enciso (Enciso, Ambas Aguas y Munilla) ponen de manifiesto la existencia de dos unidades litoestratigráficas (relacionadas mediante cambios verticales de facies y, en menor medida, laterales) reconocibles en todos los sectores de la cuenca y, probablemente, con rango de formación (figura 6.1).

La secuencia inferior es de naturaleza predominantemente siliciclástica. Corresponde a grandes rasgos a la unidad de transición entre los Grupos Urbión y Enciso C $C_{12-13}^{34 \mathrm{sc}}$ (CÁMARA-RUPELO Y DURÁNTEZ-ROMERO, 1981), a la unidad $C_{12-13}^{4}$ (DURÁNTEZ et al., 1982) y al Conjunto Detrítico Inferior (DOUBLET et al., 2003). Esta unidad muestra un importante acuñamiento en la zona de Ambas Aguas, con dos depocentros, uno hacia el estey el otro hacia el oeste (figura 6.1). Así pues, es probable que durante las etapas iniciales de la sedimentación del Grupo Enciso, la cuenca hubiera estado compartimentada en dos subcubetas separadas por un umbral en la zona de Ambas Aguas. Estas dos subcubetas ya fueron activas en épocas anteriores (SALINASY MAS, 1989; 1990). Esta exposición de umbrales intracuencales en un contexto rift se genera por el crecimiento de segmentos aislados de fallas paralelas que terminan uniéndose y constituyendo una única cubeta mayor (WITHJ ACK et al., 2002).

La secuencia superior exhibe un marcado contraste litológico con la infrayacente. Está constituida por una alternancia recurrente de paquetes métricos-decamétricos siliciclásticos y carbonatados con un claro predominio de los sedimentos carbonatados. Corresponde a las unidades agrupadas bajo la denominación de Grupo Enciso en las Hojas MAGNA (CÁMARARUPELO Y DURÁNTEZ-ROMERO, 1981; DURÁNTEZ et al., 1982) y al Conjunto Carbonatado (DOUBLET et al., 2003). 


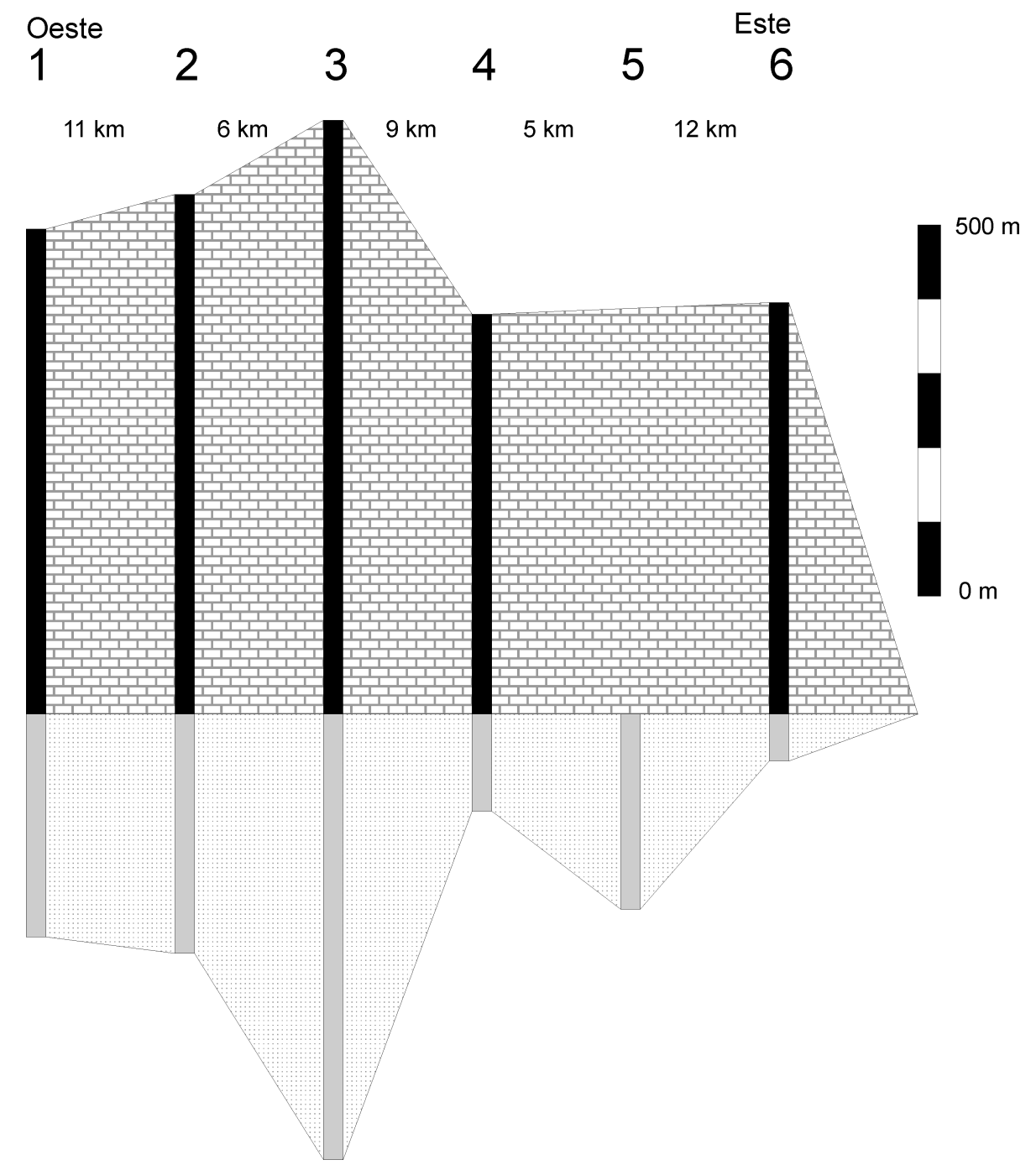

Figura 6.1: Panel de correlación de las unidades diferenciadas en el Grupo Enciso. Los números indican las columnas utilizadas: 1-Vadillos (DOUBLET et al., 2003), 2-Munilla, 3-Enciso, 4Ambas Aguas, 5-Zona entre Ambas Aguas y Cornago (DURÁNTEZ et al., 1982), 6-Grávalos (ALONSO-AZCÁRATE, 1997). Se indica la distancia entre columnas.

Ambas unidades presentan diferencias relevantes entre sí, tanto en la abundancia de las facies como en la arquitectura de los depósitos. Sin embargo, se ha optado por realizar una descripción e interpretación conjunta (tanto de las columnas como de las unidades) de los elementos arquitectónicos para no complicar más el desarrollo del capítulo.

\subsection{ELEMENTOS ARQUITECTÓNICOS SEDIMENTARIOS}

La arquitectura estratigráfica es una herramienta muy utilizada en la determinación de la evolución temporal y espacial de los medios sedimentarios, en respuesta a los factores alocíclicos y autocíclicos que los gobiernan. La arquitectura aluvial comenzó su desarrollo en los inicios del análisis de facies (ALLEN, 1978; FRIEND, 1983), hasta desembocar en la definida por MIALL (1985; 2006) que es la más aceptada a día de hoy. Posteriormente, estos conceptos se han aplicado con éxito a sistemas lacustres (LEMONS Y CHAN, 1999; RAJCHL et al., 2008; PLA-PUEYO et al., 2009).

El elemento arquitectónico se define como un cuerpo sedimentario (litosoma) caracterizado por su geometría, facies y escala, siendo el producto final de uno o varios procesos operando en un sistema deposicional (MIALL, 2000). Siguiendo las recomendaciones de MIALL (1985; 2006) en cada elemento arquitectónico se describe: 
a) Naturaleza de las superficies limitantes: erosiva o gradacional; plana, irregular, cóncava o convexa.

b) Geometría externa: tabular, lentejonar, cuneiforme o acanalada.

c) Escala: potencia y extensión lateral.

d) Litología: asociaciones de facies y secuencia vertical.

e) Geometría interna: naturaleza y organización de las superficies limitantes internas, así como las relaciones con la estratificación.

\begin{tabular}{|c|c|c|c|c|c|c|c|c|c|c|c|c|c|c|c|c|c|c|c|c|c|c|c|c|}
\hline \multirow{5}{*}{ EA1 } & EN & As & $A p$ & & & & $A m_{1}$ & $\mathrm{Am}_{2}$ & $\mathrm{Lh}_{1}$ & $\mathrm{Lh}_{2}$ & $\mid L m_{1}$ & & & & & & & & & & Qm & & $20-783$ & 3,9 \\
\hline & AA & As & $\mathrm{Ap}$ & & $A h_{1}$ & & & $\mathrm{Am}_{2}$ & $\mathrm{Lh}_{1}$ & & & & & & & & & & & & & & $12-438$ & 1,7 \\
\hline & CG & As & & & & & $A m_{1}$ & & & & & & & & & & & & & & & & $25-213$ & 0,9 \\
\hline & MN & As & Ap & & & & & & & & & $\mathrm{Lm}_{2}$ & & & & & & & & & & & $30-229$ & 1,8 \\
\hline & PR & As & $\mathrm{Ap}$ & & & & & & $\mathrm{Lh}_{1}$ & & & & & & & & & & & & & & $60-350$ & 4,1 \\
\hline \multirow{5}{*}{ EA2 } & EN & & & $\mathrm{Ar}$ & $A h_{1}$ & $A h_{2}$ & $A m_{1}$ & $\mathrm{Am}_{2}$ & & $\mathrm{Lh}_{2}$ & $\mathrm{Lm}_{1}$ & $\mathrm{Lm}_{2}$ & & & & & & & & & Qm & & $39-358$ & 1,2 \\
\hline & $\mathrm{AA}$ & & & & $A h_{1}$ & $A h_{2}$ & $A m_{1}$ & $\mathrm{Am}_{2}$ & & $\mathrm{Lh}_{2}$ & & & & & & & & & & & & & $18-140$ & 2,1 \\
\hline & CG & & & Ar & $A h_{1}$ & $A h_{2}$ & $A m_{1}$ & & & $\mathrm{Lh}_{2}$ & & & & & & & & & & & & & $14-143$ & 2,5 \\
\hline & MN & & & & $A h_{1}$ & $A h_{2}$ & & $\mathrm{Am}_{2}$ & & & & & & & & & & & & & & & $20-240$ & 4,1 \\
\hline & $\mathrm{PR}$ & & & & $A h_{1}$ & $\mathrm{Ah}_{2}$ & $A m_{1}$ & $\mathrm{Am}_{2}$ & & & & & & & & & & & & & & & $54-230$ & 3,4 \\
\hline \multirow{5}{*}{ EA3 } & EN & & & $\mathrm{Ar}$ & $A h_{1}$ & $A h_{2}$ & $A m_{1}$ & $\mathrm{Am}_{2}$ & $\mathrm{Lh}_{1}$ & $\mathrm{Lh}_{2}$ & $L m_{1}$ & \begin{tabular}{|l|l|}
$\mathrm{Lm}_{2}$ \\
\end{tabular} & & & & & & & & CAm & & & $12-354$ & 2,6 \\
\hline & AA & & & Ar & & $A h_{2}$ & $A m_{1}$ & & & & & & & & & & & & & & & & $28-116$ & 0,4 \\
\hline & CG & & & Ar & $A h_{1}$ & $A h_{2}$ & $A \mathrm{~m}_{1}$ & $\mathrm{Am}_{2}$ & $\mathrm{Lh}_{1}$ & $\mathrm{Lh}_{2}$ & & $\mathrm{Lm}_{2}$ & $\mathrm{Lg}$ & & & & & & & & & & $11-200$ & 6,8 \\
\hline & MN & & & $\mathrm{Ar}$ & $A h_{1}$ & $\mathrm{Ah}_{2}$ & $A m_{1}$ & $\mathrm{Am}_{2}$ & $\mathrm{Lh}_{1}$ & $\mathrm{Lh}_{2}$ & & \begin{tabular}{|l|l|}
$m_{2}$ \\
\end{tabular} & & & & & & & & & & & $22-488$ & 8,3 \\
\hline & PR & & & Ar & $A h_{1}$ & & $A m_{1}$ & & $\mathrm{Lh}_{1}$ & & & & & & & & & & & & & & 64-169 & 5,5 \\
\hline \multirow{5}{*}{ EA4 } & EN & & & & & $A h_{2}$ & $A m_{1}$ & $\mathrm{Am}_{2}$ & $\mathrm{Lh}_{1}$ & $\mathrm{Lh}_{2}$ & $L \mathrm{~m}_{1}$ & \begin{tabular}{|l|l|}
$\mathrm{Lm}_{2}$ \\
\end{tabular} & $\mathrm{Lg}$ & LMm & & & & & & CAm & & & $9-253$ & 5,0 \\
\hline & $\mathrm{AA}$ & & & & $A h_{1}$ & $\mathrm{Ah}_{2}$ & $A \mathrm{~m}_{1}$ & $\mathrm{Am}_{2}$ & & & $L \mathrm{~m}_{1}$ & \begin{tabular}{|l|l|}
$\mathrm{Lm}_{2}$ \\
\end{tabular} & & & & & & & & & & & $12-370$ & 4,9 \\
\hline & CG & & & & & $\mathrm{Ah}_{2}$ & $A \mathrm{~m}_{1}$ & $\mathrm{Am}_{2}$ & $\mathrm{Lh}_{1}$ & $\mathrm{Lh}_{2}$ & $\mathrm{Lm}_{1}$ & $\mathrm{Lm}_{2}$ & $\mathrm{Lg}$ & & & & & & & & & & $15-104$ & 4,2 \\
\hline & MN & & & & & $\mathrm{Ah}_{2}$ & $A \mathrm{~m}_{1}$ & $\mathrm{Am}_{2}$ & & $\mathrm{Lh}_{2}$ & & $\mathrm{Lm}_{2}$ & & & & & & & & & & & $16-575$ & 8,6 \\
\hline & PR & & & & & & $A m_{1}$ & $\mathrm{Am}_{2}$ & & & & & & & & & & & & & & & $60-270$ & 5,3 \\
\hline \multirow{5}{*}{ EA5 } & EN & As & & $\mathrm{Ar}$ & $A h_{1}$ & $\mathrm{Ah}_{2}$ & $A m_{1}$ & $\mathrm{Am}_{2}$ & $\mathrm{Lh}_{1}$ & $\mathrm{Lh}_{2}$ & $L \mathrm{Lm}_{1}$ & \begin{tabular}{|l|l|} 
\\
\end{tabular} & & & & & & & & & Qm & Qo & $20-2947$ & 30,0 \\
\hline & $\mathrm{AA}$ & & & & & & $A m_{1}$ & $\mathrm{Am}_{2}$ & $\mathrm{Lh}_{1}$ & & $L \mathrm{Lm}_{1}$ & & & & & & & & & CAm & & & $30-344$ & 4,3 \\
\hline & CG & & & $\mathrm{Ar}$ & $A h_{1}$ & $\mathrm{Ah}_{2}$ & $A m_{1}$ & $\mathrm{Am}_{2}$ & $\mathrm{Lh}_{1}$ & $\mathrm{Lh}_{2}$ & $L \mathrm{Lm}_{1}$ & & $\mathrm{Lg}$ & & & & $\mathrm{Cm}$ & & & & Qm & & $15-510$ & 13,7 \\
\hline & MN & & & Ar & & $\mathrm{Ah}_{2}$ & $A m_{1}$ & $\mathrm{Am}_{2}$ & $\mathrm{Lh}_{1}$ & & $L \mathrm{~m}_{1}$ & & $\mathrm{Lg}$ & & & & & & & & & & $20-579$ & 15,5 \\
\hline & PR & & & $\mathrm{Ar}$ & & $\mathrm{Ah}_{2}$ & & & $\mathrm{Lh}_{1}$ & & $L \mathrm{~m}_{1}$ & & $\mathrm{Lg}$ & & & & & & $C_{n}$ & & & & $74-627$ & 21,7 \\
\hline \multirow{4}{*}{ EA6 } & EN & & & $\mathrm{Ar}$ & $A h_{1}$ & $A h_{2}$ & $A m_{1}$ & $\mathrm{Am}_{2}$ & & $\mathrm{Lh}_{2}$ & $L \mathrm{Lm}_{1}$ & $\mathrm{Lm}_{2}$ & $\mathrm{Lg}$ & & $\mathrm{Mm}$ & & $\mathrm{Cm}$ & & & & Qm & & $20-896$ & 13,2 \\
\hline & $\mathrm{AA}$ & & & & $A h_{1}$ & & $A m_{1}$ & $\mathrm{Am}_{2}$ & $\mathrm{Lh}_{1}$ & $\mathrm{Lh}_{2}$ & & $\mathrm{Lm}_{2}$ & & & & & & & & CAm & & Qo & 14-368 & 6,3 \\
\hline & CG & As & & Ar & $A h_{1}$ & & $A m_{1}$ & $\mathrm{Am}_{2}$ & $\mathrm{Lh}_{1}$ & $\mathrm{Lh}_{2}$ & $L \mathrm{Lm}_{1}$ & $\mid \mathrm{Lm}_{2}$ & $\mathrm{Lg}$ & & & & & & & & Qm & & $15-268$ & 14,3 \\
\hline & \begin{tabular}{|l|} 
MN \\
\end{tabular} & & & Ar & $A h_{1}$ & & $A m_{1}$ & $\mathrm{Am}_{2}$ & & $\mathrm{Lh}_{2}$ & $\mid \mathrm{Lm}_{1}$ & $\mathrm{Lm}_{2}$ & $\mathrm{Lg}$ & & & & & & & & & & $20-600$ & 17,5 \\
\hline \multirow{5}{*}{ EA7 } & \begin{tabular}{|l|} 
EN \\
\end{tabular} & & & $\mathrm{Ar}$ & & & & & $\mathrm{Lh}_{1}$ & & $L \mathrm{Lm}_{1}$ & & & LMm & $\mathrm{Mm}$ & $\mathrm{Ch}$ & $\mathrm{cm}$ & & $C n$ & CAm & Qm & Qo & $10-623$ & 14,3 \\
\hline & AA & & & & & & & & & & & & & & $\mathrm{Mm}$ & & $\mathrm{Cm}$ & & & CAm & Qm & Qo & $16-378$ & 18,4 \\
\hline & CG & & & & & & & & & & & & & LMm & & & $\mathrm{Cm}$ & & & CAm & Qm & Qo & 14-348 & 8,8 \\
\hline & \begin{tabular}{|l|} 
MN \\
\end{tabular} & & & Ar & & & & & & & & & & & $\mathrm{Mm}$ & & $\mathrm{Cm}$ & & $\mathrm{Cn}$ & CAm & Qm & Qo & $17-710$ & 23,6 \\
\hline & \begin{tabular}{|l|} 
PR \\
\end{tabular} & & & & & & & & & & & & & & & & $\mathrm{cm}$ & & & & & & $15-118$ & 10,3 \\
\hline \multirow{5}{*}{ EA8 } & EN & & & & & & & & & & & & & & $\mathrm{Mm}$ & & $\mathrm{Cm}$ & $\mathrm{Cg}$ & $C_{n}$ & & & Qo & $12-215$ & 1,8 \\
\hline & AA & & & & & & & & & & & & & LMm & $\mathrm{Mm}$ & & $\mathrm{Cm}$ & $\mathrm{Cg}$ & $\mathrm{Cn}$ & CAm & & Qo & $7-284$ & 8,0 \\
\hline & CG & & & & & & & & & & & & & LMm & $\mathrm{Mm}$ & & $\mathrm{Cm}$ & $\mathrm{Cg}$ & $\mathrm{Cn}$ & CAm & & Qo & $10-137$ & 4,7 \\
\hline & \begin{tabular}{|l|} 
MN \\
\end{tabular} & & & & & & & & & & & & & & $\mathrm{Mm}$ & & $\mathrm{Cm}$ & $\mathrm{Cg}$ & $C_{n}$ & & & Qo & $10-500$ & 6,8 \\
\hline & \begin{tabular}{|l|} 
PR \\
\end{tabular} & & & $\mathrm{Ar}$ & & & & & & & & & & & & & $\mathrm{Cm}$ & $\mathrm{Cg}$ & $C_{n}$ & CAm & Qm & Qo & $10-622$ & 10,6 \\
\hline & \begin{tabular}{|l|} 
EN \\
\end{tabular} & & & & & & & & & & & & & & $\mathrm{Mm}$ & $\mathrm{Ch}$ & $\mathrm{Cm}$ & & & & & & $47-270$ & 1,2 \\
\hline & \begin{tabular}{|l|} 
AA \\
\end{tabular} & & & & & & & & & & & & & & & $\mathrm{Ch}$ & $\mathrm{Cm}$ & & & & & & $10-190$ & 1,8 \\
\hline EA9 & CG & & & & & & & & & & & & & & & $\mathrm{Ch}$ & & & & & & & $10-48$ & 0,4 \\
\hline & MN & & & & & & & & & & & & & & & $\mathrm{Ch}$ & & & & & & & $10-220$ & 1,2 \\
\hline & \begin{tabular}{|l|} 
PR \\
\end{tabular} & & & & & & & & & & & & & & & $\mathrm{Ch}$ & & & & & & & $27-446$ & 38,0 \\
\hline & \begin{tabular}{|l|} 
EN \\
\end{tabular} & & & Ar & & $A h_{2}$ & & & & & & & & LMm & $\mathrm{Mm}$ & & $\mathrm{Cm}$ & & $\mathrm{Cn}$ & & Qm & Qo & 30-547 & 6,5 \\
\hline 5010 & AA & & & & & & & & & & & & & LMm & & & $\mathrm{Cm}$ & & $\mathrm{Cn}$ & & Qm & Qo & $15-451$ & 8,6 \\
\hline & cG & & & $\mathrm{Ar}$ & & & & $\mathrm{Am}_{2}$ & & & $\left\llcorner m_{1}\right.$ & & & LMm & $\mathrm{Mm}$ & & $\mathrm{Cm}$ & & $\mathrm{Cn}$ & CAm & Qm & Qo & $14-459$ & 18,5 \\
\hline & \begin{tabular}{|l|} 
MN \\
\end{tabular} & & & & & & & & & & & & & LMm & $\mathrm{Mm}$ & & $\mathrm{Cm}$ & & & & & Qo & $14-248$ & 1,3 \\
\hline & \begin{tabular}{|l|} 
EN \\
\end{tabular} & & & & & & & & $\mathrm{Lh}_{1}$ & & & & & LMm & $\mathrm{Mm}$ & $\mathrm{Ch}$ & $\mathrm{Cm}$ & & $\mathrm{Cn}$ & CAm & Qm & Qo & $11-1883$ & 19,6 \\
\hline & AA & & & & $A h_{1}$ & & $A m_{1}$ & & & $\mathrm{Lh}_{2}$ & & \begin{tabular}{|l|l|}
$m_{2}$ \\
\end{tabular} & & LMm & $\mathrm{Mm}$ & $\mathrm{Ch}$ & $\mathrm{Cm}$ & & $C n$ & CAm & Qm & Qo & $12-1200$ & 43,1 \\
\hline EA11 & \begin{tabular}{|l|}
$\mathrm{CG}$ \\
\end{tabular} & & & & & & & & & & $\mathrm{Lm}_{1}$ & & & LMm & $\mathrm{Mm}$ & & $\mathrm{Cm}$ & $\mathrm{Cg}$ & $\mathrm{Cn}$ & CAm & Qm & Qo & $15-400$ & 24,3 \\
\hline & \begin{tabular}{|l|} 
MN \\
\end{tabular} & & & & & & & & & & & & & & $\mathrm{Mm}$ & & $\mathrm{Cm}$ & & & & Qm & Qo & $22-405$ & 10,9 \\
\hline & \begin{tabular}{|l|}
$\mathrm{PR}$ \\
\end{tabular} & & & & & & & & & & & & & & $\mathrm{Mm}$ & $\mathrm{Ch}$ & & & & & & & $\begin{array}{l}55-63 \\
\end{array}$ & 1,2 \\
\hline & \begin{tabular}{|l|} 
EN \\
\end{tabular} & & & & & & & & & & & & & & & & $\mathrm{Cm}$ & & & & $Q \mathrm{Qm}$ & Qo & $28-130$ & 0,6 \\
\hline FA & AA & & & & & & & & & & & & & LMm & $\mathrm{Mm}$ & & & & & & Qm & Qo & 17-93 & 0,5 \\
\hline & CG & & & & & & & & & & & & & LMm & & & & & & & Qm & & $10-120$ & 1,0 \\
\hline & \begin{tabular}{|l|}
$\mathrm{MN}$ \\
\end{tabular} & & & & & & & & & & & & & & & & & & & & Qm & Qo & $10-60$ & 0,5 \\
\hline
\end{tabular}


Tabla 6.2: Facies presentes en cada elemento arquitectónico de las cinco columnas muestreadas: Enciso (EN), Ambas Aguas (AA), Cornago (CG), Munilla (MN) y Préjano (PR). En negrita se indican las facies fundamentales de cada elemento. Las dos columnas de la derecha hacen referencia a la potencia $(\mathrm{cm})$ y abundancia (\%) de cada elemento.

Con estos parámetros, se establecen doce elementos arquitectónicos. Cada elemento costa de una o dos facies fundamentales, en cuanto a abundancia y desarrollo, que se complementan con otra serie de facies menos importantes, todas ellas relacionadas genéticamente (tabla 6.2) Así pues, en teoría, cada elemento determina la sedimentación acaecida en un subambiente sedimentario asociado a unas condiciones determinadas (energéticas, ambientales, fisicoquímicas, etc.).

Para el estudio de las relaciones entre las facies presentes en cada elemento arquitectónico se realiza un análisis markoviano delas facies presentes según el modelo propuesto por HARPER J R. (1984a; 1984b), utilizando el programa Strati-Signal (NDIAYE, 2007).

El análisis de cadenas de Markov calcula la dependencia de una transición simple entre las sucesivas facies, y reconoce la existencia de algún patrón preferencial. Para este análisis se consideran los siguientes niveles de confianza (tabla 6.3):

\begin{tabular}{|c|c|c|}
\cline { 2 - 3 } \multicolumn{1}{c|}{} & Probabilidad binomial [a] & Nivel de confianza [1- $\boldsymbol{\alpha}]$ \\
\hline Significación alta & $<0^{\prime} 005$ & $>99 ' 5 \%$ \\
\hline Significación moderada & $0^{\prime} 005-0^{\prime} 05$ & $95-99^{\prime} 5 \%$ \\
\hline Significativa & $0^{\prime} 05-0^{\prime} 10$ & $90-95 \%$ \\
\hline Significación débil & $0^{\prime} 10-0^{\prime} 15$ & $85-95 \%$ \\
\hline No significativa & $>0$ 0'15 & $<85 \%$ \\
\hline
\end{tabular}

Tabla 6.3: Niveles de confianza utilizados para el análisis markoviano de Harper [modificado deXUY MACCARTHY (1998)].

De cada columna se obtiene la matriz de transiciones, a partir de la cual se calcula la matriz con los niveles de confianza para cada transición. En todas las columnas se ha constatado que los datos no son aleatorios. Los datos utilizados provienen de las cinco columnas muestreadas: Enciso con 1.480 transiciones (anexo IX.1), Ambas Aguas con 1.104 transiciones (anexo IX.2), Cornago con 1.104 transiciones (anexo IX.3), Munilla con 902 transiciones (anexo IX.4) y, Préjano con 139 transiciones (anexo IX.5).

Además, para detectar las relaciones existentes entre los elementos arquitectónicos se realiza otro análisis markoviano: Enciso con 412 transiciones (anexo X.1), Ambas Aguas con 466 transiciones (anexo X.2), Cornago con 106 transiciones (anexo X.3), Munilla con 505 transiciones (anexo X.4) y Préjano con 85 transiciones (anexo X.5). Estas relaciones (tabla 6.4) serán la base de la interpretación de los medios sedimentarios.

\subsubsection{EA1: canales acintados (ribbon)}

Equivale a los elementos arquitectónicos CH y CR de MiALL (1985; 2006). Está compuesto por sets decimétricos de areniscas de grano fino-medio que se agrupan en cosets que forman mesoformas acanaladas con potencias comprendidas entre 2 y $4 \mathrm{~m}$, excepcionalmente hasta $8 \mathrm{~m}$ (tabla 6.2). Su extensión lateral es limitada (10-30 m), siendo raros los canales que superan dicho valor. Es un elemento arquitectónico escaso $(<5 \%)$ en términos de abundancia (tabla 6.2). Estas medidas se han de tomar con cierta cautela ya que la ausencia de afloramientos tridimensionales no permite discernir si son medidas perpendiculares u oblicuas al cuerpo. Los datos indican una geometría tipo acintada (ribbon) con un valor entre la extensión lateral (anchura) respecto a la potencia $\leq 30$ (NADON, 1994) o < 15 (FRIEND et al., 1979; FRIEND, 1983; GIBLING, 2006). 
Análisis sedimentológico: elementos arquitectónicos y medios sedimentarios

\begin{tabular}{|c|c|c|c|c|c|c|c|c|c|c|c|c|c|}
\hline & & EA1 & EA2 & EA3 & EA4 & EA5 & EA6 & EA7 & EA8 & EA9 & EA10 & EA11 & EA12 \\
\hline EN & \multirow{5}{*}{ EA1 } & & & & $E A 1 \rightarrow E A 4$ & $\mathrm{EA} 1 \rightarrow \mathrm{EA} 5$ & $\mathrm{EA} 1 \rightarrow \mathrm{EA} 6$ & & & & & & \\
\hline AA & & & & & EA1 $\rightarrow$ EA4 & & $\mathrm{EA} 1 \rightarrow \mathrm{EA} 6$ & EA1 $\rightarrow E A 7$ & & & & & \\
\hline CG & & & $\mathrm{EA} 1 \rightarrow \mathrm{EA} 2$ & & & $\mathrm{EA} 1 \rightarrow \mathrm{EA} 5$ & & & & & & & \\
\hline MU & & & & & $E A 1 \rightarrow E A 4$ & $\mathrm{EA} 1 \rightarrow \mathrm{EA} 5$ & $\mathrm{EA} 1 \rightarrow \mathrm{EA} 6$ & & & & & & \\
\hline PR & & & & & & $\mathrm{EA} 1 \rightarrow \mathrm{EA} 5$ & & & & & & & \\
\hline EN & \multirow{5}{*}{ EA2 } & & & $\mathrm{EA} 2 \rightarrow \mathrm{EA} 3$ & EA2 $\rightarrow$ EA4 & $E A 2 \rightarrow E A 5$ & $\mathrm{EA} 2 \rightarrow \mathrm{EA} 6$ & $E A 2 \rightarrow E A 7$ & & & $E A 2 \rightarrow E A 10$ & & \\
\hline AA & & & & $\mathrm{EA} 2 \rightarrow \mathrm{EA} 3$ & EA2 $\rightarrow$ EA4 & & $\mathrm{EA} 2 \rightarrow \mathrm{EA} 6$ & & & & & & \\
\hline CG & & & & $E A 2 \rightarrow E A 3$ & EA2 $\rightarrow$ EA4 & $\mathrm{EA} 2 \rightarrow \mathrm{EA} 5$ & $\mathrm{EA} 2 \rightarrow \mathrm{EA} 6$ & & & & & $E A 2 \rightarrow E A 11$ & \\
\hline MU & & & & $E A 2 \rightarrow E A 3$ & $\mathrm{EA} 2 \rightarrow \mathrm{EA} 4$ & $\mathrm{EA} 2 \rightarrow \mathrm{EA} 5$ & $\mathrm{EA} 2 \rightarrow E A 6$ & & $E A 2 \rightarrow E A 8$ & & & & \\
\hline PR & & $\mathrm{EA} 2 \rightarrow \mathrm{EA} 1$ & & & & $\mathrm{EA} 2 \rightarrow \mathrm{EA} 5$ & & & $\mathrm{EA} 2 \rightarrow \mathrm{EA} 8$ & & & & \\
\hline EN & \multirow{5}{*}{ EA3 } & & $\mathrm{EA} 3 \rightarrow \mathrm{EA} 2$ & & $\mathrm{EA} 3 \rightarrow \mathrm{EA4}$ & $\mathrm{EA} 3 \rightarrow \mathrm{EA} 5$ & $\mathrm{EA} 3 \rightarrow \mathrm{EA} 6$ & & & & & & \\
\hline$A A$ & & & & & EA3 $\rightarrow$ EA4 & & $\mathrm{EA} 3 \rightarrow \mathrm{EA} 6$ & & & & & EA3 $\rightarrow$ EA11 & \\
\hline CG & & & $\mathrm{EA} 3 \rightarrow \mathrm{EA} 2$ & & $E A 3 \rightarrow E A 4$ & $\mathrm{EA} 3 \rightarrow \mathrm{EA} 5$ & $\mathrm{EA} 3 \rightarrow \mathrm{EA} 6$ & & & & $E A 3 \rightarrow E A 10$ & $E A 3 \rightarrow E A 11$ & \\
\hline MU & & & $\mathrm{EA} 3 \rightarrow \mathrm{EA} 2$ & & EA3 $\rightarrow$ EA4 & $\mathrm{EA} 3 \rightarrow \mathrm{EA} 5$ & $\mathrm{EA} 3 \rightarrow \mathrm{EA} 6$ & $E A 3 \rightarrow E A 7$ & EA3 $\rightarrow$ EA8 & & & $E A 3 \rightarrow E A 11$ & $\mathrm{EA} 3 \rightarrow \mathrm{EA} 12$ \\
\hline PR & & & & & EA3 $\rightarrow$ EA4 & $\mathrm{EA} 3 \rightarrow \mathrm{EA} 5$ & & & & & & EA3 $\rightarrow$ EA11 & \\
\hline EN & \multirow{5}{*}{ EA4 } & $E A 4 \rightarrow E A 1$ & & $E A 4 \rightarrow E A 3$ & & EA4 $\rightarrow$ EA5 & EA4 $\rightarrow$ EA6 & $E A 4 \rightarrow E A 7$ & & & $E A 4 \rightarrow E A 10$ & EA4 $\rightarrow$ EA11 & \\
\hline$A A$ & & $\mathrm{EA} 4 \rightarrow \mathrm{EA} 1$ & EA4 $\rightarrow E A 2$ & $E A 4 \rightarrow E A 3$ & & $\mathrm{EA4} \rightarrow \mathrm{EA} 5$ & EA4 $\rightarrow$ EA6 & $E A 4 \rightarrow E A 7$ & $E A 4 \rightarrow E A 8$ & & $E A 4 \rightarrow E A 10$ & $E A 4 \rightarrow E A 11$ & \\
\hline CG & & & $E A 4 \rightarrow E A 2$ & $\mathrm{EA} 4 \rightarrow \mathrm{EA} 3$ & & $\mathrm{EA4} \rightarrow \mathrm{EA} 5$ & EA4 $\rightarrow$ EA6 & & $E A 4 \rightarrow E A 8$ & & $E A 4 \rightarrow E A 10$ & $E A 4 \rightarrow E A 11$ & \\
\hline MU & & & $\mathrm{EA4} \rightarrow \mathrm{EA} 2$ & $E A 4 \rightarrow E A 3$ & & EA4 $\rightarrow$ EA5 & EA4 $\rightarrow$ EA6 6 & $E A 4 \rightarrow E A 7$ & & EA4 $\rightarrow$ EA9 & & $E A 4 \rightarrow E A 11$ & $E A 4 \rightarrow E A 12$ \\
\hline PR & & $\mathrm{EA4} \rightarrow \mathrm{EA} 1$ & & & & & & & & & & EA4 $\rightarrow$ EA11 & \\
\hline EN & \multirow{5}{*}{ EA5 } & $\mathrm{EA} 5 \rightarrow \mathrm{EA} 1$ & $E A 5 \rightarrow E A 2$ & $E A 5 \rightarrow E A 3$ & EA5 $\rightarrow$ EA4 & & EA5 $\rightarrow$ EA6 & EA5 $\rightarrow$ EA7 & EA5 $\rightarrow$ EA8 & EA5 $\rightarrow$ EA9 & $E A 5 \rightarrow E A 10$ & $E A 5 \rightarrow$ EA11 & $\overline{E A 5 \rightarrow E A 12}$ \\
\hline AA & & $\mathrm{EA} 5 \rightarrow \mathrm{EA} 1$ & $\mathrm{EA} 5 \rightarrow \mathrm{EA} 2$ & $\mathrm{EA} 5 \rightarrow \mathrm{EA} 3$ & EA5 $\rightarrow$ EA4 & & $E A 5 \rightarrow E A 6$ & $E A 5 \rightarrow E A 7$ & & & $E A 5 \rightarrow E A 10$ & EA5 $\rightarrow$ EA11 & \\
\hline CG & & $\mathrm{EA} 5 \rightarrow \mathrm{EA} 1$ & $\mathrm{EA} 5 \rightarrow \mathrm{EA} 2$ & $\mathrm{EA} 5 \rightarrow \mathrm{EA} 3$ & EA5 $\rightarrow$ EA4 & & $E A 5 \rightarrow E A 6$ & $E A 5 \rightarrow E A 7$ & & EA5 $\rightarrow E A 9$ & $\mathrm{EA} 5 \rightarrow \mathrm{EA} 10$ & EA5 $\rightarrow$ EA11 & \\
\hline MU & & $\mathrm{EA} 5 \rightarrow \mathrm{EA} 1$ & $\mathrm{EA} 5 \rightarrow \mathrm{EA} 2$ & $\mathrm{EA} 5 \rightarrow \mathrm{EA} 3$ & EA5 $\rightarrow$ EA4 & & $E A 5 \rightarrow E A 6$ & $E A 5 \rightarrow E A 7$ & EA5 $\rightarrow$ EA8 & & & $E A 5 \rightarrow E A 11$ & $\mathrm{EA} 5 \rightarrow \mathrm{EA} 12$ \\
\hline PR & & & $\mathrm{EA} 5 \rightarrow \mathrm{EA} 2$ & $\mathrm{EA} 5 \rightarrow \mathrm{EA} 3$ & EA5 $\rightarrow$ EA4 & & & & & $E A 5 \rightarrow E A 9$ & & & \\
\hline EN & \multirow{5}{*}{ EA6 } & $\mathrm{EA} 6 \rightarrow \mathrm{EA} 1$ & $\mathrm{EA} 6 \rightarrow \mathrm{EA} 2$ & $\mathrm{EA} 6 \rightarrow \mathrm{EA} 3$ & EA6 $\rightarrow$ EA4 & $E A 6 \rightarrow E A 5$ & & $E A 6 \rightarrow E A 7$ & & & $E A 6 \rightarrow E A 10$ & EA6 $\rightarrow$ EA11 & $E A 6 \rightarrow E A 12$ \\
\hline AA & & $\mathrm{EA} 6 \rightarrow \mathrm{EA} 1$ & $\mathrm{EA} 6 \rightarrow \mathrm{EA} 2$ & & EA6 $\rightarrow$ EA4 & $E A 6 \rightarrow E A 5$ & & $E A 6 \rightarrow E A 7$ & & & $E A 6 \rightarrow E A 10$ & $E A 6 \rightarrow E A 11$ & $E A 6 \rightarrow E A 12$ \\
\hline CG & & & $\mathrm{EA} 6 \rightarrow \mathrm{EA} 2$ & $\mathrm{EA} 6 \rightarrow \mathrm{EA} 3$ & EA6 $\rightarrow$ EA4 & & & $E A 6 \rightarrow E A 7$ & $E A 6 \rightarrow E A 8$ & & & $E A 6 \rightarrow E A 11$ & $\mathrm{EA} 6 \rightarrow \mathrm{EA} 12$ \\
\hline MU & & $E A 6 \rightarrow E A 1$ & $\mathrm{EA} 6 \rightarrow \mathrm{EA} 2$ & $\mathrm{EA} 6 \rightarrow \mathrm{EA} 3$ & EA6 $\rightarrow$ EA4 & $E A 6 \rightarrow E A 5$ & & $E A 6 \rightarrow E A 7$ & $E A 6 \rightarrow E A 8$ & & & $E A 6 \rightarrow E A 11$ & $E A 6 \rightarrow E A 12$ \\
\hline PR & & & & & & & & & & & & & \\
\hline EN & \multirow{5}{*}{ EA7 } & $E A 7 \rightarrow E A 1$ & & $E A 7 \rightarrow E A 3$ & $E A 7 \rightarrow E A 4$ & $E A 7 \rightarrow E A 5$ & $E A 7 \rightarrow E A 6$ & & $\mathrm{EA7} \rightarrow \mathrm{EA} 8$ & $\mathrm{EA7} \rightarrow \mathrm{EA} 9$ & $\mathrm{EA} 7 \rightarrow \mathrm{EA} 10$ & $\mathrm{EA} 7 \rightarrow \mathrm{EA} 11$ & $E A 7 \rightarrow E A 12$ \\
\hline AA & & & & & & $E A 7 \rightarrow E A 5$ & $E A 7 \rightarrow E A 6$ & & $E A 7 \rightarrow E A 8$ & $E A 7 \rightarrow E A 9$ & $E A 7 \rightarrow E A 10$ & $\mathrm{EA} 7 \rightarrow \mathrm{EA} 11$ & \\
\hline CG & & & & & & $E A 7 \rightarrow E A 5$ & $E A 7 \rightarrow E A 6$ & & $\mathrm{EA} 7 \rightarrow \mathrm{EA} 8$ & $\mathrm{EA} 7 \rightarrow \mathrm{EA} 9$ & EA7 $\rightarrow$ EA10 & $\mathrm{EA} 7 \rightarrow \mathrm{EA} 11$ & \\
\hline MU & & & $E A 7 \rightarrow E A 2$ & $E A 7 \rightarrow E A 3$ & $E A 7 \rightarrow E A 4$ & $E A 7 \rightarrow E A 5$ & $E A 7 \rightarrow E A 6$ & & $\mathrm{EA} 7 \rightarrow \mathrm{EA} 8$ & $\mathrm{EA} 7 \rightarrow \mathrm{EA} 9$ & $\mathrm{EA} 7 \rightarrow \mathrm{EA} 10$ & EA7 $\rightarrow$ EA11 & \\
\hline PR & & & & & & & & & $E A 7 \rightarrow E A 8$ & $\mathrm{EA} 7 \rightarrow \mathrm{EA} 9$ & & & \\
\hline EN & \multirow{5}{*}{ EA8 } & & & & $E A 8 \rightarrow E A 4$ & & & $\mathrm{EA} 8 \rightarrow \mathrm{EA} 7$ & & EA8 $\rightarrow$ EA9 & & EA8 $\rightarrow$ EA11 & \\
\hline AA & & & & & & $E A 8 \rightarrow E A 5$ & & $\mathrm{EA8} \rightarrow \mathrm{EA} 7$ & & $E A 8 \rightarrow E A 9$ & $\mathrm{EA} 8 \rightarrow \mathrm{EA} 10$ & EA8 $\rightarrow$ EA11 & \\
\hline CG & & & & & & & & EA8 $\rightarrow E A 7$ & & EA8 $\rightarrow$ EA9 & $E A 8 \rightarrow E A 10$ & EA8 $\rightarrow$ EA11 & \\
\hline MU & & $E A 8 \rightarrow E A 1$ & $E A 8 \rightarrow E A 2$ & & & $E A 8 \rightarrow E A 5$ & $E A 8 \rightarrow E A 6$ & EA8 $\rightarrow$ EA7 & & EA8 $\rightarrow E A 9$ & $\mathrm{EA} 8 \rightarrow \mathrm{EA} 10$ & $E A 8 \rightarrow E A 11$ & \\
\hline PR & & & & EA8 $\rightarrow E A 3$ & & $E A 8 \rightarrow E A 5$ & & $E A 8 \rightarrow E A 7$ & & $E A 8 \rightarrow E A 9$ & & & \\
\hline EN & \multirow{5}{*}{ EA9 } & & & & & $E A 9 \rightarrow E A 5$ & & $\mathrm{EA} 9 \rightarrow \mathrm{EA} 7$ & & & $E A 9 \rightarrow E A 10$ & EA9 $\rightarrow$ EA11 & \\
\hline AA & & $\mathrm{EA} 9 \rightarrow \mathrm{EA} 1$ & & & & & & $E A 9 \rightarrow E A 7$ & & & $E A 9 \rightarrow E A 10$ & EA9 $\rightarrow$ EA11 & \\
\hline CG & & & & & & $\mathrm{EA} 9 \rightarrow \mathrm{EA} 5$ & & EA9 $\rightarrow E A 7$ & & & & $E A 9 \rightarrow E A 11$ & \\
\hline MU & & & & & & & & $\mathrm{EA} 9 \rightarrow \mathrm{EA} 7$ & EA9 $\rightarrow E A 8$ & & & $E A 9 \rightarrow E A 11$ & \\
\hline PR & & & & & & & & $\mathrm{EA} 9 \rightarrow \mathrm{EA} 7$ & $\mathrm{EA9 \rightarrow EA8}$ & & & & \\
\hline EN & \multirow{5}{*}{ EA10 } & $\mathrm{EA} 10 \rightarrow \mathrm{EA} 1$ & $E A 10 \rightarrow E A 2$ & $E A 10 \rightarrow E A 3$ & $E A 10 \rightarrow E A 4$ & $E A 10 \rightarrow E A 5$ & $\mathrm{EA} 10 \rightarrow \mathrm{EA} 6$ & $E A 10 \rightarrow E A 7$ & $E A 10 \rightarrow E A 8$ & & & $\mathrm{EA} 10 \rightarrow \mathrm{EA} 11$ & $E A 10 \rightarrow E A 12$ \\
\hline AA & & & & & $E A 10 \rightarrow E A 4$ & & $E A 10 \rightarrow E A 6$ & $E A 10 \rightarrow E A 7$ & $\mathrm{EA} 10 \rightarrow \mathrm{EA} 8$ & $\mathrm{EA} 10 \rightarrow \mathrm{EA} 9$ & & EA10 $\rightarrow$ EA11 & \\
\hline CG & & & $E A 10 \rightarrow E A 2$ & $E A 10 \rightarrow E A 3$ & $E A 10 \rightarrow E A 4$ & $\mathrm{EA} 10 \rightarrow \mathrm{EA} 5$ & $E A 10 \rightarrow E A 6$ & $\mathrm{EA} 10 \rightarrow \mathrm{EA} 7$ & $E A 10 \rightarrow E A 8$ & & & EA10 $\rightarrow$ EA11 & EA $10 \rightarrow E A 12$ \\
\hline MU & & & & & & EA10 $\rightarrow$ EA5 & & $\mathrm{EA} 10 \rightarrow \mathrm{EA} 7$ & $\mathrm{EA} 10 \rightarrow \mathrm{EA} 8$ & & & $E A 10 \rightarrow E A 11$ & \\
\hline PR & & & & & & & & & & & & & \\
\hline EN & \multirow{5}{*}{ EA11 } & & $\mathrm{EA} 11 \rightarrow \mathrm{EA} 2$ & $E A 11 \rightarrow E A 3$ & EA11 $\rightarrow$ EA4 & $E A 11 \rightarrow E A 5$ & $\mathrm{EA11 \rightarrow \textrm {EA } 6}$ & $\mathrm{EA} 11 \rightarrow \mathrm{EA} 7$ & EA11 $\rightarrow$ EA8 & EA11 $\rightarrow E A 9$ & $\mathrm{EA} 11 \rightarrow \mathrm{EA} 10$ & & $E A 11 \rightarrow E A 12$ \\
\hline AA & & & $E A 11 \rightarrow E A 2$ & & $E A 11 \rightarrow E A 4$ & $E A 11 \rightarrow E A 5$ & EA11 $\rightarrow$ EA6 6 & $\mathrm{EA} 11 \rightarrow \mathrm{EA} 7$ & EA11 $\rightarrow$ EA8 & $\mathrm{EA} 11 \rightarrow \mathrm{EA} 9$ & EA11 $\rightarrow$ EA10 & & EA11 $\rightarrow$ EA 12 \\
\hline CG & & & $E A 11 \rightarrow E A 2$ & $E A 11 \rightarrow E A 3$ & $E A 11 \rightarrow E A 4$ & $E A 11 \rightarrow E A 5$ & $E A 11 \rightarrow E A 6$ & $\mathrm{EA} 11 \rightarrow \mathrm{EA} 7$ & EA11 $\rightarrow$ EA8 & $E A 11 \rightarrow E A 9$ & $\mathrm{EA} 11 \rightarrow \mathrm{EA} 10$ & & $\mathrm{EA} 11 \rightarrow \mathrm{EA} 12$ \\
\hline MU & & & & $E A 11 \rightarrow E A 3$ & EA11 $\rightarrow$ EA4 & $E A 11 \rightarrow E A 5$ & $E A 11 \rightarrow E A 6$ & $\mathrm{EA} 11 \rightarrow \mathrm{EA} 7$ & $E A 11 \rightarrow E A 8$ & EA11 $\rightarrow$ EA9 & $E A 11 \rightarrow E A 10$ & & $\mathrm{EA} 11 \rightarrow \mathrm{EA} 12$ \\
\hline PR & & & & EA11 $\rightarrow$ EA3 & & & & & EA11 $\rightarrow$ EA8 & & & & \\
\hline EN & \multirow{5}{*}{ EA12 } & EA12 $\rightarrow$ EA1 & & & & $\mathrm{EA12} \rightarrow \mathrm{EA5}$ & & $E A 12 \rightarrow E A 7$ & & & $E A 12 \rightarrow E A 10$ & & \\
\hline AA & & & & & & & & & EA12 $\rightarrow$ EA8 & & $\mathrm{EA} 12 \rightarrow \mathrm{EA} 10$ & EA12 $\rightarrow$ EA11 & \\
\hline CG & & & & & & EA12 $\rightarrow$ EA5 & $E A 12 \rightarrow E A 6$ & & & & $E A 12 \rightarrow E A 10$ & EA12 $\rightarrow$ EA11 & \\
\hline MU & & & & $\mathrm{EA} 12 \rightarrow \mathrm{EA} 3$ & & $E A 12 \rightarrow E A 5$ & & & & & & EA12 $\rightarrow E A 11$ & \\
\hline PR & & & & & & & & & & & & & \\
\hline
\end{tabular}

Tabla 6.4: Principales transiciones entre los elementos de las columnas analizadas. En negrita se marcan las transiciones significativas. El resto representan transiciones no significativas.

Se dispone en cuerpos de morfología plano-cóncava, con un techo más o menos plano de contacto gradual o neto con el suprayacente, y un muro cóncavo, neto y marcadamente erosivo (figuras 6.2A y B). A veces, a muro se observan pequeñas microformas o estructuras scour and fill. No se observa la presencia de fenómenos pedogenéticos a techo de estos paquetes. Tampoco se ha advertido su conexión con otros cuerpos canalizados. Así pues, según los modelos de arquitectura aluvial, los canales aislados (no coalescentes ni interconectados) intercalados en 
potentes series de finos indican un área deposicional con una alta subsidencia (ALLEN, 1978; BRIDGE Y LEEDER, 1979; HELLER Y PAOLA, 1996).

Litológicamente, el relleno del canal está constituido casi exclusivamente por el apilamiento cuerpos de areniscas con estratificación cruzada de gran escala, de forma que o bien predomina la de surco (As) o la planar (Ap), siendo muy escasos los canales donde coexisten ambos tipos de estratificación [elemento SB de MiALL (1985; 2006)]. Estas facies indican canales poco profundos, con carga de fondo arenosa en los cuales las dunas eran las formas de lecho predominantes. La ausencia de superficies de acreción lateral sugiere canales relativamente estables que han sido rellenados verticalmente más quelateralmente (HASZELDINE, 1984). La falta de superficies erosivas internas de importancia apunta a canales monoepisódicos (FRIEND et al., 1979).

En algunos canales se observa una disminución en el espesor de los sets hacia techo, registrando una progresiva somerización del canal debido a la colmatación por la agradación (CANT Y WALKER, 1978).

Como facies subordinadas, estos canales pueden presentar intercalados escasos niveles tabulares o lenticulares de espesor centimétricos de lutitas $\left(\mathrm{Lh}_{1}, \mathrm{Lh}_{2}, \mathrm{Lm} \mathrm{m}_{1}, \mathrm{y} \mathrm{Lm} 2\right)$, areniscas masivas $\left(\mathrm{Am}_{1}\right.$ y $\left.\mathrm{Am}_{2}\right)$, arenitas con laminación horizontal $\left(\mathrm{Ah}_{1}\right)$ y lumaquelas de conchas fragmentadas de moluscos (Qm) (tabla 6.2).

En este contexto, la sedimentación se produce predominantemente por tracción y/o decantación en el fondo de canales fluviales. Las areniscas con estratificación cruzada indican la migración de dunas en el fondo de canales. La facies As corresponde a dunas 3D de cresta sinuosa en corrientes efímeras (WILLIAMS, 1971) o permanentes (CANT Y WALKER, 1976). La facies Ap señala la presencia de dunas $2 \mathrm{D}$ de crestas rectas formadas por corrientes permanentes o efímeras (WILLIAMS, 1971), e indica un flujo con menor energía que la facies As (HARMS et al., 1975; HARMS, 1979). La facies $A h_{1}$ pone de manifiesto la migración de formas de lecho de poco relieve en el fondo de canales poco profundos (BEST Y BRIDGE, 1992) durante etapas con un régimen de flujo alto (MCKEE et al., 1967; LORENZY NADON, 2002) o etapas de inundación (CANT Y WALKER, 1976). Las areniscas masivas ( $\mathrm{Am}_{1}$ y Am 2 ) representan episodios de decantación en corrientes con gran carga arenosa (LOWE, 1988; ARNOTT Y HAND, 1989), que se originan durante etapas de inundación o grandes avenidas (MAIZELS, 1993). Las lutitas ( $\mathrm{Lh}_{1}, \mathrm{Lh} 2$, Lm1 y Lm2) registran la decantación de la carga lutítica en suspensión en el canal durante fases de baja competencia (COLEMAN et al., 1964; GIBLING et al., 1998). Las lumaquelas de moluscos (Qm) se interpretan como concentraciones sedimentarias relacionadas a depósitos de carga residual (lags) (HANLEY, 1988).

Así pues, aunque lo habitual eran unos paleocauces con un flujo relativamente estable, permitiendo la migración de dunas en el fondo del canal. Existen evidencias de etapas temporales en las cuales la velocidad de la corriente era muy fluctuante. El elemento EA1, en general, se interpreta como:

a) Canales acintados asociados a sistemas fluviales avulsivos (EA1 canal avulsión) (apartado 6.4) (KRAUS y Wells, 1999; PÉrEZ-ARLUCEA y SMith, 1999; SLINGERLAND y SMITH, 2004).

b) Canales distributarios en aparatos deltaicos lacustres y/o derrames deltaicos

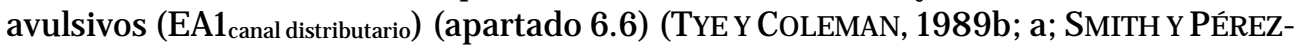
ARLUCEA, 1994; PÉREZ-ARLUCEA Y SMITH, 1999).

Existen otros canales, menos comunes, cuyo relleno está constituido por areniscas con estratificación cruzada épsilon (figura 6.2C) (ALLEN, 1963). Se identifican con el elemento arquitectural LA (MIALL, 1985; 2006), y caracterizan paleocauces de alta sinuosidad con preferencia a desarrollar procesos de acreción lateral debida a la migración de barras de meandro (PUIGDEFABREGAS, 1973; BRIDGE et al., 1986). La presencia de LA también sugiere canales móviles (FRIEND, 1983). 

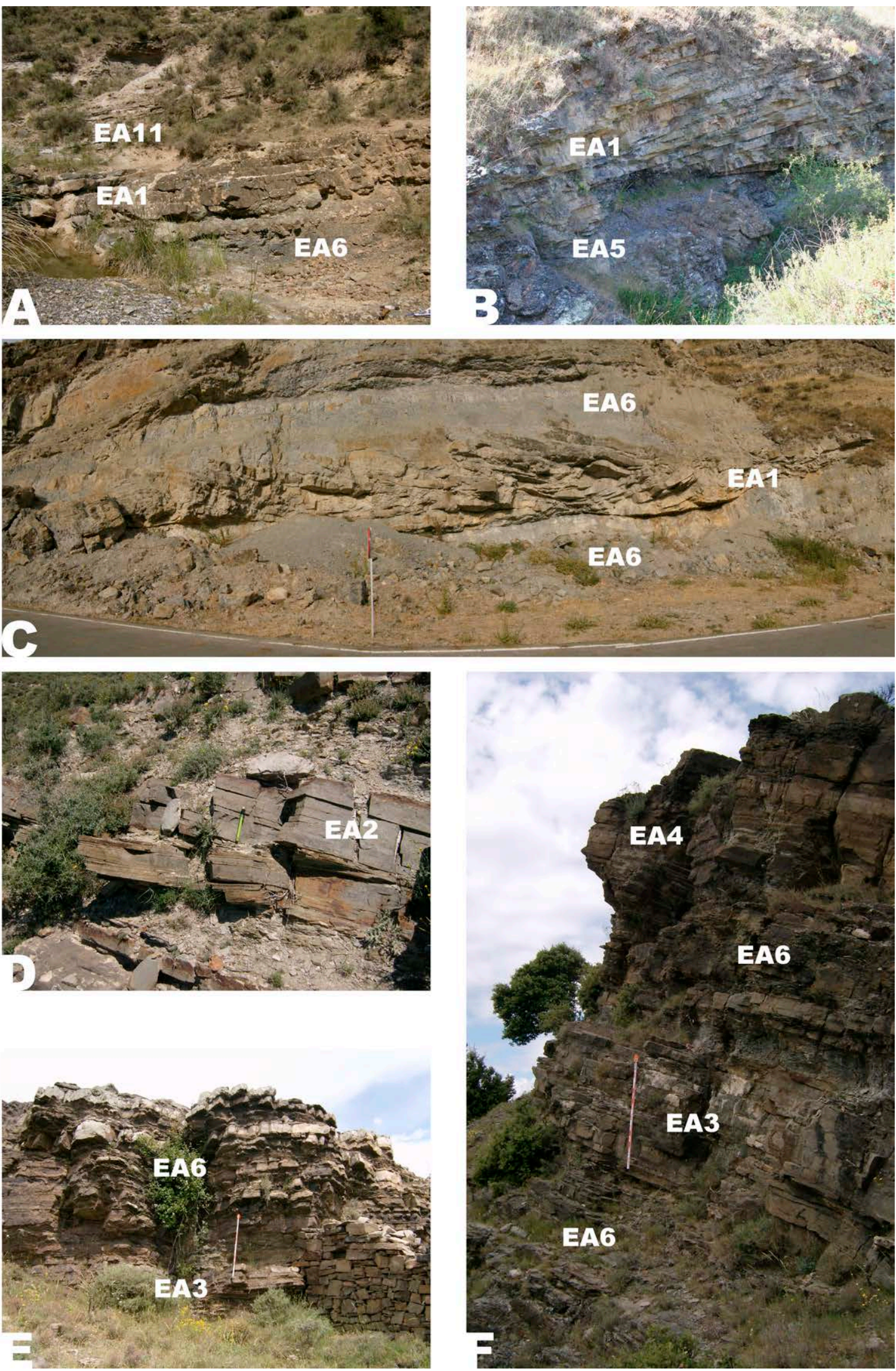

Figura 6.2: Principales elementos arquitectónicos presentes en el Grupo Enciso. A) EA1 en Ambas Aguas (tramo 59). B) EA1 a techo de la serie de Préjano (tramos 103-105). C) EA1 con acreción lateral en la zona de Rabanera-San Román de Cameros. D) Elemento de areniscas con laminación horizontal (EA2) en Ambas Aguas (tramo 406). E) Elementos deareniscas (EA3) y lutitas (EA6) en Enciso (tramos 817-820). F) Elementos de areniscas (EA3 y EA4) entre paquetes de lutitas EA6 en Enciso (tramos 684-689). 

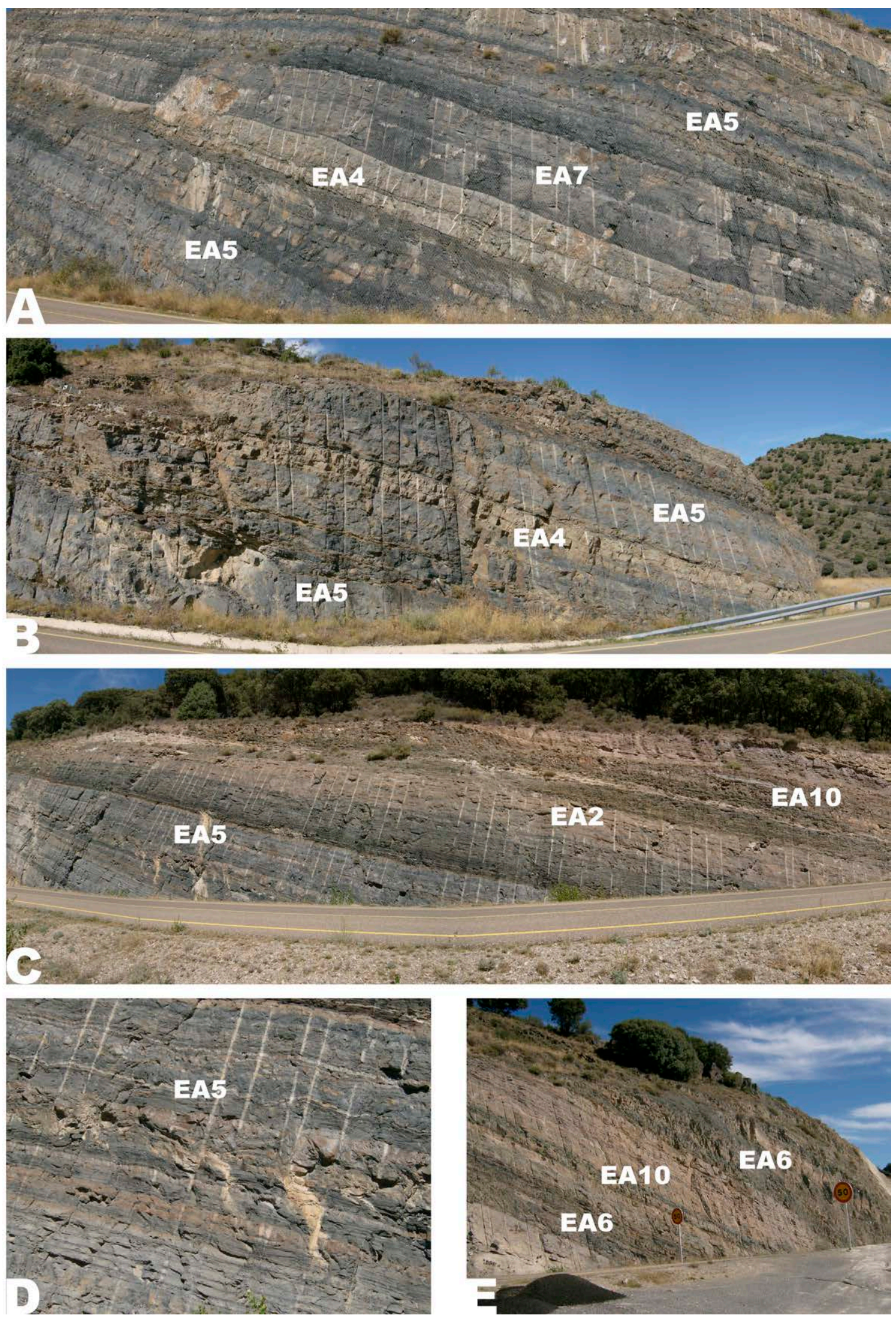

Figura 6.3: Principales elementos arquitectónicos presentes en el Grupo Enciso. A) Elementos de areniscas EA4 y de calizas EA7 entre paquetes de lutitas oscuras EA5 en Enciso (tramos 115125). B) Elementos de areniscas masivas entre EA5 en Enciso (tramos 144-148). C) Elementos EA5, EA2 y EA10 en Enciso (tramos 273-314). D) Detalle del elemento EA5 que aparece en la fotografía anterior. E) Elemento EA10 comprendido entre EA6 en Enciso (tramos 7-13). 

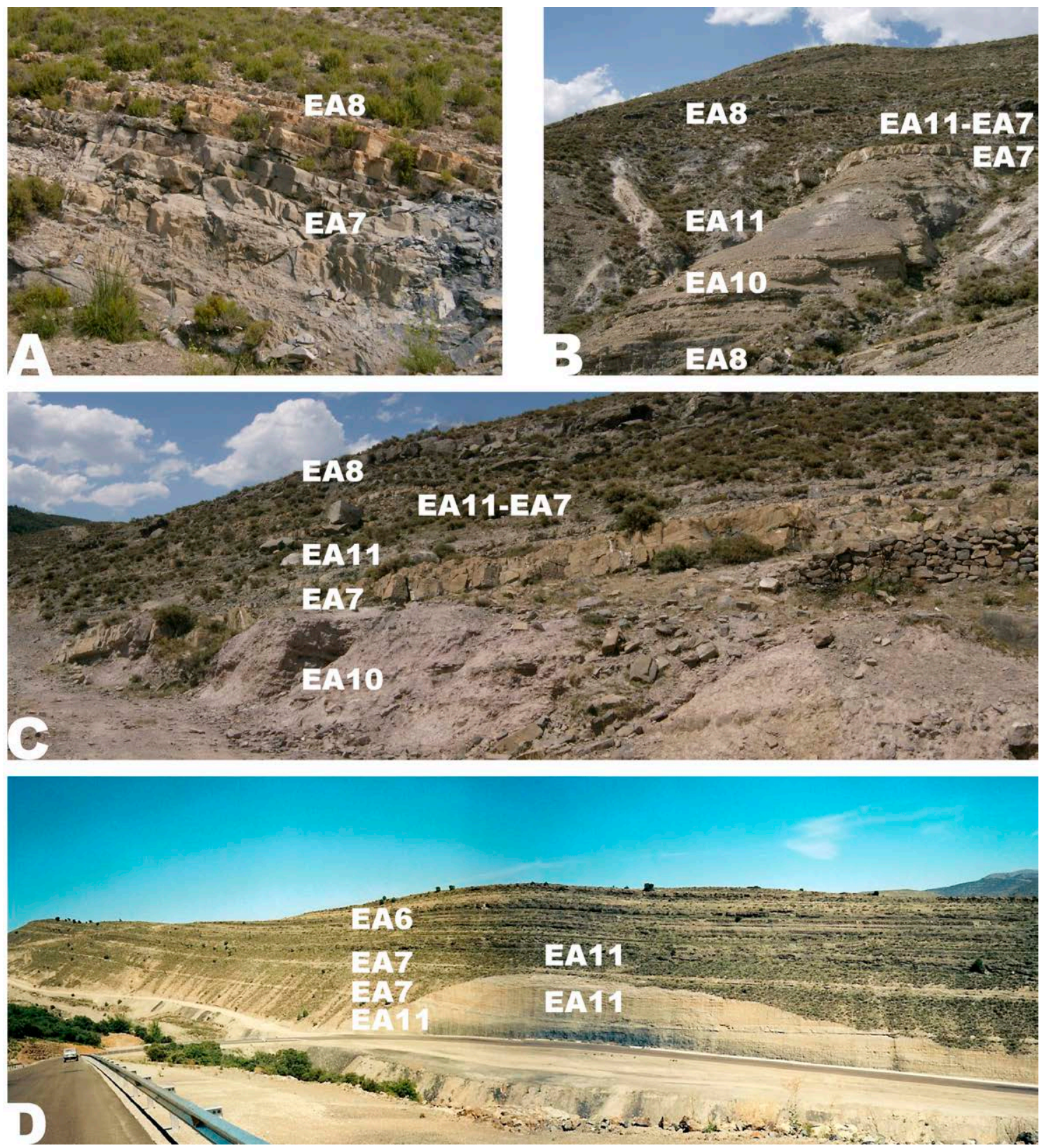

Figura 6.4: Principales elementos arquitectónicos presentes en el Grupo Enciso. A) Elementos de calizas en Cornago (tramo 70). B) Elementos de margas (EA11) y calizas (EA7 y EA8) con pasadas de EA10 en Ambas Aguas (tramos 124-169). C) Misma sección quela anterior tomada aproximadamente un kilómetro de distancia. El paquete naranja EA7 mantiene su continuidad lateral y potencia (tramo 176). D) Elemento de margas EA11 con intercalaciones de calizas EA7. A techo se observa un elemento EA6. Fotografía tomada en las inmediaciones del pueblo de Enciso (tramos 447-486).

Se han incluido en este elemento arquitectónico unos canales menores con características propias. Corresponde a los elementos HO y CS (MIALL, 2006). Este elemento arquitectónico está organizado en cuerpos lenticulares-acanalados de escaso relieve con base cóncava, neta y erosiva, y techo plano-convexo neto. Presentan una extensión lateral muy limitada $(<5 \mathrm{~m})$ y espesores de escala decimétrica (tabla 6.2), constituyendo micro y mesoformas (FRIEND, 1983; MIALL, 1985). El relleno del canal está formado por areniscas finas a medias masivas (facies Am1 y $\mathrm{Am}_{2}$ ), apareciendo siempre contenidos entre sedimentos siliciclásticos finos.

La falta de cicatrices internas y su aspecto homogéneo apuntan hacia un único evento sedimentario. Las total ausencia de estructuras deposicionales primarias indica una deposición rápida por decantación lo cual apunta a canales con flujos muy cargados en sedimento en relación 
a su competencia (BAKER et al., 1983; ALEXANDER et al., 2001). Este exceso resulta en la inhibición del desarrollo de formas delecho y, en consecuencia, de estructuras sedimentarias. Se interpretan como canales formados por el confinamiento de mantos de arroyada o derrames como consecuencia de la pérdida de competencia (DREYER, 1993; FISHER et al., 2007). En el presente trabajo, el término manto de arroyada hace referencia a cualquier manto de agua no canalizada moviéndose a favor de la pendiente, englobando los términos sheetflood, sheetwash y sheetflow (HoGG, 1982).

\subsubsection{EA2: cuerpos tabulares de areniscas con laminación horizontal}

Se identifica con el elemento arquitectónico LS y/o CS (MIALL, 1985; 2006). Está constituido por el apilamiento de estratos tabulares centimétricos-decimétricos de areniscas finas a medias. Conforman cuerpos tabulares o ligeramente lenticulares-cuneiformes, escasa abundancia (tabla 6.2), espesor decimétrico-métricos (tabla 6.2) y, gran continuidad lateral a escala del afloramiento (decamétrica-hectométrica) (figuras 6.2D y 6.3C). Puede exhibir muros ligeramente erosivos. En términos de abundancia es un elemento escaso $(<5 \%)$ en las cinco columnas estudiadas.

Las facies dominantes son las arenitas $\left(\mathrm{Ah}_{1}\right)$ y grauvacas $\left(\mathrm{Ah}_{2}\right)$ con laminación horizontal. Constituyen paquetes monótonos de $\mathrm{Ah}_{1}, \mathrm{Ah}_{2}$, o interestratificadas significativamente entre sí $\left(\mathrm{Ah}_{1} \leftrightarrow \mathrm{Ah}_{2}\right)$. Como facies subordinadas aparecen estratos poco potentes de areniscas masivas $\left(\mathrm{Am}_{1}\right.$ y $\left.\mathrm{Am}_{2}\right)$ y, en menor proporción, estratos de areniscas con rizaduras (Ar), lutitas ( $\mathrm{Lh}_{2}, \mathrm{Lm}_{1}$, $\mathrm{Lm}_{2}$ ), y lumaquelas de conchas de moluscos fracturadas (Qm) (tabla 6.2). Según su posición respecto al resto de elementos arquitectónicos, tanto el elemento como las facies asociadas tienen tres posibles interpretaciones.

a) Derrames - mantos de arroyada en un sistema fluvial avulsivo (EA2derrame) (apartado 6.4) (MCKeE et al., 1967; WiLliamS, 1971; FROSTICK Y REID, 1977; PÉREZ-ARLUCEA Y SMITH, 1999; FARRELL, 2001). En este ambiente sedimentario, los sedimentos se depositan fundamentalmente por tracción y/o decantación. La sedimentación originada por la migración de formas de lecho en aguas someras durante etapas de flujo alto viene determinada por la presencia de las facies $\mathrm{Ah}_{1}$ (BEST Y BRIDGE, 1992) y $\mathrm{Lh}_{2}$ (HARMS et al., 1975; SOUTHARD, 1991). Los períodos de flujo bajo quedan registrados por la deposición de las facies $\mathrm{Ah}_{2}$ (SMTTH, 1971; MCBRIDE et al., 1975) y Ar (HARMS et al., 1975; HARMS, 1979; ASHLEY, 1990). Las areniscas masivas (Am1 y $\mathrm{Am}_{2}$ ) sugieren la presencia de etapas de decantación en masa por una corriente con gran carga arenosa que sufre una desaceleración rápida (LOWE, 1988; ARNOTT Y HAND, 1989). También pueden representar a cualquiera de las otras facies arenosas que hayan sido homogeneizadas por bioturbación. Las lutitas masivas ( $\operatorname{Lm}_{1}$ y $\mathrm{Lm}_{2}$ ) registran etapas de decantación en una corriente con poca competencia (MIALL, 1977). Finalmente la facies Qm apunta a acumulaciones sedimentarias por procesos tractivos. En general, la ausencia de superficies de acreción lateral y el amalgamamiento de estratos en la vertical, sugieren una sedimentación por varios eventos. Cuando los cuerpos están formados únicamente por el apilamiento de estratos $\mathrm{Ah}_{1}$, la inexistencia de estructuras de tracción menos energéticas a techo indica flujos con una importante pérdida de competencia debido a la rápida caída del agua que no permiten, en última instancia, la formación de formas de lecho de baja velocidad (TUNBRIDGE, 1981). En el resto de los casos, la presencia de las otras facies apuntan a eventos con fluctuaciones en su competencia y velocidad.

b) Depósitos intralitorales lacustres sometidos a un intenso oleaje (EA2intralitoral) (apartado.6.5.1.2), bien sea debido a un flujo en capas tipo sheet flow (Ah 1 ) (CLIFTON, 1976) o a la decantación del material arenoso puesto en suspensión por un oleaje fuerte $\left(\mathrm{Ah}_{2}\right)$ (REINECK Y SiNGH, 1972; SINGH, 1972). Durante las etapas de oleaje normal, se produce la tracción y migración de rizaduras en un flujo oscilatorio (Ar) (HARMS, 1969; ALLEN, 1984; DUMAS et al., 2005), acumulación tractiva de caparazones de moluscos (Qm) (DE DECKKER, 1988b; TYE Y COLEMAN, 1989b; a; RENAUT y OWEN, 1991; PlaZiat y YounIS, 2005; MCGlue et al., 2010), y/o la decantación del material fino resuspendido por el oleaje ( $\left.\mathrm{Lh}_{2}\right)$ (REINECK Y SINGH, 
1972; DE RAAF et al., 1977). Las facies Am1 y Am² son el resultado de la resuspensión y decantación del material arenoso litoral (LICK, 1982; HILTON, 1985). También, en otros casos, se vincula a la acción bioturbadora de los organismos litorales. Por último, durante las etapas de poco oleaje se produce la decantación del material fino en suspensión $\left(\mathrm{Lm}_{1}\right.$ y $\left.\mathrm{Lm}_{2}\right)$. La textura de las areniscas, dominadas por arenitas, evidencia un medio intralitoral lo suficientemente energético como para eliminan los materiales finos resedimentándolos en los sectores más profundos de la cubeta lacustre.

c) Barras de desembocadura en deltas lacustres (EA2barra) (apartado 6.6.1) (TYE Y COLEMAN, 1989b; a; PÉREZ-ARLUCEA Y SMITH, 1999; FARRELL, 2001). Las facies principales y subordinadas serían el resultado de una sedimentación por tracción y decantación, que posteriormente son retrabajadas por el oleaje.

\subsubsection{EA3: cuerpos tabulares de areniscas con evidencias de oleaje}

Este elemento arquitectónico se organiza en cuerpos tabulares o cuneiformes relativamente potentes (11-488 cm), con una continuidad lateral de varias decenas a centenas de metros (figuras 6.2E y F). En términos de abundancia, varía entre frecuente (CG, MN y PR) y escaso (EN y AA) (tabla 6.2). Está constituido por el apilamiento de estratos centimétricosdecimétricos de la litofacies $\mathrm{Ar}$, que puede originar sucesiones monótonas o aparecer interestratificada con niveles poco potentes de areniscas masivas ( $\mathrm{Am}_{1}$ y Am2 $)$ y/o con laminación horizontal $\left(\mathrm{Ah}_{1} \mathrm{y} \mathrm{Ah}_{2}\right)$. De manera más esporádica se encuentran estratos centimétricos de lutitas $\left(L m_{2}, L h_{2}, L m_{1}, L h_{1}\right.$ y $\left.L g\right)$ o calizas arenosas (CAm). En función de sus relaciones verticales y laterales con el resto de elementos, se consideran dos interpretaciones:

a) Depósito intralitoral sometido a la actividad del oleaje (EA3intralitoral) (apartado 6.5.1.2), en el cual las intercalaciones de otras facies indican etapas breves de fluctuaciones en la energía del oleaje. La presencia de rizaduras de oscilación y laminación cruzada (Ar) indica una sedimentación por tracción y migración de rizaduras oscilatorias en aguas someras (zona intralitoral) bajo la acción del oleaje (HARMS, 1969; ALLEN, 1984; DUMAS et al., 2005). Las areniscas masivas ( $\mathrm{Am}_{1}$ y Am $\mathrm{Am}_{2}$ se consideran el producto final de la acción bioturbadora de los numerosos organismos que habitan en la zona litoral y/ o a la resuspensión y decantación del material arenoso litoral (LICK, 1982; HILTON, 1985). Las arenitas laminadas (Ah $)$ son el resultado de un flujo oscilatorio en capas (sheet flow) (CLIFTON, 1976), y las grauvacas laminadas $\left(\mathrm{Ah}_{2}\right)$ indican etapas de decantación del material resuspendido por el oleaje o las tormentas (REINECK Y SINGH, 1972; SINGH, 1972). La aparición ocasional de delgadas intercalaciones de lutitas $\left(\mathrm{Lm}_{1}, \mathrm{Lm}_{2}, \mathrm{Lh}_{1}\right.$ y $\left.\mathrm{Lh}_{2}\right)$ apunta a períodos de menor energía del oleaje que permite la decantación del material fino resuspendido en el litoral (REINECK Y SINGH, 1972; DE RAAF et al., 1977). Si este material lutítico sufre una emersión subaérea, se origina la facies Lg (REINECK Y SINGH, 1980). Finalmente, la facies CAm registra la precipitación y decantación de carbonatos en áreas lacustres litorales con un leve aporte por tracción de material arenoso (GLASS Y WILKINSON, 1980; ARRIBAS, 1986).

b) Barras de desembocadura en deltas lacustres (EA3barra) (apartado 6.6.1) (TYE Y COLEMAN, 1989b; a; SMITH Y PÉREZ-ARLUCEA, 1994; PÉREZ-ARLUCEA Y SMTTH, 1999). $\mathrm{Al}$ igual que ocurría en las barras EA2, las facies principales y subordinadas son el producto final del retrabajamiento por el oleaje de los niveles depositados inicialmente por tracción y/ o decantación.

\subsubsection{EA4: cuerpos tabulares de areniscas masivas}

Este elemento arquitectónico se compone de apilamientos verticales de estratos centimétricos-decimétricos (en menor medida un único estrato decimétrico-métrico) de areniscas finas-medias de naturaleza masiva $\left(\mathrm{Am}_{1} \mathrm{y} / \mathrm{o} \mathrm{Am}_{2}\right)$ que componen paquetes con espesores comprendidos entre $12-575 \mathrm{~cm}$ (tabla 6.2). Muestran una geometría tabular o levemente cuneiforme con extensiones laterales de decenas a centenares de metros. Muchas veces es posible observar su acuñamiento lateral con otros elementos (figuras 6.2F; 6.3A y B). Están 
limitados a techo y a base por superficies planas no erosivas, aunque a veces la base puede ser irregular o ligeramente erosiva. Su abundancia en las secciones varía entre escasa (AA y CG) y frecuente (EN, MNy PR) (tabla 6.2).

La mayoría de los elementos están compuestos por sucesiones monótonas de $\mathrm{Am}_{1} \mathrm{o} \mathrm{Am}_{2}$, o una combinación de ambos $\mathrm{Am}_{1} \leftrightarrow \mathrm{Am}_{2}$. De manera subordinada, aparecen niveles centimétricos de areniscas laminadas $\left(\mathrm{Ah}_{1}\right.$ y $\left.\mathrm{Ah}_{2}\right)$ y, más raramente, delgadas pasadas de lutitas masivas (LMm, Lg, $L m_{1}$ y $L m_{2}$ ) y/ o laminadas ( $L_{1}$ y $\left.L h_{2}\right)$, y calizas arenosas (CAm). La superficie plana y no erosiva del elemento es indicativa de flujos poco confinados.

En muchos casos, esta masividad $\left(\mathrm{Am}_{1}\right.$ y $\left.\mathrm{Am}_{2}\right)$ se puede vincular a la acción de organismos, ya que se observa gran bioturbación tanto en superficie como internamente. Si la masividad no se puede atribuir a la bioturbación, se interpretan como decantaciones en masa originadas por corrientes con una gran carga arenosa en suspensión que sufren una fuerte desaceleración (LOWE, 1988; ARNOTT Y HAND, 1989). En numerosos ejemplos, presentan a base estructuras de carga, sugiriendo un alto grado de aportes y de agradación. Esta desaceleración rápida de la corriente se produce cuando una corriente cargada de arena alcanza una masa de agua (barras de desembocadura o depósito litoral) o por la pérdida de competencia debido a la expansión de la corriente al llegar a un área extensa (derrame o manto de arroyada). Así pues, el elemento EA4 puede interpretarse como:

a) Barras de desembocadura en deltas lacustres (EA4barra) (apartado 6.6.1) (WELLS et al., 1994; PÉREZ-ARLUCEA Y SMTTH, 1999).

b) Depósitos que se originan por el retrabajamiento en la orla litoral lacustre de material arenoso de origen aluvial (EA4 eulitoral-EA4 intralitoral) (apartado 6.5.1) (MAIZELS, 1993). La sedimentación es básicamente por decantación, tanto en el sedimento arenoso $\left(\mathrm{Ah}_{1}\right.$ y Ah $\mathrm{A}_{2}$ ) (REINECK Y SINGH, 1972; SINGH, 1972) como lutítico (Lh1 y Lh L $_{2}$ (REINECK Y SINGH, 1972; DE RAAF et al., 1977). Los delgados niveles de CAm se producen por precipitación y decantación de carbonatos en áreas litorales durante etapas de menor entrada de siliciclásticos (GLASS Y WILKINSON, 1980; ARRIBAS, 1986). Cuando tiene lugar una caída del nivel del lago aparecen facies indicadoras de ciertas etapas de exposición subaérea como grietas de desecación (Lg) p marmorización (LMm).

c) Mantos de arroyada-derrames sobre la llanura de inundación en un sistema fluvial avulsivo (EA4derrame) (apartado 6.4) (FARRELL, 2001; SLINGERLAND Y SMITH, 2004). La sedimentación es una mezcla de tracción y decantación en el seno de una corriente somera. La migración de formas de lecho genera $\mathrm{Ah}_{1}$ (BEST Y BRIDGE, 1992), $\mathrm{Ah}_{2}$ (SMITH, 1971; MCBRIDE et al., 1975), Lh1 y Lh2 (HARMS et al., 1975; SOUTHARD, 1991). La decantación en una corriente poco competente es el mecanismo básico en la deposición de las lutitas masivas ( $\mathrm{Lm}_{1}$ y Lm 2 ) (MIALL, 1977), que pueden sufrir emersión subaérea (REINECK Y SiNGH, 1980). LMm y CAm no aparecen en este ambiente.

\subsubsection{EA5: cuerpos tabulares de lutitas oscuras}

Se pueden asimilar, con ciertas restricciones, al elemento arquitectónico FF (MIALL, 2006). En este elemento dominan claramente los depósitos lutíticos. Está constituido por una sucesión monótona delimolitas y/ o arcillolitas oscuras, organógenas, masivas y/ o con laminación horizontal. Su desarrollo relativo dentro del elemento es desigual, alternando entre elementos compuestos exclusivamente por lutitas laminadas ( $\left.\mathrm{Lh}_{1}\right)$, o masivas $\left(\mathrm{Lm}_{1}\right)$, o una interestratificación de ambas ( $\left.\mathrm{Lh}_{1} \leftrightarrow \mathrm{Lm}_{1}\right)$. Se caracteriza por conformar cuerpos tabulares de potencia desigual (15-2.947 cm) (tabla 6.2) y extensión lateral muy variable. El techo y la base varían entre planos e irregulares cuando se adaptan a la morfología de los niveles infra- y suprayacentes (figuras 6.2B y 6.3A, B, C y D). Su abundancia en las columnas varía entre escasa (AA), frecuente (CG), común (MN y PR) y abundante (EN) (tabla 6.2).

Sedimentológicamente, todas ellas exhiben las siguientes características destacables: los fósiles límnicos, el tamaño de grano fino y la casi total ausencia de fenómenos tractivos indican que han sido depositadas por fenómenos de decantación del material fino en suspensión en un 
cuerpo de aguas leníticas. La falta de estructuras típicas de emersión apunta a una masa de agua de carácter permanente. La práctica inexistencia de estructuras de oleaje revela una sedimentación por debajo del nivel de base del oleaje (sublitoral-abierto). La presencia de abundante materia orgánica y pirita pone de manifiesto etapas anóxicas, aunque la aparición de tramos bioturbados y moteados refleja ciertos períodos de oxigenación (etapas aeróbicas).

De manera esporádica y subordinada aparecen delgadas intercalaciones de otras facies lutíticas $\left(\mathrm{Lg}, \mathrm{Lm}_{2}\right.$ y $\left.\mathrm{Lh}_{2}\right)$. Esta sedimentación se ve recurrentemente alterada por la presencia de estratos centimétricos de litologías más groseras. En todos ellos, los techos y muros netos, planos-irregulares y no erosivos son indicativos de flujos no confinados. Las facies más típicas son areniscas con estratificación cruzada planar (Ap), masivas (Am1 y Am2), areniscas laminadas ( $\mathrm{Ah}_{1}$ y Ah2), areniscas con rizaduras (Ar). También muestran niveles de naturaleza carbonatada (Cm, Cn, CAm, Qm y Qo) (tabla 6.2). El tipo de sedimentación fundamental es por decantación de finos desde las zonas pelágicas que proceden de plumas de resuspensión, supraflujos o interflujos (STURM Y MATTER, 1978). El resto de niveles sugieren la entrada ocasional de flujos turbidíticos. Así, los delgados niveles de arenitas micáceas, tanto masivas ( $\mathrm{Am}_{1}$ ) como laminadas $\left(\mathrm{Ah}_{1}\right)$, se interpretan como turbiditas, y son muy parecidas a las existentes en el lago Malaui (OWEN Y CROSSLEY, 1989). Otros eventos de naturaleza turbidítica son registrados por las facies $\mathrm{Ah}_{2}$ (LOWE, 1982; LECLAIR Y ARNOTT, 2005), Am2 (MARTIN Y TURNER, 1998), Lm2 (PICKERING et al., 1986), Lh 2 (PASIERBIEWICZY KOTLARCZYK, 1997; LECLAIRY ARNOTT, 2005) y Qo (COHEN, 1987). La presencia de lumaquelas de moluscos litorales con conchas fracturadas $(\mathrm{Qm})$ sugiere niveles transportados desde las zonas más someras y concentrados en las aguas abiertas profundas (J OHNSONY GRAHAM, 2004). Las areniscas con rizaduras de oscilación (Ar) pone de manifiesto la acción del oleaje: en general, éste se restringe a la zona litoral, aunque durante las tormentas puede alcanzar el dominio sublitoral e incluso abierto (KOMAR, 1974; ALLEN, 1982a). Así pues, podrían corresponder a materiales depositados o modificados durante tormentas (MYROW Y SOUTHARD, 1996). Durante las etapas de bajo nivel del lago y escaso aporte de siliciclásticos, la orla profunda puede funcionar, temporalmente, como una zona somera permitiendo la precipitación y deposición de carbonatos (facies $\mathrm{Cm}$ y CAm), e incluso sufrir cierto grado de exposición subaérea (facies Lgy Cn).

Su interpretación está sujeta a ciertas consideraciones. En función de su espesor y extensión lateral se asumen tres interpretaciones:

a) Elementos de geometría tabular, potencia métrica-decamétrica y, gran extensión lateral (hectométricas-kilométricas). Este elemento aparece muy desarrollado en la parte inferior del Grupo Enciso en las columnas de Enciso y, en menor medida, Munilla. Representan la sedimentación acontecida en la zona abierta-sublitoral de sistemas lacustres de cierta profundidad (EA5abierto y EA5sublitoral) (apartado 6.5.1.1). Este elemento es característico de muchos lagos rift meromícticos donde reciben diferentes nombres: drape hemipelágico en el lago Malaui (WELLS et al., 1999), facies de relleno de cubeta en el lago Eduardo (MCGLUE et al., 2006) y sheet drape en el lago Tanganica (TIERCELIN et al., 1992; TIERCELIN et al., 1994). Si el lago está estratificado, este elemento representa la sedimentación acaecida en la parte más hipolimnética del lago. Sin embargo, pueden también aparecer en lagos polimícticos como los fangos cuencales del lago Turkana (COHEN, 1984; 1989a).

b) Elementos tabulares de potencia menor ( $1-6 \mathrm{~m}$ ) con una extensión lateral del orden de centenares hasta miles de metros. Se interpretan como depósitos abiertossublitorales en sistemas lacustres más someros que los anteriores (EA5abierto y EA5 sublitoral) (apartados 6.5.1.2 y 6.5.2.1). También corresponden a lagos-lagunas de menor entidad instalados en el cinturón de avulsión de sistemas fluviales donde funcionan como cubetas de decantación de los depósitos procedentes de las avulsiones (EA5palustre) (apartado 6.4), y/ o materiales del prodelta durante derrames deltaicos (EA5prodelta) (apartado 6.6.1) (HYNE et al., 1979a; SMITH Y PÉREZ-ARLUCEA, 1994; PÉREZ-ARLUCEA Y SMITH, 1999).

c) Elementos tabulares de poca potencia (desde unos pocos decímetros hasta tres metros) y escasa extensión lateral (desde unos pocos metros hasta varias decenas). Es frecuente que muestren una gran bioturbación y estén formados exclusivamente 
por la facies $\mathrm{Lm}_{1}$. Se interpretan como depósitos de abandono del canal (EA5abandono canal) (apartado 6.4) o depósitos de pantanos-ciénagas (EA5palustre) localizados en el cinturón de avulsión (apartado 6.4) o en la orla supralitoral de sistemas lacustres (apartado 6.5.1) (HyNE et al., 1979a; SMITH y PÉREZ-ARLUCEA, 1994; ASLAN Y AUTIN, 1999; PÉREZ-ARLUCEA Y SMITH, 1999).

\subsubsection{EA6: cuerpos tabulares de lutitas de colores variados}

Este elemento arquitectónico se identifica con el elemento FF (MIALL, 2006). Está compuesto dominantemente por facies lutíticas (limolitas y arcillolitas localmente algo arenosas) de color verde, gris, azul y rojo, tanto laminadas $\left(\mathrm{Lh}_{2}\right)$ como masivas $\left(\mathrm{Lm}_{2}\right)$, o una combinación de ambas $\left(\mathrm{Lm}_{2} \leftrightarrow \mathrm{Lh}_{2}\right)$. Ocasionalmente muestran evidencias de emersión, sobre todo, grietas de retracción (Lg). Afloran en paquetes tabulares con potencias muy dispares, desde 14 cm hasta 896 $\mathrm{cm}$, y extensiones laterales de varios centenares de metros (figuras 6.2A, C, E, F y 6.3E). Este elemento no aparece registrado en la columna de Préjano, variando su abundancia en el resto entre frecuente (EN, AA y CG) y común (MN) (tabla 6.2).

Este elemento engloba todos los depósitos finos, del cinturón de avulsión (EA6avulsión) (apartado 6.4), formados como consecuencia de la decantación bajo lámina de agua del material en suspensión procedente de las inundaciones y desbordamientos de los canales activos durante las avulsiones (SLINGERLAND Y SMITH, 2004; MIALL, 2006). Así, la laminación horizontal ( $\left.\mathrm{Lh}_{2}\right)$ se produce por la decantación selectiva en aguas prácticamente estancadas durante la inundación. Posteriormente, estos sedimentos son retrabajados por los organismos bioturbadores originando los tramos masivos moteados $\left(\mathrm{Lm}_{2}\right)$. Los períodos entre crecidas quedan registrados por la formación de paleosuelos ( $\mathrm{Lm}_{2}$ de colores rojos y anaranjados) y niveles con evidencias de emersión (Lg).

Entre los sedimentos finos afloran, de manera subordinada, niveles tabulares o lentejonares centimétricos a decimétricos de areniscas querepresentan la llegada de siliciclásticos más gruesos a la llanura de inundación durante las inundaciones. Se interpretan como depositados por eventos tractivos no canalizados en zonas proximales que se originan durante los desbordamientos del canal: Ah 1 (BEST Y BRIDGE, 1992), Ah2 (SMITH, 1971; MCBRIDE et al., 1975), Ar (HARMS et al., 1975; HARMS, 1979; ASHLEY, 1990), As (WILLIAMS, 1971; CANT Y WALKER, 1976), $\mathrm{Am}_{1}$ y Am 2 (LOWE, 1988; ARNOTT Y HAND, 1989). De manera esporádica pueden aparecer lentejones decimétricos de lutitas oscuras $\left(\mathrm{Lm}_{1}\right.$ y $\left.\mathrm{Lh}_{1}\right)$ o margas $(\mathrm{Mm})$, calizas $(\mathrm{Cm})$, calizas arenosas (CAm), y lumaquelas de ostrácodos (Qo) o de moluscos (Qm). Estas facies ponen de manifiesto la presencia de zonas distales deprimidas en la llanura de inundación donde se instauran lagos efímeros o zonas pantanosas, algunos con capacidad para producir carbonatos (TYE y COLEMAN, 1989b; a; SMITH y PÉREZ-ARLUCEA, 1994; PÉREZ-ARLUCEA Y SMITH, 1999).

Si la avulsión tiene lugar en las cercanías de un lago, este elemento se atribuye a los depósitos distales de la progradación del cinturón de avulsión sobre el lago, llegando a constituir el prodelta EA6prodelta (orla sublitoral-intralitoral) de un derrame deltaico (apartado 6.6.1) (SMTTH Y PÉREZ-ARLUCEA, 1994; PÉREZ-ARLUCEA Y SMITH, 1999). A veces, este elemento también corresponde a los depósitos de la orla sublitoral EA6sublitoral (apartado 6.5.1.1).

\subsubsection{EA7: cuerpos tabulares de calizas masivas}

Este elemento arquitectónico está formado por el apilamiento vertical de estratos centimétrico a decimétricos de calizas masivas $(\mathrm{Cm})$ y/ o calizas arenosas $(\mathrm{CAm})$. Constituyen paquetes monótonos de $\mathrm{Cm}$ o $\mathrm{CAm}$, o una combinación de ambos $(\mathrm{Cm} \leftrightarrow \mathrm{CAm})$. Los estratos son tabulares o ligeramente lenticulares y se agrupan componiendo cuerpos tabulares con potencias comprendidas entre $10 \mathrm{~cm}$ y $710 \mathrm{~cm}$ (tabla 6.2), de gran extensión lateral a escala del afloramiento (figuras 6.4A, B, C y D). Su abundancia en las secciones varía entre frecuente (EN, CG y PR) y común (AA y MN) (tabla 6.2).

En todos ellos, la ausencia de rasgos de exposición subaérea indica un ambiente de deposición subacuático permanente. Las calizas masivas $(\mathrm{Cm})$ se depositan en zonas donde se 
favorece la producción y deposición del carbonato en ausencia de aportes terrígenos significativos. Las calizas arenosas (CAm) se sedimentan durante etapas con cierto aporte de terrígenos y/ o en áreas cercanas a la entrada deríos en el lago (GLASSYWILKINSON, 1980; ARRIBAS, 1986). Las texturas mudstone-wackestone (dominantes) y la carencia de evidencias de tracción sugieren cuerpos de aguas con poca o nula energía.

De manera subordinada y aunque significativa, aparecen intercalados niveles poco potentes de otras litofacies. En general, como ya se ha comentado, este elemento se asocia a un ambiente poco energético donde domina la decantación del sedimento: las margas (Mm y LMm) en zonas ricas en producción de carbonatos y las lutitas ( $\mathrm{LMm}, \mathrm{Lm}_{1}$ y $\mathrm{Lh}_{1}$ ) durante etapas de entrada de siliciclásticos finos que no permiten o enmascaran la precipitación de carbonatos. De manera ocasional la acción del oleaje se manifiesta en la facies Ar (muchas de ellas calizas arenosas) y en algunas lumaquelas con evidencias de transporte: Qo (DE DECKKER, 1988a; ARP, 1995) y Qm (RENAUT Y OWEN, 1991; MCGLUE et al., 2010). La gran productividad característica de la zona litoral viene indicada por la presencia de acumulaciones biológicas que no muestran señales de transporte: Qo (CARBONEL et al., 1988) y Qm (DE BERNARDI et al., 1976). La facies Ch también sugiere etapas con cierta energía del medio donde se depositan como corrientes tractivas (ANADÓN et al., 1988; BELLANCA et al., 1992; PLATT, 1992). De manera ocasional aparecen algunos niveles de calizas con evidencias de emersión (Cn) que registrarían eventos temporales de caída del nivel de las aguas.

En función del contenido en fósiles límnicos (ostrácodos, gasterópodos, bivalvos, carófitas) se pueden diferenciar calizas con abundancia de bioclastos (mudstone-packstone) y calizas micríticas mudstone con un contenido en bioclastos nulo o escaso. En cada caso, según la facies predominante, se atribuye a orlas diferentes dentro de la cubeta lacustre.

a) El elemento EA7, dominado por la facies $\mathrm{Cm}$ rica en bioclastos, indica zonas con una gran productividad, típica dela orla intralitoral (EA7intralitoral) (apartados 6.5.2 y 6.5.3) (EUGSTER Y KELTS, 1983; ARP, 1995).

b) El elemento EA7, dominado por la facies $\mathrm{Cm}$ micrítica, con una menor abundancia en las series muestreadas, caracteriza la sedimentación en la zona abierta-sublitoral de lagos someros carbonatados (EA7abierto y EA7sublitoral) (apartado 6.5.3.1) (DEAN, 1981; GIERLOWSKI-KORDESCH, 2010).

c) Cuando este elemento aparece con poco desarrollo dentro de depósitos típicos del cinturón de avulsión, se interpreta como pequeños lagos o lagunas (EA7laguna) (apartado 6.4).

\subsubsection{EA8: cuerpos tabulares de calizas con evidencias de emersión}

Este elemento arquitectónico está constituido por el apilamiento vertical de estratos decimétricos de calizas masivas nodulares $(\mathrm{Cn})$, calizas masivas con grietas de retracción ( $\mathrm{Cg}$ ) y/o una combinación de ambas facies $(\mathrm{Cm} \leftrightarrow \mathrm{Cn})$. De manera más subordinada, pueden aparecer calizas masivas oscuras $(\mathrm{Cm})$ con un gran desarrollo de microtexturas indicativas de pedogénesis tales como trazas de raíces, marmorización, grietas circumgranulares, porosidad fenestral, etc. $(\mathrm{Cm} \leftrightarrow \mathrm{Cny} \mathrm{Cm} \leftrightarrow \mathrm{Cg})$. Forman paquetes de geometría tabular con espesores comprendidos entre 7-622 cm (tabla 6.2) con una continuidad lateral notable, de varios centenares de metros (sobre todo en Ambas Aguas y Enciso) (figuras 6.4A, B y C). En términos de abundancia varían entre escaso (EN y CG) y frecuente (AA, MN y PR).

Las facies Cg y Cn evidencian los procesos pedogenéticos que se desarrollan sobre los depósitos carbonatados previos $(\mathrm{Cm})$ expuestos de modo permanente o periódico a condiciones subaéreas debido a la caída del nivel de agua en la cubeta lacustre. Ambas, Cg y Cn, se originan debido a los procesos de desecación que terminan fisurando la roca (FREYTET, 1973; FREYTET Y VERRECCHIA, 2002). Estas facies representan los estadios palustres menos evolucionados y de menor intensidad (ALONSO-ZARZA Y WRIGHT, 2010) por lo que se considera que representan etapas palustres con poco tiempo de residencia. 
De manera más ocasional, aunque con significación, pueden aparecer otras litologías. Es habitual la presencia, a techo, de lumaquelas de ostrácodos (Qo) interpretadas como niveles de acumulación selectiva de los bioclastos transportados por el viento o lavados durante una etapa de aguas bajas (DE DECKKER, 1988a; b). Las lumaquelas de moluscos (Qm) se interpretan como acumulaciones por flotación depositados en la orla litoral emergida (PLAZIAT YYOUNIS, 2005). En esta zona emergida se produce la entrada ocasional de corrientes tractivas poco competentes que aportan siliciclásticos tanto arenosos (CAm) que pueden ser posteriormente retrabajados por el oleaje (Ar), como lutíticos (Mm, LMm, y las calizas margosas $\mathrm{Cm}$ ).

Este elemento EA8 se interpreta como depósitos palustres (lacustres emergidos) desarrollados en la orla eulitoral de sistemas lacustres de cierta entidad (EA8 eulitoral) (apartados 6.5.2 y 6.5.3). También se asignan a pequeños lagos (lagunas) carbonatadas temporales situados en los cinturones avulsivos (EA8laguna) (apartado 6.4).

\subsubsection{EA9: cuerpos tabulares de calizas con laminación horizontal}

Este elemento arquitectónico está organizado por el apilamiento de estratos de calizas oscuras organógenas con laminación horizontal (Ch) como facies más característica. Constituye paquetes tabulares de espesores comprendidos entre 10-446 cm (tabla 6.2), y extensión lateral de centenares de metros. Aparece formando paquetes constituidos únicamente por la facies $\mathrm{Ch} \mathrm{o}$, de manera más subordinada, interestratificado con margas (Ch $\leftrightarrow \mathrm{Mm})$ y/o calizas micríticas masivas $(\mathrm{Ch} \leftrightarrow \mathrm{Cm})$. Es un elemento escaso en casi todas las series (EN, AA, CGy MN) aunque en la columna de Préjano es abundante (tabla 6.2).

La ausencia de rasgos de exposición subaérea, la escasez de fósiles límnicos autóctonos, la escasa o nula bioturbación que permite la preservación de la laminación, la inexistencia de estructuras de oleaje o tracción y la abundancia de materia orgánica sugieren una sedimentación subacuática en aguas de cierta profundidad, poco oxigenadas y de baja energía. La laminación está formada por acumulaciones de ostrácodos de origen mecánico, aunque la presencia de caparazones enteros y/ o aplastados sugiere un transporte mínimo desde las zonas más someras por corrientes tractivas poco energéticas (ANADÓN et al., 1988; BELLANCA et al., 1992; PLATT, 1992). Se asemejan en algunos aspectos a las acumulaciones que se originan por el lavado de los finos en la zona sublitoral del lago Turkana (COHEN, 1987).

Se interpreta como un depósito abierto-sublitoral típico de lagos carbonatados

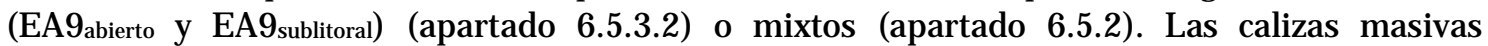
micríticas $(\mathrm{Cm})$ con un escaso o nulo contenido en bioclastos límnicos sugieren una sedimentación más profunda y aislada de los aportes siliciclásticos procedentes del litoral. Las margas $(\mathrm{Mm})$ se depositan por decantación de materiales siliciclásticos finos en suspensión en la orla abierta (GIERLOWSKI-KORDESCH, 2010). La ausencia de fósiles límnicos en ambas facies indica depósitos alejados de las zonas litorales.

También, en ciertas ocasiones, puede representar la sedimentación acontecida en lagos implantados en el cinturón de avusión (EA9laguna) (apartado 6.4).

\subsubsection{EA10: cuerpos tabulares de margas y/o lutitas con evidencias de emersión}

Este elemento arquitectónico está constituido por margas-lutitas poco competentes de aspecto masivo y/o laminado (facies LMm) de colores rojizos, anaranjados o púrpuras. Se disponen en cuerpos de geometría tabular de espesores comprendidos entre 14 y $547 \mathrm{~cm}$ (tabla 6.2). Se extienden lateralmente centenares de metros sin apreciarse cambios en su litología o potencia. En ciertas columnas es habitual que exhiban un cambio lateral y vertical con el elemento EA11. El techo y el muro son netos o graduales acomodándose a la topografía preexistente. Es un elemento arquitectónico, que en términos de abundancia, varía entre escasa $(\mathrm{MN})$, frecuente ( $\mathrm{EN}$ y AA) y común (CG). No aparece en la columna de Préjano (tabla 6.2).

Litológicamente, aparte de la facies $\mathrm{LMm}$ aparecen intercalados significativamente niveles delgados de calizas masivas $(\mathrm{Cm})$, calizas nodulares $(\mathrm{Cn})$, lumaquelas de ostrácodos (Qo) 
y moluscos (Qm), calizas arenosas (CAm), margas (Mm), areniscas (Ar, $\mathrm{Ah}_{2}$ y Am 2$)$ y lutitas $\mathrm{Lm}_{1}$ (tabla 6.2).

La facies dominante (LMm) se atribuyen a la decantación del material siliciclástico fino en una masa de agua rica en carbonatos, bien oxigenada y periódicamente expuesta subaéreamente. Las calizas ( $\mathrm{Cm}$ y $\mathrm{Cn}$ ) representan etapas de producción de carbonatos en zonas someras con un nulo aporte de siliclásticos finos y sometidas a emersiones. En ocasiones, la precipitación de los carbonatos se acompaña de la decantación de siliciclásticos finos $(\mathrm{Mm})$ o gruesos (CAm), así como de eventos turbidíticos poco importantes: Ah2 (LOWE, 1982; BAAS,

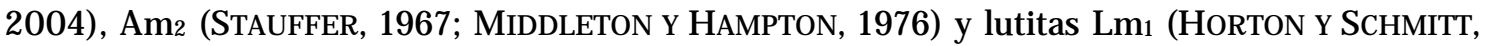
1996), que pueden ser modificados posteriormente por el oleaje (Ar). Las lumaquelas (Qo y Qm) se interpretan como niveles de acumulación durante las regresiones (DE DECKKER, 1988a; b).

Este elemento atribuye a depósitos palustres sensu stricto localizados en la orla supralitoral de sistemas lacustres (EA10 palustre). Facies semejantes a estas en el registro geológico se interpretan de manera análoga (llanuras palustres) (LUZÓN et al., 2002; MELÉNDEZ et al., 2009).

También se puede interpretar como como el resultado de los procesos pedogenéticos sobre el elemento arquitectónico EA11 en la zona eulitoral emergida del lago (EA10 eulitoral) (HUBERT et al., 1976; PlATT, 1989b).

\subsubsection{EA11: cuerpos tabulares de margas}

Este elemento arquitectónico es muy común en todas las columnas levantadas (excepto Préjano), pudiendo presentar sólo ligeras diferencias en las facies subordinadas que presenta. Su abundancia y gran desarrollo hace que sea el elemento más representativo del sistema lacustre carbonatado, sobre todo en la mita superior del Grupo Enciso. Su gran persistencia vertical y lateral sugiere unas condiciones estables durante gran parte del espectro temporal que registran. A grandes rasgos, en las columnas de Enciso y Ambas Aguas, su mayor desarrollo se observa en las "facies de las margas con ostrácodos" (TISCHER, 1966b) y en la unidad $C_{13}^{4 m}$ (CÁMARA-RUPELO Y DURÁNTEZ-ROMERO, 1981). En la zona de Munilla y Cornago presenta un menor desarrollo donde se denomina unidad $C_{12-13}^{4}$ (DURÁNTEZ et al., 1982), estando prácticamente ausente en Préjano.

Estos paquetes están compuestos dominantemente por margas masivas y/o laminadas $(\mathrm{Mm})$ dispuestas en cuerpos tabulares con potencias variables comprendidas entre $11-1.883 \mathrm{~cm}$ ) (tabla 6.2). Los elementos de orden métrico, se extienden lateralmente desde unos centenares de metros hasta varios kilómetros con variaciones mínimas del espesor. Su abundancia está comprendida entre escasa (PR), frecuente (MN), común (ENy CG), y muy abundante (AA) (tabla 6.2). Como en general las margas son poco competentes, el techo y el muro varían desde planos (netos y graduales) hasta irregulares cuando se amoldan a la morfología de los elementos supra e infrayacentes, en este caso con contactos siempre netos. Estos mantos están formados por un único nivel de margas de aspecto incompetente o bien por el apilamiento vertical de estratos decimétricos a métricos cuando presentan un aspecto más consolidado. Se repite de forma monótona en la vertical y no exhibe una organización secuencial precisa y reconocible en campo.

El contenido en fósiles límnicos y la ausencia de estructuras tractivas o de emersión en las margas (Mm) indica una sedimentación en zonas lacustres abiertas-sublitorales (EA11abierto y EA11 sublitoral) (apartado 6.5.2.3) por debajo del nivel del oleaje, debida a la decantación de materiales siliciclásticos finos en suspensión dentro de una columna de agua rica en carbonatos (STREET-PERROTT et al., 1993; HOLMES et al., 1995; COLMAN, 2006; DEAN et al., 2006; GIERLOWSKIKORDESCH, 2010).

Este elemento muestra intercalaciones muy significativas de estratos poco potentes de calizas masivas $(\mathrm{Cm})$ y lumaquelas de ostrácodos (Qo). Las calizas oscuras organógenas ( $\mathrm{Mm} \leftrightarrow$ $\mathrm{Cm}$ ) representan etapas con ausencia de aportes siliciclásticos finos en la cubeta que favorecen la producción y sedimentación de los carbonatos puros. Alternativamente, algunos niveles pueden 
representar depósitos litorales redepositados en la zona más profunda del lago (LUDLAM, 1974; DEAN Y FOUCH, 1983; LAST, 1993a). Es también muy frecuente que estas margas presenten intercalados abundante niveles milimétricos o centimétricos de lumaquelas de ostrácodos $(\mathrm{Mm} \leftrightarrow \mathrm{Qo})$ que corresponden a acumulaciones tractivas postmortem, y constituyen un elemento característico de este elemento arquitectónico.

De manera más ocasional (con menor significación) afloran niveles aislados tabulares o levemente cuneiforme de poca continuidad lateral de lumaquelas de moluscos $(\mathrm{Qm})$, calizas con evidencias de emersión ( $\mathrm{Cg}$ y $\mathrm{Cn}$ ), lutitas-margas rojizas (LMm), calizas con laminación horizontal (Ch), calizas arenosas (CAm), areniscas masivas o con laminación horizontal (Am1 y $\left.A h_{1}\right)$ y lutitas $\left(L m_{1}, L m_{2}, L h_{1}\right.$ y $\left.L h_{2}\right)$.

Las conchas de las lumaquelas de moluscos (Qm) están en general muy fragmentadas, en algunos casos no se reconocen los elementos, por lo cual se interpretan como acumulaciones sedimentarias transportadas por tracción desde las zonas litorales hasta la zona profunda (J OHNSONY GRAHAM, 2004). Los delgados estratos de calizas y margas con evidencias de emersión (Cg, Cn y LMm) testifican los períodos, esporádicos, de fuertes caídas del nivel de lago que se extienden hasta los sectores más profundos de la cubeta (ALONSO-ZARZA Y WRIGHT, 2010). Las calizas con laminación horizontal (Ch) corresponden a sedimentos aguas abiertas-sublitorales depositados durante etapas de escasa bioturbación y nula entrada de finos siliciclásticos (GIERLOWSKI-KORDESCH, 2010). En el extremo opuesto, las lutitas $\left(\mathrm{Lm}_{1}, \mathrm{Lm}_{2}, \mathrm{Lh}_{1}\right.$ y $\left.L \mathrm{~h}_{2}\right)$ son el resultado de fases con un elevado aporte de finos siliciclásticos sin precipitación de carbonatos y/ o episodios turbidíticos (HORTONY SCHMITT, 1996; PASIERBIEWICZY KOTLARCZYK, 1997; LECLAIR Y ARNOTT, 2005). La caliza arenosa (CAm) prueba la entrada ocasional de siliciclásticos gruesos procedentes de la zona litoral (GLASS Y WILKINSON, 1980; ARRIBAS, 1986). Cuando estos aportes de arenas son masivos se producen eventos turbidíticos que quedan registrados por niveles tabulares poco potentes de areniscas de aspecto masivo Am 1 (STAUFFER, 1967; MIDDLETON Y HAMPTON, 1976) o con laminación horizontal Ah1 (LOWE, 1982; EYLES et al., 1987; BAAS, 2004).

Cuando este elemento arquitectónico muestra una composición de facies más simple, así como un espesor y extensión lateral mucho menor, se interpreta como depósitos de pequeños lagos instaurados en el cinturón de avulsión (EA11 laguna) (apartado 6.4) (FRIENDY MOODY-STUART, 1970).

\subsubsection{EA12: cuerpos tabulares de lumaquelas}

Este elemento arquitectónico está constituido por el apilamiento vertical de niveles centimétrico a decimétricos de lumaquelas de ostrácodos (Qo) y/ o lumaquelas de moluscos (Qm). Constituyen paquetes monótonos de Qo o Qm, pero nunca una combinación de ambos. Los estratos son tabulares o ligeramente lenticulares y se apilan componiendo cuerpos tabulares con espesores comprendidos entre $17 \mathrm{~cm}$ y $130 \mathrm{~cm}$ (tabla 6.2), de gran extensión lateral a escala del afloramiento. Su abundancia en las secciones es siempre escasa (EN, AA, CG y MN) estando ausente en la columna de Préjano (tabla 6.2).

De manera subordinada y significativa, aparecen intercalados niveles poco potentes de calizas (Cm) y margas (Mm y LMm).

Debido al espesor de este elemento y a su continuidad lateral se interpreta, básicamente, como acumulaciones sedimentarias en la zona litoral (EA12 litoral) (apartado 6.5.1.1 y ) (DE DECKKER, 1988b; a; RENAUT Y OWEN, 1991; ARP, 1995; MCGLUE et al., 2010), sublitoral (EA12 sublitoral) (apartado 6.5.1.1) (COHEN, 1989b) o abierta (EA12abierto) (apartados 6.5.1.1y 6.5.2.3) (COHEN, 1987; J OHNSONY GRAHAM, 2004).

\subsection{INTRODUCCIÓN A LOS MODELOS SEDIMENTARIOS}

Una vez formalizados los elementos y basándose en las transiciones significativas encontradas en el análisis markoviano, se procede a determinar los medios sedimentarios más plausibles que permitan explicar todas las transiciones observadas (tanto significativas como no). 
Las transiciones significativas ponen de manifiesto las relaciones entre elementos (ambientes) que ocurren de manera recurrente (no aleatoria). En teoría, este análisis permite deducir las pautas secuenciales lineales entre los elementos constituyentes de un determinado medio sedimentario. Por desgracia no es así, quedando muchas secuencias incompletas y, por este motivo, se utilizan las transiciones no significativas para rellenar los vacíos existentes. Estas son de gran utilidad a la hora de establecer el modelo final ya que informan de multitud de procesos de carácter más ocasional. Al tener en cuenta todas las transiciones, se deduce que su ordenación no es el resultado de una evolución secuencial y lineal de ambientes, sino más bien el producto de ciclos repetitivos y cambios acusados no lineales. Este hecho sugiere que los sistemas lacustres estudiados presentaron grandes fluctuaciones en el nivel de sus aguas, lo cuales originaron una gran variedad de transiciones resultado de una evolución compleja.

A efectos de claridad, los diversos medios sedimentarios se han ilustrado en bloques diagramas sintetizando todos los depósitos presentes en el Grupo Enciso. Para un mejor entendimiento de las relaciones verticales ligadas a las fluctuaciones de la lámina de agua, en cada bloque diagrama se ha proyectado una regresión - transgresión gradual (mitad superior) así como una serie de transgresiones-regresiones bruscas abarcando una gran extensión (mitad inferior). Estos modelos son simplificaciones descriptivas, gráficas y matemáticas que relacionan algunos conjuntos de procesos de transporte, deposición y diagenético a un depósito concreto. Se utilizan como herramientas que ayudan a conceptuar la evolución de un medio sedimentario y crear su secuencia sedimentaria teórica. La heterogeneidad de los lagos, tanto en el tiempo como en el espacio, hace que este proceso de simplificación sea bastante difícil. Así pues, el modelo es una síntesis derivada de la información disponible sobre un medio concreto. Estos modelos además han de estar bien documentados con sistemas tanto actuales como fósiles, lo cual no siempre es posible. En general, los modelos representan unos puntos extremos de una amplia gama de posibilidades. Por desgracia, en la naturaleza existen todos los posibles casos intermedios entre estos modelos finales o extremos.

Lo primero que llama la atención en las columnas estudiadas es la evidente alternancia entre paquetes siliciclásticos y carbonatados. Ambos muestran una gran continuidad lateral, y se extienden durante varios kilómetros con variaciones mínimas en el espesor. Los paquetes siliciclásticos están dominados por los materiales lutíticos (tabla 6.1). La columna de Enciso presenta una relación lutitas/ areniscas de 3,5 (47,7\% y 13,8\%), la columna de Ambas Aguas 2,0 (18,6\% y 9,2\%), la columna de Cornago 3,0 (46,3\% y 15,3\%), la columna de Munilla 1,4 (33,3\% y $23,6 \%)$ y, la columna de Préjano 1,1 (21,4\% y 19,0\%). Lateralmente aparecen numerosos canales acintados, generalmente, a techo de la secuencia. Constituyen sucesiones con tendencia granocreciente, y con rápidos cambios de facies laterales y verticales, indicando multitud de ambientes deposicionales. Los paquetes carbonatados constituyen una parte importante del registro total (tabla 6.1): 72,2\% en Ambas Aguas, 59,6\% en Préjano, 43,1\& en Munilla, 38,4\% en Cornago y Enciso. Se pueden seguir lateralmente durante kilómetros sin que aparezcan intercalados canales fluviales, aunque si algunos cuerpos deltaicos siliciclásticos. La presencia de carbonatos con cierto contenido en detríticos (sobre todo cuarzo y mica) así como de delgados niveles siliciclásticos intercalados entre los carbonatos sugieren aportes por flujos episódicos no canalizados.

De manera general, estos dispositivos se interpretan como sistemas lacustres poco profundos y de gran extensión. Periódicamente recibía los aportes siliciclástico derivados de avulsiones cercanas, que modificaban de manera importante la configuración de la cubeta lacustre. En la actualidad, cuando estas avulsiones se producen en las cercanías de grandes lagos, el cinturón de avulsión programa sobre el lago cubriendo y haciendo desaparecer extensas áreas costeras lacustres. La histórica avulsión de 1885 del Río Saskatchewan en las Cumberland Marshes [figura 2 de SMITH Y PÉREZ-ARLUCEA (2004)] transformó unos $8.000 \mathrm{~km}^{2}$ de áreas lacustres en un complejo sistema anastomosado. Lo mismo ocurrió durante la avulsión del Río Yangtze sobre el Lago Dongting [figura 7 de WANG et al. (2005)] o las avulsiones del Río Atchafalaya sobre los lagos Grand y Six Mile (SMITH et al., 1986b; a). 


\subsection{MODELO SEDIMENTARIO FLUVIAL AVULSIVO}

En este apartado se describen todos aquellos ambientes presentes en el cinturón de avulsión (depósitos aluviales). Son muy abundantes en la parte alta del Grupo Enciso. La avulsión es el proceso por el cual el flujo de un cauce fluvial establecido se desvía por un nuevo curso (canal de avulsión) sobre la llanura de inundación colindante (SLINGERLAND Y SMITH, 2004). No constituye un evento deposicional aislado, más bien, es un fenómeno frecuente e iterativo con períodos interavulsivos que varían desde pocas decenas hasta miles de años (STOUTHAMER Y BERENDSEN, 2001). Esto hace que las avulsiones, hoy en día, se consideren como unos procesos fundamentales en la construcción de llanuras de inundación agradantes (BRIDGE Y LEEDER, 1979; MACKEY Y BRIDGE, 1995; HELLER Y PAOLA, 1996), originando depósitos con una gran continuidad lateral en el registro geológico. Por ejemplo, la citada avulsión del Río Saskatchewan originó un cinturón de $60 \mathrm{~km}$ de longitud de depósitos predominantemente lutíticos entre los cuales aparecen incluidos cuerpos arenosos de tamaño y geometría variable (PÉREZ-ARLUCEA Y SMITH, 1999).

Los depósitos aluviales con una parte predominante de su sedimentación debida a fenómenos de avulsión se distinguen, en general, por los siguientes caracteres (KRAUS Y WELLS, 1999; SLINGERLAND Y SMITH, 2004) (figura 6.5):

a) Las avulsiones son procesos sedimentarios intermitentes en el tiempo, pudiendo cubrir un amplio espectro temporal, pero que se significan por mostrar un inicio y un final. Es frecuente que estos dos momentos queden registrados en el sedimento de tal modo que la secuencia de avulsión aparece contenida entre dos capas límite (bounding strata) a techo y muro. En algunos casos, esta intermitencia temporal permite que grandes áreas de la llanura (o cubeta) de inundación queden aisladas de las avenidas durante largos periodos de tiempo, favoreciendo el desarrollo de niveles u horizontes edáficos a techo y muro de la secuencia de avulsión (KRAUS, 1996; KRAUS Y WELLS, 1999). En otros casos, estas capas límite están formadas depósitos ricos en materia orgánica: peats en las Cumberlan Marshes (SMITH Y PÉREZ-ARLUCEA, 1994; PÉREZ-ARLUCEA Y SMITH, 1999; FARRELL, 2001) o carbón en la Formación Dakota (KIRSCHBAUMY MCCABE, 1992). Sin embargo, no siempre se forman o conservan estas capas límite en el registro geológico, sobre todo cuando la avulsión alcanza un lago (MOROZOVA Y SMITH, 1999). En el Grupo Enciso, el inicio y final de la avulsión suele estar representado por delgados depósitos palustres (EA5 palustre y EA10 palustre), lacustres eulitorales (EA8 eulitoral, EA10 eulitoral y EA4 eulitoral), así como niveles edáficos desarrollados a techo de derrames (EA2derrame, EA3derrame y EA4derrame).

b) Las lutitas (EA6avulsión) son el sedimento predominante de las avulsiones depositándose en las áreas deprimidas existentes entre los canales. En el cinturón de avulsión aparecen pequeños lagos o lagunas (EA11 laguna, EA7laguna, EA8laguna y EA9laguna), humedales o pantanos (EA5palustre), etc., componiendo un mosaico complejo de subambientes con unas características sedimentológicas propias. Además, es bastante frecuente que estos depósitos, en conjunto, se ordenen en secuencias granocrecientes hacia techo a medida que la avulsión progresa como ocurre en las Cumberland Marshes (SMTtH Y PÉREZ-ARLUCEA, 1994; PÉREZ-ARLUCEA Y SMITH, 1999; FARRELL, 2001; SMITH y PÉREZ-ARLUCEA, 2004) o en la cuenca Atchafalaya (TyE Y COLEMAN, 1989b; a).

c) Mantos de arenisca de poca potencia que representan derrames (EA2derrame y EA4derrame) (PÉREZ-ARLUCEA Y SMITH, 1999; FARRELL, 2001).

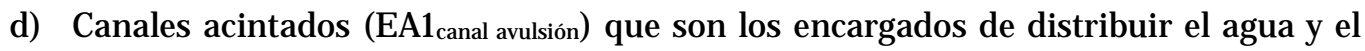
sedimento por todo el complejo. Suelen aparecer intercalados entre los sedimentos finos.

Así pues, según lo expuesto anteriormente, una sucesión teórica de los elementos de un cinturón de avulsión sería de la forma:

EA6avulsión $\rightarrow($ EA2 derrame y/ o EA4derrame $) \rightarrow$ EA1 avulsión 


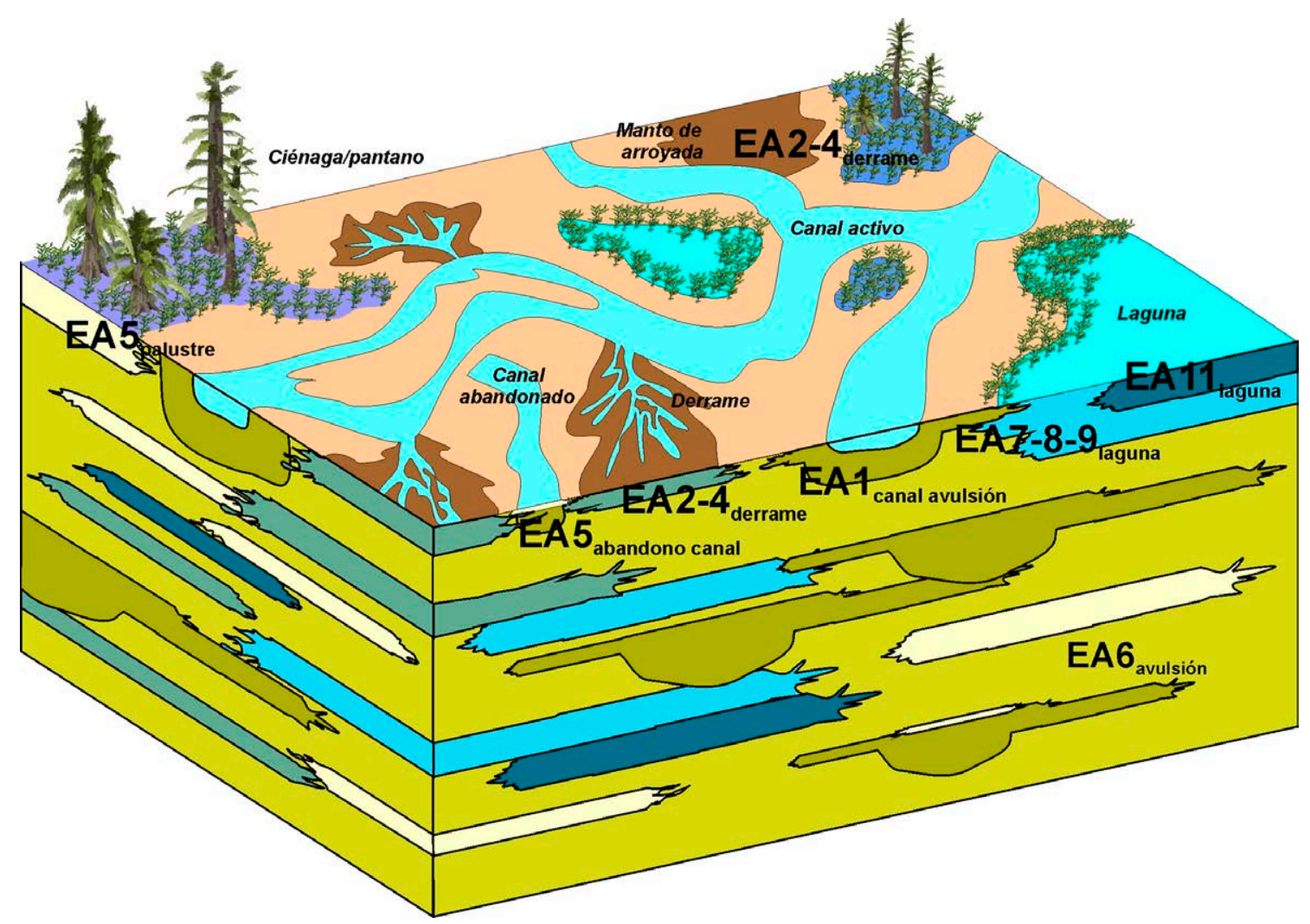

Figura 6.5: Bloque diagrama teórico del medio sedimentario constituido por el cinturón de avulsión del sistema fluvial.

Esta secuencia es la más típica, y correspondea una avulsión transicional (J ONESY HAJ EK, 2007). En ocasiones, la avulsión se produce de manera abrupta y se caracteriza por la aparición del canal directamente sobre la llanura deinundación (J ONESY HAJEK, 2007). Su secuencia teórica sería:

EA6avulsión $\rightarrow$ EA1 lavulsión.

A grandes rasgos, a partir de las transiciones significativas, se puede afirmar que ambos tipos de avulsiones están presentes en cuatro de las cinco columnas muestreadas del Grupo Enciso:

$\begin{array}{ll}\text { Enciso } & \text { EA1 } \rightarrow \text { EA6 } \rightarrow \text { EA2 } \\ & \text { EA1 } \rightarrow \text { EA6 } \\ \text { EAmbas Aguas } \rightarrow \text { EA6 } \leftrightarrow \text { EA4 } \\ & \text { EA6 } \leftrightarrow \text { EA2 } \\ & \text { EA6 } \leftrightarrow \text { EA2 } \leftrightarrow \text { EA4 } \rightarrow \text { EA1 } \\ & \text { EA6 } \leftrightarrow \text { EA4 } \rightarrow \text { EA1 } \\ & \text { EA6 } \leftrightarrow \text { EA1 } \\ \text { Cornago } & \text { EA6 } \leftrightarrow \text { EA2 } \leftarrow \text { EA1 } \\ & \text { EA6 } \leftrightarrow \text { EA4 } \\ \text { Munilla } & \text { EA1 } \rightarrow \text { EA6 } \rightarrow \text { EA2 } \rightarrow \text { EA4 } \\ & \text { EA1 } \rightarrow \text { EA6 } \\ & \text { EA1 } \rightarrow \text { EA6 } \leftrightarrow \text { EA4 }\end{array}$

Algunos canales pueden mostrar a techo paquetes poco potentes de lutitas organógenas $(\mathrm{EA} 1 \rightarrow \mathrm{EA5}$ abandono canal) que representan etapas del abandono del canal (EA1 $\leftrightarrow$ EA5 en CG, MN y EN).

Los depósitos estudiados parecen indicar fenómenos deavulsión por progradación [sensu SLINGERLAND Y SMITH (2004)]. Este tipo de avulsión se origina en llanuras deinundación con poca 
pendiente, donde la descarga del sedimento tiende a ocupar una gran área de la llanura, produciéndose una pérdida importante en la competencia y capacidad de transporte de la corriente que acarrea el sedimento. Los mecanismos promotores de una avulsión son de lo más diversos y variados (RICHARDS et al., 1993; J ONES Y SCHUMM, 1999). De todos ellos los más plausibles en el área de Enciso son una caída del nivel del lago (J ONES y SCHUMM, 1999) y/ o el basculamiento tectónico (BLAIR Y MCPHERSON, 1994; PEAKALL, 1998).

\subsection{MODELO SEDIMENTARIO LACUSTRE}

Los modelos lacustres utilizados se han interpretado en términos de dominios lacustres (KeLtS, 1988; GLENNY KeLTS, 1991; GIERLOWSKI-KORDESCH Y KeLTS, 1994; FERBER Y WELLS, 1995; FREGENAL-MARTÍNEZY MELÉNDEZ, 2010). Como los procesos y dinámica propios de cada dominio han sido ya ampliamente explicados en el capítulo 4, se hace un breve recordatorio en este apartado.

El dominio supralitoral comprende los terrenos que bordean el lago por encima del límite del agua. Puede mostrar una cobertera vegetal notable, así como una gran icnodiversidad (HASIOTIS, 2007; HAMER Y SHELDON, 2010). Los sedimentos exhiben trazas de fijación por vegetación y/o de pedogénesis por fluctuaciones en el nivel del lago y freático (ALONSO-ZARZA, 2003), que eliminan casi todos los caracteres primarios. Litológicamente, muestran texturas típicas de medios de poca o nula energía: siliciclástico de grano fino (LAST, 1989b; HAMER Y SHELDON, 2010) o carbonatos fango-soportados con abundante matriz (ARP, 1995; CABALERI Y ARMELLA, 2005). Los ambientes sedimentarios reconocidos en este trabajo están constituidos por llanuras fangosas (localmente carbonatadas) y/o áreas pantanosas adosadas al lago, identificándose con los elementos arquitectónicos EA10 palustre y EA5palustre. Estos ambientes son frecuentes en lagos con una topografía suave (RYDER etal., 1976; SURDAMY STANLEY, 1979; CASTLE, 1990; FERBERY WELLS, 1995).

El dominio litoral se desarrolla desde la línea de costa hasta donde llega el 1\% de la luz solar. En los lagos someros y/ o con un bajo gradiente topográfico puede abarcar la casi totalidad de la cubeta lacustre (PETERS Y LODGE, 2009). El dominio litoral se subdivide en eulitoral e intralitoral. El dominio eulitoral es la zona de transición entre el lago y el terreno anexo emergido. Está definido por las fluctuaciones de la lámina de agua a escala anual, y en lagos con poca pendiente puede tener una extensión importante (HUTCHINSON, 1967; ARP, 1995; WETZEL, 2001). Son frecuentes las grietas de retracción y las icnitas de vertebrados (HAMER Y SHELDON, 2010). Los elementos asignados a este dominio están constituidos por sedimentos (intra)litorales que muestran evidencias de emersión que hayan modificado su estructura original (EA8eulitoral, EA10 eulitoral, y EA4 eulitoral). En el caso de sedimentos carbonatados es un equivalente del medio palustre asociado a un lago somero (DUNAGAN Y DRIESE, 1999; TANNER, 2000; BUSTILLO et al., 2002). El dominio intralitoral está formado por la zona costera permanentemente inundada a escala anual, aunque de manera ocasional, durante bajadas importantes del nivel del lago puede sufrir exposición subaérea. Se caracteriza por exhibir secuencias transgresivas-regresivas (EUGSTER Y KELTS, 1983) y una clara ausencia de fenómenos de emersión o pedogénesis (ARP, 1995). Presenta gran diversidad de hábitats y los sedimentos muestran un gran contenido en fósiles (carófitas, ostrácodos, bivalvos y gasterópodos). Los procesos hidrodinámicos dominantes son el viento (oleaje) y los afluentes, por lo cual presenta estructuras de tracción (oleaje y/o unidireccionales). La acción continua del oleaje elimina los finos en el sedimento depositado, aunque, los macrófitos pueden amortiguar dicha acción y favorecer la deposición de sedimentos finos (WETZEL, 2001; KALFF, 2002). Los sedimentos contienen un mayor contenido en carbonato que los sedimentos en zonas más profundas (DEAN, 1981). La orla intralitoral se identifica con los elementos arquitectónicos EA7intralitoral, EA11 intralitoral (ocasionalmente), EA2 intralitoral, EA3intralitoral, y EA4 intralitoral.

El dominio sublitoral siempre permanece inundado, y no muestra evidencias de exposición subaérea. Mantiene las características sedimentarias de la zona abierta aunque con presencia de vida. Su extensión depende de la topografía y profundidad de la cubeta lacustre: en ciertos lagos someros de poco gradiente topográfico puede no desarrollarse este dominio. Sedimentológicamente se identifica con la zona donde se produce el cambio abrupto de tamaño 
del sedimento de grueso a fino (KALFF, 2002). Se han interpretado como elementos típicos de esta

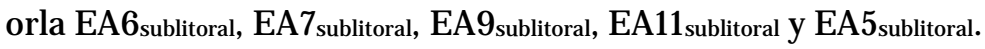

El dominio abierto comprende la zona central y de mayor profundidad de la cubeta. En algunos lagos someros, la orla sublitoral y profunda pueden formar un único cinturón sin diferenciación. La biota es poco significativa, aunque pueden aparecer restos transportados de las zonas someras. Como se encuentra por debajo del nivel de base del oleaje, presenta sedimentos depositados en aguas tranquilas, fundamentalmente por decantación desde la zona pelágica. De manera ocasional existe ciertos aportes siliciclásticos por turbiditas-infraflujos, interflujos y slumps (PHARO Y CARMACK, 1979; HALFMAN Y SCHOLZ, 1993; LAST, 1993b; CHEN et al., 2006b; MCCULLOUGH Y BARBER, 2007; MCCULlOUGH et al., 2007). El contenido en carbonatos suele ser menor, ya que las temperaturas bajas y la descomposición de materia orgánica favorecen su disolución (DEAN Y GORHAM, 1976; MURPHY Y WILKINSON, 1980), aunque algunos carbonatos litorales pueden redepositarse en este dominio (LUDLAM, 1974; DEANY FOUCH, 1983; LAST, 1993b). Los elementos típicos de esta orla son EA5abierto y EA11abierto, de manera más ocasional está representado por EA7abierto y/ o EA9abierto.

\subsubsection{Modelo sedimentario lacustre siliciclástico}

La distribución espacial de los sedimentos en lagos siliciclásticos está relacionada con la batimetría y muestran una gradación hacia depósitos cada vez más finos desde las zonas marginales hacia el centro de la cubeta. Este fenómeno es un simple reflejo de la atenuación dela energía del oleaje, de la influencia de los ríos y de la resuspensión-aventamiento (KALFF, 2002; White y MiLLER, 2008). Se han identificado dos modelos denominados como lacustre siliciclástico A (modelo LS-A) y B (modelo LS-B).

\subsubsection{Modelo lacustre siliciclástico A (LS-A)}

Este modelo es muy común en los primeros $600 \mathrm{~m}$ de la sección de Enciso (anexo IV) y muestra una secuencia teórica completa formada por las siguientes transiciones (figura 6.6):

$$
\begin{aligned}
& \mathrm{EA}_{\text {abierto }} \rightarrow\left(\mathrm{EA}_{\text {sublitoral }} \text { o EA5 } 5_{\text {sublitoral }}\right) \rightarrow \mathrm{EA}_{\text {intralitoral }} \rightarrow \mathrm{EA}_{\text {eulitoral }} \rightarrow \mathrm{EA}_{\text {palustre }} \\
& \mathrm{EA} 5_{\text {abierto-sublitoral }} \leftrightarrow \mathrm{EA}_{\text {abierto-sublitoral }}
\end{aligned}
$$

Las transiciones significativas que aparecen en la columna de Enciso y que permiten definir este modelo lacustre son:

$$
\begin{aligned}
& \mathrm{EA} 5 \rightarrow \mathrm{EA} 6 \leftrightarrow \mathrm{EA} 4 \leftrightarrow \mathrm{EA} 5 \\
& \mathrm{EA} 5 \leftrightarrow \mathrm{EA} 4 \leftrightarrow \mathrm{EA} 5 \\
& \mathrm{EA} 5 \leftrightarrow \mathrm{EA} 12
\end{aligned}
$$

Esta secuencia tiene un espesor variable comprendido entre 5 y $32 \mathrm{~m}$, y una evolución vertical granocreciente (figura 6.7). El término inferior (EA5abierto) es dominante, mostrando una gran potencia (5-30 m) en relación a los elementos (sub)litorales $(0,3-2 \mathrm{~m})$, cuya presencia es casi anecdótica. La secuencia comienza con las lutitas organógenas que caracterizan la decantación acontecida en el dominio abierto (EA5abierto). Estos depósitos pueden contener potentes niveles interestratificados de conchas fracturadas de lumaquelas de moluscos (EA12 abierto), depositados por flujos turbidíticos procedentes de la zona litoral. Es probable quelos sectores dominados por la facies de lutitas con laminación horizontal $\left(L_{1} h_{1}\right)$ representen la sedimentación en la zona abierta más profunda. Las zonas dominadas por lutitas masivas ( $\left.\mathrm{Lm}_{1}\right)$ simbolizan la franja abierta con menor batimetría situada próxima o incluso en el dominio sublitoral. 


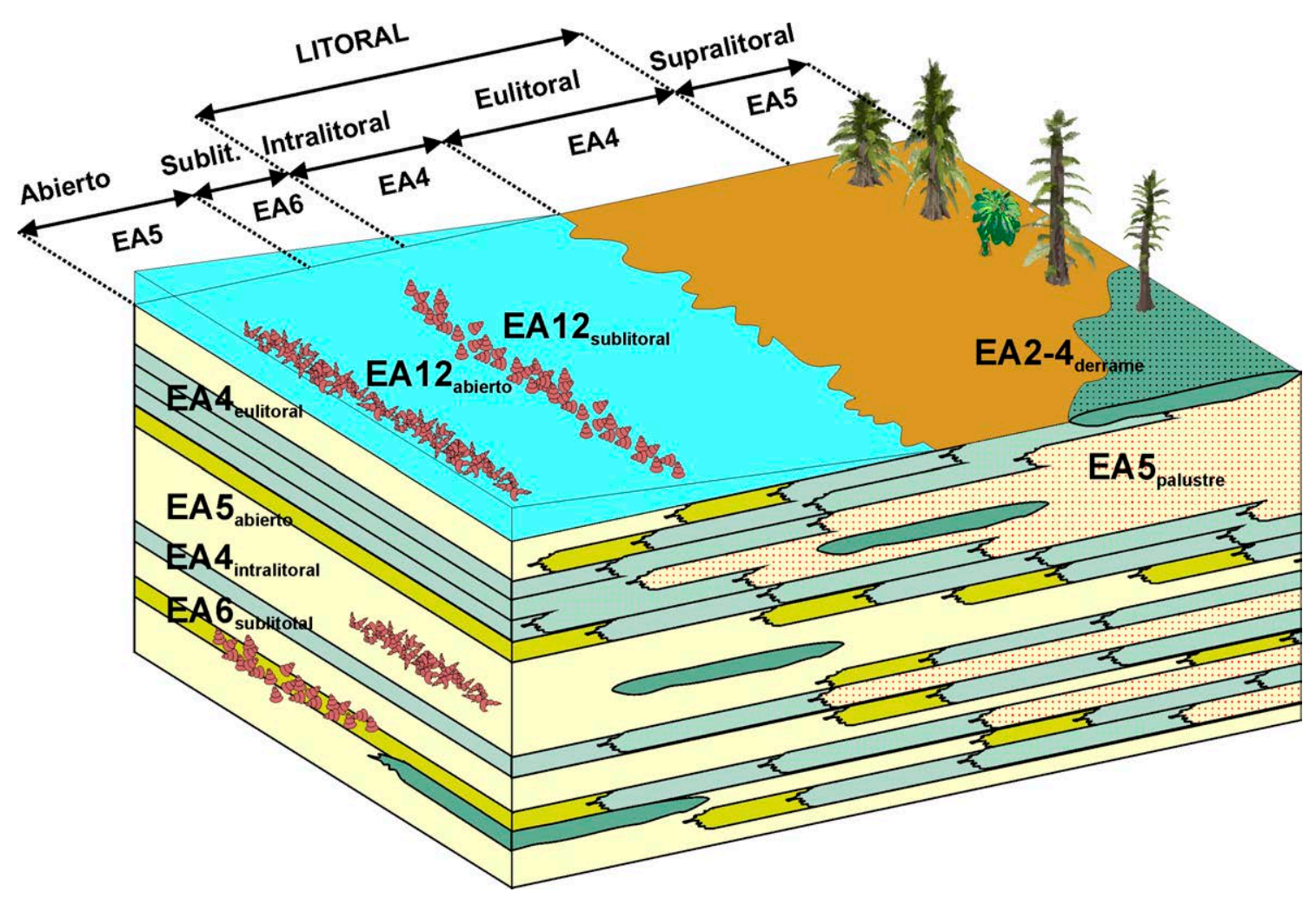

Figura 6.6: Bloque diagrama teórico del modelo lacustre siliciclástico A (LS-A).

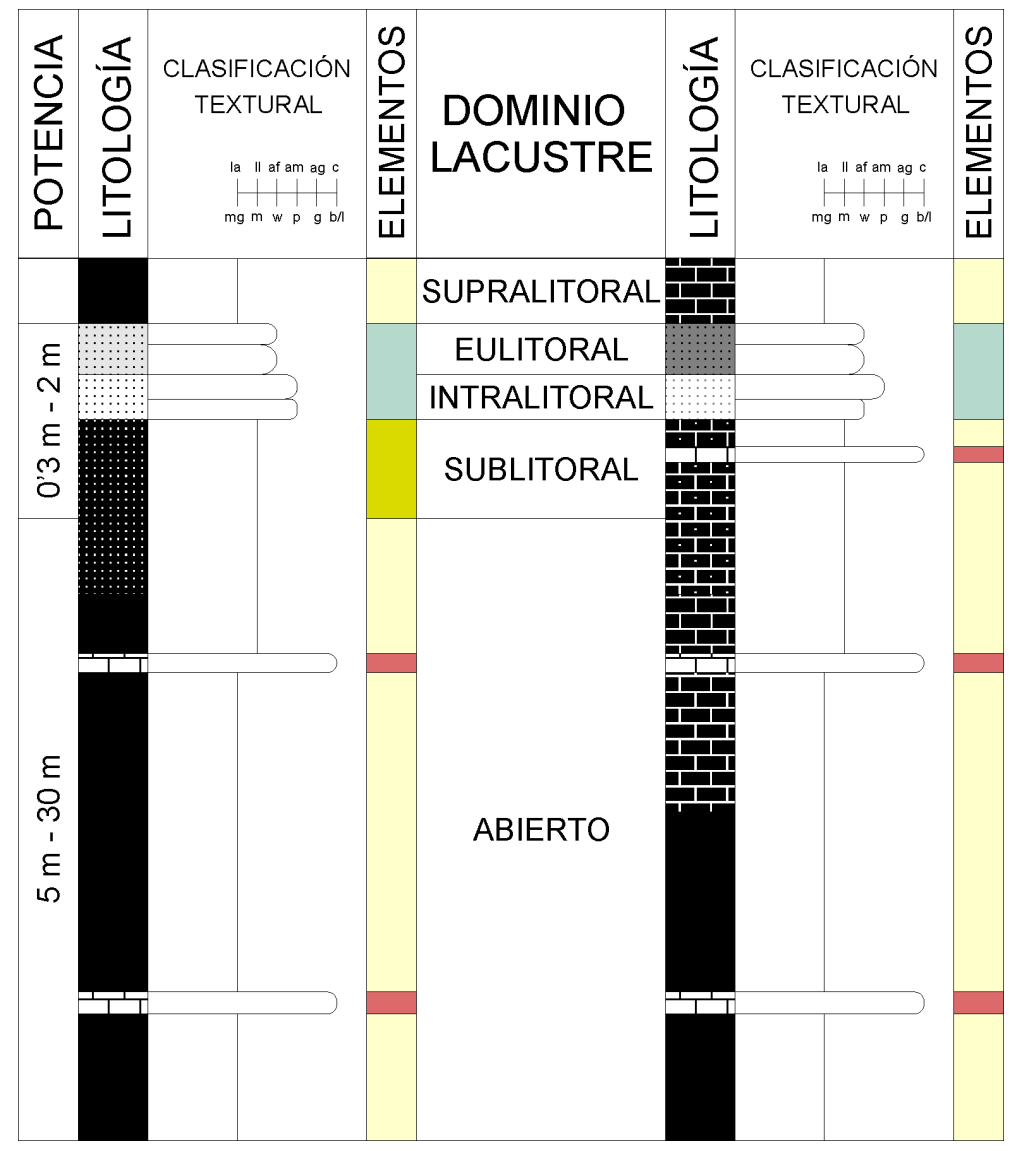

Figura 6.7: Secuencia teórica y variaciones litológicas del modelo lacustre siliciclástico A (LSA). 
Sobre la orla abierta aparecen los depósitos del dominio sublitoral, los cuales están formado por paquetes poco potentes del elemento EA6sublitoral. No siempre está presente y, entonces, la zona sublitoral puede estar compuesta por el elemento EA5sublitoral. En este último caso, de manera significativa, aparecen lumaquelas de moluscos EA12sublitoral (formados por conchas enteras). La secuencia culmina con la orla litoral que está constituida por los sedimentos siliciclásticos más gruesos (EA4). Tentativamente, el dominio eulitoral (EA4 eulitoral) se asigna a los depósitos constituidos preferentemente por grauvacas $\left(\mathrm{Am}_{2}\right)$, mientras que los elementos dominados por arenitas $\left(\mathrm{Am}_{1}\right)$ se atribuyen al dominio intralitoral (EA4intralitoral), ya que en esta zona existe la suficiente energía como para eliminar los materiales finos (J OHNSON Y NG'ANG'A, 1990; TALLING, 1992).

Los caracteres principales que permiten reconocer esta facies en el registro sedimentario son: el gran desarrollo y espesor del elemento EA5abierto (desde varios metros hasta decamétrico) y el escaso desarrollo (decimétrico a métrico) de los elementos litorales (EA4 $4_{\text {intralitoral y EA4 }}$ eulitoral)

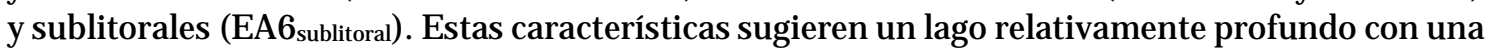
gran pendiente topográfica.

\subsubsection{Modelo lacustre siliciclástico B (LS-B)}

Este modelo está presente en todas las secciones levantadas (figura 6.8). Aunque es difícil encontrarla desarrollada en su totalidad, la secuencia tipo teórica está compuesta por:

$$
\text { EA5 }_{\text {abierto }} \rightarrow \text { EA5 }_{\text {sublitoral }} \rightarrow \text { EA3intralitoral }_{\text {y/ o EA2intralitoral }} \rightarrow \text { EA4 }_{\text {eulitoral }} \rightarrow \text { EA6 }_{\text {avulsión }}
$$

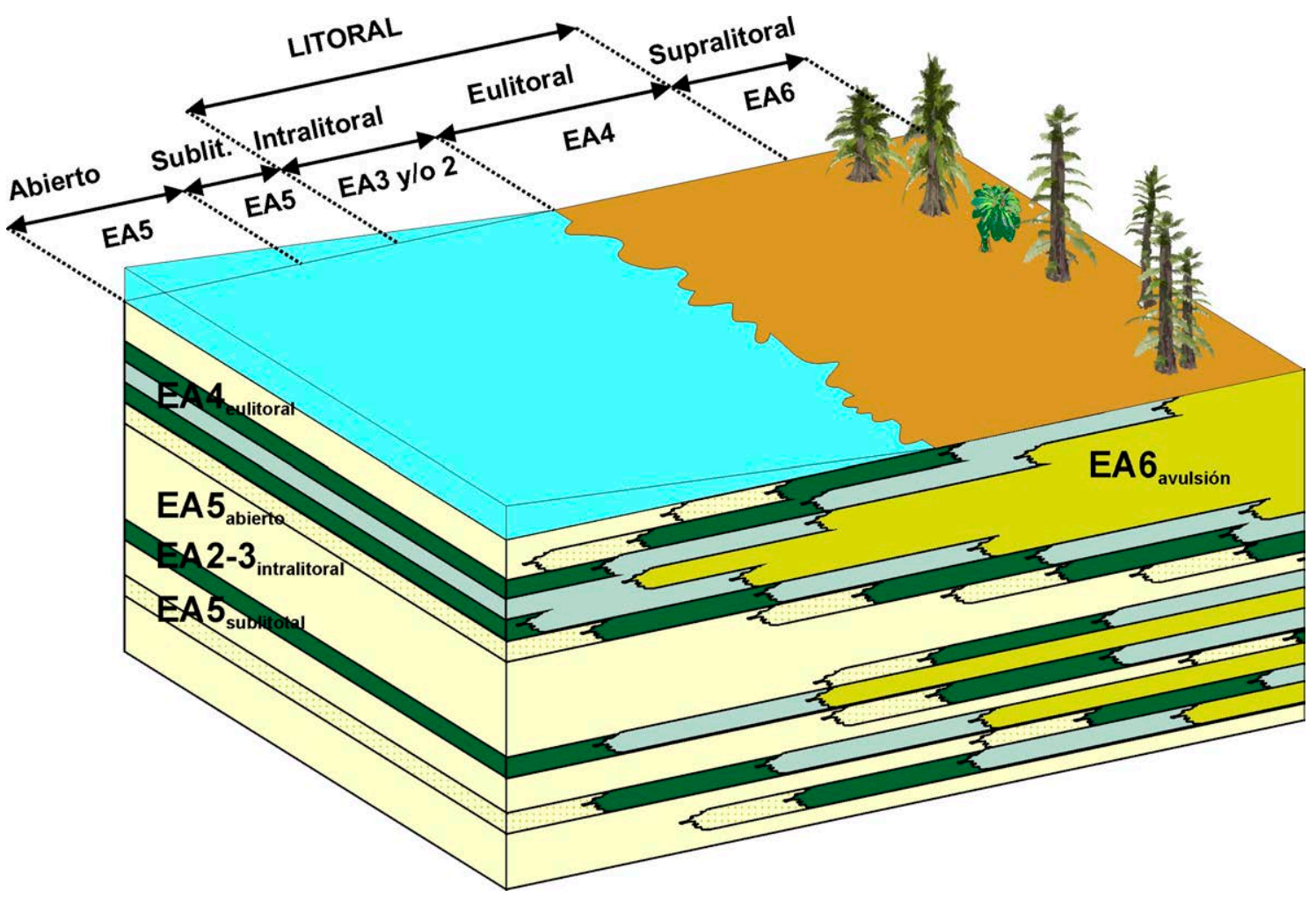

Figura 6.8: Bloque diagrama teórico del modelo lacustre siliciclástico B (LS-B).

Las transiciones significativas que definen este modelo en las cinco columnas analizadas son de la siguiente forma:

$$
\begin{array}{ll}
\text { Enciso } & \text { EA5 } \leftrightarrow \text { EA4 } \leftrightarrow \text { EA6 } \\
\text { Ambas Aguas } & \text { EA5 } \leftrightarrow \text { EA4 } \leftrightarrow \text { EA2 } \leftrightarrow \text { EA6 } \\
& \text { EA5 } \leftrightarrow \text { EA4 } \leftrightarrow \text { EA2 } \rightarrow \text { EA3 } \\
& \text { EA5 } \leftrightarrow \text { EA4 } \leftrightarrow \text { EA6 } \\
& \text { EA5 } \rightarrow \text { EA3 }
\end{array}
$$




$\begin{array}{ll}\text { Cornago } & \text { EA5 } \leftrightarrow \text { EA2 } \leftrightarrow \text { EA6 } \\ & \text { EA5 } \leftrightarrow \text { EA3 } \leftrightarrow \text { EA6 } \\ \text { Munilla } & \text { EA5 } \leftrightarrow \text { EA4 } \leftrightarrow \text { EA6 } \\ & \text { EA5 } \leftarrow \text { EA2 } \leftarrow \text { EA3 } \leftrightarrow \text { EA6 } \\ & \text { EA5 } \leftarrow \text { EA2 } \leftarrow \text { EA6 } \\ & \text { EA5 } \leftarrow \text { EA2 } \rightarrow \text { EA4 } \leftrightarrow \text { EA6 } \\ & \text { EA5 } \leftrightarrow \text { EA4 } \leftrightarrow \text { EA6 } \\ \text { Préjano } & \text { EA5 } \leftrightarrow \text { EA3 } \rightarrow \text { EA4 } \\ & \text { EA5 } \rightarrow \text { EA2 } \\ & \text { EA5 } \rightarrow \text { EA4 }\end{array}$

Esta secuencia muestra unos espesores menores (1-10 m), gran extensión lateral (centenares de metros hasta kilométrico), así como una evidente tendencia granocreciente (figura 6.9). El término inferior caracteriza el dominio abierto - sublitoral, y está formado por el elemento de lutitas organógenas EA5abierto y EA5sublitoral. El término superior representa a la zona litoral, constituida por areniscas finas a medias. Los elementos arenosos con evidencias de oleaje EA3intralitoral y, en menor medida, EA2 intralitoral, se atribuyen al dominio intralitoral, mientras que el dominio eulitoral está conformado por el elemento EA4eulitoral. El dominio abierto, a diferencia del modelo lacustre anterior, tiene un desarrollo y espesor mucho menor (escasos metros), y la orla litoral está mejor representada (escala métrica). Se interpreta como un sistema lacustre somero siliciclástico con una alternancia repetitiva entre el dominio abierto y litoral. Este dinamismo se manifiesta en marcadas oscilaciones del nivel de la lámina de agua (patrón de vaciado-llenado), permitiendo cambios frecuentes entre ambientes abiertos y litorales, lo cual explicaría la ausencia de secuencialidad observada en algunas columnas analizadas.

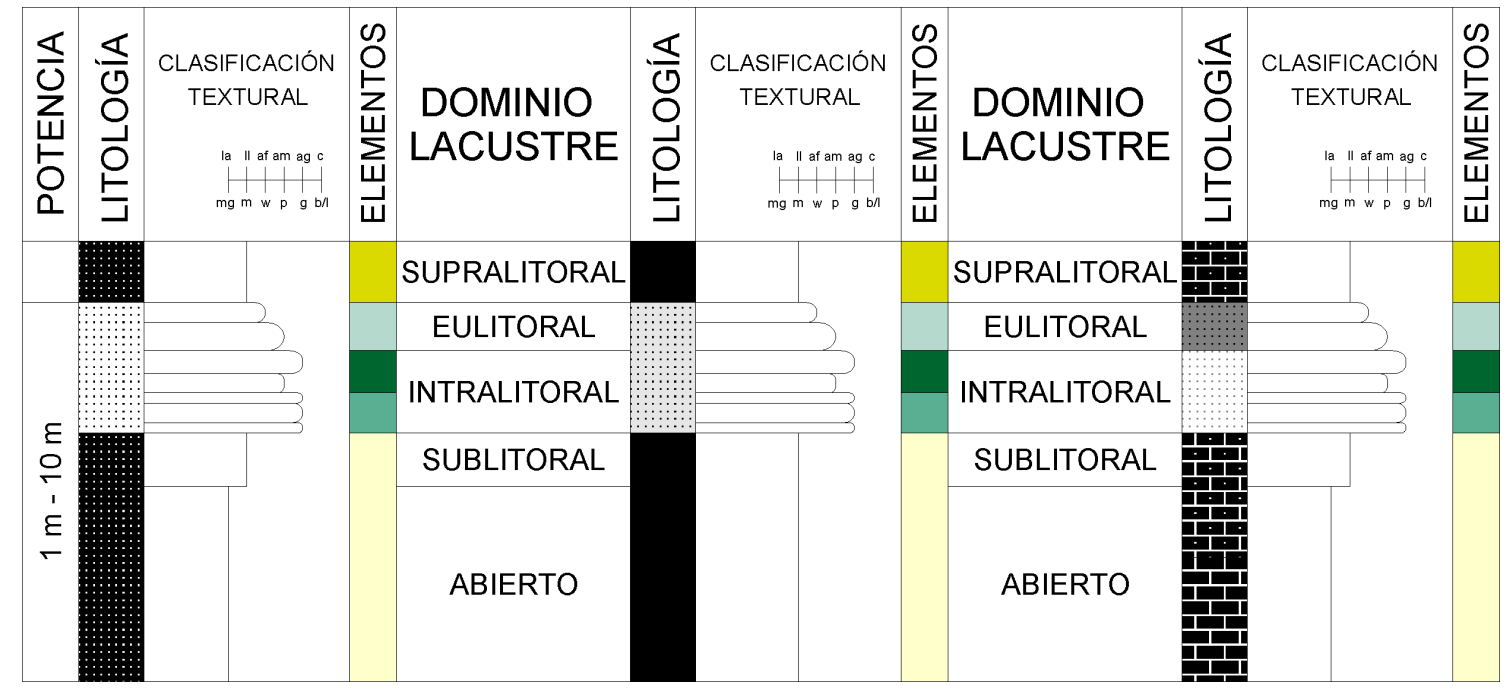

Figura 6.9: Secuencia teórica y variaciones litológicas del modelo lacustre siliciclástico B (LSB).

\subsubsection{Modelo sedimentario lacustre mixto}

Los sistemas lacustres mixtos carbonatados-siliciclásticos pueden corresponder a dos contextos diferentes. En el primer caso, ambas litologías coexisten lateralmentey se acumulan de forma sincrónica en áreas adyacentes. Cuando existe un dominio de los depósitos carbonatados sobre los siliciclásticos, se interpretan como sistemas carbonatados de poca pendiente, donde los materiales siliciclásticos se relacionan a deltas o lóbulos deltaicos debidos a la entrada puntual de sistemas fluviales (CABRERA Y SAEZ, 1987; GIERLOWSKI-KORDESCH et al., 1991; SÁEZ et al., 1999). Por el contrario, cuando existe un evidente predominio de los sedimentos siliciclásticos, los carbonatos se depositan en zonas donde el aporte de material siliciclástico es mínimo, es decir, áreas alejadas de la entrada o de la influencia de los ríos. El ejemplo paradigmático es el Lago Tanganica (COHEN Y THOUIN, 1987; COHEN, 1989a; 1990; TIERCELIN et al., 1992; SOREGHAN Y COHEN, 1996). Sin embargo, en algunas ocasiones los carbonatos se depositan en la 
desembocadura de ríos que drenan un área madre carbonatada, como ocurre en el lago Kelly en Canadá (RENAUT, 1990; FERRIS et al., 1997). En el segundo tipo lacustre, ambos depósitos coexisten en la vertical. Los siliciclásticos finos se localizan en el dominio abierto y los carbonatos en las orlas más someras. En el lago Knowiton (Canadá) existe un margen en plataforma carbonatado mientras que los sedimentos del dominio abierto están formados por lutitas ricas en materia orgánica (GILBERTY LEASK, 1981). En la Formación Horton Bluff (Carbonífero de Canadá) los carbonatos se depositaron en zonas someras relacionados a procesos diagenéticos tempranos (MARTEL Y GIBLING, 1991). En el lago Titicaca (Bolivia-Perú) se observa una distribución de los materiales más compleja que aglutina ambos modelos (BOULANGÉ et al., 1981; RODRIGO Y WIRRMANN, 1991; WIRRMANN, 1994).

En el Grupo Enciso se han identificado tres modelos básicos de lagos mixtos que se han denominado como LM-A, LM-B y LM-C. En todos ellos, los elementos pertenecientes a la orla litoral permanecen fijos, y son los elementos del dominio abierto y/ o sublitoral los que varían en cada modelo estudiado. En ocasiones se ha observado que son cambios laterales entre sí dentro la cubeta lacustre.

\subsubsection{Modelo lacustre mixto A (LM-A)}

El modelo LM-A está constituido por un término inferior (dominio abierto) denaturaleza siliciclástica fina y un término superior (dominio litoral) de naturaleza carbonatada. Su secuencia teórica completa es de la forma (figura 6.10):

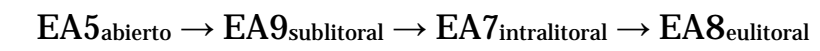

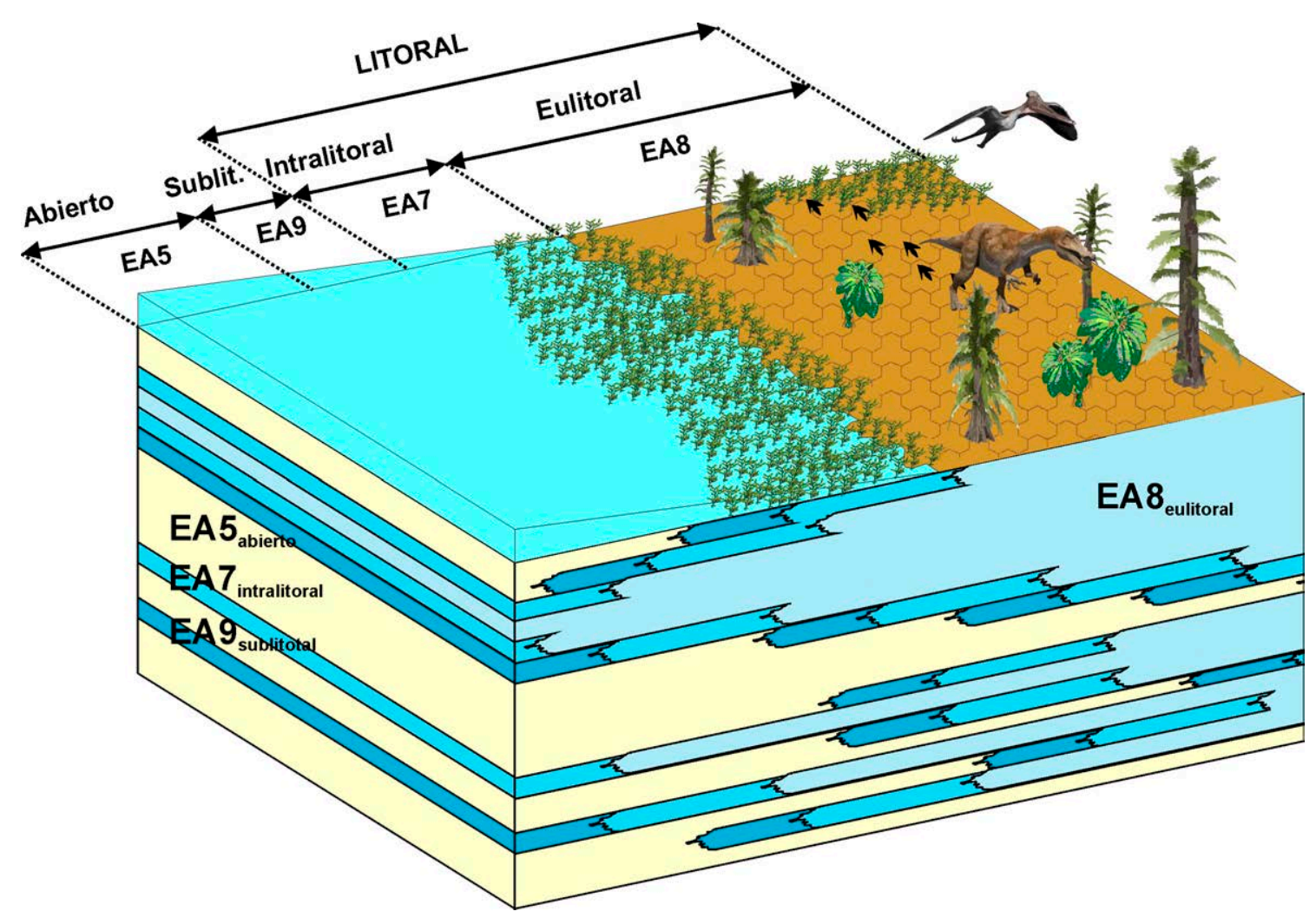

Figura 6.10: Bloque diagrama teórico del modelo lacustre mixto A (LM-A).

Aunque las transiciones entre el elemento siliciclástico EA5 con los elementos carbonatados no sean significativos $(\leftrightarrow)$, se ha creído interesante crear este modelo, ya que aparece en las columnas de Enciso y Cornago. El modelo está constituido por las siguientes transiciones: 


\author{
EA5 $(\leftrightarrow)$ EA7 $\leftarrow(\rightarrow)$ EA8 \\ EA5 $(\rightarrow)$ EA8 $\rightarrow$ EA7 \\ Cornago $\quad$ EA5 $(\leftrightarrow)$ EA9 $\leftrightarrow$ EA7 $\leftrightarrow$ EA8 \\ $\mathrm{EA} 5(\leftrightarrow) \mathrm{EA} 7 \leftrightarrow \mathrm{EA} 8$
}

Constituye paquetes con espesores comprendidos aproximadamente entre 1-5m (figura 6.11) y gran extensión lateral. Este modelo comienza con un término inferior formado por lutitas organógenas (EA5abierto) depositadas por decantación en el dominio abierto. En algunas sucesiones completas se puede observar un ligero enriquecimiento hacia techo en carbonatos y fósiles. En este momento se produce el cambio de litología, pasando de sedimentos de naturaleza siliciclástica a carbonatada. Por encima aparece el dominio sublitoral, compuesto por niveles de calizas laminadas (EA9 sublitoral). Este dominio sólo aparece en algunas series completas, lo cual no es lo normal, y suele estar ausente. Los elementos de calizas masivas (EA7intralitoral) forman el cinturón intralitoral, que cuando sufren procesos de emersión o pedogénesis se transforman en el elemento EA8eulitoral (dominio eulitoral o litoral emergido). Se interpreta como un sistema lacustre mixto siliciclástico—carbonatado, somero, y de poca pendiente.

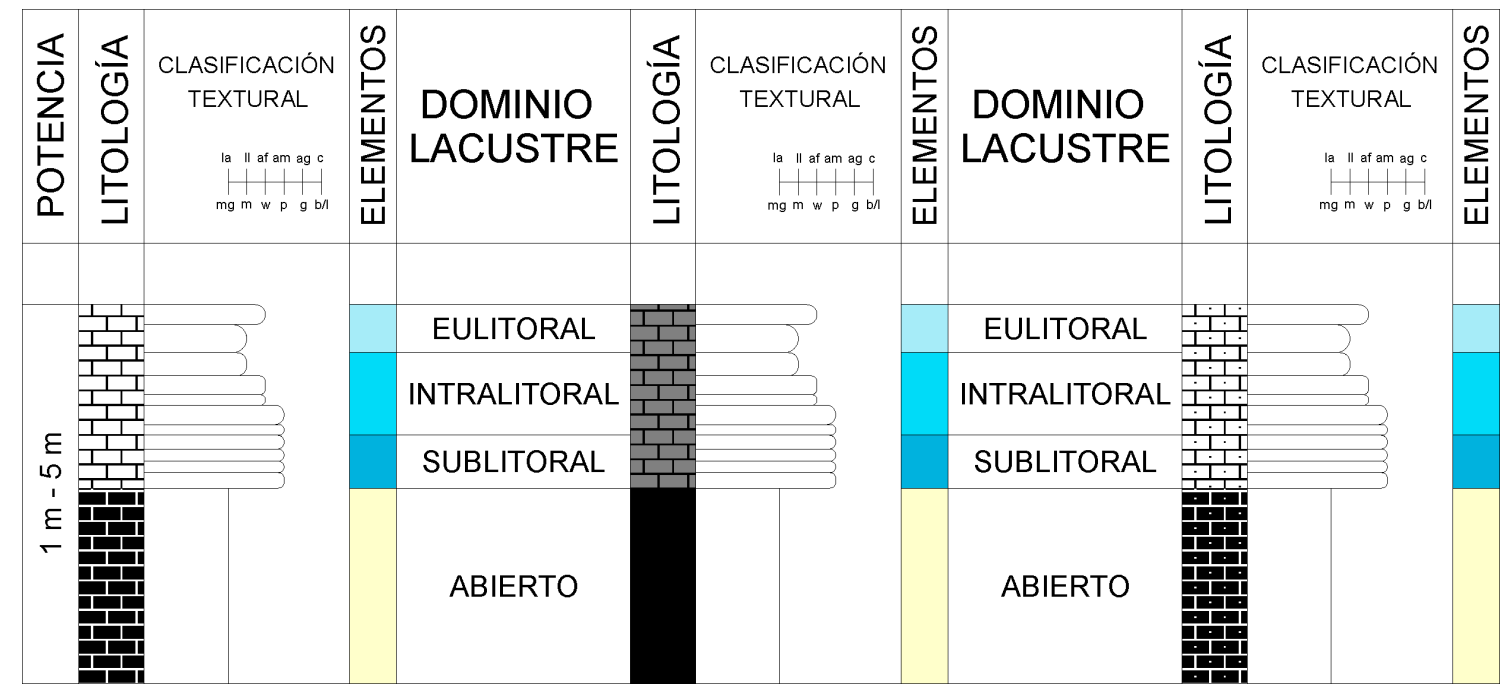

Figura 6.11: Secuencia teórica y variaciones litológicas del modelo lacustre mixto A (LM-A).

\title{
6.5.2.2 Modelo lacustre mixto B (LM-B)
}

Este modelo aparece representado en las columnas de Cornago y Munilla, y menos significativamente (más ocasional) en la series de Enciso y Ambas Aguas. Presenta un término inferior lutítico-margoso y otro superior carbonatado. La secuencia teórica completa es de la forma (figura 6.12):

$$
\mathrm{EA10}_{\text {abierto }} \rightarrow \mathrm{EA}_{\text {intralitoral }} \rightarrow \mathrm{EA}_{\text {eulitoral }}
$$

Esta serie teórica se ha obtenido a partir de las siguientes transiciones observadas en el registro estratigráfico:

$\begin{array}{ll}\text { Enciso } & \text { EA10 } \leftrightarrow \text { ( }) \text { EA7 } \leftarrow(\rightarrow) \text { EA8 } \\ & \text { EA10 } \rightarrow \text { EA8 } \rightarrow \text { EA7 } \\ \text { Ambas Aguas } & \text { EA10 } \leftrightarrow \text { EA8 } \rightarrow \text { EA7 } \\ & \text { EA10 } \leftrightarrow \text { EA7 } \leftarrow(\rightarrow) \text { EA8 } \\ \text { Cornago } & \text { EA10 } \leftrightarrow \text { EA7 } \leftrightarrow \text { EA8 } \\ \text { Munilla } & \text { EA10 } \leftrightarrow \text { EA7 } \leftrightarrow \text { EA8 }\end{array}$

Constituye paquetes con espesores comprendidos entre 1-4 metros (figura 6.13). El dominio abierto (término inferior) está constituido por paquetes de lutitas o margas con evidencias de oxidación y bioturbación (EA10 abierto). Las calizas masivas (EA7intralitoral) constituyen 
la orla intralitoral, que durante las caídas del nivel del lago, se transforman en el elemento

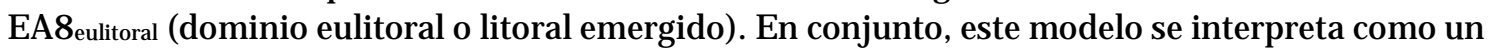
lago somero, de poca pendiente y bien oxigenado en toda la columna de agua.

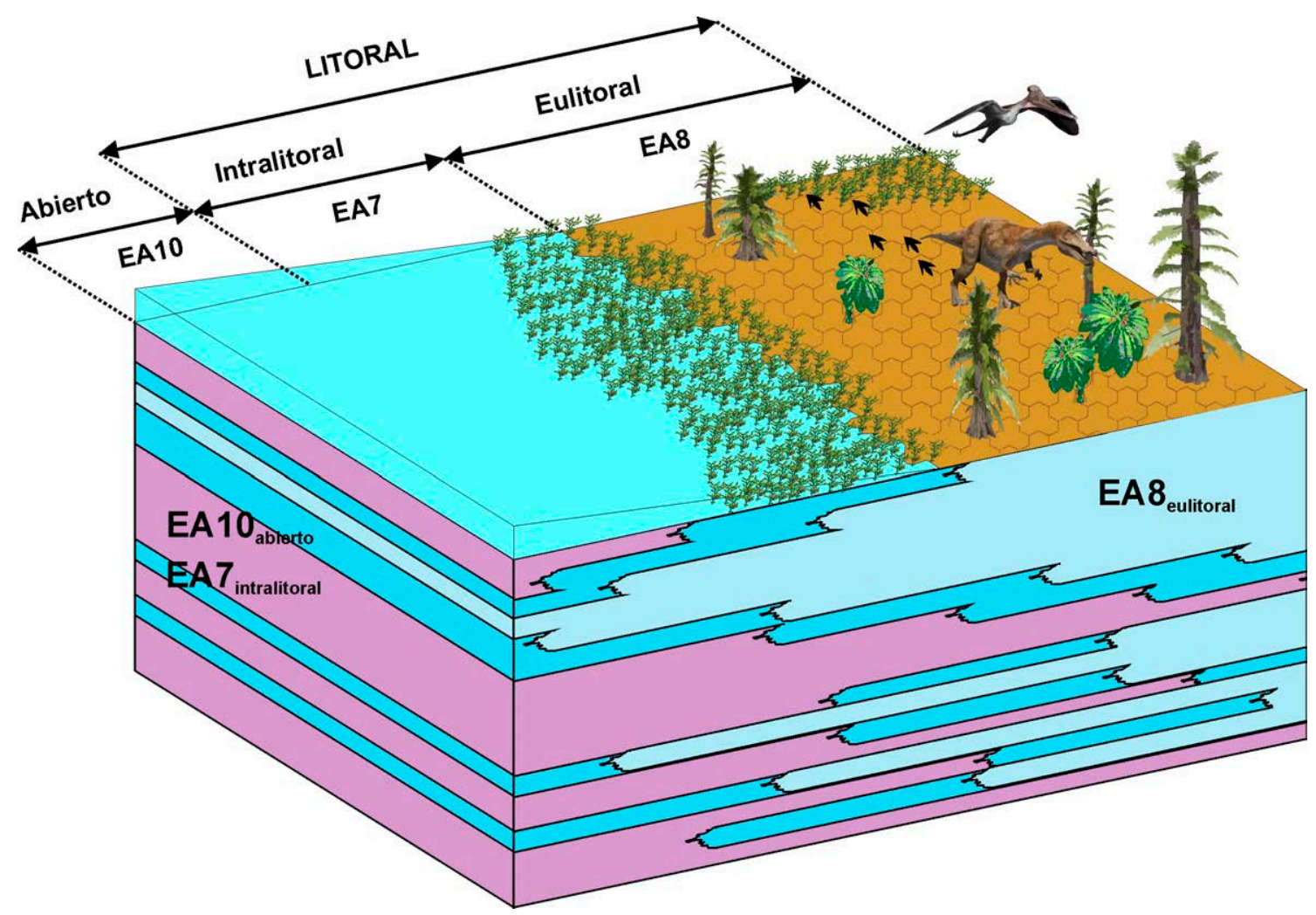

Figura 6.12: Bloque diagrama teórico del modelo lacustre mixto B (LM-B).

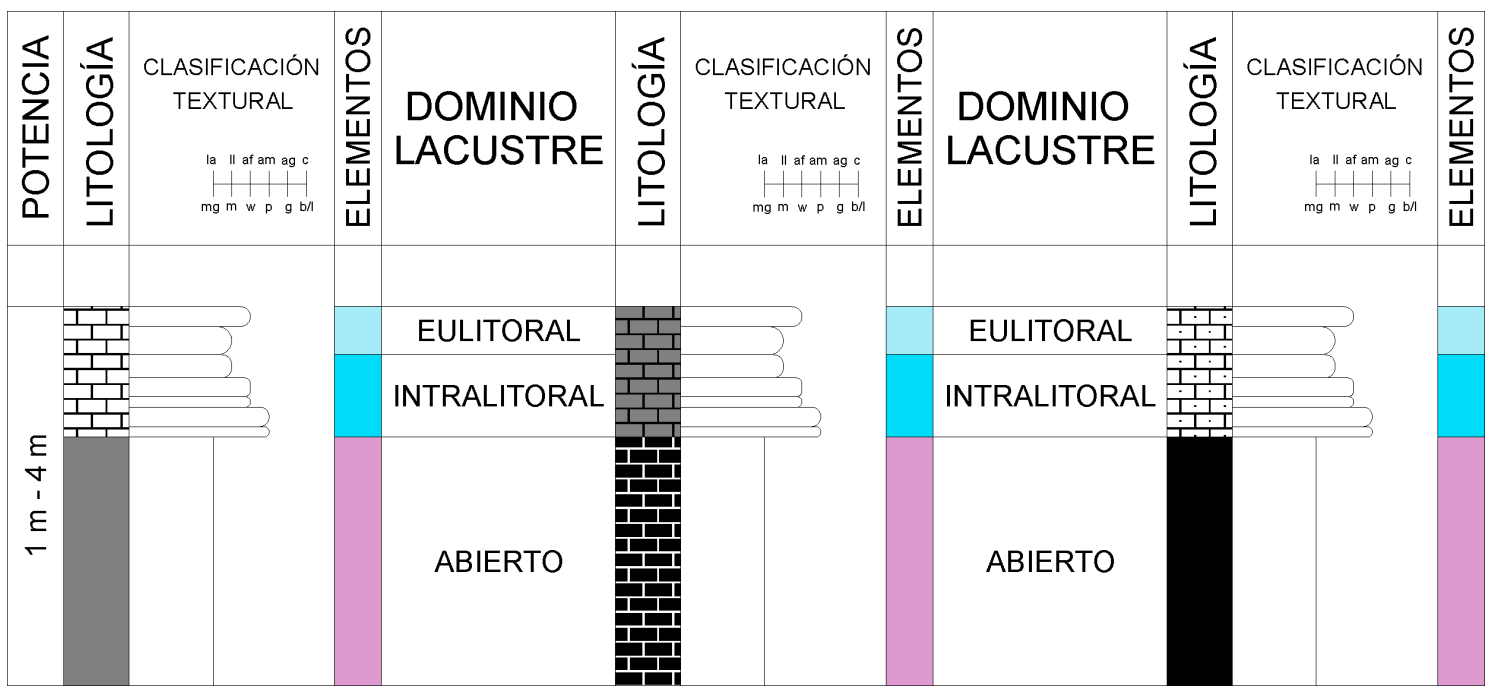

Figura 6.13: Secuencia teórica y variaciones litológicas del modelo lacustre mixto B (LM-B).

\subsubsection{Modelo lacustre mixto C (LM-C)}

Este modelo queda registrado en todas las columnas levantadas excepto en Préjano (figura 6.14). Aunque es difícil que aparezca desarrollada en su totalidad, la secuencia tipo teórica está constituida por las transiciones:

$$
\begin{aligned}
& \mathrm{EA11}_{\text {abierto }} \rightarrow \mathrm{EA}_{\text {sublitoral }} \rightarrow \mathrm{EA}_{\text {intralitoral }} \rightarrow \mathrm{EA}_{\text {eulitoral }} \\
& \mathrm{EA11}_{\text {abierto }} \rightarrow \mathrm{EA}_{2} \text { abierto }
\end{aligned}
$$




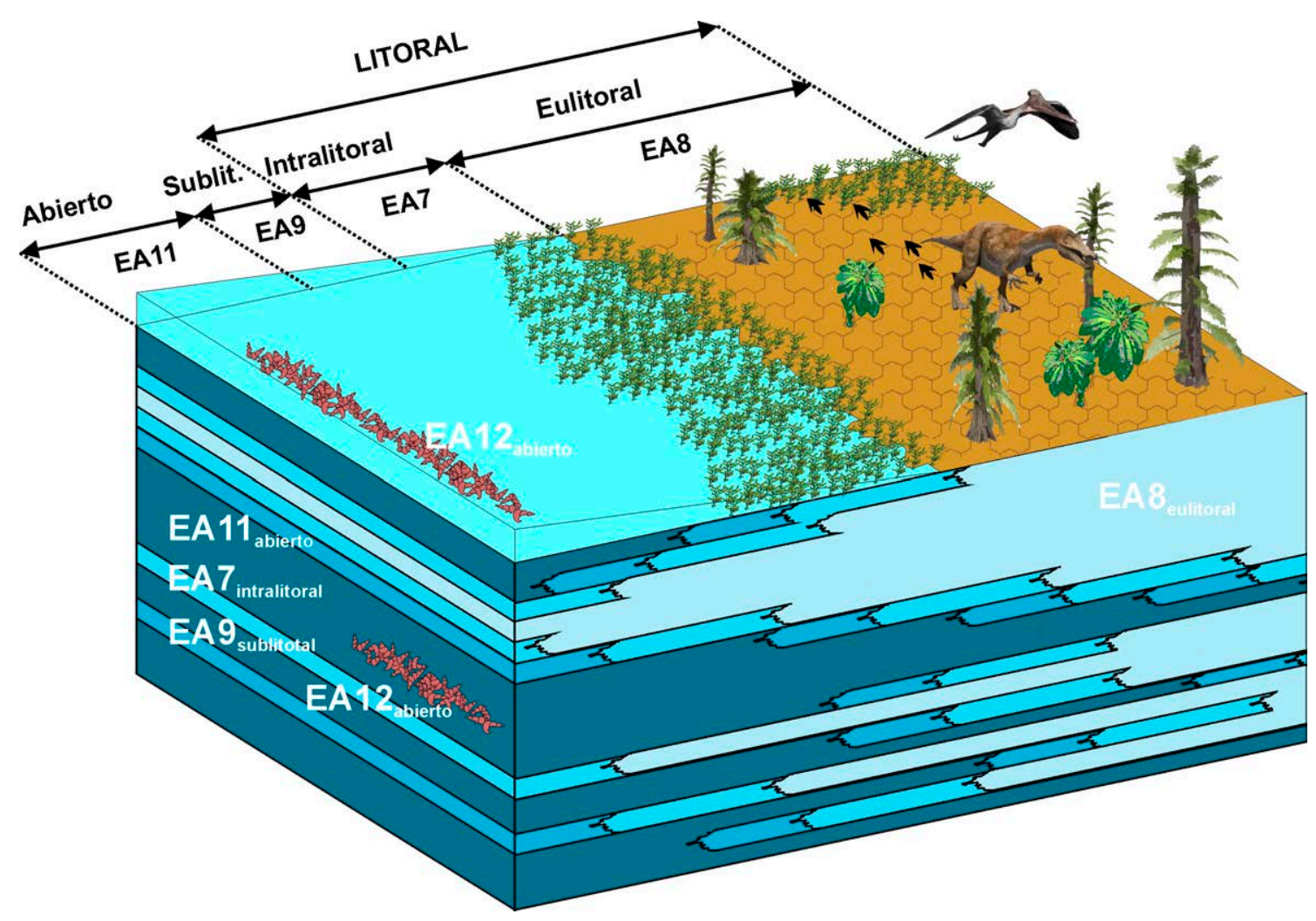

Figura 6.14: Bloque diagrama teórico del modelo lacustre mixto C (LM-C). lacustre son:

Las transiciones que aparecen en las columnas y que permiten definir este modelo

$\begin{array}{ll}\text { Enciso } & \text { EA11 } \leftrightarrow \text { EA EA } \leftrightarrow \text { EA7 } \leftarrow(\rightarrow) \text { EA8 } \\ & \text { EA11 } \leftrightarrow \text { EA7 } \leftrightarrow \text { EA9 } \\ & \text { EA11 } \leftrightarrow \text { EA8 } \rightarrow \text { EA7 } \leftrightarrow \text { EA9 } \\ \text { Ambas Aguas } & \text { EA11 } \leftarrow(\rightarrow) \text { EA9 } \rightarrow \text { EA7 }(\rightarrow) \leftarrow \text { EA8 } \\ & \text { EA9 } \rightarrow \text { EA11 } \leftrightarrow \text { EA7 } \leftarrow \text { EA8 } \\ & \text { EA11 } \rightarrow \text { EA12 } \\ \text { Cornago } & \text { EA11 } \leftrightarrow \text { EA9 } \leftrightarrow \text { EA7 } \leftrightarrow \text { EA8 } \\ & \text { EA11 } \leftrightarrow \text { EA7 } \leftrightarrow \text { EA9 } \\ & \text { EA11 } \leftrightarrow \text { EA7 } \leftrightarrow \text { EA8 } \\ & \text { EA11 } \leftrightarrow \text { EA8 } \leftrightarrow \text { EA7 } \leftrightarrow \text { EA9 } \\ & \text { EA11 } \leftrightarrow \text { EA8 } \leftrightarrow \text { EA7 } \\ & \text { EA11 } \rightarrow \text { EA12 } \\ \text { EA11 } \rightarrow \text { EA9 } \leftrightarrow \text { EA7 } \leftrightarrow \text { EA8 } \\ \text { Munilla } & \text { EA11 } \leftrightarrow \text { EA7 } \leftrightarrow \text { EA9 } \rightarrow \text { EA8 } \\ & \text { EA11 } \rightarrow \text { EA9 } \rightarrow \text { EA8 } \leftrightarrow \text { EA7 } \\ & \text { EA11 } \rightarrow \text { EA12 }\end{array}$

Esta secuencia tiene una potencia muy variable entre 1-23 m (figura 6.15). El término inferior (EA11abierto), preponderante, muestra un gran espesor (1-18 $\mathrm{m}$ ) respecto a los depósitos (sub)litorales $(1-5 \mathrm{~m})$. La serie se inicia con un potente paquete de margas resultado de la decantación de las lutitas en aguas tranquilas y ricas en carbonatos características del dominio abierto (EA11abierto). Ocasionalmente, aunque de manera recurrente (transición significativa en Munilla, Ambas Aguas y Cornago), ocurren episodios turbidíticos que depositan niveles de conchas fracturadas de lumaquelas de moluscos (EA12abierto). En algunas secciones óptimas se observa cierta transición vertical relacionada con la batimetría entre margas laminadas y masivas. Así pues, se puede asumir, de manera tentativa, que los paquetes de margas con laminación horizontal sean el producto de la decantación en la zona abierta más profunda, mientras que las margas masivas sean depositadas en la orla abierta más cercana al litoral. 


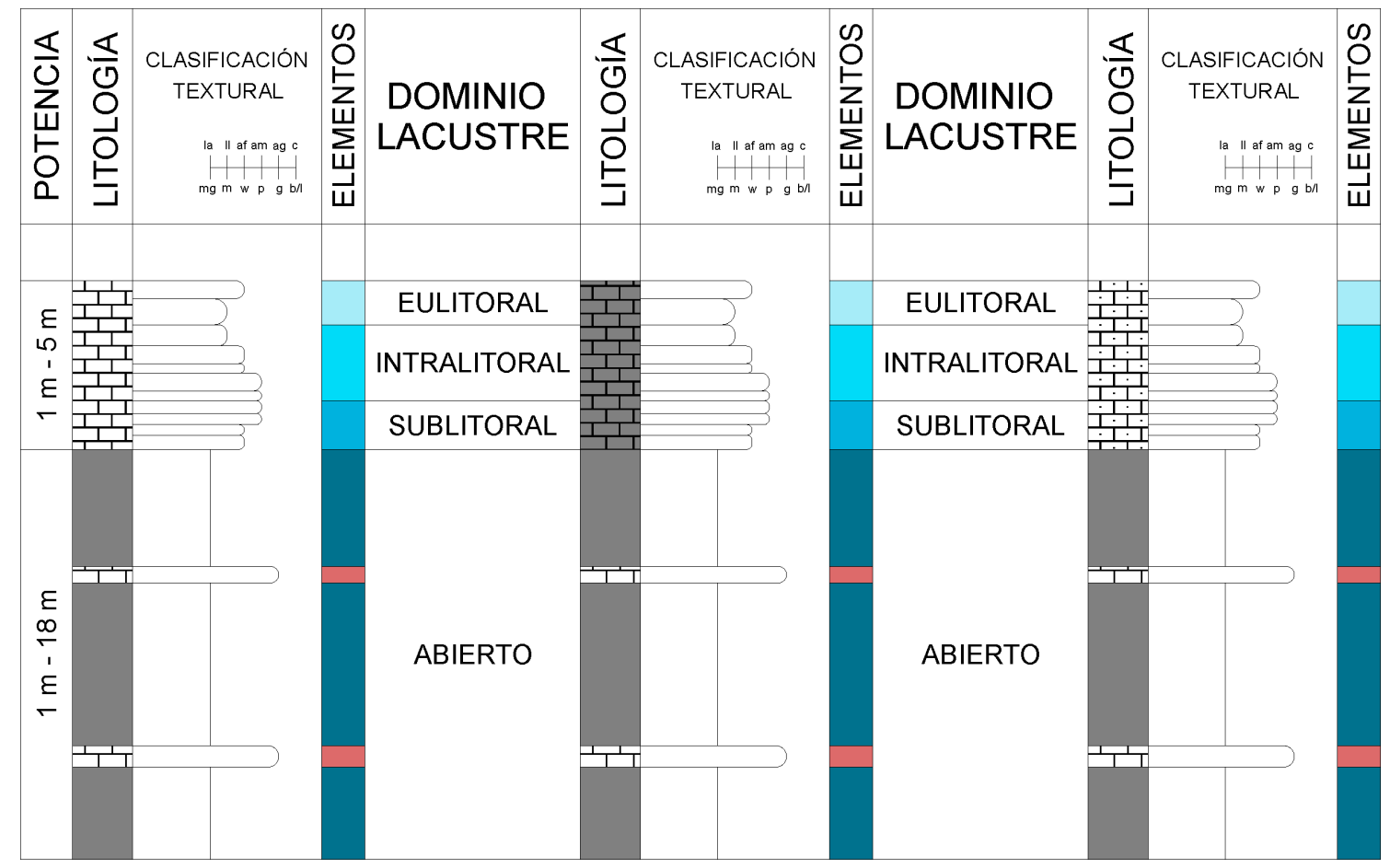

Figura 6.15: Secuencia teórica y variaciones litológicas del modelo lacustre mixto C (LM-C).

Por encima del dominio abierto se depositan las calizas laminadas del dominio sublitoral EA9 sublitoral. La serie culmina con la orla litoral de naturaleza carbonatada. Está formada por

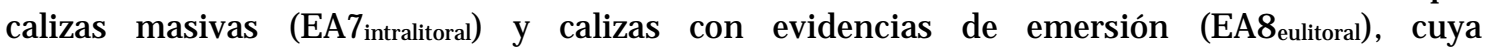
interpretación es exactamenteigual a lo ya comentado en los modelos LM-Ay LM-B. Se interpreta como un lago relativamente profundo.

Se han reconocido dos variaciones de esta secuencia. La primera (LM-C1) ocurre cuando el elemento EA9 intralitoral no está presente. Entonces, la zona sublitoral está constituida por el elemento EA11 sublitoral (figura 6.16). En este escenario, de manera significativa, aparecen paquetes de conchas enteras de lumaquelas de moluscos EA12 sublitoral. Esta serie presenta un espesor variable comprendida entre 6-23 m (figura 6.17).

$$
\begin{aligned}
& \text { EA11 }_{\text {abierto }} \rightarrow \text { EA11 }_{\text {sublitoral }} \rightarrow \mathrm{EA}_{\text {intralitoral }} \rightarrow \text { EA8 }_{\text {eulitoral }} \\
& \text { EA11 abierto } \rightarrow \text { EA12 abierto } \\
& \text { EA11 sublitoral } \rightarrow \text { EA12 } \text { sublitoral }
\end{aligned}
$$

Estas condiciones, a grandes rasgos, son predominantes en las "facies de las margas con ostrácodos" de TISCHER (1966b) y en la unidad $C_{3}^{4 m}$ de CÁMARA-RUPELO y DURÁNTEZ-ROMERO (1981).

La segunda variación (LM-C2) representa lagos someros y con poca pendiente, cuya secuencia tipo es:

$$
\text { EA11abierto } \rightarrow \text { EA7intralitoral } \rightarrow \text { EA8eulitoral }
$$

No se ha desarrollado la orla sublitoral y su potencia es significativamente menor ( $1-6$

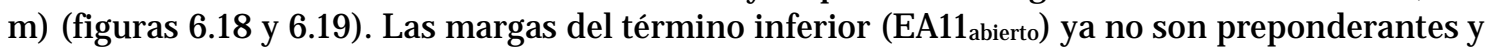
muestran un espesor muy reducido con respecto a los depósitos litorales que, en ocasiones son más potentes. Las calizas masivas (EA7intralitoral) se depositan en la orla intralitoral. Algunos paquetes de EA7 exhiben un enriquecimiento en carbonatos hacia techo, pasando de calizas margosas a calizas puras. Durante las etapas regresivas (caídas del nivel del lago), los sedimentos del dominio intralitoral quedan expuestos subaéreamente y su modificación produce las calizas del dominio eulitoral EA8eulitoral. 


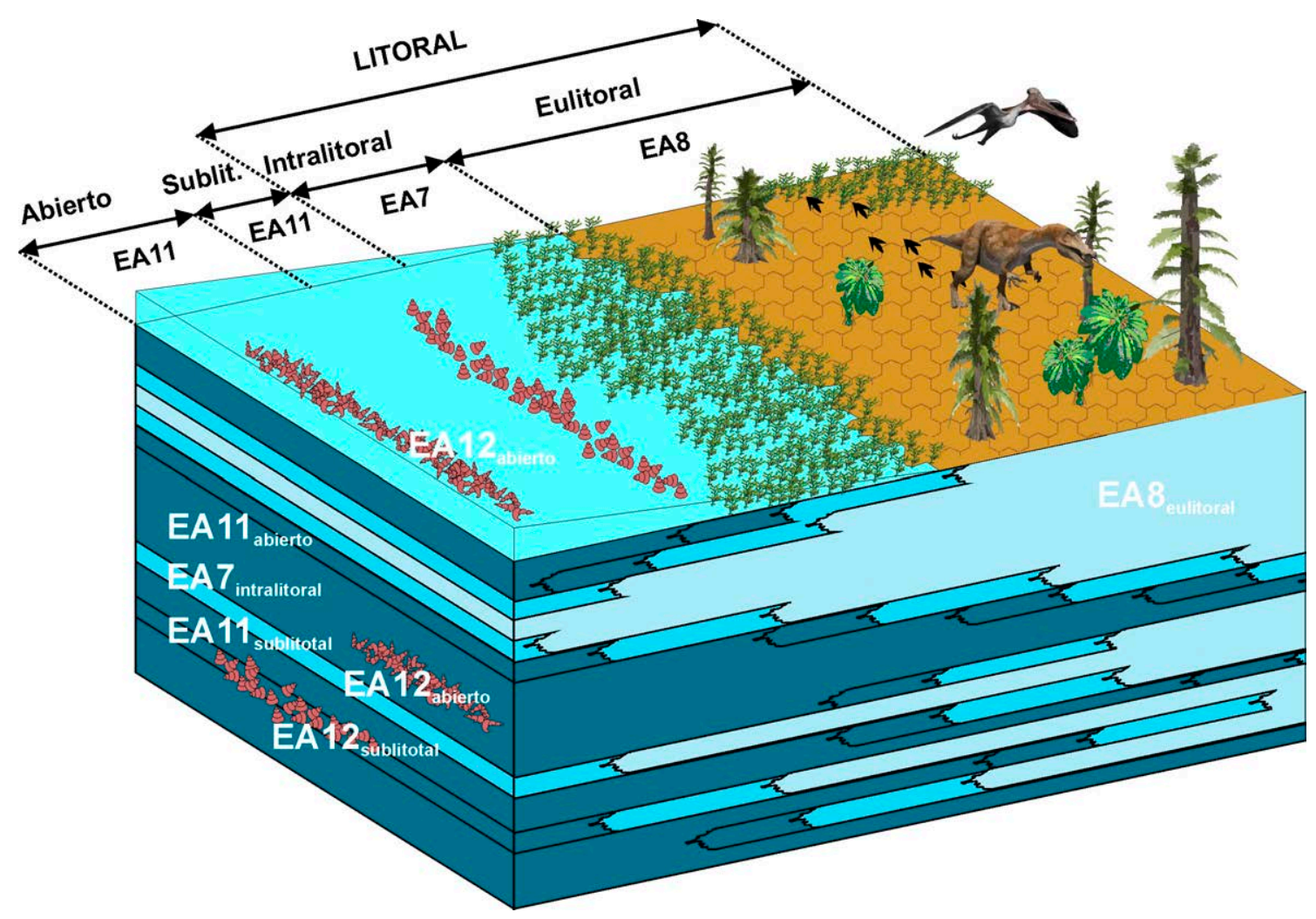

Figura 6.16: Bloque diagrama teórico del modelo lacustre mixto C1 (LM-C1).

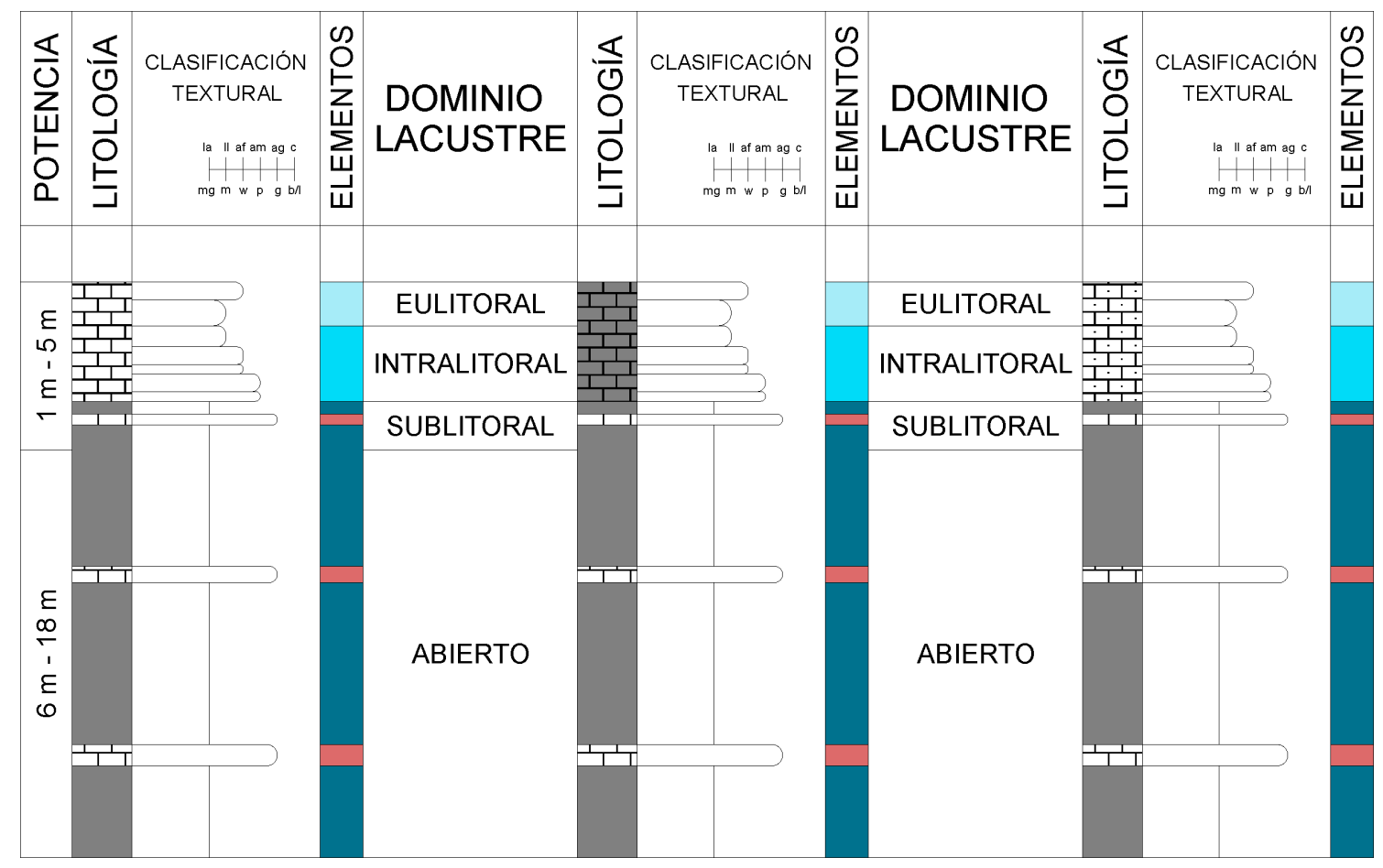

Figura 6.17: Secuencia teórica y variaciones litológicas del modelo lacustre mixto C1 (LM-C1). 


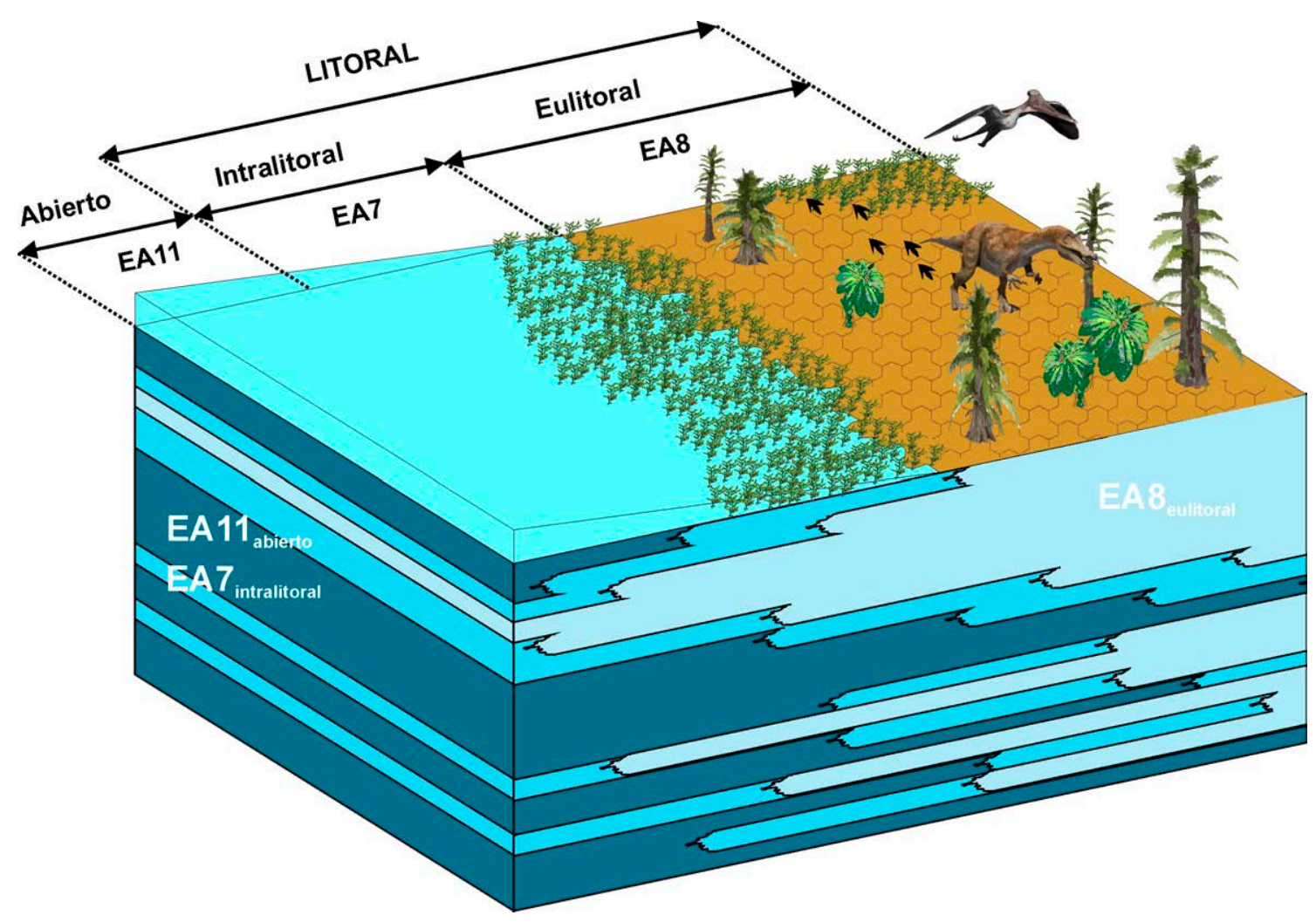

Figura 6.18: Bloque diagrama teórico del modelo lacustre mixto C2 (LM-C2).

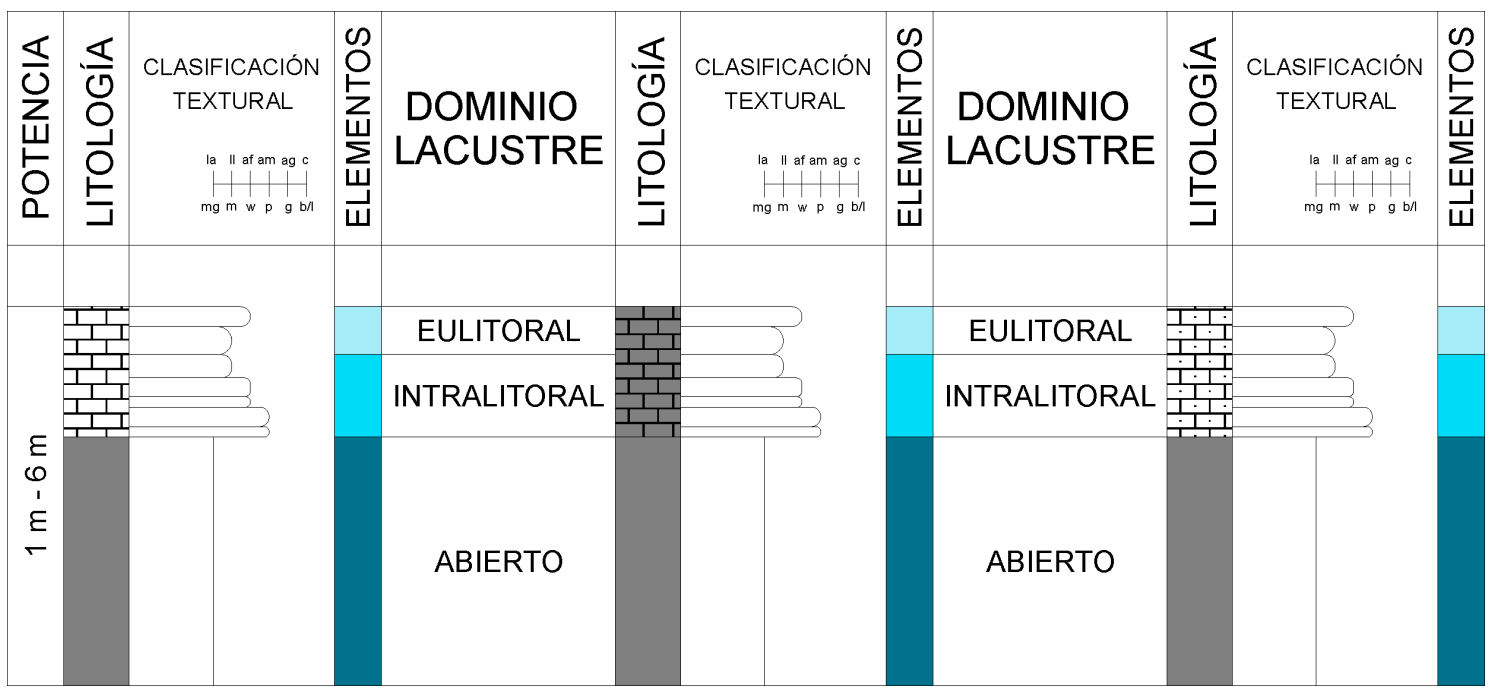

Figura 6.19: Secuencia teórica y variaciones litológicas del modelo lacustre mixto C2 (LM-C2).

\subsubsection{Modelo sedimentario lacustre carbonatado}

Los lagos con sedimentación carbonatada se clasifican atendiendo a dos caracteres principales: la energía del medio y la morfología de sus márgenes. Estos caracteres constituyen los casos extremos de un sistema continuo o gradación de posibilidades por lo que existen multitud de casos intermedios. La morfología de la zona litoral presenta dos tipos: margen en rampa (ramp margin) con un gradiente suave desde la zona eulitoral hasta la profunday, margen de plataforma (bench o shelf margin) con una morfología configurada por una zona poco profunda y de gradiente bajo denominada plataforma (platform bench) y otra más pronunciada 
denominada talud (bench slope). Se han definido cuatro tipos básicos (TUCKER Y WRIGHT, 1990; PLATT Y WRIGHT, 1991):

Los lagos carbonatados de margen de plataforma de baja energía (bench margin-low energy) se caracterizan porque la zona litoral exhibe una alta tasa de producción y, lo que es más importante, de sedimentación de carbonatados. Este hecho resulta en la progradación de los depósitos litorales sobre los profundos, como se ha observado en el lago Lawrence (OTSUKI Y WETZEL, 1974) y el lago Littlefield (DUSTIN et al., 1986). Los análogos modernos mejor conocidos y cuyos modelos de facies son ampliamente utilizados son el lago Littlefield (MURPHY Y WILKINSON, 1980) y el lago Sucker (TREESE Y WILKINSON, 1982), ambos localizados en Michigan. En el registro geológico exclusivamente se ha reconocido en la Caliza Peterson del Cretácico Inferior de los Estados Unidos (GLASSY WILKINSON, 1980) y en el Mioceno de la cuenca Las Minas en España (CALVO et al., 2000).

Los lagos carbonatados de margen de plataforma de alta energía influenciados por el oleaje (bench margin-high energy-wave dominated) se caracterizan por una marcada asimetría de sus facies debido a la cambiante energía producida por el oleaje. No existen análogos actuales, así pues su modelo se basa en la Formación Pliocena de Glenn Ferry Shooofly Oolite (SWIRYDCZUK et al., 1979; SWIRYDCZUK et al., 1980) y la Formación Terciaria de Camp Davis (DAVIS Y WILKINSON, 1983), ambas en los Estados Unidos.

Los lagos carbonatados de margen en rampa de baja energía (ramp margin-low energy) son generalmente someros. Las calizas presentan bajos contenidos en detríticos debido a la acción de pantalla y filtro de las praderas de carófitas que suelen crecer en las zonas marginales. Debido al bajo gradiente topográfico, los depósitos resultantes están formados por el apilamiento de extensas capas tabulares. Además, esta topografía suave permite que una pequeña caída del nivel del agua cause la exposición subaérea de extensas áreas de la cubeta lacustre. Esta categoría presenta una interesante contradicción, ya que siendo la más abundante en el registro fósil, por el contrario, no existen en la actualidad. Uno de los ejemplos más clásico (que sirvió para definir este modelo) se localiza en la cuenca de Cameros, en la Formación Rupelo (PLATT, 1989b; 1991). Otras referencias son la Formación Calizas de Draney en el Cretácico de los Estados Unidos (BROWN Y WiLKINSON, 1981), los depósitos del Cretácico Superior-Eoceno de Languedoc en Francia (FREYTET, 1973; FREYTET y PlAZIAT, 1982; FREYTET, 1984), la Formación El Molino (CAMOIN et al., 1997), y la Formación Paleoceno-Eoceno de Maíz Gordo en Argentina (DEL PAPA, 1999).

Los lagos carbonatados de margen en rampa influenciados por el oleaje (ramp marginwave influenced) se caracterizan por una amplia línea de costa fuertemente influenciada por las olas. No existen fenómenos de resedimentación, y no se produce la progradación de los depósitos litorales sobre los profundos (TUCKER Y WRIGHT, 1990). Los análogos modernos principales son el Gran Lago Salado de Utah (EARDLEY, 1938; DEAN Y FOUCH, 1983) y ciertas zonas del lago Tanganica (COHENY THOUIN, 1987). En el registro fósil se han reconocido en la Formación Green River en el Terciario de los Estados Unidos (WILLIAMSON Y PICARD, 1974; RYDER et al., 1976), la Formación Lagoa Feia en el Cretácico de Brasil (BERTANI Y CAROZZI, 1985a; BERTANI Y CAROZZI, 1985b), el Grupo Caithness Flagstone en el Devoniano de Escocia (DONOVAN, 1975; ROGERS Y AstiN, 1991), y el Grupo Mercia Mudstone en el Triásico de Inglaterra (MILROY Y WRIGHT, 2000).

En el Grupo Enciso, la disposición tabular de los depósitos carbonatados, su gran continuidad lateral, la ausencia de estructuras de oleaje y su textura mudstone-wackestone indican lagos carbonatados de margen en rampa de baja energía. La poca energía del medio se debe al bajo gradiente topográfico: el oleaje sufre una atenuación por fricción con el fondo, que se incrementa por el efecto pantalla de las praderas de carófitas que habitan estos lagos. Además los lagos con margen en rampa son sistemas muy dinámicos y cambiantes: reaccionan rápidamente frente a pequeñas fluctuaciones de cualquier factor que modifique su régimen hidrológico. Este dinamismo se manifiesta en marcadas oscilaciones del nivel dela lámina deagua y en sus patrones de vaciado-llenado, permitiendo cambios bruscos entre condiciones lacustres abiertas, someras y palustres, lo cual explica la poca secuencialidad observada en el análisis markoviano. 


\subsubsection{Modelo lacustre carbonatado A (LC-A)}

Este modelo está poco desarrollado y está constituido en su totalidad por términos de naturaleza carbonatada. El modelo de lago carbonatado LC-A muestra una secuencia teórica de colmatación lacustre (figura 6.20):

EA7abierto $\rightarrow$ EA7intralitoral $\rightarrow$ EA8 eulitoral

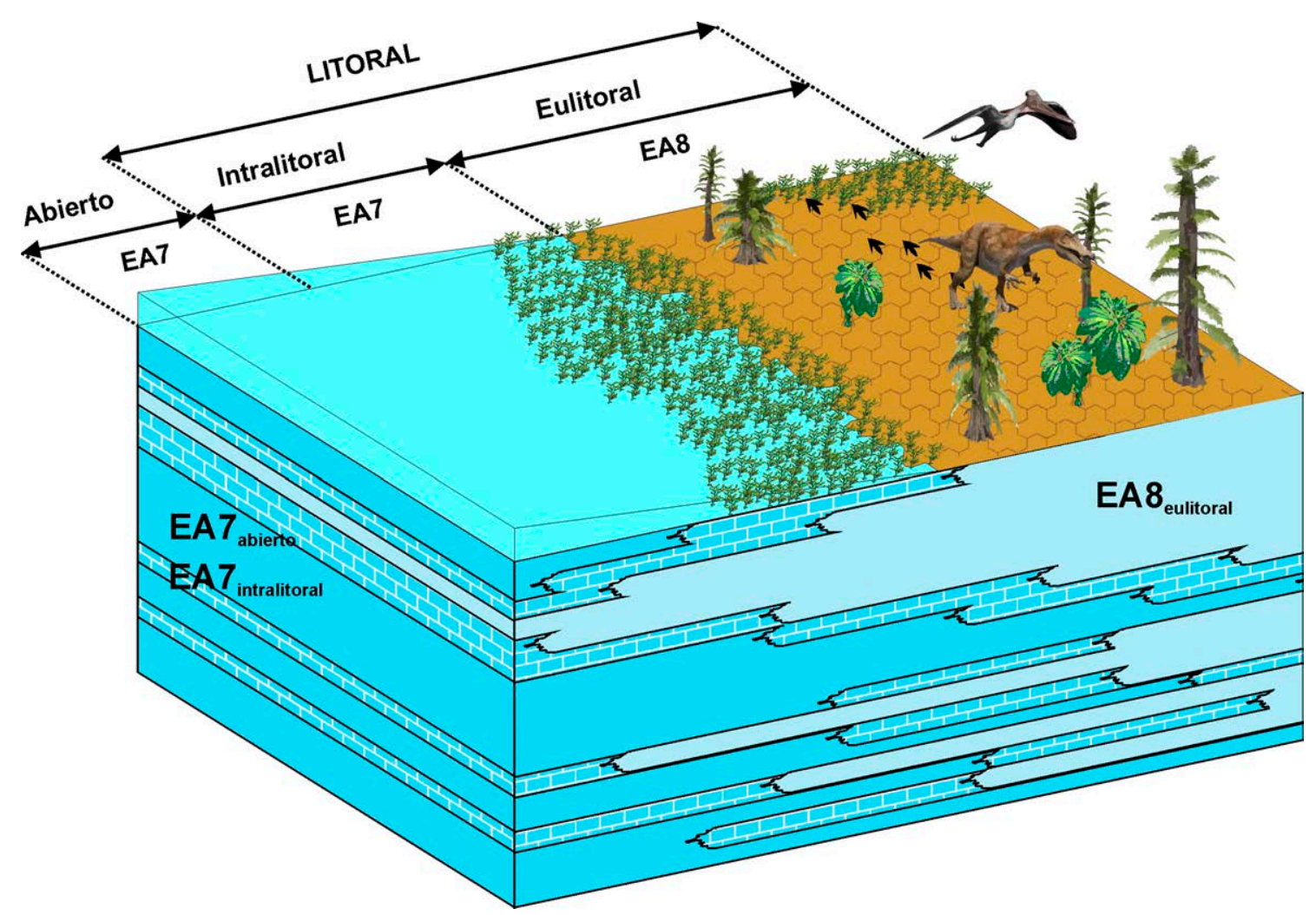

Figura 6.20: Bloque diagrama teórico del modelo lacustre carbonatado A (LC-A).

Las transiciones observadas en las columnas estratigráficas levantadas que sirven para identificar este modelo lacustre son:

$\begin{array}{ll}\text { Enciso } & \text { EA7 } \leftarrow \rightarrow \text { EA8 } \\ \text { Ambas Aguas } & \text { EA7 } \rightarrow \text { E } \leftarrow \text { EA8 } \\ \text { Cornago } & \text { EA7 } \leftrightarrow \text { EA8 } \\ \text { Munilla } & \text { EA7 } \leftrightarrow \text { EA8 }\end{array}$

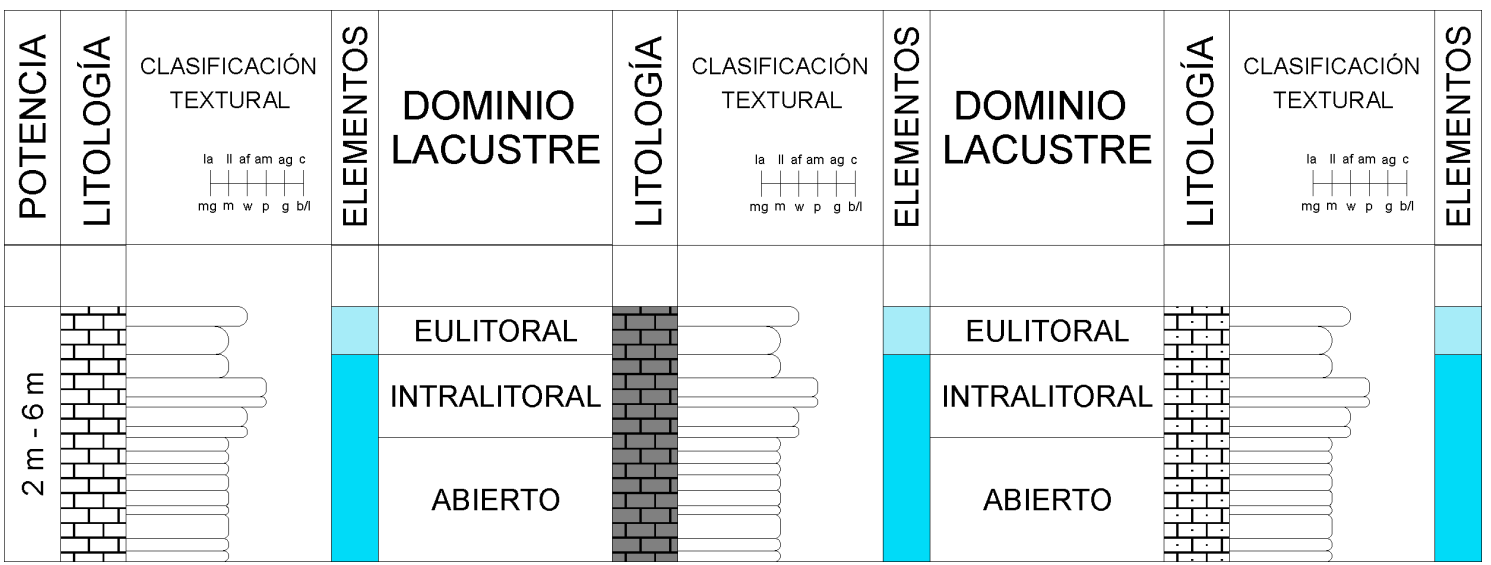


Figura 6.21: Secuencia teórica y variaciones litológicas del modelo lacustre carbonatado A (LCA).

Constituye paquetes con espesores comprendidos entre 2-6 metros (figura 6.21). El dominio abierto (término inferior) está formado por paquetes de calizas micríticas con un contenido bajo o nulo en bioclastos (EA7abierto). Las calizas masivas ricas en bioclastos, sobre todo ostrácodos, se depositan en la orla intralitoral (EA7intralitoral). El dominio eulitoral o litoral emergido se identifica con el elemento de calizas con evidencias de emersión (EA8 eulitoral). Este modelo representa un lago somero, de margen en rampa de baja energía, de poca pendientey bien oxigenado.

\subsubsection{Modelo lacustre carbonatado B (LC-B)}

La secuencia del modelo lacustre LC-B se compone de tres elementos arquitectónicos carbonatados que exhibe una secuencia teórica de colmatación lacustre (figura 6.22):

EA9abierto-sublitoral $\rightarrow$ EA7intralitoral $\rightarrow$ EA8 eulitoral

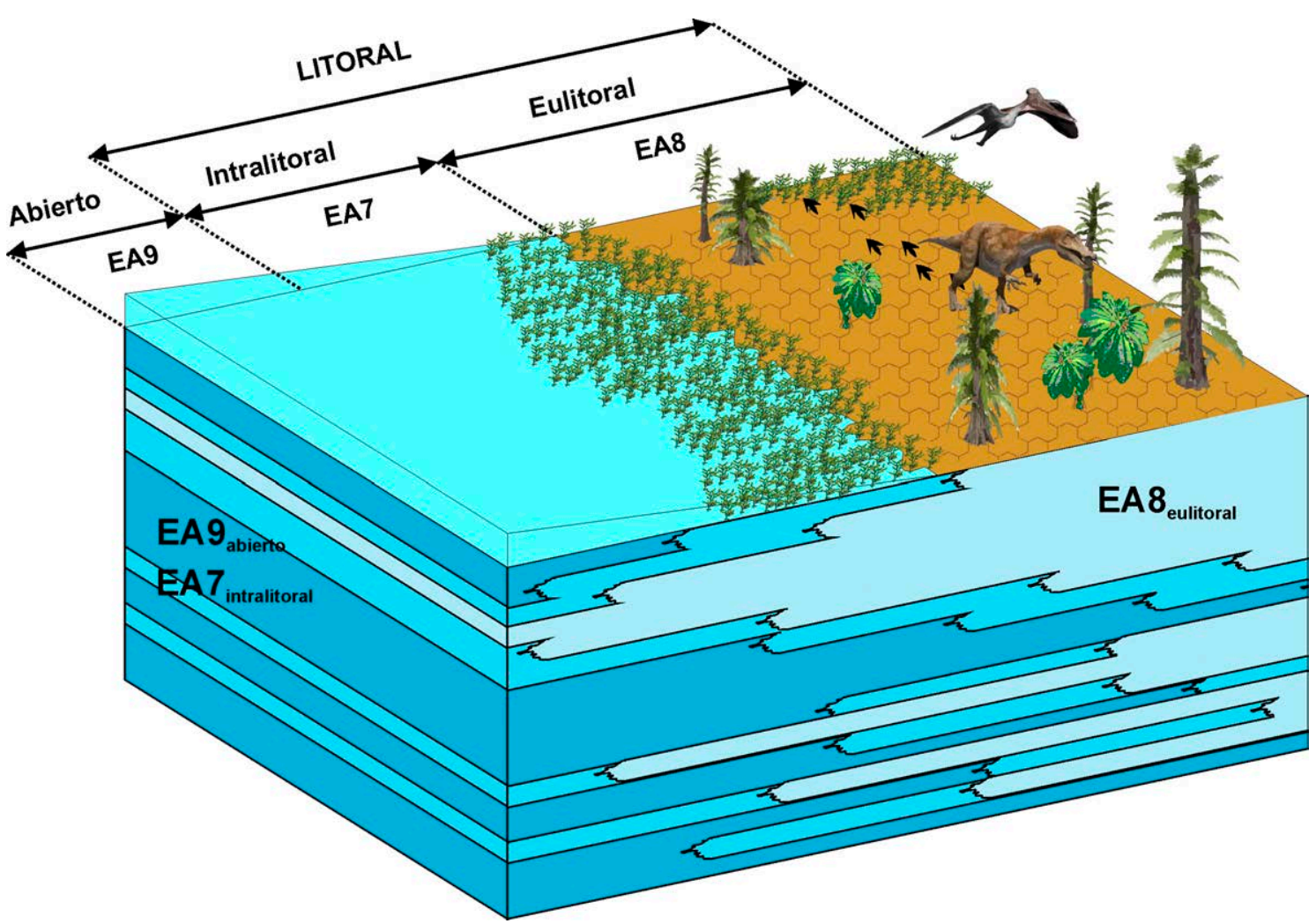

Figura 6.22: Bloque diagrama teórico del modelo lacustre carbonatado B (LC-B).

Este modelo está perfectamente desarrollado en la columna de Préjano (anexo VIII) donde predomina en los primeros $70 \mathrm{~m}$ de la serie levantada, mostrando un escaso desarrollo en el resto de columnas. Las transiciones presentes en las series levantadas son las siguientes:

$\begin{array}{ll}\text { Enciso } & \text { EA9 } \leftrightarrow \text { EA7 } \leftarrow \rightarrow \text { EA8 } \\ \text { Ambas Aguas } & \text { EA9 }(\rightarrow) \text { EA7 }(\rightarrow) \leftarrow \text { EA8 } \\ \text { Cornago } & \text { EA9 } \leftrightarrow \text { EA7 } \leftrightarrow \text { EA8 } \\ \text { Munilla } & \text { EA9 } \leftrightarrow \text { EA7 } \leftrightarrow \text { EA8 } \\ & \text { EA9 } \rightarrow \text { EA8 } \leftrightarrow \text { EA7 } \\ \text { Préjano } & \text { EA9 } \leftrightarrow \text { EA7 }(\leftrightarrow) \text { EA8 }\end{array}$

Constituye secuencias poco potentes variando entre 2 a $5 \mathrm{~m}$ (figura 6.23). El término inferior corresponde al dominio abierto-sublitoral que está representado por el elemento de 
calizas laminadas EA9abierto-sublitoral. El elemento suprayacente EA7 está formado por calizas masivas ricas en bioclastos que engloban a los carbonatos intralitorales (EA7intralitoral). Como es normal en esta zona, durante las etapas de caída del nivel del lago, los depósitos del dominio intralitoral quedan expuestos subaéreamente creando carbonatos con evidencias de emersión que corresponden a los medios eulitorales (EA8 eulitoral).

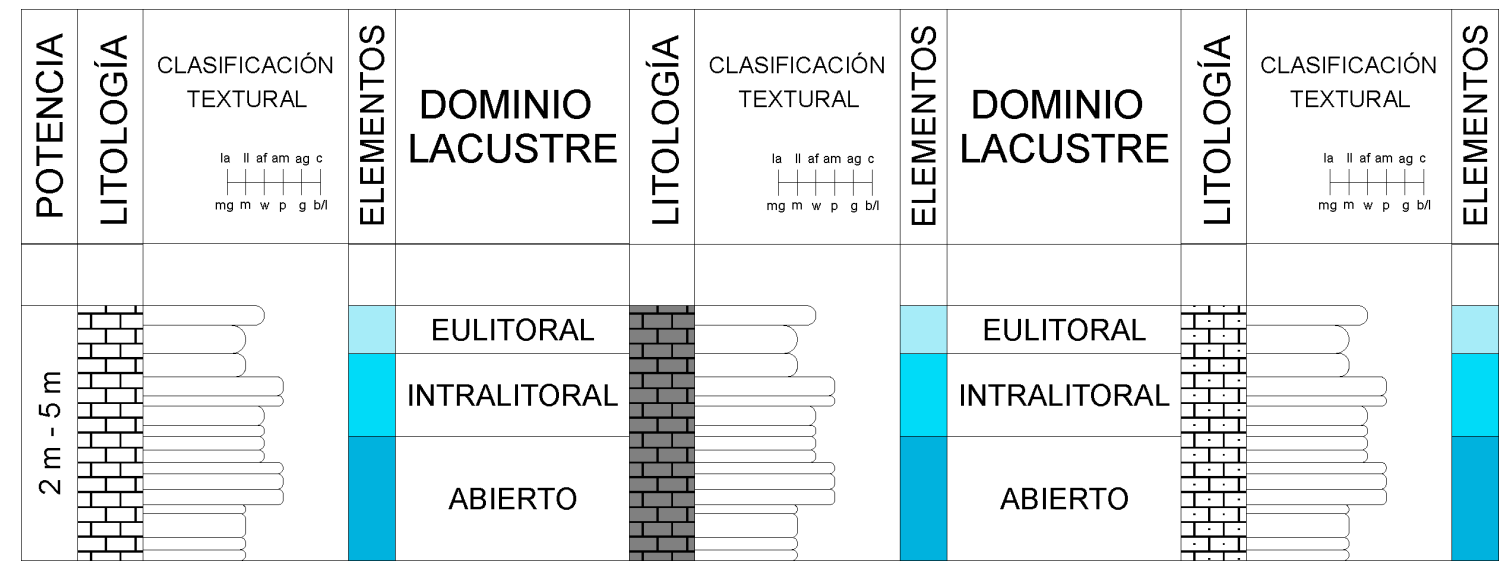

Figura 6.23: Secuencia teórica y variaciones litológicas del modelo lacustre carbonatado B (LCB).

\subsection{MODELO SEDIMENTARIO DELTAICO}

Los deltas son las áreas preferentes de entrada de sedimentos siliciclásticos en los lagos y, por consiguiente, constituyen zonas muy importantes de sedimentación. La dinámica de los deltas lacustres suele estar regida fundamentalmente por la dinámica fluvial debido a mínimo régimen mareal existente en los sistemas lacustres y a la moderación del oleaje (apartado 3.15). Lo normal es que los deltas lacustres se formen por la entrada de ríos en un lago, sin embargo, en ciertos casos también se pueden originar en las salidas o desagües de los mismos. Se conocen en la literatura anglosajona como outlet deltas (CALDWELL Y FITZGERALD, 1995).

Los depósitos deltaicos constituyen sistemas que evolucionan por agradación y progradación a partir de los aportes fluviales por lo que la parte emergida (superior) presenta una constante renovación de ambientes y, en consecuencia, de facies en el registro sedimentario. La arquitectura de los deltas lacustres es muy variada y está subordinada a multitud de parámetros de forzamiento, de los cuales los más importantes son:

a) La pendientedel margen y la textura dominante en la carga de fondo que transportan. Ambos parámetros están muy relacionados con la tectónica dominante en el área (SCHOLZ et al., 1993; LEMONS Y CHAN, 1999).

b) La batimetría (WRIGHT, 1977).

c) El régimen climático dominante (ScHOLZ et al., 1998).

De manera secundaria, las olas, las corrientes litorales y las fluctuaciones del nivel de base pueden retrabajar eficazmente estos materiales modificándolos en gran medida (SCHOLZ Y ROSENDAHL, 1990; SCHOlZ et al., 1990a; J OHNSON et al., 1995; SCHOLZ, 1995b). Los principales tipos de deltas en sistemas lacustres descritos en la literatura son:

a) Deltas tipo Gilbert (GILBERT, 1885; FÖRSTNER et al., 1968).

b) Abanicos deltaicos (COHEN, 1990).

c) Deltas dominados por la acción fluvial directa (AXELSSON, 1967; HYNE et al., 1979a) o por avulsiones o derrames (TYE Y COLEMAN, 1989b; a; SMITH Y PÉREZ-ARLUCEA, 1994; PÉREZ-ARLUCEA Y SMITH, 1999).

En una misma cubeta lacustre pueden aparecer varios morfotipos deltaicos diferentes, como ocurre hoy en día en el lago Malaui (J OHNSON et al., 1995; SCHOLZ, 1995a), y en la cuenca 
aluvial del Río Misisipi (FISK, 1944). También existen ejemplos en el registro fósil como el lago Bonneville (LEMONS Y CHAN, 1999) y el lago Hazar (DUNNE Y HEMPTON, 1984).

En una cuenca rift, esta variabilidad en la arquitectura deltaica puede atribuirse a los dominios estructurales y, en menor medida, a la fluctuaciones de gran amplitud y alta frecuencia (SCHOLZ, 1995a). Los deltas en lagos rift pueden tipificarse según el tipo de margen en el cual se instauren: margen axial, flexural, de borde de falla y/ o de acomodación (SCHOLZ, 1995a). Las variaciones del nivel del lago (limnoeustasia) repercuten de manera muy intensa en los deltas, de tal forma que, la deposición y sus cortejos sedimentarios son diferentes y en consecuencia dan lugar a complejos modelos del apilamiento (SCHOLZ et al., 1990a; LEMONS Y CHAN, 1999). En función de las fluctuaciones se clasifican en deltas de estadio de nivel alto (highstand delta) y deltas de estadio de nivel bajo (lowstand delta) (ScHOlZ et al., 1990a; SCHOLZ, 1995a).

En general, a macroescala, los depósitos deltaicos exhiben un marcado carácter granocreciente como consecuencia de la transición de ambientes lacustres profundos, con poca energía, hacia ambientes más someros que poseen mecanismos de deposición más energéticos. Esta disposición suele considerarse como uno de los caracteres diagnósticos. Estos paquetes granocrecientes pueden aparecer aislados o constituyendo múltiples ciclos agrupados debido a la subsidencia, actividad tectónica, migración de los lóbulos deltaicos o de las fluctuaciones del nivel de lago (COHEN, 2003).

\subsubsection{Modelo delta lacustre (DL)}

Cuando los márgenes de la cubeta lacustres son poco profundos, las corrientes cargadas de sedimentos sufren una rápida expansión y desaceleración. Son los denominados efluentes dominados por la fricción (WRIGHT, 1977) que originan deltas dominados por la acción fluvial tipo sheet deltas (FLINT et al., 1989; SMOOT, 1991; MAESTRO, 2008) o derrames deltaicos avulsivos (SMITH Y PÉREZ-ARLUCEA, 1994; PÉREZ-ARLUCEA Y SMITH, 1999). En estos casos se favorece la deposición de su carga en extensos mantos de arena que pueden sufrir el posterior retrabajamiento de las olas o las corrientes (FISHER et al., 2007).

En ambos casos se diferencian tres elementos arquitecturales principales (subambientes deltaicos) que constituyen secuencias granocrecientes hacia techo, resultantes de una progresiva transición hacia condiciones más someras y energéticas. Se caracteriza por un incremento en la energía del medio (aumento del tamaño de grano y de la proporción arena hacia techo) y un cambio en el mecanismo de sedimentación (decantación a tractivo). La sucesión teórica de los elementos en un delta lacustre es de la siguiente manera:

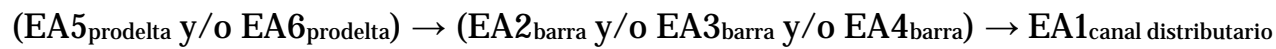

Las transiciones significativas que permiten caracterizar este modelo son:

\begin{tabular}{|c|c|}
\hline Enciso & $\mathrm{EA} 5 \rightarrow \mathrm{EA} 6 \rightarrow \mathrm{EA} 2$ \\
\hline & EA5 $\rightarrow$ EA6 $\leftrightarrow$ EA3 \\
\hline & $\mathrm{EA} 5 \rightarrow \mathrm{EA} 6 \leftrightarrow \mathrm{EA} 4 \leftrightarrow \mathrm{EA} 5 \leftrightarrow \mathrm{EA} 1$ \\
\hline & EA5 $\leftrightarrow$ EA1 \\
\hline & EA5 $\leftrightarrow$ EA4 \\
\hline & $\mathrm{EA} 1 \rightarrow \mathrm{EA} 6$ \\
\hline Ambas Aguas & $\mathrm{EA} 6 \leftrightarrow \mathrm{EA} 2 \rightarrow \mathrm{EA} 3 \leftarrow \mathrm{EA} 5$ \\
\hline & $\mathrm{EA} 6 \leftrightarrow \mathrm{EA} 2 \leftrightarrow \mathrm{EA} 4 \rightarrow \mathrm{EA} 1$ \\
\hline & $\mathrm{EA} 6 \leftrightarrow \mathrm{EA} 4 \rightarrow \mathrm{EA} 1$ \\
\hline & EA6 $\leftrightarrow$ EA1 \\
\hline & $\mathrm{EA} 5 \leftrightarrow \mathrm{EA} 4 \leftrightarrow \mathrm{EA} 2 \rightarrow \mathrm{EA} 3 \leftarrow \mathrm{EA} 5$ \\
\hline & $\mathrm{EA} 5 \leftrightarrow \mathrm{EA} 4 \rightarrow \mathrm{EA} 1$ \\
\hline Cornago & $\mathrm{EA} 6 \leftrightarrow \mathrm{EA} 2 \leftarrow \mathrm{EA} 1$ \\
\hline & $\mathrm{EA} 6 \leftrightarrow \mathrm{EA} 2 \leftrightarrow \mathrm{EA} 5 \leftrightarrow \mathrm{EA} 1$ \\
\hline & $\mathrm{EA} 6 \leftrightarrow \mathrm{EA} 3 \leftrightarrow \mathrm{EA} 5 \leftrightarrow \mathrm{EA} 1$ \\
\hline & $\mathrm{EA} 6 \leftrightarrow \mathrm{EA} 4 \leftrightarrow \mathrm{EA} 5 \leftrightarrow \mathrm{EA} 1$ \\
\hline
\end{tabular}




$\begin{array}{ll} & \text { EA5 } \leftrightarrow \text { EA4 } \\ & \text { EA5 } \leftrightarrow \text { EA3 } \\ & \text { EA5 } \leftrightarrow \text { EA2 } \leftarrow \text { EA1 } \\ & \text { EA5 } \leftrightarrow \text { EA1 } \\ \text { Munilla } & \text { EA1 } \rightarrow \text { EA6 } \rightarrow \text { EA2 } \rightarrow \text { EA4 } \\ & \text { EA1 } \rightarrow \text { EA6 } \leftrightarrow \text { EA3 } \rightarrow \text { EA2 } \rightarrow \text { EA4 } \\ & \text { EA1 } \rightarrow \text { EA6 } \leftrightarrow \text { EA4 } \\ & \text { EA5 } \leftrightarrow \text { EA1 } \\ & \text { EA1 } \leftrightarrow \text { EA5 } \leftrightarrow \text { EA4 } \leftarrow \text { EA2 } \leftarrow \text { EA3 } \\ & \text { EA1 } \leftrightarrow \text { EA5 } \leftarrow \text { EA2 } \leftarrow \text { EA3 } \\ & \text { EA1 } \leftrightarrow \text { EA5 } \leftarrow \text { EA2 } \rightarrow \text { EA4 } \leftrightarrow \text { EA5 } \\ \text { PAéjano } & \text { EA } \leftrightarrow \text { EA3 } \rightarrow \text { EA4 } \rightarrow \text { EA1 } \rightarrow \text { EA5 } \\ & \text { EA5 } \rightarrow \text { EA4 } \rightarrow \text { EA1 } \rightarrow \text { EA5 } \\ & \text { EA5 } \rightarrow \text { EA2 } \rightarrow \text { EA1 } \rightarrow \text { EA5 }\end{array}$

Constituye paquetes con espesores comprendidos entre 2-10 metros (figura 6.24). Los depósitos del prodelta constituyen el término inferior del complejo deltaico. Se presenta en paquetes métricos de geometría tabular (en ocasiones algo lenticular) de gran extensión lateral exhibiendo las granulometrías más finas del complejo deltaico. Se caracteriza por ser un subambiente enteramente subacuático y poco energético, por debajo del nivel de base de las olas, cuya sedimentación de produce por decantación de los materiales siliciclásticos más finos queson transportados como carga en suspensión hasta el lago, probablemente ayudados por fenómenos de floculación (HyNE et al., 1979b). Por tanto, desde un punto de vista sedimentológico, constan principalmente de arcillolitas y limolitas, localmente arenosas (EA5 prodelta $\mathrm{y} /$ o EA6 prodelta). Se apoyan sobre los depósitos lacustres de manera gradacional o levemente erosiva.

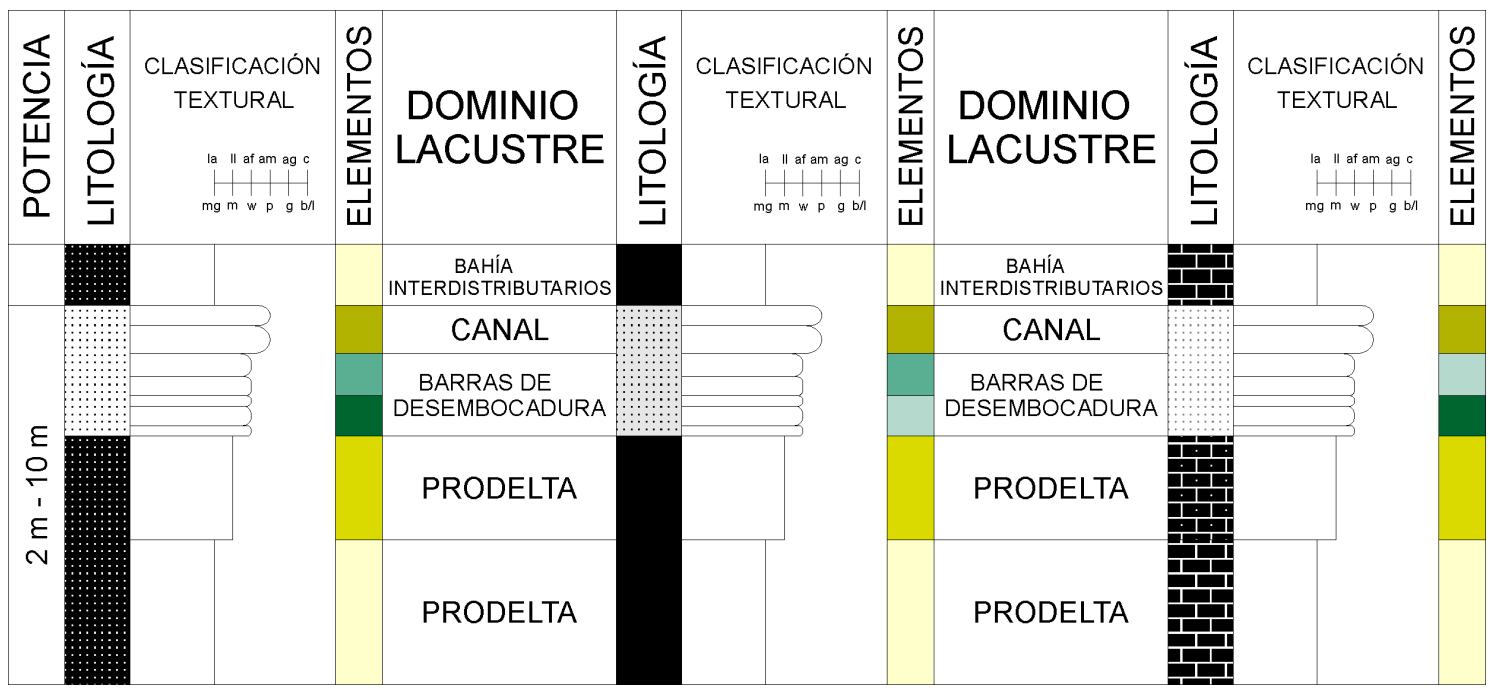

Figura 6.24: Secuencia teórica y variaciones litológicas del modelo de delta lacustre (DL).

Los depósitos de barra de desembocadura constituyen un ambiente de transición, más energético que el prodelta. La sedimentación se caracteriza por un tamaño de grano arena depositada por fenómenos tractivos (EA2barra y/o EA3barra y/o EA4barra). La amplia extensión lateral y su tendencia a coalescer lateralmente sugieren deltas que progradan sobre lagos de pendientes suaves, someros y poco energéticos típicos de sheet deltas y/o derrames deltaicos avulsivos. Finalmente, a techo aparece el canal distributario (EA1 canal distributario), que puede presentar elementos lutíticos reflejo de la etapa de abandono del canal (EA5abandono canal). También es posible que aparezcan depósitos de palustres localizados en las bahías interdistributarios (EA5palustre). 
Análisis sedimentológico: elementos arquitectónicos y medios sedimentarios 


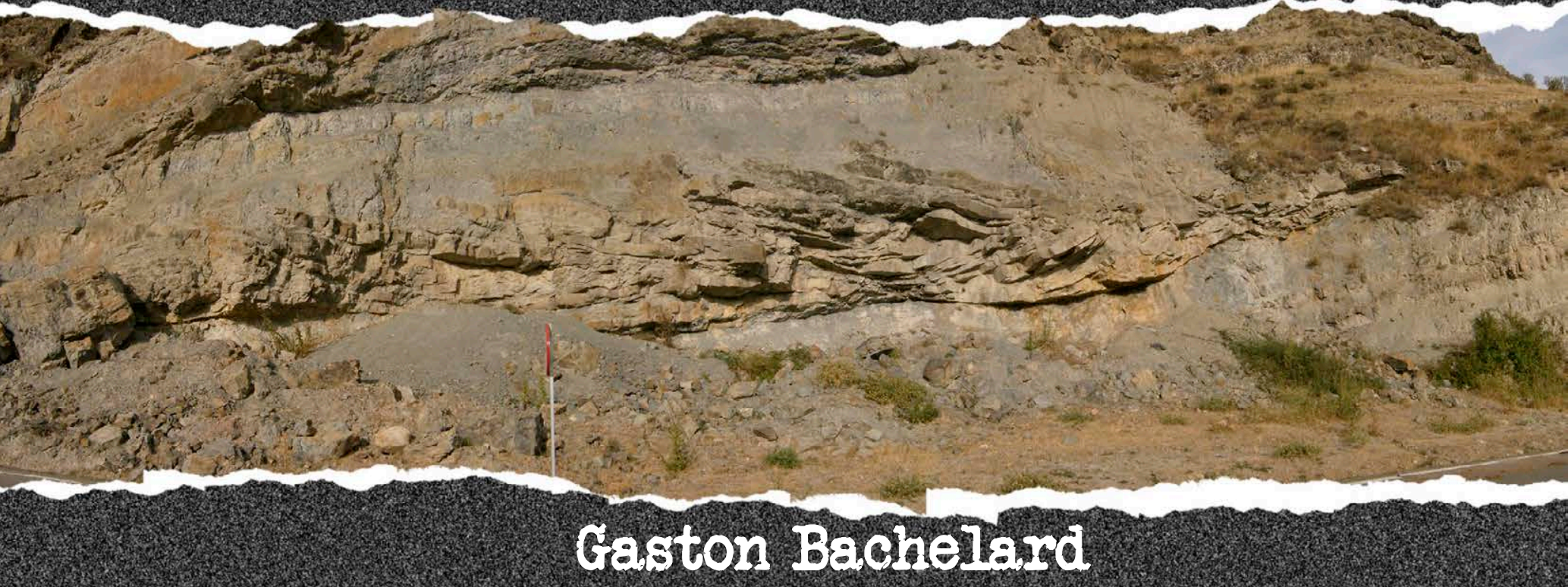

\section{Ia formation de l'esprit scientifique (1938)}

(7)

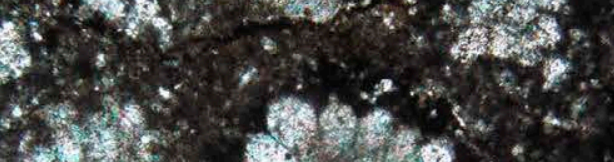

\section{el conocinitento de 10 real es una lua que} siempre projecta sombras hacia

\section{algun lugast}

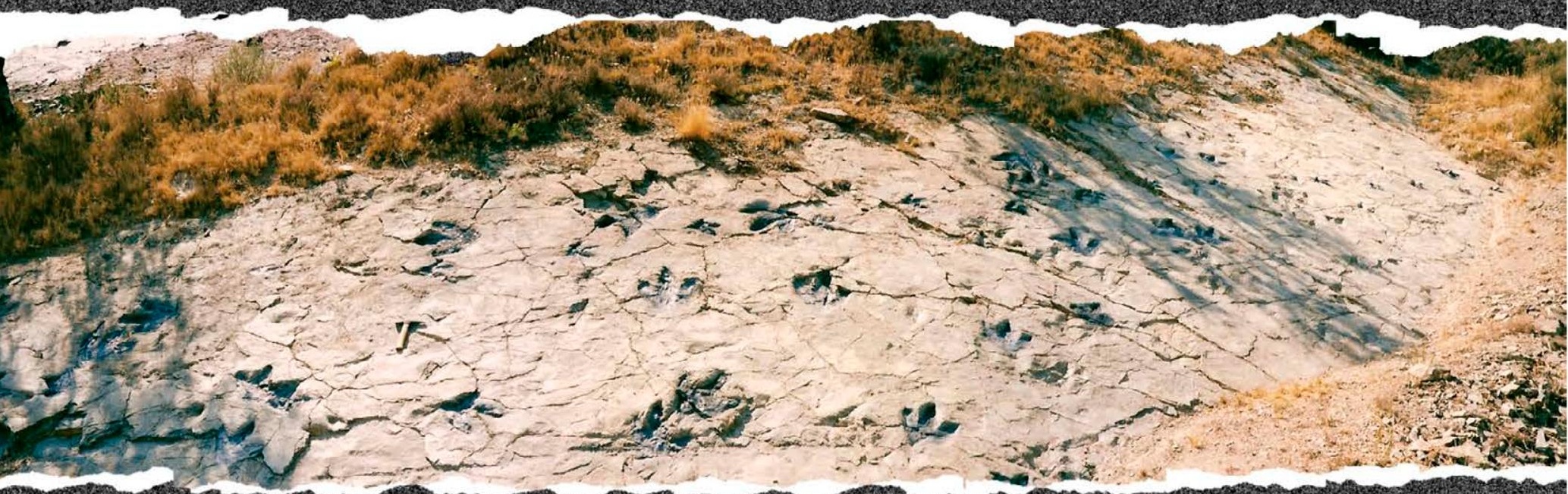




\subsection{CONSIDERACIONES INICIALES}

Los sedimentos lacustres son excelentes archivos donde queda registrada la historia del lago. De las múltiples técnicas paleolimnológicas existentes, el análisis de isótopos estables, $\delta^{18} \mathrm{O}$ y $\delta^{13} \mathrm{C}$, constituye una herramienta ampliamente utilizada como indicadores de las fluctuaciones del balance hidrológico, producción primaria, aportes autóctonos versus alóctonos, etc.

Sin embargo, el análisis isotópico de los carbonatos lacustres se caracteriza por la complejidad asociada al elevado número de procesos naturales (en nuestro caso se puede excluir los procesos antropogénicos) que pueden influir en su precipitación. Así pues, el valor isotópico es el resultado de la composición isotópica del carbonato inicial (reflejando características fisicoquímicas del ambiente donde ha precipitado), así como de los eventuales cambios isotópicos post-deposicionales ligados a su historia diagenética.

La utilidad de los isótopos estables se fundamenta en la existencia de fraccionamientos cuantificables entre diferentes reacciones que producen una composición característica. Así pues, poseen la capacidad de aportar información tanto del origen como de los procesos de fraccionamiento operantes.

\subsection{ISÓTOPOS DEL CARBONO-EL CICLO DEL CARBONO}

El carbono aparece en una amplia variedad de compuestos terrestres, tanto inorgánicos como orgánicos. Las variaciones en la naturaleza en la composición isotópica del carbono son del orden de $170 \%$, excluyendo los materiales de origen extraterrestre. Así, el valor más elevado (+37,5\%o) corresponde al agua intersticial presente en el fondo oceánico (CLAYPOOL et al., 1985). El valor más negativo $(-130,3 \%$ ) se encontró en una biomolécula (crocetano) recogida en una surgencia fría (cold-seep) (ELVERT et al., 2000).

La complejidad del ciclo del carbono en un sistema lacustre da lugar a un complicado entramado de fraccionamientos entre las diferentes especies existentes $\left(\mathrm{CaCO}_{3}, \mathrm{CO}_{2 \text { (gas), }} \mathrm{CO}_{2 \text { (ac) }}\right.$, $\mathrm{H}_{2} \mathrm{CO}_{3}, \mathrm{HCO}_{3}{ }^{-}, \mathrm{CO}_{3}{ }^{2-}, \mathrm{CH}_{4}$ y materia orgánica), así como a la coexistencia de diversas fases (gaseosa, en solución y sólida). La concentración relativa de cada una de las especies carbonatadas en solución depende del $\mathrm{pH}$, permitiendo que, dentro de un determinado rango del $\mathrm{pH}$, exista una especie mayoritaria (figura 3.9). $\mathrm{El} \mathrm{CO}_{2}$ atmosférico se disuelve en el agua para formar $\mathrm{CO}_{2}$ disuelto y ácido carbónico:

$$
\begin{aligned}
& \mathrm{CO}_{2 \text { (gas) }} \leftrightarrow \mathrm{CO}_{2 \text { (ac) }} \\
& \mathrm{CO}_{2 \text { (ac) }}+\mathrm{H}_{2} \mathrm{O} \leftrightarrow \mathrm{H}_{2} \mathrm{CO}_{3}
\end{aligned}
$$
reacciones:

$\mathrm{El} \mathrm{H}_{2} \mathrm{CO}_{3}$ (muy inestable) y el $\mathrm{CO}_{2}$ disuelto se disocian generando bicarbonato según las

$$
\begin{aligned}
& \mathrm{CO}_{2(\mathrm{ac})}+\mathrm{H}_{2} \mathrm{O} \leftrightarrow \mathrm{H}^{+}+\mathrm{HCO}_{3}^{-} \\
& \mathrm{H}_{2} \mathrm{CO}_{3} \leftrightarrow \mathrm{HCO}_{3}^{-}+\mathrm{H}^{+}
\end{aligned}
$$

Finalmente, una parte del bicarbonato se disocia generando carbonato y elevando la acidez del medio.

$$
\mathrm{HCO}_{3}^{-} \leftrightarrow \mathrm{H}^{+}+\mathrm{CO}_{3}^{2-}
$$

El Carbono Inorgánico Disuelto (CID) existente en la masa de agua se define como la suma de la concentración de todas las especies inorgánicas disueltas y su valor isotópico, en un momento dado, se puede expresar como:

$$
\delta^{13} \mathrm{C}_{\mathrm{CID}}=\frac{\mathrm{a} \cdot \delta^{13} \mathrm{C}_{\mathrm{H}_{2} \mathrm{CO}_{3}+\mathrm{CO}_{2(\mathrm{ac})}}+\mathrm{b} \cdot \delta^{13} \mathrm{C}_{\mathrm{HCO}_{3}^{-}}+\mathrm{c} \cdot \delta^{13} \mathrm{C}_{\mathrm{CO}_{3}^{2-}}}{\mathrm{CID}}
$$




$$
\begin{aligned}
& \mathrm{a}=\left[\mathrm{H}_{2} \mathrm{CO}_{3}\right]+\left[\mathrm{CO}_{2(\mathrm{ac})}\right] \leftrightarrow \mathrm{b}=\left[\mathrm{HCO}_{3}^{-}\right] \leftrightarrow \mathrm{c}=\left[\mathrm{CO}_{3}^{2-}\right] \\
& \mathrm{CID}=\left[\mathrm{H}_{2} \mathrm{CO}_{3}\right]+\left[\mathrm{CO}_{2(\mathrm{ac})}\right]+\left[\mathrm{HCO}_{3}^{-}\right]+\left[\mathrm{CO}_{3}^{2-}\right]=\mathrm{a}+\mathrm{b}+\mathrm{c}
\end{aligned}
$$

El valor $\delta^{13} \mathrm{C}$ cid de los lagos actuales está comprendido entre -31\% y +2,6\%o (MOOK Y TAN, 1991; STRIEGL et al., 2001; BADE et al., 2004). A su vez, cada lago de manera individual, suele exhibir un rango temporal de variación de $\pm 5 \%$ on su valor medio (BADE et al., 2004).

La composición isotópica del carbono inorgánico disuelto $\delta^{13} \mathrm{C}$ CID en un lago es el resultado final de una serie de entradas y salidas (ANDERSONY ARTHUR, 1983; BADE et al., 2004; LENG Y MARSHALL, 2004; TRANVIK et al., 2009) (figura 7.1). Las entradas en un sistema lacustre comprenden:

a) Intercambio con el $\mathrm{CO}_{2}$ atmosférico, es decir, la disolución del dióxido de carbono atmosférico.

b) Respiración aeróbica de la materia orgánica.

c) Respiración anaeróbica (metanogénesis y posterior oxidación del metano).

d) Admisión de $\mathrm{CO}_{2}$ acuoso y de alcalinidad $\left(\mathrm{HCO}_{3}-\mathrm{y} \mathrm{CO}_{3}^{2-}\right)$ por aguas superficiales y/o subterráneas.

e) Carbonatación (disolución de la calcita).

f) Litología de la cuenca de drenaje (rocas del área madre).

Las salidas más significativas de CID de la cubeta lacustre están representadas por los siguientes procesos:

a) Escape de $\mathrm{CO}_{2}$ hacia la atmósfera.

b) Precipitación del carbonato.

c) Consumo fotosintético.

d) Salida de agua por los drenajes o por infiltración.

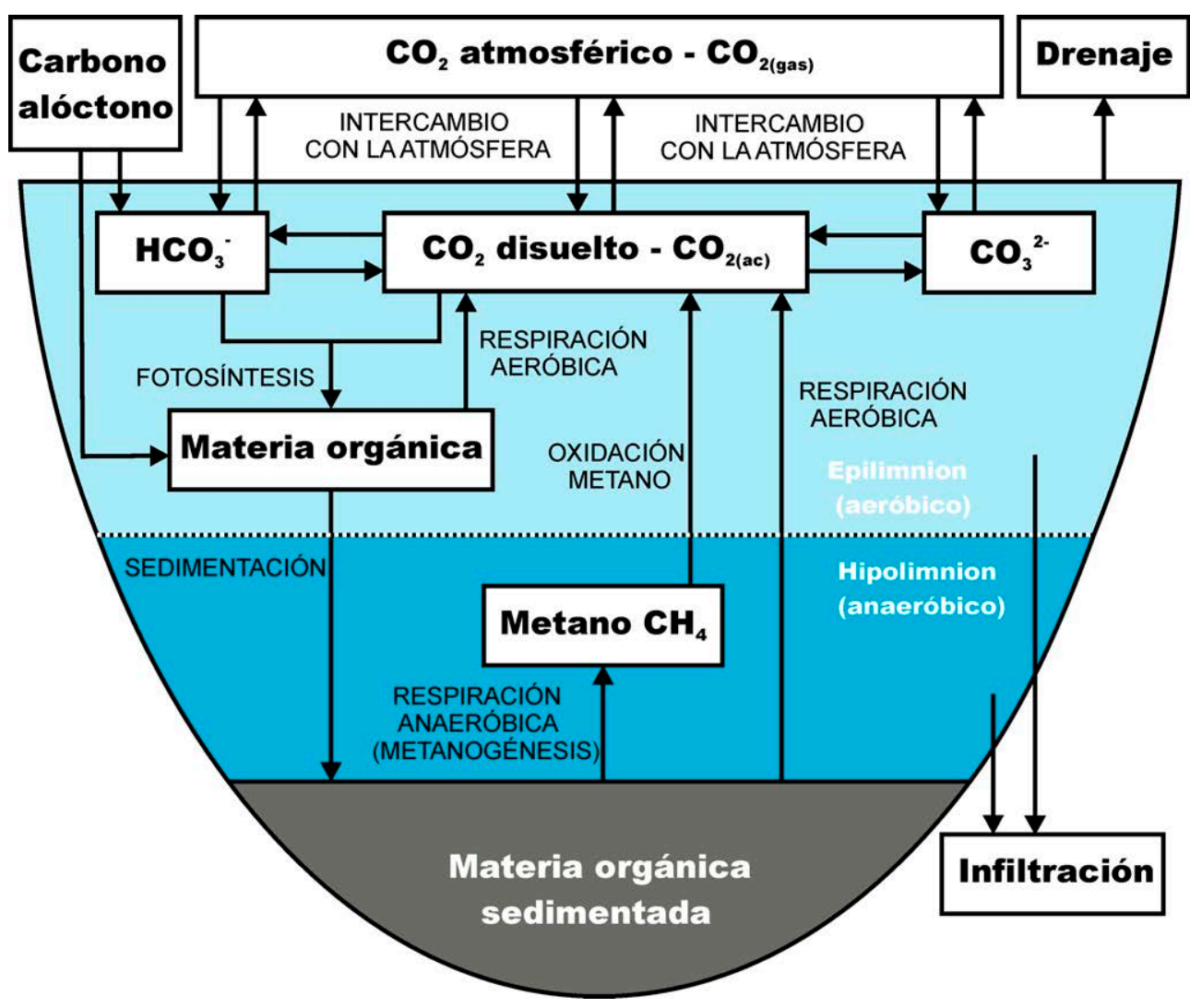

Figura 7.1: Ciclo del carbono simplificado en los lagos, con indicación de los procesos de fraccionamiento más comunes. 
De todos ellos, los principales mecanismos susceptibles de modificar la signatura isotópica del CID son: a) la composición de las aguas que entran (subterráneas y/ o superficiales), b) los intercambios de $\mathrm{CO}_{2}$ entre las aguas del lago y la atmósfera y, c) la fotosíntesis-respiración de las plantas acuáticas. MYRBO Y SHAPLEY (2006) demuestran que en los lagos de aguas duras, el valor $\delta^{13}$ CIC está dominado fundamentalmente por el tamaño del reservorio (pool) de CID en relación a los flujos de carbono en el lago, por la presión parcial del $\mathrm{CO}_{2}$ del agua, y por la estratificación-circulación del lago. BADE et al. (2004) consideran que el valor $\delta^{13} \mathrm{C}$ cID está influenciado por procesos de naturaleza geoquímica (CID, $\mathrm{pH}$, alcalinidad, etc.) y morfométricas. Por el contrario, los mecanismos biológicos (productividad primaria, respiración, etc.) son poco significativos en el cómputo total.

También se ha observado que los lagos de mayor extensión muestran valores más elevados de $\delta^{13} \mathrm{C}$ ciD. Las causas no están claras pero podrían deberse a la relación entre el espejo del lago y el área de drenaje (RASMUSSEN et al., 1989) ya que, proporcionalmente, reciben menor cantidad de materia orgánica terrestre (BADE et al., 2004). Otra explicación se relaciona con su posición en zonas geográficamente deprimidas, lo cual les hace recibir una mayor cantidad de agua subterránea (KRATZ et al., 1997). Por consiguiente, el $\delta^{13} \mathrm{C}$ CID en los grandes lagos está gobernado por las entradas externas y los intercambios atmosféricos (BADE et al., 2004).

\subsubsection{Entrada de carbono desde fuera de la cubeta (carbono alóctono)}

Los aportes de carbono alóctono pueden ser tanto de origen orgánico como inorgánico. Todo el carbono existente en las aguas superficiales y subterráneas procede de la producción de $\mathrm{CO}_{2}$ en los suelos y de la respiración de las plantas (LENG Y MARSHALL, 2004). Los ríos, además, aportan una proporción importante de carbono inorgánico alóctono y, al igual que los lagos, suelen estar supersaturados respecto al $\mathrm{CO}_{2}$ (COLE Y CARACO, 2001).

El $\mathrm{CO}_{2}$ del suelo está enriquecido en ${ }^{13} \mathrm{C}$ aproximadamente un 4,4\%o respecto al valor medio ${ }^{13} \mathrm{C}$ de la materia orgánica o del $\mathrm{CO}_{2}$ respirado debido al fraccionamiento por difusión (CERLING et al., 1991; DAVIDSON, 1995). Así pues, el aporte de agua subterránea tiende disminuir el valor $\delta^{13}$ Cic del agua del lago.

Tanto en las aguas superficiales como subterráneas, los aportes de carbono procedentes delas plantas terrestres son de una importancia extrema. Alrededor del 90\% del carbono orgánico que entra en los lagos lo hace en forma de materia orgánica disuelta (PRAIRIE y COLE, 2009). Las cuencas de alimentación húmedas y vegetadas favorecen un valor negativo de $\delta^{13} \mathrm{C}$ (TALBOT, 1990). Así pues, es imprescindible conocer el fraccionamiento que se produce durante la asimilación del $\mathrm{CO}_{2}$ por las plantas terrestres (fotosíntesis). De manera general, las plantas discriminan en contra de ${ }^{13} \mathrm{CO}_{2}$, ya que el ${ }^{13} \mathrm{C}$ se difunde y reacciona más despacio que el ${ }^{12} \mathrm{C}$. De esta manera, los vegetales siempre contienen menos ${ }^{13} \mathrm{C}$ que el $\mathrm{CO}_{2}$ atmosférico (FARQUHAR et al., 1989a). Esta discriminación es, sin embargo, variable y está determinada fundamentalmente por la ruta fotosintética realizada:

a) $\mathrm{C}_{3}$ o ciclo fotosintético Calvin-Brensen que producen valores $\delta^{13} \mathrm{C}$ comprendidos entre -37\% y - 20\%. En general, se les suele asignar un valor medio aproximado de $-27,0 \%$ o (KOHN, 2010).

b) $\mathrm{C}_{4}$ o ciclo Hatch-Slack con valores en el rango - 12 a - $16 \%$, y un valor medio de - $14 \%$ (DEINES, 1980; O'LEARY, 1988).

c) MAC (Metabolismo Ácido de las Crasuláceas) o CAM (Crassulacean Acid Metabolism) que cubren todo el espectro de variación de las $\mathrm{C}_{3}$ y $\mathrm{C}_{4}$ con valores de $\delta^{13} \mathrm{C}$ en el rango - 10 a-20\%o (DEINES, 1980; O'LEARY, 1981; 1988).

Además de los procesos biológicos, las áreas madre de naturaleza carbonatada pueden ser una fuente importante de carbono al sistema lacustre. Las rocas carbonatadas constituyen el mayor reservorio de carbono a escala mundial (LIU Y ZHAO, 2000), ocupando aproximadamente unos 22 millones de $\mathrm{km}^{2}$ (YUAN, 1997) o un 12\% de la superficie terrestre emergida. Por ejemplo, 
el lago Pinarbasi (Turquía) tiene un área madre de calizas que hace que los carbonatos precipitados tengan un valor medio de $+2,0 \pm 1,4 \%$ ( (LENG et al., 1999).

\subsubsection{Intercambio de carbono entre el agua y la atmósfera}

Los intercambios de $\mathrm{CO}_{2}$ entre la atmósfera y el lago son vitales en el ciclo del carbono en un sistema lacustre. El $\mathrm{CO}_{2}$ atmosférico ( $\left.\mathrm{CO}_{2 \text { (gas) }}\right)$ se intercambia con el $\mathrm{CO}_{2}$ disuelto en el agua $\left(\mathrm{CO}_{2(\mathrm{ac})}\right)$ según la reacción de equilibrio:

$$
{ }^{12} \mathrm{CO}_{2 \text { (gas) }}+{ }^{13} \mathrm{CO}_{2 \text { (ac) }} \leftrightarrow{ }^{13} \mathrm{CO}_{2 \text { (gas) }}+{ }^{12} \mathrm{CO}_{2 \text { (ac) }}
$$

Bajo condiciones de equilibrio, el fraccionamiento puede calcularse con cualquiera de las siguientes fórmulas:

$$
\begin{aligned}
& 1000 \cdot \ln \alpha_{\mathrm{CO}_{2(\mathrm{ac})}-\mathrm{CO}_{2 \text { (gas) }}=-(0,0049 \pm 0,003) \cdot \mathrm{T}_{\mathrm{C}}-(1,31 \pm 0,06) \% \text { o (ZHANG et al., 1995) }}=(0,0041 \pm 0,0005) \cdot \mathrm{T}_{\mathrm{C}}-(1,18 \pm 0,01) \% \text { (VOGEL et al., 1970) }
\end{aligned}
$$

En todas las fórmulas de los fraccionamientos que van a aparecer a lo largo del presente capítulo, la temperatura sigue la notación $T_{\mathrm{K}}$ (grado Kelvin) y $\mathrm{T}_{\mathrm{C}}$ (grados Celsius) siendo la relación entre ambos $\mathrm{T}_{\mathrm{K}}=273,15+\mathrm{T}_{\mathrm{C}}$.

También es útil la ecuación del fraccionamiento existente en la reacción de equilibrio entre el $\mathrm{CO}_{2}$ atmosférico y el bicarbonato disuelto:

$$
\begin{aligned}
& \mathrm{H}^{12} \mathrm{CO}_{3}^{-}+{ }^{13} \mathrm{CO}_{2 \text { (gas) }} \leftrightarrow \mathrm{H}^{13} \mathrm{CO}_{3}^{-}+{ }^{12} \mathrm{CO}_{2 \text { (gas) }} \\
& \varepsilon_{\mathrm{CO}_{2(\text { gas })}-\mathrm{HCO}_{3}^{-}}=(9,483 \pm 0,22) \cdot \frac{10^{3}}{\mathrm{~T}_{\mathrm{K}}}+(23,89 \pm 0,75) \% \text { (MoOK et al., 1974) }
\end{aligned}
$$

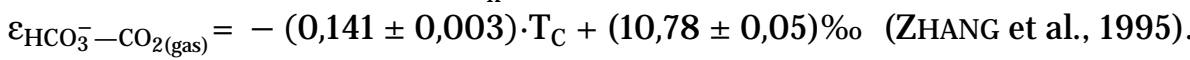

En general, el $\mathrm{CO}_{2}$ atmosférico se encuentra casi en equilibrio isotópico con el bicarbonato oceánico disuelto (TANS et al., 1990; TANS et al., 1993). Si no existe equilibrio, tanto la captura

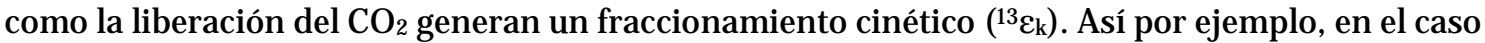
del intercambio océano $\rightarrow$ atmósfera, durante el escape de $\mathrm{CO}_{2}$, el fraccionamiento cinético se sitúa

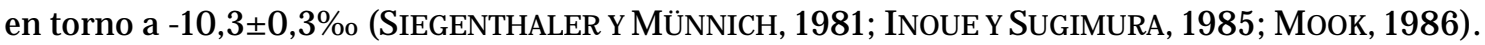
Por el contrario, durantela captación de $\mathrm{CO}_{2}$ (atmósfera $\rightarrow$ océano), el fraccionamiento cinético es del orden de $-2,0 \pm 0,2 \%$ o (SIEGENTHALER Y MÜNNICH, 1981; INOUE Y SUGIMURA, 1985; WANNINKHOF, 1985; MOOK, 1986).

A diferencia de los océanos, los lagos suelen estar supersaturados ya que el equilibrio es un fenómeno infrecuente, y constituyen una fuente significativa de $\mathrm{CO}_{2}$ hacia la atmósfera (COLE et al., 1994; DUARTE Y PRAIRIE, 2005; SOBEK et al., 2005; DUARTE et al., 2008; MAROTTA et al., 2009; KOSTEN et al., 2010). Sólo los lagos con un gran área del espejo tienden a estar cerca del equilibrio, ya que la acción del viento favorece la tasa de intercambio gaseoso (BADE et al., 2004). STRIEGL et al. (2001) observaron que los lagos actuales con mayores presiones parciales de $\mathrm{CO}_{2}$ muestran valores bajos de $\delta^{13} \mathrm{C}$ CID, debido a que en sus aguas existe un domino de la respiración de la materia orgánica terrestre. Aunque la supersaturación es un fenómeno ligeramente más frecuente en los lagos situados fuera de los trópicos $(\approx 92 \%)$ respecto a los lagos propiamente tropicales $(\approx 87 \%)$, estos últimos muestran una supersaturación mucho mayor $\left(\rho \mathrm{CO}_{2}=1804 \pm 35\right.$ $\mu \mathrm{atm})$ que el resto $\left(\rho \mathrm{CO}_{2}=1070 \pm 6 \mu \mathrm{atm}\right)$, probablemente relacionada con la temperatura (MAROTTA et al., 2009) (figura 7.2).

El escape preferente de ${ }^{12} \mathrm{CO}_{2}$ hacia la atmósfera, conlleva un enriquecimiento en ${ }^{13} \mathrm{C}$ en las aguas del lago (MichAELIS et al., 1985; TALBOT, 1990; MEES et al., 1998). En el lago Blue (Australia), la entrada de $\mathrm{CO}_{2}$ atmosférico en las aguas del lago añade $\mathrm{CO}_{2}$ con un valor $\delta^{13} \mathrm{C}=$ $9 \%$, mientras que el escape hacia la atmósfera elimina $\mathrm{CO}_{2}$ con $\delta^{13} \mathrm{C} \approx-14 \%$ o (HERCZEG et al., 2003). En el Mar Muerto (Israel), con una presión parcial del $\mathrm{CO}_{2} \approx 2000 \mu \mathrm{atm}$, el factor de 
fraccionamiento cinético asociado al escape de $\mathrm{CO}_{2}$ hacia la atmósfera varían entre ${ }^{13} \varepsilon_{\mathrm{k}}=$ $16,2 \pm 0,3 \%$ o (BARKAN et al., 2001) y ${ }^{13} \varepsilon_{\mathrm{k}}=-18,2 \%$ o (STILLER et al., 1985).

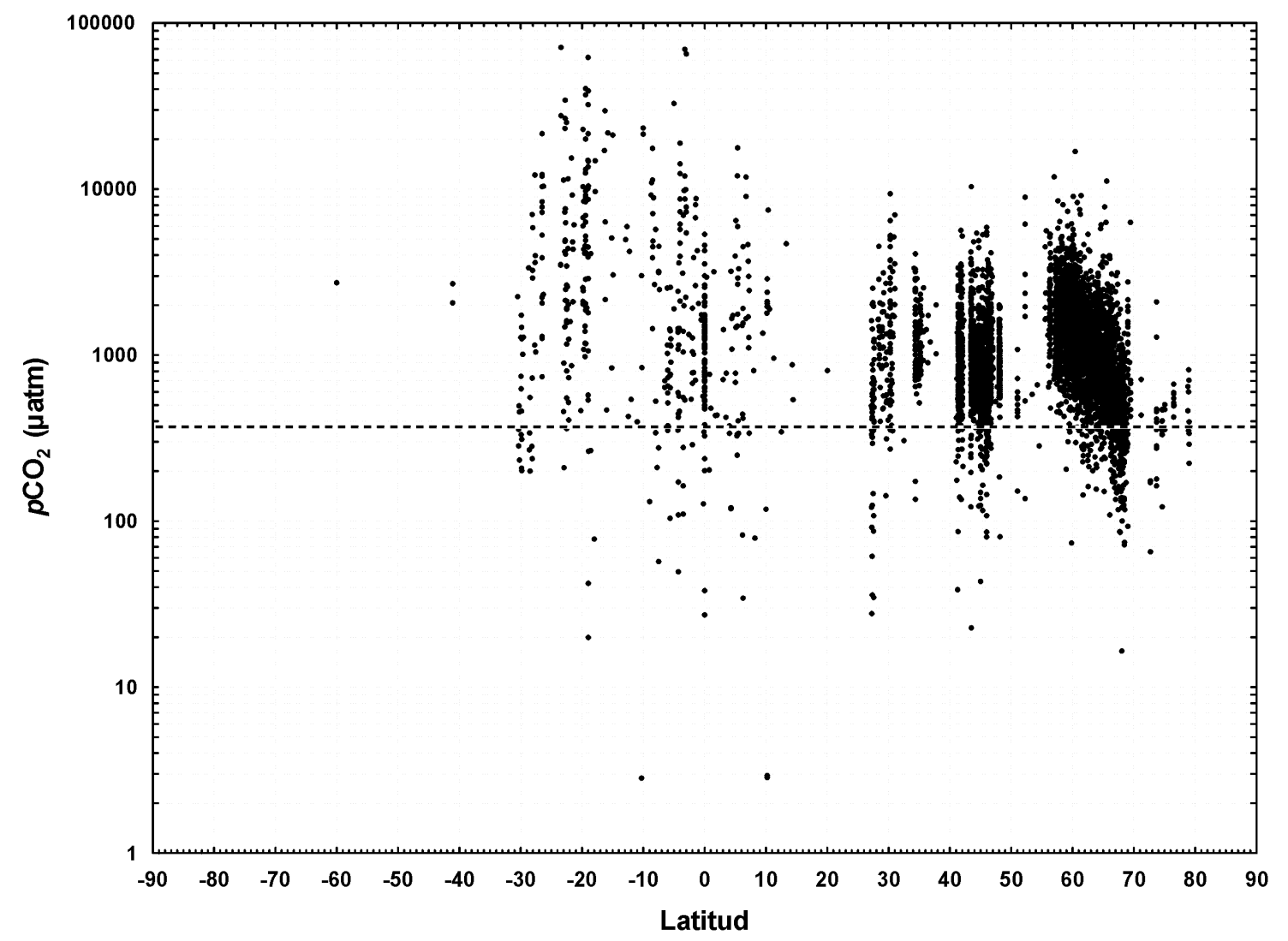

Figura 7.2: Gráfica de la presión parcial del $\mathrm{CO} 2$ en los lagos en función de la latitud. La línea discontinua horizontal representa la presión parcial media actual de la atmósfera ( $\approx 370 \mu a t m)$. En la figura se observa claramente la frecuente supersaturación de los lagos actuales. La figura se ha realizado a partir de los datos de MAROTTA et al. (2009). lacustres son:

Las causas más comunes que pueden provocar una supersaturación en los sistemas

a) Tasa elevada de la respiración respecto a la fijación fotosintética del carbono (heterotrófico), siendo la causa más común en numerosos lagos (COLE et al., 1994; DUARTE Y PRAIRIE, 2005).

b) Entrada de aguas subterráneas ricas en $\mathrm{CO}_{2}$ que toman de la respiración del suelo y de la meteorización de las rocas carbonatadas (GONFIANTINI et al., 1968; TURNER et al., 1983; STRIEGL Y MICHMERHUIZEN, 1998).

c) Precipitación de carbonato cálcico que conlleva la producción de $\mathrm{CO}_{2}$ (BARKAN et al., 2001; DUARTE et al., 2008).

d) Evaporación elevada en aguas con un pH bajo (STILLER et al., 1985; POTTER et al., 2004).

e) La salinidad de las aguas provoca un aumento químico de la tasa de intercambio de $\mathrm{CO}_{2}$ debido a la hidratación de $\mathrm{CO}_{2}$ atmosférico directamente a bicarbonato. Este fenómeno hace que un lago salino tenga de media una tasa 2,5 veces mayor que un lago dulceacuícola con un $\rho \mathrm{CO}_{2}$ equivalente. Aproximadamente el $50-70 \%$ de los lagos salinos están supersaturados (DUARTE et al., 2008).

Por el contrario, un agotamiento del $\mathrm{CO}_{2}$ disuelto por intensa actividad fotosintética puedefavorecer la entrada de $\mathrm{CO}_{2}$ atmosférico en las aguas del lago (ENZEL et al., 1999; PEŁECHATY et al., 2010). 


\subsubsection{Producción primaria (fotosíntesis)}

Aparte del carbono orgánico procedente de las plantas terrestres (alóctono), dentro de la masa de agua lacustre se producen otros fraccionamientos como consecuencia de la producción orgánica y de la actividad fotosintética. La materia orgánica autóctona, producida en el lago, proviene de las algas y de los macrófitos (sumergidos y emergidos). La composición isotópica de los macrófitos emergidos es parecida a la de las plantas terrestres ya que comparten la misma fuente de carbono ( $\mathrm{CO}_{2}$ atmosférico). Las algas dulceacuícolas y los macrófitos sumergidos, por el contrario, usan el $\mathrm{CO}_{2}$ disuelto presente en la columna de agua. En este caso, también discriminan en contra de ${ }^{13} \mathrm{CO}_{2}$ durante la fotosíntesis. Como el carbono fijado proviene del $\mathrm{CO}_{2}$ disuelto en la masa de agua, la fotosíntesis está condicionada por la gran resistencia a la difusión del $\mathrm{CO}_{2}$ en el medio acuático. Esta utilización preferente de ${ }^{12} \mathrm{CO}_{2}$ conlleva dos consecuencias significativas:

a) Creación de productos fotosintéticos (materia orgánica) empobrecidos en ${ }^{13} \mathrm{C}$. Los macrófitos sumergidos presentan valores notablemente superiores a las de las plantas superiores terrestres $\mathrm{C}_{3}$ debido a los problemas de difusión (SMITH Y WALKER, 1980; LAZERTE Y SZALADOS, 1982). La materia orgánica producida por el fitoplancton (algas lacustres) tiene valores comprendidos entre -26\%o a -31\%o, también en el rango comprendido por las plantas C 3 (MEYERS Y LALLIER-VERGĖS, 1999).

b) Enriquecimiento en ${ }^{13} \mathrm{C}$ del $\mathrm{CID}$ de la masa de agua. Por ejemplo, en el lago J aspe (Polonia) las praderas de carófitas, cubriendo hasta el 60\% de la superficie del lago, causan un importante enriquecimiento en ${ }^{13} \mathrm{C}$ en el CID (PEŁECHATY et al., 2010).

Sin embargo, cuando la disponibilidad de $\mathrm{CO}_{2}$ disuelto es limitada, las algas comienzan a utilizar $\mathrm{HCO}_{3}^{-}$disuelto (SMTTH Y WALKER, 1980; LUCAS, 1983). En consecuencia, la materia orgánica se enriquece ligeramente en ${ }^{13} \mathrm{C}$, pudiendo alcanzar valores de hasta -9\%o, en el rango de las plantas tipo $C_{4}$ (KEELEY Y SANDQUIST, 1992; MEYERS Y LALLIER-VERGĖS, 1999) y se incrementa significativamente el valor $\delta^{13} \mathrm{C}$ CID de la cubeta lacustre. O'LEARY (1988) afirma que en experimentos de laboratorio se han obtenido fraccionamientos pequeños, a veces de hasta $0 \%$, si el $\mathrm{CO}_{2}$ está limitado y, fraccionamientos de hasta $20 \%$ o más cuando la concentración de $\mathrm{CO}_{2}$ es elevada. Esta limitación en el dióxido de carbono disponible en la masa de agua pueden ocasionarse por:

a) Los blooms algales o períodos de gran productividad. Los lagos eutróficos son ejemplos paradigmáticos de este comportamiento: se han citado enriquecimientos del CID en las aguas epilimnéticas de hasta 3,9\%o el lago Lugano (Suiza-Italia) (BERNASCONI et al., 1997) y de aproximadamente 2,5\%o en el lago Greifen (Suiza) (HOLLANDER Y MCKENZIE, 1991). En el lago Washington (E.E.U.U.) el CID en el epilimnion pasa de - 7,7 a -4,5\%, mientras que el hipolimnion presenta mínimos de -11\%o debidos a la respiración (QUAY et al., 1986). De manera similar se comporta el lago Biwa (J apón) (MIYAJIMA et al., 1997). Un caso extremo lo constituye el Mar Muerto, cuyo valor $\delta^{13} \mathrm{C}$ CID pasa de $-3,4 \%$ o a $+5,1 \%$ o durante el bloom de Dunaliella (OREN et al., 1995).

b) Aguas alcalinas con un $\mathrm{pH}$ elevado donde el carbono está preferentemente en forma de bicarbonato. Así, en el lago Bosumtwi aparece materia orgánica de origen algal con un valor $\delta^{13} \mathrm{C}$ de -11,9\%o (TALBOT Y J OHANNESSEN, 1992) y en el lago Swan de -9,7\%o (HASSAN et al., 1997).

c) Largos tiempos de residencia de las aguas (HINGA et al., 1994; TALBOT Y LÆRDAL, 2000).

d) Incremento en el pH y salinidad debido a una caída del nivel del lago (LENG et al., 2005).

e) Combinación de alta temperatura y salinidad, típica de lagos heliotérmicos, que favorece la presencia de $\mathrm{HCO}_{3}^{-}$como fuente principal de carbono. El valor $\delta^{13} \mathrm{C}$ de la materia orgánica en el lago Solar (Israel) es $-5,7 \pm 1,4 \%$ y - 10,0 0 2,6\% en el sabkha Gavish (Israel) (SCHIDLOWSKI et al., 1984). 


\section{Análisis isotópico y geoquímico del Grupo Enciso}

En las etapas en las cuales la cantidad de $\mathrm{CO}_{2}$ disuelto está limitada, el fitoplancton también es capaz de utilizar $\mathrm{HCO}_{3}^{-}$durante la fijación del carbono, lo cual representa una ventaja ecológica importante. Así por ejemplo, Sinechococcus, un género de alga verde-azulada muy abundante en los lagos actuales (NJ UGUNA, 1988; THOMPSONY FERRIS, 1990; ARFI Y BOUVY, 1995), tiene la capacidad de utilizar $\mathrm{HCO}_{3}^{-}$como fuente principal del carbono inorgánico (MILLER Y COLMAN, 1980; BADGER et al., 1985). Este alga, además, juega un papel muy importante como elemento nucleador durante la precipitación de la calcita (DITTRICH et al., 2003; PLÉE etal., 2008) y en los fenómenos de whiting (THOMPSON et al., 1997).

La precipitación de la calcita conlleva un incremento de la disponibilidad del $\mathrm{CO}_{2}$ disuelto y disminuye el $\mathrm{pH}$, provocando un desplazamiento del equilibrio del carbono a favor de la especie $\mathrm{CO}_{2 \text { (ac) }}$ (HODELL Y SCHELSKE, 1998).

\subsubsection{Mineralización del carbono orgánico (oxidación-respiración)}

La mineralización es el proceso de degradación completa de la materia orgánica, transformándola en $\mathrm{CO}_{2}$ bajo condiciones óxicas, o $\mathrm{CO}_{2} \mathrm{y} \mathrm{CH}_{4}$ bajo condiciones anóxicas (ENRICHPRAST et al., 2009). La mineralización óxica incluye a la respiración aeróbica y la quimiosíntesis. La mineralización anóxica sólo se produce por la respiración anaeróbica (metanogénesis). El término respiración hace referencia a cualquier proceso de mineralización que sea realizado por la acción de seres vivos.

Una gran parte del carbono orgánico (tanto alóctono como autóctono) es incorporado al reservorio CID debido a que los lagos son medios favorables a la mineralización de la materia orgánica. La tasa de mineralización de la materia orgánica depende de tres factores fundamentales: la temperatura, el tiempo de residencia y, la relación entre el área de la cuenca hidrográfica respecto espejo del lago (DEN HEYER Y KALFF, 1998). La temperatura también influye en la actividad microbiana, ya que las bacterias son más abundantes, activas y productivas a mayor temperatura. Así pues, la temperatura exhibe una correlación positiva con las tasas de mineralización pudiéndose considerar como el factor más determinante (GUDASZ et al., 2010). En la zona epilimnética (zona litoral) se produce el 54-100\% de la mineralización de la materia orgánica, siendo de media unas tres veces mayor que en la zona hipolimnética (DEN HEYER Y KALFF, 1998).

Una parte de la materia orgánica puede ser mineralizada por reacciones fotoquímicas llevadas a cabo por la radiación ultravioleta de la luz solar, bien produciendo una foto-oxidación del carbono orgánico disuelto a $\mathrm{CO}_{2}$ (GRANÉLI et al., 1996) o por una fotolisis que favorece la acción metabólica de las bacterias (WETZEL et al., 1995).

La mayoría de los lagos constituyen sistemas heterotróficos, es decir, espacios donde la destrucción de la materia orgánica excede a la producción primaria fotosintética (COLE et al., 1994; WANG Y VEIZER, 2000; DUARTE Y PRAIRIE, 2005). Así pues, la respiración es el proceso dominante en la mineralización del carbono orgánico, el cual, aporta ${ }^{12} \mathrm{C}$ presente en la materia orgánica y favorece un CID con valores $\delta^{13}$ CID muy bajo (LENG et al., 2005).

La respiración aeróbica (oxidación de la materia orgánica) no produce fraccionamiento alguno o es mínimo (WILLIAMSY GORDON, 1970; HERCZEG, 1987; MEYERSY EADIE, 1993; SCHELSKE Y HODELL, 1995; CURRY et al., 1997; LINY EHLERINGER, 1997). En el lago Lugano se ha observado una disminución del 1,5\% en la materia orgánica sedimentada con respecto a la presente en la columna de agua (LEHMANN et al., 2002).

En el extremo opuesto, la respiración anaeróbica (metanogénesis) muestra los mayores fraccionamientos existentes en el ciclo del carbono. A este hecho se debe añadir que la metanogénesis constituye el 10-50\% de la mineralización total en ambientes dulceacuícolas (BASTVIKEN et al., 2008).

La metanogénesis, en la naturaleza, se produce básicamente por dos procesos: la metanogénesis hidrogenotrófica en la cual se produce la reducción del $\mathrm{CO}_{2}$ por hidrógeno 
molecular, y la metanogénesis aceticlástica (acetotrófica) por fermentación del acetato. Los sedimentos lacustres exhiben un predominio de la metanogénesis acetotrófica sobre todo cuando son totalmente mineralizados (CONRAD, 1999). Es responsable aproximadamente de un 54-73\% de la metanogénesis en ambientes dulceacuícolas, aunque la proporción relativa puede variar (GELWICKS et al., 1994; WHITICAR, 1999; CONRAD et al., 2010). La metanogénesis hidrogenotrófica es menos significativa (WHITICAR, 1999) y sólo es dominante cuando se produce una degradación incompleta de la materia orgánica (CONRAD, 1999; CONRAD et al., 2009).

El metano originado en los medios acuáticos continentales tiene un valor $\delta^{13} \mathrm{Cmínimo} \mathrm{de}$ -86\% (OREMLAND Y KING, 1989) y máximo de -50\% (WHITICAR et al., 1986), aunque los valores normalmente varían entre -65 a -50\%o (WHITICAR et al., 1986). El efecto principal es un enriquecimiento extremo en ${ }^{13} \mathrm{C}$ del CID de las aguas lacustres. Así, los carbonatos precipitados en aguas donde se produce la metanogénesis muestran valores ${ }^{13} \mathrm{C}$ muy elevados (Hudson, 1977). En el lago Bosumtwi (Ghana) alcanzan $\delta^{13} \mathrm{C}_{\text {dolomita }}=+26,32-+26,55 \%$ y $\delta^{13} \mathrm{C}_{\text {calcita }}=+8,28-$ $+25,72 \%$ o (TALBOT Y KeLTS, 1986) y, en el oasis Kajemarum (Nigeria) toma valores de +5,9\%o (HOLMES et al., 1997).

En general, los fraccionamientos isotópicos del carbono asociado a la producción de metano en ambientes dulceacuícolas son menores que los encontrados en ambientes marinos (GELWICKS et al., 1994). La metanogénesis hidrogenotrófica $\mathrm{CO}_{2}+4 \mathrm{H}_{2} \rightarrow \mathrm{CH}_{4}+2 \mathrm{H}_{2} \mathrm{O}$ presenta fraccionamientos $\varepsilon_{\mathrm{CO}_{2} \rightarrow \mathrm{CH}_{4}} \approx 39$ a $58 \%$ o, aunque pueden existir desviaciones significativas de estos valores (WHITICAR, 1999; GALIMOV, 2006). La metanogénesis aceticlástica $\mathrm{CH}_{3} \mathrm{COOH} \rightarrow \mathrm{CH}_{4}+$ $\mathrm{CO}_{2}$ exhibe fraccionamientos en el orden de $\delta{ }^{13} \mathrm{C}_{\mathrm{CH}_{4}}=\delta^{13} \mathrm{C}_{\mathrm{CO}_{2}}-49 \%$ (GALIMOV, 2006).

Una gran parte del metano originado se oxida y pasa a formar parte del $\mathrm{CO}_{2}$ disuelto en las aguas según la reacción: $\mathrm{CH}_{4}+2 \mathrm{O}_{2} \rightarrow \mathrm{CO}_{2(\mathrm{ac})}+2 \mathrm{H}_{2} \mathrm{O}$. En los sistemas lacustres, aproximadamente un 80\% (30-99\%) del metano que no escapa por burbujeo es oxidado antes de alcanzar la atmósfera (GUÉRIN Y ABRIL, 2007; BASTVIKEN et al., 2008; BASTVIKEN, 2009). Esta oxidación del $\mathrm{CH}_{4}$ puede ser aeróbica y/ o anaeróbica. La oxidación anaeróbica es poco importante en los medios acuáticos dulceacuícolas (dominante en ambientes marinos) aunque se produce en algunos lagos salinos/ alcalinos: lago Big Soda (IVERSEN et al., 1987) y lago Mono (J OYE et al., 1999), ambos en Los Estados Unidos, y el lago Cadagno en Italia (SCHUBERT et al., 2011). La oxidación aeróbica es predominante en los medios límnicos y se desarrolla en la columna de agua (J ANNASCH, 1975; RUDD, 1980), en la interfase sedimento-agua (FRENZEL et al., 1990; MURASE et al., 2005) y en las raíces de las plantas acuáticas (KING, 1994).

La oxidación del metano presenta fraccionamientos $\varepsilon_{\mathrm{CO}_{2} \rightarrow \mathrm{CH}_{4}}$ variando entre 4-39\%o, aunque en general son menores de 10 (WHITICAR Y FABER, 1986; WHITICAR, 1999; TEMPLETON et al., 2006).

\subsubsection{Sedimentación de la materia orgánica}

Los lagos son zonas preferentes de sedimentación de la materia orgánica (SOBEK et al., 2009). DEAN Y GORHAM (1998) han estimado que la tasa de enterramiento anual de carbono orgánico en los sedimentos lacustres es aproximadamente la mitad (42 Tg) que la tasa en los sedimentos marinos $(\approx 100 \mathrm{Tg})$. Teniendo en cuenta que los lagos cubren aproximadamente un 1,3-1,8\% de la superficie terrestre (DownING et al., 2006) y los océanos un 71\%, es evidente que los sedimentos lacustres constituyen un sumidero muy eficiente de carbono. Este fenómeno es más importante en los lagos someros ya que el poco espesor de la columna de agua deja poco tiempo para la descomposición de las partículas orgánicas, permitiendo que una gran fracción de las mismas alcance el sedimento (KALFF, 2002).

La sedimentación de la materia orgánica elimina ${ }^{12} \mathrm{C}$ de la masa de agua favoreciendo el enriquecimiento en ${ }^{13} \mathrm{C}$ de la columna de agua (SCHELSKE Y HODELL, 1991). 


\subsubsection{Precipitación de carbonatos}

El valor isotópico del carbonato autígeno en un lago $\delta^{13} C_{\text {calcita }}$ está directamente relacionado con el CID (Carbono Inorgánico Disuelto) existente en la masa de agua en la cual precipita. La precipitación del $\mathrm{CaCO}_{3}$ se produce según la siguiente reacción:

$$
\mathrm{Ca}^{2+}+2 \mathrm{HCO}_{3}^{-} \leftrightarrow \mathrm{CaCO}_{3}+\mathrm{CO}_{2}+\mathrm{H}_{2} \mathrm{O}
$$

Esta reacción conlleva un fraccionamiento isotópico que es prácticamente independiente de la temperatura, con un gradiente de $0,035 \pm 0,013 \%{ }^{\circ} \mathrm{C}^{-1}$ (EMRICH et al., 1970). A efectos prácticos, se puede utilizar un valor medio de $1,0 \pm 0,2 \%$ en el rango de temperaturas desde $10^{\circ} \mathrm{C}$ hasta $40^{\circ} \mathrm{C}$ (ROMANEK et al., 1992). Sin embargo, valores más precisos pueden obtenerse de la ecuación definida por МоOK (1986):

$$
1000 \ln \alpha_{\text {calcita- }-\mathrm{HCO}_{3}^{-}}=-\frac{4232}{\mathrm{~T}_{\mathrm{K}}}+15,1(\%)
$$

En muchos casos, también es útil la ecuación existente entre la calcita y el $\mathrm{CO}_{2}$ atmosférico definida por ROMANEK et al. (1992):

$$
\varepsilon_{\text {calcita- }-\mathrm{CO}_{2(\text { gas })}}=11,98( \pm 0,13)-0,12( \pm 0,01) \mathrm{T}_{\mathrm{C}}(\% \circ)
$$

Para obtener el valor ${ }^{13} \mathrm{C}$ de la calcita precipitada a partir del $\mathrm{CO}_{2}$ disuelto (muy útil en los medios lacustres), se requiere previamente conocer el fraccionamiento entre el $\mathrm{CO}_{2}$ disuelto y el bicarbonato, que se puede calcular según la siguiente ecuación (MoOK et al., 1974):

$$
\begin{aligned}
& \mathrm{H}^{12} \mathrm{CO}_{3}^{-}+{ }^{13} \mathrm{CO}_{2(\text { ac })} \leftrightarrow \mathrm{H}^{13} \mathrm{CO}_{3}^{-}+{ }^{12} \mathrm{CO}_{2(\text { ac })} \\
& \varepsilon_{\mathrm{CO}_{2(\mathrm{ac})}-\mathrm{HCO}_{3}^{-}}=-(9,866 \pm 0,23) \frac{10^{3}}{\mathrm{~T}_{\mathrm{K}}}+(24,12 \pm 0,78) \% \text { o }
\end{aligned}
$$

\subsection{ISÓTOPOS DEL OXÍGENO}

El oxígeno es el elemento más abundante en la naturaleza. El valor más negativo corresponde a una muestra de la precipitación en la Antártida de -62,8\% SMOW (ALDAZ Y DEUTSCH, 1967). El mayor valor se ha encontrado en el $\mathrm{N}_{2} \mathrm{O}$ marino con un valor de $+109 \%$ o SMOW (YOSHINARI et al., 1997).

La composición isotópica $\delta^{18} \mathrm{O}$ del carbonato precipitado en equilibrio isotópico, depende de la composición del agua del lago, la temperatura a la cual se produce dicha precipitación y los efectos de "desequilibrio" (o vitales para el carbono biogénico y/o bioinducido) (LENG Y MARSHALL, 2004; LENG et al., 2005). Sin embargo, la precipitación de la calcita no siempre se produce en equilibrio isotópico con las aguas del lago. Numerosos estudios de laboratorio han demostrado que el valor $\delta^{18} \mathrm{O}$ de la calcita inorgánica puede estar influenciado por ciertos fraccionamientos cinéticos debidos a la química de la solución y/ o a la tasa de precipitación (KIM y O'NEIL, 1997; BECK et al., 2005; DiETZEL et al., 2009). En el lago Arresø (Dinamarca), durante los episodios de alta tasa de precipitación existe un fraccionamiento cinético que causa un empobrecimiento de la calcita precipitada (FRONVAL et al., 1995).

\subsubsection{Temperatura}

El fraccionamiento isotópico del oxígeno durante la formación de la calcita precipitada en medio acuoso depende, principalmente, de la temperatura. De esta dependencia de la temperatura provienen los numerosos estudios paleoclimáticos que utilizan la denominada como ecuación de la paleotemperatura. El fraccionamiento viene dado por la ecuación (KIM Y O'NEIL, 1997). 


$$
10^{3} \ln \alpha_{\text {calcita-agua }}=18,03 \frac{10^{3}}{\mathrm{~T}_{\mathrm{K}}}-32,42
$$

La precipitación de la dolomita muestra un fraccionamiento mayor que el de la calcita, pudiéndose calcular según la siguiente fórmula (VASCONCELOS et al., 2005):

$$
10^{3} \ln \alpha_{\text {dolomita-agua }}=2,73 \frac{10^{6}}{\mathrm{~T}_{\mathrm{K}}^{2}}-0,26
$$

\subsubsection{Composición isotópica del agua del lago $\left(\delta_{L}\right)$ - Balance hídrico}

La composición isotópica de las aguas del lago en función de la fracción de agua existente $\delta_{\mathrm{L}}(\mathrm{f})$ se define mediante la fórmula (para la formulación completa y más detalles véase anexo XI) (GIBSON, 2002):

$$
\delta_{L}(f)=\delta_{S}-\left(\delta_{S}-\delta_{0}\right) f^{\frac{-(1+m x)}{1-x-y}}
$$

El primer término de la ecuación representa el término del régimen estacionario que corresponde a $\delta^{*}$ (enriquecimiento isotópico límite) si la entrada de agua es insignificante y a $\delta \mathrm{s}$ (composición isotópica en régimen estacionario) si la masa de agua tiene una entrada de agua apreciable. El segundo término hace referencia al término transitorio, donde $\delta_{0}$ es la composición isotópica inicial de las aguas del lago, $\mathrm{x}$ es la fracción de agua entrante que se pierde por evaporación, y es la fracción de agua entrante que se pierde por descargas, f es la fracción de agua remanente del lago donde $\mathrm{V}$ es el volumen residual, $\mathrm{V}_{0}$ es el volumen original del lago y, $\mathrm{m}$ es la pendiente temporal de enriquecimiento.

\subsection{COVARIANZA ENTRE $\delta^{18} \mathrm{O}$ Y $\delta^{13} \mathrm{C}$}

La covarianza $(r>0,7)$ entre los valores de $\delta^{18} \mathrm{O}$ y $\delta^{13} \mathrm{C}$ del carbonato precipitado es un carácter típico de los lagos cerrados (TALBOT, 1990; LI Y KU, 1997), aunque, en menor medida, también ocurre en algunos lagos abiertos (DRUMMOND et al., 1995; COHEN etal., 1997) (figura 7.3). En una cubeta cerrada, cuando el volumen de la masa de agua decrece, tanto $\delta^{13} \mathrm{C}$ como $\delta^{18} \mathrm{O}$, tienden a valores más pesados y, por el contrario, cuando el volumen se incrementa, los valores isotópicos $\delta^{13} \mathrm{Cy} \delta^{18} \mathrm{O}$ se hacen más ligeros ( $\mathrm{LI}$ Y KU, 1997).

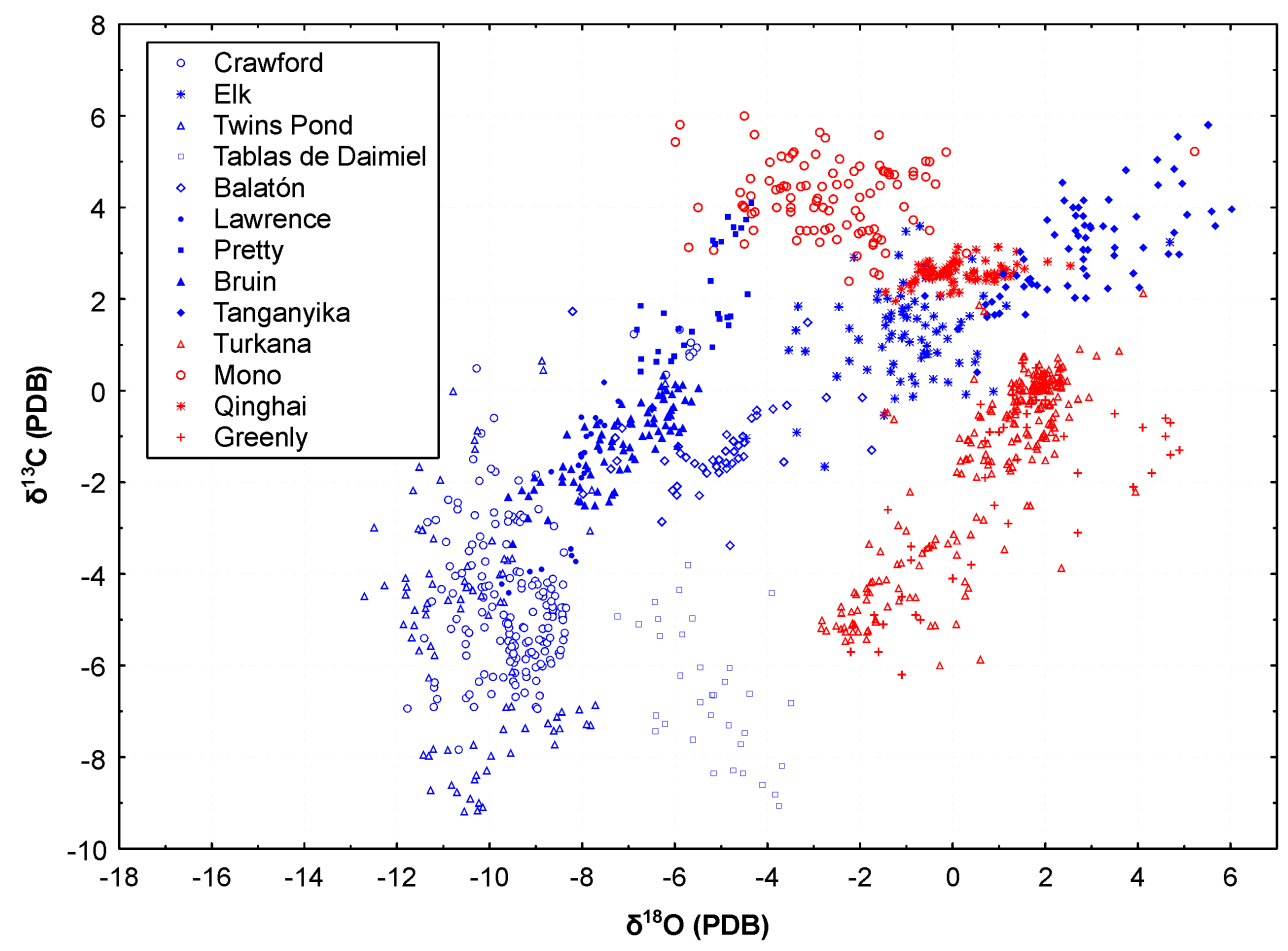




\section{Análisis isotópico y geoquímico del Grupo Enciso}

Figura 7.3: Gráfico mostrando los valores $\delta^{18} O$ y $\delta^{13} \mathrm{C}$ delos carbonatos precipitados en diversos lagos actuales. En color rojo se representan los lagos cerrados: Turkana $(r=0,85)$ (RICKETTS Y ANDERSON, 1998), Mono (LI Y KU, 1997), Qinghai (XU et al., 2006), y complejo Greenly ( $r=0,67)$ (DUTKIEWICZ et al., 2000). En color azul se representan los lagos abiertos: Crawford (YU Y EICHER, 1998), Elk (SMitH et al., 1997), Twins Pond, Tablas de Daimiel (VALDEOLMILlosRoDRíGUEZ, 2004), Balatón (CSERNYI et al., 1995), Lawrence ( $r=0$,84) (DRUMMOND et al., 1995), Pretty $(r=0,71)$ (DRUMMOND et al., 1995), Bruin ( $r=0,82)$ (DRUMMOND et al., 1995), y Tanganica $(r=0,71)$ (COHEN et al., 1997).

Por el contrario, la falta de covarianza, o si es muy pequeña $(r<0,7)$, puede interpretarse de múltiples maneras:

a) Cuerpos de agua hidrológicamente abiertos (TALBOT, 1990).

b) Entrada de aguas subterráneas (QUADE et al., 1995; DUNAGANY TURNER, 2004).

c) Lagos con salinidad y/o alcalinidad significativamente más elevada que la del agua que entra en la cubeta como en el lago Owens (LI et al., 2000) y lago Mono (LI Y KU, 1997).

d) Medio palustre (AlONSO-ZARZA Y WRIGHT, 2010).

La pendiente entre $\delta^{13} \mathrm{C}$ y $\delta^{18} \mathrm{O}$ se relaciona con la relación entre el espejo del lago y la profundidad. Así, una pendiente baja en la covarianza indica una razón elevada, es decir, un lago somero. Por el contrario, los lagos con un ratio bajo (lagos profundos) tienden a presentar pendientes altas.

\subsection{MODELIZACIÓN ISOTÓPICA DEL PALEOLAGO ENCISO}

Una vez revisados los procesos que modifican los valores $\delta^{13} \mathrm{C}$ y $\delta^{18} \mathrm{O}$ en un sistema lacustre, se procede al estudio de los isótopos estables obtenidos en los carbonatos del Grupo Enciso (los valores están en el anexo XII). En general, los datos están en consonancia con otros sistemas lacustres bajo unas condiciones climáticas semejantes (figura 7.4).

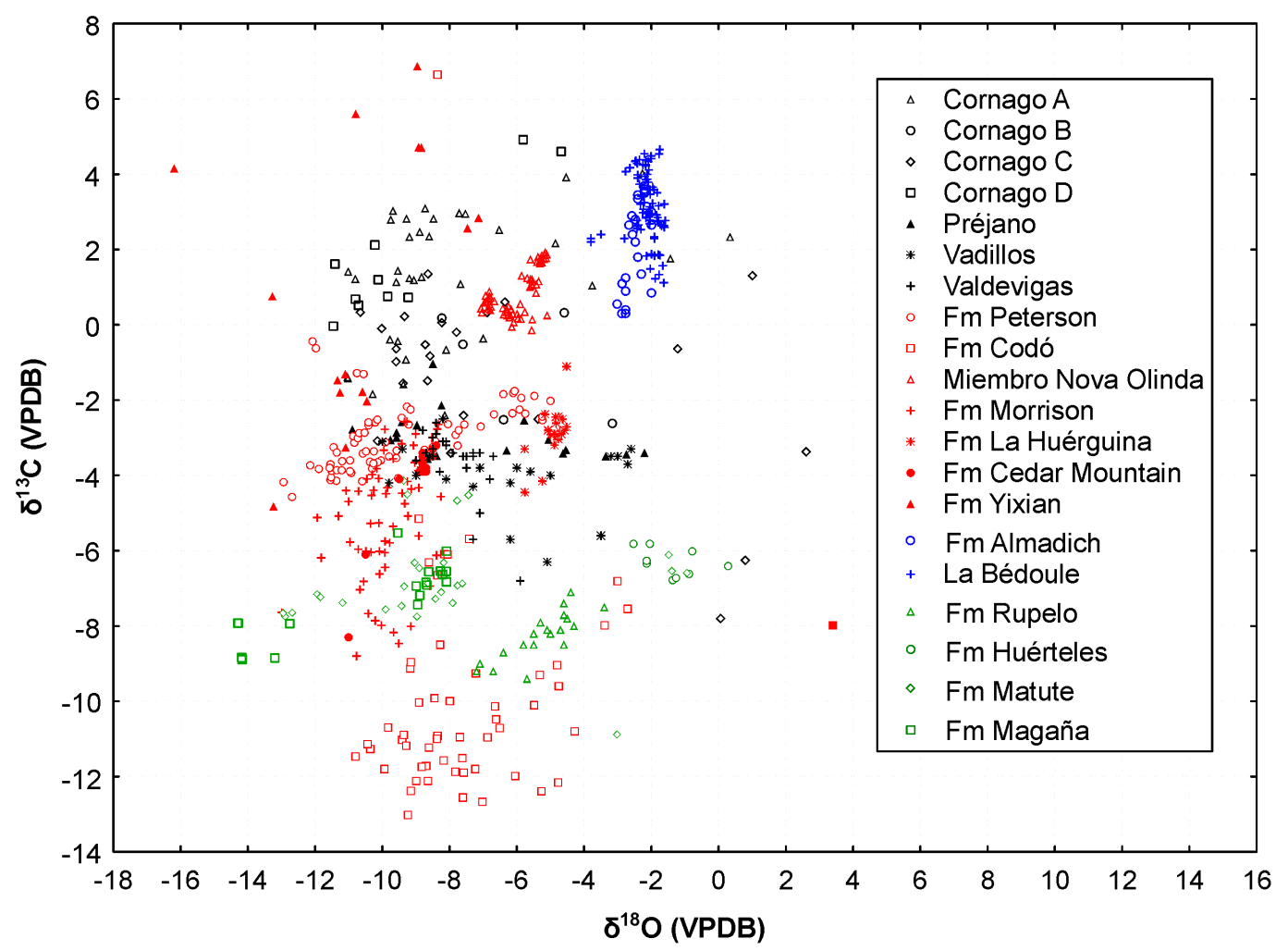

Figura 7.4: Representación $\delta^{18} \mathrm{O}$ y $\delta^{13} \mathrm{C}$ de los valores del Grupo Enciso en su contexto espacial y temporal. En color negro se indican los valores pertenecientes al Grupo Enciso: las series 
Cornago A-D y Préjano son datos propios, y las series Vadillos y Valdevigas corresponden a la tesis de DOUBLET (2004). En verde se señalan los valores de otras formaciones de la cuenca de Cameros: Fm. Rupelo (Berriasiense) (PlatT, 1989b), Fm. Huérteles (Berriasiense) (AlONSOAZCÁRATE et al., 2006), y las formaciones Matute y Magaña (Titoniense) (GONZÁLEZ-ACEBRÓN, 2009). En azul se marcan los valores correspondientes al ámbito marino tetisiano Aptiense: La Bédoule en Francia (KUHNT et al., 1998) y la Fm Almadich en las Béticas (DE GEA et al., 2003). En rojo se presentan valores de sistemas continentales coetáneos: las formaciones Peterson (DRUMMOND et al., 1996) y Cedar Mountain (SHAPIRO et al., 2009) ambas del Aptiense de los Estados Unidos; la Fm Codó (PAZ y RosSETTI, 2006) y el Miembro Nova Olinda de la Fm Crato (HEIMHOFER et al., 2010), ambas del Aptiense-Albiense de Brasil; la Fm Morrison (DUNAGANY TURNER, 2004) del J urásico superior de los Estados Unidos; la Fm Yixian (CHEN et al., 2011) del Aptiense de China; y la Fm Huérguina (PoYATO-ARIZA et al., 1998) del Barremiense de España.

\subsubsection{Isotopía del carbono en el paleolago Enciso}

Para los cálculos se van a utilizar todas las ecuaciones de fraccionamientos ya citadas a una temperatura fijada en $27 \pm 2^{\circ} \mathrm{C}$ como un valor aceptable basándose en las siguientes evidencias:

a) Numerosos autores han afirmado que en los lagos actuales, la temperatura media del agua es muy próxima a la temperatura media anual del aire (TMA) (WETZEL, 1975; COLE, 1983; PENTECOST et al., 2006). Para comprobar esta afirmación se han analizado 669 valores de temperaturas del agua y del aire en 28 lagos actuales localizados en latitudes tropicales (SHARMA et al., 2015) y se han obtenido los siguientes ajustes (figura 7.5). Los valores de las temperaturas del agua proceden de dos fuentes: CRU (Climatic Research Unit) y NCEP (National Centers for Environmental Prediction).

$$
\begin{aligned}
& \mathrm{T}_{\text {agua }}=6,2475+0,78301 \mathrm{~T}_{\text {aire(CRU) }}\left(\mathrm{r}=0,89271 ; \mathrm{r}^{2}=0,79693\right) \\
& \mathrm{T}_{\text {agua }}=8,7350+0,73305 \mathrm{~T}_{\text {aire(NCEP) }}\left(\mathrm{r}=0,84753 ; \mathrm{r}^{2}=0,71831\right)
\end{aligned}
$$

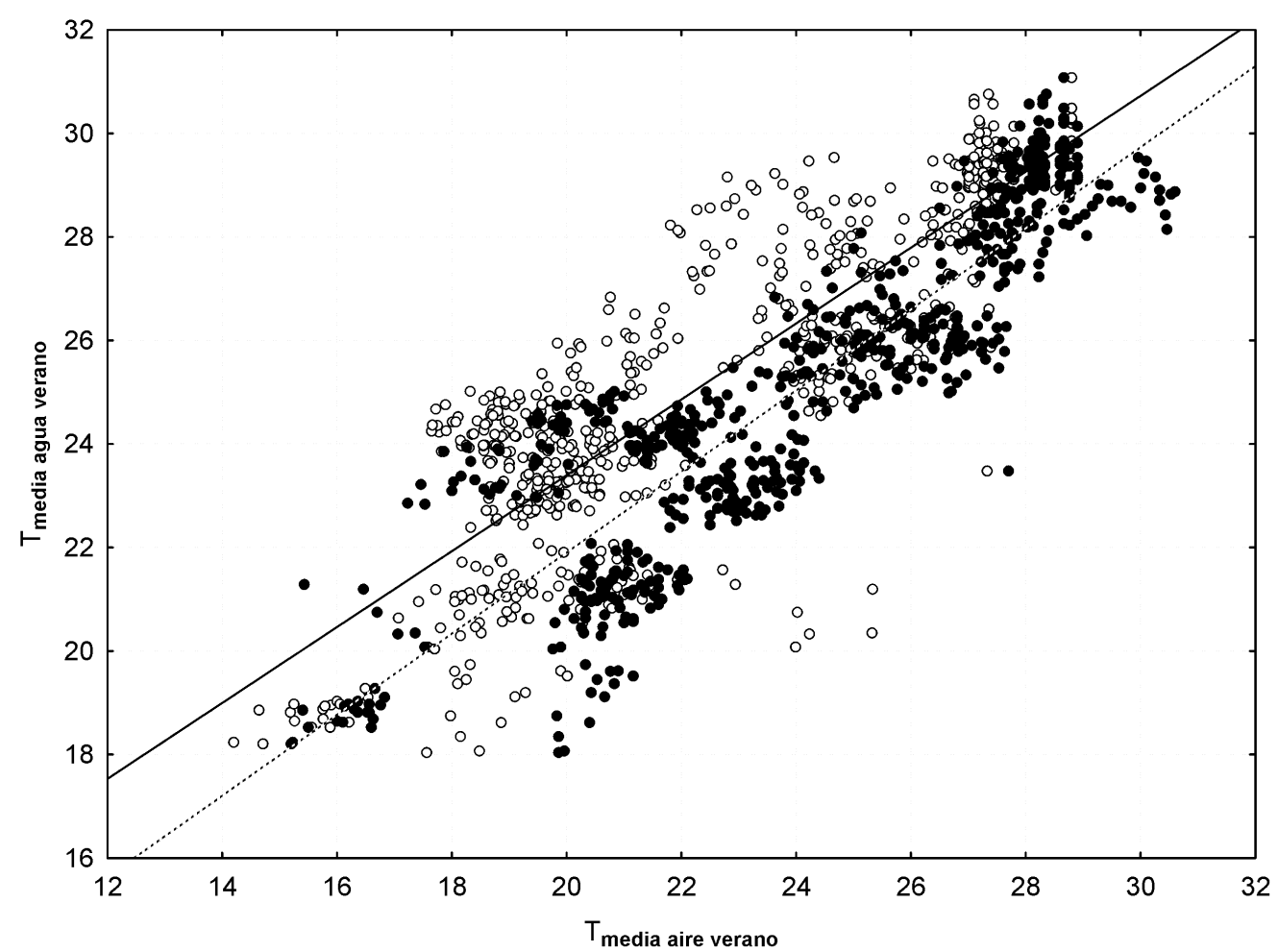

Figura 7.5: Ajuste obtenido entre la temperatura media del aire y la temperatura media del agua del lago a partir de 669 valores obtenidos en 28 lagos actuales localizados en latitudes 


\section{Análisis isotópico y geoquímico del Grupo Enciso}

tropicales. Los puntos negros hacen referencia a los valores CRU (Climatic Research Unit) y los puntos blancos a NCEP (National Centers for Environmental Prediction).

b) Según los Modelos de Ciculación General, la Placa Ibérica durante el Aptiense tendría una temperatura media anual del aire en los meses de verano en tomo a los $26-30^{\circ} \mathrm{C}$ (apartado 9.2) (FLUTEAU et al., 2007; OHBA Y UEDA, 2010). Con estos valores se obtienen unas temperaturas medias del agua en torno a $26,6-29,7^{\circ} \mathrm{C}$ (CRU) y $27,8-$ 30,70 C (NCEP).

c) Otro método para obtener los valores de la temperatura del aire es a partir de la temperatura de la superficie del mar según la relación (SINGH et al., 2005):

$$
\mathrm{T}_{\text {aire }}=\mathrm{T}_{\text {agua superficial del mar }}-\Delta \mathrm{T}
$$

En las zonas tropicales actuales el valor de $\Delta \mathrm{T}$ es de $0,7^{\circ} \mathrm{C}$ (SINGH et al., 2005). A partir del análisis de 247 valores de TEX 86 del Aptiense se obtiene un valor de Tagua superficial del mar de $31,4 \pm 3,3^{\circ} \mathrm{C}$ (apartado 9.2). Todos estos valores permiten obtener una temperatura del aire en torno a $30,7 \pm 3,3^{\circ} \mathrm{C}$.

d) La precipitación del carbonato lacustre se produce mayoritariamente durante los meses más cálidos (MCKENZIE, 1985; ROSEN et al., 1995; HERCZEG et al., 2003). En el lago Hayward (Australia) la precipitación de la calcita ocurre a temperaturas $<30^{\circ} \mathrm{C}$ a pesar de que el agua puede superar los 45으 (ROSEN et al., 1995).

Como se ha visto en los apartados anteriores, el ${ }^{13} \mathrm{CO}_{2}$ atmosférico es de vital importancia en el ciclo del carbono lacustre. El cálculo de este valor se puede realizar, con un alto grado de confianza, a partir de las plantas $C_{3}$, ya que muestran una dependencia significativa del $\delta^{13} \mathrm{C}$ atmosférico según las ecuaciones descritas por ARENS et al. (2000) en la primera ecuación o FARQUHAR et al. (1989b) y GRÖCKE (2002) en la segunda.

$$
\begin{aligned}
& \delta^{13} C_{\text {atmosférico }}=\frac{\delta^{13} C_{\text {plantas }}+18,67}{1,10}(\% \text { o }) \\
& \delta^{13} C_{\text {atmosférico }}=\delta^{13} C_{\text {plantas }}+20,22(\% \circ)
\end{aligned}
$$

Se ha realizado una recopilación de todos los datos $\delta^{13} \mathrm{C}$ de la materia orgánica terrestre durante el Aptiense $(n=564)$ y se ha obtenido un valor medio $\delta^{13} C=-23,15 \pm 1,29 \%$ o (figura 7.6). Como era previsible, este valor se ajusta al rango de las plantas $\mathrm{C}_{3}$ ya que las plantas $\mathrm{C}_{4}$ no se desarrollaron hasta el Mioceno (QUADE et al., 1992; CERLING et al., 1993) o Cretácico superior (EHLERINGER et al., 1991). Con este valor se ha calculado un valor $\delta^{13}$ Catmosférico durante el Aptiense de $-4,08 \pm 0,05 \%$ o si se usa la primera ecuación (ARENS et al., 2000) y de $-2,93 \pm 0,05 \%$ o con la segunda (FARQUHAR et al., 1989b; GRÖCKE, 2002). Estos valores están en consonancia con otros previamente calculados para el Aptiense (J AHREN et al., 2001; GRÖCKE, 2002).

Por tanto la calcita precipitada por efecto del equilibrio entre la atmósfera y la superficie del paleolago Enciso tendría un valor teórico de $+5,7 \%$ o $\left(\delta^{13}\right.$ Catmosférico $=-3 \%$ o $) \quad$ o $+4,7 \%$ o $\left(\delta^{13}\right.$ Catmosférico $=-4 \%$ ) (figura 7.7) utilizando el fraccionamiento ${ }^{13} \varepsilon_{\text {calcita-CO }} \mathrm{CO}_{2 \text { (gas) }}$ de ROMANEK et al. (1992). Sin embargo, como se ha comentado anteriormente, los lagos suelen estar supersaturados y el $\mathrm{CO}_{2}$ escapa hacia la atmósfera. Así, utilizando un ${ }^{13} \varepsilon_{\mathrm{K}}=10,3 \%$ o para el desgaseado, el valor isotópico del $\mathrm{CO}_{2}$ disuelto se podría calcular en torno a $+7,3 \%$ o $\left(\delta^{13} C_{\text {atmosférico }}=-3 \%\right.$ o $)$ y $+6,3 \%$ o $\left(\delta^{13}\right.$ Catmosférico $=-4 \%$ ), que respectivamente precipitarían una calcita con un valor teórico $\delta^{13} \mathrm{C}$ calcita $=$ $+17,1 \%$ y $\delta^{13} \mathrm{C}_{\text {calcita }}=+16,1 \%$ o (figura 7.7 ).

La influencia de la litología del área madre estaría gobernada por la presencia de calizas jurásicas. En el margen norte de la cuenca de Cameros aflora la Formación Torrecilla, de la cual existen evidencias que constituyó un área madre al inicio de la secuencia deposicional 7 (Barremiense superior-Aptiense inferior) (ALONSO Y MAS, 1993). Por lo tanto no se descarta que durantela deposición del Grupo Enciso pudiera hacer constituido también un área local deaporte. 


\section{Análisis isotópico y geoquímico del Grupo Enciso}

La Formación Torrecilla está formada por carbonatos marinos con un valor medio $\delta^{13} \mathrm{C}=+2.4 \%$ o y un rango comprendido entre $+1.1 \%$ y $+2.8 \%$ o (BÁDENAS et al., 2005) (figura 7.7).

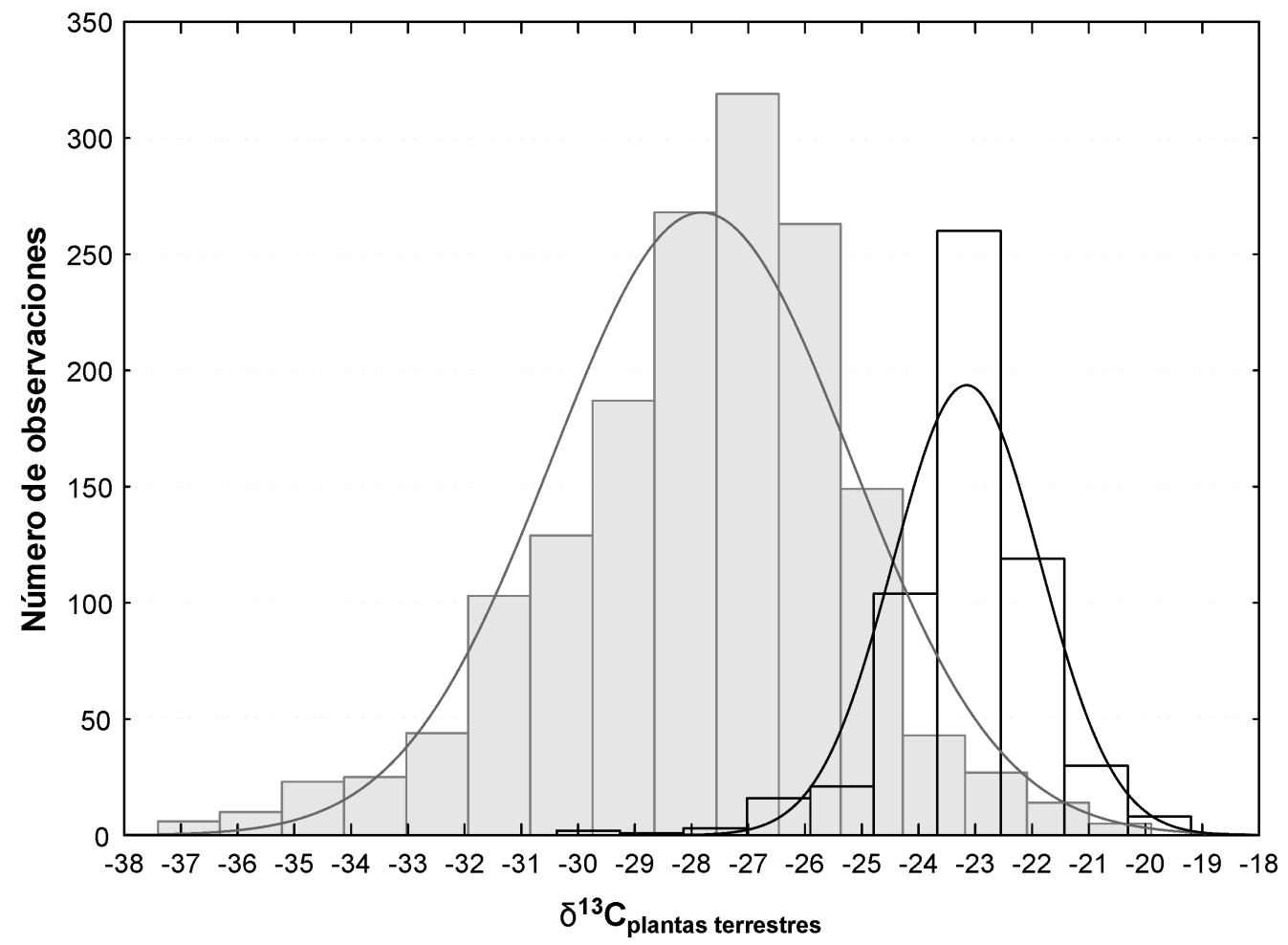

Figura 7.6: En trama transparente aparece el histograma del valor $\delta^{13}$ Cdelas plantas terrestres durante el Aptiense ( $\mathrm{n}=564$; valor medio $-23,15 \pm 1,29 \%$ ). Los datos provienen de la Fm. Wonthaggi en Australia (GRÖCKE, 1998), Grupo Lower Greensand en Gran Bretaña (GRÖCKE, 2002), Grupos Sorachi y Yezo en J apón (ANDO et al., 2003), Fm. Arundel en Estados Unidos (J AHREN et al., 2005), Fm. Bhuj en la India (CHAKRABORTY et al., 2011) y una formación sin nombre en el Aptiense de Colombia (J AHREN et al., 2001). En gris aparece el histograma del valor $\delta^{13} \mathrm{C}$ delas plantas terrestres actuales ( $\mathrm{n}=1615$; valor medio $-27,82 \pm 2,63 \%$ o) $(\mathrm{KOHN}, 2010)$.

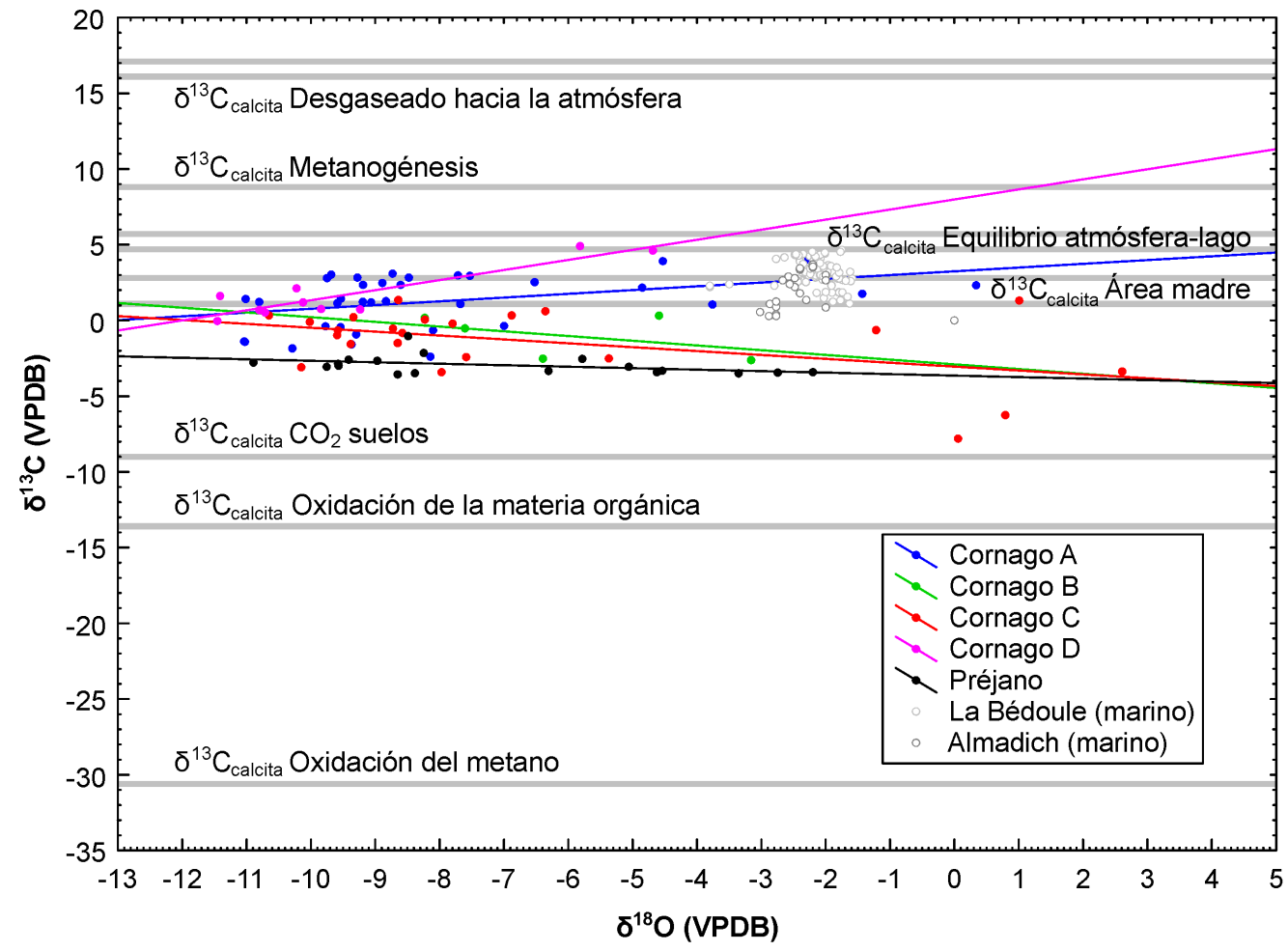




\section{Análisis isotópico y geoquímico del Grupo Enciso}

Figura 7.7: Gráfico $\delta^{18} O$ y $\delta^{13} \mathrm{C}$ de los carbonatos del Grupo Enciso (Cornago y Préjano) con indicación de los valores $\delta^{13} \mathrm{C}$ teóricos, calculados para una calcita precipitada a una temperatura de $27^{\circ} \mathrm{C}$, en función de los diferentes procesos operantes en un lago. También se han trazado los datos pertenecientes a dos formaciones marinas aptienses: La Bédoule en Francia (KUHNT et al., 1998) y la Fm. Almadich en España (DE GEA et al., 2003).

El aporte de $\mathrm{CO}_{2}$ disuelto por la entrada de aguas subterráneas y/ o superficiales tendría un valor teórico de -18,7\%o. Este dato se ha obtenido aplicando el fraccionamiento por difusión $\left(+4,4 \%\right.$ o) al valor ${ }^{13} \mathrm{C}$ de las plantas terrestres. Así pues, la calcita precipitada tendría un valor teórico $\delta^{13} \mathrm{C}_{\text {calcita }}=-9 \%$ o al emplear los fraccionamientos ${ }^{13} \varepsilon_{\text {calcita- }-\mathrm{HCO}_{3}}$ de MOOK (1986) y ${ }^{13} \varepsilon_{\mathrm{CO}_{2(\mathrm{ac})}-\mathrm{HCO}_{3}^{-}}$de MOOK et al. (1974) (figura 7.7).

Si se suponen valores del metano en el rango de los lagos actuales (-65 a -50\%o), la metanogénesis aceticlástica originaría un valor del $\mathrm{CO}_{2}$ disuelto entre -1 y $-16 \%$, lo cual podría llegar a precipitar una calcita enriquecida ${ }^{13} \mathrm{C}$ con un valor teórico $\delta^{13} \mathrm{C}$ calcita comprendido entre $+8,8 \%$ o $-6,3 \%$ o (figura 7.7 ).

Por último, la mineralización de la materia orgánica aptiense precipitaría una calcita con un valor teórico $\delta^{13} C_{\text {calcita }}=-13,6 \%$, asumiendo que no existe fraccionamiento durante la respiración aeróbica (figura 7.7). La oxidación del metano con fraccionamientos entre 4-10\%o daría un ${ }^{13} \mathrm{CO}_{2}$ disuelto en el rango - 61 a -40\%o precipitando una calcita con un rango teórico $\delta^{13}$ Calcita comprendido entre -51,8 y -30,6\%o (figura 7.7).

Con todas estas aproximaciones, la observación de la modelización realizada permite extraer algunas conclusiones iniciales, tales como:

a) La metanogénesis, la oxidación del metano y el desgaseado de $\mathrm{CO}_{2}$ no parecen constituir procesos, a priori, importantes en el paleolago Enciso.

b) Los mecanismos más significativos son el $\mathrm{CO}_{2}$ del suelo, los aportes del área madrey el equilibrio entre la atmósfera y la superficie del lago.

\subsubsection{Isotopía del oxígeno en el paleolago Enciso}

Para estimar el balance isotópico ${ }^{18} \mathrm{O}$ del paleolago Enciso se admitirán ciertos supuestos iniciales que permitan simplificar la ecuación del balance de lagos.

Primero: por criterios sedimentológicos se considera un sistema lacustre, en general, cerrado por lo que la descarga Q (tanto superficial como subterránea, ésta última más difícil de evaluar) se considera nula o poco significativa. La gran presencia de depósitos finos tanto siliciclásticos como carbonatados con poca permeabilidad, así como la abundancia de materia orgánica hidrofóbica, sugiere aportes subterráneos limitados. Por tanto, la evaporación es el único mecanismo plausible que elimina agua del sistema lacustre.

Segundo: en muchos lagos actuales, la composición isotópica de la precipitación $(\delta \mathrm{P})$, se puede asimilar con el valor más empobrecido de las aguas del lago puesto que es el que teóricamente más se aproxima a la Línea de Agua Meteorológica Mundial (DARLING et al., 2005). En nuestro caso, como la diagénesis ha podido modificar los valores ${ }^{18} \mathrm{O}$, no es seguro hacer esta aproximación inicial. Sin embargo, el valor $\delta_{\mathrm{P}}$ puede calcularse a partir de la paleolatitud (L) utilizando la estimación de las Líneas Meteóricas de las Esferosideritas, como un aproximador (proxy) de la precipitación, obtenidas en multitud de sedimentos de edad Aptiense-Albiense (SUAREZ et al., 2011):

$$
\delta^{18} \mathrm{O}_{\mathrm{VSMOW}}=-0,0042 \mathrm{~L}^{2}+0,08 \mathrm{~L}-4,33
$$

Así pues, para una paleolatitud estimada de $32^{\circ}$ (apartado 9.2) se obtiene un valor $\delta_{\mathrm{P}(\mathrm{VSMOW})}=-6,07 \%$ o que precipitaría una calcita con un valor teórico $\delta^{18} \mathrm{O}_{\text {calcita }}=-8,84 \%$. Estos valores concuerdan bien con los $\delta^{18} \mathrm{O}_{\text {calcita }}=-8,1 \pm 0,16 \%$ y $\delta^{18} \mathrm{O}_{\text {calcita }}=-8,0 \pm 0,17 \%$ o obtenidos a 


\section{Análisis isotópico y geoquímico del Grupo Enciso}

partir de las Líneas Meteóricas de la Calcita en el Miembro Ruby Ranch (Aptiense) de la Formación Cedar Mountain en Estados Unidos (paleolatitud $\approx 34^{\circ}$ ) (LUDVIGSON et al., 2010). Las Líneas Meteóricas de la Calcita se definen como una serie de muestras con valores variables del ${ }^{13} \mathrm{C}$ mientras que los correspondientes valores ${ }^{18} \mathrm{O}$ permanecen prácticamente invariables. Se forman en ambientes meteóricos de diagénesis temprana y se consideran proxies de la paleoprecipitación (LOHMANN, 1988). También son semejantes al valor $\delta_{\mathrm{P}(\mathrm{VSMOW})}=-6,79 \%$ o $\left(\delta^{18} \mathrm{O}_{\text {calcita }}=-9,55 \%\right.$ o) obtenido a partir del Modelo de Circulación General de ZHOU et al. (2008) utilizando la ecuación de ajuste de SUAREZ et al. (2011) (figura 7.8). Un análisis detallado de la tabla de frecuencias de todas las muestras del Grupo Enciso ( $n=167)$, tanto las propias como las de la tesis de DOUBLET (2004), muestra que aproximadamente el $25 \%$ de los valores $\delta^{18} \mathrm{O}_{\text {calcita }}$ están comprendidos entre -8 a $-9 \%$ o (valor medio $-8,52 \pm 0,04$ ) (figura 7.9A). Estos valores muestran, además, un rango de variación $\delta^{13} \mathrm{C}$ muy amplio $(-4,1 \mathrm{a}+3,1 \%$ ), sugiriendo que estamos en presencia de una plausible Línea Meteórica de Calcita, así como de un sistema lacustre muy influenciado por la precipitación acontecida sobre la superficie del lago y/ o sobre la cuenca de drenaje. Por consiguiente, se asume un valor $\delta_{\mathrm{P}(\mathrm{VSMOW})}=-5,73 \%$ o para la precipitación en el paleolago Enciso, que corresponde a una calcita precipitada con un valor VPBD de -8,5\% (figura 7.9B).

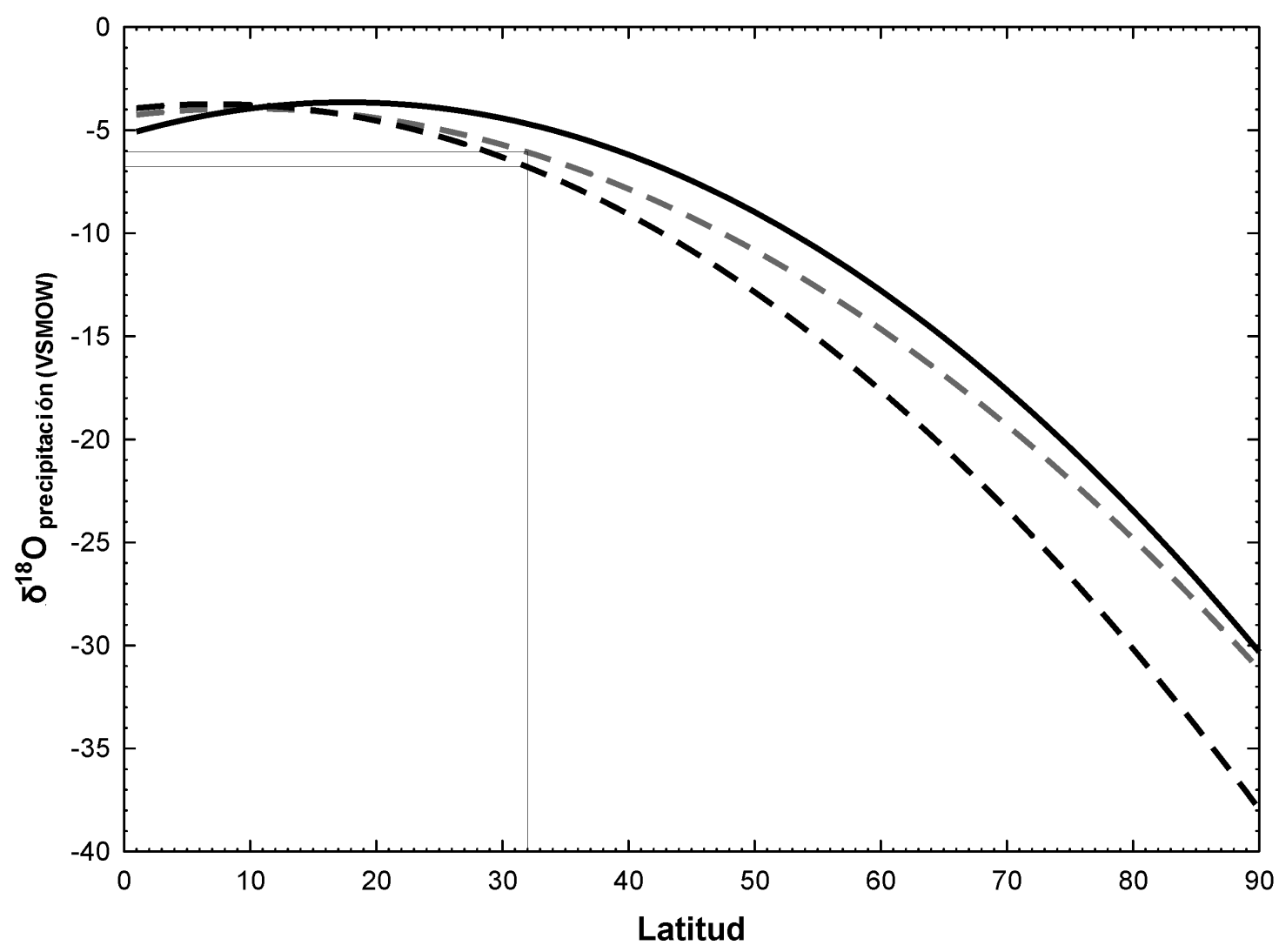

Figura 7.8: Comparación del valor $\delta^{18} \mathrm{O}$ (VSMOW) de la precipitación en función de la latitud. La línea continua negra representa el valor actual (BOWEN Y WILKINSON, 2002). La línea discontinua gris muestra el valor estimado de la paleoprecipitación obtenido a partir del análisis de las esferosideritas (SUAREZ et al., 2011). La línea discontinua negra es el valor de la paleoprecipitación proveniente del Modelo de Circulación General de ZHOU et al. (2008) según la ecuación de SUAREZ et al. (2011).

Tercero: en el contexto de un sistema lacustre tropical con poca altitud, los aportes meteóricos se limitan a las aguas pluviales, obviándose los aportes por nievey hielo.

Cuarto: los valores $\delta^{18} \mathrm{O}_{\text {calcita }}$ de los filones rellenos de calcita registran la diagénesis de los carbonatos $\left(n=8\right.$; valor medio $\left.\delta^{18} \mathrm{O}_{\text {calcita }}=-12,10 \pm 0,71\right)$. Así pues, todas las muestras comprendidas 


\section{Análisis isotópico y geoquímico del Grupo Enciso}

entre estos valores y el de la Línea Meteórica de Calcita, se considera que han sufrido algún tipo de modificación diagenética y no conservan su señal original (figura 7.9B).

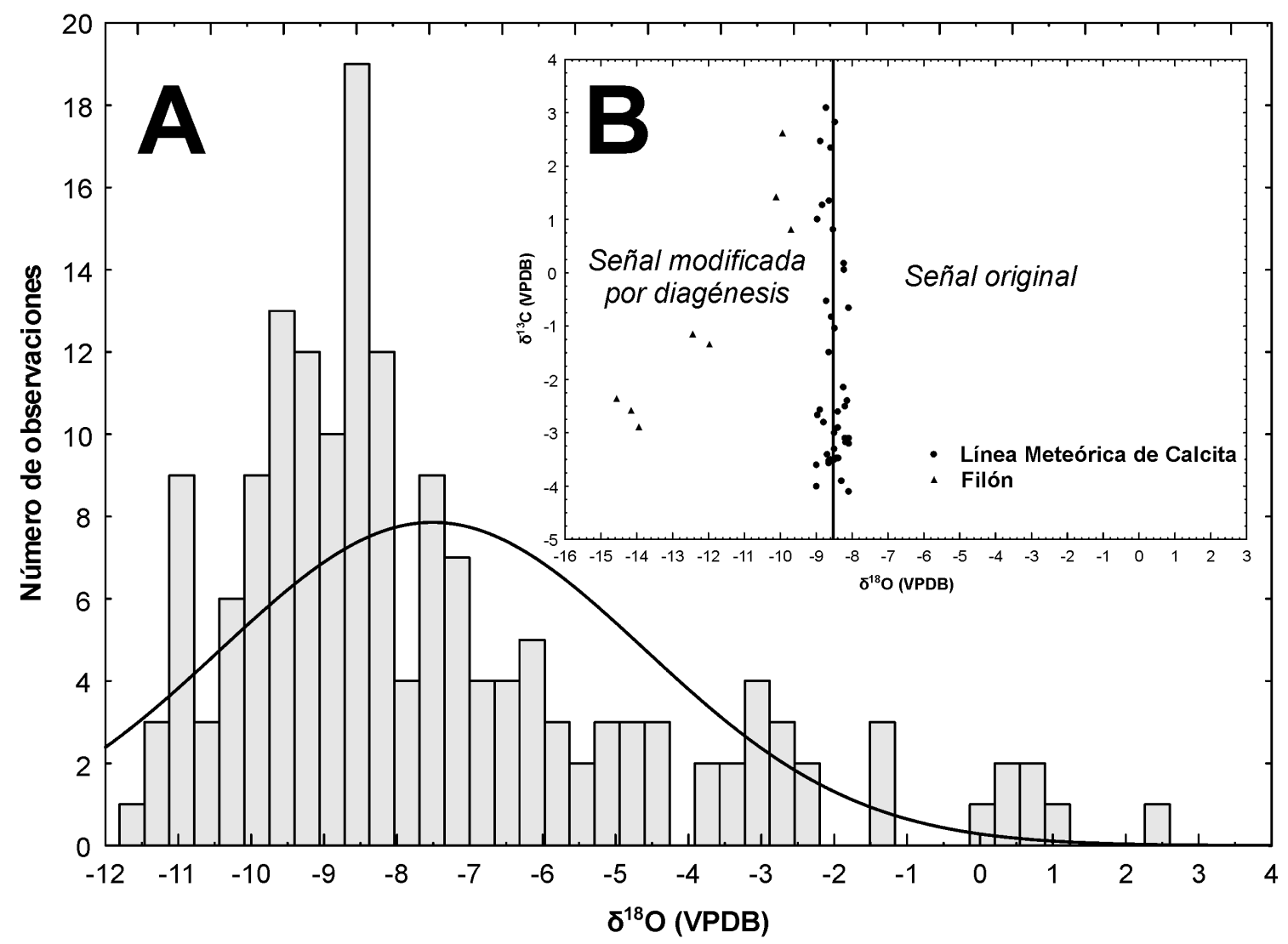

Figura 7.9: A) Histograma de valores $\delta^{18} \mathrm{O}_{\text {calcita }}$ del Grupo Enciso. B) Línea Meteórica de Calcita y ambiente diagenético (filones rellenos de calcita).

Quinto: para calcular el valor de $\delta_{\mathrm{A}}$ del vapor atmosférico se asume que está en equilibrio con la precipitación, lo cual es cierto para lagos situados en latitudes bajas (GIBSON et al., 2008), obteniéndose un valor VSMOW de $+12,8 \%$.

Sexto: el flujo entrante, como primera aproximación, puede considerarse como un reflejo de la composición isotópica acontecida en la cuenca de drenaje (TALBOT, 1990). En el Grupo Enciso, los paquetes carbonatados se siguen lateralmente durante kilómetros sin que aparezcan grandes canales o formas fluviales semejantes, admitiéndose que toda la entrada de agua en el lago es principalmente a través de la precipitación acaecida (o escorrentía limitada), por tanto $\delta_{\mathrm{I}}$ $=\delta \mathrm{P}$.

Con estos supuestos, el balance hidrológico permite obtener una relación entre $\delta^{18} \mathrm{O}_{\text {calcita }}$ y $\delta^{18} \mathrm{O}_{\text {dolomita }}$ teórica precipitada en equilibrio con la aguas del lago $\left(27^{\circ} \mathrm{C}\right)$ en función dela fracción de agua remanente (figura 7.10) a partir de diferentes humedades relativas.

Del análisis de esta figura se puede afirmar que el paleolago Enciso sufrió a lo largo de su historia importantes caídas del nivel de sus aguas con pérdidas de volumen significativas asociadas a etapas secas.

Aplicando todos los supuestos iniciales anteriores, los datos isotópicos se pueden reorganizar de la siguiente manera (figura 7.11): 


\section{Análisis isotópico y geoquímico del Grupo Enciso}

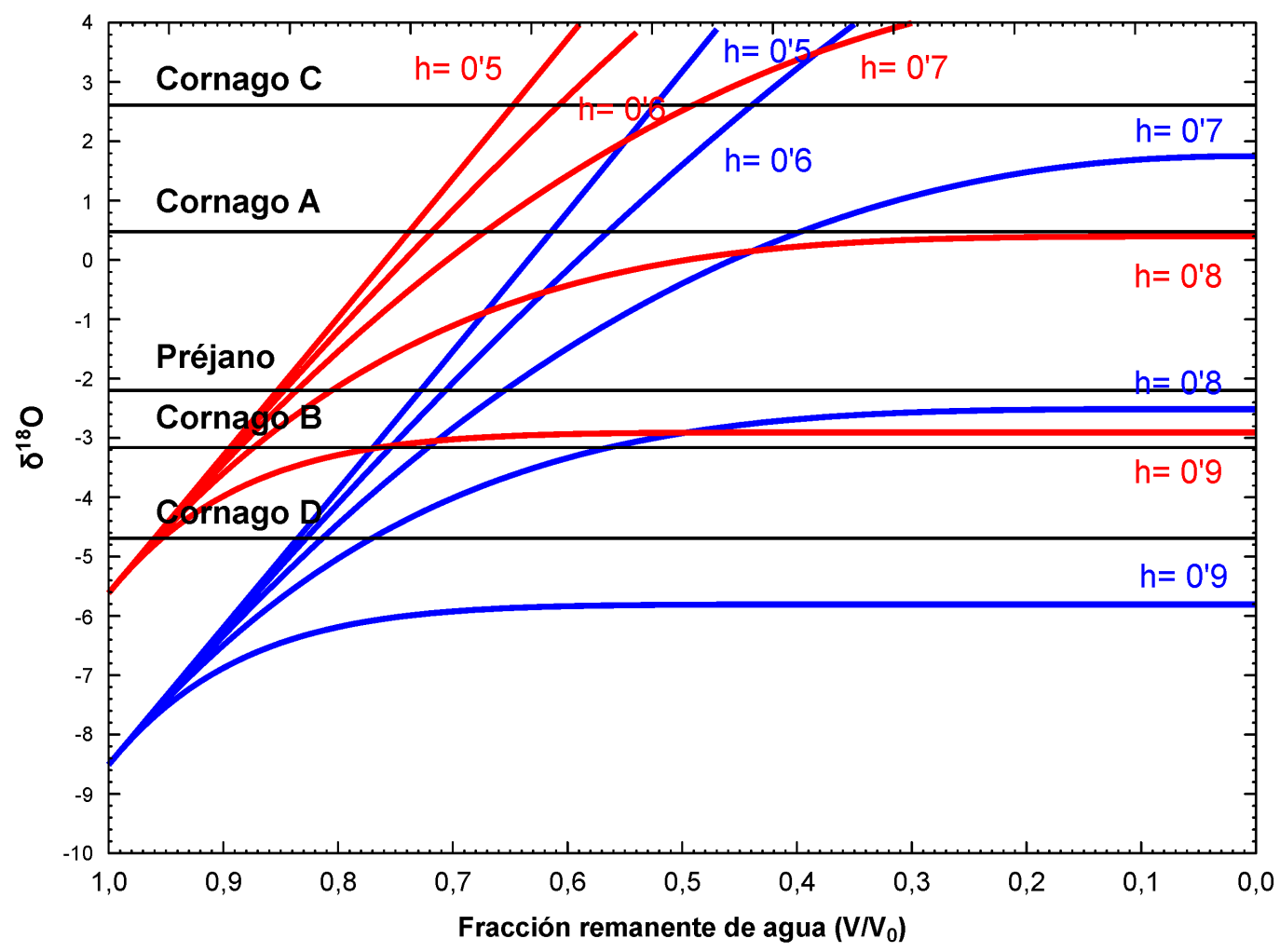

Figura 7.10: Gráfica que muestra la evolución de los valores $\delta^{18} \mathrm{O}_{\text {calcita }}$ (azul) y $\delta^{18} \mathrm{O}_{\text {dolomita }}$ (rojo), calculados considerando que ambos precipitan en equilibrio en aguas con una composición inicial igual a la de la precipitación, a una temperatura de $27^{\circ} \mathrm{C}$, y en función de la fracción de agua remanente en el lago para diferentes humedades relativas (h). Las líneas horizontales negras marcan los valores máximos $\delta^{18} \mathrm{O}$ de las muestras analizadas en cada columna muestreada.

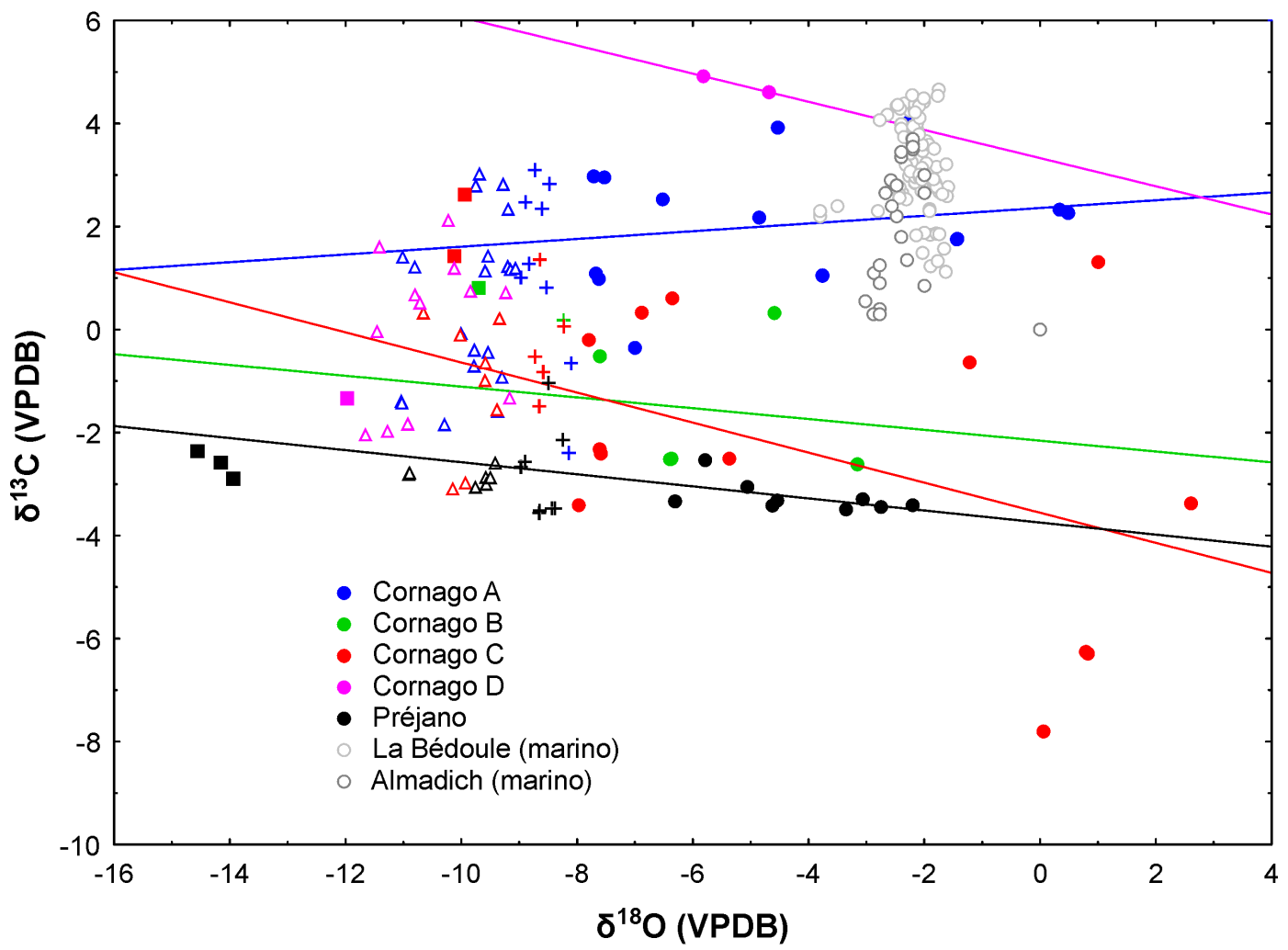

Figura 7.11: Gráfico delos isótopos de las muestras del Grupo Enciso reorganizadas. Los colores son los mismos que para la figura 7.7. Los cuadrados hacen referencia a los valores delos filones 


\section{Análisis isotópico y geoquímico del Grupo Enciso}

rellenos de calcita (diagénesis). Los triángulos representan los valores afectados probablemente por diagénesis. Las cruces marcan la Línea de Meteórica de Calcita. Los círculos corresponden a los valores que guardan su señal isotópica original.

Las nuevas correlaciones de los valores isotópicos cuya señal es original (marcados por un círculo en la figura anterior) varían ligeramente con respecto a la obtenida a partir de todos los valores (figura 7.7).

La serie Cornago A muestra una leve covarianza positiva $(r=+0,19)$ que sugiere una etapa de un lago somero (baja covarianza) y, probablemente, con aguas salinas. Presenta cierta tendencia hacia los valores marinos, con lo que no se descarta cierta influencia marina en sus aguas. Sin embargo, esta tendencia puede corresponder a un lago con una gran evaporación durante etapas áridas que, al perder volumen en sus aguas (figura 7.10), incrementa la salinidad (incremento de ${ }^{18} \mathrm{O}$ ) y la producción orgánica y/ o desgasificación hacia la atmósfera (incremento de ${ }^{13}$ ). Las series Cornago B y D no tienen suficientes valores válidos para ser analizados con cierto grado de solvencia (en la serie de Cornago D la mayoría de sus valores están influenciados por la diagénesis). La serie Cornago $\mathrm{C}$ muestra una covarianza negativa $(\mathrm{r}=-0,42)$ que se asocia a un cuerpo lacustre somero evaporativo durante etapas muy áridas (figura 7.10). Al caer el nivel del lago, la vegetación invade las zonas someras y su degradación (oxidación de la materia orgánica) in situ aporta ${ }^{12} \mathrm{C}$ a las aguas del lago. La serie de Préjano muestra covarianza negativa $(\mathrm{r}=-0,55)$ asociada a un incremento concomitante de ${ }^{18} \mathrm{O}$ y ${ }^{12} \mathrm{C}$, y su interpretación es similar a la de la serie Cornago C.

\subsection{GEOQUÍMICA INORGÁNICA}

En cualquier roca se pueden diferenciar los elementos mayoritarios $(>1 \%)$, minoritarios $(1 \%-0,1 \%)$ y trazas $(<1 \%)$. Todos ellos proporcionan una información muy interesante tanto de la procedencia del sedimento como de aspectos paleoclimáticos/paleoecológicos. Algunos elementos traza y mayoritarios como los alcalinos y alcalinotérreos pueden utilizarse como aproximadores valiosos en paleoclimatología (WEI et al., 2004). También permiten un conocimiento más preciso de los parámetros fisicoquímicos del medio de sedimentación así como de los procesos diagenéticos (COHEN, 2003). Para las posteriores explicaciones, a fin de no ser repetitivo, se analizan de manera somera los diferentes indicadores geoquímicos utilizados en la interpretación de los perfiles.

Un clima húmedo favorece la eliminación de $\mathrm{Ca}^{2+}, \mathrm{Mg}^{2+}, \mathrm{Na}^{+}$y K+ de los feldespatos por meteorización química mientras que enriquece los elementos insolubles hidrolizados $\left(\mathrm{Al}^{3+}, \mathrm{Si}^{4+}\right.$, $\mathrm{Ti}^{4+}$ ) en la fracción detrítica de los sedimentos (NESBITT Y YOUNG, 1982; TAYLOR Y MACLENNAN, 1985). Como la meteorización química es más intensa en los climas cálidos y húmedos que en los climas más áridos, el ratio $\mathrm{Ca} / \mathrm{Ti}$ y Na/ Ti es bajo durantelas etapas húmedas, y alto durante etapas áridas (DEAN, 1997; WEI et al., 2004; SINHA et al., 2006).

El Ti es liberado de las rocas por la meteorización física, siendo poco o nada móvil por disolución debido a su baja solubilidad (FARGES, 1998). Por tanto, es frecuente que se use como un indicador de la entrada alóctona de detríticos en la cubeta, así como de la variabilidad hidrológica (escorrentía y/ o precipitación) (HAUG et al., 2003; DEMORY et al., 2005; EUSTERHUES et al., 2005). Como en los lagos cerrados, la escorrentía es un factor importante en las variaciones del nivel del lago, el Ti puede también reflejar las fluctuaciones de dicho lago.

El aluminio suele indicar entradas de aportes detríticos y, en algunos casos, un $\mathrm{pH}$ ácido ya que el Al puede ser movilizado por la acidificación del medio (NELSONY CAMPBELL, 1991; BOYLE, 1994). El Al tiene poca movilidad aunque con $\mathrm{pH}$ por debajo de 5,5 su solubilidad se incrementa y es eliminado de las rocas silicatadas, y con pH por encima de 8 (altamente alcalina) puede también ser movilizado en forma iónica (SHILIER Y FRILOT, 1996).

Así pues, el incremento de $\mathrm{Si}$ y $\mathrm{Al}$ terrígeno en los testigos lacustres se utilizan como indicadores de condiciones climáticas (humedad-aridez) y de la intensidad de la meteorización (COHEN, 2003). 
El $\mathrm{K}^{+}$y $\mathrm{Na}^{+}$son cationes conservativos y normalmente precipitan en los minerales autígenos lacustres sólo en condiciones muy salinas o cuando son adsorbidos por los sedimentos finos (ENGSTROM Y WRIGHT, 1984). Todas las sales de sodio y potasio son muy solubles por lo que tienden a permanecer en forma disuelta aunque su movilidad puede reducirse por la adsorción de minerales arcillosos. El potasio es un indicador típico de materiales ricos en arcillas y se considera un buen indicador de entrada detrítica (EUSTERHUES et al., 2005).

La variaciones de $\mathrm{Ca}\left(\mathrm{CaCO}_{3}\right)$ puede indicar la abundancia de fragmentos fósiles (CAMPBELL et al., 2000) o fluctuaciones en el nivel del lago (BISCHOFF et al., 1997b; HABERZETTL et al., 2007; SAHAJ PAL et al., 2011). En general, el aumento en Ca se origina por un incremento de la concentración debida a la evaporación. Sin embargo, esta relación puede ser más compleja ya que en el lago Mono, el aumento de Ca (o su precipitación) se produce durante las etapas altas de nivel del lago asociada a la entrada de agua superficiales (SAHAJ PAL et al., 2011). Para minimizar este posible efecto, los datos del Ca se suelen normalizar con respecto al Ti. Esta relación $\mathrm{Ca} / \mathrm{Ti}$ en los sedimentos refleja mejor la variabilidad hidrológica del lago, con valores altos durante las etapas de precipitación de carbonato autígeno (concentración) o áridas, y bajos en épocas de dilución o húmedas (HABERZETTL et al., 2007; MARTÍN-PUERTAS et al., 2011; RODYSILL et al., 2012).

El bario y el estroncio tienen un comportamiento químico muy parecido al calcio. Son elementos solubles en el agua y los iones $\mathrm{Ba}^{2+}$ y $\mathrm{Sr}^{2+}$, frecuentemente, sustituyen a $\mathrm{Ca}^{2+}$ en la calcita (PINGITORE J R. Y EASTMAN, 1984; 1986; SIMMONS, 1998; SMITH, 1998). Por esta razón, las relaciones $\mathrm{Ba} / \mathrm{Ti}$ y $\mathrm{Sr} / \mathrm{Ti}$ se incrementan durante los períodos de precipitación de carbonato endógeno (WEI et al., 2004; MARTÍN-PUERTAS et al., 2011). Por otra parte, el estroncio es un elemento propenso a ser lixiviación en los suelos mientras que el bario es relativamente inactivo y no proclive al lavado. Así pues, el ratio $\mathrm{Ba}$ / $\mathrm{Sr}$ es un buen indicador de la intensidad del lavado y puede utilizarse como un indicador de las variaciones en la humedad (GALLET et al., 1996).

$\mathrm{El} \mathrm{Sr}{ }^{2+}$ disuelto en la masa de agua es incorporado de forma preferente en los carbonatos autígenos y/o adsorbido en la superficie de los óxidos de Fe y Mn (GOLDSTEIN Y J ACOBSEN, 1988; J IN et al., 2001). El estroncio también se comporta de manera semejante al magnesio de tal manera que cuando la salinidad en el lago se incrementa se produce un enriquecimiento en el carbonato precipitado. Así pues, la relación Sr/Ca puede utilizarse como un indicador de la salinidad del lago, de la calcita biogénica, o de la tasa de precipitación del carbonato (BAKER et al., 1982; VALERO-GARCÉS et al., 1999b). Por otra parte, la relación Sr/ Al muestra picos relacionados con la precipitación de carbonatos debido a la concentración por evaporación en la cubeta lacustre (MARTÍN-PUERTAS et al., 2010; MARTÍN-PUERTAS et al., 2011).

El carbono orgánico presente en el sedimento no es un reflejo fiel de la productividad orgánica, aunque en ciertos casos pueda utilizarse como tal (RODYSILL et al., 2012). La presencia o ausencia de materia orgánica en el sedimento es un delicado equilibrio entre la producción en el epilimnion y la descomposición en la columna de agua y/ o en la interfase sedimento-agua. Las etapas productividad en los lagos templados están gobernadas por el ciclo térmico del lago, por el contrario, en los lados tropicales se rigen por las estaciones de lluvia y sequía (ROLDÁN-PÉREZY RAMÍREZ-RESTREPO, 2008). Por los tanto, el contenido en carbono orgánico puede documentar ciclos climáticos a largo plazo sobre todo en sistemas lacustres que experimentan fluctuaciones apreciables en la productividad y/o niveles del lago (COHEN, 2003). En el lago Owens se observa un incremento del valor en carbono orgánico durante las etapas más cálidas y secas (BISCHOFF et al., 1997a). En el Gran Lago Salado de Utah los mayores contenidos en carbono orgánico están asociados con los niveles bajos del lago (EUGSTER Y KELTS, 1983). Sin embargo, el reflejo de la señal climática puede ser diverso, de tal manera que, bajo condiciones cálidas, una fluctuación relevante del nivel de las aguas (por evaporación) expone una considerable área del fondo del lago a condiciones pedogenéticas que oxidan y degradan de manera rápida la materia orgánica formada previamente (BEUNING et al., 1997). EINSELE et al. (2001) consideran que una variación de un clima húmedo a uno más árido tiende a disminuir la cantidad total de carbono enterrado en el lago. Por último, se debe tener en cuenta que la preservación de la materia orgánica está favorecida por los ambientes salinos (EUGSTER Y KELTS, 1983). 


\section{Análisis isotópico y geoquímico del Grupo Enciso}

El P da información de la productividad ya que es un nutriente básico para los organismos y, por tanto, limitante de la productividad orgánica. Como el fósforo es consumido durante la fotosíntesis, durante las etapas de productividad se produce su reducción (BEIN, 1986).

La relación Mg/ Mg+Ca es útil para determinar procesos evaporativos en una masa de agua. La precipitación de calcita consume calcio, por lo que cada vez existe menos $\mathrm{Ca}^{2+}$ y más $\mathrm{Mg}^{2+}$, originando un incremento en el ratio $\mathrm{Mg} / \mathrm{Mg}+\mathrm{Ca}$ tanto del agua residual como dela calcita precipitada. Una correlación entre $\delta^{18} \mathrm{O}$ y la relación $\mathrm{Mg} / \mathrm{Mg}+\mathrm{Ca}$ sugiere que la variación de $\delta^{18} \mathrm{O}$ está influenciado por el enriquecimiento por evaporación de las aguas del lago (DUTKIEWICZ et al., 2000; SINHA et al., 2006). De manera más puntual puede asociarse a la productividad debida a la precipitación bioinducida del carbonato (MARTíN-PUERTAS et al., 2011). También sirve para discernir entre los carbonatos precipitados: calcita y dolomita. La calcita tiende a presentar ratios bajos de Mg/ Mg+Ca concurrentes con valores elevados de $\mathrm{Sr} / \mathrm{Fe}$ y Sr/ Mg.

Los elementos sensibles a las condiciones redox se pueden agrupar en dos categorías. La primera categoría se refiere a los elementos que presentan un gran contraste en la solubilidad de sus formas oxidadas y reducidas (As, $\mathrm{Co}, \mathrm{Cr}, \mathrm{Fe}, \mathrm{Mn}, \mathrm{y} \mathrm{V}$ ). En aguas oxigenadas forman especies iónicas muy solubles, pero son reducidas a especies insolubles en ambientes anóxicos (BOYLE, 2001). La segunda categoría comprende los elementos que no cambian de valencia pero que forman sulfuros muy insolubles ( $\mathrm{Cd}, \mathrm{Cu}, \mathrm{Ni}, \mathrm{y} \mathrm{Zn}$ ), y que son eliminados de la disolución en presencia de $\mathrm{H}_{2} \mathrm{~S}$. Así pues, los sedimentos depositados en ambientes anóxicos suelen estar enriquecidos en estos elementos (CALVERT Y PEDERSEN, 1993).

Las condiciones redox también se pueden determinar utlilizando las relaciones $\mathrm{MnO}$ y $\mathrm{Mn} / \mathrm{Fe}$. Esta interpretación se basa en la mayor solubilidad del Mn respecto del Fe y permite su utilización como un indicador paleoredox en medios lacustres (WERSIN et al., 1991; BRÜCHMANN Y NEGENDANK, 2004; GRANINA et al., 2004). En un medio reductor se originan carbonatos pobres en Mn y con ratios bajos, mientras que en un medio oxidante, el carbonato está enriquecido en Mn y Mn/ Fe (RENARD, 1975; KORPONAI et al., 2010). A veces, un valor elevado Mn/Fe aparece en sedimentos con un gran contenido orgánico y puede utilizarse como indicador dela productividad (MARTÍN-PUERTAS et al., 2011).

El vanadio es un elemento que presenta tres estados de oxidación en los ambientes sedimentarios. El vanadio (V) es un ión en el rango del $\mathrm{pH}$ natural y la cantidad disuelta en aguas oxigenadas está poco limitada por la solubilidad de la especie. El V (IV) y V(III) son menos solubles que el V (V) debido a su tendencia a formar oxihidróxidos insolubles en el rango de pH de las aguas naturales (WEHRLI Y STUMM, 1989). El vanadio suele mostrar una fuerte afinidad con la materia orgánica (WEHRLI Y STUMM, 1989) y/ o los carbonatos (HOLLAND, 1979).

Las relaciones $\mathrm{Ni} / \mathrm{V}$ y V/Cr dependen de la sensibilidad del $\mathrm{V}$ a las condiciones redox (J ONES Y MANNING, 1994). En condiciones oxidantes, el V es relativamente insoluble y se concentra en el sedimento, resultando en un ratio Ni/V bajo y V/Cr alto, mientras que bajo condiciones reductoras es soluble y se disipa en la columna de agua (HARRIS et al., 2004).

En muchos sistemas lacustres actuales como el lago Owens (BISCHOFF et al., 1997b; LI et al., 2000), Mono (SAHAJ PAL et al., 2011), El Peinado y Las Coladas (VALERO-GARCÉS et al., 1999a), el Li es un buen indicador de la salinidad.

El Rb es un elemento muy sensible a los cambios climáticos (NESBITT et al., 1980), pudiendo ser lixiviado durante la meteorización química. Así pues el ratio $\mathrm{Rb} / \mathrm{Al}$ se incrementa durante etapas de meteorización química o de entrada de detríticos (MARTÍN-PUERTAS et al., 2010). En ambos casos está gobernado por un clima más húmedo que conlleva mayores precipitaciones y escorrentía. La razón $\mathrm{Rb}$ / Sr puedeutilizarse como indicador dela meteorización bajo diferentes condiciones climáticas (J IN et al., 2006; LI et al., 2008) aumentando cuando existe poca meteorización química (J IN et al., 2003). Sin embargo, cuando el ratio $\mathrm{Rb} / \mathrm{Sr}$ disminuye también puede indicar un incremento de la salinidad por evaporación (RoY et al., 2009). 


\subsection{ANÁLISIS GEOQUÍMICO DE LA COLUMNA CORNAGO A}

En el perfil estratigráfico Cornago A se han realizado 44 análisis isotópicos (9 de ellos repetidos) además de 27 análisis de elementos mayoritarios, minoritarios y trazas (anexo XIII.1y XIII.2). Corresponde a la serie comprendida entre los tramos 70b-115 de la columna de Cornago (anexo VI). En el anexoXIII.3 se muestran las correlaciones entre todos los elementos analizados que previamente han sido normalizados (apartado 2.5.2.1).

El análisis de factores (tabla 7.1 y 7.2) muestra que el 85,44\% de la varianza geoquímica está definida por 4 factores obtenidos a partir de los componentes principales con rotación Varimax: factor $1(55,24 \%)$, factor $2(15,63 \%)$, factor $3(7,47 \%)$, y factor $4(7,10 \%)$.

\begin{tabular}{|c|c|c|c|c|}
\hline & Factor 1 & Factor 2 & Factor3 & Factor 4 \\
\hline$\delta^{18} \mathrm{O}$ (VPDB) & $-0,18950$ & $-0,825408$ & 0,464777 & 0,113613 \\
\hline$\delta^{13} \mathrm{C}$ (VPDB) & $-0,09258$ & $-0,644112$ & $-0,284579$ & 0,570891 \\
\hline $\operatorname{lnSiO}{ }_{2}$ & 0,88222 & 0,316939 & $-0,056036$ & 0,235229 \\
\hline $\ln \mathrm{Al}_{2} \mathrm{O}_{3}$ & 0,90000 & 0,257445 & 0,142178 & 0,290498 \\
\hline $\mathrm{Fe}_{2} \mathrm{O}_{3}$ & 0,72934 & $-0,272338$ & 0,201820 & 0,475568 \\
\hline $\mathrm{CaO}$ & $-0,85793$ & 0,186352 & $-0,092422$ & $-0,360630$ \\
\hline $\ln \mathrm{TiO}_{2}$ & 0,89847 & 0,284914 & 0,073576 & 0,278211 \\
\hline MnO & $-0,15368$ & $-0,565538$ & 0,510447 & $-0,118813$ \\
\hline $\ln \mathrm{K}_{2} \mathrm{O}$ & 0,91092 & 0,242287 & 0,085259 & 0,215702 \\
\hline MgO & $-0,04776$ & $-0,909442$ & 0,106541 & $-0,062328$ \\
\hline $\mathrm{P}_{2} \mathrm{O}_{5}$ & 0,37283 & $-0,077332$ & 0,817627 & 0,122750 \\
\hline $\ln \mathrm{Na}_{2} \mathrm{O}$ & 0,32221 & $-0,085827$ & 0,350914 & 0,804922 \\
\hline InBa & 0,92766 & 0,062778 & 0,057737 & 0,206902 \\
\hline $\mathrm{Be}$ & 0,73028 & 0,178903 & 0,261308 & 0,269062 \\
\hline $1 / \mathrm{Ce}$ & $-0,46649$ & $-0,199931$ & 0,019294 & $-0,825708$ \\
\hline InCo & 0,65669 & 0,241988 & 0,285436 & 0,389321 \\
\hline InCr & 0,69779 & 0,108004 & 0,389251 & 0,544171 \\
\hline $\ln \mathrm{Cu}$ & 0,39649 & 0,672158 & 0,170053 & 0,398280 \\
\hline 1/La & $-0,38812$ & $-0,202783$ & 0,012526 & $-0,852186$ \\
\hline InLi & 0,85273 & 0,128883 & 0,080529 & 0,216449 \\
\hline $\ln R \mathbf{b}$ & 0,67898 & $-0,399944$ & $-0,150228$ & 0,012059 \\
\hline $\mathrm{Sr}$ & $-0,84294$ & 0,095856 & $-0,238609$ & $-0,210107$ \\
\hline $\ln V$ & 0,91584 & 0,285203 & 0,172366 & 0,164457 \\
\hline $\mathbf{Y}$ & 0,28939 & $-0,298159$ & 0,523811 & 0,635036 \\
\hline Zn & 0,53337 & 0,039603 & 0,308635 & 0,660663 \\
\hline $\ln \mathrm{C}_{\text {orgánico }}$ & 0,02420 & $-0,117808$ & 0,869220 & 0,126874 \\
\hline Carbonato $^{2}$ & $-0,60663$ & $-0,193577$ & $-0,618724$ & $-0,291497$ \\
\hline
\end{tabular}

Tabla 7.1: Principales factores en la columna Cornago A (Varimax normalizado). En gris se indican las cargas principales $(>0,7)$ y en negrita las cargas significativas $(>0,4)$. 


\begin{tabular}{|l|c|c|c|c|}
\cline { 2 - 5 } \multicolumn{1}{c|}{} & Valores propios & \% Total & Acumulado & \% Acumulado \\
\hline Factor 1 & 14,92 & 55,24 & 14,92 & 55,24 \\
\hline Factor 2 & 4,22 & 15,63 & 19,14 & 70,88 \\
\hline Factor 3 & 2,02 & 7,47 & 21,15 & 78,34 \\
\hline Factor 4 & 1,92 & 7,10 & 23,07 & 85,44 \\
\hline
\end{tabular}

Tabla 7.2: Valores propios y acumulados delos factores extraídos en la columna Cornago A.

El factor 1 muestra cargas positivas principales para el $\ln \mathrm{SiO}_{2}, \ln \mathrm{Al}_{2} \mathrm{O}_{3}, \mathrm{Fe}_{2} \mathrm{O}_{3}, \ln \mathrm{TiO}_{2}$, $\ln \mathrm{K}_{2} \mathrm{O}, \operatorname{lnBa}, \mathrm{Be}, \operatorname{lnLi} \mathrm{y}, \operatorname{lnV}$, y cargas positivas significativas para el $\operatorname{lnCo}, \operatorname{lnCr}, \operatorname{lnRb}$ y $\mathrm{Zn}$ (asociación I). También registra cargas negativas principales para $\mathrm{CaO}$ y $\mathrm{Sr}$, y significativas para el contenido en carbonato ${ }^{2}$ y $1 /$ Ce (asociación II).

a) La asociación I incluye los elementos, típicamente aluminosilicatos, procedentes de fuera del lago (alóctonos).

b) La asociación II representa a los elementos asociados a la precipitación de carbonatos en el lago durante etapas con poca entrada de material siliciclástico.

c) La correlación negativa tanto del $\mathrm{CaO}$ como del contenido en carbonatos con respecto a los indicadores de escorrentía (asociación I) sugiere que todo el carbonato es de origen autóctono y que se puede descartar la entrada de carbonatos detríticos en la cubeta lacustre.

d) La presencia de Li (lnLi) y Ba (lnBa) en la asociación I permite eliminar el litio como un indicador útil de la salinidad y del bario como aproximador (proxy) de etapas de precipitación de carbonato asociado a evaporación.

El factor 2 muestra una carga significativa positiva con lnCu, así como una carga principal negativa con $\delta^{18} \mathrm{O}$ y $\mathrm{MgO}$ y significativa con el $\delta^{13} \mathrm{C}$ y $\mathrm{MnO}$.

a) Se interpreta como un proceso de enriquecimiento del $\delta^{18} \mathrm{O}$ por evaporación de las aguas del lago (DUTKIEWICZ et al., 2000; SINHA et al., 2006).

b) Esta evaporación conlleva un incremento del contenido en $\mathrm{MgO}$ como resultado de la precipitación selectiva de calcita de bajo $\mathrm{Mg} \rightarrow$ calcita de alto $\mathrm{Mg} \rightarrow$ aragonito $\rightarrow$ dolomita (MÜLLER et al., 1972), y al aumento en la producción orgánica por la caída del nivel del agua $\left(\delta^{13} \mathrm{C}\right)$.

El factor 3 muestra una carga principal positiva para el para $\mathrm{P}_{2} \mathrm{O}_{5}$ y $\ln \mathrm{C}_{\text {orgánico }} \mathrm{y}$, significativa para $\delta^{18} \mathrm{O}, \mathrm{MnO}$ e Y. Además muestra una carga negativa significativa para el contenido en carbonato ${ }^{2}$. Esta asociación refleja elementos asociados a la productividad.

El factor 4 presenta una carga principal positiva para $\operatorname{lnNa} 2 \mathrm{O}$, y significativa para $\delta^{13} \mathrm{C}$, $\mathrm{Fe}_{2} \mathrm{O}_{3}, \operatorname{lnCr}, \mathrm{Y}$, y Zn. La carga negativa principal está marcada por 1/Ce y 1/La. Es difícil de interpretar, aunque parece estar asociada a las condiciones redox del sistema.

Finalmente, para la interpretación de los isótopos estables y de los elementos se ha dividido la columna en 11 zonas (figura 7.12), en función de las tendencias que muestran los valores isotópicos, así como los elementos analizados (o relaciones entre ellos).

El tramo 1 se interpreta como un incremento suave de $\delta^{18} \mathrm{O}$ debido a la evaporación sin fluctuaciones del volumen del nivel del lago (estacionario) ya que no existen evidencias sedimentológicas de emersión, durante una etapa de aridez ( $\mathrm{Na} / \mathrm{Ti}$ ). Esta evaporación favorecela precipitación de calcita $(\mathrm{Sr} / \mathrm{Ca}$ y $\mathrm{CaO})$ y valores bajos de terrígenos extracuencales $\left(\mathrm{TiO}_{2}\right)$. El valor ${ }^{13} \mathrm{C}$ se incrementa de manera suave y está asociado a pequeños incrementos en la productividad $\left(\mathrm{P}_{2} \mathrm{O}_{5}\right)$, con cierta tendencia hacia condiciones reductoras $(\mathrm{Mn} / \mathrm{Fe}$ y $\mathrm{MnO})$ que permite la sedimentación de la materia orgánica (Corgánico). 


\section{Análisis isotópico y geoquímico del Grupo Enciso}

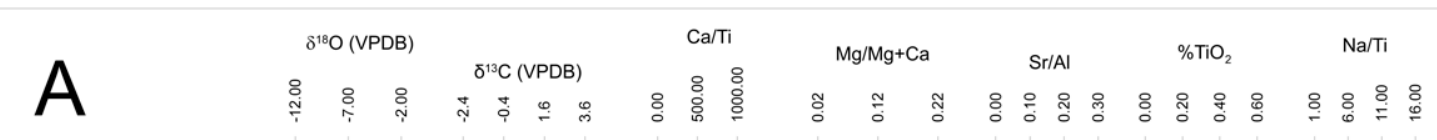
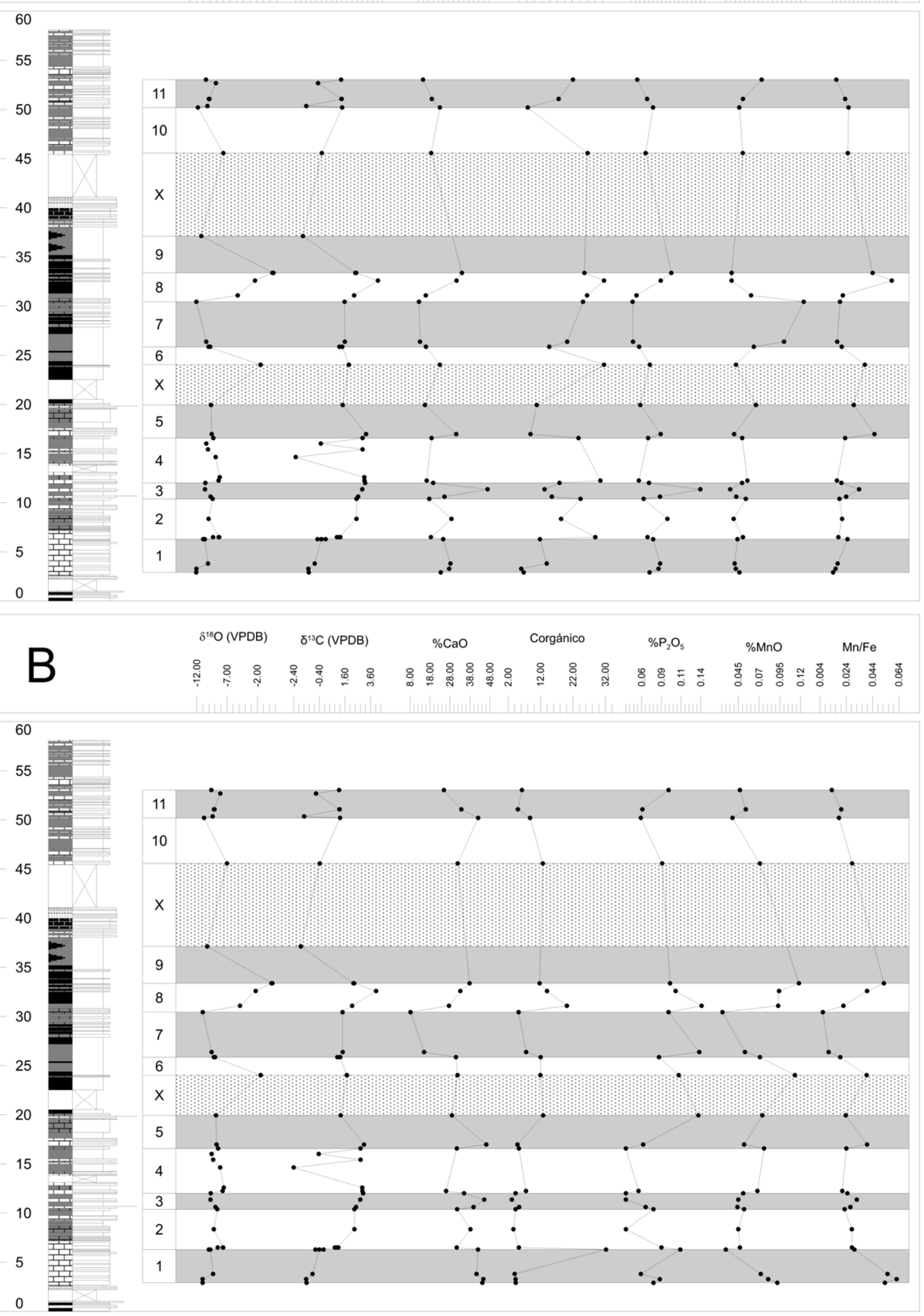

Figura 7.12: Geoquímica de la columna de Cornago A (tramos 70b—115).

El tramo 2 muestra de inicio un incremento acusado $\left(\approx 3 \%\right.$ o en el valor $\delta^{18} \mathrm{O}$ asociado a una zona con numerosos indicios de emersión (grietas de desecación, icnitas de dinosaurios) por lo cual se asocia a una evaporación con pérdida de volumen del lago. Utilizando el balance 


\section{Análisis isotópico y geoquímico del Grupo Enciso}

hidrológico del lago (figura 7.10) se estima una disminución del 10-15\% del volumen del lago, mucho menos si se admite la precipitación de dolomita como parecen sugerir ciertos indicadores $(\mathrm{Mg} / \mathrm{Mg}+\mathrm{Ca})$. El valor $\delta^{13} \mathrm{C}$ muestra un incremento que seasocia inicialmente a un incremento de la productividad $\left(\mathrm{P}_{2} \mathrm{O}_{5}\right)$, para posteriormente deberse, probablemente, a la desgasificación de $\mathrm{CO}_{2}$ hacia la atmósfera ya que se asocia a una etapa de evaporación, incremento de la salinidad $(\mathrm{Mg} / \mathrm{Mg}+\mathrm{Ca})$ y precipitación de carbonatos.

El tramo 3 presenta un descenso del valor $\delta^{18} \mathrm{O}(\approx 1 \%)$ y leve enriquecimiento de $\delta^{13} \mathrm{C}$ asociado a niveles que presentan grietas de retracción. Se observa un gran pico de aridez ( $\mathrm{Ca}$ / Ti y $\mathrm{Na} / \mathrm{Ti}$ ), adjunto a una gran precipitación de calcita por evaporación ( $\mathrm{Sr} / \mathrm{Al}$ y $\mathrm{CaO}$ ), condiciones oxidantes $(\mathrm{Mn} / \mathrm{Fe})$ y sin evidencias de cambios en la productividad. La abundancia de margas se relaciona con el descenso del ${ }^{18} \mathrm{O}$ por entrada de aguas de escorrentía. Además, como el valor ${ }^{13} \mathrm{C}$ está en torno a $+2 \%$, esta agua podrían provenir de un área madre en las calizas J urásicas de la Fm Torrecilla.

El tramo 4 muestra un pequeño descenso del valor $\delta^{18} \mathrm{O}$ y elevadas fluctuaciones de la señal de $\delta^{13} \mathrm{C}$ en una zona con numerosas grietas de desecación y margas. No existen datos geoquímicos por falta de muestreo. Sin embargo las fluctuaciones de ${ }^{13} \mathrm{C}$ entre las calizas $(+3 \%$ ) y las margas $(-2,4 \%$ o) sugiere cierto equilibrio entre las aguas de lago y la atmósfera durante la precipitación de la calcita, junto a la entrada de aguas cargadas en ${ }^{12} \mathrm{C}$ procedente de la materia orgánica terrestre durante la sedimentación de las margas.

El tramo 5 no muestra variación en la señal ${ }^{18} \mathrm{O}$ aunque existe un descenso moderado de ${ }^{13} \mathrm{C}$. Hay un incremento en los indicadores de entrada de detríticos $\left(\mathrm{TiO}_{2}\right)$ y humedad $(\mathrm{Ca} / \mathrm{Ti}, \mathrm{Sr} / \mathrm{Al}$ y Na/Ti), acompañado de un descenso en los indicadores de precipitación del carbonato ( $\mathrm{Ca}$ / Ti y $\mathrm{CaO}$ ). El descenso ${ }^{13} \mathrm{C}$ se considera debido a la entrada de ${ }^{12} \mathrm{C}$ derivado de la materia orgánica terrestre (Corgánico).

El tramo 6 presenta un gran descenso del valor ${ }^{18} \mathrm{O}(\approx 8 \%$ ) pasando desde una muestra con evidencias de desecación y pedogénesis $(-1,4 \%)$ a otra con laminación horizontal y cercana a los valores de la Línea Meteórica de Calcita. Se interpreta como el llenado de la cubeta asociado a indicadores de etapas húmedas $(\mathrm{Ca} / \mathrm{Ti}$ y Na/ $\mathrm{Ti})$, entrada de aguas de escorrentía $\left(\mathrm{TiO}_{2}\right)$ y cierta tendencia a condiciones reductoras ( $\mathrm{MnO}$ y $\mathrm{Mn} / \mathrm{Fe}$ ). Se calcula un llenado del $30-40 \%$ del volumen del lago a partir de la figura 7.10 a partir de la calcita. El valor ${ }^{13} \mathrm{C}$ permanece casi constante.

El tramo 7 exhibe un ligero descenso de $\delta^{18} \mathrm{O}\left(\approx 2 \%\right.$ ) y un valor constante de $\delta^{13} \mathrm{C} \approx$ $+1,2 \%$ o. Los valores bajos de $\mathrm{Ca} / \mathrm{Ti}, \mathrm{Na} / \mathrm{Ti}$ y $\mathrm{Sr} / \mathrm{Al}$ indican una etapa húmeda, estable y sin evaporación, con entrada de detríticos $\left(\mathrm{TiO}_{2}\right)$, baja precipitación de carbonatos $(\mathrm{CaO})$ y tendencia reductora $(\mathrm{MnO}$ y $\mathrm{Mn} / \mathrm{Fe})$. La abundancia de margas y lutitas sugiere entrada de aguas de escorrentía pobres en ${ }^{18} \mathrm{O}$ y con una señal ${ }^{13} \mathrm{C}$ similar a la de las calizas de la Formación Torrecilla.

El tramo 8 muestra un incremento importante en ${ }^{18} \mathrm{O}$ que sólo puede ser explicado por una evaporación con fluctuación del volumen del lago. Para obtener el valor $\delta^{18} \mathrm{O}=+0,48$ seadmite una etapa árida con poca escorrentía recogida por múltiples proxies $\left(\mathrm{TiO}_{2}, \mathrm{Ca} / \mathrm{Ti}\right.$ y Na/ Al). En la figura 7.10 no se puede alcanzar dicho valor con humedades relativas de 0,9 y 0,8 (típicas de ambientes tropicales). Se requiere humedades en el rango 0,5-0,7, asociada a una evaporación del 40-65\% del volumen del lago para la calcita y del 25-35\% para la dolomita. La serie muestra abundantes evidencias de un medio oxidante (moteado, colores anaranjados) que se corresponden con un incremento en los indicadores de medios oxidantes ( $\mathrm{MnO}$ y $\mathrm{Mn} / \mathrm{Fe}$ ). En valor ${ }^{13} \mathrm{C}$ también muestra un incremento importante (desde $+1,42 \%$ o hasta $+4,03 \%$ ) que no se correlaciona con los indicadores de la productividad por lo que se asigna a etapas de equilibrio en el intercambio de $\mathrm{CO}_{2}$ entre las aguas del lago y la atmósfera (con un valor teórico de +4,74\%).

El tramo 9 representa un nuevo descenso del valor $\delta^{18} \mathrm{O}$ hasta alcanzar valores típicos de la precipitación. El valor $\delta^{13} \mathrm{C}$ desciende desde un valor de $+2,33$ hasta $-1,84$. No existen datos geoquímicos que ayuden en la interpretación por falta de muestreo. Sin embargo, se considera que tras la gran desecación acontecida en el tramo 8, el lago se rellena por aportes meteóricos o 


\section{Análisis isotópico y geoquímico del Grupo Enciso}

derivados de la lluvia (escorrentía) que transmiten su señal ${ }^{18} \mathrm{O}$ a las aguas del lago y diluyen el ${ }^{13} \mathrm{C}$ hasta alcanzar dicho valor mínimo.

El tramo 10 muestra un descenso del valor $\delta^{18} \mathrm{O}$ de $\approx 3 \%$ o asociado a la entrada de aguas empobrecidas en ${ }^{18} \mathrm{O}$ al lago, como sugieren los indicadores de una etapa ligeramente húmeda que evoluciona hacia una mayor sequedad $(\mathrm{Ca} / \mathrm{Ti}$ y Na/Ti), con poca o nula entrada de detríticos $\left(\mathrm{TiO}_{2}\right)$. Existe además un leve aumento en la precipitación de carbonatos ( $\mathrm{CaO}$ y $\left.\mathrm{Sr} / \mathrm{Al}\right)$. El valor $\delta^{13} \mathrm{C}$ exhibe un enriquecimiento de $\approx 1 \%$ o. Se observa un ligero incremento en la productividad $\left(\mathrm{P}_{2} \mathrm{O}_{5}\right)$ y una leve tendencia hacia condiciones más reductoras que en el tramo anterior $(\mathrm{MnO}$ y $\mathrm{Mn} / \mathrm{Fe}$ ). A medida que el lago se llena, presenta un mayor espejo que permite un mayor equilibrio con la atmósfera y el consiguiente incremento en $\delta^{13} \mathrm{C}$.

El tramo 11 muestra un ligero aumento de ${ }^{18} \mathrm{O}$, que se interpreta como consecuencia de una caída del nivel del lago ya que aparecen asociadas a grietas de desecación. Los valores altos de $\mathrm{Ca} / \mathrm{Ti}$ y $\mathrm{Na}$ / Ti sugieren una etapa árida que progresivamente evoluciona hacia períodos más húmedos, y con mayor escorrentía $\left(\mathrm{TiO}_{2}\right)$. El valor $\delta^{13} \mathrm{C}$ fluctúa de manera parecida a lo que ocurría en el tramo 4 . Estas variaciones entre las calizas $(\approx+1 \%$ o y las margas $(\approx-1 \%$ o) indica la entrada de agua enriquecida en ${ }^{12} \mathrm{C}$ procedente de la materia orgánica terrestre.

\subsection{ANÁLISIS GEOQUÍMICO DE LA COLUMNA DE PRÉJ ANO}

En la columna de Préjano se han realizado 27 análisis isotópicos (6 repetidos) así como 16 análisis de elementos mayoritarios, minoritarios y trazas (anexo XIV.1 y XIV.2) cuyas correlaciones aparecen en el anexo XIV.3 y que previamente han sido normalizados (apartado 2.5.2.1). Esta secuencia se localiza entre los tramos 52-69 de la columna de Préjano (anexo VIII).

El análisis de factores (tabla 7.3 y 7.4) indica que el 91,01\% de la varianza observada está determinada por 5 factores aplicando una rotación Varimax: factor 1 (56,39\%), factor 2 (16,51\%), factor $3(8,03 \%)$, factor 4 (5,48\%), y factor 5 (4,60\%). A continuación se analizan los dos primeros factores con los cuales se puede explicar el 72,90\% de la varianza encontrada.

El factor 1 muestra cargas positivas principales para el $\operatorname{lnSiO}_{2}, \mathrm{Al}_{2} \mathrm{O}_{3}, \mathrm{Fe}_{2} \mathrm{O}_{3}, \operatorname{lnTiO}_{2}, \mathrm{~K}_{2} \mathrm{O}$, $\mathrm{Ba}, \mathrm{Be}, \mathrm{Co}, \mathrm{Cr}$, lnLi, Rb, Scy, V, y cargas positivas significativas para el Cu (asociación I). Además muestra cargas negativas principales para $\mathrm{CaO}, 1 / \mathrm{Na}_{2} \mathrm{O}, \mathrm{Sr}$, y contenido en carbonato, y cargas negativas significativas para el contenido en $\mathrm{MnO}, \mathrm{La}$, y $1 / \mathrm{Zn}$ (asociación II). Al igual que ocurría en la columna anterior, la asociación I agrupa a todos los aluminosilicatos alóctonos relacionados con la escorrentía, y la asociación II representa a los elementos relacionados a la precipitación de carbonatos.

El factor 2 muestra una carga positiva principal para $\delta^{18} \mathrm{O}, \mathrm{MgO}$ y Corgánico, y significativa con $\mathrm{Fe}_{2} \mathrm{O}_{3}$ y $\mathrm{MnO}$. También presenta una carga negativa significativa para $1 / \mathrm{P}_{2} \mathrm{O}_{5}$. Este factor agrupa los elementos asociados a las caídas del nivel del lago. Por un lado se produce un enriquecimiento $\delta^{18} \mathrm{O}$ por evaporación concomitante con el incremento $\mathrm{MgO}$ debido a la precipitación selectiva de los carbonatos (MÜLLER et al., 1972). Además, los niveles bajos del lago son etapas de gran acumulación de carbono orgánico (EUGSTER Y KELTS, 1983; BISCHOFF et al., 1997a).

La interpretación conjunta de los isótopos estables y los elementos permite definir 10 zonas para su análisis (figura 7.13), en función de las tendencias que presentan:

El tramo 1 no muestra variación importante en la señal ${ }^{18} \mathrm{O}$ aunque existe un incremento en la señal ${ }^{13} \mathrm{C}$. Se asocia a una etapa de aridez $(\mathrm{Ca} / \mathrm{Ti}$ y Na/Ti), aumento de la precipitación de calcita $\left(\mathrm{CaO}\right.$ y Sr/ Al) y descenso de la entrada de detríticos $\left(\mathrm{TiO}_{2}\right)$. La productividad permanece estable en valores altos $\left(\mathrm{P}_{2} \mathrm{O}_{5}\right)$ y la señal redox es confusa. El aumento del valor $\delta^{13} \mathrm{C}$ se atribuye a la eliminación de ${ }^{12} \mathrm{C}$ durante la fotosíntesis asociada a una alta productividad en las aguas del lago. El valor $\mathrm{TiO}_{2}$, aunque disminuye, se inicia en un valor alto lo que explica la presencia de calizas arenosas y margosas en este tramo. La etapa de aridez se confirma por la presencia de numerosas grietas de retracción en los estratos. 
Análisis isotópico y geoquímico del Grupo Enciso

\begin{tabular}{|c|c|c|c|c|c|}
\hline & Factor 1 & Factor 2 & Factor 3 & Factor 4 & Factor 5 \\
\hline$\delta^{18} O(V P D B)$ & $-0,10992$ & 0,90756 & $-0,02913$ & $-0,29915$ & $-0,11538$ \\
\hline$\delta^{13} C(V P D B)$ & $-0,00873$ & $-0,21622$ & 0,09453 & 0,94091 & $-0,04093$ \\
\hline $\operatorname{lnSiO}_{2}$ & 0,96413 & 0,06775 & 0,02922 & $-0,05719$ & 0,09661 \\
\hline $\mathbf{A l}_{2} \mathbf{O}_{3}$ & 0,98242 & $-0,10735$ & 0,11246 & 0,00048 & 0,04804 \\
\hline $\mathrm{Fe}_{\mathbf{2}} \mathrm{O}_{3}$ & 0,78092 & $\mathbf{o , 4 6 5 7 7}$ & 0,06629 & $-0,28895$ & 0,17060 \\
\hline $\mathrm{CaO}$ & $-0,93389$ & $-0,19719$ & $-0,09007$ & 0,20158 & $-0,03851$ \\
\hline $\operatorname{lnTiO}_{2}$ & 0,97501 & 0,02188 & 0,04793 & 0,01829 & 0,11626 \\
\hline MnO & $-0,61910$ & 0,46552 & 0,20803 & $-0,16297$ & 0,30996 \\
\hline $\mathbf{K}_{2} \mathbf{O}$ & 0,96552 & 0,00564 & 0,04097 & 0,07345 & 0,08043 \\
\hline MgO & $-0,18229$ & 0,84177 & $-0,00526$ & $-0,44059$ & $-0,06075$ \\
\hline $\mathbf{1} / \mathbf{P}_{2} \mathbf{O}_{5}$ & $-0,07903$ & $-0,60706$ & 0,65726 & 0,10709 & $-0,22186$ \\
\hline $1 / \mathrm{Na}_{\mathbf{2}} \mathrm{O}$ & $-0,89614$ & 0,06466 & $-0,01777$ & $-0,23218$ & $-0,02870$ \\
\hline $\mathbf{B a}$ & 0,97377 & $-0,04511$ & 0,02427 & 0,09329 & 0,05705 \\
\hline $\mathbf{B e}$ & 0,87266 & 0,07288 & 0,19097 & 0,22104 & 0,08047 \\
\hline $\mathrm{Ce}$ & $-0,03491$ & 0,20932 & $-0,91779$ & $-0,16502$ & 0,13766 \\
\hline Co & 0,76383 & $-0,14649$ & $-0,14618$ & 0,09825 & 0,24079 \\
\hline $\mathrm{Cr}$ & 0,98685 & $-0,08644$ & 0,05757 & 0,02800 & 0,08384 \\
\hline $\mathbf{C u}$ & 0,63843 & $-0,21586$ & $-0,06195$ & $-0,01879$ & 0,39661 \\
\hline La & $-0,40645$ & $-0,15852$ & $-0,87120$ & $-0,00849$ & $-0,14564$ \\
\hline $\ln L i$ & 0,88328 & $-0,05221$ & 0,11835 & $-0,20158$ & 0,22297 \\
\hline $\mathbf{R b}$ & 0,95426 & 0,10702 & $-0,00657$ & 0,08752 & 0,11179 \\
\hline Se & 0,95674 & $-0,07864$ & o,07727 & 0,06309 & 0,14979 \\
\hline $\mathbf{S r}$ & $-0,82630$ & $-0,33870$ & $-0,18679$ & 0,30669 & $-0,01494$ \\
\hline $\mathbf{V}$ & 0,98504 & $-0,07112$ & 0,04806 & 0,04343 & 0,09660 \\
\hline $\mathbf{Y}$ & 0,17818 & 0,19201 & $-0,01709$ & $-0,02387$ & 0,89490 \\
\hline $\mathbf{1} / \mathbf{Z n}$ & $-0,50302$ & 0,35333 & 0,21884 & $-0,17282$ & $-0,65547$ \\
\hline C $_{\text {orgánico }}$ & 0,31922 & 0,85262 & $-0,20204$ & 0,11643 & 0,13124 \\
\hline Carbonato & $-0,98095$ & $-0,06578$ & o,00555 & 0,02536 & $-0,07821$ \\
\hline
\end{tabular}

Tabla 7.3: Principales factores en la columna de Préjano (Varimax normalizado). En gris se indican las cargas principales $(>0,7)$ y en negrita las cargas significativas $(>0,4)$.

\begin{tabular}{|l|c|c|c|c|}
\cline { 2 - 5 } \multicolumn{1}{c|}{} & Valores propios & \% Total & Acumulado & \% Acumulado \\
\hline Factor 1 & 16,35 & 56,39 & 16,35 & 56,39 \\
\hline Factor 2 & 4,79 & 16,51 & 21,14 & 72,90 \\
\hline Factor 3 & 2,33 & 8,03 & 23,47 & 80,93 \\
\hline Factor 4 & 1,59 & 5,48 & 25,06 & 86,41 \\
\hline Factor 5 & 1,33 & 4,60 & 26,39 & 91,01 \\
\hline
\end{tabular}

Tabla 7.4: Valores propios y acumulados de los factores extraídos en la columna Préjano. 


\section{Análisis isotópico y geoquímico del Grupo Enciso}

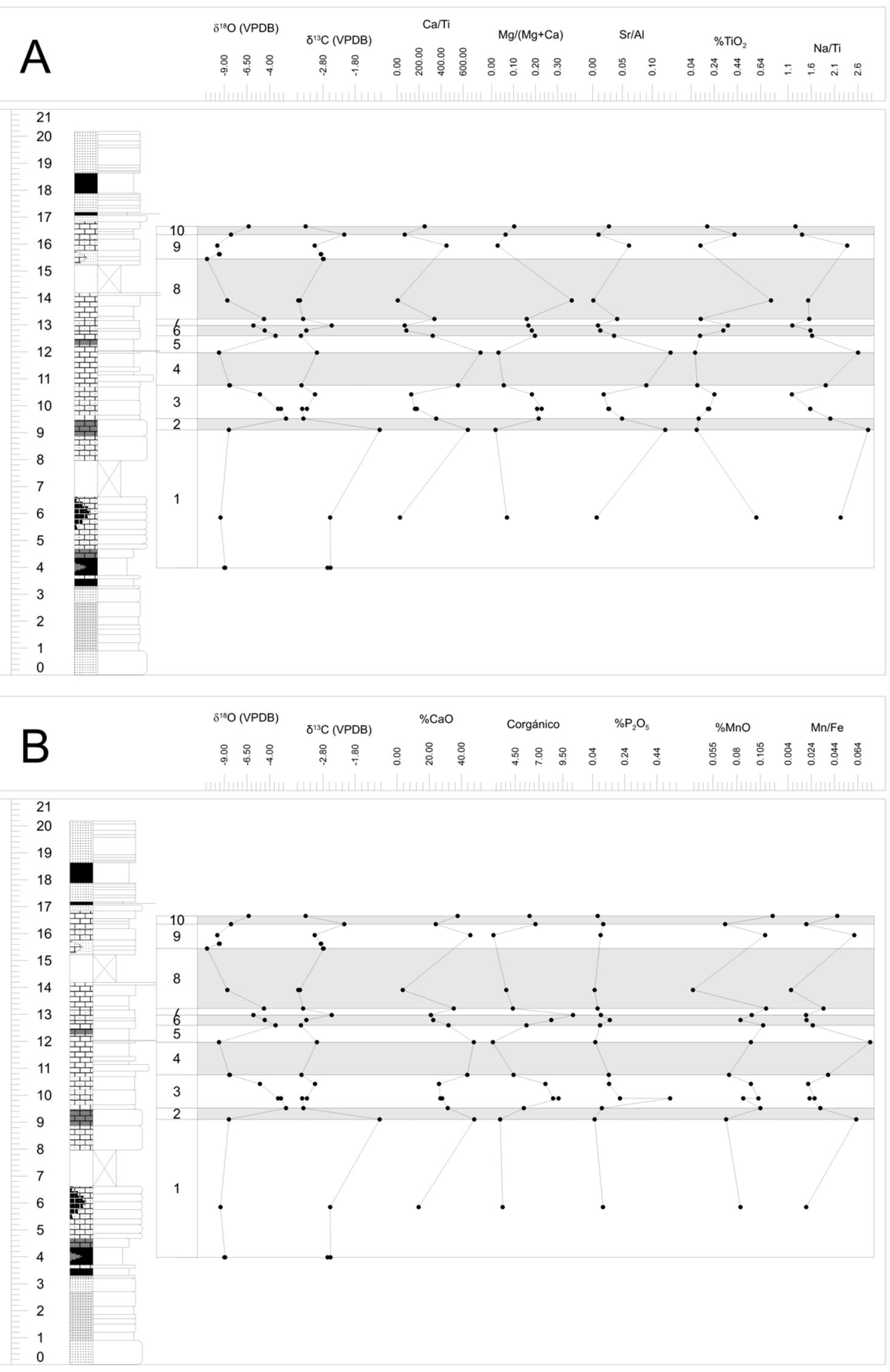

Figura 7.13: Geoquímica de la columna de Préjano (tramos 52-69).

El tramo 2 muestra un gran aumento en el valor $\delta^{18} \mathrm{O}$ asociado a una caída del nivel del lago (aparecen numerosas grietas de retracción) que conlleva una evaporación del 30-35\% del volumen del lago (figura 7.10), para una calcita con un valor $\delta^{18} \mathrm{O}=-2,20 \%$ o. Se produce durante 


\section{Análisis isotópico y geoquímico del Grupo Enciso}

una etapa de gran aridez aunque los indicadores sugieren una tendencia hacia etapas más húmedas $(\mathrm{Ca} / \mathrm{Ti}$ y Na/Ti) y un descenso en la precipitación de la calcita ( $\mathrm{CaO}$ y $\mathrm{Sr} / \mathrm{Al})$. Con la caída de nivel de las aguas se produce un aumento en el Corgánico y una pequeña disminución de $\delta^{13} \mathrm{C}$ debido a la oxidación de la materia orgánica acumulada.

El tramo 3 exhibe una disminución del valor $\delta^{18} \mathrm{O}$ dela misma magnitud que el acontecido en el tramo 2. En este caso se asocia a unas condiciones húmedas ( $\mathrm{Ca} / \mathrm{Ti}$ y $\mathrm{Na} / \mathrm{Ti})$, aunque al final del tramo se vuelve a condiciones áridas. Esta etapa húmeda conlleva un descenso de la calcita precipitada $(\mathrm{CaO}$ y $\mathrm{Sr} / \mathrm{Al})$ y un aumento de los aportes de detríticos $\left(\mathrm{TiO}_{2}\right)$. El valor $\delta^{13} \mathrm{C}$ permanece inalterable.

El tramo 4 manifiesta un ligero descenso de $\delta^{18} \mathrm{O}$ y leve aumento de $\delta^{13} \mathrm{C}$. El aumento de los valores de $\mathrm{Ca} / \mathrm{Ti}$ y $\mathrm{Na} / \mathrm{Ti}$ indican una etapa árida con precipitación de carbonatos $(\mathrm{CaO}$ y $\mathrm{Sr} / \mathrm{Al})$, baja entrada de detríticos $\left(\mathrm{TiO}_{2}\right.$ ) y tendencia oxidante ( $\mathrm{MnO}$ y $\left.\mathrm{Mn} / \mathrm{Fe}\right)$.

En tramo 5 vuelve a producirse un nuevo incremento importante en el valor de ${ }^{18} \mathrm{O}$ asociado a una pérdida del 20-30\% del volumen del lago (figura 7.10) y una leve disminución del ${ }^{13} \mathrm{C}$. La caída del nivel del agua no se asocia a una nueva etapa de aridez ( $\mathrm{Ca} / \mathrm{Ti}$ y Na/Ti), ni tampoco comporta una mayor precipitación de calcita (CaO y Sr/ Al). Sin embargo, la fluctuación de la masa de agua se confirma, en campo, por la presencia de trazas de emersión en los estratos, tales como grietas de retracción y huellas de dinosaurios.

El tramo 6 presenta una ligera disminución de $\delta^{18} \mathrm{O}$ (asociado a la entrada de aguas empobrecidas en ${ }^{18} \mathrm{O}$ al lago) y un leve aumento de $\delta^{13} \mathrm{C}$. Se inicia una nueva etapa húmeda $(\mathrm{Ca} / \mathrm{Ti}$ y Na/Ti), con entrada de detríticos $\left(\mathrm{TiO}_{2}\right)$ y disminución de la precipitación de carbonatos $(\mathrm{CaO}$ y $\mathrm{Sr} / \mathrm{Al}$ ). El incremento de $\delta^{13} \mathrm{C}$ se asocia a la productividad del lago (Corgánico y $\mathrm{P}_{2} \mathrm{O}_{5}$ ) y/o cierta tendencia no clara a un medio reductor ( $\mathrm{MnO}$ y $\mathrm{Mn} / \mathrm{Fe})$.

El tramo 7 muestra un ligero aumento de ${ }^{18} \mathrm{O}$ y un leve aumento de ${ }^{13} \mathrm{C}$. En este tramo aparecen grietas de retracción y costras de Fe que, desde el punto de vista sedimentológico, atestiguan una leve caída del nivel del lago. Se asocia a una fase de mayor aridez ( $\mathrm{Ca} / \mathrm{Ti}$ y Na/ Ti) que comporta un incremento en la calcita precipitada ( $\mathrm{CaO}$ y $\mathrm{Sr} / \mathrm{Al}$ ) y una menor entrada de detríticos $\left(\mathrm{TiO}_{2}\right)$. El aumento de $\delta{ }^{13} \mathrm{C}$ se asocia con una productividad alta $\left(\mathrm{P}_{2} \mathrm{O}_{5}\right)$ y/ o a la oxidación de la materia orgánica que se acumula (Corgánico) en un ambiente más oxidante ( $\mathrm{MnO}$ y Mn/ Fe).

El tramo 8 pone de manifiesto un descenso importante de $\delta^{18} \mathrm{O}(\Delta \approx 6 \%)$ y muy ligero aumento de $\delta^{13} \mathrm{C}\left(\Delta \approx 1 \%\right.$ o). El valor $\delta^{18} \mathrm{O}$ es el producto de la entrada, inicialmente, de aguas de escorrentía $\left(\mathrm{TiO}_{2}\right)$ durante un episodio de mayor humedad $(\mathrm{Ca} / \mathrm{Ti})$ y tendencia reductora $(\mathrm{MnO}$ y $\mathrm{Mn} / \mathrm{Fe}$ ), aunque la falta de algunos análisis geoquímicos no permite hacer mayores precisiones.

El tramo 9 expresa un nuevo incremento de $\delta^{18} \mathrm{O}\left(\Delta \approx 3 \%\right.$ ) y leve incremento de $\delta^{13} \mathrm{C}(\Delta \approx$ $1 \%$ o). La variación ${ }^{18} \mathrm{O}$ se asocia a una etapa ligeramente más húmeda $(\mathrm{Ca} / \mathrm{Ti}$ y Na/Ti) y de mayor escorrentía $\left(\mathrm{TiO}_{2}\right)$, menor calcita precipitada $(\mathrm{CaO}$ y $\mathrm{Sr} / \mathrm{Al})$. El aumento de ${ }^{13} \mathrm{C}$ se asocia a la acumulación de materia orgánica (Corgánico) en un medio levemente reductor ( $\mathrm{MnO}$ y Mn/ Fe). De nuevo, la ausencia de algunos valores geoquímicos no permite una mayor exactitud.

El tramo 10 manifiesta un ligero aumento de $\delta^{18} \mathrm{O}\left(\Delta \approx 2 \%\right.$ ) y descenso de $\delta^{13} \mathrm{C}(\Delta \approx 1 \%$ o). $\mathrm{El}$ incremento del valor ${ }^{18} \mathrm{O}$ es debido a la instauración de una fase de mayor aridez $(\mathrm{Ca} / \mathrm{Ti})$ y descenso de la escorrentía $\left(\mathrm{TiO}_{2}\right)$ que favorece la precipitación de carbonatos en sus aguas $(\mathrm{CaO}$ y Sr/ Al). La disminución de ${ }^{13} \mathrm{C}$ se relaciona a la oxidación de la materia orgánica (Corgánico) en un medio oxidante ( $\mathrm{MnO}$ y $\mathrm{Mn} / \mathrm{Fe}$ ). 
Análisis isotópico y geoquímico del Grupo Enciso 


\section{Análisis cicloestratigráfico del Grupo Enciso}

\subsection{TEORÍA DE MILANKOVITCH (CONTROL ORBITAL DEL CLIMA)}

El análisis de los ciclos climáticos inducidos por causas orbitales, constituye un tema de gran aceptación en los estudios estratigráficos. Se fundamenta en los trabajos del astrónomo serbio Milutin Milankovitch (MILANKOVITCH, 1941). Las alteraciones orbitales, causadas por las mutuas interacciones gravitatorias entre la Tierra y el resto de cuerpos del Sistema Solar (Sol, planetas y satélites), modifican la distribución y cantidad de radiación recibida del Sol (insolación), y originan el forzamiento climático. Estas variaciones de la órbita son periódicas (típicamente del orden de $10^{4}-10^{6}$ años) y se denominan tradicionalmente como los "ciclos de Milankovitch". Existen tres parámetros astronómicos responsables de los cambios en el sistema climático terrestre: excentricidad, oblicuidad y precesión (figura 8.1). Los términos "forzamiento orbital" y "forzamiento astronómico" se consideran sinónimos aunque siendo rigurosos, la oblicuidad y precesión no tienen un origen orbital sensu stricto (HINNOV, 2013).

La excentricidad (e) cuantifica la desviación de la órbita terrestre respecto de una circunferencia perfecta, modificando la distancia entrela Tierray el Sol (figura 8.1). El valor actual de la excentricidad es aproximadamente 0,01671, aunque puede variar entre 0,005 (una órbita casi circular) y 0,06 (PÄLIKE, 2005). Es el único parámetro orbital que controla la cantidad total de radiación solar recibida del Sol.

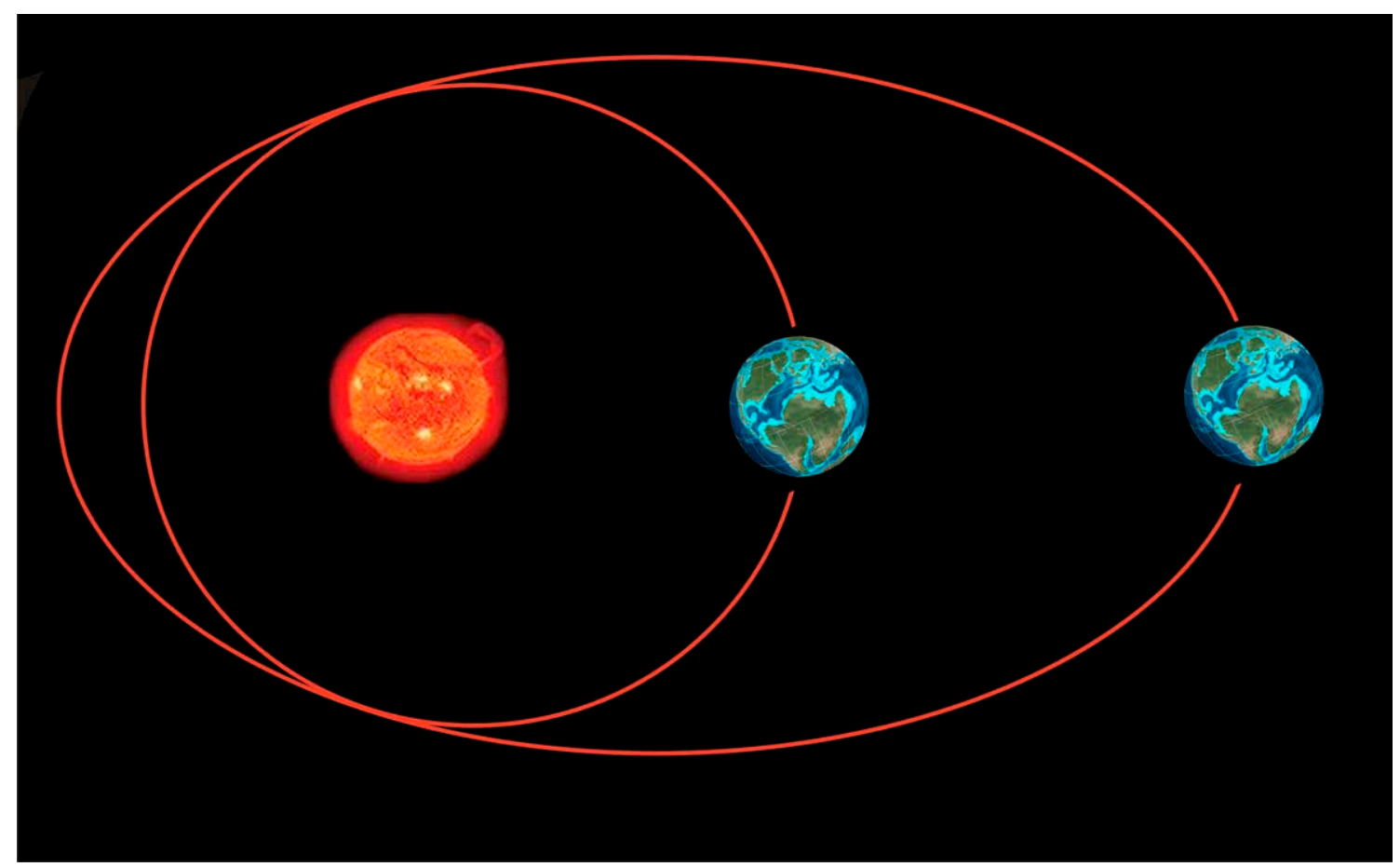

Figura 8.1: Esquema del movimiento de la órbita terrestre respecto del Sol, mostrando la variación en su excentricidad.

La oblicuidad hace referencia a la inclinación del eje de rotación de la Tierra con respecto a su eje orbital (figura 8.2A). Aunque la oblicuidad terrestre es relativamente estable debido al efecto estabilizador de la Luna (valor actual 23,45ㅇ), puede manifestar pequeñas variaciones de $\pm 1,3$ o alrededor de un valor medio de 23,3o (LASKAR et al., 1993b; PÄLIKE, 2005). La evolución en el tiempo de la oblicuidad es debida a la disipación en el sistema Tierra- Luna (disminución de la velocidad de rotación de la Tierra y aumento de la distancia entre ambas), y al efecto resonante resultante de las perturbaciones de Júpiter y Saturno (LASKAR et al., 1993a). Los efectos de la disipación por las mareas se manifiestan en un incremento en la oblicuidad, así como una disminución de la periodicidad desde el pasado hasta la actualidad (LASKAR et al., 2004). El principal efecto sobre el clima reside en la estacionalidad, ya que la insolación anual total no se ve afectada. Así pues, controla la distribución latitudinal de la radiación solar. Estos cambios en la oblicuidad tienen poca importancia en latitudes bajas, siendo más notables en latitudes altas (PÄLIKE, 2005). 


\section{Análisis cicloestratigráfico del Grupo Enciso}
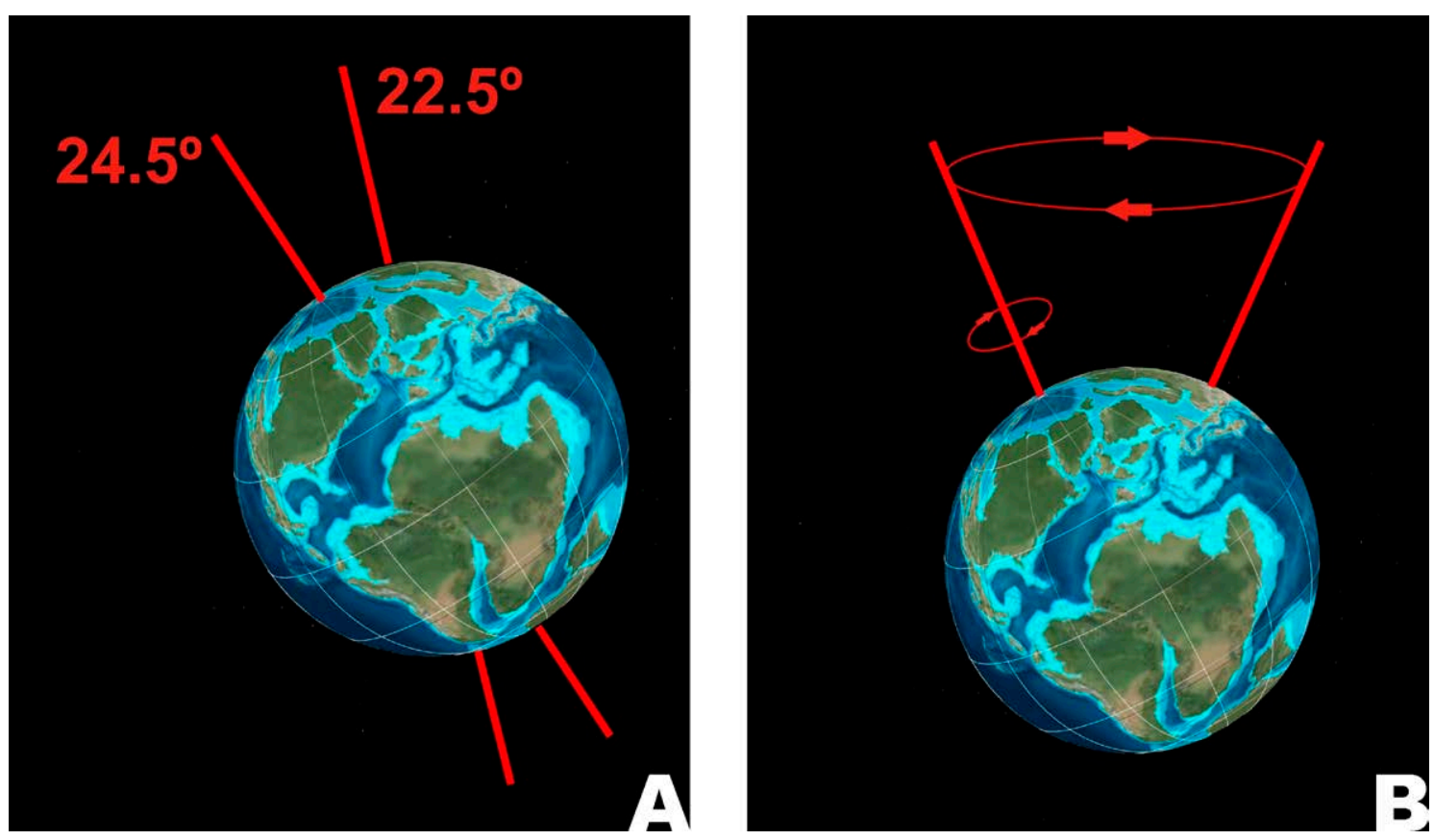

Figura 8.2: Esquema de los movimientos orbitales de la Tierra, mostrando los principales parámetros orbitales; (A) oblicuidad, y (B) precesión.

La precesión es el movimiento circular que describe el eje de la Tierra en el firmamento, respecto a la referencia fija de las estrellas lejanas de manera simultánea al giro del planeta sobre sí mismo (figura 8.2B). Este parámetro determina los momentos del año en los que se alcanza el perihelio y el afelio. Presenta dos componentes, la precesión de la elipse de la órbita y la del eje terrestre. Al igual que la oblicuidad, la precesión está forzada por el sistema Tierra-Luna y tampoco afecta a la cantidad total de insolación recibida por la Tierra, sino a su distribución hemisférica (PÄLIKE, 2005).

\subsection{ANÁLISIS ESPECTRAL}

En este apartado se aborda el análisis de la señal climática registrada en los sedimentos del Grupo Enciso. Cualquier estudio de la ciclicidad se fundamenta en la técnica del análisis espectral, que permite descomponer cualquier señal en la suma de sus componentes senoidales (o cosenoidales), según múltiples frecuencias y amplitudes. En el estudio cicloestratigráfico se utiliza una señal discreta a lo largo del espesor de la columna analizada. Esta señal estratigráfica se genera asignando a cada muestra del registro un valor relacionado con algún aspecto relevante (granulometría, color, facies, isótopos, etc.). Dicha señal puede ser tratada en función del número de ciclo (método metronómico) o en función de su posición estratigráfica (método estratigráfico) (WEEDON, 2003). En general, un valor elevado $f$ (pico del espectro) en el espectro de frecuencias (periodograma) indica que un determinado fenómeno se repite cada $1 / \mathrm{f}$ metros. Por último, estas periodicidades presentes en la señal estratigráfica se correlacionan con el espectro de frecuencias de los ciclos de Milankovitch, para de esta forma, determinar la duración de la ciclicidad en los sedimentos.

A la hora de realizar un análisis de series temporales en sucesiones sedimentarias antiguas aparecen numerosos problemas. El primero radica en la dificultad de encontrar variables continuas. En este caso, se aconseja utilizar rangos, es decir, variables discontinuas que no tienen que representar un intervalo de tiempo constante (WEEDON, 2003). En nuestro análisis, el aproximador del clima utilizado en el análisis espectral es el denominado "rango de profundidad". Se define como una secuencia de facies y/ o asociaciones de facies relacionadas con la profundidad relativa del lago, y proporciona una medida del nivel del lago, que a su vez, se enlaza con el clima existente durante su sedimentación (OLSEN, 1984; OLSEN, 1986; OLSENY KENT, 1996; OlSEN et al., 1996; OLSENY KENT, 1999). 
Un segundo contratiempo reside en la regularidad de la señal a analizar, ya que en cicloestratigrafía, las series regulares son la excepción más que la norma (PARDO-IGÚZQUIZA Y RODRÍGUEZ-TOVAR, 2013). Por una parte, la presencia habitual de discontinuidades (hiatos erosivos o no deposicionales) genera un registro sedimentario incompleto en el cual la señal estratigráfica no presenta la continuidad requerida. Aunque los datos de dicha señal sean muestreados a intervalos regularmente espaciados, siempre existe la duda de que una parte se hayan perdido y, por tanto, aparezcan en continuidad valores de la señal que en origen estaban separados. Por otra parte, la compactación diferencial de las litologías y/o la existencia de tasas de sedimentación no constantes, permite que valores regularmente espaciados en la columna representen, en realidad, valores irregularmente distribuidos en la escala temporal. Todos estos inconvenientes incrementan el nivel de ruido y son una fuente de error en la distribución de frecuencias, falseando el valor de los picos de frecuencias (WEEDON, 2003; PARDO-IGÚZQUIZA Y RODRÍGUEZ-TOVAR, 2013). Para solventar esta dificultad se ha utilizado el programa de análisis espectral REDFIT de SCHULZ y MUDELSEE (2002), que calcula el espectro de una serie irregularmente espaciada por medio de la transformada de Fourier de Lomb-Scargle (LOMB, 1976; SCARGLE, 1982; SCARGLE, 1989). Aunque inicialmente se desarrolló en el campo de la astronomía, su aplicación en estudios cicloestratigráficos proporciona excelentes resultados (D'ARGENIO et al., 1997). El programa REDFIT se encuentra disponible de manera gratuita en el paquete PAST (PAleontological STatistics) (HAMMER et al., 2001).

El tercer y último inconveniente procede de la escasa resolución bioestratigráfica de los fósiles encontrados en el Grupo Enciso, impidiendo la realización de atribuciones temporales precisas.

\subsubsection{Ciclicidad de la señal estratigráfica}

El rango de profundidad se ha creado a partir de los elementos arquitectónicos y su pertenencia a un dominio lacustre determinado, asignándoles el siguiente valor numérico según su profundidad relativa: 0 (aluvial), 1 (supralitoral palustre), 2 (eulitoral), 3 (intralitoral), 4 (sublitoral), y 5 (abierto). La señal estratigráfica se ha codificado con un intervalo regular de muestreo de $10 \mathrm{~cm}$.

Posteriormente, la curva de rangos de profundidad se somete a un análisis espectral REDFIT para identificar todos los picos de frecuencia con un nivel de confianza superior al $90 \%$, el cual asegura que los picos se vinculan exclusivamente con la señal original. Cada pico en el periodograma muestra el intervalo de recurrencia de los rangos de profundidad a lo largo de la sección analizada, aunque esto no lleva implícito que todos los picos sean de origen orbital. Sólo los picos que manifiesten una buena correlación con los períodos de orbitales, se podrán considerar como ciclos de Milankovitch. El resto de picos, representan ciclos debidos a otros factores: alocíclicos, autocíclicos, ruido en la señal o derrame espectral.

\subsubsection{Señal estratigráfica de la columna de Enciso}

La curva de rangos se ha obtenido del análisis de una serie de $1.215 \mathrm{~m}$ de potencia, perteneciente a la columna estratigráfica de Enciso, obteniéndose una señal discreta de 8.648 puntos (figura 8.3A). El análisis REDFIT de la señal estratigráfica reconoce 27 picos de frecuencia con un nivel de confianza superior al 90\% (figura 8.4A).

1) Ciclo de 202,51 m (nivel de confianza $>95 \%$ ).

2) Ciclo de $121,50 \mathrm{~m}$ (nivel de confianza $>95 \%$ ).

3) Ciclo de 93,47 $\mathrm{m}$ (nivel de confianza $>99 \%$ ).

4) Ciclo de $57,86 \mathrm{~m}$ (nivel de confianza $>99 \%$ ).

5) Ciclo de $30,38 \mathrm{~m}$ (nivel de confianza $>99 \%$ ).

6) Ciclo de 22,50 m (nivel de confianza $>90 \%$ ).

7) Ciclo de $10,66 \mathrm{~m}$ (nivel de confianza $>90 \%$ ).

8) Ciclo de 4,78 m (nivel de confianza $>99 \%$ ).

9) Ciclo de 4,26 m (nivel de confianza $>95 \%$ ).

10) Ciclo de 4,06 m (nivel de confianza $>95 \%$ ). 


\section{Análisis cicloestratigráfico del Grupo Enciso}
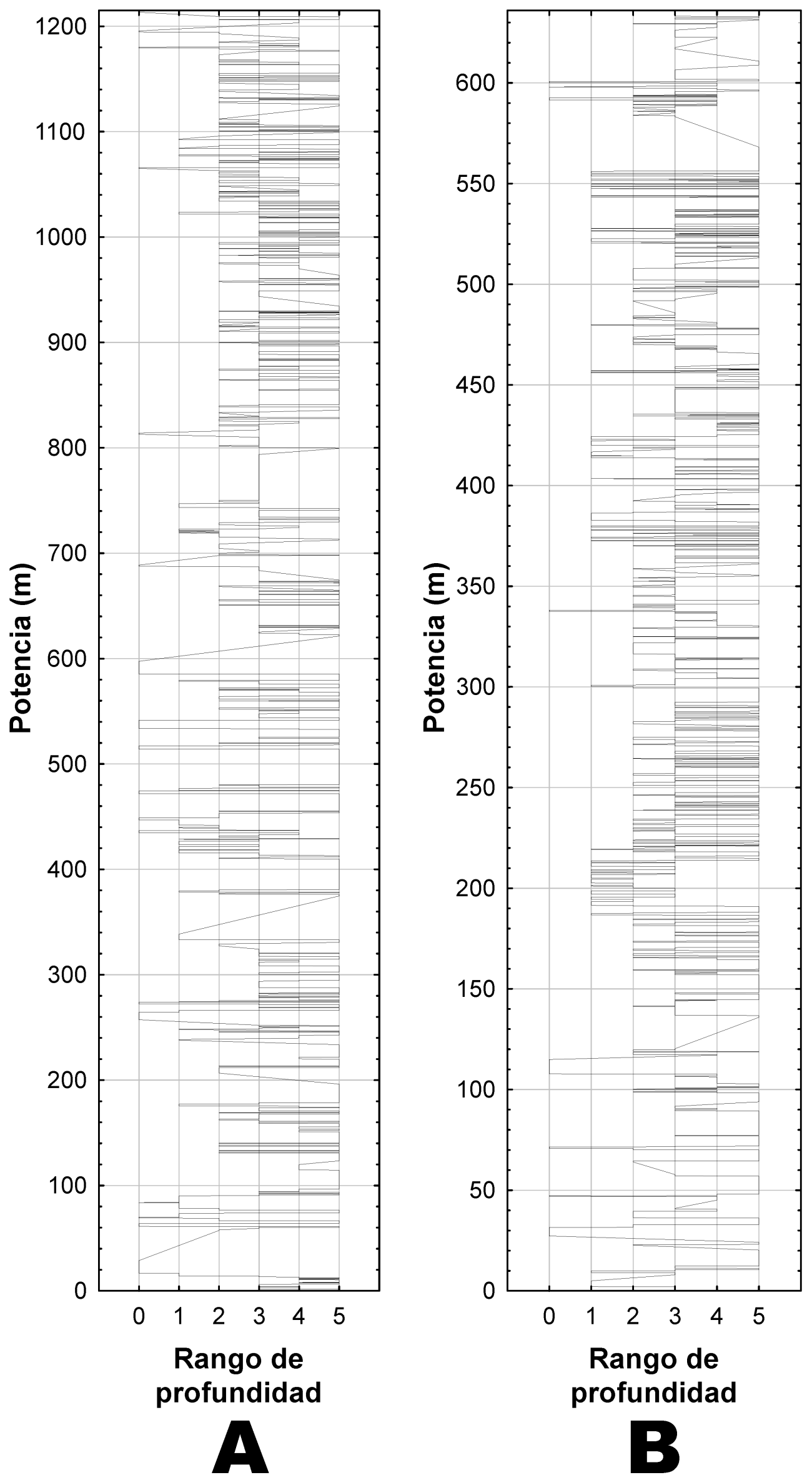

Figura 8.3: Señal estratigráfica obtenida a partir delos rangos de profundidad en las columnas estratigráficas de A) Enciso (1.215 m) y B) Ambas Aguas (636 m). 


\section{Análisis cicloestratigráfico del Grupo Enciso}
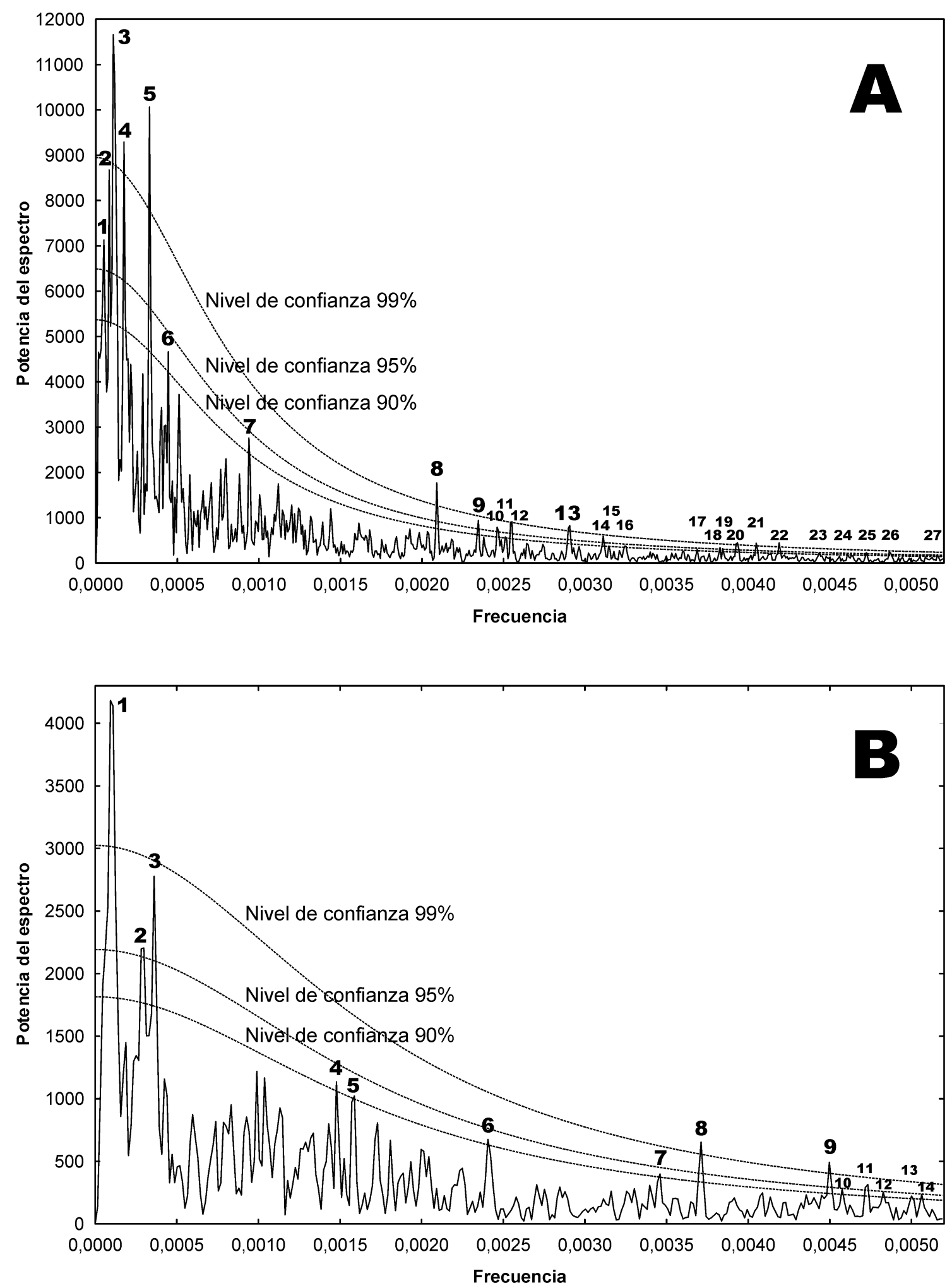

Figura 8.4: Periodogramas de la señal estratigráfica delas columnas de: A) Enciso y B) Ambas Aguas. Las líneas discontinuas representan los niveles de confianza. Los números marcan los picos de frecuencia y corresponden a los números que aparecen en el texto.

11) Ciclo de $3,98 \mathrm{~m}$ (nivel de confianza $>90 \%$ ).

12) Ciclo de 3,92 m (nivel de confianza $>99 \%$ ).

13) Ciclo de 3,44 m (nivel de confianza $>99 \%$ ).

14) Ciclo de $3,21 \mathrm{~m}$ (nivel de confianza $>95 \%$ ).

15) Ciclo de 3,18 m (nivel de confianza $>90 \%$ ).

16) Ciclo de $3,08 \mathrm{~m}$ (nivel de confianza $>90 \%$ ). 
17) Ciclo de $2,71 \mathrm{~m}$ (nivel de confianza $>90 \%$ ).

18) Ciclo de 2,61 $\mathrm{m}$ (nivel de confianza $>95 \%$ ).

19) Ciclo de $2,60 \mathrm{~m}$ (nivel de confianza $>95 \%$ ).

20) Ciclo de $2,54 \mathrm{~m}$ (nivel de confianza $>99 \%$ ).

21) Ciclo de $2,47 \mathrm{~m}$ (nivel de confianza $>99 \%$ ).

22) Ciclo de 2,39 m (nivel de confianza $>99 \%$ ).

23) Ciclo de 2,25 m (nivel de confianza $>95 \%$ ).

24) Ciclo de $2,17 \mathrm{~m}$ (nivel de confianza $>90 \%$ ).

25) Ciclo de 2,12 $\mathrm{m}$ (nivel de confianza $>95 \%$ ).

26) Ciclo de $2,06 \mathrm{~m}$ (nivel de confianza $>95 \%$ ).

27) Ciclo de 1,94 m (nivel de confianza >95\%).

\subsubsection{Señal estratigráfica de la columna de Ambas Aguas}

La curva de rangos de la columna de Ambas Aguas se ha elaborado a partir de una sección de $636 \mathrm{~m}$ de espesor, constituyendo una señal discreta de 4.711 puntos (figura 8.3B). El periodograma del análisis REDFIT de la señal estratigráfica registra 14 picos de frecuencia con un nivel de confianza superior al 90\% (figura 8.4B).

1) Ciclo de 105,98 $\mathrm{m}$ (nivel de confianza $>99 \%$ ).

2) Ciclo de $33,47 \mathrm{~m}$ (nivel de confianza $>95 \%$ ).

3) Ciclo de 27,65 $\mathrm{m}$ (nivel de confianza $>99 \%$ ).

4) Ciclo de 6,76 $\mathrm{m}$ (nivel de confianza $>90 \%$ ).

5) Ciclo de 6,30 $\mathrm{m}$ (nivel de confianza $>90 \%$ ).

6) Ciclo de 4,16 $\mathrm{m}$ (nivel de confianza $>90 \%$ ).

7) Ciclo de 2,89 $\mathrm{m}$ (nivel de confianza $>90 \%$ ).

8) Ciclo de 2,69 $\mathrm{m}$ (nivel de confianza $>99 \%$ ).

9) Ciclo de 2,22 $\mathrm{m}$ (nivel de confianza $>99 \%$ ).

10) Ciclo de $2,19 \mathrm{~m}$ (nivel de confianza $>90 \%$ ).

11) Ciclo de $2,11 \mathrm{~m}$ (nivel de confianza $>95 \%$ ).

12) Ciclo de $2,07 \mathrm{~m}$ (nivel de confianza $>90 \%$ ).

13) Ciclo de $2,00 \mathrm{~m}$ (nivel de confianza $>90 \%$ ).

14) Ciclo de $1,97 \mathrm{~m}$ (nivel de confianza $>90 \%$ ).

\subsubsection{Ciclicidad orbital durante el Aptiense inferior}

La periodicidad de los parámetros orbitales no es constante, variando a lo largo del tiempo. Si bien los ciclos de excentricidad han permanecido casi invariables a lo largo de la historia de la Tierra, la periodicidad de los ciclos de oblicuidad y precesión ha ido disminuyendo hasta nuestros días (LASKAR et al., 2004; LASKAR et al., 2011). Los períodos orbitales más significativos se calculan a partir del análisis espectral de la solución nominal La2010 para la excentricidad (figura 8.5A) (LASKAR et al., 2011) y La2004 para la oblicuidad (figura 8.6A) y precesión (figura 8.7A) (LASKAR et al., 2004). Se han utilizado solamentelos valores orbitales para el rango temporal de 123- 126,3 Ma, que según GTS2012 es la duración del Aptiense inferior (OGG et al., 2012), la edad más probable para el Grupo Enciso.

El periodograma de Lomb-Scargle (nivel de confianza >99,9\%) muestra 13 términos en la excentricidad. El número de cada ciclo es el mismo que el número queaparece en la figura 8.5B. El término gi representa la frecuencia secular, y los subíndices hacen referencia a los siguientes planetas (LASKAR et al., 2004): 1 (Mercurio), 2 (Venus), 3 (Tierra), 4 (Marte), 5 (Júpiter), y 6 (Saturno).

1) Ciclo de 2.399.981 años producido por la interacción entre Marte y la Tierra ( $\left.g_{4}-g_{3}\right)$.

2) Ciclo de 977.804 años producido por la interacción entre Mercurio y J úpiter (g1-g5).

3) Ciclo de 713.521 años producido por la interacción entre Venus y Mercurio ( $\left.g_{2}-g_{1}\right)$.

4) Ciclo de 406.157 años producido por la interacción entre Venus y J úpiter ( $\left.\mathrm{g}_{2}-\mathrm{g}_{5}\right)$.

5) Ciclo de 138.947 años producido por la interacción entre Saturno y Venus $\left(\mu 6-g_{2}\right)$.

6) Ciclo de 131.344 años producido por la interacción entre la Tierra y Venus ( $\left.g_{3}-g_{2}\right)$. 

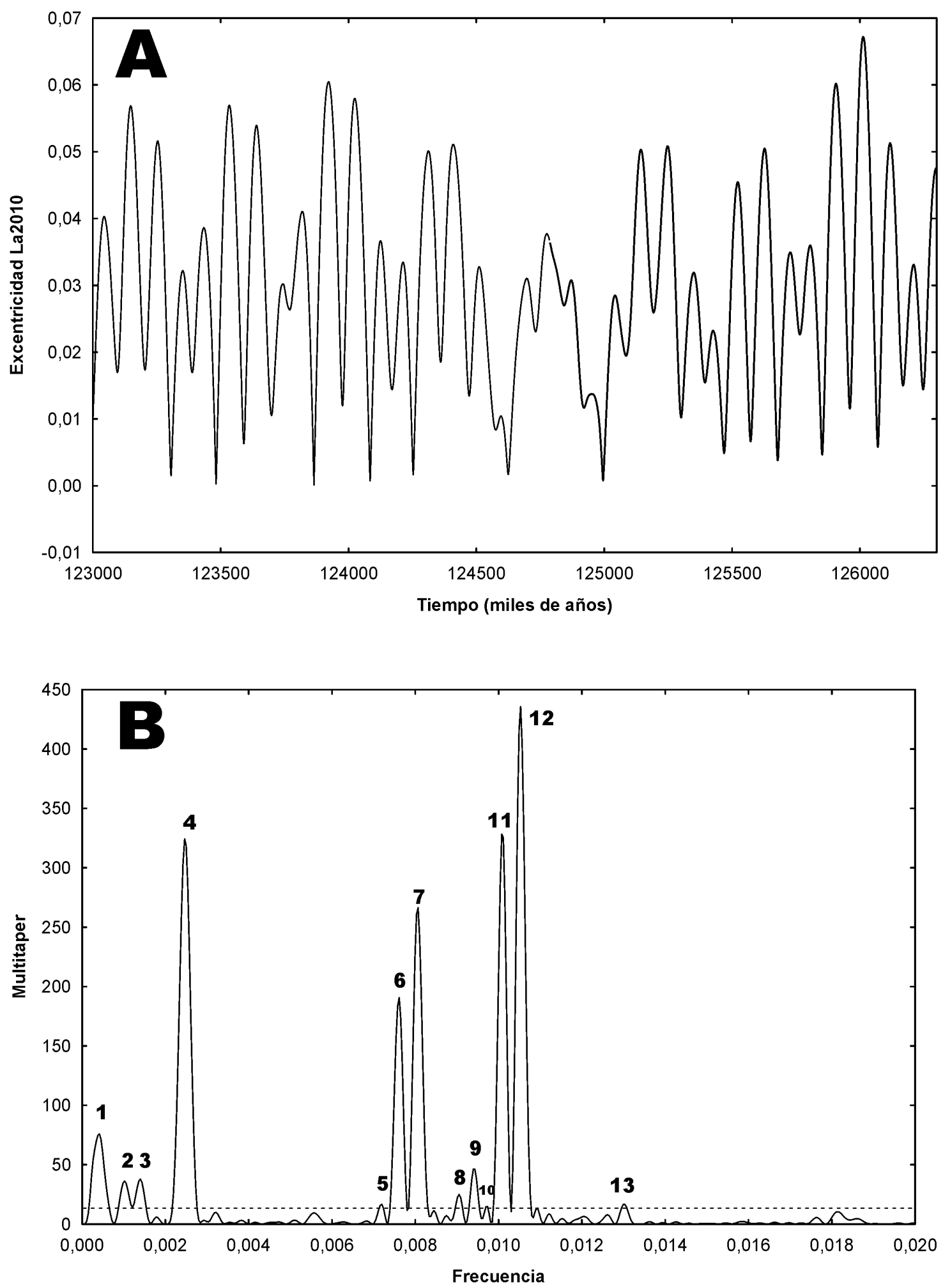

Figura 8.5: A) Valores de la excentricidad orbital de la Tierra durante el Aptiense inferior basados en la solución nominal La2010. B) Periodograma de Lomb-Scargle de las principales periodicidades de la excentricidad durante el Aptiense inferior. La línea discontinua marca el nivel de confianza del 99,9\%. La numeración de los picos de frecuencia corresponde a los números que aparecen en el texto. 

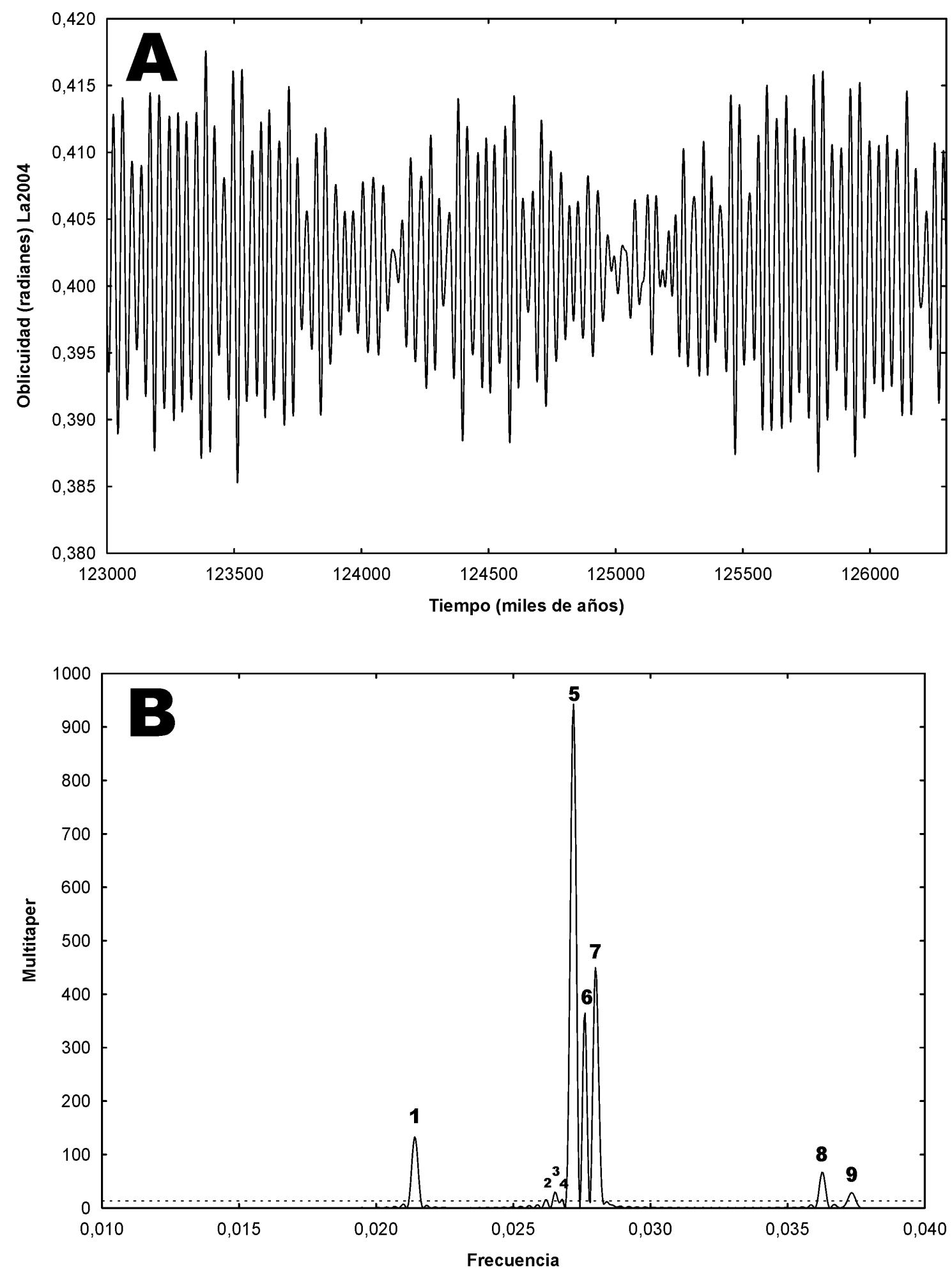

Figura 8.6: A) Valores de la oblicuidad de la Tierra durante el Aptiense inferior obtenidos de la solución nominal La2004. B) Periodograma de Lomb-Scargle de las principales periodicidades de la oblicuidad durante el Aptiense inferior. La línea discontinua marca el nivel de confianza del 99,9\%. La numeración de los picos de frecuencia corresponde a los números que aparecen en el texto. 

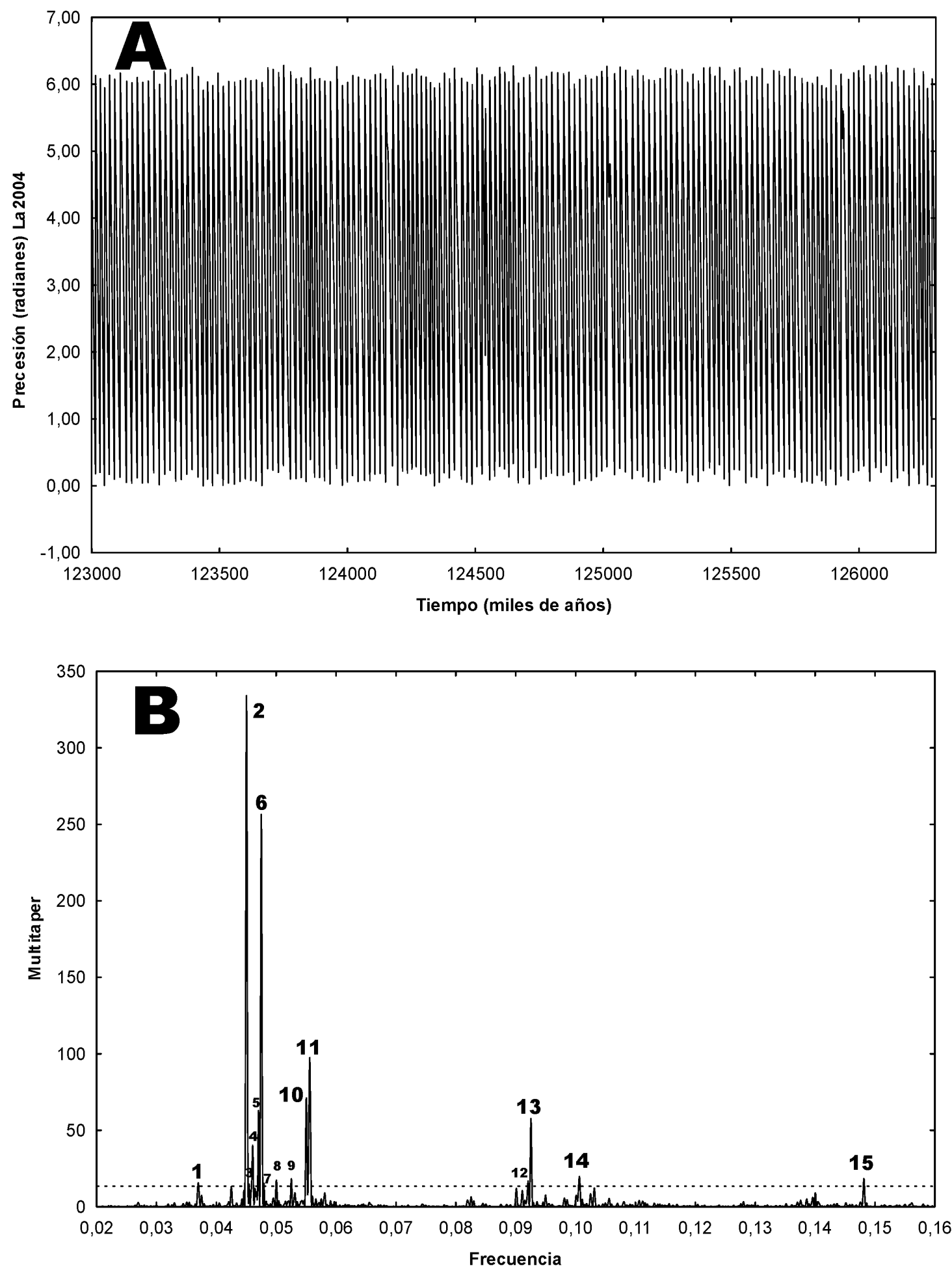

Figura 8.7: A) Valores de la precesión de la Tierra durante el Aptiense inferior obtenidos de la solución nominal La2004. B) Periodograma de Lomb-Scargle de las principales periodicidades dela precesión durante el Aptienseinferior. La línea discontinua marca el nivel deconfianza del 99,9\%. La numeración de los picos de frecuencia corresponde a los números que aparecen en el texto. 


\section{Análisis cicloestratigráfico del Grupo Enciso}

7) Ciclo de 123.943 años producido por la interacción entre Marte y Venus ( $\left.g_{4}-g_{2}\right)$.

8) Ciclo de 110.461 años producido por la interacción entre Mercurio y la Tierra ( $\left.g_{1}-g_{3}\right)$.

9) Ciclo de 106.024 años producido por la interacción entre Marte y Mercurio ( $\left(g_{4}-g_{1}\right)$.

10) Ciclo de 102.724 años producido por la interacción entre la Tierra, Marte y Júpiter $\left(2 g_{3}-g_{4}-g_{5}\right)$.

11) Ciclo de 99.246 años producido por la interacción entre la Tierra y J úpiter ( $\left.g_{3}-g_{5}\right)$.

12) Ciclo de 94.967 años producido por la interacción entre Marte y Júpiter (g4-g5).

13) Ciclo de 76.746 años producido por la interacción entre Venus, Marte y Júpiter $\left(g_{2}+g_{4}+2 g_{5}\right)$.

El periodograma de Lomb-Scargle (nivel de confianza $>99,9 \%$ ) registra 9 ciclos en la solución nominal de la oblicuidad. El número de cada ciclo es el que aparece en la figura 8.6B.

1) Ciclo de 46.725 años.

2) Ciclo de 38.150 años.

3) Ciclo de 37.715 años.

4) Ciclo de 37.341 años.

5) Ciclo de 36.769 años.

6) Ciclo de 36.214 años.

7) Ciclo de 35.724 años.

8) Ciclo de 27.586 años.

9) Ciclo de 26.775 años.

La precesión presenta 15 picos en el periodograma de Lomb-Scargle, todo ellos con un nivel de confianza $>99,9 \%$. La numeración de cada ciclo se corresponde con la que aparece en la figura 8.7B.

1) Ciclo de 27.049 años.

2) Ciclo de 22.203 años.

3) Ciclo de 22.000 años.

4) Ciclo de 21.710 años.

5) Ciclo de 21.256 años.

6) Ciclo de 21.053 años.

7) Ciclo de 20.853 años.

8) Ciclo de 19.985 años.

9) Ciclo de 19.034 años.

10) Ciclo de 18.169 años.

11) Ciclo de 17.984 años.

12) Ciclo de 10.860 años.

13) Ciclo de 10.806 años.

14) Ciclo de 9.936 años.

15) Ciclo de 6.750 años.

\subsection{COMPARACIÓN DE LA CICLICIDAD ESTRATIGRÁFICA Y ORBITAL}

La siguiente etapa consiste en evaluar la banda temporal abarcada por las diferentes periodicidades de la señal estratigráfica reconocidas en el periodograma. Si la serie estratigráfica presentase biozonas bien definidas, el proceso sería muy sencillo einmediato. Sin embargo, en el Grupo Enciso, el registro incompleto y el escaso valor bioestratigráfico hacen que el procedimiento sea más complicado. Para solventar estas dificultades se asume una hipótesis inicial plausible: algunas periodicidades estratigráficas de la serie analizada tienen un origen orbital, es decir, pertenecen a la banda de periodicidades de Milankovitch.

Para poder comparar ambos grupos de períodos, orbital en años y estratigráfico en metros, los valores deben ser normalizados. Para la normalización, se adimensionan ambas periodicidades hasta obtener dos tablas de ratios relativos, las cuales, se calculan dividiendo cada periodicidad entre el resto de su grupo. De esta manera, se obtienen dos tablas de ratios relativos, tanto orbitales como estratigráficos, cuya naturaleza adimensional permite su comparación. 


\section{Análisis cicloestratigráfico del Grupo Enciso}

Finalmente, se hace un análisis comparativo entre ambos grupos, buscando, entre todas las combinaciones posibles, aquellas que presenten ratios relativos con la mayor correlación posible. La correlación se realiza por filas de ratios, comparando cada fila de ratios orbitales con todas las filas de los ratios estratigráficos.

\subsubsection{Resultados en la columna de Enciso}

Del análisis comparativo de los ratios orbitales (anexo XV.1) y estratigráficos (anexo XV.2) se obtienen dos resultados, ambos factibles, denominados en este trabajo como Enciso A y B.

\subsubsection{Solución Enciso A}

La solución Enciso A consta, a su vez, de tres variantes: A1, A2 y A3. Todas ellas reúnen las mismas componentes estratigráficas correlacionadas con las mismas componentes orbitales referentes a la excentricidad, oblicuidad y parte de la precesión, solamente variando algunos parámetros en la precesión.

La solución Enciso A1 se obtiene de comparar la fila 6 de la tabla estratigráfica y la fila 11 de la tabla orbital (correlación de 0,999038) (tabla 8.1).

\begin{tabular}{|c|c|c|c|c|}
\hline Ratios estratigráficos & Ratios orbitales & Potencia (m) & Tiempo (año) & \\
\hline 9,00002 & 9,85235 & 202,51 & 977804 & \multirow{4}{*}{ Excentricidad } \\
\hline 4,15394 & 4,09244 & 93,47 & 406157 & \\
\hline 1,34999 & 1,32342 & 30,38 & 131344 & \\
\hline 1,00000 & 1,00000 & 22,50 & 99246 & \\
\hline 0,47368 & 0,47080 & 10,66 & 46725 & Oblicuidad \\
\hline 0,21260 & 0,21213 & 4,78 & 21053 & \multirow{5}{*}{ Precesión } \\
\hline 0,18947 & 0,19178 & 4,26 & 19034 & \\
\hline 0,18060 & 0,18120 & 4,06 & 17984 & \\
\hline 0,10609 & 0,10888 & 2,39 & 10806 & \\
\hline 0,10018 & 0,10012 & 2,25 & 9936 & \\
\hline
\end{tabular}

Tabla 8.1: Correlación entre ratios orbitales y estratigráficos en la solución Enciso A1.

La solución Enciso A2 se calcula comparando la fila 7 de la tabla estratigráfica y la fila 14 de la tabla orbital (correlación 0,999047) (tabla 8.2).

\begin{tabular}{|c|c|c|c|c|}
\hline Ratios estratigráficos & Ratios orbitales & Potencia (m) & Tiempo (año) & \\
\hline 19,00002 & 20,92696 & 202,51 & 977804 & \multirow{4}{*}{ Excentricidad } \\
\hline 8,76942 & 8,69258 & 93,47 & 406157 & \\
\hline 2,84997 & 2,81102 & 30,38 & 131344 & \\
\hline 2,11111 & 2,12406 & 22,50 & 99246 & \\
\hline 1,00000 & 1,00000 & 10,66 & 46725 & Oblicuidad \\
\hline 0,44881 & 0,45057 & 4,78 & 21053 & \multirow{6}{*}{ Precesión } \\
\hline 0,40000 & 0,40736 & 4,26 & 19034 & \\
\hline 0,38127 & 0,38886 & 4,06 & 18169 & \\
\hline 0,37377 & 0,38489 & 3,98 & 17984 & \\
\hline 0,22397 & 0,23242 & 2,39 & 10860 & \\
\hline 0,21150 & 0,21266 & 2,25 & 9936 & \\
\hline
\end{tabular}

Tabla 8.2: Correlación entre ratios orbitales y estratigráficos en la solución Enciso A2. 


\section{Análisis cicloestratigráfico del Grupo Enciso}

La solución Enciso A3 procede de comparar la fila 8 de ratios estratigráficos y la fila 28 de ratios orbitales (correlación 0,999025) (tabla 8.3)

\begin{tabular}{|c|c|c|c|c|}
\hline Ratios estratigráficos & Ratios orbitales & Potencia (m) & Tiempo (año) & \\
\hline 42,33410 & 46,44568 & 202,51 & 977804 & \multirow{4}{*}{ Excentricidad } \\
\hline 19,53921 & 19,29247 & 93,47 & 406157 & \\
\hline 6,35005 & 6,23884 & 30,38 & 131344 & \\
\hline 4,70378 & 4,71417 & 22,50 & 99246 & \\
\hline 2,22811 & 2,21942 & 10,66 & 46725 & Oblicuidad \\
\hline 1,00000 & 1,00000 & 4,78 & 21053 & \multirow{4}{*}{ Precesión } \\
\hline 0,89124 & 0,90411 & 4,26 & 19034 & \\
\hline 0,84952 & 0,85422 & 4,06 & 17984 & \\
\hline 0,47125 & 0,47198 & 2,25 & 9936 & \\
\hline
\end{tabular}

Tabla 8.3: Correlación entre ratios orbitales y estratigráficos dela solución Enciso A3.

Así pues, a la vista de los resultados, se aprecia que existen cuatro ciclos de excentricidad, uno de oblicuidad y tres de precesión, comunes a todas las soluciones Enciso A (tabla 8.4). Asimismo, se pueden reconocer otros dos ciclos de precesión menos marcados (sólo aparecen repetidos en dos de las soluciones) de 4,06 m (17.984-18.169 años) y de 2,39 m de 10.860 años.

\begin{tabular}{|c|c|l|}
\hline Potencia (m) & Tiempo (año) & \\
\cline { 1 - 2 } 202,51 & 977804 & \\
\cline { 1 - 2 } 93,47 & 406157 & \multirow{2}{*}{ Excentricidad } \\
\hline 30,38 & 131344 & \\
\hline 22,50 & 99246 & \multirow{2}{*}{ Oblicuidad } \\
\hline 10,66 & 46725 & \multirow{2}{*}{ Precesión } \\
\cline { 1 - 2 } 4,78 & 21053 & \\
\hline 4,26 & 19034 & 9936 \\
\hline 2,25 & &
\end{tabular}

Tabla 8.4: Correlación entre ciclos orbitales y estratigráficos comunes a todas las soluciones Enciso A.

Si se acepta el ciclo principal de excentricidad de 93,47 m (406.157 años), se puede estimar una tasa lineal de sedimentación de $0,23 \mathrm{~mm} /$ año, y una duración de 5,45 Ma para el Grupo Enciso (1.254 m de potencia total).

Utilizando las ocho periodicidades comunes a las tres soluciones de Enciso A, se obtiene una tasa de sedimentación lineal media de $0,23 \pm 0,01 \mathrm{~mm} /$ año $(0,21-0,23 \mathrm{~mm} /$ año), así como una duración media de 5,57£0,20 Ma (5,42-6,05 Ma).

Al descompactar la serie de Enciso (anexo XVI), se obtiene una potencia real de $2.785 \mathrm{~m}$, con lo que la tasa de sedimentación lineal real es de 0,50 mm/ año.

\subsubsection{Solución Enciso B}

La solución Enciso B presenta otras tres variaciones: B1, B2 y B3. Todas las soluciones coinciden en tres componentes estratigráficas correlacionadas con las mismas tres componentes 


\section{Análisis cicloestratigráfico del Grupo Enciso}

orbitales de la excentricidad. La oblicuidad y precesión muestran una mayor dispersión y variedad.

La solución Enciso B1 deriva de cotejar la fila 7 de los ratios estratigráficos y la fila 20 de los ratios orbitales (correlación 0,999626) (tabla 8.5).

\begin{tabular}{|c|c|c|c|c|}
\hline Ratios estratigráficos & Ratios orbitales & Potencia (m) & Tiempo (año) & \\
\hline 19,00002 & 19,97289 & 202,51 & 713521 & \multirow{4}{*}{ Excentricidad } \\
\hline 11,39997 & 11,36916 & 121,50 & 406157 & \\
\hline 2,84997 & 2,77809 & 30,38 & 99246 & \\
\hline 2,11111 & 2,14827 & 22,50 & 76746 & \\
\hline 1,00000 & 1,00000 & 10,66 & 35724 & Oblicuidad \\
\hline 0,30159 & 0,30399 & 3,21 & 10860 & \multirow{4}{*}{ Precesión } \\
\hline 0,29843 & 0,30249 & 3,18 & 10806 & \\
\hline 0,28934 & 0,27814 & 3,08 & 9936 & \\
\hline 0,18182 & 0,18896 & 1,94 & 6750 & \\
\hline
\end{tabular}

Tabla 8.5: Correlación entre ratios orbitales y estratigráficos de la solución Enciso B1.

La solución Enciso B2 se elabora al confrontar la fila 14 de la tabla estratigráfica y la fila 34 de la tabla orbital (correlación de 0,999627) (tabla 8.6).

\begin{tabular}{|c|c|c|c|c|}
\hline Ratios estratigráficos & Ratios orbitales & Potencia (m) & Tiempo (año) & \\
\hline 62,99994 & 65,70318 & 202,51 & 713521 & \multirow{4}{*}{ Excentricidad } \\
\hline 37,79981 & 37,40019 & 121,50 & 406157 & \\
\hline 9,44990 & 9,76304 & 30,38 & 106024 & \\
\hline 6,99998 & 7,06700 & 22,50 & 76746 & \\
\hline 3,31578 & 3,33465 & 10,66 & 36214 & Oblicuidad \\
\hline 1,00000 & 1,00000 & 3,21 & 10860 & \multirow{3}{*}{ Precesión } \\
\hline 0,98954 & 0,99508 & 3,18 & 10806 & \\
\hline 0,63960 & 0,62159 & 2,06 & 6750 & \\
\hline
\end{tabular}

Tabla 8.6: Correlación entre ratios orbitales y estratigráficos de la solución Enciso B2.

La solución Enciso B3 se calcula comparando la fila 27 de la tabla estratigráfica y la fila 37 de la tabla orbital (correlación 0,999615) (tabla 8.7).

\begin{tabular}{|c|c|c|c|c|}
\hline Ratios estratigráficos & Ratios orbitales & Potencia (m) & Tiempo (año) & \\
\hline 104,49971 & 105,70103 & 202,51 & 713521 & \multirow{4}{*}{ Excentricidad } \\
\hline 62,69957 & 60,16815 & 121,50 & 406157 & \\
\hline 15,67480 & 15,70644 & 30,38 & 106024 & \\
\hline 11,61105 & 11,36915 & 22,50 & 76746 & \\
\hline 5,49998 & 5,44692 & 10,66 & 36769 & Oblicuidad \\
\hline 2,46845 & 2,66410 & 4,78 & 17984 & \multirow{3}{*}{ Precesión } \\
\hline 1,59136 & 1,60086 & 3,08 & 10806 & \\
\hline 1,00000 & 1,00000 & 1,94 & 6750 & \\
\hline
\end{tabular}

Tabla 8.7: Correlación entre ratios orbitales y estratigráficos de la solución Enciso B3. 


\section{Análisis cicloestratigráfico del Grupo Enciso}

En el supuesto Enciso B, se reconocen únicamente tres ciclos de excentricidad, comunes a todos ellos (tabla 8.8). Sin embargo, existe un ciclo de 30,38 m atribuible a la excentricidad corta con una duración comprendida entre 99.246-106.024 años. Además, el ciclo de 10,66 m representa un ciclo de oblicuidad de 35- 36 ka (35.724, 36.214 y 36.769). Los ciclos de precesión son más variables, aunque parece existir un ciclo común a todos ellos de $\approx 3 \mathrm{~m}$ de $\approx 10 \mathrm{ka}$.

\begin{tabular}{|c|c|l|}
\hline Potencia (m) & Tiempo (año) & \\
\cline { 1 - 2 } 202,51 & 713521 & \\
\cline { 1 - 2 } 121,50 & 406157 & \multirow{2}{*}{ Excentricidad } \\
\cline { 1 - 2 } 22,50 & 76746 & \\
\hline
\end{tabular}

Tabla 8.8: Correlación entre ciclos orbitales y estratigráficos comunes a todas las soluciones Enciso B.

Utilizando el mismo razonamiento que en el caso anterior, el ciclo principal de excentricidad de 121,50 m (406.157 años) permite calcular una tasa de sedimentación lineal de 0,30 mm/ año y una duración de 4,19 Ma para el Grupo Enciso.

Si se usan las tres periodicidades de la excentricidad de la solución Enciso B, se estima

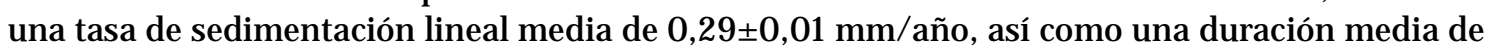
$4,30 \pm 0,11 \mathrm{Ma}$.

La tasa de sedimentación lineal real, descompactada la sección estratigráfica, es de unos $0,65 \mathrm{~mm} /$ año.

\subsubsection{Resultados en la columna de Ambas Aguas}

Del análisis comparativo de los ratios orbitales (anexo XV.1) y estratigráficos (anexo $\mathrm{XV}$.3) se obtienen un único resultado, que al igual que en los casos anteriores, presenta tres variantes.

Todas ellas registran las mismas componentes de la excentricidad y oblicuidad, y varían en los ciclos de precesión.

La solución Ambas Aguas 1 se obtiene al comparar la fila 4 de la tabla de ratios orbitales y fila 1 de la tabla de los ratios estratigráficos (correlación de 0,999963) (tabla 8.9).

\begin{tabular}{|c|c|c|c|c|}
\hline Ratios estratigráficos & Ratios orbitales & Potencia (m) & Tiempo (año) & \\
\hline 1,000000 & 1,000000 & 105,98 & 406157 & \multirow{3}{*}{ Excentricidad } \\
\hline 0,315787 & 0,323382 & 33,47 & 131344 & \\
\hline 0,260870 & 0,261042 & 27,65 & 106024 & \\
\hline 0,063830 & 0,065923 & 6,76 & 26775 & Oblicuidad \\
\hline $\mathrm{o}, 027272$ & 0,026738 & 2,89 & 10860 & \multirow{2}{*}{ Precesión } \\
\hline 0,025423 & 0,024464 & 2,69 & 9936 & \\
\hline
\end{tabular}

Tabla 8.9: Correlación entre ratios orbitales y estratigráficos de la solución Ambas Aguas 1.

La solución Ambas Aguas 2 se calcula cotejando la fila 6 de la tabla orbital y la fila 2 de la tabla estratigráfica (correlación de 0,99970) (tabla 8.10). 


\section{Análisis cicloestratigráfico del Grupo Enciso}

\begin{tabular}{|c|c|c|c|c|}
\hline Ratios estratigráficos & Ratios orbitales & Potencia (m) & Tiempo (año) & \\
\cline { 1 - 4 } 3,16669 & 3,09232 & 105,98 & 406157 & \multirow{2}{*}{ Excentricidad } \\
\cline { 1 - 4 } 1,00000 & 1,00000 & 33,47 & 131344 & \\
\hline 0,82609 & 0,80723 & 27,65 & 106024 & \multirow{2}{*}{ Oblicuidad } \\
\hline 0,20213 & 0,20386 & 6,76 & 26775 & Precesión \\
\hline 0,08051 & 0,08228 & 2,69 & 10806 & \\
\hline
\end{tabular}

Tabla 8.10: Correlación entre ratios orbitales y estratigráficos dela solución Ambas Aguas 2.

Finalmente, la solución Ambas Aguas 3 se obtiene comparando la fila 9 de ratios orbitales y la fila 3 de ratios estratigráficos (correlación de 0,999967) (figura 8.11).

\begin{tabular}{|c|c|c|c|c|}
\hline Ratios estratigráficos & Ratios orbitales & Potencia (m) & Tiempo (año) & \\
\hline 3,83333 & 3,83079 & 105,98 & 406157 & \multirow{3}{*}{ Excentricidad } \\
\hline 1,21052 & 1,23881 & 33,47 & 131344 & \\
\hline 1,00000 & 1,00000 & 27,65 & 106024 & \\
\hline 0,24468 & 0,25254 & 6,76 & 26775 & Oblicuidad \\
\hline 0,10454 & 0,10243 & 2,89 & 10860 & \multirow{2}{*}{ Precesión } \\
\hline 0,09746 & 0,10192 & 2,69 & 10806 & \\
\hline
\end{tabular}

Tabla 8.11: Correlación entre ratios orbitales y estratigráficos de la solución Ambas Aguas 3.

En la columna de Ambas Aguas, el análisis cicloestratigráfico muestra la existencia de tres ciclos de excentricidad y uno de oblicuidad, comunes a todas las soluciones posibles (tabla 8.12). Asimismo, existe un ciclo de precesión de 2,89 m con una duración de 10.860 años que aparece en dos de las soluciones. Además, aparece otro ciclo de precesión de 2,69 m con una duración comprendida entre 9.936-10.806 años.

\begin{tabular}{|c|c|c|}
\hline Potencia (m) & Tiempo (año) & \\
\hline 105,98 & 406157 & \multirow{2}{*}{ Excentricidad } \\
\hline 33,47 & 131344 & \\
\hline 27,65 & 106024 & Oblicuidad \\
\hline 6,76 & 26775 & \\
\hline
\end{tabular}

Tabla 8.12: Correlación entre ciclos orbitales y estratigráficos comunes a todas las soluciones en la columna de Ambas Aguas.

El ciclo fundamental de excentricidad de 105,98 m (406.157 años) permite estimar una tasa lineal de sedimentación de 0,26 mm/ año, así como, una duración de 2,44 Ma para el Grupo Enciso en la zona de Ambas Aguas ( $636 \mathrm{~m}$ de potencia total).

A partir de las cuatro periodicidades comunes a todas las soluciones, se calcula una tasa de sedimentación lineal media de 0,26 mm/año $(0,25-0,26 \mathrm{~mm} /$ año), así como una duración media de 2,47 $\pm 0,04 \mathrm{Ma}(2,44-2,52 \mathrm{Ma})$.

La serie de Ambas Aguas descompactada presenta una potencia real de $1.398 \mathrm{~m}$ (anexo XVI), que permite determinar una tasa de sedimentación lineal real de 0,57 mm/año. 


\subsection{COMENTARIOS FINALES}

En la bibliografía consultada, solamente existen dos referencias sobre cicloestratigrafía aplicada al Grupo Enciso.

a) La primera referencia abarca el estudio de una sección de $1.000 \mathrm{~m}$ en la zona de Vadillos (DOUBLET, 2004). Este autor identifica dos ciclos de excentricidad (ciclo de $68 \mathrm{~m}$ de 404 ka y ciclo de 18,55 m de $95 \mathrm{ka}$ ), dos ciclos de oblicuidad (ciclo de 8,50 m de $49 \mathrm{ka}$, y ciclo de 7,29 m de $38 \mathrm{ka}$ ), y uno de precesión (ciclos de 3,14 m de $18 \mathrm{ka}$ ). Determina una duración temporal del Grupo Enciso de 5,6 $\pm 0,4$ Ma (DOUBLET, 2004).

b) La segunda referencia es una serie levantada en la localidad de Munilla (996 m) con una duración temporal de 5,7 Ma (ANGULO Y MUÑOZ, 2013). Identifican dos ciclos de excentricidad (ciclo de 90,56 m de $405 \mathrm{ka}$, y ciclo de 16,66 m de 94,8 ka), un ciclo de oblicuidad (ciclo de 7,14 m de 37,1 ka), y dos modas del ciclo de precesión de 5,37y $3,93 \mathrm{~m}$.

Los resultados obtenidos sugieren que los ciclos de excentricidad son los más comunes y tienen las mayores probabilidades de quedar registrados en los sedimentos antiguos. Más aún, de todos ellos, el ciclo de excentricidad $\mathrm{g}_{2}-\mathrm{g}_{5}(405 \mathrm{ka}$ ) presenta una gran estabilidad a lo largo del tiempo geológico, así como una importante componente paleoclimática (LASKAR et al., 2004; LASKAR et al., 2011). Es por esta razón, que tanto en el presente estudio como en los anteriormente citados, siempre se reconozca dicho ciclo de excentricidad $\left(\mathrm{g}_{2}-\mathrm{g}_{5}\right)$. Conjuntamente, la posición (sub)tropical del paleolago Enciso hace que los ciclos de oblicuidad-precesión tengan menos representatividad (PÄLIKE, 2005). A esto hay que añadir que sus valores son menos precisos debido al movimiento caótico del Sistema Solar, siendo sólo fiables hasta hace unos 40-50 Ma (LASKAR et al., 2004; LASKAR et al., 2011).

Respecto a la duración temporal del Grupo Enciso, los valores de 5,6 $\pm 0,4$ Ma de DOUBLET (2004) y 5,7 Ma de ANGULO Y MUÑOZ (2013), sugieren que en la columna de Enciso la solución

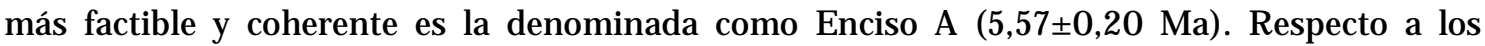
2,47 $\pm 0,04$ Ma obtenidos en la sección de Ambas Aguas, se explican por el casi nulo desarrollo de la secuencia inferior siliciclástica debido a su posición en un umbral intracuencal (apartado 6.1). Por el contrario la secuencia superior está registrada en su totalidad y muestra una tasa de sedimentación semejante a la de la columna de Enciso.

La Secuencia Deposicional 7, a la cual pertenece el Grupo Enciso, se considera Barremiense superior-Aptiense inferior (MARTÍN-ClOSAS Y ALONSO-MILLÁN, 1998; MAS et al., 2002; 2003; MAS et al., 2011). El Grupo Enciso no ha podido ser datado con precisión, aunque tradicionalmente, se ha considerado en su mayor parte como Aptiense inferior por su relación lateral y vertical con la Formación Leza, la cual está bien datada como Aptiense inferior (ALONSO Y MAS, 1993; SUÁREZ-GONZALEZ et al., 2015). Con los datos obtenidos de la cicloestratigrafía se hacen ciertas precisiones sobre la edad del Grupo Enciso:

a) SCHUDACK (1987) cita la presencia de la carófita Atopochara trivolvis var. triquetra, perteneciente a la biocronozona Atopochara trivolvis triquetra de abarca desde el Barremiense inferior (130,81 Ma) hasta la parte inferior del Barremiense superior (127,47 Ma) según RIVELINE et al. (1996).

b) GUIRAUD y SÉGURET (1985) y DOUBLET y GARCIA (2004) citan, en la parte alta del Grupo Enciso, la presencia de la carófita Clavator grovesii var. lusitanicus, que define la biocronozona Clavator grovesii lusitanicus de edad Aptiense superior (123 Ma) a Albiense medio (107,59 Ma). DOUBLET Y GARCIA (2004), en su figura 2, señalan que la base de la serie de Arnedillo se localiza en los últimos $100 \mathrm{~m}$ del Grupo Enciso. Estos $100 \mathrm{~m}$ corresponden a aproximadamente a un tiempo de 0,44 Ma.

Así pues, si se admite una duración de 5,57 Ma para el Grupo Enciso, el rango temporal abarcado es 122,56-128,13 Ma, desde el Barremiense superior hasta el Aptiense superior (figura 8.8). 


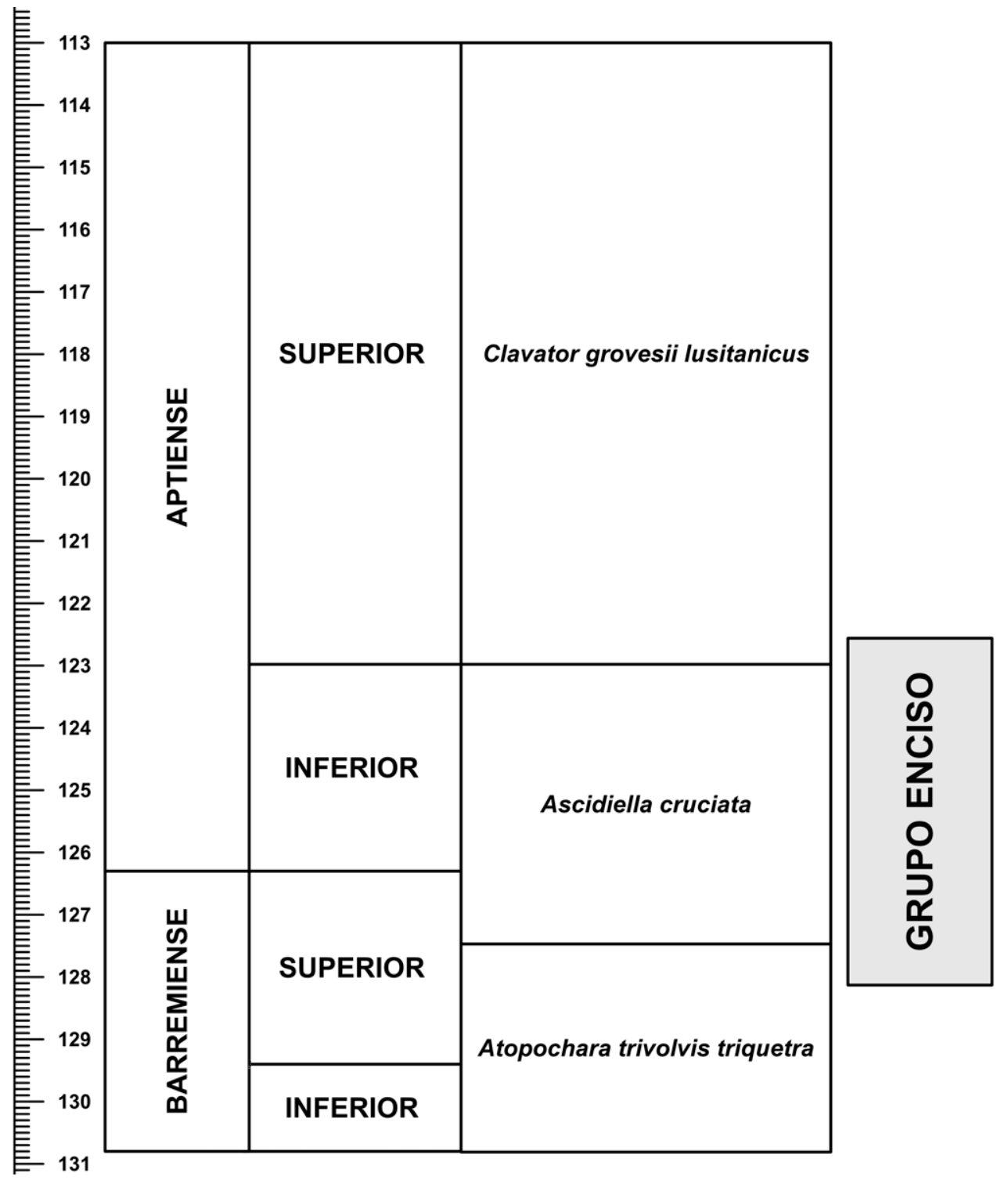

Figura 8.8: Posiblerango temporal del Grupo Enciso si se asume una duración temporal de 5,57 Ma. Las edades de los pisos y subpisos se han tomado de GTS2012 (OGG et al., 2012) y la biocronozona de RIVELINE et al. (1996). 
Análisis cicloestratigráfico del Grupo Enciso 


\section{Antonio Machado \\ Poestias}
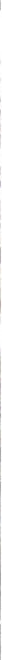

Y otra ver roca y roca, pedregales

desnulios t pellados sermijones.

1a tiema de las águilas cavalales,

malezas y jarales,

hierbas nonteses, zameras it jarales

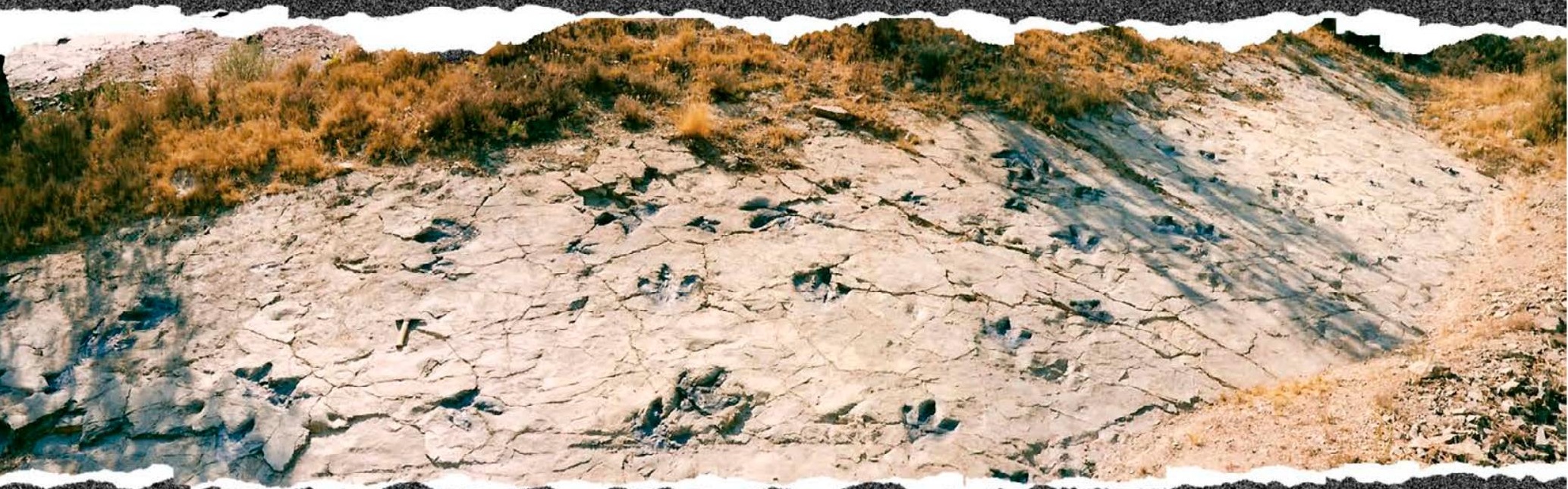




\section{Modelo conceptual del paleolago Enciso}

En el presente capítulos se pretende determinar, con el mayor nivel de detalle posible, aquellos factores de forzamiento de la sedimentación descritos en el capítulo 4, que sean los más viables basándose en la abundante información disponible sobre la cuenca de Cameros (y áreas aledañas), y en los datos adquiridos durante las últimas décadas provenientes deámbitos diversos tales como la geoquímica, paleoclimatología, tectónica, paleontología, mineralogía, etc. No siempre se dispone de los datos necesarios para su caracterización precisa, aunque siempre ofrecen pistas importantes sobre la sedimentación acontecida. En esteanálisis lleno de conjeturas e interpretaciones hay que "hilar muy fino", por lo que no se descarta que en más de una ocasión se haya dado una "puntada sin hilo".

\subsection{CONTEXTO TECTÓNICO}

Durante el intervalo de tiempo finijurásico-eocretácico, el escenario tectónico dela placa Iberia, se enmarca en un régimen marcadamente extensional [ciclo 2 de rifting de SALAS et al. (2001)]. La cuenca de Cameros se localiza en el Sistema de Rift Mesozoico Ibérico, el cual estuvo compartimentado en numerosas cuencas rift (figura 3.3). Las principales características de este Sistema de Rift son:

a) Emplazado sobre una corteza continental adelgazada (SALAS Y CASAS, 1993; GUIMERÀ et al., 1996).

b) Asociado a la apertura del dominio del Atlántico Norte y al rifting transtensional en el Golfo de Vizcaya (MALOD Y MAUFFRET, 1990; OLIVET, 1996).

c) Desarrollado desde el Oxfordiense terminal hasta el Albiense medio (SALAS Y CASAS, 1993).

Uno de los rasgos más significativo de la sedimentación acontecida en estas cuencas eocretácicas es el notable desarrollo de sistemas lacustres carbonatados (ALONSO et al., 1991; FREGENAL-MARTÍNEZ Y MELÉNDEZ, 1993; SORIA et al., 1997; LIESA et al., 2000; MELÉNDEZ et al., 2000b; MELÉNDEZ et al., 2009). Si este análisis se circunscribe exclusivamente a la cuenca de Cameros, destacan los episodios lacustres carbonatados de las formaciones Boleras, Campolara, Matute, Río de San Marcos, Huérteles, Calizas de Peñacoba, Hortigüela, y Calizas de Cabretón (apartado 3.3). En esa época y en un escenario tectónico similar, destacan los lagos rift carbonatados asociados a la apertura del Atlántico Sur (ABRAHÃO Y WARME, 1990; DE CARVALHO et al., 2000).

De lo anteriormente expuesto y lo explicado en el apartado 3.2, es evidente que el paleolago Enciso tiene un origen tectónico, más concretamente, un lago rift según la clasificación de COHEN (2003) o HINDERER Y EINSELE (2001). De hecho, presenta numerosas características propias de los lagos tectónicos rift explicadas en el apartado 4.5:

a) Los principales factores de forzamiento son el clima y la tectónica, aunque en el caso concreto de la cuenca de Cameros, la influencia del vulcanismo es nula.

b) Distribución cíclica de los depósitos lacustres y fluviales: el relleno sinrift dela cuenca de Cameros (capítulo 3) está formado por ocho Secuencias Deposicionales (42 Ma), cada una de las cuales está integrada, a grandes rasgos, por depósitos fluviales que evolucionan lateral y/ o hacia techo a depósitos lacustres (figura 3.5).

c) Perdurabilidad temporal: según los datos de la cicloestratigrafía (capítulo 8), el Grupo Enciso se extiende desde el Barremiense superior hasta el Aptiense superior. Por tanto, estamos hablando de un paleolago Enciso con una vida estimada de 5,57 Ma según la escala de tiempo GTS2012 (OGG et al., 2012).

d) Endemismo: la biota presente en el paleolago Enciso muestra un alto endemismo en los ostrácodos, sobre todo en los géneros Cypridea y Theriosynoecum (KNEUPERHAACK, 1966; BRENNER, 1976) siendo menor en los gasterópodos y bivalvos. Este escaso endemismo entrelos moluscos podría guardar relación con la profundidad, ya que, los lagos someros actuales en regiones tropicales no suelen presentar endemismos, a excepción del lago Victoria (TALLING, 2001). 


\section{Modelo conceptual del paleolago Enciso}

e) Espesores potentes: el área depocentral definida por la columna de Enciso (anexo IV) tiene una potencia de $1.254 \mathrm{~m}$ que descompactada supone una estimación de 2.785 m de sedimentos depositados.

f) Elevada tasa de sedimentación lineal: según los cálculos realizados con la ayuda de la cicloestratigrafía (apartado 8.3.1.1) se ha calculado una tasa lineal de $0,50 \mathrm{~mm} /$ año en la serie de Enciso. Estevalor está en el rango de los lagos rift, aunque hay que tener en cuenta que la tasa de sedimentación no es homogénea en toda la cubeta.

En la actualidad no existe un consenso evidente sobre la influencia que la tectónica, de manera aislada de otros mecanismos de forzamiento, ejerce sobre los medios sedimentarios continentales. Por un lado, hay autores que sostienen que los períodos de gran actividad tectónica favorecen la instauración de sistemas aluviales, mientras que las etapas de quiescencia tectónica fomentan la expansión de los sistemas lacustres (LuZÓN et al., 2002). En el extremo antagónico, otros autores consideran que las épocas tectónicamente activas favorecen la instauración de sistemas lacustres y fluviales, mientras que las fases menos tectónicas se manifiestan por el desarrollo de abanicos aluviales (BLAIR Y BILODEAU, 1988). Por ejemplo, en el Grupo Newark, la disminución en la tasa deagradación asociada a la extensión dela cuenca, ocasiona quelos medios fluviales tengan cada vez que ocupar un área mayor y no puedan alcanzar el nivel del desagüe, resultando en la formación de una cuenca cerrada y favoreciendo la formación de lagos (OLSEN et al., 1989; SMOOT, 1991).

En la cuenca de Cameros Oriental, se han reconocido dos pulsos discretos importantes del rifting: el primero se origina durante el intervalo Titoniense-Berriasiense y el segundo, más moderno, abarca el período Barremiense-Albiense inferior (MAS et al., 1993). Este último pulso aptiense se ha reconocido también en la cuenca Vasco-Cantábrica (GARCÍA-MONDÉJAR et al., 2005), algunas cuencas pirenaicas (VERGÉSY GARCÍA-SENZ, 2001) y, en las cuencas del Maestrazgo y Sur Ibérica (VAN WEES et al., 1998). Estos dos pulsos tectónicos coinciden de manera significativa con las dos etapas que muestran un mayor desarrollo de sistemas lacustres en la cuenca de Cameros: la Formación Huérteles de edad Berriasiense y el Grupo Enciso de edad Aptiense inferior (MORATALLA Y HERNÁN, 2010). Así pues, parece que el relleno sinrift camerano favorece las ideas defendidas por BLAIR Y BILODEAU (1988).

A escala de la cuenca de Cameros, las evidencias a favor de una importante actividad tectónica sinsedimentaria son la migración progresiva de las áreas depocentrales de las Secuencias Deposicionales hacia el norte y, un relleno sinrift de unos 9.000 metros de potencia que apunta a una subsidencia acusada (MAS et al., 1993; MAS et al., 2002; OMODEO-SALÈ et al., 2014). Se han determinado dos direcciones de extensión para la cuenca de Cameros, NE-SO y NO-SE (GUIRAUD Y SÉGURET, 1985; GONZÁLEZ-CASADO Y GARCÍA-CUEVAS, 2002).

A menor escala, los sedimentos del Grupo Enciso revelan numerosos testimonios de esta tectónica coetánea con la sedimentación y asociada, con gran probabilidad, a pulsos ligados a terremotos (sismitas). En los alrededores del pueblo de Enciso se han observado tres niveles con numerosos volcanes de arena (figura 9.1A). La presencia de volcanes de arena ya había sido advertida por GUIRAUD Y SÉGURET (1987) en la zona deYanguas. Sin embargo, en esta nueva zona, los volcanes presentan un admirable estado de preservación del cono de extrusión, en algunos casos conservando el cráter (figuras 9.1By C). En muchas ocasiones, los volcanes se suelen asociar a una misma fisura (MONTENAT et al., 2007). En este ejemplo camerano, los volcanes aparecen alineados en dirección N158트, perpendicular a la extensión NE-SO. El cono, en general, es una estructura efímera que es fácilmente erosionada en unas pocas semanas, así pues, su preservación en el registro geológico se considera un suceso excepcional (MONTENAT et al., 2007). Lo normal es que se conserve la parte subterránea donde es posible reconocer muchos caracteres típicos (figura 9.1D).

También se observan estructuras de escape de agua (GUIRAUD y SÉGURET, 1987), estratificación o laminación convoluta asociada a sismoslumps o deslizamientos inducidos por terremotos (figuras 9.2A, B, Cy D), estructuras generadas por licuefacción (figura 9.2E y F), fallas normales sinsedimentarias de escala métrica hasta hectométrica (figura 9.3A). De más dudosa atribución como sismitas son ciertos niveles con importantes estructuras de carga (figura 9.3B), 


\section{Modelo conceptual del paleolago Enciso}

loop bedding poco desarrollado (figura 9.3C) y quizá un deslizamiento (figura 9.3D) semejante al descrito por GIBERT et al. (2005). De hecho, en ciertos estratos con icnitas, el paso de los dinosaurios sobre el sedimento forma estructuras, a menor escala, semejantes a ciertas sismitas como convoluciones (figura 9.3E), fallas blow-out sensu MONTENAT et al. (2007) (figura 9.3F) y estructuras en llama y almohadillas (figura 9.3G y H).
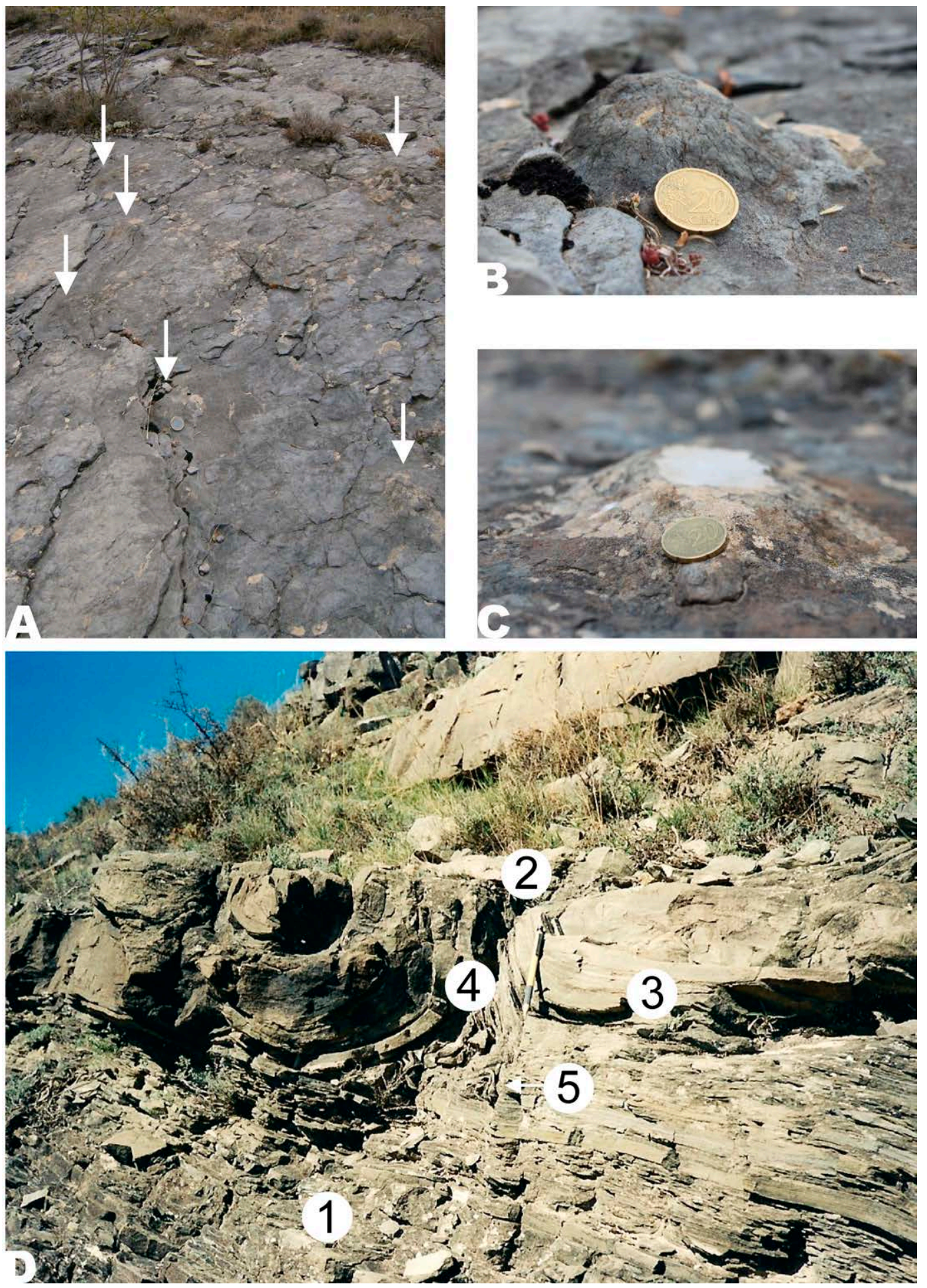

Figura 9.1: A) Fotografía de uno de los niveles con múltiples volcanes de arena. B) y C) Detalle de los conos de los volcanes de arena, en el segundo ejemplo (C) se aprecia el cráter. D) Volcán de arena donde se observan numerosos caracteres distintivos (1) capa basal sin deformar, (2) capa superior no deformada, (3) preservación de las estructuras sedimentarias de la capa deformada hacia arriba, (4) expulsión del sedimento licuefactado y, (5) fragmentos convolutos transportados por el flujo licuefactado. 


\section{Modelo conceptual del paleolago Enciso}
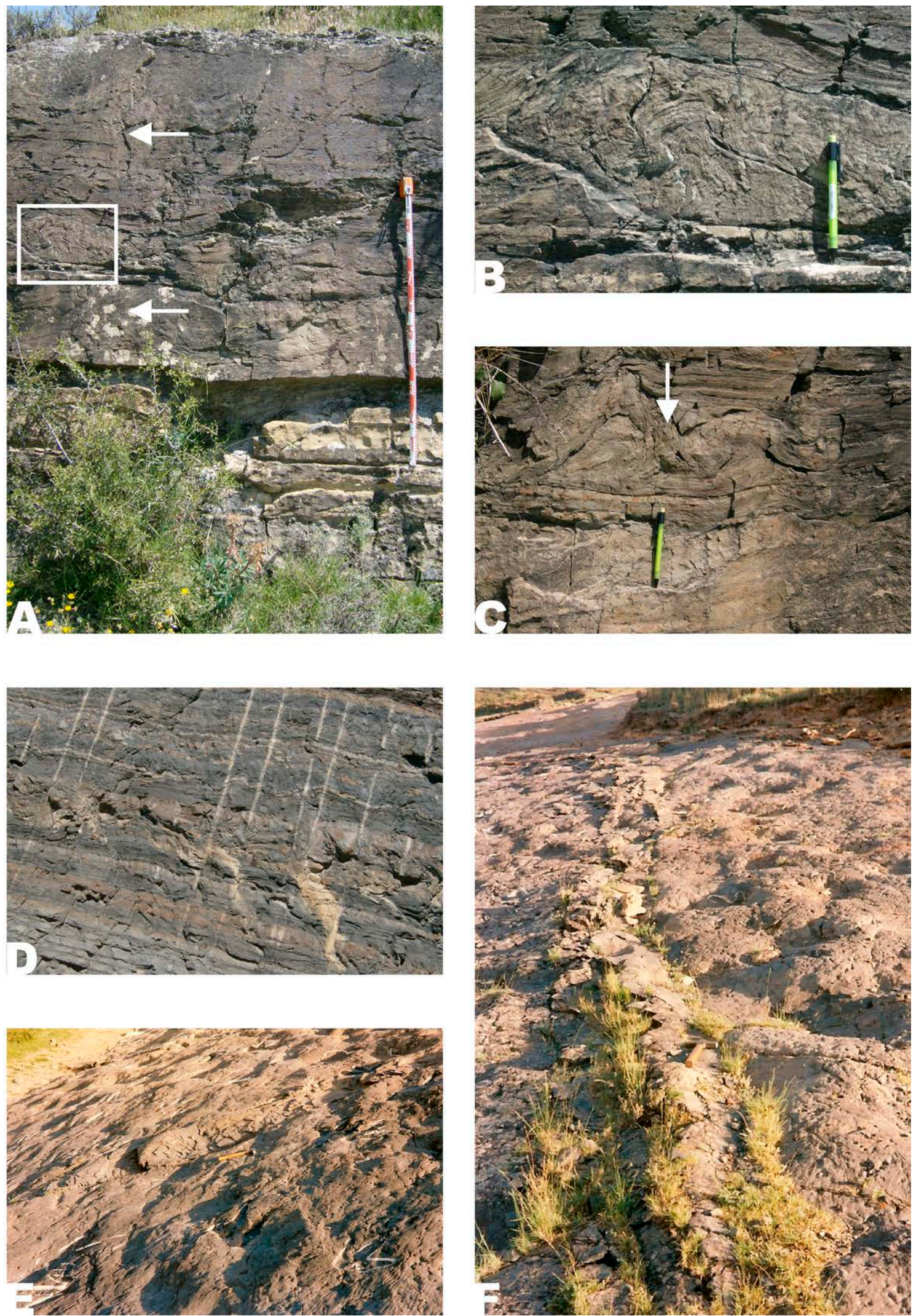

Figura 9.2: A) Nivel con evidencias de laminación convoluta (las flechas indican los niveles no deformados). B) Detalle de la laminación convoluta (corresponde al recuadro de la fotografía anterior). C) Detalle de otra laminación convoluta en el mismo nivel. D) Pseudonódulos asociados a terremotos. E) y F) Detalle de un flujo licuefactado en la superficie del yacimiento paleoicnológico de la Virgen del Campo (Enciso). 


\section{Modelo conceptual del paleolago Enciso}
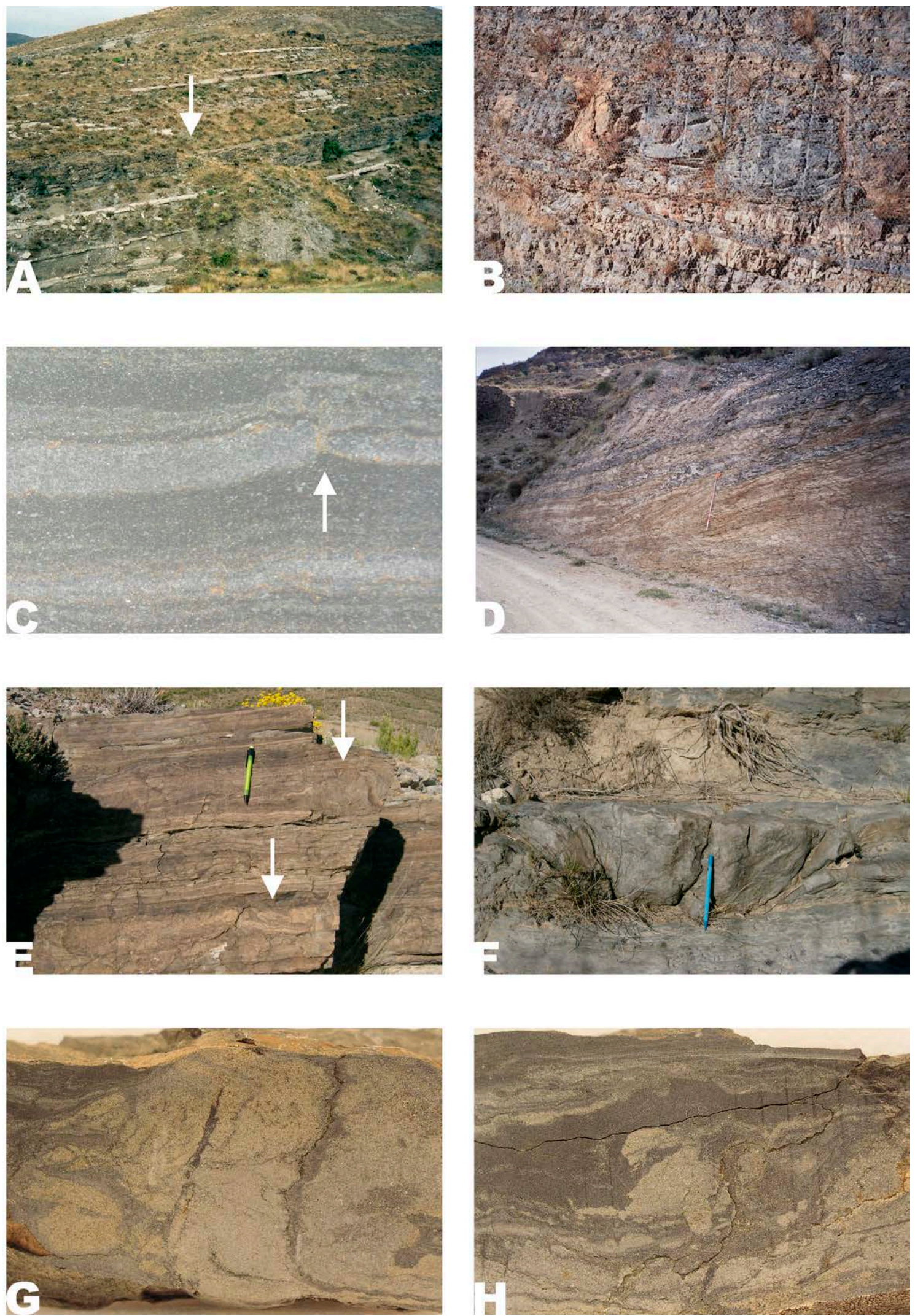

Figura 9.3: A) Falla normales sinsedimentarias de escala métrica. B) Nivel con importantes estructuras de carga. C) Posible loop bedding poco desarrollado. D) Posible deslizamiento atribuible a un terremoto. Las siguientes fotos son estructuras creadas por el paso de los dinosaurios que podrían atribuirse a sismitas, tales como pequeñas convoluciones (E), fallas blow-out (F) y estructuras en llama y almohadillas (G y H). 


\section{Modelo conceptual del paleolago Enciso}

\subsection{ESCENARIO CLIMÁTICO DURANTE EL APTIENSE}

El sistema climático terrestre está constituido por una serie de subsistemas que interaccionan entre sí, intercambiando masa, energía y cantidad de movimiento. Los subsistemas básicos son: la atmósfera (capa gaseosa que rodea la Tierra), la hidrosfera (conjunto de las aguas existente en forma líquida), la criosfera (totalidad de aguas en estado sólido; nieve e hielo), la litosfera (envoltura rocosa del globo terrestre) y, la biosfera (conjunto de los medios donde se desarrollan los seres vivos). En el presente apartado se va a realizar una aproximación a dichos subsistemas, así como a su posible influencia en el contexto del paleolago Enciso.

Las condiciones climáticas de la Tierra han permutado multitud de veces a lo largo delos tiempos geológicos. Tradicionalmente, se ha considerado como una sucesión entre etapas glaciales (icehouse) y de efecto invernadero (greenhouse). Sin embargo, descubrimientos recientes apuntan a que el clima Fanerozoico puede ser un poco más complejo, aproximándose más a una alternancia entre tres modelos climáticos mutuamente excluyentes: glacial (20-25\%), efecto invernadero ( $>70 \%$ ) y hothouse $(<4 \%)$. La etapa de efecto invernadero sería el modelo por defecto, representando más del $70 \%$ del registro terrestre. Cada modelo está caracterizado por diferencias fundamentales en la circulación oceánica y atmosférica (KIDDER Y WORSLEY, 2010). El Aptiense, desde siempre, se ha considerado como una etapa de efecto invernadero, aunque en los últimos años nuevas investigaciones parecen sugerir que pudo ser una etapa hothouse (KIDDER Y WORSLEY, 2010) o de efecto superinvernadero (supergreenhouse) (HASEGAWA et al., 2012).

A escala terrestre, uno de los factores más determinantes en el clima aptiense fue la elevada concentración atmosférica de gases de efecto invernadero:

a) Dióxido de carbono $\left(\mathrm{CO}_{2}\right)$ procedente de la actividad volcánica debido al emplazamiento de las Grandes Provincias Ígneas (Large Igneous Provinces) de Ontong J ava y Kerguelen (MÉHAY et al., 2009; TEJADA et al., 2009; KELLER et al., 2011). Los dos procedimientos básicos para el cálculo del $\mathrm{CO}_{2}$ atmosférico son las modelizaciones de los ciclos biogeoquímicos y los aproximadores paleobarométricos. Los ejemplos de estas complejas modelizaciones de los ciclos biogeoquímicos son numerosos: TAJIKA (1998), WALLMANN (2001), HANSEN Y WALLMANN (2003), GEOCARB de BERNER (1994) y BERNER Y KOTHAVALA (2001), GEOCARBSULF de BERNER (2006), y COPSE de BERGMAN et al. (2004). Los valores obtenidos con los aproximadores paleobarométricos presentan diferentes grados de confidencialidad, así como resultados dispares ya que cada aproximador asume unos prerrequisitos. $\mathrm{Si}$ se utiliza como aproximador la composición isotópica de los paleosuelos se estiman valores comprendidos entre 1900-3200 ppmV (LEE, 2003) y 1480-2710 ppmV (EKART et al., 1999). Si el aproximador es la relación entre la composición isotópica de la materia orgánica y los carbonatos marinos se obtienen rangos comprendidos entre 3-4 veces el valor preindustrial según HEIMHOFER et al. (2004) y de 2-2,5 veces el valor actual según ROTHMAN (2002) (se asume un valor preindustrial de 280 ppmV). Finalmente, si el paleobarómetro considerado es la densidad de estomas en las hojas de plantas fósiles, las estimaciones varían entre 4000 ppmV (RETALLACK, 2002), 637-1175 ppmV (HAWORTH et al., 2005) y 466-1156 ppmV (PASSALIA, 2009).

b) Metano (J AHREN et al., 2001; BEERLING et al., 2002; BEERLING et al., 2009).

c) Vapor de agua a consecuencia del aumento de la temperatura del aire.

Los cambios más importantes del sistema climático a escala global debidos a la presencia de gases de efecto invernadero son el aumento mundial de la temperatura del aire y del océano, así como la modificación de ciertos componentes del ciclo hidrológico (SOLOMON et al., 2007; BATES et al., 2008).

Se puede obtener una aproximación inicial a las temperaturas del aire en la placa ibérica durante el aptiense, utilizando los Modelos de Circulación General. Según FLUTEAU et al. (2007), si se supone un fuerte gradiente de la Temperatura Superficial del Mar (TSM) entre el polo y el ecuador, lo cual implica la presencia de hielo en los polos, las temperaturas medias durante Diciembre, Enero y Febrero estarían comprendidas entre $14-18^{\circ} \mathrm{C}$, y en J unio, J ulio y Agosto 


\section{Modelo conceptual del paleolago Enciso}

entre $26-30^{\circ} \mathrm{C}$. Por el contrario, si el gradiente TSM es suave. Es decir, sin hielo permanente en los polos, la temperatura durante los meses fríos sería de $10-18^{\circ} \mathrm{C}$ y de $26-30^{\circ} \mathrm{C}$ durante los meses cálidos. De este mismo orden de magnitud $\left(26-30^{\circ} \mathrm{C}\right)$ son los valores de la Temperatura Media Anual (TMA) obtenidos por OHBA Y UEDA (2010) con un gradiente TSM elevado.

La otra gran fuente de información cuantitativa sobre la Temperatura Media Anual en medios continentales proviene del registro sedimentario y paleontológico. En general coinciden con los valores anteriormente citados:

a) La bauxita se reconoce como un excelente indicador paleoclimático, siendo muy utilizada en la interpretación de los regímenes climáticos del pasado. En la actualidad, los terrenos sometidos a procesos de lateritización presentan una Temperatura Media Anual superior a los $22^{\circ} \mathrm{C}$ (TARDY et al., 1991; PRICE et al., 1997). En la cuenca de Cameros se ha citado la aparición de alteritas y bauxitas en el contacto entre la Formación Leza con el Grupo Enciso (DOUBLET, 2004). Fuera dela cuenca de Cameros, existen referencias de edad aptiense en la colindante Zona de Enlace (MOLINA Y SALAS, 1993), así como múltiples citas en los Pirineos, tanto en el paleomargen ibérico como europeo (PEYBERNĖs, 1982b; PEYBERNĖSY COMBES, 1995; COMBES et al., 1998; MARTÍNCHIVELET et al., 2002) (figura 9.4).

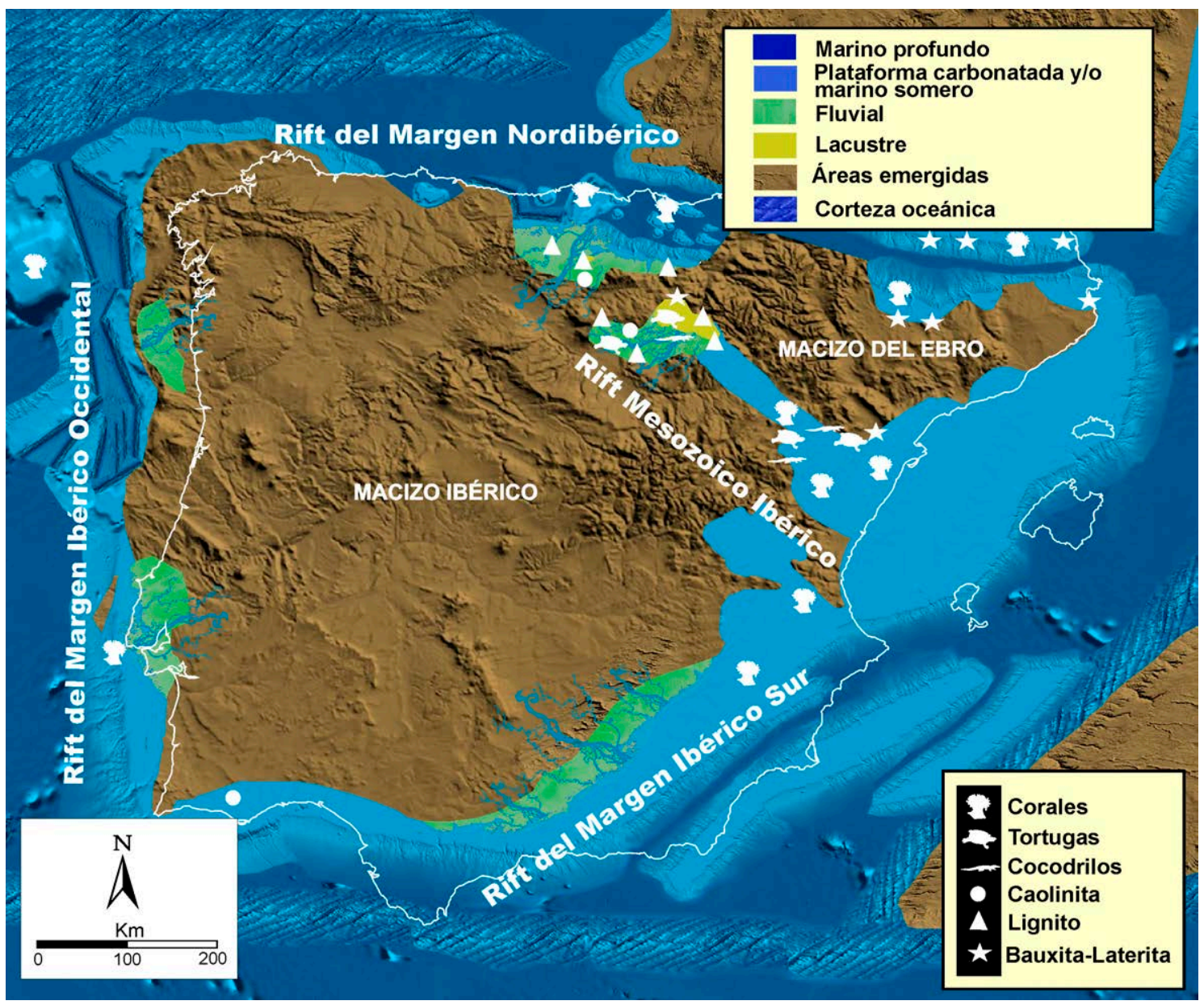

Figura 9.4: Mapa paleogeográfico en detalle de la placa Iberia mostrando los aproximadores paleoclimáticos citados en el texto.

b) La caolinita sugiere una Temperatura Media Anual por encima de $15^{\circ} \mathrm{C}$ (HEIMHOFER et al., 2008). Por desgracia, el metamorfismo acontecido en la subcuenca oriental ha eliminado la mineralogía original de las arcillas (ALONSO-AZCÁRATE et al., 1999a). Sin embargo, en la subcuenca occidental donde no ha existido metamorfismo, en las denominadas secuencias de "Lagunas de Neila" y "Salas de Los Infantes" se ha 
observado una proporción importante de caolinita diagenética en depósitos coetáneos al Grupo Enciso (SANTOS-DELGADO Y BLANCO-SÁNCHEZ, 1993). También aparecen en la contemporánea Capas con Palobitolina de la cuenca del Algarve (HEIMHOFER et al., 2008) (figura 9.4).

c) Los cocodrilos son considerados unos excelentes aproximadores climáticos por su fuerte dependencia de la temperatura (MARKWICK, 1994; 1998b; a; CARVALHO et al., 2010). Los cocodrilos modernos habitan zonas con una Temperatura Media Anual mínima de unos 14,2ํㅡ (MARKWICK, 1998b). Las citas de cocodrilos aptienses son escasas en el Grupo Enciso (ORTEGA et al., 2010) aunque relativamente frecuentes en la placa Ibérica: Fm. Castrillo de la Reina (TORCIDA FERNÁNDEZ-BALDOR et al., 2011), Fm. Artoles (CANUDO et al., 1996) y en la Fm. Morella (CANUDO et al., 2008; GASULLA et al., 2011) (figura 9.4).

d) Las tortugas actuales suelen vivir en ambientes con rangos de temperatura comprendidos entre 20-35으 (HUTCHISON, 1977; BARRICK et al., 1999). En el Grupo Enciso, aparecen tanto restos óseos (PÉREZ-GARCía et al., 2012; PÉREZ-GARCía Y Murelaga, 2013) como icnitas (MORATALla et al., 1990; MORATALLA y HERNÁN, 2009). En la cuenca de Cameros Occidental aparecen en la Fm. Castrillo de la Reina (PÉREZ-GARCíA et al., 2012), y en la placa Iberia se han citado en la cubeta de Oliete (DE LAPPARENT DE BROIN, 2001), en la Fm. Morella (PÉREZ-GarCía et al., 2008; PÉREZ-GARCía et al., 2009) y en la Fm. Artoles (MuRELAGA-BEREIKUA, 1998) (figura 9.4).

Los valores de la Temperatura Superficial del Mar (TSM) pueden también calcularse utilizando Modelos deCirculación General, aunque está más extendido el uso delos denominados paleotermómetros $\left(\delta^{18} \mathrm{O}\right.$ y TEX 86 ). El Modelo de Circulación General aptiense de OHBA Y UEDA (2010) registra unos valores en los alrededores de la placa ibérica de $24-28^{\circ} \mathrm{C}$. Este rango de paleotemperaturas concuerda con los valores $\mathrm{TEX}_{86}$ obtenidos en localizaciones cercanas (figura 9.5): A39 y Alstätte en la cuenca Lower Saxony (paleolatitud $\approx 39^{\circ} \mathrm{N}$ ) en Alemania (MUTTERLOSE et al., 2010; MUTTERLOSE et al., 2014), ODP Site 545 (paleolatitud $\approx 270$ N) en el Plateau Mazagan (MCANENA et al., 2013), ODP Site 641C (paleolatitud $\approx 35^{\circ} \mathrm{N}$ ) en el Margen de Galicia (HOFMANN et al., 2010), ODP Site 1207 (paleolatitud $\approx 1 \underline{0}$ ) en el Shatsky Rise (DUMITRESCU Y BRASSELL, 2006), ODP Site 511 (paleolatitud $\approx 60^{\circ} \mathrm{S}$ ) en el Plateau Falkland (J ENKYNS et al., 2012) y Cismon (paleolatitud $\approx 29^{\circ} \mathrm{N}$ ) en Italia (BOTTINI et al., 2015). En todos los casos, para homogeneizar los valores de las temperaturas, se ha utilizado la fórmula de Kim et al. (2010).

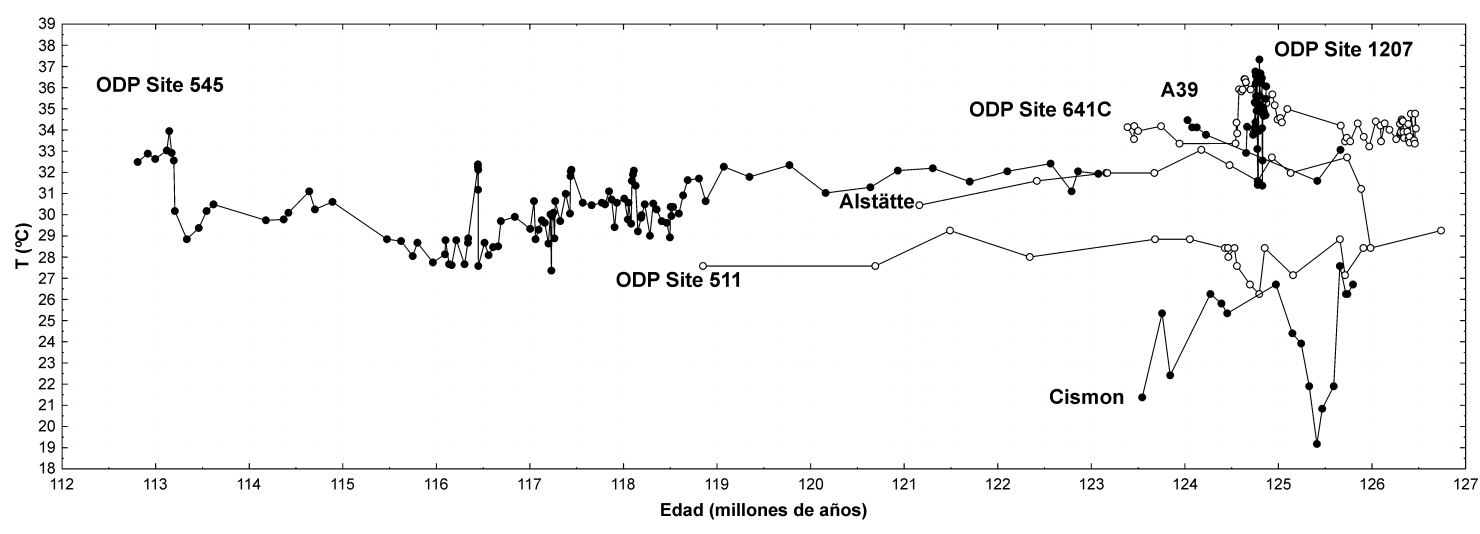

Figura 9.5: Rango de la Temperatura Superficial del Mar a partir de los valores TEX ${ }_{86}$ durante el Aptiense.

Estas paleotemperaturas son también muy similares a las obtenidas a partir delos valores $\delta^{18} \mathrm{O}: 19-27^{\circ} \mathrm{C}$ en la plataforma de Ereño en la cuenca Vascocantábrica durante el AptienseAlbiense (DAMAS-MOLLÁ et al., 2009), 13,5-27ํㅡ en el ámbito tetisiano (PUCÉAT et al., 2003), y los 22-27으 calculados en la cuenca South Provence (KuHNT et al., 2011).

A pesar del efecto invernadero o hothouse, los estudios isotópicos demuestran que durante el Aptiense tuvo lugar una etapa de enfriamiento documentada en diversas cuencas de la 


\section{Modelo conceptual del paleolago Enciso}

placa ibérica: la Formación Forcall de la cuenca del Maestrazgo (BOVER-ARNAL et al., 2011) y la Formación Patrocinio en la cuenca Vasco-Cantábrica (NAJARRO et al., 2011b). Este evento de enfriamiento se ha observado también en el ámbito tetisiano (WEISSERT Y LINI, 1991; HOCHULI et al., 1999; LUCIANI et al., 2006; KUHNT et al., 2011; STEIN et al., 2011), así como en otras regiones (ANDO et al., 2008; MUTTERLOSE et al., 2009; J ENKYNS et al., 2011), por lo cual se considera un suceso a escala mundial. Además de los isótopos, las asociaciones palinológicas descritas en la cuenca del Maestrazgo, lindante con la de Cameros, muestran dicho episodio de enfriamiento del clima. Desde el Valanginiense hasta el Aptiense inferior la abundancia de esporas sugiere un clima cálido y húmedo. Desde el Aptiense inferior terminal hasta el Aptiense superior, el declive de las formas vegetales adaptadas a condiciones cálidas (esporas) y el predominio de elementos característicos de temperaturas más bajas (polen bialado de Gimmnospermas), indica un cambio a un clima más seco y probablemente más frío (SOLE DE PORTA Y SALAS, 1994). En la cuenca VascoCantábrica, las asociaciones palinológicas indican un clima cálido y de cierta aridez (Fm. Patrocinio) que va cambiando hacia una etapa de enfriamiento (NAJARRO et al., 2011b).

Como ya se comentó anteriormente, la presencia de los gases de efecto invernadero inducen, además, una alteración del ciclo hidrológico con cambios en:

a) Modificación de las pautas de la precipitación (DouviLLE et al., 2002; PALL et al., 2007). Durante el Cretácico se ha observado dicha intensificación en las precipitaciones (BARRON et al., 1989; UFNAR et al., 2002; UFNAR et al., 2008; SUAREZ et al., 2011). A escala de la Placa Iberia, la presencia de indicios de bauxitas (figura 9.4) sugiere, por comparación con los medios actuales (valores cualitativos y cuantitativos bien establecidos), una pluviosidad mayor que la evaporación, con una pluviosidad anual mayor de $1.200 \mathrm{~mm}$, y con seis o menos meses <60 mm (TARDY et al., 1991; PRICE et al., 1997). La presencia de caolinita (figura 9.4) es indicativa de una meteorización química bajo condiciones húmedas en un clima tropical a subtropical (RUFFELL et al., 2002). El carbón (figura 9.4) es otro buen aproximador paleoclimático de áreas con una pluviosidad regular a escala anual y donde la precipitación supera a la evaporación (SELLWOOD Y PRICE, 1993; LOTTES Y ZIEGLER, 1994). En la subcuenca Cameros Occidental (Burgos-Soria) son frecuentes las capas de lignitos aptienses (IGME, 1984; IMINSA, 1984; BALTUILE-MARTÍN et al., 1987). Dentro de la Secuencia Deposicional 7 se han citado capas de lignito de poco espesor en la Formación Castrillo dela Reina (HUERTA et al., 2003) y en la Formación Abejar (CLEMENTE Y ALONSO, 1990). También existen algunas citas de lignitos en el Grupo Enciso (VIERA Y AGUIRREZABALA, 1982; MATA-PERELLÓ, 1984; VIERA et al., 1984; HERNÁNDEZ-SAMANIEGO et al., 1990b). Durante el levantamiento de las columnas estratigráficas no es infrecuente encontrar algunos niveles de lignito de escasa potencia (escala milimétrica) discontinuos o bien fragmentos carbonizados dispersos. En la colindante cuenca Vasco-Cantábrica son abundantes las citas de lignitos contemporáneos (GARCíA-GARMILLA Y BADILLOLARRIETA, 1989; ARNÁIZ et al., 1991; GARCÍA-BLANCO et al., 2004) (figura 9.4).

b) Incremento de la escorrentía y la meteorización continental (LABAT et al., 2004; BATES et al., 2008). De nuevo, esta tendencia se confirma en el registro aptiense tanto en la Placa Ibérica (NAJ ARRO et al., 2011a) como en el ámbito tetisiano (ERBA, 1994; FÖLLMI et al., 1994; FÖLLMI, 1995; WORTMANN et al., 2004).

c) Contracción de la extensión de la criosfera. En general se ha aceptado queel Aptiense fue una etapa sin masas de hielo importantes. Sin embargo, el debate sobre la ausencia de hielos permanentes no está completamente resuelto ya que existen evidencias que sugieren cierta persistencia de hielos en latitudes altas. Algunos Modelos de Circulación General sugieren la presencia de una capa de hielo en los polos durante el Aptiense (RAMSTEIN et al., 1997; FRAKES Y BARRON, 2001). La evidencia más aceptada a favor de la presencia de casquetes polares es la variación de gran amplitud y alta frecuencia del nivel del mar (GRÉSELLE Y PITTET, 2005; STEUBER et al., 2005; MAURER et al., 2013). En la propia Placa Iberia, BOVER-ARNAL et al. (2009) y PEROPADRE et al. (2013) admiten que las caídas del nivel del mar observadas en la Formación Villarroya de los Pinares (cuenca de Galve) podrían sugerir un control glacio-eustático. Sin embargo, durante el paso de una etapa de efecto invernadero a un hothouse, los episodios HEATT (Haline Euxinic Acidic Thermal 


\section{Modelo conceptual del paleolago Enciso}

Transgression) pueden causar transgresiones marinas detercer orden originadas por la expansión térmica delas aguas oceánicas (KIDDER Y WORSLEY, 2010), sin necesidad de un control glacio-eustático. Existen, además, aproximadores sedimentarios que sugieren la presencia de mantos de hielos en latitudes altas, aunque estas evidencias son más ambiguas. En Spitbergen se ha citado la presencia de glendonitas (KEMPER, 1987) así como clastos erráticos de posible origen glacial (PICKTON, 1981). En la Formación Chistopher (Aptiense superior-Albiense superior) de la cuenca Sverdrup situada en las islas canadienses árticas también se han encontrado glendonitas (FRAKES et al., 1995). Sin embargo, la mayoría de estas evidencias sedimentarias provienen de Australia. En la Formación Bulldog Shale (Aptiense-Albiense) de la cuenca Eromanga se han citado glendonitas (DE LURIO Y FRAKES, 1999) y posibles dropstones glaciales (FRANCIS Y FRAKES, 1993), aunque otros autores consideran que no existen evidencias claras de transporte por arrastre del hielo, pudiendo haber sido transportados por troncos (BENNETT Y DOYLE, 1996). En la Formación Wonthaggi de la cuenca Gippsland se han citado estructuras de crioturbación de edad Aptiense (CONSTANTINE et al., 1998), y acumulaciones de peces interpretadas como muertes en masa debidas a la congelación invernal de los lagos (WALDMAN, 1971). El estudio isotópico de concreciones carbonatadas en las cuencas Otway y Gippsland sugiere una temperatura media anual en torno a $-2^{\circ} \mathrm{C} \pm 5^{\circ} \mathrm{C}$, con posibilidad de condiciones favorables para la formación de hielos permanentes (GREGORY et al., 1989).

d) El escaso desarrollo de masas de hielo permanentes en los polos provoca un debilitamiento de la circulación general atmosférica, permitiendo un mayor desplazamiento latitudinal del cinturón anticiclónico subtropical, tal y como se observa en la actualidad (SEIDEL et al., 2008; LU et al., 2009; BIRNER, 2010). Muchos autores aceptan que, durante el Aptiense, este debilitamiento provocó un desplazamiento hacia los polos y un engrosamiento del cinturón tropical (ZIEGLER et al., 1987; FlUTEAU et al., 2007; KELLER et al., 2011; HASEGAWA et al., 2012). Sin embargo, un reciente trabajo sugiere que debido a las condiciones extremas de efecto invernadero (supergreenhouse), pudo en realidad producirse una contracción del cinturón tropical (HASEGAWA et al., 2012).

e) Las modelizaciones climáticas actuales sugieren que las altas temperaturas en la superficie del mar junto a los niveles elevados de $\mathrm{CO}_{2}$, favorecen una disminución de la frecuencia en los ciclones tropicales, a la vez que inducen un incremento de la intensidad de las precipitaciones así como un aumento en la cantidad de grandes huracanes (KNUTSON et al., 1998; WEBSTER et al., 2005; EMANUEL et al., 2008). A grandes rasgos, estas proyecciones se han observado en el registro geológico, con un gran desarrollo de depósitos asociados a ciclones tropicales durante el Cretácico (MARSAGLIA Y KLEIN, 1983; BARRON, 1989; AGUSTSDOTTIR et al., 1999), así como un incremento en su intensidad (ITO et al., 2001). Por consiguiente, es lógico suponer que un Tetis con temperaturas altas favorecería la formación de huracanes o tormentas tropicales que afectarían a la Placa Iberia, hecho que se ve refrendado en el registro geológico por la descripción de numerosos depósitos coetáneos asociados a grandes tormentas: en la cuenca de Las Parras (PEROPADRE et al., 2005; PEROPADRE et al., 2007), en la cuenca de Galve (BOvER-ARNAL et al., 2011) y en Cameros (DOUBLET, 2004). Por el contrario, no se observan depósitos de tormentas en la plataforma asturiana (ALONSO-GARCÍA Y BAHAMONDE, 2006).

A nivel más regional, el factor determinante del clima, durante la sedimentación del Grupo Enciso, fue la paleolatitud de la cuenca de Cameros. Aunque con ciertas diferencias e incertidumbres, todos los paleomapas consultados están de acuerdo en situarla durante el Aptiense inferior (anomalía M0) en una paleolatitud aproximada al paralelo 30ㅜ: variando según autores entre 28ㅇN (MASSE et al., 2000), 30ํN (FORD Y GOLONKA, 2001; NEUGEBAUER et al., 2001; STAMPFLI Y HOCHARD, 2009) y $32^{\circ} \mathrm{N}$ (SCOTESE Y DREHER, 2012). Otra fuente de información sobre la paleolatitud proviene de los datos paleomagnéticos. La relación entre la latitud $(\varphi)$ y la inclinación magnética (I) es:

$$
\operatorname{tg} I=2 \operatorname{tg} \varphi \leftrightarrow \varphi=\operatorname{arctg} \frac{\operatorname{tg} I}{2}
$$


Al utilizar esta fórmula en los valores de la inclinación magnética registrados en terrenos aptiense de la microplaca ibérica se obtienen paleolatitudes en consonancia: $28^{\circ} \pm 10^{\circ}$ en la cuenca Lusitana (GALDEANO et al., 1989), 28,9o en la cuenca de Algarve (MOREAU et al., 1997) y 33,70 (DiNARĖS-TURELl Y GARCÍA-SENZ, 2000) o 34,8o (GONG et al., 2008) en la cuenca de Orgaña. Por desgracia en el Grupo Enciso no se han realizado estudios detallados: sólo existe el dato de una única muestra AEC3 ( $\mathrm{I}=56,2^{\circ}$ ) (VILLALAÍN et al., 2003) que daría una paleolatitud de 36,8o. A efectos de la presente tesis el valor utilizado para el paleolago Enciso es de $32^{\circ} \mathrm{N}$ obtenido con el programa GPlates para la anomalía M0 (figura 9.6).

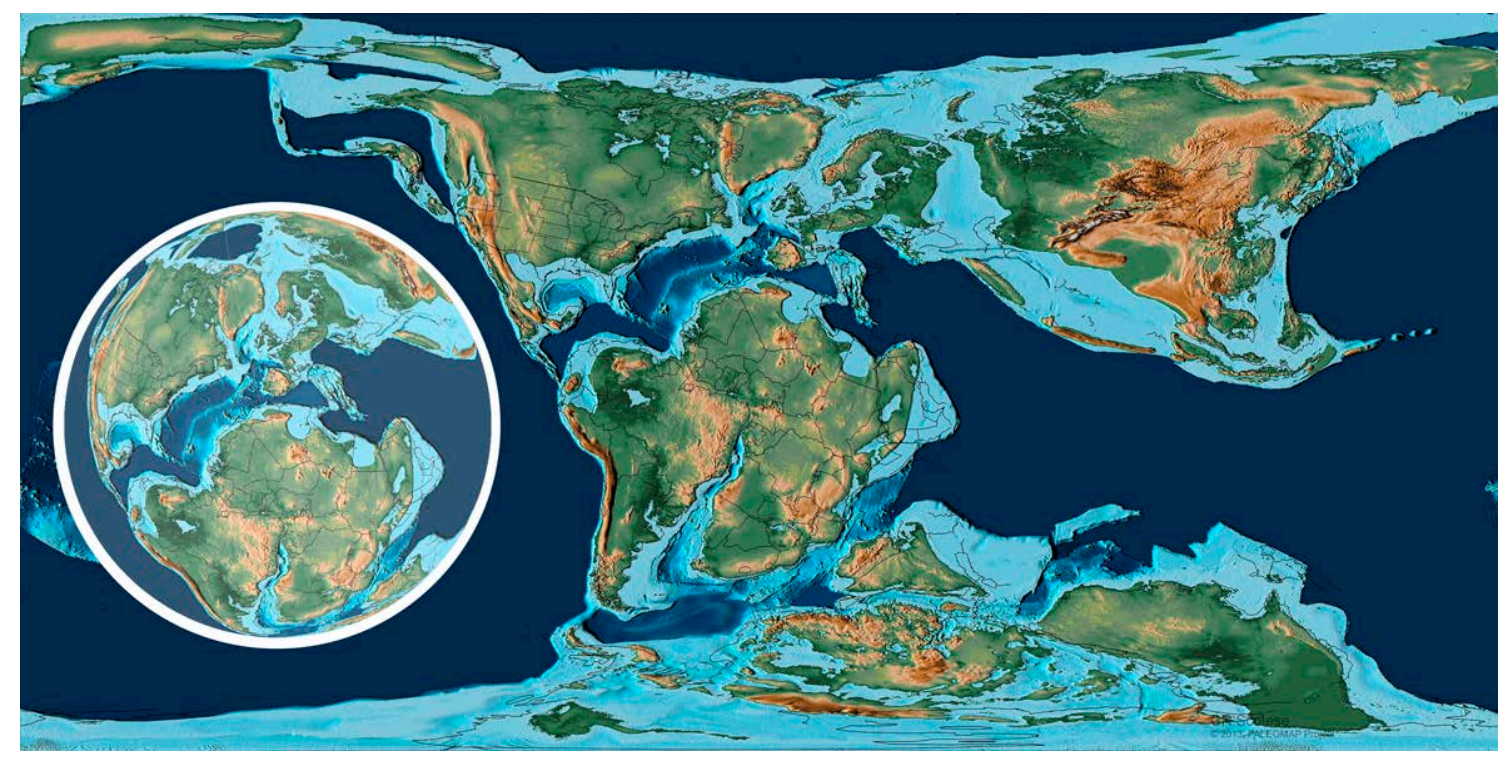

Figura 9.6: Mapa del Aptiense inferior según SCOTESE Y DREHER (2012)

Desde un enfoque puramente geográfico, la región tropical se limita a la zona comprendida entre el Trópico de Cáncer (latitud 23,5ㅇN) y el Trópico de Capricomio (latitud 23,5으). Sin embargo, desde una perspectiva climática, la región tropical (o área con clima tropical) se define como el área comprendida entre las regiones subtropicales de alta presión o cinturón de anticiclones subtropicales (latitud 30-35N N y S) (HENRY, 2005). Así pues, los 32ㅇN de paleolatitud obtenidos (con su error correspondiente) sugiere que la cuenca de Cameros podría haber estado localizada en la zona de anticiclones subtropicales aptienses. Estos anticiclones generan vientos divergentes (alisios y westerlies) que impiden la entrada de lluvias, así que cuando se asientan sobre los continentes favorecen la aridezy el desarrollo de grandes desiertos. En el registro geológico continental esta zona puede deducirse a partir de la posición de los depósitos eólicos (HASEGAWA et al., 2010; HASEGAWA et al., 2012). En el registro marino, la zona de los anticiclones subtropicales coincide con lo que tradicionalmente se ha denominado como ámbito boreal (VOIGT et al., 1999; HAY, 2008). Así pues, otro factor influyente en la climatología fue su pertenencia al dominio del Tetis donde el bioma tropical arquetipo marino (zona tropical) está constituido por los arrecifes coralinos (BEAUVAIS, 1992; VOIGT et al., 1999; ZIEGLER etal., 2003). Del mismo modo, las plataformas carbonatadas también suelen estar limitadas a las zonas tropicales tanto desde la actualidad como durante todo el Fanerozoico (KIESSLING et al., 2003). Por lo tanto, basándose en los datos sedimentarios y paleontológicos anteriormente comentados (indicadores de humedad) se puede admitir que la cuenca de Cameros no estuvo localizada sobre el cinturón de los anticiclones subtropicales. Por otra parte, la abundancia de depósitos aptienses, en los paleomárgenes de la placa Iberia, de plataformas carbonatadas y colonias de corales (FERNÁNDEZMENDIOLA Y GARCÍA-MONDÉJ AR, 1991; MALCHUS et al., 1995; VOIGT et al., 1999; LÖSER Y SALDAÑAVILLODRE, 2008; EMBRY et al., 2010), sugiere una evidente pertenencia al dominio tropical (figura 9.4).

Los datos de STEUBER et al. (2005) indican que esta paleolatitud registra los mayores extremos estacionales de temperatura. Sin embargo, gran parte de los restos paleoxilológicos 


\section{Modelo conceptual del paleolago Enciso}

descritos en Cameros durante este periodo muestran una acusada ausencia de anillos de crecimiento (DEL NIDO et al., 1998; GARCíA-ESTEBAN et al., 2006), sugiriendo un clima homogéneo sin estacionalidad (CREBER, 1977; CREBER Y CHALONER, 1985; CRABTREE, 1987). CHALONER Y CREBER (1990) definen, a partir del estudio de la paleoflora Mesozoica, un cinturón de temperaturas uniformes comprendido entre la latitud $32^{\circ} \mathrm{N}$ hasta $32^{\circ} \mathrm{S}$. Esta discrepancia, podría ser explicada por el denominado efecto lago (BATES et al., 1993; LAIRD et al., 2003). La presencia de una lámina de agua extensa (en el caso del presente estudio, estaría constituida tanto por el paleolago Enciso como por el brazo de mar tetisiano) comporta ciertas modificaciones de las condiciones atmosféricas a escala regional $(20-200 \mathrm{~km})$. El primer efecto modulador se debe a que la masa de agua aumenta la evaporación, por consiguiente constituye una fuente importante de humedad en su entorno. El segundo efecto es debido a la diferencia en el albedo e inercia térmica entre la masa de agua y la tierra colindante, favoreciendo la disminución del rango de temperaturas a escala diaria y anual. Durante el día, la evaporación produce una absorción de calor del entorno colindante (calor latente) que provoca un descenso de la temperatura diurna. Por el contrario, durantela noche la condensación del vapor conlleva el desprendimiento del calor almacenado aumentando la temperatura nocturna.

A modo de resumen, todas las evidencias presentadas en este apartado apuntan a un escenario climático cálido y húmedo de tipo tropical, donde la precipitación era mayor que la evaporación.

\subsection{BIOTA DEL PALEOLAGO ENCISO}

A continuación se sintetiza un listado de la biota típicamente lacustre encontrada hasta el momento en el Grupo Enciso a nivel de género. Algunas de estas referencias corresponden a citas que no han sido descritas o figuradas adecuadamente por lo que su asignación puede ser dudosa.

Los ostrácodos constituyen el grupo taxonómico más abundante. Las tres principales familias identificadas en el Grupo Enciso son Cyprideidae, Darwinulidae y Limnocytheridae. La primera está caracterizada por el género Cypridea (con un elevado número de especies endémicas), la segunda está representada por Darwinula, y la tercera por Theriosynoecum. En menor proporción, en algunos casos de manera anecdótica, se han citado Fabanella, Rhinocypris, Dictyocythere, Cyprideisy Cipria (KNEUPER-HAACK, 1966; SALOMON, 1973; BRENNER, 1976; CÁMARARUPELO Y DURÁNTEZ-ROMERO, 1981; GUIRAUD, 1983; HERNÁNDEZ-SAMANIEGO et al., 1990b; SCHUDACKY SCHUDACK, 2009).

Los bivalvos son abundantes con géneros representativos de dos órdenes. Los más diversificados pertenecen al Orden Unionoida con un predominio de las náyades (bivalvos de la superfamilia Unionoidea): Margaritifera (VIERA Y AGUIRREZABALA, 1982; AGURRREZABALA et al., 1985; DelVENE y ARAUJ O, 2009a), Unio (CAIZADA-BADÍA, 1977; VieRA Y TORRES, 1979; CÁMARARUPELO Y DURÁNTEZ-ROMERO, 1981; VIERA et al., 1984; AGUIRREZABALA et al., 1985), Teruella (CÁMARA-RUPELO Y DURÁNTEZ-ROMERO, 1981; AGUIRREZABALA et al., 1985), Elliptio ((CALZADABADÍA, 1977; AGUIRREZABALA et al., 1985), Tamesnella? (CÁMARA-RUPELO y DURÁNTEZ-ROMERO, 1981), y Cuneopsis (CÁMARA-RUPELO Y DURÁNTEZ-ROMERO, 1981). Las citas referentes a Unio idubedae se consideran Margaritifera idubedae según DELVENE Y ARAUJ O (2009a). El único género de los uniónidos no perteneciente a las náyades es Nippononaia (DELVENE Y MUNT, 2011). También

son numerosas las citas de bivalvos del Orden Veneroida, con dos representantes de la familia Neomiodontidae: Eomiodon (CAIZADA-BADÍA, 1977; VIERA YTORRES, 1979; VIERA Y AGUIRREZABALA, 1982; VIERA et al., 1984; AGUIRREZABALA et al., 1985; VIERA, 1991) y Neomiodon? (CÁMARA-RUPELOY DURÁNTEZ-ROMERO, 1981; DELVENE Y MUNT, 2011).

Los gasterópodos existentes pertenecen a tres superfamilias. La superfamilia Viviparoidea presenta dos géneros muy comunes, ambos de la familia Viviparidae: Viviparus (=Paludina) (SALOMON, 1973; VIERA YTORRES, 1979; AGUIRREZABALA et al., 1985) y Wealdenia (AGUIRREZABALA et al., 1985). La superfamilia Cerithiodea está representada por otros dos géneros: Paraglauconia (familia Cassiopidae) (AGUIRREZABALA et al., 1985; MENNESSIER y CALZADA, 1985; VIERA, 1991; DELVENE Y MUNT, 2011) y Cerithium (familia Cerithiidae) (CALZADA-BADÍA, 1977; VIERA et al., 1984; 
AGUIRREZABALA et al., 1985; VIERA, 1991). Por último, la superfamilia Epitonioidea está representada por el género Confusiscala (VIERA, 1991).

Los descubrimientos de restos de tiburones comienzan a ser significativos con dientes y restos óseos atribuibles a los géneros: Hybodus (VIERA et al., 1984; AGUIRREZABALA et al., 1985; VIERA, 1991; BERMÚDEZ-ROCHAS, 2006), Egertonodus (BERMÚDEZ-ROCHAS, 2006), Lonchidion (BERMÚDEZ-ROCHAS, 2006) y, Polyacrodus (BERMÚDEZ-ROCHAS, 2006).

Los restos de tortugas son escasos, habiéndose identificado Chitracephalus dumonii (= Salasemys pulcherrima) y Camerochelys vilanovai (VIERA Y TORRES, 1996; PÉREZ-GARCÍA, 2012; PÉREZ-GARCÍA et al., 2012; PÉREZ-GARCÍA Y MuRELAGA, 2013).

Respecto a los cocodrilos, aparte de los restos craneales de Goniopholis encontrados en el límite entre la Fm. Urbión D y el Grupo Enciso (MORATALLA et al., 1994; ORTEGA et al., 1996), se han citado Bernissartia (ORTEGA et al., 2010), así como numerosos restos dispersos sin mayores precisiones (VIERA et al., 1984; AGUIRREZABALA et al., 1985).

\subsection{CARACTERIZACIÓN MORFOMÉTRICA DEL PALEOLAGO ENCISO}

En este apartado se pretende estimar el mayor número posible de los parámetros morfométricos descritos en el apartado 4.9. Como ya se discutió con anterioridad, dichos parámetros ejercen un papel significativo en multitud de fenómenos fisicoquímicos en el sistema lacustre. En el ejemplo del paleolago Enciso, los valores que se pueden extraer son aproximativos y, en la mayoría de los casos, muchos de dichos parámetros son imposibles de calcular.

La primera cuestión que surge es determinar si el paleolago Enciso se estructuró en una única gran cubeta o podría tratarse de varias cubetas conectadas o aisladas entre sí. Las columnas levantadas indican que el Grupo Enciso presenta dos áreas depocentrales bien definidas (figura 6.1), sugiriendo que durante las etapas iniciales pudieron existir dos cubetas separadas por un paleoalto en la zona de Ambas Aguas. La cubeta occidental es la más extensay profunda (principal área depocentral), mientras que la cubeta oriental [cubeta de Cervera del Río Alhama sensu SALINASY MAS (1989; 1990)] exhibe una menor extensión y menor potencia de relleno (figura 9.7). Esta compartimentación en cubetas separadas por umbrales es común en muchos lagos rift (LAMBIASE Y BOSWORTH, 1995; TULLNER Y CSERNY, 2003).

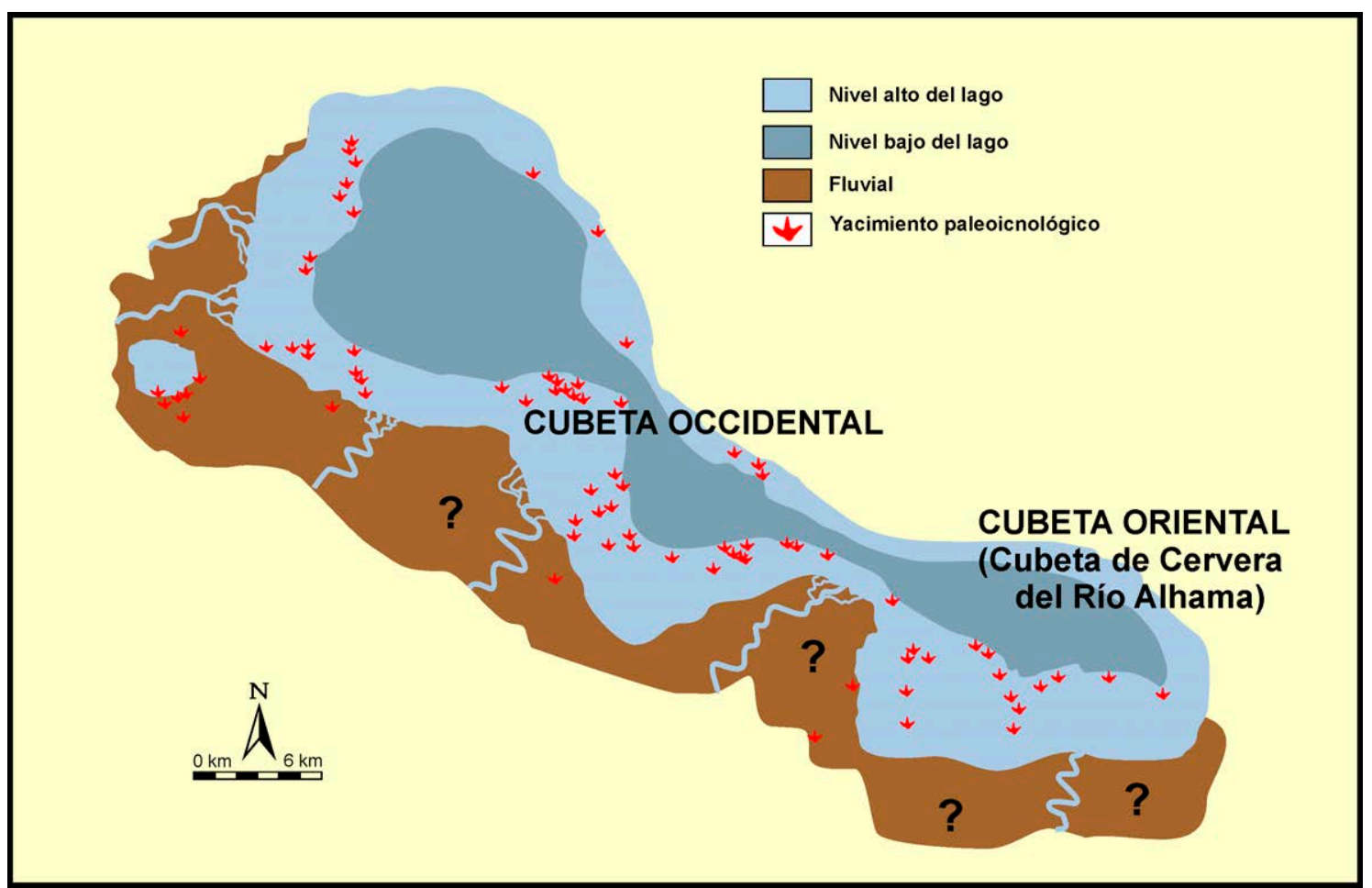




\section{Modelo conceptual del paleolago Enciso}

Figura 9.7: Representación del paleolago Enciso estructurado en dos áreas depocentrales bien definidas: la cubeta occidental y la cubeta oriental (o cubeta de Cervera del Río Alhama). Además se esboza la posible extensión del lago durante las etapas de retracción a partir de los yacimientos paleoicnológicos y las evidencias de emersión.

\subsection{1Área superficial}

A partir de los datos cartográficos publicados a día de hoy (figura 3.6), se puede asumir un paleolago Enciso cuyo margen $\mathrm{N}-\mathrm{NE}$ estaría claramente delimitado por el actual cabalgamiento norcamerano, ya que no aparecen sedimentos del grupo Enciso en los sondeos realizados en la depresión del Ebro (LANAJA, 1987). También se puede establecer con precisión su borde NO por cambio lateral de facies hacia los sistemas fluviales del Grupo Urbión D (MAS et al., 2002), y su margen SE por constituir el límite de la cuenca (GUIMERÀ et al., 2004). Así pues, sólo quedaría por delimitar su margen sur. Parece justificado asumir que gran parte del Grupo Enciso en el sector meridional ha sido erosionado (MATA et al., 2001; CASAS et al., 2009). Además, teniendo en cuenta que la línea de costa meridional parece ser más o menos paralela a los actuales afloramientos, según DOUBLET (2004) y observaciones propias, podría deducirse la extensión a partir de los afloramientos disponibles. Los resultados obtenidos indican un paleolago Enciso ocupando una extensión próxima a los $420 \mathrm{~km}^{2}$. En las etapas de retracción del sistema lacustre pudo alcanzar un área superficial de unos $200 \mathrm{~km}^{2}$, estimados a partir de los yacimientos icnológicos más septentrionales del margen meridional y los yacimientos más meridionales del borde norte, así como por la presencia grietas de desecación en posiciones muy centrales de la cubeta lacustre (figura 9.7). Durante estas etapas regresivas es difícil establecer si permanecía como un cuerpo lacustre único o bien como varias masas de agua separadas entre sí como ocurre en el lago Chad (ROCHE, 1977; DUMONT, 1992). En ambos casos, como no se ha tenido en cuenta la deformación y plegamiento se puede asumir que son valores conservadores. Para la determinación del área se ha utilizado el programa Global Mapper y la cartografía geológica PLAN GEODE a escala 50.000 disponible en SIGECO (Sistema de Consulta y Difusión Web de Cartografía Geológica Continua) del IGME. El valor límite propuesto por HERDENDORF (1982) como típico de un lago grande es cuando posee un espejo de más de $500 \mathrm{~km}^{2}$.

\subsubsection{Profundidad}

Para la determinación dela paleobatimetría del paleolago Enciso se han seleccionado dos métodos: el primero, a partir del estudio de las rizaduras de oscilación (DIEM, 1985) y el segundo, a partir de secciones descompactadas completas de deltas (DEVRIES-KLEIN, 1974).

El estudio de 73 trenes de rizaduras (la metodología detallada está descrita en el anexo XVII) indica un lago unos valores medios de la profundidad máxima de: 3,0 $\pm 0,5 \mathrm{~m}(\mathrm{n}=5)$ en la sección de Munilla, 1,6 $\pm 0,3 \mathrm{~m}(\mathrm{n}=21)$ en la columna de Enciso y, 2,5 $\pm 0,4 \mathrm{~m}(\mathrm{n}=47)$ en Cornago (tabla 9.1). Esta profundidad así calculada es representativa de la profundidad de la zona de influencia del oleaje (dominio litoral), más que de la profundidad en sí de la cubeta.

Por otra parte, se han descompactado tres secciones completas de deltas lacustres: dos en la columna de Cornago y otra en la sección de Enciso. Para estar seguros deobtener una medida de la profundidad real se han utilizado secciones deltaicas que se apoyan sobre facies profundas, así se asegura que el cálculo se realiza en un delta que alcance las partes centrales del lago y que la medida sea más exacta. Estas secciones se han descompactado siguiendo la metodología explicada en el anexo XVI. La primera corresponde a los tramos 256-263 de la columna de Cornago que con una potencia de 9,6 $\mathrm{m}$ da un valor descompactado de 18,5 m. La otra medida en Cornago corresponde a la zona del yacimiento icnológico Los Cayos E (tramos 308-317) con una potencia inicial de 11,5 m que descompactada determina una profundidad de 23,8 m. Finalmente, la sección de Enciso (tramos 441-445) establece una profundidad de 5,2 m partiendo de una potencia inicial de $2,5 \mathrm{~m}$.

Si se utiliza el diagrama ETA (apartado 4.3.3), se obtiene un valor $\mathrm{D}_{\text {T-A }}$ (que sería equivalente a la zona límite entre el dominio litoral y sublitoral—profundo de 18,4 m en Munilla, 10,7 m en Enciso y 5,0 m en Cornago. 
Modelo conceptual del paleolago Enciso

\begin{tabular}{|c|c|c|c|c|c|c|c|}
\hline Muestra & Columna & $\mathrm{D}(\mu \mathrm{m})$ & $\lambda(\mathrm{cm})$ & Profundidad mínima $(\mathrm{m})$ & Profundidad máxima $(m)$ & $T_{\text {mínimo }}(s)$ & $T_{\text {máximo }}(\mathrm{s})$ \\
\hline Tramo 346 (estrato inferior) & \multirow{5}{*}{$\underset{\sum}{\stackrel{\Xi}{\Xi}}$} & 120 & 4,3 & 0,007 & 2,38 & 0,77 & 1,78 \\
\hline \multirow{2}{*}{ Tramo 346 (estrato superior) } & & \multirow{2}{*}{220} & 5,6 & 0,011 & 2,46 & 0,88 & 1,86 \\
\hline & & & 6,1 & 0,011 & 2,84 & 0,92 & 1,99 \\
\hline $\operatorname{Tramo}_{366}$ & & 100 & 6,1 & 0,008 & 4,80 & 0,92 & 2,42 \\
\hline Tramo 39 columna San Vicente XI-XIII & & 220 & 5,5 & 0,011 & 2,38 & 0,87 & 1,84 \\
\hline \multirow{10}{*}{ Tramo $445\left(\mathrm{NgO}^{\circ} \mathrm{E}\right)$} & \multirow{21}{*}{ 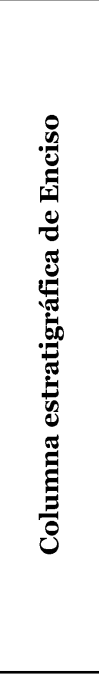 } & \multirow{10}{*}{130} & 2,1 & 0,005 & 0,67 & 0,54 & 1,02 \\
\hline & & & 1,8 & 0,005 & 0,52 & 0,50 & 0,91 \\
\hline & & & 2,3 & 0,005 & 0,78 & 0,56 & 1,09 \\
\hline & & & 2,5 & 0,006 & 0,90 & 0,59 & 1,16 \\
\hline & & & 2,3 & 0,005 & 0,78 & 0,56 & 1,09 \\
\hline & & & 1,9 & 0,005 & 0,57 & 0,51 & 0,94 \\
\hline & & & 2 & 0,005 & 0,62 & 0,53 & 0,98 \\
\hline & & & 1,9 & 0,005 & 0,57 & 0,51 & 0,94 \\
\hline & & & 2 & 0,005 & 0,62 & 0,53 & 0,98 \\
\hline & & & 1,4 & 0,004 & 0,33 & 0,44 & 0,75 \\
\hline \multirow{4}{*}{$\operatorname{Tramo} 445\left({\left.\mathrm{~N} 180^{\circ} \mathrm{E}\right)}^{2}\right.$} & & \multirow{4}{*}{130} & 2,6 & 0,006 & 0,97 & 0,60 & 1,19 \\
\hline & & & 2,6 & 0,006 & 0,97 & 0,60 & 1,19 \\
\hline & & & 2,4 & 0,006 & 0,84 & 0,58 & 1,13 \\
\hline & & & 2,3 & 0,005 & 0,78 & 0,56 & 1,09 \\
\hline & & & 2,9 & 0,004 & 1,96 & 0,63 & 1,57 \\
\hline & & & 3,7 & 0,005 & 2,93 & 0,72 & 1,89 \\
\hline Tramo 25 columna El Villar-Poyales & & 60 & 3,4 & 0,004 & 2,55 & 0,69 & 1,77 \\
\hline & & & 3,7 & 0,005 & 2,93 & 0,72 & 1,89 \\
\hline & & & 3,5 & 0,005 & 2,67 & 0,70 & 1,81 \\
\hline Tramo 29 columna El Villar-Poyales & & 80 & 5,6 & 0,007 & 4,82 & 0,88 & 2,40 \\
\hline 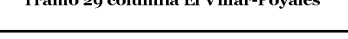 & & 80 & 5,7 & 0,007 & 4,96 & 0,89 & 2,43 \\
\hline & & & 7,8 & 0,010 & 6,07 & 1,04 & 2,72 \\
\hline Tramo 100 (estrato inferior) & & 130 & 6,7 & 0,009 & 4,72 & 0,96 & 2,43 \\
\hline & & & 9,2 & 0,011 & 7,98 & 1,13 & 3,08 \\
\hline & & & 4,3 & 0,005 & 3,76 & 0,77 & 2,11 \\
\hline & & & 4,8 & 0,005 & 4,51 & 0,81 & 2,30 \\
\hline Tramo 100 (estrato superior) & & 60 & 4,5 & 0,005 & 4,05 & 0,79 & 2,19 \\
\hline & & & 5,2 & 0,005 & 5,14 & 0,85 & 2,44 \\
\hline & & & 4,5 & 0,005 & 4,05 & 0,79 & 2,19 \\
\hline & & & 2,7 & 0,007 & 0,76 & 0,61 & 1,10 \\
\hline & & & 3,6 & 0,008 & 1,24 & 0,71 & 1,37 \\
\hline & & & 2,7 & 0,007 & 0,76 & 0,61 & 1,10 \\
\hline & & & 3,3 & 0,008 & 1,07 & 0,68 & 1,28 \\
\hline & & & 2,9 & 0,008 & 0,86 & 0,63 & 1,16 \\
\hline & & & 3,2 & 0,008 & 1,02 & 0,67 & 1,25 \\
\hline & & & 1,9 & 0,006 & 0,41 & 0,51 & 0,85 \\
\hline & & & 2,5 & 0,007 & 0,67 & 0,59 & 1,04 \\
\hline & 8 & & 2,3 & 0,007 & 0,58 & 0,56 & 0,98 \\
\hline & שี & & 1,8 & 0,006 & 0,38 & 0,50 & 0,81 \\
\hline & 0 & & 2,1 & 0,007 & 0,49 & 0,54 & 0,91 \\
\hline & 己ૅ & & 2,5 & 0,007 & 0,67 & 0,59 & 1,04 \\
\hline Tramo 17 b (tramo 40 columna Cayos A) & تِ & 200 & 3,3 & 0,008 & 1,07 & 0,68 & 1,28 \\
\hline & త్ర & & 3,4 & 0,008 & 1,13 & 0,69 & 1,31 \\
\hline & 番 & & 3,0 & 0,008 & 0,91 & 0,64 & 1,19 \\
\hline & 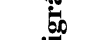 & & 3,1 & 0,008 & 0,96 & 0,65 & 1,22 \\
\hline & 矛 & & 2,6 & 0,007 & 0,71 & 0,60 & 1,07 \\
\hline & $\frac{E}{0}$ & & 1,7 & 0,006 & 0,34 & 0,48 & 0,78 \\
\hline & 2 & & 2,0 & 0,006 & 0,45 & 0,53 & 0,88 \\
\hline & 沓 & & 2,1 & 0,007 & 0,49 & 0,54 & 0,91 \\
\hline & 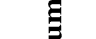 & & 2,4 & 0,007 & 0,62 & 0,58 & 1,01 \\
\hline & $\frac{5}{0}$ & & 1,4 & 0,006 & 0,24 & 0,44 & 0,67 \\
\hline & & & 2,1 & 0,007 & 0,49 & 0,54 & 0,91 \\
\hline & & & 2,0 & 0,006 & 0,45 & 0,53 & 0,88 \\
\hline & & & 1,4 & 0,006 & 0,24 & 0,44 & 0,67 \\
\hline & & & 4,4 & 0,007 & 2,34 & 0,78 & 1,77 \\
\hline Tramo 195 & & 130 & 4,5 & 0,008 & 2,43 & 0,79 & 1,80 \\
\hline & & & 4,3 & 0,007 & 2,25 & 0,77 & 1,74 \\
\hline Tramo 309 (tramo 4 columna Cayos E) & & 130 & 7,6 & 0,010 & 5,82 & 1,03 & 2,67 \\
\hline & & & 2,0 & 0,005 & 0,62 & 0,53 & 0,98 \\
\hline Tramo 317 (tramo 28 columna Cayos E) & & 130 & 2,0 & 0,005 & 0,62 & 0,53 & 0,98 \\
\hline & & & 1,8 & 0,005 & 0,52 & 0,50 & 0,91 \\
\hline Tramo 321a (estrato inferior) & & 130 & 7,2 & 0,010 & 5,32 & 1,00 & 2,56 \\
\hline Tramo $321 \mathrm{a}$ (estrato superior) & & 130 & 9,5 & 0,011 & 8,41 & 1,15 & 3,16 \\
\hline 1Famo 321 (estrato superior) & & 130 & 9,6 & 0,011 & 8,56 & 1,15 & 3,18 \\
\hline Tramo 28 columna Cayos E nuevo & & 220 & 13 & 0,017 & 10,02 & 1,34 & 3,50 \\
\hline & & & 13 & 0,017 & 10,02 & 1,34 & 3,50 \\
\hline Tramo 29 columna Cayos E nuevo & & 130 & 4,2 & 0,007 & 2,17 & 0,76 & 1,71 \\
\hline Tramo 29 columna Cayos É nuevo & & 130 & 4,5 & 0,008 & 2,43 & 0,79 & 1,80 \\
\hline
\end{tabular}

Tabla 9.1: Rango de profundidades máximas y mínimas obtenidos a partir del estudio de las rizaduras de oscilación. También se muestra los períodos (T) máximos y mínimos calculados. 


\section{Modelo conceptual del paleolago Enciso}

$\mathrm{Al}$ aplicar la formulación de la profundidad límite de deposición del fango para unas pendientes comprendidas entre $0-5 \%$ (apartado 4.3.3), se obtienen unos valores quevarían entre 5,7-12,0 m en Munilla, 3,1-6,7 m en Enciso, y 1,6-3,4 m en Cornago.

Los valores del alcance efectivo se han calculado según la metodología descrita por HÅKANSON (1981a), con ayuda de la cartografía existente y el programa SIG Global Mapper 13. En la sección de Munilla se obtiene un valor de 14,4 km, en Enciso de 6,5km y en Cornago de 2,6km.

Otras evidencias que apuntan hacia la poca profundidad del paleolago Enciso y que refuerzan los datos de profundidades obtenidos por criterios sedimentarios son:

a) Las pendientes suaves de las regresiones isotópicas indican un ratio muy alto entre el área superficial y la profundidad (TALBOT, 1990; CAMOIN et al., 1997) (figuras $7.7 \mathrm{y}$ 7.11).

b) La presencia de una vegetación hidrófila dominada por limnófitos (carófitas) con unos límites de profundidad entre 10-15 m (GARCÍA, 1994; MIDDELBOE Y MARKAGER, 1997).

c) MURPHY Y WILKINSON (1980) y FREYTET (1984) consideran que los ostrácodos son organismos frecuentes en lagos poco profundos. Darwinula, por ejemplo, es un género típico de aguas someras: en los lagos recientes vive a profundidades de $0-12$ m con un máximo desarrollo a 6 m (MEISCH, 2000).

d) La mayoría de los bivalvos de agua dulce ocupan hábitats someros (1-5 m) aunque en ocasiones puedan vivir a mayor profundidad si el agua está bien oxigenada (CUMMINGS Y GRAF, 2010). Elliptio complanata ocupa ambientes lacustres someros, en general, a profundidades menores de 3-5 m (MATTESON, 1948; GHENT et al., 1978; AMYOT Y DOWNING, 1991; CYR, 2008), aunque pueden alcanzar profundidades de hasta $12 \mathrm{~m}$ (GHENT et al., 1978). Margaritifera margaritifera prefiere profundidades entre 0,5-2 m (ZIUGANOV et al., 1994).

e) La masividad delos sedimentos estudiados. A partir del análisis de 297 lagos, LARSEN et al. (1998) obtuvieron una relación empírica que permite obtener la profundidad umbral máxima donde el sedimento depositado es siempre masivo [ $\mathrm{P}_{\text {crítica }}=3 \cdot \mathrm{A}^{0,294}$ ], donde $\mathrm{P}$ es la profundidad umbral o crítica (m) y A es el área superficial (Ha). Para un espejo del paleolago Enciso estimado entre $200-420 \mathrm{~km}^{2}$ se obtiene una $P_{\text {crítica }}$ de 55,2-68,6 m. La abundante masividad existente en los sedimentos estudiados, sugiere una profundidad del paleolago siempre por debajo de estos valores.

f) Otro criterio de la someridad de la masa de agua proviene del estudio de las direcciones preferentes de las icnitas de dinosaurios que sugieren etapas que permitieron el paso de los dinosaurios a través del paleolago (MORATALLA Y HERNÁN, 2010).

g) El predominio de las (asociaciones de) facies relacionadas al dominio litoral con respecto a las de ambientes pelágicos (profundos).

\subsubsection{Pendiente o gradiente topográfico}

La cuenca de Cameros estaba dispuesta como una rampa basculada hacia el nordeste configurando una paleotopografía con una pendiente suave hacia el borde de cuenca nororiental (ALONSO Y MAS, 1993). DOUBLET (2004), en su tesis doctoral, estima una pendiente media para el paleolago Enciso de aproximadamente un 0,5\%. En general, existen indicios sedimentarios que apuntan a una topografía con un bajo gradiente deposicional de la cubeta, aunque ninguno es determinante:

a) El margen sur y norte muestra una topografía deposicional muy suave caracterizada por extensos bancos de depósitos finos con un amplio desarrollo de evidencias de exposición subaérea (icnitas, grietas de retracción, etc.), indicando reiteradas fluctuaciones de la lámina de agua afectando a extensas áreas de la cubeta.

b) Las grietas de retracción indican también áreas con poca pendiente. La casi totalidad de las grietas encontradas están constituidas por un patrón de polígonos cerrados (pentágonos, hexágonos) (figuras 5.25 y 5.30) sin mostrar el patrón ortogonal 
orientado característico de pendientes mayores de 5o (DONOVAN Y ARCHER, 1975). Sólo en un afloramiento se ha observado grietas de tipo ortogonal.

c) En el lago Littlefield, la sedimentación se produce en bancos de cierta inclinación en los cuales se ha observado que los talos de carófitas (Chara) se disponen de manera paralela a la pendiente (MURPHY Y WILKINSON, 1980). En los niveles con restos de talos de carófitas del paleolago Enciso no se ha observado ninguna orientación preferente lo que sugiere una paleopendiente deposicional pequeña.

\subsection{GEOLOGÍA DE LA CUENCA DE DRENAJ E}

Respecto al relieve en las áreas adyacentes a la cuenca de Cameros, parece haber estado caracterizado por extensas superficies con un relieve residual suave o de escasa entidad, es decir, con una total ausencia de grandes sistemas montañosos:

a) Las intrusiones marinas reconocidas en la Formación Leza (ALONSO Y MAS, 1993; SUÁREZ-GONZÁLEZ et al., 2013; SUÁREZ-GONZALEZ et al., 2015), así como la presencia de depósitos marinos aptienses en zonas marginales de la cuenca como en las cercanías del Moncayo (ALONSO y MAS, 1988; GUIMERÀ et al., 2004) o en el labio levantado septentrional de la propia cuenca de Cameros (ARRIBAS et al., 2009), indican una cota cercana a la del nivel del mar.

b) La paleotopografía heredada del J urásico superior parece haberse caracterizado por plataformas (AURELL et al., 2003) que homogeneizaron y nivelaron todo el relieve creado durante la primera etapa rift Pérmico final-Triásico (SALAS et al., 2001).

c) Las principales áreas emergidas estaban constituidas por el Macizo del Ebro y el Macizo Ibérico, ambas con poca elevación. En general, a escala global, algunos autores asumen un paleorrelieve menor que el actual con una elevación continental media unos 100-200 m menor que la media actual (DONNADIEU et al., 2006; FLUTEAU et al., 2007).

Para la sedimentación acontecida durante la Secuencia Deposicional 7, se han determinado varias áreas madre. La más importante se situaría hacia el oeste, en la zona de Burgos, y estaba constituida las rocas cristalinas granítico-néisicas del basamento Paleozoico (ARRIBAS et al., 2003). También se han citado otro área de menor entidad y de ámbito local en la zona norte de la cuenca donde es probable que estuvieran exhumados, al menos localmente, los depósitos del Keuper (ALONSO-AZCÁRATE et al., 2005) y más extensamente los carbonatos J urásicos (ALONSO Y MAS, 1993). Por otra parte, la ausencia en el borde norte de las zonas de ostrácodos Encisiensis y Demandae (KNEUPER-HAACK, 1966; GUIRAUD, 1983) podría indicar cierto canibalismo de los materiales inferiores del Grupo Enciso o su no deposición.

Una acumulación de sedimentos carbonatados tan potente y extensa lateralmente como la acontecida en el paleolago Enciso sugiere un área madre rica en rocas carbonatadas, probablemente localizada en el jurásico. En el ámbito del Sistema de Rift Mesozoico Ibérico existen numerosos ejemplos de lagos carbonatados con áreas madre jurásicas: la Sierra de Altomira (PEROPADRE Y MELÉNDEZ, 2004), la Fm. La Huérguina (GÓMEZ-FERNÁNDEZY MELÉNDEZ, 1991; FREGENAL-MARTÍNEZ Y MELÉNDEZ, 1993), la Fm. Artoles (MELÉNDEZ Y SORIA, 1999), la Fm. Aguilón (SORIA et al., 1997; MELÉNDEZ et al., 2000b), y la Fm. Blesa (MELÉNDEZ et al., 2000a).

Otro aspecto interesante es la relación entre la cuenca de drenaje y el área del espejo de la cubeta lacustre. Una primera aproximación, basada en los modernos lagos rift, indicaría que dicha área de drenaje estaría limitada a la propia cuenca de Cameros. La relación entre el área de drenaje (aproximadamente $5.500 \mathrm{~km}^{2}$ ) y la cubeta del paleolago Enciso $\left(200-420 \mathrm{~km}^{2}\right)$ se estima entre 27,5-13,1, cercano al rango obtenido para los lagos rift actuales (apartado 4.8). Si se utiliza la fórmula obtenida para el cálculo de la superficie teórica del área de drenaje a partir del análisis de 81 lagos (sub)tropicales (apartado 4.8), se obtiene que el área de drenaje teórica para el paleolago Enciso estaría comprendida entre $2.756-5.316 \mathrm{~km}^{2}$, sugiriendo que durante las etapas altas del lago, el valor del área madre coincide a grandes rasgos con el valor de toda la cuenca de Cameros $\left(5.500 \mathrm{~km}^{2}\right)$. 


\section{Modelo conceptual del paleolago Enciso}

En una cuenca con tantas áreas madre regionales es posible que las fluctuaciones entre las etapas con sedimentación siliciclástica y carbonatada tengan su origen en desplazamientos del área fuente. Son numerosos los ejemplos en los cuales una sutil actividad tectónica puede ejercer un control importante en la cuenca de drenaje (KOWALEWSKA Y COHEN, 1998; MAY et al., 1999; SÁEZ et al., 1999).

\subsection{HIDROLOGÍA}

\subsubsection{Modo de abastecimiento}

Con respecto al abastecimiento de agua en el paleolago Enciso, basándose en los datos disponibles, se pueden hacer las siguientes suposiciones:

La cercanía del brazo de mar tetisiano (ALONSO y MAS, 1988; GUIMERÀ et al., 2004) y la presencia de escasos fósiles talásicos sugieren ocasionales entradas del mar que podrían contribuir a la componente epigénica.

Por otra parte, en un paleolago como Enciso, un sistema lacustre tropical a poca altitud y sometido a un efecto invernadero importante, los aportes meteóricos serían muy importantes limitándose a las aguas pluviales, obviándose por supuesto los aportes por nieve e hielo. Los datos paleoclimáticos (apartado 9.2) indican numerosas precipitaciones y un aumento dela escorrentía, lo cual sugiere abundancia de aguas superficiales meteóricas. Además, los datos isotópicos aptienses sugieren que las plantas existentes eran de tipo $C_{3}$, ya que las plantas tipo $C_{4}$ se desarrollaron con posterioridad (apartado 7.5.1). Así pues la ausencia de plantas de tipo $C_{4}$, entre las cuales se incluyen las actuales herbáceas, pudo favorecer una mayor erosión y escorrentía que la existente en la actualidad (SCHUMM, 1968).

Por criterios estratigráficos, cambio lateral de facies entre el Grupo Urbión D y Grupo Enciso según MAS et al. (2002), es posible suponer un aportede agua de tipo axial sensu TIERCELIN et al. (1992)) desde el extremo NO (área del Camero Viejo).

En cuanto a los aportes de tipo lateral, es conveniente diferenciar dos etapas lacustres que se repiten en la vertical: lagos carbonatados y lagos siliciclásticos. En principio, es lógico pensar que los sedimentos detríticos (siliciclásticos) sean aportados por las aguas superficiales mientras que los sedimentos químicos (carbonatos) sean transportados por aguas tanto epigénicas (como carga de fondo, en suspensión o en disolución) como hipogénicas.

a) Durante las etapas lacustres carbonatadas, la casi total ausencia de sedimentos detríticos sugiere que los aportes fluviales eran mínimos. Los paquetes carbonatados se pueden seguir multitud de kilómetros sin que aparezcan intercalados dispositivos canalizados siliciclásticos de entidad. La presencia de carbonatos con cierto contenido en detríticos (sobre todo cuarzo y mica) o bien pequeños niveles siliciclásticos intercalados entre los carbonatos sugieren aportes por flujos no canalizados de manera episódica.

b) Sin embargo, durante las etapas lacustres siliciclásticas parece evidente que el abastecimiento fluvial fue de gran importancia. El abundante registro de canales fluviales, cinturones de avulsión y de depósitos deltaicos indican la presencia de una escorrentía superficial significativa.

Así pues, el abastecimiento por aguas superficiales debido al aporte lateral parece haber variado entre abundante (etapas siliciclásticas) a escaso o episódico (etapas carbonatadas), y entre canalizado a mantos de arroyada (flujos no canalizados).

Además, durante las etapas lacustres carbonatadas, la gran abundancia de carbonatos mudstone-wackestone (poca permeabilidad) y la relativa abundancia de materia orgánica (hidrofóbica) parecen sugerir una limitada posibilidad de aportes subterráneos en el paleolago Enciso. Sin embargo, la ausencia de covarianza entre $\delta^{18} \mathrm{O}$ y $\delta^{13} \mathrm{C}$ en algunas secciones 


\section{Modelo conceptual del paleolago Enciso}

muestreadas no permite excluir la existencia de alguna etapa con cierta entrada de aguas subterráneas (figuras 7.7 y 7.11).

\subsubsection{Modo de drenaje}

A partir de lo comentado en el apartado 4.10.2, los depósitos del paleolago Enciso muestran numerosas evidencias propias de una sedimentación lacustre acontecida en una cuenca hidrológicamente cerrada:

a) Numerosas secuencias sedimentarias lacustres transgresivas-regresivas (apartado 6.5).

b) Frecuentes intercalaciones entre depósitos lacustres y fluviales (capítulos 6).

c) Amplio rango de variación en los valores $\delta^{18} \mathrm{O}$ que se asignan a etapas de fuerte evaporación de las aguas del lago (figuras 7.7y 7.11).

d) Covarianza entre los valores de $\delta^{18} \mathrm{O}$ y $\delta^{13} \mathrm{C}$ en ciertas secciones (figuras 7.7 y 7.11).

e) Amplias fluctuaciones de la salinidad de sus aguas (apartado 9.7.1).

f) Incremento de la concentración iónica con el paso del tiempo.

g) Baja icnodiversidad relacionada con superficies indicadoras de exposición subaérea (grietas de desecación, rasgos pedogenéticos, etc.).

h) La abundancia de Darwinula es considerada como un indicador de descarga de agua subterránea (SCHWALB, 2003).

\subsubsection{Hidroperíodo}

El paleolago Enciso muestra ciertos caracteres indicadores de una persistencia permanente de la masa de agua, con ciertas adaptaciones a etapas de desecación parcial.

La presencia de calizas, escaso lignito (materia orgánica), rizolitos y grietas de retracción permite inducir un hidroperíodo aproximado de $>225$ días en las zonas litorales con un índice de exposición <38\%, según el cuadro desarrollado por PLATT Y WRIGHT (1992) (figura 4.7).

Las asociaciones de ostrácodos pueden utilizarse para discernir entre cuerpos de aguas temporales o permanentes. Los grandes cuerpos dulceacuícolas permanentes de Australia muestran una asociación característica de ostrácodos: Darwinula, Gomphocythere, Limnocythere y Bennelongia (DE DECKKER, 1983). Además, la actual Darwinula stevensoni no es resistente a la desecación, prefiriendo los lagos permanentes (RANTA, 1979). La asociación de ostrácodos encontrada en el paleolago Enciso, a nivel de familia, es muy similar a la presente en los actuales lagos permanentes australianos (apartado 9.3). Los ostrácodos del género Cypridea se consideran un indicador de cierta temporalidad en la masa de agua ya que son capaces de poner huevos resistentes a la desecación. Por el contrario, se admite que Darwinula y Theriosynoecum no tenían esa capacidad y, por consiguiente, estaban confinados a cuerpos de agua permanentes. Bajo esta perspectiva, HORNE (1995; 2002) reexamina los ciclos faunísticos del Purbeck-Weald inglés, y considera que podrían indicar la persistencia de la masa de agua, en última instancia forzados por el clima. Así pues, la asociación dominada por Cypridea (fase C) representa cuerpos de agua efímeros mientras que la asociación dominada por Darwinula y Theriosynoecum (fase S) está confinada a masas de agua permanentes.

La existencia de un gran número de invertebrados que requieren la presencia de masas de aguas perennes tales como las náyades (GoOD, 2004) (apartado 9.3) sugiere de nuevo aguas permanentes. Sin embargo, hay que tener en cuenta que en la actualidad, algunos bivalvos, sobre todo los que viven en los trópicos, muestran ciertas adaptaciones a etapas de emersión prolongadas (CUMMINGS Y GRAF, 2010), en algunos casos sobreviviendo hasta 12 meses (DANCE, 1958).

La presencia de oogonios fósiles de carófitas sugiere cierta persistencia del cuerpo de agua, siempremayor detres meses que es el tiempo mínimo necesario para su desarrollo (SoULIÉMÄRSCHE, 1991). 


\section{Modelo conceptual del paleolago Enciso}

\subsection{HIDROQUÍMICA}

Sobre la mineralización de las aguas del paleolago Enciso se pueden hacer algunas precisiones iniciales.

La sílice puede ser importante, sobre todo en lagos dominados por las diatomeas, aunque su trascendencia en el paleolago Enciso (Aptiense) se puede considerar nula, ya que las diatomeas lacustres más antiguas están datadas como Maastrichtiense (CHACÓN-BACA et al., 2002; AMBWANI et al., 2003; SiNGH et al., 2006).

Durante el Aptiense, el océano se caracterizó por ser del tipo denominado como "mar de calcita" (LOWENSTEIN et al., 2003; BERNER, 2004) con un enriquecimiento en $\mathrm{Ca}^{2+}$. A partir del estudio de inclusiones fluidas en halitas de la Formación Muribeca (cuenca Sergipe, Brasil), se ha estimado un valor $\mathrm{m}\left(\mathrm{Ca}^{2+}\right)$ de $32-39 \mathrm{mmol} / \mathrm{kg} \mathrm{H}_{2} \mathrm{O}$, aproximadamente unas tres veces mayor que en la actualidad ( $11 \mathrm{mmol} / \mathrm{kg} \mathrm{H} 2 \mathrm{O}$ ), y una relación $\mathrm{m}\left(\mathrm{Mg}^{2+}\right) / \mathrm{m}\left(\mathrm{Ca}^{2+}\right)$ comprendida entre 1,11,3, siendo 5,2 el valor actual (TIMOFEEFF et al., 2006). Estos valores son parecidos a los obtenidos a partir del estudio de rudistos en el Barremiense superior y el Albiense medio (STEUBER Y RAUCH, 2005). También existen estudios isotópicos del calcio de ciertas sales marinas aptienses que indican un exceso en Ca (BLÄTTLER Y HIGGINS, 2014). Por consiguiente, debido a su proximidad al mar Tetis, no se descarta que el aporte de Ca al paleolago Enciso estuviese afectado por los aportes procedentes del mar, bien por la pluviosidad o por intrusiones ocasionales.

Durante la evaporación de una salmuera, las aguas pueden seguir tres rutas (EUGSTER Y HARDIE, 1978; EUGSTER, 1980). La ruta I o carbonatada (agua blanda) muestra un enriquecimiento en el anión bicarbonato $\mathrm{HCO}^{-}$sobre los cationes $\mathrm{Ca}^{2+} \mathrm{y} \mathrm{Mg}^{2+}$. La ruta II o salina neutra (agua dura) con un enriquecimiento de los cationes respecto al anión bicarbonato. La ruta III o intermedia. En el lago Bogoria, las dos rutas principales (I y II) exhiben unas asociaciones de ostrácodos específicas que evolucionan en respuesta a los cambios de concentración (CARBONEL et al., 1983; CARBONEL et al., 1988). Esta idea ha sido, de nuevo, aplicada a los ostrácodos del Purbeck-Weald inglés por HORNE (2002). Así, la ruta I (carbonatada) estaría caracterizada por una asociación de ostrácodos pertenecientes a los géneros Theriosynoecum, Darwinula y Cipridea. La ruta II (salina neutra) conduce a una fauna de ostrácodos dominada por Cyprideis y Fabanella. Las asociaciones de ostrácodos presentes en el paleolago Enciso (apartado 9.3) indican unas aguas que evolucionan predominantemente según la ruta I y, de manera más ocasional, según la ruta II.

Por último, teniendo en cuenta que la mineralogía de los carbonatos está determinada por la química de la masa de agua (TALBOT Y KELTS, 1990), se pueden hacer algunas precisiones sobre el paleolago Cameros. La abundancia de calcita con bajo contenido en Mg indica unas aguas inicialmente con una relación $\mathrm{Mg}^{2+} / \mathrm{Ca}^{2+}<2$ (MÜLLER et al., 1972). Por otro lado, la gran correlación observada entre el valor de $\delta^{18} \mathrm{O}$ y la relación $\mathrm{Mg}^{2+} / \mathrm{Mg}^{2+}+\mathrm{Ca}^{2+}$ sugiere que el enriquecimiento en $\mathrm{Mg}^{2+}$ estuvo muy influenciado por el grado de evaporación de la masa de agua (figura 9.8).

\subsubsection{Salinidad}

Para la determinación de la salinidad del paleolago Enciso, la mejor opción consiste en analizar las asociaciones de fósiles existentes, ya que ciertos organismos del pasado son muy útiles en la cuantificación de la paleosalinidad imperante en un momento dado (figura 9.9).

Aunque todavía existe cierta controversia sobre los requerimientos paleoambientales de los ostrácodos ya que son organismos muy sensibles a multitud de factores bióticos y abióticos, la distribución de géneros (o incluso a nivel de familias) y asociaciones de ostrácodos se considera como un indicador fiable de la tolerancia a la salinidad (CARBONEL et al., 1988; HORNE, 2002). Como ya se comentó en el apartado de la biota (apartado 9.3), las tres familias fundamentales de ostrácodos reconocidos en el Grupo Enciso son Cyprideidae, Darwinulidae y Limnocytheridae. Todos ellos se consideran como organismos reputados de medios no marinos. Nunca se ha citado géneros de ostrácodos pertenecientes a formas típicas de medios marinos como ocurre en el 


\section{Modelo conceptual del paleolago Enciso}

Aptiense de Francia (BABINOT et al., 2007), Inglaterra (KAYE, 1965; WILKINSON, 2008) o Portugal (CABRAL, 1998); lo cual, en principio, excluye ambientes marinos francos, aunque no descarta ciertas intrusiones marinas ocasionales.

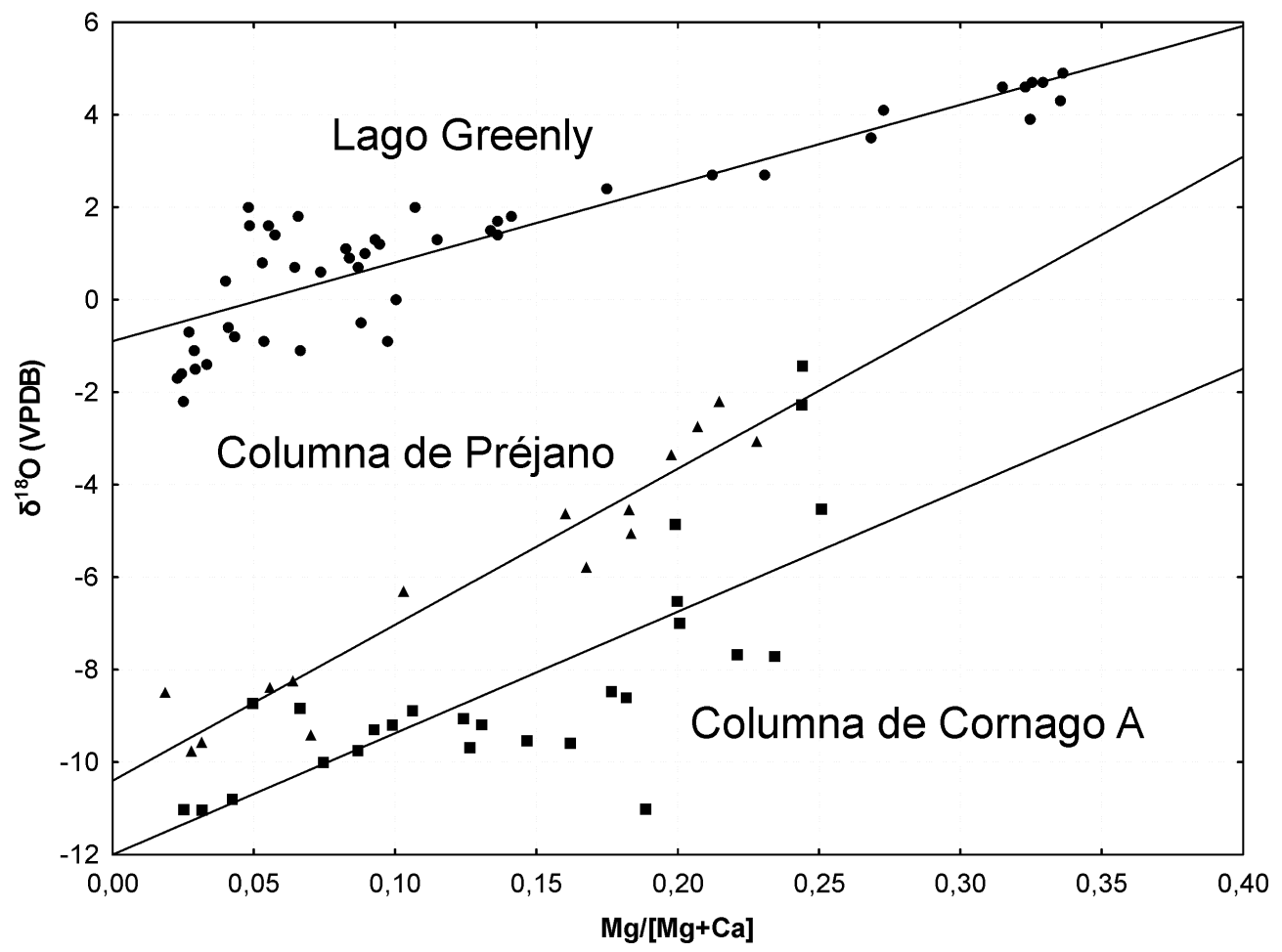

Figura 9.8: Correlación entre el valor de $\delta^{18} \mathrm{O}$ y la relación $\mathrm{Mg}^{2+} / \mathrm{Mg}^{2+}+\mathrm{Ca}^{2+}$ en un lago actual tipo playa (lago Greenly en Australia) y dos secciones del paleolago Enciso. Los datos del lago Greenly se han tomado de DUTKIEWICZ et al. (2000).

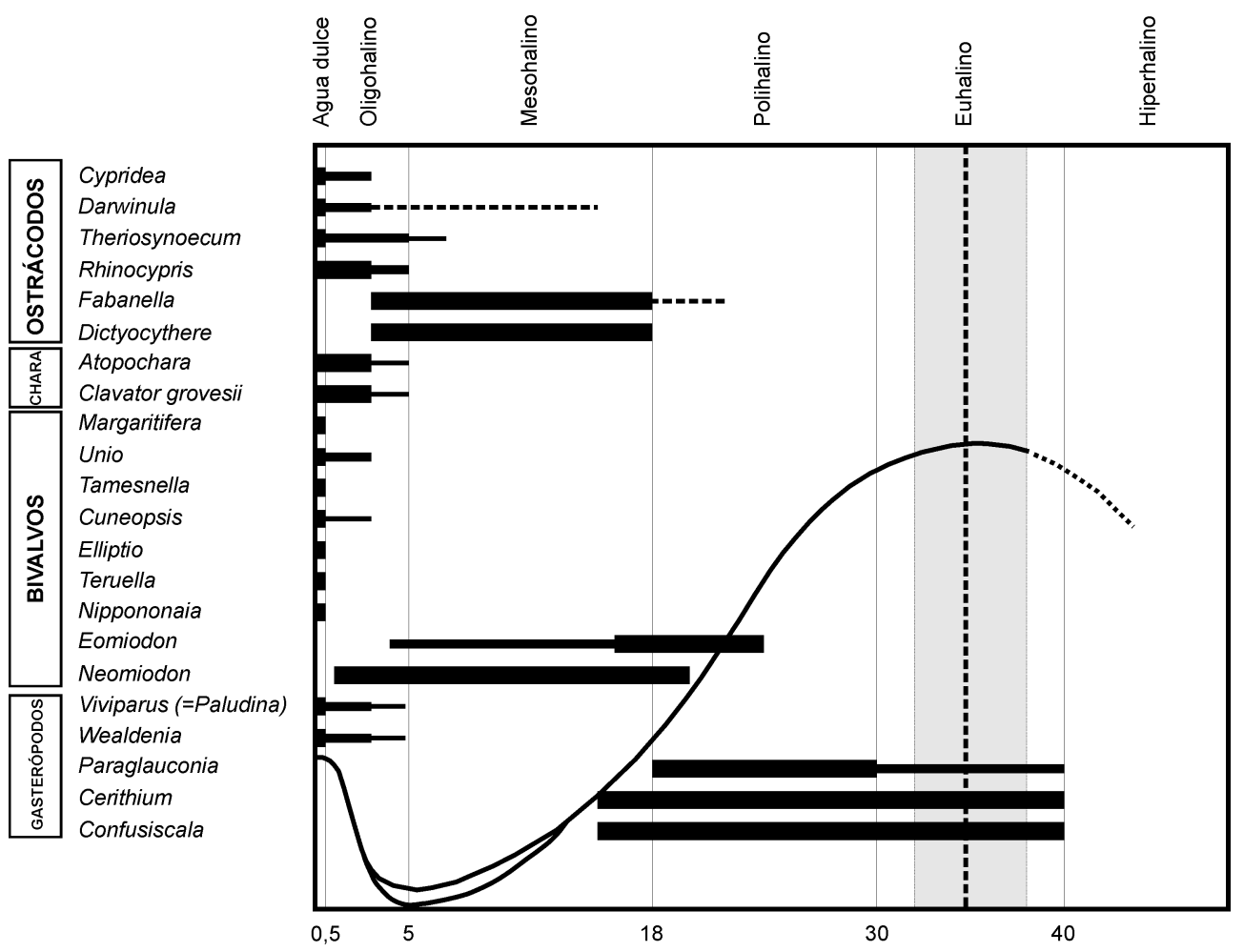

Figura 9.9: Rango de salinidad estimado para los diferentes fósiles encontrados en el paleolago Enciso. La línea negra representa el diagrama de Remane. En gris se indica el rango de paleosalinidades para el océano durante el Aptiense. 


\section{Modelo conceptual del paleolago Enciso}

- Cypridea es un género fósil que surge en el J urásico tardío, se desarrolla y diversifica durante el Cretácico inferior, para finalmente desaparecer en el Paleogeno (HORNE y COLIN, 2005). Tradicionalmente, ha sido considerado por muchos autores como un ostrácodo típico de aguas dulces $(0-0,5 \%)$ (KILENYI Y ALLEN, 1968; SOHN, 1979), aunque otros investigadores suponen que podía tolerar aguas levemente oligohalinas (0-3\%o) (BRENNER, 1976; SCHUDACK, 1993; WILKINSON, 2008) (figura 9.9). HORNE (2002) considera que la mayoría de las especies de Cypridea eran dulceacuícolas sin excluir que algunas pudieran tolerar aguas más salinas.

- El género Theriosynoecum (en muchas publicaciones citado como Gomphocythere) se extinguió durante el Albiense (COLLIN Y DANIELOPOL, 1979). En general, se califica como un ostrácodo característico de aguas dulces (0-0,5\%o) (KILENYI Y ALLEN, 1968; NEALE, 1988; METTE, 1997), aunque otros autores postulan que pudo tolerar aguas oligo- a levemente mesohalinas (0-7\%o) (ANDERSON et al., 1967; BRENNER, 1976; WAKEFIELD, 1995) (figura 9.9). En el Grupo Enciso es frecuente que aparezca asociado con otros organismos típicos de aguas dulces como Cypridea o Darwinula (GUIRAUD, 1983; HERNÁNDEZ-SAMANIEGO et al., 1990b) o Viviparus (SALOMON, 1973).

- Darwinula es un género con numerosas especies actuales dulciacuícolas repartidas por todo el mundo (SOHN, 1987). En general, su tolerancia a la salinidad en el pasado se ha basado en los datos observados en la actualidad en Darwinula stevensoni: especie eurihalina con una preferencia por las aguas dulces a levemente oligohalinas, desarrollándose en abundancia en un rango de salinidades entre 0-2\%o (DANIELOPOL, 1968; KILENYI Y ALLEN, 1968; KEYSER, 1977), aunque pueden tolera salinidades de 12-15\%o (LÖFFLER, 1961; KEYSER, 1977) (figura 9.9). En experimentos de laboratorio se ha observado que D. stevensoni presenta una alta tasa de supervivencia a salinidades de hasta 30\%o(VANDONINCK et al., 2002). El registro fósil del género Darwinula, que abarca desde el Carbonífero (SOHL, 1987; BENNETT, 2008) hasta la nuestros días, sugiere unas tolerancias y preferencias similares al género actual (WHATLEY, 1990). Sin embargo, durante el Triásico y Jurásico, algunas especies pudieron tener una mayor tolerancia a la salinidad ya que se han encontrado en facies hiperhalinas (GRAMANN, 1971).

- Rhinocypris es un género ya extinto de la familia Ilocyprididae, siendo Ilyocypris su descendiente moderno. Ilyocypris es un ostrácodo preferentementedulceacuícola (DELORME, 1970; KÜLKÖYLÜOĜLU Y VINYARD, 2000) aunque algunas especies toleran salinidades de hasta el 5\%o (KILENYI Y ALLEN, 1968; DE DECKKER, 1981) (figura 9.9). En la literatura consultada, estos requerimientos se aplican a Rhinocypris (KILENYI Y ALLEN, 1968; BRENNER, 1976; SCHUDACK, 1993).

- Dictyocythere es un ostrácodo con un rango estimado de salinidad entre 3-18\%o (BRENNER, 1976) (figura 9.9).

- Fabanella es un ostrácodo fósil con tolerancias altas a la salinidad en aguas atalásicas (HORNE, 2002). Algunos autores estiman un rango entre 5-18\%o (OERTLI, 1963) o 5-22\%o (KILENYI Y ALLEN, 1968; METTE, 1997) (figura 9.9).

Otros organismos útiles en la reconstrucción de la paleosalinidad son los moluscos. El registro fósil de moluscos bentónicos está fuertemente condicionado por la salinidad de tal modo que se puede afirmar que éste es el factor dominante en su distribución (HUDSON et al., 1995; HOLMDENY HUDSON, 2003).

Los bivalvos de la familia Neomiodontidae fueron, en su origen, organismos marinos que a finales del J urásico y comienzo del Cretácico comenzaron a colonizar cuerpos de aguas menos salobres (GRAY, 1988). Se les consideran formas eurihalinas, es decir, organismos que pueden tolerar un rango amplio de salinidades (GRAY, 1988; HOLMDEN Y HUDSON, 2003). Parecen haber sido colonizadores oportunistas, adaptados a salinidades en el límite oligo- a mesohalino, que 


\section{Modelo conceptual del paleolago Enciso}

coincide con el mínimo en especies según el cuadro de Remane (figura 9.9), por lo que sus asociaciones muestran muy poca diversidad. Por consiguiente, en el registro geológico es frecuente que aparezcan constituyendo asociaciones poco diversificadas o monogenéricas (MORTER, 1984; NOE-NYGAARD et al., 1987; HOLMDEN Y HUDSON, 2003). Al ser formas extintas, sus requerimientos ecológicos son difíciles de evaluar.

- En el Jurásico de Portugal, los datos isotópicos de Eomiodon securiformis indican paleosalinidades comprendidas entre 16,5-21,5\%o (YIN et al., 1995). Los análisis estrictamente paleoecológico sugieren paleosalinidades dispares según la especie estudiada: 4-18\%o para Eomiodon angulatus (Bathoniense de Causses, Francia) (FÜRSICH et al., 1995), 11-24\%o para Eomiodon securiformis (Kimmeridgiense de la cuenca Lusitana) (FÜRSICH Y WERNER, 1984; FÜRSICH, 1993). Eomiodon se asocia a medios marinos marginales deltaicos o estuarinos en el Jurásico-Cretácico de Asia (TASHIRO, 1987; KONDO et al., 2006) (figura 9.9). En el paleolago Enciso, las lumaquelas de Eomiodon suelen ser monogenéricas o en asociación con Paraglauconia (CALZADA-BADÍA, 1977; MENNESSIER Y CALZADA, 1985). En algunos casos se han citado una lumaquela de Eomiodon y Cerithium (VIERA et al., 1984; AGUIRREZABALA et al., 1985) o lumaquelas con la asociación Eomiodon, Cerithium, Paraglauconia y Confussiscala (VIERA, 1991).

- Neomiodon se considera un organismo muy eurihalino, quedando este comportamiento muy patente en el registro geológico. Durante el J urásico es frecuente que aparezca en medios transicionales marinos-continentales. Así, un estudio isotópico indica que: Neomiodon sp. aparece en el rango oligo- a levemente mesohalino en la Fm. Staffin Bay (Calloviense) (1$6 \%$ ), y en la Fm. Duntulm (Bathoniense) (3-6\%o), aunque puede alcanzar salinidades entre 17-20\% en las etapas con mayor influencia marina en la Fm. Staffin Bay (HoLMDEN Y HuDSON, 2003). Otros análisis isotópicos en el Jurásico de China asignan a Neomiodon yanshipingenis un rango mesohalino (16,5\%o) (YIN, 1991). A partir del análisis meramente paleoecológico, las paleosalinidades obtenidas son similares. En el Bathoniense de Causses (Francia), N. ruthenensis tolera salinidades entre 4-20\%o. En el Purbeck-Weald inglés Neomiodon puede presentarse en tres asociaciones: a) asociación Viviparus/Unio (dulceacuícola), b) asociación Neomiodon sp. (oligohalino) y, c) asociación Neomiodon fasciatus-medius (mesohalino, 5-9\%o) (MORTER, 1984) (figura 9.9).

Las actuales náyades son los moluscos paradigmáticos de medios dulceacuícolas. Datan del Triásico (HAAS, 1969) y todas las familias modernas son reconocibles desde el Cretácico (WATTERS, 2001). El registro de náyades en el paleolago Enciso es bastante diversificado, con varios géneros actuales y dos extintos (Teruella y Tamesnella).

- Margaritifera (o mejillón de río) es un género dulceacuícola que en la actualidad agrupa a 13 especies reconocidas que prefieren aguas lóticas (arroyos y ríos). Sus requerimientos en el Cretácico parecen haber sido semejantes asociándose a medios de agua dulce en China (MA, 1994; J IANG et al., 2007), Mongolia (SHA et al., 2006), África (MONGIN Y FISCHER, 1963; BUSSON Y CORNÉE, 1991) y, en el Purbeck-Weald inglés (MORTER, 1984; RADLEY Y BARKER, 2000a) (figura 9.9).

- Unio es otro género moderno con 13 especies: todos ellos son formas exclusivamente de agua dulce con poca tolerancia a la salinidad, aunque pueden, en algunos casos, vivir en aguas levemente oligohalinas. En el lagoon Curonian (Mar Báltico), Unio tumidis y U. pictorum toleran aguas con salinidades de hasta 3\% (OLENINY DAUNYS, 2005). Esta preferencia por un hábitat dominantemente dulceacuícola parece haber sido una característica a lo largo de su historia evolutiva como lo confirma su registro fósil. El estudio de isótopos de ${ }^{87} \mathrm{Sr} /{ }^{86} \mathrm{Sr}, \delta^{18} \mathrm{O}$ y $\delta^{13} \mathrm{C}$ indica que Unio andersoni, en el Bathoniense de Escocia, presenta un rango de salinidad entre 0-3\%o en el Miembro Kildonnan y entre 0-2\%o en la Fm. Duntulm (HOLMDEN Y HUDSON, 2003). En el J urásico de China, Unio sp. Exhibe una composición isotópica en el rango limnético (YIN, 1991). En el rango dulceacuícola existen numerosas especies eocretácicas: Unio yambianensis (KOMATSU Y J IN-HUA, 2000) y U. longus (SHA et al., 2006) en China, Unio cf. planus y U. subsinuatus en Inglaterra (MORTER, 1984) y, Unio 


\section{Modelo conceptual del paleolago Enciso}

farri y U. douglassi en Estados Unidos (YEN, 1951). En el rango limnético—oligohalino se ha citado Unio ogamigoensis (KoZAI et al., 2005) (figura 9.9).

- Elliptio es un bivalvo dulceacuícola que a día de hoy está representado por 39 especies que habitan medios lóticos y leníticos limnéticos (MATTESON, 1948; GRIFFTTHS Y CYR, 2006). (figura 9.9). No existe registro fósil en el Cretácico, a excepción de Elliptio galvensis, la especie citada en Enciso, que fue descrita por MONGIN (1966) a partir del material encontrado en la Fm. Camarillas, la cual se interpreta como un sistema fluvio-lacustre (MELÉNDEZ Y SORIA, 1999). De manera tentativa se le asignan tolerancias afines a las especies actuales.

- Cuneopsis es un género con 6 especies actuales características de medios dulceacuícolas (SIMPSON, 1900; 1914; GRAF Y CUMMINGS, 2007). Su tolerancia a la salinidad en el pasado parece haber sido semejante a la actual. En el J urásico de China, los análisis isotópicos en conchas de Cuneopsis sichuanensis indican condiciones limnéticas, mientras que C. cf. nachamensis define paleosalinidades levemente oligohalinas (2\%o) (YIN, 1991). Por otra parte, Cuneopsis es un género habitual en numerosas formaciones continentales (J urásicoCretácico) donde aparece, de manera reiterada, formando asociaciones con otros organismos dulceacuícolas (bivalvos, gasterópodos y ostrácodos), lo cual sugiere requerimientos ecológicos afines a los existentes en la actualidad (MONGINY FISCHER, 1963; KOZAI et al., 2005; CHEN et al., 2006a; PANY SHA, 2009) (figura 9.9).

- Teruella es un bivalvo extinto. Se ha citado en la Fm. Camarillas (CLIMENT-DOMĖNECH et al., 2007) y en una formación sin determinar, donde se descubrió, considerándola una forma típica de aguas dulces (MOISSENET Y GAUTIER, 1971; MONGIN, 1978). En Enciso, Teruella aparece asociado a Viviparus y Wealdenia (AgUIRREZABALA et al., 1985), por lo que se considera una forma limnética (figura 9.9).

- Tamesnella es otro género extinto cuya única cita corresponde a medios dulceacuícolas de África (MONGINY FISCHER, 1963; BUSSONY CORNÉE, 1991) (figura 9.9).

Aparte delas náyades, los uniónidos están representados por Nippononaia. Es un género fósil indicador de agua dulce en el Cretácico de Asia (ISAJ I, 1993; MA, 1994; KOMATSU Y J IN-HUA, 2000; KoZAI et al., 2005; J IANG et al., 2007; SHA, 2007; 2010). En J apón, es frecuente que aparezca asociada con Viviparus en ríos y pequeñas charcas de agua dulce (ISAJ I, 1993; KOMATSU Y J IN-HUA, 2000) (figura 9.9).

Los gasterópodos actuales de la familia Viviparidae son organismos característicos de medios dulceacuícolas (PRASHAD, 1928; STRONG et al., 2008). Según SPIRO et al. (2009), la tolerancia a la salinidad de las poblaciones recientes de Viviparidae es menor de $0,3-0,7 \%$. Sin embargo, HUDSON et al. (1995) considera que los vivipáridos del Jurásico-Cretácico no estuvieron confinados a aguas dulces, pudiendo ocupar aguas levemente oligohalinas.

- Viviparus es un género actual distintivo de aguas dulces, aunque existen algunas especies que están adaptadas a aguas levemente oligohalinas. En el delta de río Volga (Mar Caspio), Viviparus viviparus tolera un rango de salinidad 1-1,5\% (TARASOVY KAZANTSEVA, 1994). En el lagoon Curonian (Mar Báltico), V. viviparus y V. contectus habitan aguas con salinidades de hasta 3\% (OLENINY DAUNYS, 2005) (figura 9.9). En la cuenca de Cameros es frecuentes en los ambientes fluviales de la Fm. Urbión D (Barremiense-Aptiense) (BERMÚDEZ-RoCHAS et al., 2006; DELVENE Y ARAUJ O, 2009b). En la placa Ibérica se han citado, además, en la Fm Villaro (GARCíA-GARMILLA, 1989), y en la Fm. Vega de Pas (Miembro Capas de Viviparus) (DELVENE y ARAUJ O, 2009a), ambas en la cuenca Vasco-Cantábrica en España. En la Fm. Weald Clay de Inglaterra (Hauteriviense-Aptiense inferior), V. fluviorum es considerado un gasterópodo de aguas dulces, mientras que $V$. infracretacicus se estima que es un gasterópodo más tolerante y oportunista que pudo habitar aguas con salinidades de hasta 5\% (RADLEY, 1999). En la Fm. Wessex de Inglaterra (Barremiense), V. fluviorum se estima que es un organismo fluvial (RADLEY Y BARKER, 2000a). 


\section{Modelo conceptual del paleolago Enciso}

- Wealdenia es otro gasterópodo de la familia Viviparidae, por lo que en principio, se considera otra forma dulceacuícola. Se ha encontrado en los medios fluvio-lacustres de la Fm. Vega de Pas (Miembro Capas de Viviparus) asociado a Viviparus (BERMÚDEZ-RoCHAS et al., 2007) (figura 9.9).

Los gasterópodos cassiópidos del género Paraglauconia se caracterizan por ser formas extintas (Berriasiense-Cenomaniense) relacionadas a ambientes costeros salobres (estuario) y marinos puros (MENNESSIER, 1984; CLEEVELYY MORRIS, 1988). En la Fm. Villaro, que representa un medio lacustre, Paraglauconia aparece durante ocasionales incursiones marinas (GARCíAGARMILLA, 1989; POYATO-ARIZA et al., 2000). En la revisión llevada a cabo por MENNESSIER (1984), se considera que los cassiópidos habitaban mares epicontinentales (zona inframarealinfralitoral) en el rango polihalino, pudiendo en algunos casos llegar a euhalino. En la Fm. Vectis de Inglaterra, Paraglauconia fittoni se asigna a aguas mesohalinas (RADLEY Y BARKER, 1998). En el Cretácico inferior-medio, existen numerosas citas asociadas a un medio tipo lagoon: P. fittoni en la Fm. Vectis (Barremiense-Aptiense inferior, Inglaterra) (STEWART et al., 1991; RADLEY Y BARKER, 2000b), P. lujani en la Fm. Kotroman (Albiense-Cenomaniense, Serbia) (BAN AC et al., 2007; BANJ AC et al., 2008), Paraglauconia sp. en la Fm Santana (Albiense, Brasil) (MARTILL, 1993; 2001; MARTILL, 2007) y, en la Fm. Mal Paso (Albiense, México) (GARCíA-BARRERA, 1995) (figura 9.9).

Confusiscala es otro gasterópodo extinto que aparece asociado a medios marinos (SEPKOSKI, 2002). En la placa Ibérica, cuenca del Maestrazgo, se ha citado la presencia de Confusiscala caneroti en la Fm. Xert (CALZADA, 1988) y la Fm. Morella (CALZADA-BADÍA, 1973). Fuera de la placa Ibérica, aparece asociado a medios marinos someros en la Fm. Ishido (Barremiense, Japón) y Fm. Hiraiga (Aptiense, Japón) (KASE, 1984), a una plataforma epicontinental en el Barremiense superior de Turkmenistán (CECCA et al., 1999), en el Aptiense superior de Egipto (HAMAMA, 2010), en la Fm. Atherfield Clay (Aptiense inferior, Inglaterra) (CASEY, 1961; SIMPSON, 1985) y la Fm. Ferruginous Sand (Aptiense, Inglaterra) (CASEY, 1961) (figura 9.9).

Cerithium es un gasterópodo con representantes actuales siendo un género típico de ambientes marinos someros (SEPKOSKI, 2002; SÄLGEBACKY SAVAZZI, 2006). En la Bahía de Florida vive en aguas con una salinidad de 15-40\%o (BREWSTER-WINGARD Y ISHMAN, 1999). Los experimentos de laboratorio con el género Cerithium muscarum revelan que puede sobrevivir en una amplio rango de salinidades, e incluso, bajo condiciones hiperhalinas (57-62\%o) su capacidad reproductora se incrementa (MURRAY Y WINGARD, 2006). El género Cerithium es también muy abundante en lagos costeros, lagoones o charcas con conexiones al mar (aguas talásicas) (AHARON et al., 1977; THOMAS et al., 1991; MOHAMMAD, 2008; BECKING et al., 2011). En la placa Ibérica, la única cita fósil la constituye Cerithium vidalium en la Fm. Morella (cuenca del Maestrazgo, España) (CALZADA-BADIA, 1975). El análisis de los sedimentos contemporáneos en el resto del mundo, sugieren un hábitat marino somero para Cerithium: las formaciones Ishido (Barremiense, J apón) e Hiraiga (Aptiense, J apón) (HAYAMI Y KASE, 1977; KASE, 1984) y la Fm. Alisitos (Aptiense-Albiense, México) (ALLISON, 1955). También se ha citado en la Formación Amba Arandan, depositada en un medio fluvial, pero que exhibe una delgada banda marina (Caliza Graua) donde aparece Cerithium, la cual se interpreta como una inundación marina del cratón etíope durante la transgresión aptiense (BOSELLINI et al., 1999). La Formación Santana (Albiense, Brasil), de manera análoga a la anterior, es resultado de otra transgresión marina que penetra hasta la cuenca intracratónica de Araripe: se interpreta como un medio marino restringido o lagoon somero (MARTILL, 1993; 2001; MARTILL, 2007) (figura 9.9).

Las carófitas actuales constituyen densas praderas vegetadas en masas de aguas dulces a oligohalinas (GARCÍA, 1994), aunque existen formas que pueden colonizar aguas más saladas (BURNE et al., 1980; BLINDOW et al., 2003; SOUliÉ-MäRSCHE, 2008). Según SOULIÉ-MÄRSCHE (1991), nunca habitan medios marinos ni cuerpos de agua con una salinidad elevada permanente.

- El género Atopochara habitaba medios dulceacuícolas a levemente oligohalinos (0-3\%), pudiendo tolerar condiciones oligohalinas elevadas de hasta el 5\%o según SCHUDACK (1993) (figura 9.9). En la cuenca del Maestrazgo, Atopochara trivolvis se ha citado en multitud de 


\section{Modelo conceptual del paleolago Enciso}

subcuencas habitando medios marinos confinados transicionales a continentales (SORIA et al., 1995; MARTÍN-CLOSAS Y WANG, 2008). En la cuenca Lusitana de Portugal se ha citado en medios someros submareales a continentales indicando una salinidad comprendida entre agua dulce a oligohalina (PEREIRA Y CABRAL, 2005).

- El género Clavator grovesii se desarrollaba en medios dulceacuícolas a levemente oligohalinos, y en menor medida oligohalinos aunque su tolerancia puedealcanzar ambientes ligeramente mesohalinos según SCHUDACK (1993) (figura 9.9).

Los peces de la familia Semionontidae se han descubierto en depósitos tanto dulceacuícolas como marinos (MCCUNE, 1996; MCCUNE, 2004). Así pues, los peces consignados en el Grupo Enciso no constituyen indicadores adecuados de la salinidad debido a que son formas altamente eurihalinas (BILLON-BRUYAT et al., 2005).

Los tiburones del orden Hybodontiformes identificados en el Grupo Enciso tales como Hybodus, Lonchidion y Polyacrodus (BERMúDEZ-ROCHAS, 2006) son los mismos géneros presentes en la Formación Khok Kruat (Aptiense) de Tailandia donde representan una fauna de aguas dulces (CUNY et al., 2008). En el paleolago Enciso los restos de Hybodus se han citado asociados a formas dulceacuícolas como Unio (VIERA et al., 1984) o a formas más salinas como Eomiodon y Paraglauconia (AGUIRREZABALA et al., 1985). En la actualidad, existen ciertas especies detiburones marinos lo suficientemente eurihalinos como para colonizar masas de aguas dulces continentales. Así, por ejemplo, el tiburón toro o chato (Carcharhinus leucas) vive en aguas poco profundas de mares tropicales y subtropicales, sin embargo, son abundantes las citas de su existencia en aguas interiores (COMPAGNO, 1984). Algunos ejemplos son su presencia aguas arriba de numerosos ríos tales como el Misisipi (THOMERSON et al., 1977), San Juan (THORSON et al., 1966b; THORSON, 1971), Dulce (THORSON et al., 1966a), Usumacinta (SOSA-NISHIZAKI et al., 1998), Betsiboka (TANUICHI et al., 2003) y, en el Amazonas se ha visto a distancias de hasta varios miles de kilómetros de su desembocadura (THORSON, 1974). También existen importantes poblaciones en el lago Izabal (THORSON et al., 1966a), Bayano (VÁSQUEZ-MONTOYA Y THORSON, 1982), y Nicaragua (THORSON et al., 1966b; THORSON, 1971).

Los cocodrilos actuales habitan en aguas dulces, aunque en ocasiones pueden adaptarse a medios salobres (MARTIN, 2008).

A grandes rasgos, la biota de invertebrados indica la existencia de dos tipos de salinidad. Por un lado, la totalidad de los ostrácodos, los gasterópodos de la superfamilia Viviparoidea, y los bivalvos del orden Unionoidea apuntan a aguas atalásicas. Por otro lado, los gasterópodos de la superfamilia Cerithiodea y los bivalvos de la familia Neomiodontidae sugieren aguas talásicas, así como una probable conexión del paleolago Enciso con el mar. Es de destacar que los fósiles indicadores de aguas talasohalinas y los yesos (no se constata la presencia de halita u otras sales o minerales evaporíticos) son significativamente más abundantes en la zona suroriental. Así pues, se considera como una hipótesis factible que, en ciertas etapas, el paleolago Enciso presentaba un gradiente horizontal de la salinidad creciente hacia el sureste, es decir, hacia la denominada como cubeta de Cervera del Río Alhama sensu SALINAS Y MAS (1989; 1990).

\subsection{2 pH}

Para el cálculo del pH en el contexto concreto del paleolago Enciso, hay que tener en cuenta las altas concentraciones de $\mathrm{CO}_{2}$ atmosférico durante el Aptiense, que conlleva una mayor acidez de todas las aguas marinas y continentales (apartado 9.2 y anexo II). En el caso concreto de los océanos durante el Aptiense se ha calculado un $\mathrm{pH}$ del orden de 7,5-7,7, significativamente menor que el valor actual de 8,2 (RIDGWELL, 2005).

En el paleolago Enciso, durante las etapas de entrada de siliciclásticos (suponiendo que proceden mayoritariamente de la meteorización de áreas graníticas-neisíticas, en medios vegetados tropicales y con un elevado contenido en $\mathrm{CO}_{2}$ atmosférico), se puede asumir de manera teórica una clara tendencia a la acidez de sus aguas. La presencia de algunos ostrácodos en los sedimentos siliciclásticos que muestran cierta disolución en sus conchas así parece sugerirlo. 


\section{Modelo conceptual del paleolago Enciso}

Sin embargo, durante las etapas carbonatadas existen múltiples evidencias que sugieren unas aguas lacustres no ácidas (apartado 4.11.2).

a) La presencia de una gran diversidad de organismos con conchas calcáreas indica un $\mathrm{pH}$ neutro o casi neutro (KAT, 1982). Los moluscos uniónidos actuales prefieren aguas con un $\mathrm{pH}$ neutro o ligeramente por encima de 7 , aunque pueden crecer y reproducirse en un rango amplio 5,6-8,3 (CUMMINGS Y GRAF, 2010). En un estudio en 21 lagos de Ontario, Elliptio complanata se encuentra en un rango del $\mathrm{pH}$ comprendido entre 5,9-8,3 (CAMPBELL Y EVANS, 1991). En Portugal, Margaritifera margaritifera tolera aguas con un pH entre 6-8 (REIS, 2003).

b) La gran abundanciay excelente conservación de los ostrácodos en el Grupo Enciso sugiere la presencia de aguas alcalinas (LÖFFLER, 1997).

c) Los ostrácodos actuales pertenecientes a la familia Limnocytheridae como Gomphocytherey Limnocythere son característicos de aguas con alta alcalinidad (COHEN Y NIELSEN, 1986; FORESTER, 1986). Basándose en estos requerimientos de acidez de los ostrácodos actuales, COLINY DÉPÊCHE (1997) consideran que la abundancia y predominio del género Theriosynoecum en una asociación de ostrácodos es un signo de alcalinidad, mientras que las asociaciones dominadas por Cypridea son típicas de aguas de menor alcalinidad.

d) La aparición de carófitas calcificadoras fósiles apunta a masas de aguas alcalinas por extrapolación de los requerimientos de las carófitas actuales (GARCíA, 1994).

e) La presencia ocasional de procesos de silicificación (nódulos, ostrácodos y bivalvos) en los sedimentos carbonatados, principalmente en las margas, favorece la idea de etapas con elevada alcalinidad en sus aguas.

f) La abundancia de carbonatos en los sedimentos del Grupo Enciso también sugiere con pH ligeramente básico.

Todos los datos anteriores indican, de manera general, que durante las etapas carbonatadas el paleolago Enciso podría tener un pH neutro-levemente básico. Más aún, las aguas del paleolago se comportaron como un amortiguador eficaz de la acidez debida al elevado contenido en $\mathrm{CO}_{2}$ atmosférico.

\subsection{OXÍGENO DISUELTO}

Para el cálculo del oxígeno presente en las aguas del paleolago Enciso (Aptiense) se pueden admitir las siguientes hipótesis iniciales:

a) Un contenido en oxígeno atmosférico en torno a un 16-17\% (FALKOWSKI et al., 2005; BERNER, 2006; BELCHER Y MCELWAIN, 2008) un valor significativamente menor que los $20,9 \%$ actuales.

b) Unas temperaturas altas debidas a su posición en latitudes bajas tropicales en una época de marcado efecto invernadero (apartado 9.2).

c) Una salinidad fluctuante con unos valores aproximados en el rango 0-16\%o (apartado 9.7.1).

d) Poca altitud al encontrarse localizado casi a nivel del mar.

Con estos valores se observa en la figura 9.10 un marcado descenso de la solubilidad del oxígeno con respecto a las condiciones actuales (para una completa revisión de los cálculos utilizados véase el anexo III).

El paleolago Enciso presenta evidencias favorables, a priori, a la interpretación de períodos con un bajo contenido en oxígeno, aunque estas etapas disaeróbicas-anaeróbicas sean muy escasas:

a) Su posición en latitudes tropicales con aguas a temperaturas altas favorecieron un empobrecimiento en el nivel de oxígeno disuelto (figura 9.10).

b) Una atmósfera con unos contenidos en oxígeno más bajos que los actuales (figura 9.10). 


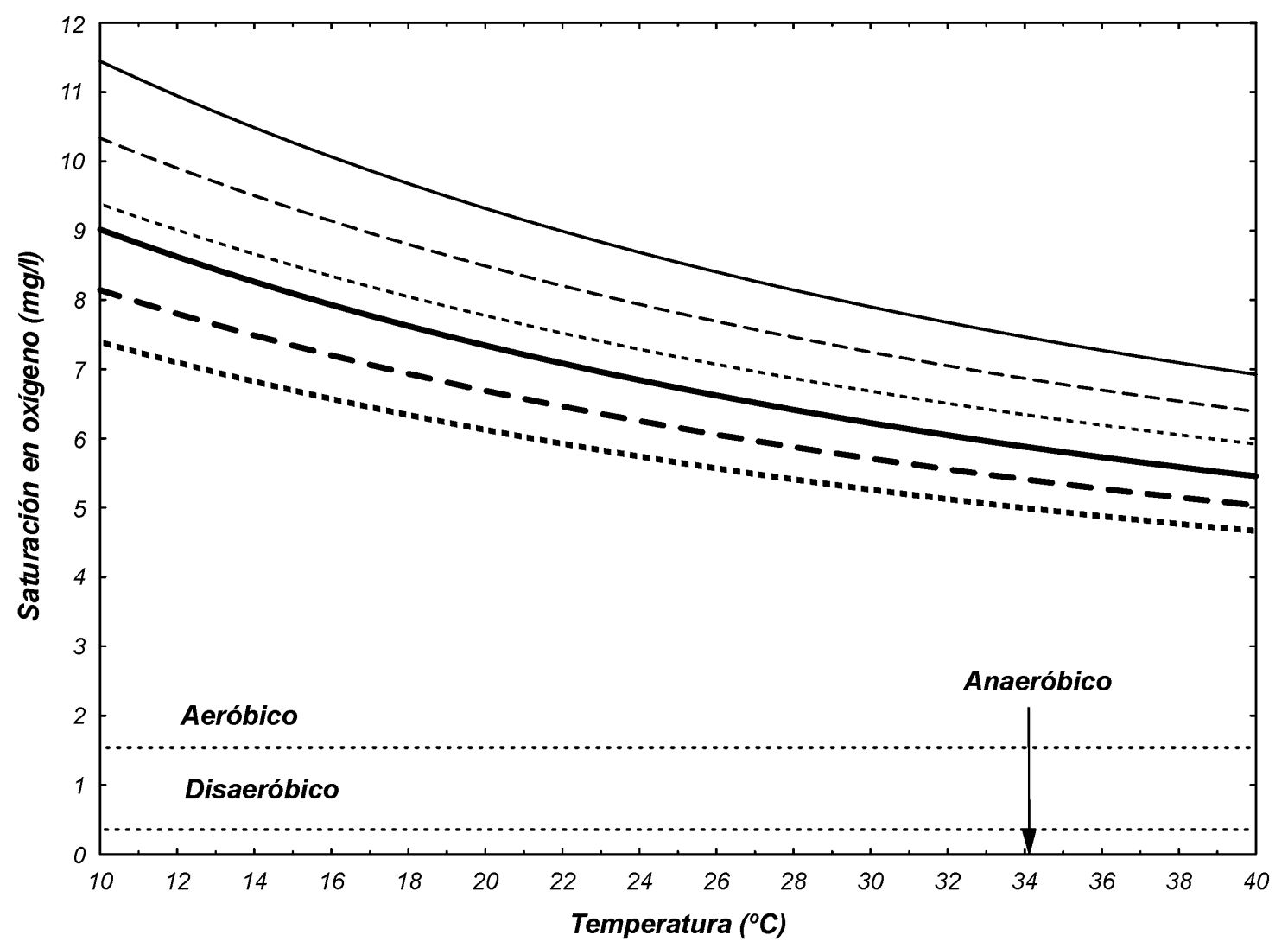

Figura 9.10: Variación de la saturación en oxígeno del agua en función de la temperatura y la salinidad. Las líneas gruesas hacen referencia a valores en el Aptiense $\left(\mathrm{O}_{2}=16 \%\right)$ y las líneas delgadas a valores actuales $\left(\mathrm{O}_{2}=20,95 \%\right)$. Las tramas indican salinidad: trama continua $(0 \%)$, trama discontinua (18\%o) y trama a puntos $(35 \%$ ).

c) Un sistema lacustre con un gradiente topográfico bajo que presenta un fondo con una gran área en contacto con el agua (gran superficie de la interfase sedimento-agua) donde se produce una gran demanda de oxígeno.

d) Un sistema con fluctuaciones de la salinidad abarcando aguas dulces a oligohalinas, sin olvidar la cercanía del mar y sus posibles entradas en el lago (figura 9.10).

e) Grandes cantidades de materia orgánica (oxidable) en los sedimentos.

f) Escasez en el registro sedimentario de facies laminadas sin señales de bioturbación como Lh $h_{1}$ y Ch, aunque en la columna de Préjano son abundantes (tabla 6.1).

g) La pirita sedimentaria encontrada en el Grupo Enciso se presenta como framboides, cristales euédricos o reemplazando las conchas de fósiles, fundamentalmente ostrácodos (ALONSO-AZCÁRATE et al., 1999b). Los framboides exhiben unos tamaños

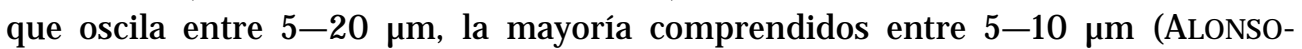
AZCÁRATE, 1997; ALONSO-AZCÁRATE et al., 1999b) lo cual parece indicar unos niveles disaeróbicos ORB5 y ORB6 (ORB Oxygen-Restricted Biofacies) en sentido de WIGNALL Y NEWTON (1998).

h) La presencia ocasional de formas juveniles de Unios articulados en posición de mariposa apunta a etapas locales de anoxia. A partir de análogos actuales se interpreta como resultado de un aumento de los niveles de ácido sulfhídrico $\left(\mathrm{H}_{2} \mathrm{~S}\right)$ en el sedimento que obligan al organismo a escapar hacia la interfase agua-sedimento donde muere (OSCHMANN, 1991).

Por el contrario, son más numerosas las evidencias a favor de etapas oxigenadas, que parecen haber sido la norma predominante en el paleolago: 


\section{Modelo conceptual del paleolago Enciso}

a) Aporte de oxígeno a través de la fotosíntesis (fuente primaria en los ambientes lacustres). En algunos estratos se observa gran número de carófitas. La poca profundidad del lago, en principio, favorece que la luz penetre en grandes volúmenes del cuerpo de agua y por consiguiente favorezca una gran actividad fotosintética.

b) Un cuerpo de agua de con una gran superficie (alcance) y poca profundidad favorece la acción del viento que mezcla deaguas y proporciona oxigenación a toda la columna de agua.

c) La abundancia de bioturbación y escasez de facies finas laminadas (tabla 6.1).

d) La abundancia de niveles turbidíticos que pueden aportar oxígeno a las aguas (apartado 4.12).

e) En general, el registro fósil de la malacofauna sugiere etapas de aguas bien oxigenadas ya que está representado por organismos que actualmente tienen unos requerimientos elevados en oxígeno para su desarrollo. Las náyades modernas y fósiles necesitan aguas oxigenadas (EVANOFF et al., 1998; GOOD, 2004). Elliptio complanata es un excelente regulador del $\mathrm{O}_{2}$, por lo que una baja concentración en oxígeno no le afecta de manera trascendental, pudiendo sobrevivir a períodos de anoxia (LEWIS, 1984). Sin embargo, la misma disminución en oxígeno limita significativamentela supervivencia de las formas juveniles de E. complanata bien sea por una mortalidad directa o favoreciendo indirectamente comportamientos que provocan el incremento de la mortalidad (SPARKS Y STRAYER, 1998). Margaritifera margaritifera necesita aguas con abundante oxígeno (ZIUGANOV et al., 1994; REIS, 2003). Los Viviparidae actuales requieren hábitats bien oxigenados aunque pueden tolerar cortos períodos de condiciones anóxicas (ALDRIDGE, 1983). No existe consenso en cuanto a los requerimientos de oxígeno de gasterópodo fósil Paraglauconia. MENNESSIER (1984) considera que podría haber sido una forma adaptada a medios con ausencia de oxígeno, aunque CLEEVELY y MORRIS (1988) lo ponen en duda.

f) Algunos géneros de ostrácodos marinos pueden utilizarse para calcular el contenido en oxígeno (WHATLEY et al., 2003). Sin embargo, no existen trabajos similares respecto a los ostrácodos no marinos. El ostrácodo actual Darwinula stevensoni precisa una alta concentración en oxígeno para airear los huevos, por lo que suele habitar aguas con un elevado nivel de oxígeno disuelto (2-14 mg/l) (MARTENS Y TUDORANCEA, 1991; SMITH y DELORME, 2010). Sin embargo, los experimentos de laboratorio llevados a cabo por Rossi et al. (2002) han demostrado que los adultos presentan cierta tolerancia a la hipoxia, y MEISCH (1990) cita la presencia de individuos en una charca anóxica en Luxemburgo.

\subsection{TURBIDEZ DEL AGUA}

La turbidez del agua es un parámetro problemático de cuantificar en el pasado. En el caso del paleolago Enciso, es seguro que ha variado a lo largo del tiempo, no permaneciendo constante, ya que existen evidencias a favor de ambos estadios.

La abundancia de sedimentos de tamaño de grano fino sugiere etapas de cierta turbidez (tabla 6.1): lutitas (EN 47,7\%; AA 18,6\%; CG 46,3\%; MN 33,3\%; PR 21,4) y margas y/ o calizas matriz-soportadas (EN 38,4\%; AA 72,2\%; CG 38,4\%; MN 43,1\%; PR 59,6\%).

Por el contrario, los fósiles apuntan a etapas de aguas poco o nada turbias. En este sentido, los uniónidos requieren hábitat de aguas claras ya que cuando la turbidez es elevada disminuyen o cesan la filtración con el fin de proteger sus branquias (BURKEY, 1983). Todas las náyades fósiles, por comparación con las náyades actuales, se interpretan como organismos que se alimentan mediantela filtración del agua. Así por ejemplo, Margaritifera margaritifera puede llegar a filtrar hasta 50 litros diarios (ZIUGANOV et al., 1994), Unio douglasiae $\approx 8$ litros diarios (KIM et al., 2011) y, U. pictorum y U. tumidis $\approx 10$ litros diarios (MCIVOR, 2004). 


\subsection{HIDRODINÁMICA LACUSTRE}

\subsubsection{Oleaje}

A partir de la medida de 53 rizaduras de oscilación se ha obtenido un valor medio de la dirección del viento de N115oE (figura 9.11). En las tres columnas donde se han tomado datos, separadas entre sí varios kilómetros, se observa una dirección preferente semejante en todas ellas:

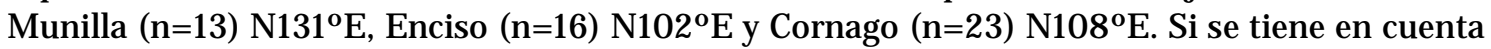
la rotación antihoraria de la placa ibérica debida a la apertura del golfo de Vizcaya desde el

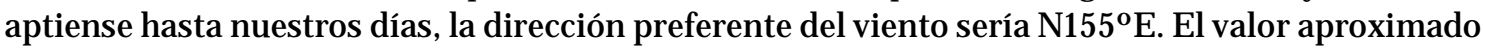
de esta rotación, basándose en las anomalías magnéticas del fondo oceánico y datos paleomagnéticos, es de unos 40으 (SIBUET et al., 2004a; SIBUET et al., 2004b; GONG et al., 2008). La figura 6A de FLUTEAU et al. (2007) indica unos vientos predominantes de dirección ONO-ESE a partir de un Modelo de Circulación General Atmosférica, datos que casan muy bien con los obtenidos a partir de las rizaduras simétricas (aplicándole la rotación acontecida).

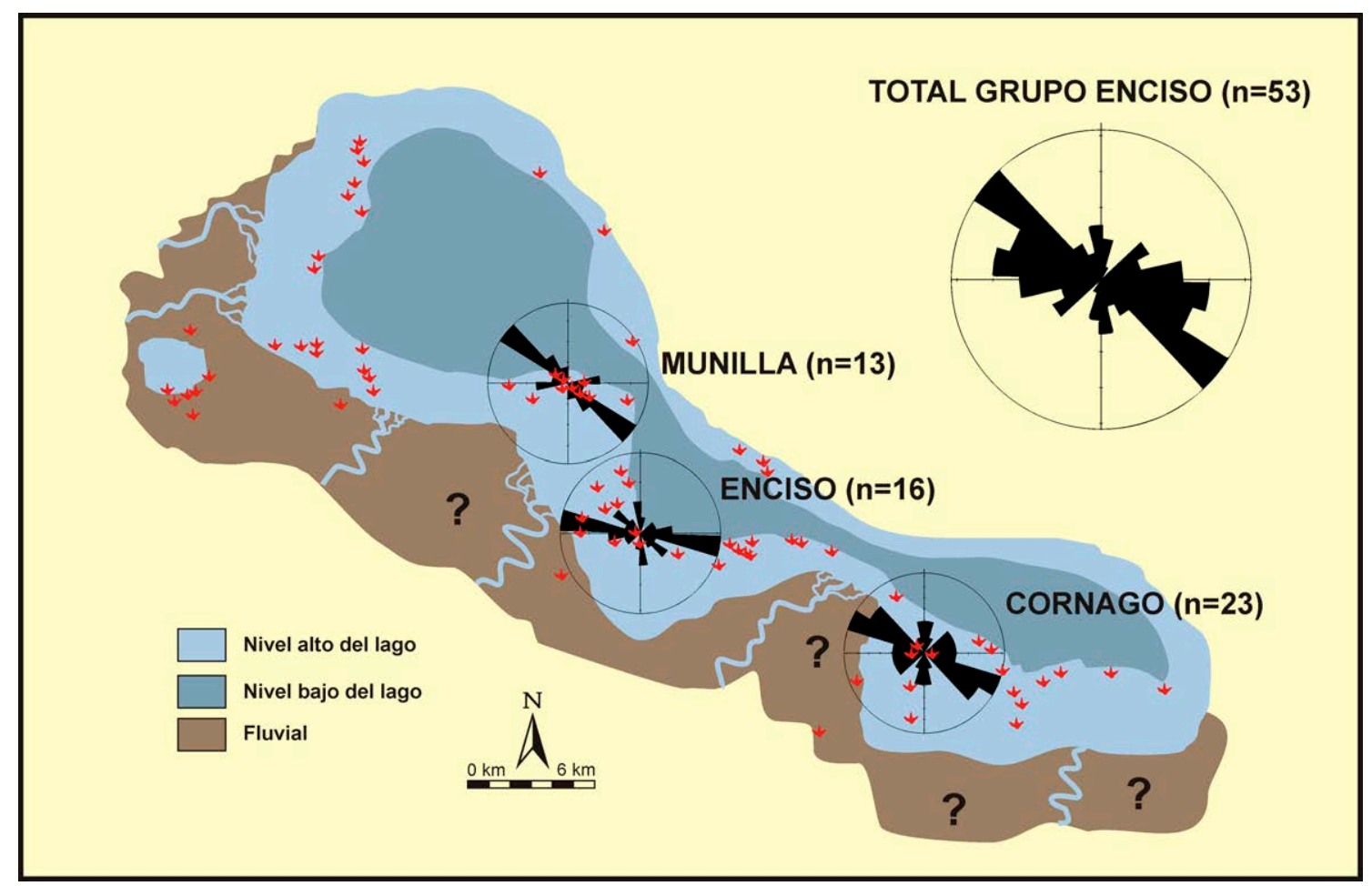

Figura 9.11: Dirección de los vientos deducida para el lago Enciso a partir del estudio de los trenes de rizaduras en tres áreas muestreadas (Munilla, Enciso y Cornago).

\subsubsection{Fuerza de Coriolis}

A partir de la formulación explicada en el apartado 4.15.3 y con los datos extrapolados para el Aptiense se puede calcular el número de Bouger. Para el rango de profundidades más probables, dicho valor es siempre menor quela unidad, lo cual sugiere que la dinámica superficial del paleolago Enciso no estuvo dominada por la fuerza de Coriolis (figura 9.12):

a) El período de rotación de la Tierra (T), en la actualidad, tiene un valor de 24 horas (86400 s). Sin embargo, la reducción progresiva de la velocidad de rotación de la Tierra provoca un aumento en la duración del día de 1,4 ms/ siglo (HIDE Y DICKEY, 1991). Si se asume este valor, la duración de un día en el aptiense (125 Ma) sería de 23,51 horas (84650 s). Este valor es muy parecido a las 23,30 horas (84600 s) obtenido utilizando la fórmula de ARBAB (2009).

b) La paleolatitud estimada para el paleolago Enciso es de 32으 (apartado 9.2).

c) La distancia máxima entre los extremos NO y SE de los afloramientos del Grupo Enciso es de unos $52 \mathrm{~km}$, lo cual da un valor de $\mathrm{L}=26 \mathrm{~km}$. 


\section{Modelo conceptual del paleolago Enciso}

d) En nuestro caso, como se investiga la influencia en las olas de gravedad superficiales (barotrópicas) el valor de la celeridad es $\mathrm{c}=\sqrt{\mathrm{g} \mathrm{z}}$, siendo $\mathrm{g}$ la constante gravitacional y z la profundidad del agua. Cuanto mayor es la profundidad, mayor es la celeridad y menor será la influencia delas fuerzas de Coriolis.

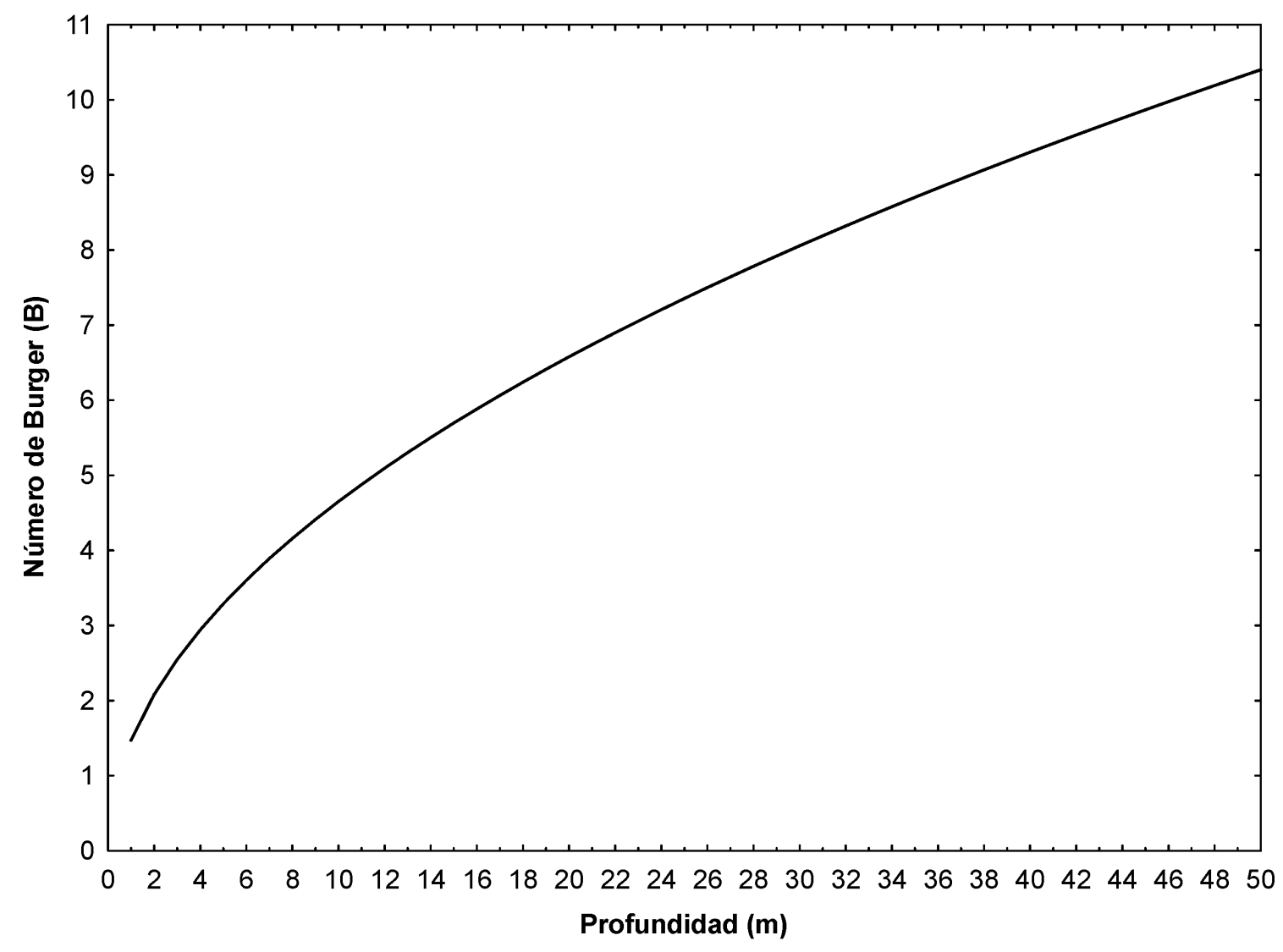

Figura 9.12: Cálculo del número de Burger para diferentes profundidades, en el rango de las previsibles para el paleolago Enciso. 
Modelo conceptual del paleolago Enciso 


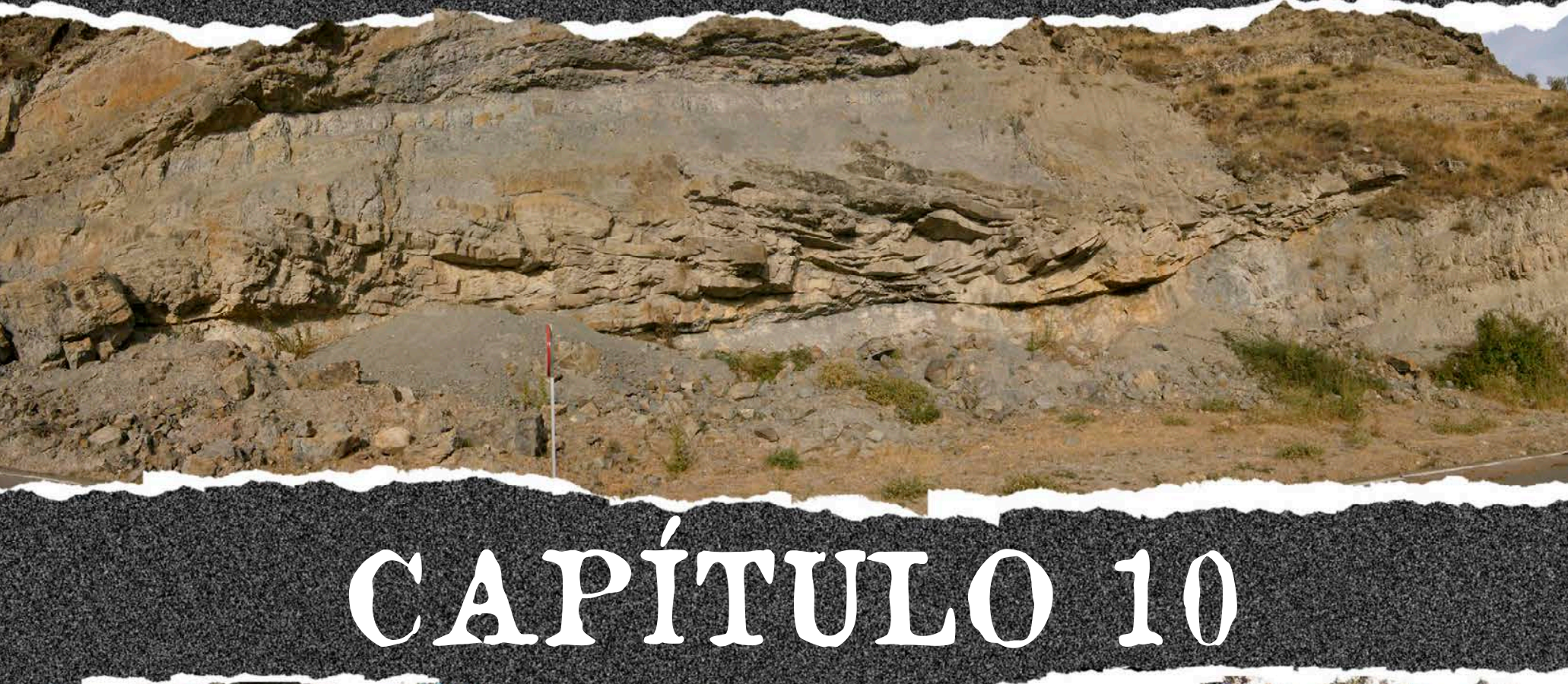

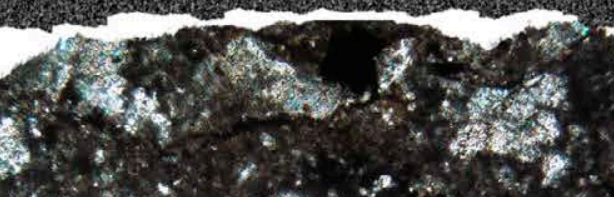
$(15)^{3}-8$

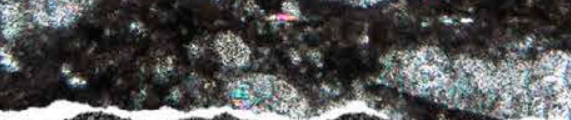

\section{TACIMIENTOS \\ ICNOLÓGICOS EN LA \\ ZONA DE ENCISO \\ AMBAS AGUAS}

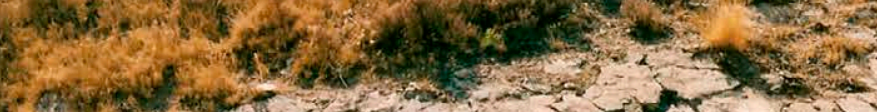

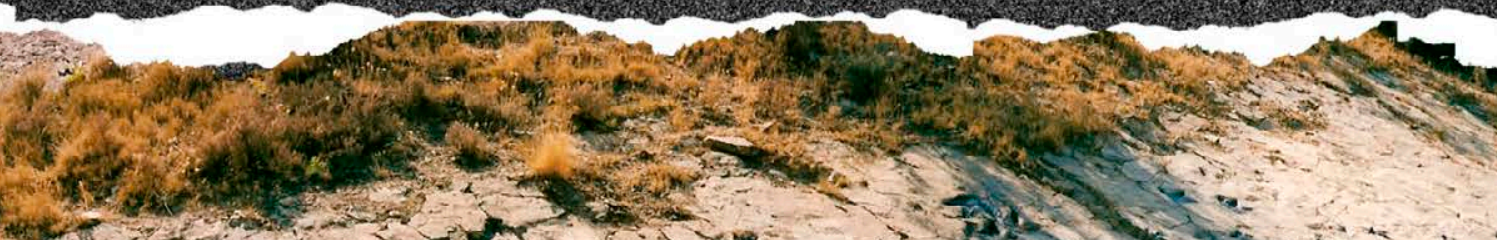

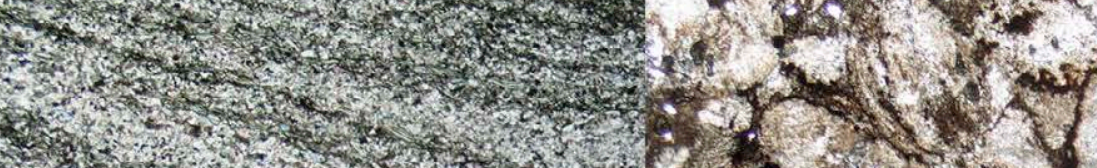

Q. Can

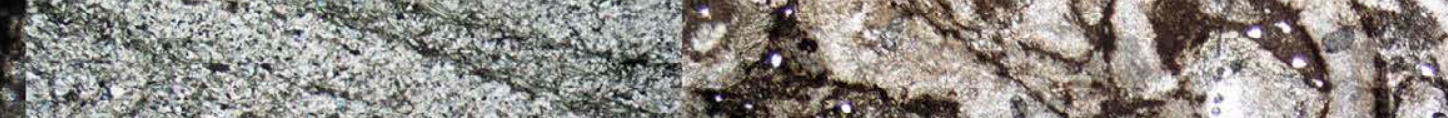

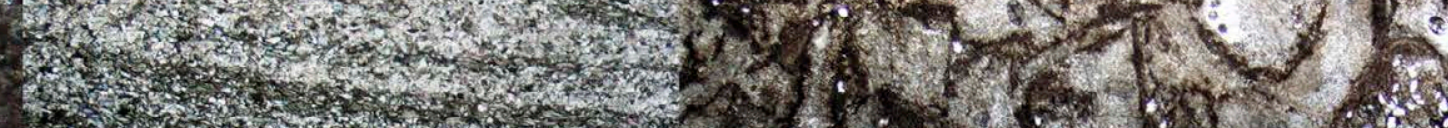
A $1,3,34$ 


\section{Michael Crichton HII Hundo Perdido}

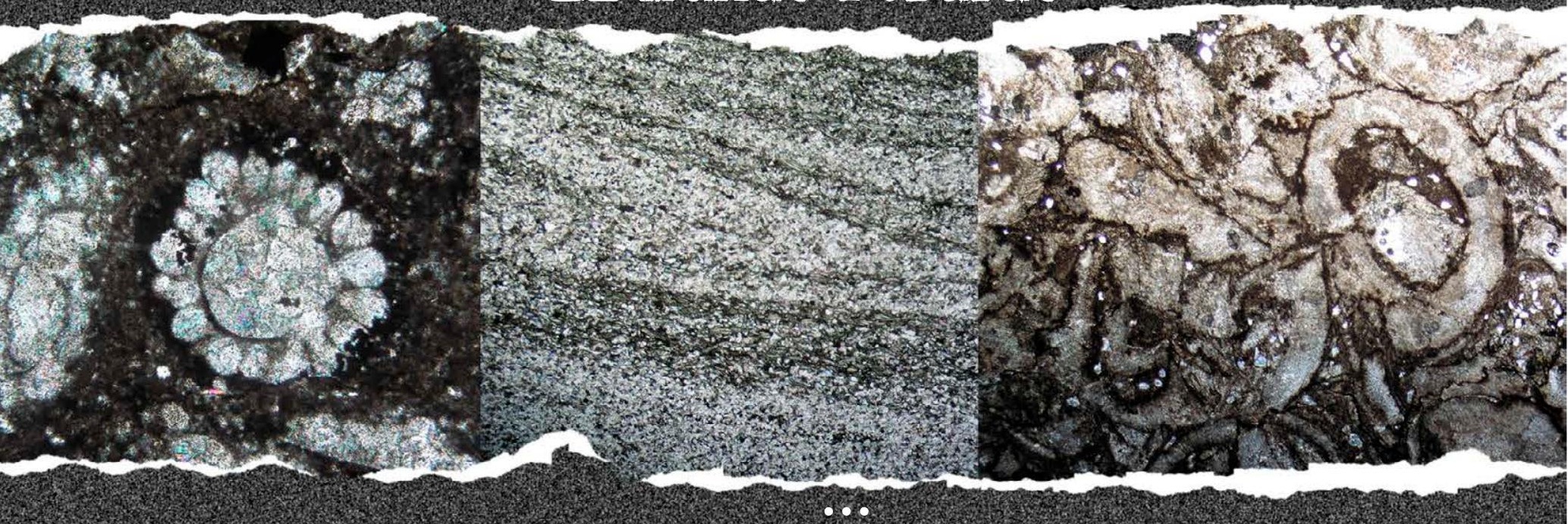

Levine ya habia visto antes huellas semejantes en senderos como el del rio Purgatoine, en Colorado, donde la antigua costa se havía fosilivado y las pisadas de 10 dinosaumios se conservaban en la piedra. Pero $1 a s$ pisadas que tenia ante sus ojos en esos instantes estaban impresas en barro, $y$ pertenecian a animales vivos

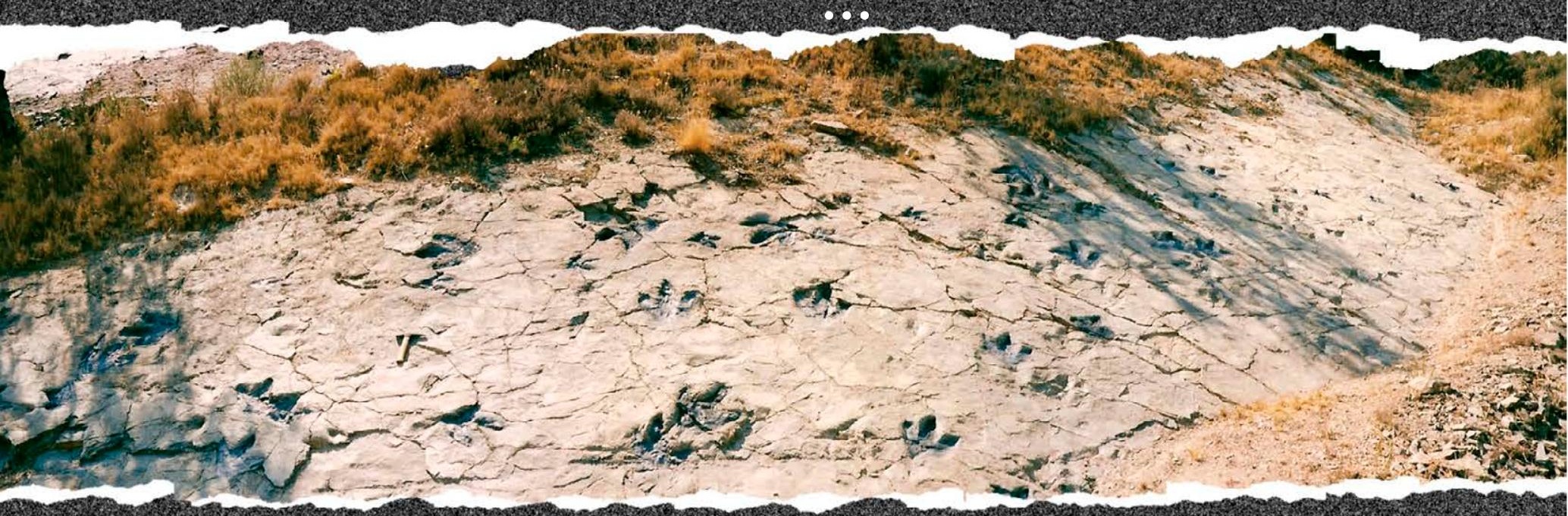




\subsection{INTRODUCCIÓN}

Los terrenos situados en los alrededores del pueblo de Enciso se caracterizan por su gran riqueza icnológica. De hecho, las huellas de dinosaurios eran conocidas desde antaño por los habitantes de la zona que las atribuían a las "pisadas del caballo de Santiago" (J IMÉNEZ, 1978). Los dos primeros estudios icnológicos serios que se realizaron en España tuvieron lugar en esta zona (CASANOVAS-ClADELLAS y SANTAFÉ-LLOPIS, 1971; 1974). Por la continuidad lateral que muestra la franja de terreno con los yacimientos icnológicos hacia el este, se ha creído conveniente agrupar la zona de Enciso con la de Ambas Aguas en una única zona de estudio (figura 10.1). En el área Enciso-Ambas Aguas existen 23 yacimientos icnológicos: 18 de ellos en el término municipal de Enciso, 3 en Préjano y 2 en Muro de Aguas. El asterisco indica que dicho yacimiento no ha sido estudiado en la presente tesis:

1. Barranco de Nocedillo (Enciso).

2. La Virgen del Campo (Enciso).

3. La Senoba (Enciso).

4. Las Losas (Enciso).

5. Barranco de Valdecevillo (Enciso).

6. Valdecevillo Este (Enciso).

7. Del Río (Enciso).

8. Corral de Valdefuentes (Enciso).

9. Llano del Cojo (Enciso).

10. Guilera (Enciso)*.

11. Barranco de Valdeño (Enciso).

12. Tomillar-Vallecuevanos (Enciso).

13. El Villar-Poyales (Enciso).

14. Navalsaz (Enciso).

15. La Cuesta de Andorra (Enciso).

16. Barranco de Valdegutierrez (Enciso)*.

17. Totico (Enciso)*.

18. Barranco Sierra del Palo (Enciso)*.

19. La Magdalena (Préjano).

20. Perosancio inferior (Muro de Aguas).

21. Perosancio (Muro de Aguas).

22. Valdeté (Préjano).

23. Tajugueras (Préjano).

A continuación se describe con mayor detalle los caracteres sedimentológicos relativos a cada yacimiento de manera individual. 


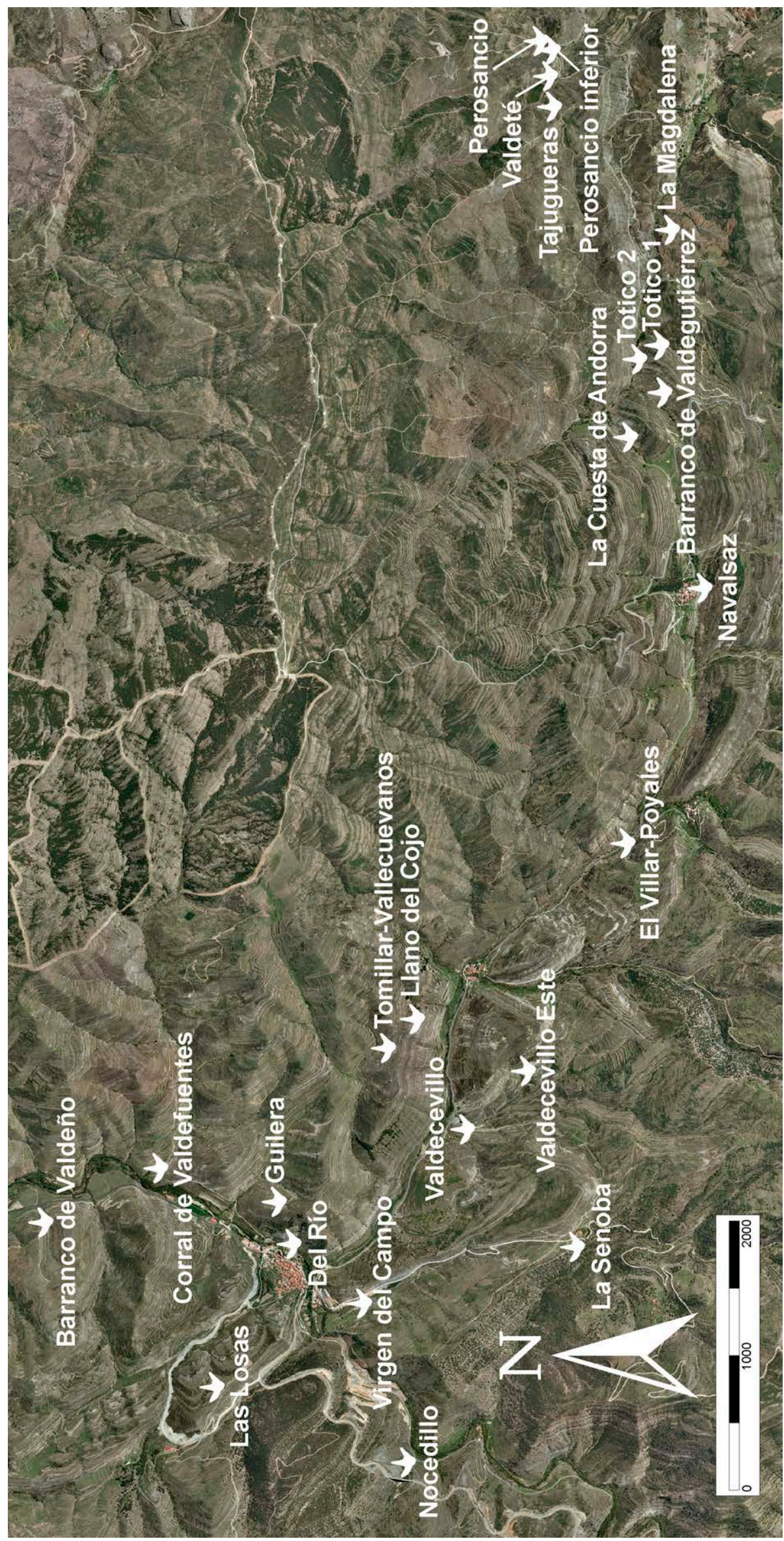

Figura 10.1: Composición con ortofoto de la localización de los yacimientos icnológicos en el área Enciso—Ambas Aguas. La escala está en metros. 


\subsection{YACIMIENTO BARRANCO DE NOCEDILLO}

En esta zona, el yacimiento del Barranco de Nocedillo es el más antiguo del Grupo Enciso, es decir, es el que presenta una posición estratigráfica más inferior. Fue citado por primera vez por BRANCAS et al. (1979) como "conjunto de lastras 8-A, B y C". Hoy en día, debido a las obras del viaducto, el afloramiento 8-C se encuentra cubierto por los taludes del desmonte. El resto de afloramientos son huellas en mal estado de conservación debido a la erosión en el lecho del barranco. Sus coordenadas ETRS89 son:

\section{Longitud: $\quad$ 2o $17^{\prime} 6.1464^{\prime \prime} \mathrm{O}$ \\ Latitud: $\quad 42^{\circ} 08^{\prime} 28.3298^{\prime \prime} \mathrm{N}$}

La columna en detalle de la zona y sus aspectos sedimentológicos, antes de las obras, puede verse en HERNÁN-MARTÍNEZ (1994). Se sitúa en el tramo 150 de la columna de Enciso (anexo IV).

El nivel icnológico (litofacies $\mathrm{Lm}_{1}$ ) aflora en un paquete continuo, de unos $27 \mathrm{~m}$ de espesor, donde predominan las lutitas organógenas (EA5abierto) con intercalaciones esporádicas de lumaquelas de moluscos (EA12abierto $\leftrightarrow$ EA5abierto), lutitas grises y azuladas (EA6sublitoral $\leftrightarrow$ EA5abierto) y areniscas masivas (EA4litoral $\leftrightarrow$ EA5abierto). Esta organización sugiere un sistema lacustre siliciclástico tipo A (LS-A) (apartado 6.5.1.1).

\subsection{YACIMIENTO LA VIRGEN DEL CAMPO (LVC)}

Este extenso yacimiento se subdivide en cuatro afloramientos o sectores (LVC, 2LVC, 3LVC y 4LVC). La zona LVC ha sido asignada, tentativamente, al "conjunto de lastras 11-A" de BRANCAS et al. (1979) por PÉREZ-LORENTE et al. (2001).

El afloramiento LVC consta de 506 icnitas (PÉREZ-LORENTE et al., 2001; PÉREZ-LORENTE, 2003), 2LVC presenta 24 huellas terópodas (CASANOVAS-CLADELLAS et al., 1991), 3LVC está todavía sin estudiar, y 4LVC muestra marcas de natación de dinosaurios y cocodrilos (EZQUERRA y PÉREZ-LORENTE, 2003; EZQUERRA et al., 2007; EZQUERRA-MigUEL et al., 2010).

Los yacimientos LVC y 2LVC afloran en el mismo estrato (CASANOVAS-CLADELLAS et al., 1991). Se desconoce la posición exacta de 3LVC aunque EzQUERRA et al. (2007) lo sitúan en el mismo estrato que LVC. Finalmente, el yacimiento 4LVC está estratigráficamente por encima (EZQUERRA et al., 2007). Las coordenadas ETRS89 de todos ellos son:

$$
\begin{array}{ll}
\text { Longitud: } & 2^{\text {o }} 16^{\prime} 18.1761^{\prime \prime} \mathrm{O} \\
\text { Latitud: } & 42^{\mathrm{o}} 08^{\prime} 38.0161^{\prime \prime} \mathrm{N}
\end{array}
$$

Los yacimientos LVC y 2LVC se localizan en el tramo 13 de la columna La Virgen del Campo (figura 10.3). Es una arenita cuarzosa masiva, de unos $17 \mathrm{~cm}$ de potencia, con un esqueleto dominado por clastos de cuarzo de tamaño arena fina-muy fina (microfacies 1) (figura 10.2A). En superficie se observan icnitas de dinosaurios, rizaduras de oscilación, restos vegetales, agujeros de bivalvos, así como algunos bivalvos (litofacies Ar) (figura 10.2B). Es de destacar la presencia de fenómenos de licuefacción asociados a terremotos (figura 9.2E y F).

En el tramo 17 de la columna La Virgen del Campo (figura 10.3) aparecen algunas icnitas de dinosaurios (figura 10.2C) asociadas a costras de Fe, rizaduras y agujeros de bivalvos. Se trata de una cuarzoarenita fina de unos $2 \mathrm{~cm}$ de potencia, muy parecida a la que aparece en LVC (microfacies 1; litofacies Ar) (figura 10.2D).

En el mismo tramo, un poco por encima, existe otro delgado nivel de unos $2 \mathrm{~cm}$ de potencia de limolita arenosa fina con huellas aisladas y abundantes rizaduras (litofacies $\mathrm{Ar}$ ). 

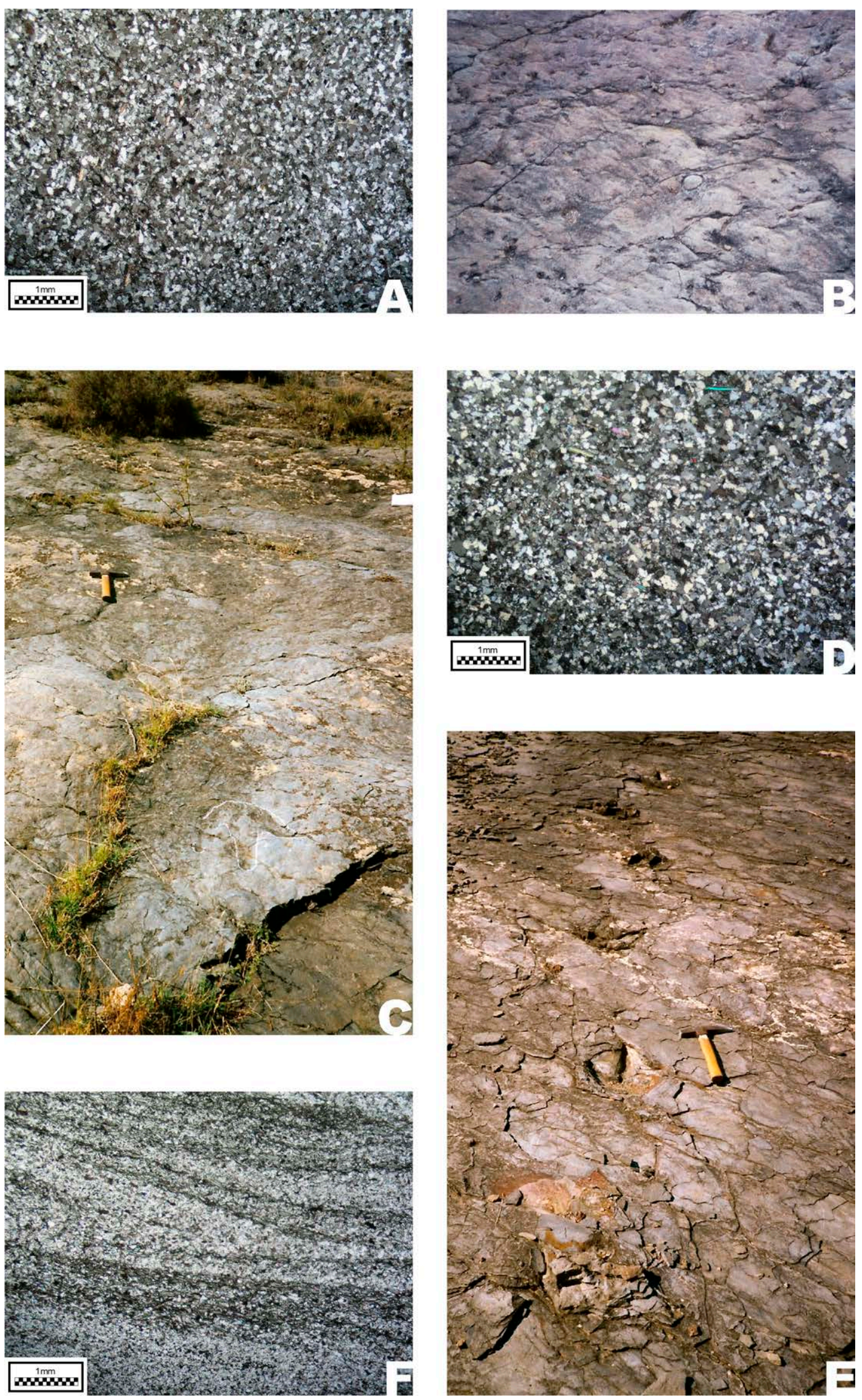

Figura 10.2: A) y B): Aspecto bajo microscopio petrográfico y en campo del yacimiento LVC y 2LVC. C) y D): Aspecto en campo y bajo microscopio del nivel icnológico aflorante en el tramo 17. E) y F) Aspecto en campo y bajo microscopio óptico del yacimiento icnológico que aparece en el tramo 18. 


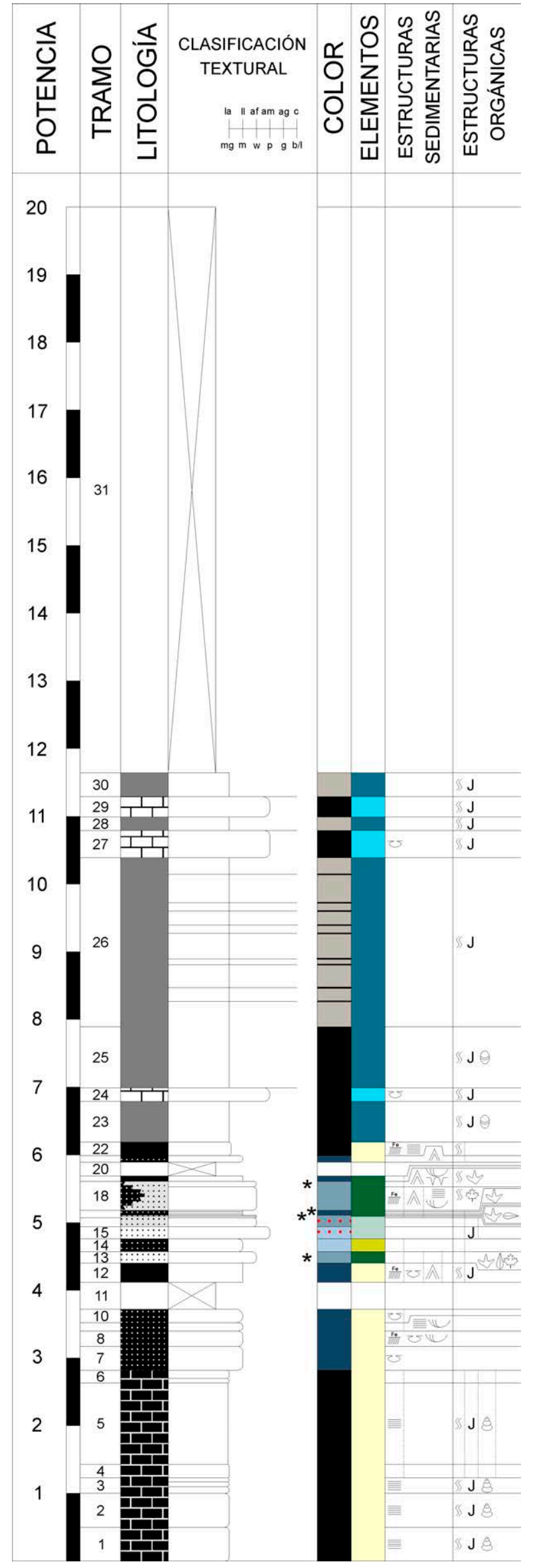

Figura 10.3: Columna estratigráfica del yacimiento icnológico La Virgen del Campo (LVC). 
En el tramo 18 (figura 10.3) se localiza otro nivel, de unos $8 \mathrm{~cm}$ de espesor, con icnitas, costras de hierro, grietas de retracción, y rizaduras (litofacies $\mathrm{Ar}$ y/o Lg) (figura 10.2E). Corresponde a una grauvaca-limolita arenosa con laminación cruzada de surco (microfacies 4) (figuras 5.6C y D; figura 10.2F). Por su litología y posición estratigráfica, podría corresponder al nivel 4LVC.

Todos los niveles icnológicos forman parte de una serie siliciclástica, de unos 6,2 $\mathrm{m}$ de espesor, constituida predominantemente por lutitas oscuras muy organógenas (EA5prodelta; 4,4 m de potencia). Hacia techo y de manera más ocasional, aparecen delgados paquetes de lutitas azuladas (EA6 prodelta) sedimentadas en el prodelta, así como areniscas con evidencias del oleaje (EA3barra) y/o masivas (EA4barra) depositadas en las barras de desembocadura. Su espesor y ordenación sugieren la presencia de un delta avulsivo lacustre (DL) (apartado 6.6.1). Los cuatro niveles con huellas afloran en sedimentos siliciclásticos con evidencias de haber estado sometidos a la acción del oleaje (EA3barra).

La correlación entre la columna general de Enciso y una columna parcial de control levantada en la zona de La Virgen del Campo (figura 10.4) indica que dicho yacimiento, lateralmente, se correlaciona perfectamente con el conjunto siliciclástico que se localiza entre los tramos 441-445 de la columna de Enciso (anexo IV).

\subsection{YACIMIENTO LA SENOBA (LS)}

Según CASANOVAS-Cladellas et al. (1989) existen 139 huellas de dinosaurios que se agrupan en 15 rastros (108 icnitas) y 31 huellas aisladas, todas ellas terópodas (figura 10.5A). Sus coordenadas ETRS89 son:

$$
\begin{array}{ll}
\text { Longitud: } & 2^{\text {o }} 16^{\prime} 2.3220^{\prime \prime} \mathrm{O} \\
\text { Latitud: } & 42^{\circ} 07^{\prime} 49.4824^{\prime \prime} \mathrm{N}
\end{array}
$$

Las huellas están impresas sobre un estrato de unos $8 \mathrm{~cm}$ de espesor, prácticamente subhorizontal, con un buzamiento de $3^{\text {o }} \mathrm{N}$. En superficie aparecen numerosas costras de hierro y abundante bioturbación. Se localiza en el tramo 26 de la columna La Senoba (figura 10.5D). Litológicamente es una arenita cuarzosa-grauvaca masiva con un esqueleto de cuarzo tamaño fino, moteado y bioturbación (microfacies 1y/o 3; litofacies Am1 y/ o Am2) (figuras 10.5B y C).

Por encima, en el mismo tramo, aparece un estrato de la misma litología de unos $6 \mathrm{~cm}$ de potencia con posibles icnitas aisladas, aunque no son muy claras. Además se observan costras ferruginosas, rizaduras asimétricas muy erosionadas, fragmentos fósiles y bioturbación (litofacies $\mathrm{Ar})$.

Ambas capas con huellas afloran en un paquete siliciclástico de unos 9,4 m de potencia que está constituido por 5 delgados episodios deltaicos avulsivos de tipo sheet (apartado 6.6.1).

El primero de ellos tiene un espesor de 1,7 m y una ordenación del tipo EA6prodelta $\rightarrow$ EA4 $4_{\text {barra }} \rightarrow$ EA3barra. Comienza por unas lutitas arenosas depositadas en el prodelta (EA6 $6_{\text {prodelta), }}$ ) las cuales pasan hacia techo a areniscas masivas (EA4barra) y areniscas con evidencias del oleaje (EA3barra) sedimentadas en las barras de desembocadura, donde quedan impresas las huellas de dinosaurios.

El siguiente evento deltaico $(0,9 \mathrm{~m})$ muestra un ordenamiento del tipo EA5prodelta $\rightarrow$ EA3barra. Los tres eventos deltaicos superiores (1,2, 2,3 y 2,5 $\mathrm{m}$ de potencia respectivamente) presenta una secuencia del tipo EA5prodelta $\rightarrow$ EA4barra.

Su posición estratigráfica es difícil de determinar debido a las numerosas fallas existentes en la zona. Es casi seguro que se sitúa por debajo del primer gran paquete de margas (tramos 447-479 en el anexo IV) y, tentativamente, podría estar cerca o a nivel del yacimiento de La Virgen del Campo. 